6 

Digitized by the Internet Archive in 2007 with funding from Microsoft Corporation 



\section{COMPARATIVE ANATOMY}

OF VERTEBRATES

KINGSLEY 



\title{
COMPARATIVE ANATOMY \\ of \\ VERTEBRATES
}

\author{
BY \\ J. S. KINGSLEY \\ PROPBSSOR OF BIOLOGY IN TUFTS COLLEGE
}

WITH 346 ILLUSTRATIONS

LARGELY FROM ORIGINAL SOURCES

$Q<805$
$K 55$
1912

PHILADELPHIA

P. BLAKISTON'S SON \& CO.

1012 WALNUT STREET

1912

\section{Liblikgir}




\section{PREFACE.}

Vertebrate anatomy is everywhere taught by the laboratory method. The student studies and dissects representatives of several classes, thus gaining an autoptic knowledge of the various organs and their positions in these forms. These facts do not constitute a science until they are properly compared and correlated with each other and with the conditions in other animals. It is the purpose of the author to present a volume of moderate size which may serve as a framework around which these facts can be grouped so that their bearings may be readily recognized and a broad conception of vertebrate structure may be obtained.

In order that this may be realized, embryology is made the basis, the various structures being traced from the undifferentiated egg into the adult condition. This renders it easy to compare the embryonic stages of the higher vertebrates with the adults of the lower and to recognize the resemblances and differences between organs in the separate classes. There has been no attempt to describe the structure of any species in detail, but rather to outline the general morphology of all vertebrates. To aid in the discrimination of the broader features and the more minor details, two sizes of type have been used, the larger for matter to be mastered by the student, the smaller for details and modifications in the separate classes to which reference may need to be made.

Considerable space has been given to the skull, as there is no feature of vertebrate anatomy which lends itself more readily to comparative study of the greatest value to the beginning student, while the same specimens can be used in the laboratory year after year. The skull also has a special interest since nowhere else is there the same chance of tracing modifications in all groups since the first appearance of vertebrates on the earth. To aid in this, extinct as well as recent species have been included.

It was the desire of the author to adopt the nomenclature of the German Anatomical Society ('BNA'), but this was often found impracticable. The BNA was based solely upon human anatomy and it fails utterly in many respects when the attempt is made to transfer its terms to other groups. The single example of 'transverse process' 
is sufficient to illustrate this. To the writer another objection is that the BNA strives to do away with all personal names. These, it would seem, have a great value as they are indications of the history of anatomical discovery and memorials of the great anatomists of the past. Dorsal and ventral are used instead of the anterior and posterior of human anatomy, while anterior indicates toward the head, posterior toward the tail, these terms being readily applied to all vertebrates, man only excepted. Cephalad and caudad, adopted by some, lead to occasional peculiar phrases. The German word 'anlage' has been adopted bodily, and seems to call for no defense. It implies the indifferent embryonic material from which a part or an organ develops.

The illustrations have been drawn or redrawn expressly for this work. Some of them are original, some based on figures in special papers. Practically none have ever appeared in any text-book in the English language. In selecting the objects to be figured especial pains has been taken to avoid the forms usually studied in our laboratories, thus relieving the student of the temptation of copying the figure, instead of drawing from nature. Especial thanks are due to Professor C. F. W. McClure, who allowed me to draw at will from the splendid collection which he has built up at Princeton. These figures are indicated by the word 'Princeton' followed by the number of the preparation in the museum of the University.

Tufts College, Mass. 


\section{CONTENTS}

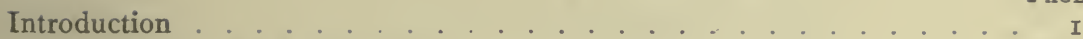

Introductory embryology . . . . . . . . . . . . . . . 6

Histology. . . . . . . . . . . . . . . . . . I6

Epithelial tissues . . . . . . . . . . . . I I

Nervous tissues. . . . . . . . . . . . . . . . I9

Muscular tissues . . . . . . . . . . . . . 20

Connective tissues . . . . . . . . . . . . . . . 2I

Comparative morphology of vertebrates . . . . . . . . . . 25

Integument . . . . . . . . . . . . 25

Skeleton . . . . . . . . . . . . . . . . 37

Dermal skeleton. . . . . . . . . . . . . 39

Endoskeleton . . . . . . . . . . . . 42

Vertebral column . . . . . . . . . . . . . 44

Ribs . . . . . . . . . . . . . 53

Sternum . . . . . . . . . . . . . ${ }_{5} 6$

Episternum . . . . . . . . . . . . . . 59

Skull . . . . . . . . . . . . . . . 59

Skull of cyclostomes . . . . . . . . . . . 75

Skull of elasmobranchs . . . . . . . . . . . 76

Skull of teleostomes . . . . . . . . . . . . 77

Skull of amphibia . . . . . . . . . . . 82

Skull of reptiles . . . . . . . . . . . . 87

Skull of birds . . . . . . . . . . . . . . 95

Skull of mammals . . . . . . . . . . . . . . . 98

Appendicular skeleton . . . . . . . . . . . . I02

Median appendages . . . . . . . . . . I03

Paired appendages. . . . . . . . . . . . . . I03

Shoulder girdle . . . . . . . . . . . . 105

Pelvic girdle . . . . . . . . . . . . . I09

Free appendages . . . . . . . . . . . II4

Cœlom (body cavities) . . . . . . . . . . . . . . I20

Muscular system . . . . . . . . . . . . . . . . I24

Parietal muscles . . . . . . . . . . . . . . I25

Visceral muscles ................ . . . I32

Dermal muscles . . . . . . . . . . . . . . I34

Diaphragm . . . . . . . . . . . . . I I 135

Electrical organs . . . . . . . . . . . . . I I35

Nervous system . . . . . . . . . . . . . . I37

Central nervous system. . . . . . . . . . . . . . . I I $^{8} 8$

Spinal cord ................... I38 
Brain . . . . . . . . . . . . . . . I 40

Brain of cyclostomes . . . . . . . . . . . I $\mathrm{I}_{52}$

Brain of elasmobranchs . . . . . . . . . . . I53

Brain of teleostomes . . . . . . . . . . . . . I53

Brain of dipnoi . . . . . . . . . . . . . . . I I55

Brain of amphibia . . . . . . . . . . . . I55

Brain of reptiles . . . . . . . . . . . . . I57

Brain of birds. . . . . . . . . . . . . . . $\mathrm{I}_{5} 8$

Brain of mammals. . . . . . . . . . . . . . . $\mathrm{I}_{58}^{8}$

Peripheral nervous system .. . . . . . . . . . . . . . . I6I

Spinal nerves . . . . . . . . . . . . . . . . . . I6I

Sympathetic system . . . . . . . . . . . . . I63

Cranial nerves . . . . . . . . . . . . . . . . 165

Sensory organs . . . . . . . . . . . . . . . . . . . I77

Nerve-end apparatus. . . . . . . . . . . . . . . . . I78

Lateral line organs . . . . . . . . . . . . . . . . . . . . . I79

Auditory organs . . . . . . . . . . . . . . . I82

Organs of taste . . . . . . . . . . . . . . . . I89

Olfactory organs .................. . . . . . . . . . . . . . . . . . . . . . . . .

Eyes. . . . . . . . . . . . . . . . . I98

Digestive organs . . . . . . . . . . . . . . . . . . 205

Oral cavity . . . . . . . . . . . . . . . . . 208

Teeth . . . . . . . . . . . . . . 208

Tongue . . . . . . . . . . . . . . . . . . 2 I7

Oral glands. . . . . . . . . . . . . . . 220

Pharynx . . . . . . . . . . . . . . . 222

Esophagus ..................... . . 222

Stomach . . . . . . . . . . . . . . . . . 223

Intestine . . . . . . . . . . . . . . . . . 227

Liver . . . . . . . . . . . . . . . . . 23 I

Pancreas . . . . . . . . . . . . . . . . . . 234

Respiratory organs . . . . . . . . . . . . . . . . 235

Gills (branchiæ) . . . . . . . . . . . . . . 236

Pharyngeal derivatives . . . . . . . . . . . . . 245

Swim bladder ... . . . . . . . . . . . . . 247

Lungs and air ducts . . . . . . . . . . . . . . . 250

Air ducts . . . . . . . . . . . . . . $25^{I}$

Lungs . . . . . . . . . . . . . . . . . 255

Accessory respiratory structures . . . . . . . . . . . . 263

Organs of circulation ............... . . . . 264

Blood and lymph . . . . . . . . . . . . . . . 265

Blood-vascular system . . . . . . . . . . . . . 266

Embryonic circulation . . . . . . . . . . . . 268

Heart . . . . . . . . . . . . . . 269

Arteries . . . . . . . . . . . . . 273

Veins ............... . . 276 
PAGE

Definitive circulation. . . . . . . . . . . 280

Heart . . . . . . . . . . . 28r

Aortic arches . . . . . . . . . . . 282

Arteries . . . . . . . . . . . . . . 284

Veins ............ . . . . . . 289

Fœtal circulation . . . . . . . . . . . . 293

Circulation in the separate classes . . . . . . . . . 294

Lymphatic system . . . . . . . . . . . . 302

Urogenital system . . . . . . . . . . . . . . . . 307

Excretory organs . . . . . . . . . . . : 308

Reproductive organs . . . . . . . . . . . 3I9

Reproductive ducts ........... . . . $32 \mathrm{I}$

Excretory organs of the separate groups . . . . . . . 326

Reproductive organs of the separate groups ....... . . 33I

Copulatory organs .......... . . . 342

Hermaphroditism . . . . . . . . . . . 346

Fœtal envelopes. . . . . . . . . . . . . . 348

Adrenal organs . . . . . . . . . . . . . . $35^{2}$

Bibliography .................... . . . 354

Definition of systematic names ............ . . . . . . . . .

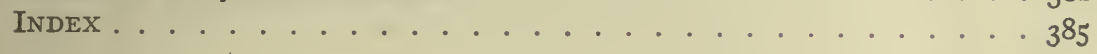




\section{INTRODUCTION.}

Any animal or any plant may be studied from several different points of view, four of which are concerned in the present volume. We may study its structure, ascertaining the parts of which it is composed and the way in which these parts are related to each other. This is the field of Anatomy. If we go into the more minute structure, for which the microscope has to be used, we are entering the special anatomical field of Histology. When two or more different animals are compared in points of structure, their resemblances and differences being traced, the study is called Comparative Anatomy, and it is only through such comparisons that we are able to arrive at the true meanings of structure. Then it is of interest to see the way in which the structure comes into existence in development from the comparatively simple egg from which it arises - the province of Embryology or Ontogeny. Anatomy and ontogeny together give us a knowledge of the form and how it has arisen and they are frequently grouped as Morphology. But morphology merely deals with the parts of a machine and these are usually studied in the dead organism; fully to appreciate the mechanism we should know how the parts and the whole perform their work, the study of function or Physiology.

In view of the foregoing the present volume is to be regarded as rather a comparative morphology of vertebrates, with here and there hints at the physiological side. Farther, there is an adaptation of the organism to the conditions in which it has to live, and the interactions of this environment upon the animal have to be considered, at least to a slight extent.

Zoologists divide all animals into two great groups, the Protozoa, in which the organism consists of a single cell, and the Metazoa, in which the body is composed of many cells, which vary according to the functions they have to perform. Of the Metazoa there are several divisions-Porifera (sponges), Cœlenterata (sea anemones, jelly fish), Echinoderma (starfish, sea urchins), Platodes (flatworms), Rotifera, Cœlhelminthes (ordinary worms), Mollusca, Arthropoda (crabs, insects), and Chordata. 
The Chordata are bilaterally symmetrical animals with metameric bodies, which agree in several features not found in the other groups. These are (I) a central nervous system, entirely on one side of the digestive tract; (2) the presence of gill slits in the young if not in the adult; (3) an unsegmented axial rod, the notochord, between the digestive tract and the nervous system. All of these features will be described later.

There are three or four divisions of Chordata, the uncertainty depending upon the position to be accorded the Enteropneusta. These are worm-like animals, occurring in the sea and represented on our shores by Balanoglossus. What has been described as a notochord is a pocket from the digestive tract, lying in a curious proboscis above the mouth.

The next division, the Tunicata, includes the (marine) 'sea-squirts.' They were long regarded as molluscs, but the discovery that the young have true gill slits, a nervous system on one side of the alimentary canal, and, above all, a notochord, placed them in the present association. Their young (larvæ) are tadpole-like, the notochord is confined to the tail, but later the tadpole features are lost and with them the tail and notochord, and the adult is a sac-like animal with no resemblances to its former state, or to its allies.

The third division, the Leptocardii, embraces Amphioxus and a few othermarine, fish-like animals. They were long classed as fishes, but are far more simple than any true fish. The body is markedly segmented, the gill slits are very numerous and the excretory organs open separately to the exterior and are vermian in character. Stomach, vertebræ and heart are lacking and the brain and sense organs are very rudimentary, while jaws and paired appendages are absent.

The last class, the Vertebrata, are most nearly related to the Leptocardii, but differ in many important respects: Thus there is always a skull and vertebral column; the brain is larger than the spinal cord; there are always nose, eyes and ears; a heart is present and the excretory organs open into a common duct on either side, with an external opening near the anus.

Most of the characteristics of a vertebrate may be seen from the accompanying diagram. The body is bilaterally symmetrical, with anterior and posterior ends, dorsal and ventral sides well differentiated. There is no external segmentation, since the muscles are not directly attached to the skin, but a metameric arrangement of parts is notice- 
able in muscles, skeleton, nerves, blood-vessels, and, to a less extent, in the excretory organs. There is no cuticular skeleton but the outer layer of the skin may be cornified or the deeper layer may give rise to ossifications (scales of fishes, etc.).

There is an internal axial skeleton, consisting of the notochord, around which are developed rings of denser material, constituting a backbone or vertebral column, while in front a skull encloses the brain and organs of special sense, and gives support to the primitive respiratory organs (gills), which are always connected with the digestive tract. Typically there are two kinds of appendages, each with an internal skeleton. These are the unpaired or median fins, dorsal and ventral, which occur only in the Ichthyopsida, and the paired appendages, of which there are two pairs, anterior and posterior in position.

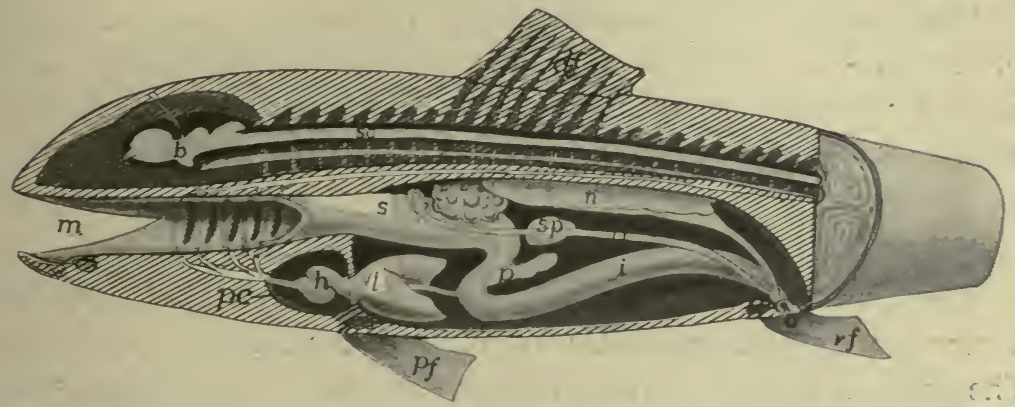

FIG. I.-Diagram of a vertebrate. $a$, anus; $b$, brain; $c$, cœlom; da, dorsal aorta; $d f$, dorsal fin; $g$, gonad; $g d$, genital duct; $h$, heart; $i$, intestine; $l$, liver; $m$, mouth; $n$, notochord; $p$, pancreas; $p c$, pericardium; $p f$, pectoral fin; $p h$, pharynx, with gill clefts; $s$, stomach; $s c$, spinal cord; $s p$, spleen; $u$, ureter; $v a$, ventral aorta; $v c$, vertebral column; $r f$, ventral fin.

The central nervous system consists of brain and spinal cord which lie dorsal to the notochord, and are usually protected by arches arising from the vertebræ and by the roof of the skull. Eyes and ears are the highest of the sense organs. The alimentary canal always has a liver connected with it, and a portion of the canal just behind the mouth is developed into a pharynx, from which, in the young of all, gill clefts extend through to or toward the exterior. In the terrestrial vertebrates these gill clefts are later replaced by lungs which develop from the hinder part of the pharyngeal region.

The blood, which always contains two kinds of corpuscles, flows through a closed system of vessels. A heart, ventral to the digestive tract and lying in a special cavity, the pericardium, is always present. 
The heart consists of two successive chambers, an auricle (atrium) and a ventricle, and in forms which respire by means of gills, contains only venous blood. With aerial respiration both chambers may become divided into arterial and venous halves. A dorsal aorta, lying above the alimentary canal, is always present.

The sexes are usually separate. The reproductive and excretory systems are closely related, giving rise to a urogenital system. The excretory ducts usually carry off the reproductive products (eggs and sperm). The urogenital ducts empty near the anus. Reproduction is strictly sexual; parthenogenesis and reproduction by budding do not occur and alternation of generations is unknown. The viscera are enclosed in a large body cavity (cœlom) which in the adult does not extend into the head. Each viscus is supported by a fold (mesentery) of the lining membrane of the cavity.

For details of the classification of vertebrates reference must be made to special text-books of zoology, but as some of the larger groups must be referred to frequently, so these with a slight definition and one or two examples are given here.

\section{SERIES I. CYCLOSTOMATA.}

These are eel-like in form, breathe by gills, have but one nostril, a circular mouth, incapable of closing, for no jaws are present. The skeleton is poorly developed and there are no paired appendages. -Lampreys and hagfishes.

\section{SERIES II. GNATHOSTOMATA.}

This includes all other vertebrates. They have usually two pairs of appendages, true jaws and a well developed skeleton.

\section{GRADE I. IChthyopsida.}

Fish-like, breathe, at least while young, by gills, have paired appendages, in the shape of legs or fins. In development there are never formed those structures to be described later as amnion and allantois.

\section{Class I. Pisces.}

Fishes respire permanently by gills developed in gill slits in the sides of the pharynx, have median and paired fins unless the latter be lost by degeneration. 


\section{Sub-class I. Elasmobranchii.}

Fishes with cartilaginous skeleton, mouth usually on the lower side of the head, the gills usually opening separately on the neck, and the tail with the upper lobe the larger (heterocercal). Sharks and skates. The Holocephali differ in having the gill slits covered with a fold of skin, so that but a single external opening appears.

\section{Sub-class II. Ganoidea.}

Intermediate between elasmobranchs and teleosts.-Garpike, sturgeon.'

\section{Sub-class III. Teleostei.}

Fishes with bony skeleton, mouth with true jaws at the tip of the snout, gill openings concealed by an operculum or gill-cover supported by bone. Tail with upper and lower lobes equal.-All common fishes.

\section{Sub-class IV. Dipnoi.}

The lung fishes are tropical forms in which the air bladder functions as a lung, the gill openings are covered with an operculum, and the tail is very primitive (diphycercal).

\section{Class II. Amphibia.}

Ichthyopsida with legs replacing the paired fins, lungs present and replacing the gills in the adult, nostrils connecting with the mouth.

\section{Sub-class I. Stegocephali.}

Extinct amphibians with well developed tail.

$$
\text { Sub-class II. Urodela. }
$$

Amphibia with well developed tail, gills sometimes retained through life.-Salamanders, Tritons, newts, efts.

\section{Sub-class III. Anura.}

Tailless as adults, the young a tadpole with external gills.-Frogs and toads.

\section{Sub.class IV. Gymnophiona.}

Blind, burrowing, legless amphibians occurring in the tropics.Cæcilians. 


\section{Grade II. Amniota.}

Vertebrates in which there are never fins, never functional gills, the respiration being by lungs. In development the embryo becomes covered by an embryonic envelope called the amnion, while a second outgrowth from the hinder end of the digestive tract is concerned in the embryonic nutrition and is called the allantois.

\section{Class I. Sauropsida.}

Body, at least in part, with scales, eggs large.

\section{Sub-class I. Reptilia.}

Cold-blooded vertebrates, the whole body covered by scales or horny plates. The living forms are turtles, lizards, snakes and alligators (crocodiles) and a New Zealand species Sphenodon. The fossil forms are more numerous and include Theromorphs, Plesiosaurs, Ichthyosaurs, Dinosaurs, and Pterodactyls.

Sub-class II. Aves.

The birds are recognized by their warm blood and their feathers.

\section{Class II. Mammalia.}

The mammals are as sharply marked by their hair as are the birds by their feathers. They have warm blood; except the monotremes they bring forth living young which are nourished by milk secreted by glands (mammæ) in the mother.

There are a few other terms of convenience which may be defined here as they will save much circumlocution. The term Teleostomes is applied to ganoids and teleosts, from the fact that they have true jaws. The amphibia and the amniotes are frequently united as Tetrapoda, from their possessing feet, in contrast to the fishes with fins.

The geological history of these groups is important; their first appearance and their geological range is indicated in the accompanying table of the geological periods.

\section{INTRODUCTORY EMBRYOLOGY.}

The structure of an adult vertebrate can be fully appreciated and the bearing of the facts recognized only by a knowledge of the development of the parts concerned. It would often appear, for example, that certain organs in different groups were exact equivalents of each 


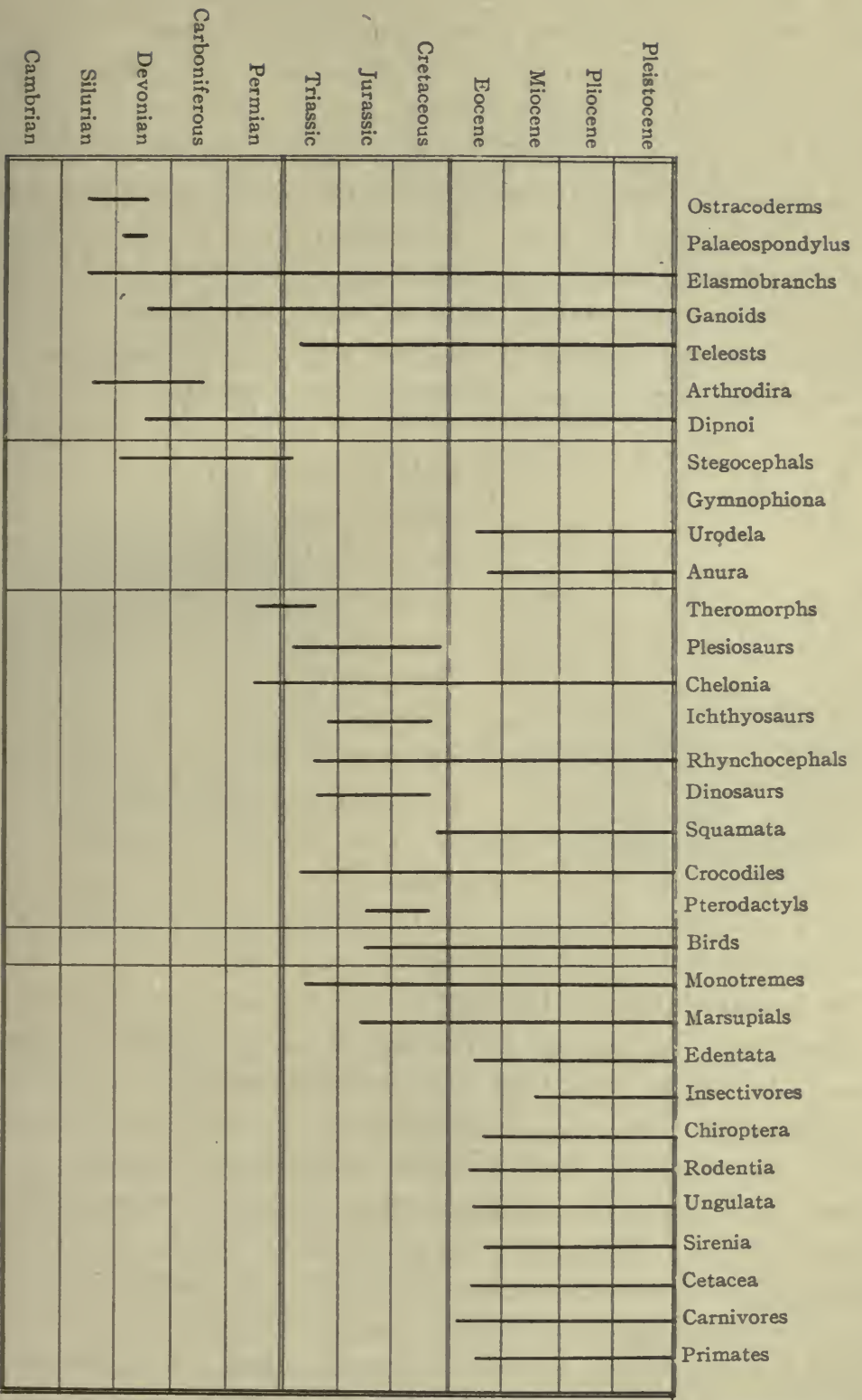

Table showing the geological distribution of the various groups of vertebrates. 
other-duplicates in function and details of structure-while a knowledge of their development may show that they have had entirely different origins and different histories, and hence cannot be identical; they are examples of what the evolutionist calls convergent evolution. Such cases are apt to lead one astray as to the relations of the forms in which they occur. Farther, the development affords a framework around which the details of organization may be arranged in a logical manner, thus aiding in their remembrance. For these reasons the following pages are based on embryology. Not only are the histories of the separate organs traced before an account is given of the adult conditions, but this introductory chapter gives in the most generalized form the earlier stages before the organs are outlined.

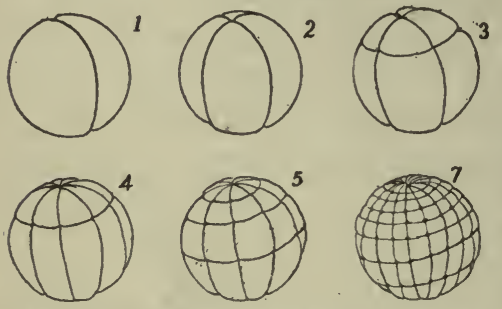

FIG. 2.- Successive stages in the segmentation of an amphibian egg. I-7, Results of the corresponding cleavage planes.

The enormously complicated body of every vertebrate is derived from a comparatively simple specialized cell, the egg or ovum. This ovum, must be fertilized by a still more specialized cell, the spermatozoon, derived from the male. After this fertilization the egg goes through an orderly but very gradual series of changes which bring it continually nearer the adult condition. The phases of this differ with different animals; here only a generalized account will be given, which is subject to modifications in the several groups, for an account of which reference must be had to embryological text-books.

The Segmentation of the Egg.- The first steps of the process are the segmentation or cleavage of the egg, in which it divides again and again, until the single-celled egg is converted into a large number of cells or blastomeres (fig. 2). The character of this segmentation is modified accordingly as the egg is large or small, as it contains varying amounts of nourishment-deutoplasm or food yolk stored up for the growing embryo. These same variations also affect the later stages of development; the description given here follows the simplest conditions.

As a result of segmentation the egg is converted into a spherical mass of cells in which a cavity appears, called the segmentation cavity because it is formed during segmentation. It also has the name archicœle as it is the first or oldest space to appear in the embryo. This stage of the embryo is called the blastula (fig. 3). 
Its cells at first show but little differentiation except in size. Next follow processes which are to differentiate the cells into layers, characterized by both position and fate.

Gastrulation.-In the simplest form this differentiation is brought about by an inversion of one-half of the blastula into the other, thus more or less completely obliterating the segmentation cavity, much as one may push one side of a rubber ball into the other, forming a doublewalled cup (fig. 4). This stage is called the gastrula, and the process of inpushing is invagination. With this the first appearance of the structures of the adult is seen. The outer wall of the cup is turned to the external world and thus act as a skin for the embryo. This layer is called the ectoderm. The opening or mouth into the cup is the

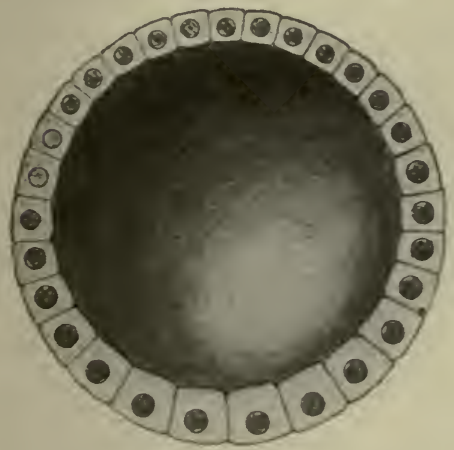

FIG. 3.-Diagram of a typical blastula with central segmentation cavity.

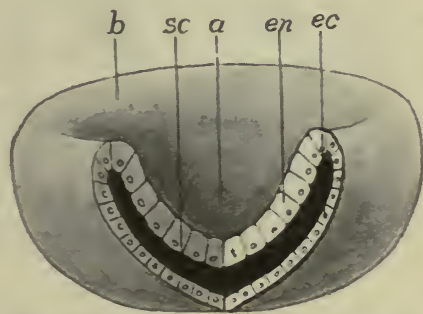

FIG. 4.-Diagram of a gastrula. $a$, archenteron; $b$, blastopore; $e c$, ectoderm; $e n$, entoderm; $s c$, segmentation cavity.

blastopore. The inside of the cup is well fitted for the digestion of food as it can be held together there and the digestive fluids are less liable to waste. Hence the cavity is called the archenteron (primitive stomach), and the layer of cells which line it is the entoderm. That these comparisons are more than analogies of position is shown by. their fates, the ectoderm forming part of the skin of the adult, the entoderm the lining of the digestive tract. Between ectoderm and entoderm are the remains of the segmentation cavity, filled with an albuminous fluid. It will be convenient later to speak of the line where ectoderm and entoderm meet at the blastopore as the ect-ental line.

Closure of the Blastopore.-Next, the blastopore closes, the process beginning at what will be the head end of the embryo and pro- 
ceeding gradually backward. Usually the closure is complete, but occasionally the hinder part remains open and forms the anus. Where it closes completely the vent is subsequently formed in the line of closure. This union of the two lips of the blastopore in closing marks the middle line of the back of the future animal, and is called at first the primitive groove, the region on either side of it being known as the primitive streak, terms of importance in understanding the gastrulation of the higher vertebrates.

Mesoderm.-With the closure of the blastopore the embryo elongates and the archenteron is converted into a tube. Next, from the region of closure and from the entodermal tissue, a fold of cells grows in on either side between ectoderm and entoderm, thus farther encroaching on the segmentation cavity. These cells form the middle

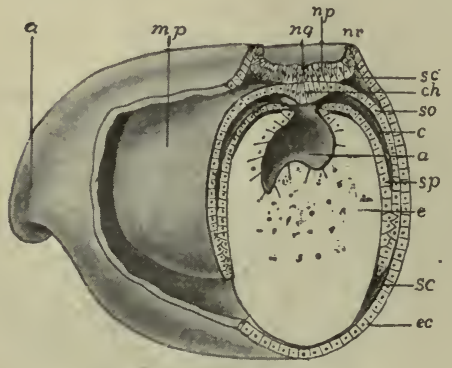

FIG. 5.

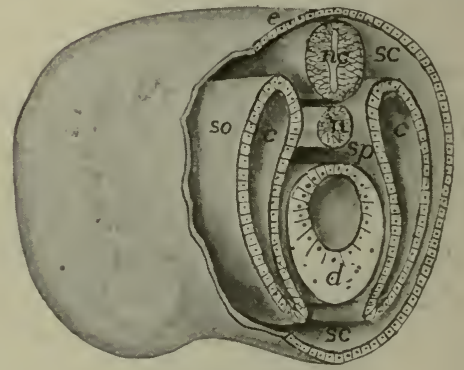

Fig. 6.

FIG. 5.-Stereogram of the anterior end of a developing amphibian, showing the out lining of the mesothelium, nervous system and notochord. $a$, anterior end; $a r$, archenteron; $c$, cœlom; $c h$, notochordal cells; $e c$, ectoderm; $m p$, mesodermal pouch; $n g$, primitive groove; $n p$, neural plate; $n r$, neural folds; $s c$, segmentation cavity; so, somatic wall of cœlom; $s p$, splanchnic wall of coelom.

FIG. 6.-Stereogram of the anterior end of a vertebrate, showing the relation of the cœlomic pouches; $c$, cœlom; $d$, digestive tract; $e$, ectoderm; $n c$, nervous system; $n$, notochord; $s c$, segmentation cavity; so, somatic and $s p$, splanchnic walls.

layer or mesoderm. Inside this fold is a space, connected at first with the archenteron, but soon the cavity of each side is cut off by a growing together of the opening into the archenteron and is henceforth known as a cœlom ${ }^{1}$ or body cavity. Each cœlomic space has two walls, one toward the ectoderm, the somatic layer, the one toward the entoderm being the splanchnic layer (figs. 5 and 6).

The mesoderm arising in this way and bounding the cœlom is called mesothelium to distinguish it from another kind-the mesen-

${ }^{1} \mathrm{~A}$ cœlom formed in this way is an enterocœle. Usually the cœlomic walls arise as a solid mass of cells from the corresponding region, which later splits internally, forming a schizocœle. The two are readily compared. 
chyme-which also comes to lie in the segmentation cavity. "This mesenchyme arises as separate cells, coming largely from the mesothelium, and to a less extent from the entoderm (see p. I6). Whether any arises from the ectoderm is disputed.

The Germ Layers.-Ectoderm, entoderm and the two types of mesoderm are called the germ layers, because in the animals first studied they were arranged like layers one on the other. Each plays its part in the formation of the adult and gives rise to its peculiar structures.

The ectoderm forms the outer layer of the skin, hair, claws, feathers, the outer layer of scales, enamel of teeth, and the essential or characteristic part of all sensory and nervous structures.

The entoderm gives rise to the lining of the digestive tract, and the various outgrowths - gills, lungs, liver, pancreas, etc.-connected with it. The notochord is also entodermal and possibly the lining of the blood-vessels is derived from this layer.

The mesothelium produces the lining of the cœlomic cavities -pericardial, pleural, peritoneal-the reproductive and excretory organs and the voluntary muscles and those of the heart.

The mesenchyme develops the deeper layer (corium) of the skin and of scales, the dentine of teeth, involuntary muscles (except those of the heart) connective tissue, ligaments, cartilage, bone, and the corpuscles of blood and lymph.

In the development of the embryo several processes of differentiation occur simultaneously, but in the written account one has to follow another. Hence it must be understood that the modifications described here may be taking place at the same time.

The Central Nervous System.-During the closure of the blastopore the ectoderm in front and to either side of the blastoporal lips becomes thickened, the cells elongating at right angles to the surface and becoming cylindrical or fusiform. These cells form the neural or medullary plate (fig. $5, n p$ ), sharply marked off from the surrounding cells, which are more flattened, and which eventually are concerned in the formation of the outer layer (epidermis) of the skin. The neural plate is to develop into the brain and the spinal cord, and it is to be noted that later it extends around the hinder end of the blastopore. After it is outlined the plate is rolled into a tube, its front end and lateral margins rising up, forming neural folds $(n r)$, between which is the medullary groove. Eventually the folds meet and fuse above so that 
the tube results (fig. $6, n c$ ), the cavity of which persists throughout life as the cavities (ventricles) of the brain and the central canal of the spinal cord. From the cells of the walls of the canal the nervous tissue arises.

This process of infolding progresses from in front backward. For a time, in some vertebrates, a small opening, the anterior neuropore, persists at the anterior end. The infolding extends back to the posterior end of the neural plate so that, as will readily be understood, the whole limits of the blastopore are included in the floor of the neural canal. Occasionally the closure of the neural folds is completed before that of the blastopore so that for a short time a short tube, the neurenteric canal (fig. 7), connects the archenteron with the neural canal. Soon after the closure of the neural tube the fused tissue splits horizont-

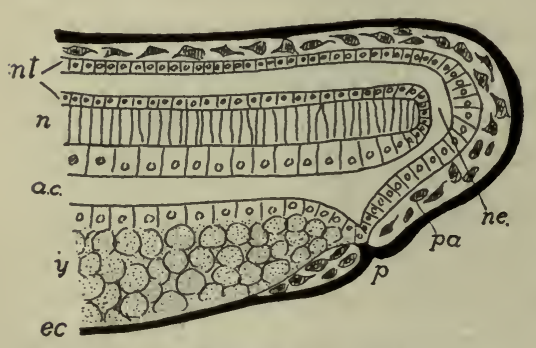

FIG. 7.-Schematic section of the hinder end of an amphibian embryo, showing the relations of the neurenteric canal. $a c$, alimentary canal; $e c$, ectoderm (black); $n$, notochord; $n e$. neurenteric canal; $n t$, neural tube; $p$, proctodeum; $p a$, post-anal gut; $y$, yolk. ally, separating the nervous system from the rest of the ectoderm. Its subsequent history will be traced in the section of the Nervous System.

The Notochord.-Immediately beneath the neural plate is an axial strip of entoderm (fig. 5, ch), bounded on either side of the outgrowing mesothelium. When the latter separates (p. Io) this band is momentarily rejoined to the rest of the entoderm but is still recognizable from its different cells. It soon rolls into a rod (a tube in some amphibians and birds), is cut off from the rest (fig. $6, n$ ) and lies between the digestive tract and the nervous system where it forms an axis around which the skull and vertebral column develop later.

The Digestive Tract.-After the separation of the notochord, the entoderm forms a tube, closed in front and usually behind as well. The anterior end of the tube abuts against the ectoderm of the ventral side of the embryo. Later the ectoderm grows in at the point of contact, carrying the entoderm before it and forming a pocket, the stomodeum, which gives rise to the cavity of the mouth. (In some the stomodeal ingrowth is at first solid, the pocket being formed later by splitting). Eventually the ectoderm and entoderm fuse at the bottom of the cup, and then the fused area breaks through, placing the archen- 
teron in connexion with the exterior. A similar, but less well defined proctodeum (fig. $7, p$ ) arises at the hinder end of the digestive tract. Thus the anterior and posterior ends of the alimentary canal are ectodermal, the middle region entodermal, in origin.

Metamerism.-In the adult, various parts, essentially like each other, are repeated one after another-are metameric. The list includes, among others, muscles, nerves, blood-vessels, vertebræ, ribs, etc. There is much evidence to show that metamerism had its origin in the mesothelial structures and has been secondarily impressed on other systems.

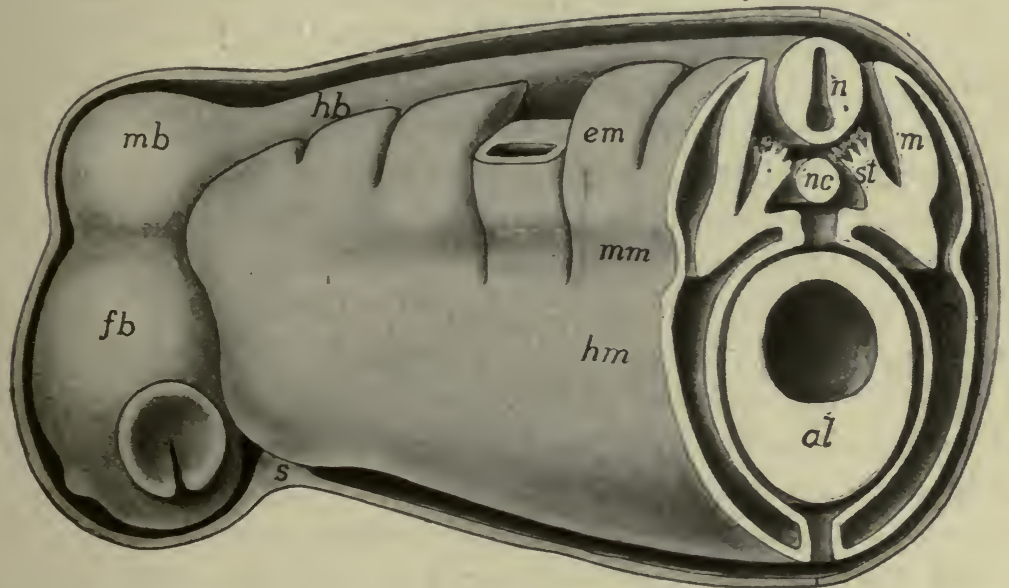

FIG. 8.- Stereogram of a later stage than fig. 6 , showing the segmentation of the mesothelium. The approach of the walls of the coelom $(c)$, dorsal and ventral to the alimentary canal, to form the mesenteries is shown. al, alimentary canal; em, epimere; $f b$, forebrain; $h b$, hind brain; $h m$, hypomere; $m$, myotome; $m b$, midbrain; $m m$, mesomere; $m c$, metacale; $m y c$, myocole; $n$, nervous system; $n c$, notochord; $s$, stomodeal region; so, sp, somatic and splanchnic layers; st, sclerotome.

The mesothelial cœlomic pouches, as left above, are near the dorsal side of the embryo. With growth they gradually extend downward on either side and tend to enclose the whole arrchenteron, and upward on either side of the notochord and spinal cord (fig. 8). The fates of the different parts of the mesothelial walls warrants the recognition of three horizontal regions or zones in the walls of each cœlom. These are a dorsal muscle-plate zone (epimere, em), a lower or lateral-plate zone (hypomere, $\mathrm{hm}$ ), and a middle-plate zone (mesomere, $\mathrm{mm}$ ) between them. All three of these occur in the trunk, but only the epimere is well developed in the anterior part of the head. 
A series of vertical constrictions begins at the dorsal margin of each cœlomic pouch and cuts down through epimere and mesomere, so that the whole may be compared to a glove with a large number of fingers extending from its upper surface, each finger being hollow, and all of the cavities connecting with that in the hypomere (palm). This process begins at front and gradually extends backward. Viewed from above in the transparent embryo, each of these fingers appears like a square box and early students thought that they gave rise to the vertebræ, and so they were called protovertebræ. Next, the dorsal part of each of these fingers is cut off from the rest, along the line between mesomere and epimere, thus forming a series of hollow cubes, known as myotomes, each with a part of the colom in its interior, the myocœle. After the separation from the rest each myotome grows upward and to a greater extent downward, insinuating itself between the ectoderm and the somatic wall of the hypomere (fig. 9, in the direction of the arrows). From these myotomes the body (somatic) musculature arises.

From the medial mesomeral part of the fingers arises the mesenchyme that gives origin to the vertebræ while the rest furnishes the material for the excretory organs. From their origin both of these are metameric at first, the skeletogenous parts being called sclerotomes, the excretory parts, nephrotomes (fig. $8, \mathrm{~mm}$, st). The history of both will be followed in their proper places.

The Cœlom.-The parts of the cœlom in the myotomes soon disappears, that in the nephrotomes, of inconsiderable size, forms the lumina of the excretory ducts. That in the hypomere (fig. 9, c) forms the large body cavity (peritoneal cavity) surrounding the chief viscera, and the smaller one (pericardial) around the heart. In surrounding the archenteron the walls of the two cœlomic cavities, which at first are separate, tend to meet above and below the entoderm, so that there is in both regions a thin membrane supporting the digestive tract above and below. Such supports are collectively called mesenteries. Usually that below ( $v$ mes) largely disappears, but the dorsal ( $d$ mes) one persists more or less completely. At first these mesenteries are merely double membranes of mesothelium, but soon mesenchyme grows in between them and extends around the digestive tract, so that mesothelium and entoderm are bound together by the invading tissue. In a similar way the somatic wall of the cœlom is bound to the muscles arising from the myotomes and these in turn to 
the ectoderm by the mesenchyme. In this way the colom comes to have two thick walls. That on the outer side, consisting of ectoderm, muscles and peritoneal lining, is called the somatopleure (so), that of peritoneum and digestive wall is the splanchnopleure $(s p)$.

For convenience the different mesenterial structures have separate names. As the digestive tract becomes coiled, the different parts of it are connected by similar membranes which are called omenta $(\mathrm{om})$. The dorsal mesentery is subdivided into regions supporting the different portions of the digestive tract.

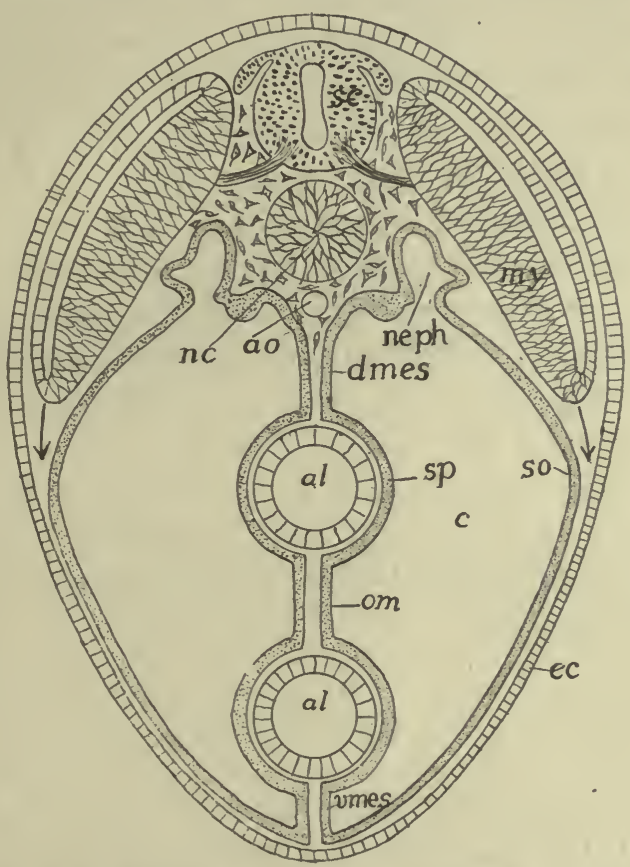

FIG. 9.-Diagrammatic transverse section of a vertebrate to illustrate mesenteries, omentum and downward growth of the myotomes. al, alimentary tract; ao, aorta; $c$, cœlom; ec, ectoderm; $d m e s$, dorsal mesentery; $m y$, myotome; nc, notochord; neph, nephrotome; $o$, omentum; sc, spinal cord; so, $s p$, somatic and splanchnic layers of mesothelium; vmes, ventral mesentery.

Thus there is a mesogaster for the stomach, a mesentery proper for most of the intestine, and mesocolon and mesorectum for colon and rectum respectively. On the ventral side there is a mesohepar, bounding the liver to the ventral body wall. In the same way the omenta are distributed into hepato-duodenal, gastro-hepatic (small omentum), etc., while in mammals there is a great omentum, a double fold of mesogaster and mesocolon which connects the stomach with the transverse colon.

Similar folds are formed in connection with other organs. Thus the heart 
for a time is bound to the pericardial walls by dorsal and ventral mesocardia; there is, in mammals, a mediastinum between the two pleural cavities, connecting the pericardium to the body wall, while frequently the ovaries and the testes project into the cœlom, carrying the peritoneum with them, thus giving rise to a mesovarium or a mesorchium, according to the sex.

The Mesenchyme has two chief places of origin. One is from the splanchnic wall of the segments of the mesomere, each of which is the centre of rapid cell proliferation and forms the sclerotome (fig. $8, s t$ ), since some cells arising from it are concerned in the formation of the axial skeleton. These cells pass in to surround the notochord, and upward on either side of the central nervous system and downward beside the alimentary canal, thus forming a partition between the two sides of the body. A second source of the mesenchymatous cells is from the somatic wall of each myotome, all of the cells of which are transformed into this layer, and lie immediately beneath the ectoderm. Thus there is a complete envelope of mesenchyme around the whole body. From these and from other sources the mesenchyme extends everywhere in the remains of the segmentation cavity-between the muscles and around the various viscera-forming a framework in which the products of all the other layers are enveloped (fig. 30). This mesenchymatous framework has great importance in the development of the skeleton and its general plan will be described in connection with the skeletal structures.

\section{HISTOLOGY.}

In the gastrula the cells differ from each other chiefly in position, and the same is true even when the germ layers are first differentiated. As development goes on the differences between the various groups of cells increase, each group becoming more specialized for some one purpose and losing the power to do more than the one kind of work. For community of work cells of the same kind become associated together, the result being tissues. A tissue then is a connected mass of cells similar in appearance and function, together with a varying amount of intercellular substance, usually formed by the cells themselves. The study of the minute structure of animals and especially of the tissues is the province of histology.

There are many kinds of tissues, only a few of which need mention here, but all may be grouped under four great heads: epithelial 
nervous, muscular and connective tissues; the members of each group having certain fundamental points in common.

\section{Epithelial Tissues.}

Epithelia are the covering tissues, and occur on any free surface, internal or external, of the body. Both comparative anatomy and embryology show them to be the primitive tissues, for there are many lower animals which are made up entirely of epithelia, while in the vertebrates the embryo consists solely of epithelia until the mesenchyme appears. Epithelia may come from any of the germ layers, in rare cases (synovial cavities) even from mesenchyme.
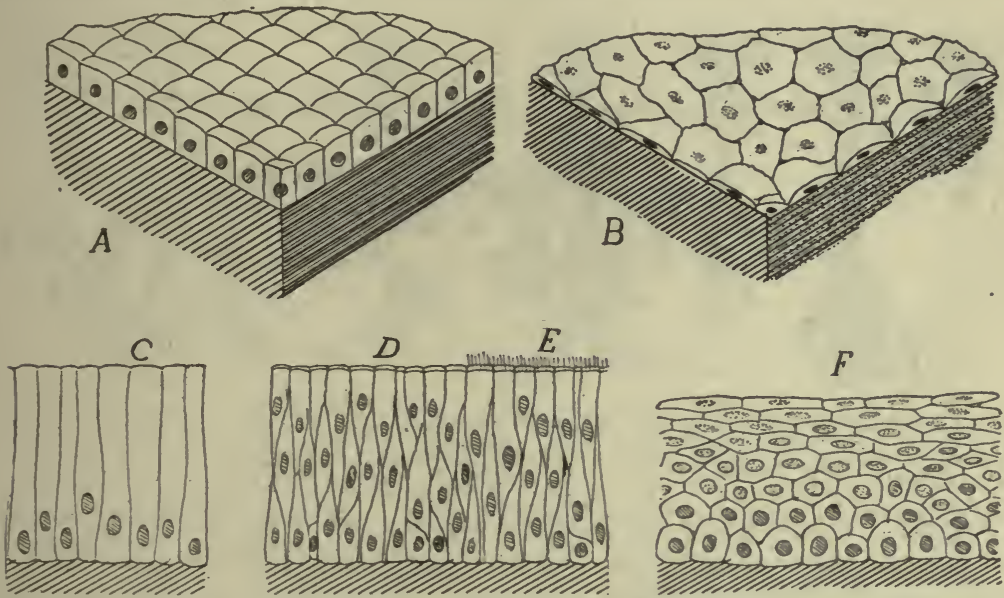

FIG. Io.-Epithelia: $A$, cubical; $B$, squamous; $C$, cylindrical; $D$, stratified cylindrical, ciliated at $E ; F$, stratified squamous.

The character of epithelium varies according to the character of the work it has to perform. That on the outside of the body is largely protective, hence it is often thickened and strengthened in different ways to afford resistance against external injuries. In other places, as glands, it has to elaborate and to allow the passage outward of material from within. In the body cavity and in the blood-vessels it has merely to form the thinnest of coverings, while in the case of sensory structures it is modified (sensory epithelium) to receive the stimuli from without.

The usual classification of epithelia is based on the shapes and arrangements of the cells. Thus in cubical epithelium (fig. Io, $A$ ) the cells are about as high as broad; in columnar $(C)$ their height 
exceeds their diameter; while in squamous epithelium, the cells are thin and flat, covering the largest amount of surface with the least amount of material $(B)$. Sometimes the epithelial cells are in a single layer, forming simple epithelium $(A, B, C)$; in other places there are several layers - the epithelium is stratified $(D, E, F)$.

Frequently epithelia, usually of the columnar variety, are called upon to move fluids slowly; then the free surface is covered with minute vibratile hairs or cilia $(E)$ which create currents. In glandular epithelium the cells, usually cubical or columnar, are specialized for the elaboration of secretions to be used by the animal or of waste products (excretions) to be voided from the body.
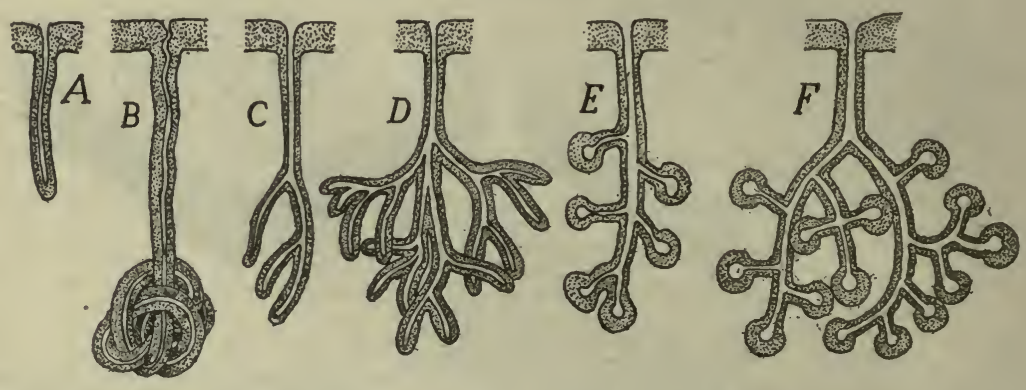

FIG. II.-Different types of glands; $A$, to $D$, tubular; $E, F$, acinous; $A$, simple; $B$, coiled; $C-F$, branched.

Glands. - The chief kinds of glands may be mentioned here. All have for their function the extraction and elaboration of certain products from the blood, consequently they have a good blood supply. Glands may be unicellular or multicellular according as they consist of isolated cells or of many cells. In unicellular glands (abundant in the digestive tract) each cell passes its own secretion directly to the place where it is to be used (fig. I $9, u$ ).

Multicellular glands occur where a large amount of secretion is necessary in a limited space, hence they are not on the surface but at some deeper point, and their product is conveyed to the desired place by a duct. Multicellular glands are of two structural kinds. In the tubular gland the whole is approximately of the same diameter throughout, with little differentiation of gland and duct. It may be simple $(A)$ or coiled $(B)$ or branched $(C, D)$, these modifications serving to increase the secreting surface. In acinous glands $(D, E)$ there is a marked differ ence between gland and duct, the glandular part forming an enlargement (acinus) on the end of the duct. Both simple and compound acinous glands are common.

Still another type of gland, the ductless or 'internal secretion' gland occurs. In this there is no duct, the secretion elaborated by the cells passing by osmose into the blood-vessels. These secretions, collectively known as hormones, have recently acquired great prominence from their influence on different organs. 


\section{Nervous Tissues.}

Nervous tissue has for its function the correlation of the animal with its environment. In order to accomplish this it must provide for the recognition of stimuli from without, the inauguration of other impulses within itself and the transfer of both to other parts. The essential constituent of the tissue is the nerve cell, ganglion cell or neuron, to which are added others of a supportive (glia cells) or nutritive character. As the parts to be connected by the nervous tissue are often remote from each other the neuron is not compact like most other cells, but gives off long processes from the central mass, these processes differing in their terminations. Some end in places where they can only

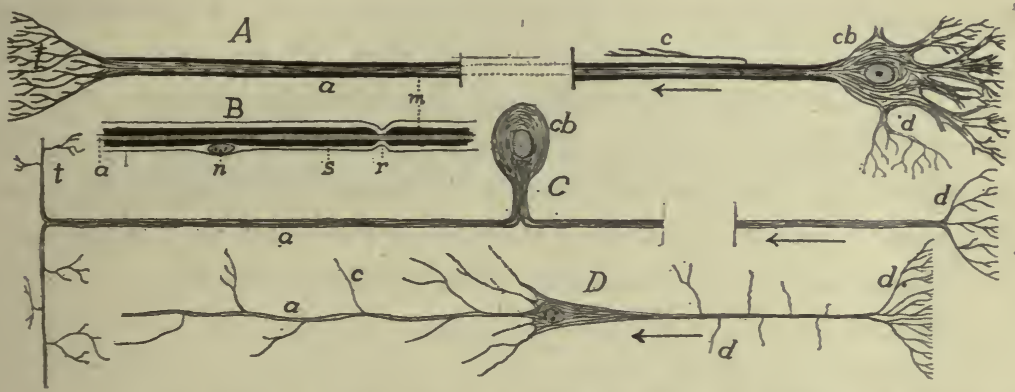

FIG. 12.-Various kinds of nerve cells. $A$, multipolar cells; $B$, portion of nerve fibre with sheaths; $C$, unipolar cell; $D$, pyramidal cell; $a$, axon; $c$, collateral; $d$, dendrites; $c b$, cell body; $m$, medullary sheath; $n$, nucleus of cell of Schwann's sheath; $s$, sheath of Schwann; $t$, telodendron.

receive stimuli, others where the stimuli can only cause parts to act. Thus the processes are physiologically divisible into afferent and efferent tracts, the body of the cell being the place for the regulation and correlation of the impulses, and apparently in many cells for the inauguration of new impulses.

A nerve cell (fig. I2) is uni-, bi- or multipolar accordingly as it has one, two or more of these processes. In the case of unipolar cells (C) the single process sooner or later divides, so that the cell in reality is at least bipolar. At the ends the processes may either break up in minute twigs (dendrites, $d$ ) or may end, as in muscles and sense organs, in special end organs. The part connecting the efferent termination and the central cell body is called the axon (a). Axons and cell bodies are gray in color, but usually the axons are surrounded by a medullary sheath $(m)$ of a peculiar white substance (myelin) rich in fat, which 
apparently acts as an insulator, preventing nervous impulses from passing from one axon to another. This sheath does not continue over the dendrites. Frequently the dendrites of two neurons interlace for the transference of stimuli from one to the other, but the present opinion is that, at least in vertebrates, there is no actual continuity of substance between neurons, only an interlacing of terminal twigs. The medullary sheath is not cellular, but frequently fibres may be surrounded by a sheath of Schwann $(s)$, with scattered nuclei. This has been regarded as mesenchymatous, but recent researches tend-to show that it is ectodermal, its cells coming from the nervous system.

Nervous tissue consists of these neurons plus connective tissue and glia cells. A nerve, as found in dissection, consists of numbers of axons, bound together by a connective-tissue envelope (perineureum). The myelin gives these nerves a white color. In the brain and spinal cord there are tracts of medullated fibres (white matter) while the parts with abundant nerve cells are gray. When such gray matter is aggregated in the course of a nerve, it causes an enlargement called a ganglion. Interlacing among the neurons in brain and spinal cord is the neuroglia, which is also derived from the ectoderm, and acts as a support but has no nervous functions. Certain of these glia cells develop many branches (mossy cells) which twine among nerve cells, axons, and dendrites.

\section{Muscular Tissues.}

While several kinds of cells have the power of changing shape, those composing muscular tissue possess it in a marked degree, acting quickly and with force, so that these tissues are preeminently the tissues of motion. The cells become elongate and develop on their interior a large amount of contractile substance (myofibrillæ), which on stimulation, contracts, shortening the cell. In the vertebrates, muscular tissue always arises from the mesoderm, yet two types are recognized, differing markedly in origin, appearance and physiological action.

The smooth or involuntary muscles arise from the mesenchyme. They consist of long and spindle-shaped cells (fig. $\mathrm{I}_{3}, A$ ), each with a single nucleus, the protoplasm traversed by numerous myofibrillæ, which appear like fine longitudinal lines. In the vertebrates the smooth muscle is not under control of the will; it contracts slowly.

In contrast to the smooth is the striped or voluntary muscular tis- 
sue, which arises from a modification of the mesothelium. Except in the case of the muscles of the heart, the striped tissue is under control of the will; it usually occurs in larger masses than does the smooth, and is capable of rapid contraction. It differs structurally from smooth muscle. Instead of distinct, uninucleate cells there are long cylindrical elements (fig. I3, B), the primitive fibres, each with several nuclei in the interior in lower vertebrates, on its periphery in the higher. Most of the protoplasm of the fibre has been altered to minute contractile fibrillæ, each crossed by lighter and darker bands, and as these come opposite each other in the different fibrillæ, they give the fibre its characteristic cross-banded appearance.

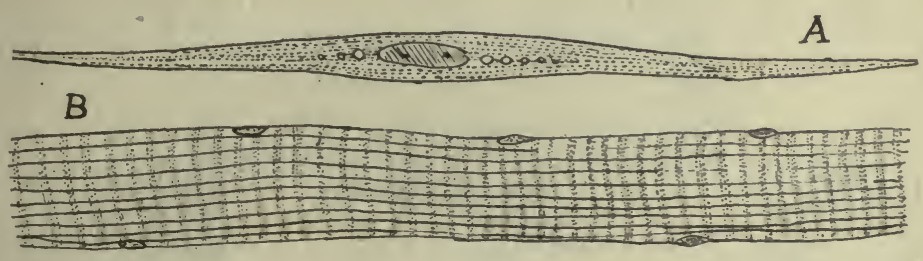

Fig. 13. $-A$, smooth muscle cell; $B$, striped muscle.

The primitive fibres rarely branch at their extremities. Each is surrounded by a structureless envelope, the sarcolemma, while numbers of fibres are bound into bundles and muscles by connective tissue (perimysium) which carries nerves and blood-vessels. At the ends of the bundles the perimysium continues into the tendons which attach the muscles to other parts.

The heart muscle also arises from the mesothelium, is cross-banded, but is removed from control of the will. The cells are usually short (usually with a single nucleus); they branch, the branches connecting adjacent muscle cells.

\section{Connective Tissues.}

The tissues grouped here arise from the mesenchyme and are distinguished from all other tissues by the great amount of intercellular substance produced by the cells themselves. This substance or matrix varies in character and determines the variety of tissue. Frequently it is dense and hence the connective tissues may give the body support, and in fact they are sometimes called supportive tissues. 
In the earliest phase, known as embryonic connective tissue (fig. I4, $A$ ), the cells are scattered, with long radiating processes, and between the cells a thin gelatinous matter. It is by increase of this intercellular substance by taking up water that many embryos gain so in size without taking food. The embryonic connective tissue may develop in various directions.

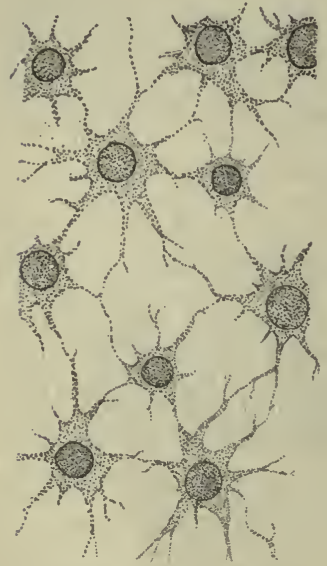

A

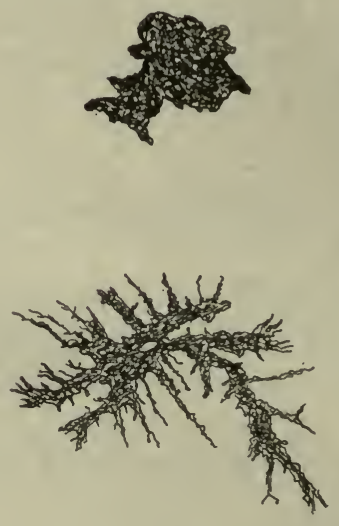

B

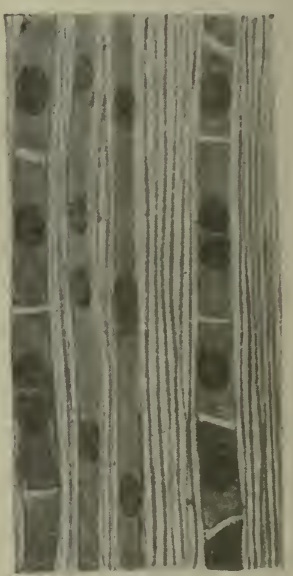

C

FIG. 14.-Connective tissues. $A$, embryonic, from Amblystoma; $B$, expanded and contracted pigment cells from Amblysioma; $C$, fibrous, from tendon.

Thus some of the cells may contain pigment granules, forming pigment cells $(B)$, or oil globules may be deposited in them to such an extent that the cells become spherical, while the intercellular substance is reduced, thus affording fat or adipose tissue. Most common of the connective tissues is fibrous tissue (white or non-elastic tissue) in which the cells are branched or spindle-shaped while the matrix is filled with fine fibrillæ of considerable strength and little elasticity.

These fibrillæ are parallel to each other in tendons $(C)$, which have to convey strains in one direction; or they may be interlaced confusedly, the tissue then forming sheets or membranes. Occasionally, as between the skin and the muscles, the fibrous tissue may be loose (areolar tissue). In elastic tissue fibres of another kind are mingled among the non-elastic fibrils. These are yellow and elastic, and when abundant give an elastic character to the whole.

In cartilage and bone the matrix is more solid and is abundant. These are the skeleton-building tissues. In cartilage the matrix is 
firm and consists of a peculiar substance called chondrin. When the chondrin is nearly pure it is milky in appearance (hyaline cartilage, fig. I5), but it may be invaded by numerous strands of fibrous or elastic tissue, resulting in fibrous or elastic cartilage. Cartilage increases in size by additions to the exterior and also by divisions of its cells and by increase in the amount of matrix. Externally it is

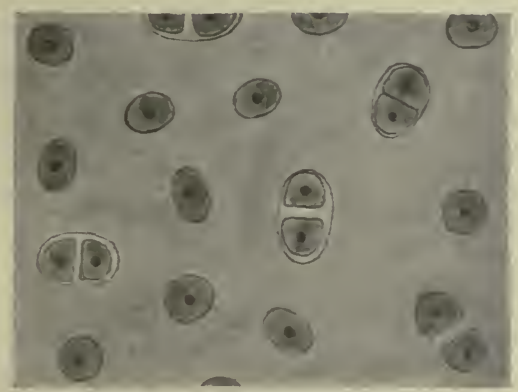

FIG. I 5.-Hyaline cartilage.

bounded by an envelope of connective tissue (perichondrium) which bears blood-vessels and may give attachment to muscles, etc.

Bone may arise directly from embryonic connective or fibrous tissue, or by the ossification of cartilage. In either case the result is a strong matrix composed of calcium phosphate and carbonate in a ground

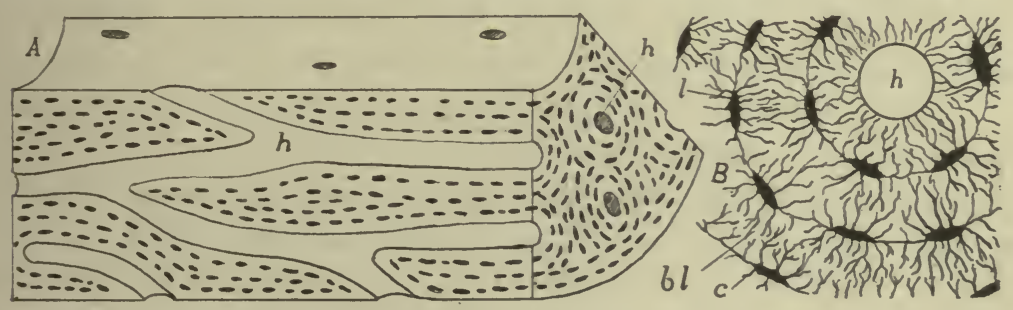

FIG. I6.- $A$, Stereogram of bone; $B$, cross-section of bone, more enlarged; $c$, canaliculi; $b l$, bone lamellæ; $h$, Haversian canal; $l$, lacuna.

substance of organic matter (ossein). Minute tubes (Haversian canals), bearing blood-vessels, etc., run through the matrix (fig. I6), and parallel to these canals or to the external surface of the bone are the cells arranged in layers. The space occupied by a cell is called a lacuna, from which minute tubules or canaliculi penetrate the matrix. There are small spaces in many bones occupied by the red marrow, 
which is especially noticeable as one of the places of formation of red blood-corpuscles. Externally every bone is covered by a layer of fibrous connective tissue, the periosteum. .

The dentine of teeth and placoid scales is closely allied to bone, the chief difference in density, the bone-forming cells (odontoblasts) not being enclosed in the matrix, while the canaliculi (here called dentinal canals) are parallel to each other.

Blood is sometimes regarded as a connective tissue, the corpuscles being the cells and the fluid part (plasma) the matrix. It is here dealt with in connection with the circulatory system. 


\section{COMPARATIVE MORPHOLOGY OF VERTEBRATES.}

\section{THE INTEGUMENT.}

The integument is the covering of the body, the term including the skin (cutis) and all structures derived from it. From its position it is a protective coat. It comes into relation with the external world and is modified in various ways, becoming hardened to ward against mechanical injury, developing sensory structures to give information of untoward conditions and being impervious so as to prevent loss of the body fluids or the entrance of others from without. Naturally the habitat, aquatic or terrestrial, has great influence in the character of the modifications.

In all vertebrates the integument consists of two layers, an outer epidermis which consists of the ectoderm after the separation of the nervous system, and a deeperlayer, the corium (derma) of mesenchyme, derived from the somatic wall of the myotomes, into which other structures (nerves, blood-vessels, etc.) extend. Strictly speaking the bony scales of fishes are integumental, but on account of their close relations to the skeleton they are best treated in that connexion.

In the epidermis, again, two layers are always present. At the base, next to the corium is the Malpighian layer (stratum germinativum), the cells of which are nourished by the fluids of the corium. Hence they can grow and divide, the new cells thus formed gradually passing to the outside where they form the second layer, the stratum corneum, the outer cells of which are usually worn away as fast as new ones are added from below. Occasionally these outer cells come off in large sheets, as when a salamander or a snake sloughs its 'skin.' In the development of the epidermis of the terrestrial vertebrates the first layer of cells budded from the Malpighian stratum form a continuous sheet which is later shed as a whole. This is the periderm (fig. I7), the older name of epitrichium being inappropriate, since the layer is found in reptiles and birds where no hair occurs. 
The Malpighian layer alone is concerned in the formation of the glands connected with the skin, and the corresponding part of the ectoderm contributes to the sensory structures like the nose and ear. The corneum, on the other hand, is concerned in the formation of protective structures like hair, nails, claws, feathers, and other cuticular outgrowths. The epidermis is generally thicker in terrestrial than in aquatic vertebrates, and in the latter, being constantly moist, shows less of the horny consistency, than occurs in animals which live in the air.

The corium lies immediately beneath the epidermis and is less sharply separated from the deeper tissues by a looser layer of connective tissue (subcutis, tela subjunctiva) in which fat is frequently extensively developed. The corium is largely composed of fibrous connective tissue, intermingled with elastic tissue, blood-vessels, nerves, smooth muscle fibres, etc. It is usually thin in the lower vertebrates,

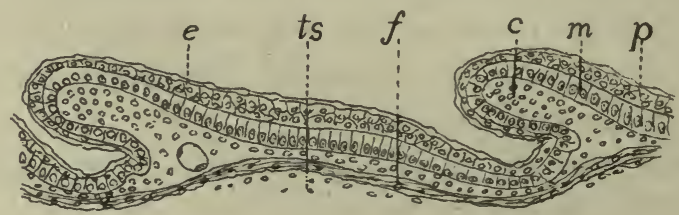

FIG. I7.-Section of developing scales of lizard, Sceleporus. c, papilla of corium; $e$, outer layer of epidermis which later becomes cornified; $f$, fibrous layer of skin; $m$, Malpighian layer; $p$, periderm; $t s$, tela subjunctiva.

but is much thicker in most mammals, and forms the whole of ordinary leather. Pigment cells may occur in both epidermis and corium. These are mesenchyme cells, loaded with pigment, which are frequently under control of the nervous (sympathetic) system, and can be altered in shape (chromatophores), thus producing color changes, which, as in the chameleons, may be very marked.

Horny scales, produced by a cornification of the epidermis, are found in all groups of terrestrial vertebrates, but they are rare in amphibians and mammals. The development is best seen in reptiles (fig. I7). By a multiplication of the cells of both corium and epidermis in definite regions the skin becomes divided into thicker areas, separated by thinner lines, each area corresponding to a future scale, which arises by the conversion of the stratum corneum into horny material. In snakes and lizards these scales, together with all of the stratum corneum (even the covering of the eye) is periodically molted, the separation tak- 
ing place at the surface of the stratum Malpighii. In turtles and alligators there is a gradual wearing away of the surface.

Closely allied to scales are claws, hoofs and nails (fig. 18). A claw may be regarded as a cap of the tip of a digit, formed by two scales one dorsal (unguis), the other ventral (subunguis). Of these the unguis is the more important. It grows continually from a root, and in mammals is forced forward over its bed. In the claw $(B)$ the unguis is curved both transversely and longitudinally, the subunguis forming its lower surface. In the human nail $(A)$ it is nearly flat in both directions and the subunguis is reduced to a narrow plate just beneath the

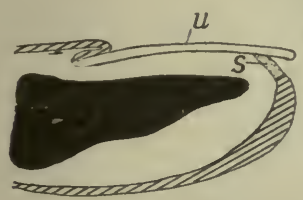

A

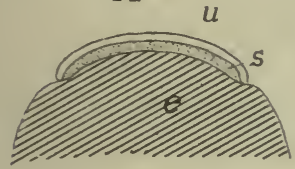

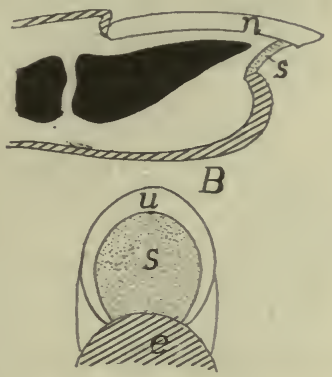

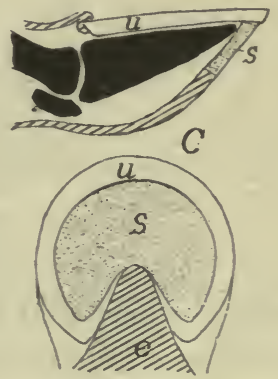

FIG. 18.-Diagrams of $(A)$ nails, $(B)$ claws, and $(C)$ hoofs, based on Boas. $e$, unmodified epidermis; $n$, unguis; $s$, subunguis.

tip of the nail. In the hoof $(C)$ the unguis is rolled around the tip of the toe, while the subunguis forms the 'sole' inside it. The 'frog' is the reduced ball of the toe which projects into the hoof from behind.

The integument presents many different conditions in the separate groups of vertebrates, and so details are best given under the special heads.

FISHES.-The aquatic life renders the epidermis of fishes soft and cornifications of it are comparatively rare, among them the peculiar 'pearl organs' which appear in the skin of some teleosts at the breeding season. Glands, on the other hand, are abundant. These are unicellular and multicellular mucus glands of different shapes in the epidermis, the secretion of which furnishes the slime on the surface. Some elasmobranchs and a number of teleosts have poison glands, usually in close relation to the spines of the fins. The elasmobranchs also have large glands in the 'claspers' of the males, but their purpose is not well understood. 
Possibly the most striking of the epidermal organs are the luminous organs or photophores, which are most common in elasmobranchs and teleosts from the deep seas, where sunlight does not exist. They are apparently modified glands, and the development is known in Porich-

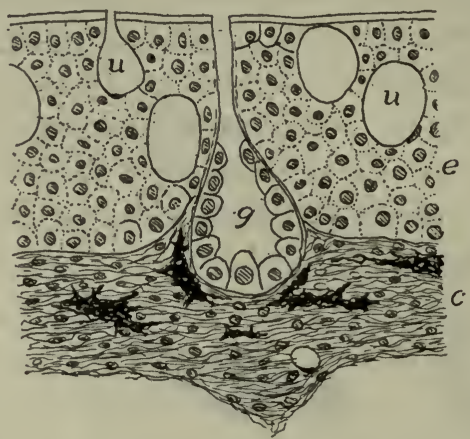

FIG. 19.-Section of skin of Protopterus. $c$, corium; $e$, epidermis; $g$, multicellular gland; $u$, unicellular gland.

thys. There is an involution of cells of the Malpighian layer into the corium, where they become cut off from their point of origin, and are differentiated into a deeper glandular layer and an outer rounded body, the lens (fig. 2I). Around this the corium forms a reflecting layer
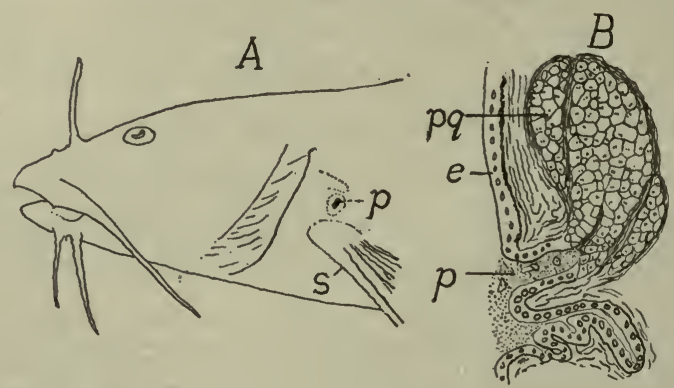

FIG. 20.-A, head of Noturus flavus; $\dot{B}$, section of poison gland of Schilbeodes miurus (after Reed). $\quad e$, epidermis; $p$, pore of poison gland, $p g ; s$, spine of pectoral fin.

enclosed in a pigment coat. The glandular layer is the seat of light production. In other photophores either reflector or pigment may be lacking, but in their highest development they so resemble an eye that at first they were described as such.

In the myxinoids the skin contains numerous thread cells in pockets which may extend into the underlying muscles. Each thread cell contains a long thread, which 
is discharged upon stimulation, the threads forming a network in which the mucus secreted by the ordinary gland cells is entangled.

The corium is thin and consists of horizontal bands of fibrous tissue, crossed at intervals by vertical strands. Fat is common in the tela subcutanea, and in some fishes this layer contains numerous crystals of guanin which gives it a silvery appearance. This guanin forms the base of 'essence of pearl' from which artificial pearls are made. The scales of fishes, although formed in the skin, are considered in connection with the skeleton.

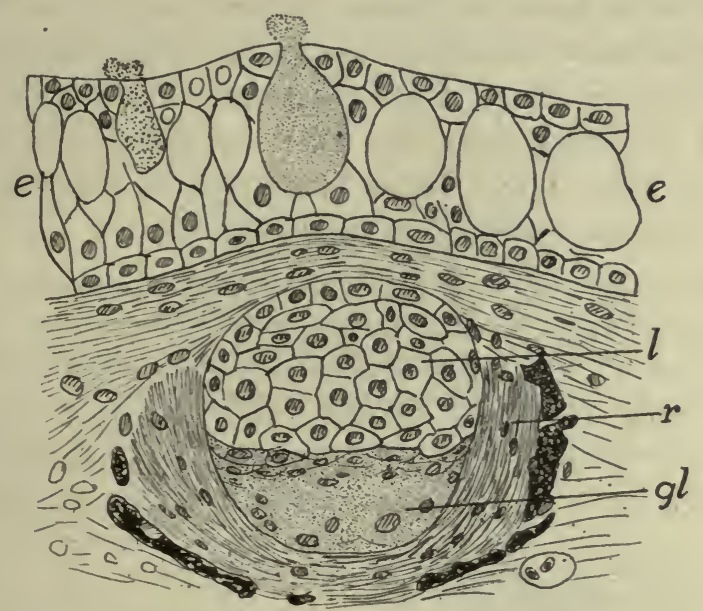

FIG. 2I.-Section of luminous organ (photophore) of Porichthys, after Greene. $e$, epidermis with mucous cells; $g l$, glandular layer of photophore; $l$, lens; $r$, reflector surrounded by pigment.

AMPHIBIA.-The amphibia are remarkable in that the epidermis of the larvæ is ciliated in the early stages, and is two cells in thickness from the first. The skin, in the larvæ and the aquatic species, contains numerous mucus glands and some for the production of poison, some of the latter being prominent like the 'parotid glands' on the neck"of the anura and the gland on the back near the base of the tail.

The corium is thin, and in the frogs is separated from the underlying parts by large lymph spaces which render the skinning of these animals so easy. As the amphibia respire largely by the skin (there are several lungless salamanders) the corium is richly supplied with blood-vessels, and at the time of the metamorphosis of the anura these penetrate even into the epidermis, as at that time the lungs are not yet functional and the gills are absorbed. The stratum corneum is shed periodically, either as a whole (urodeles) or in patches. The warts of toads are in part cornifications of the epidermis, and a similar hardening of the skin on the ends of the toes of some results in claws. In the males of an African frog (Astylosternus) the skin has the granules of the surface developed, at the breed- 
ing season into hair-like structures, supplied with nerves and apparently sensory in character.

REPTILES.-All living reptiles are characterized by the extensive development of horny scales and frequently of bony plates in the skin, but some of the fossil groups (ichthyosaurs, pterodactyls, some dinosaurs, possibly plesiosaurs) had a naked skin. Correlated with this cornification of the epidermis, glands are rare. Some turtles have scent glands beneath the lower jaw and along the line between carapace and plastron; snakes and crocodilians have them connected with the cloaca, while the latter have others, of unknown function, between the first and second rows of plates along the back, as well as protrusible musk glands on the lower jaw. These latter are not true glands as they produce no secretion but cast out the lining cells.

The corium presents two layers, the outer rich in chromatophores, but, aside from some snakes and lizards, the color changes are not remarkable. The femoral pores of lizards are not connected with glands but with branching tubes filled with cast cells. Claws are common on the toes.

BIRDS have both layers of the skin very thin, the epidermis developing both scales and feathers. Correlated with this extensive develop-

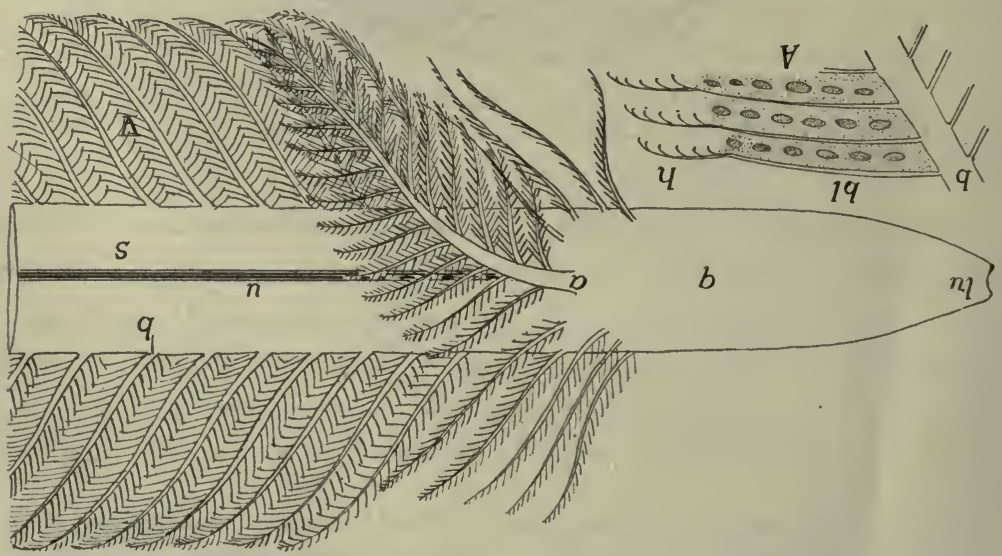

FIG. 22.-Diagram of base of contour feather. $a$, aftershaft; $b$, barbs; $b l$, barbules; $h$, hooks on ends of barbules; $l u$, lower umbilicus; $q$, quill; $s$, shaft; $u$, umbilicus; $v$, vane. $A$, portion of a barb showing the barbules and hooks.

ment of cornified structures is a striking paucity of glands. There are none in the ostriches, but others have the familar oil (uropygial) glands at the base of the tail, the secretion of which is used in dressing the fea thers. The only other dermal glands in birds are modified sebaceous 
glands near the ear in some rasores. The scales on the legs and the claws on the feet and occasionally on the wings, are derivatives from reptilian ancestors. The feąthers are also derived from scales, but are greatly modified.

Feathers.-There are several kinds of feathers but all may be grouped under three heads: hair feathers (filoplumes), down feathers (plumulæ), and contour feathers (plumæ). The latter have all of the feather features (fig. 22) and in the typical form consist of shaft and vane. The basal part of the shaft is the hollow quill, in which is a
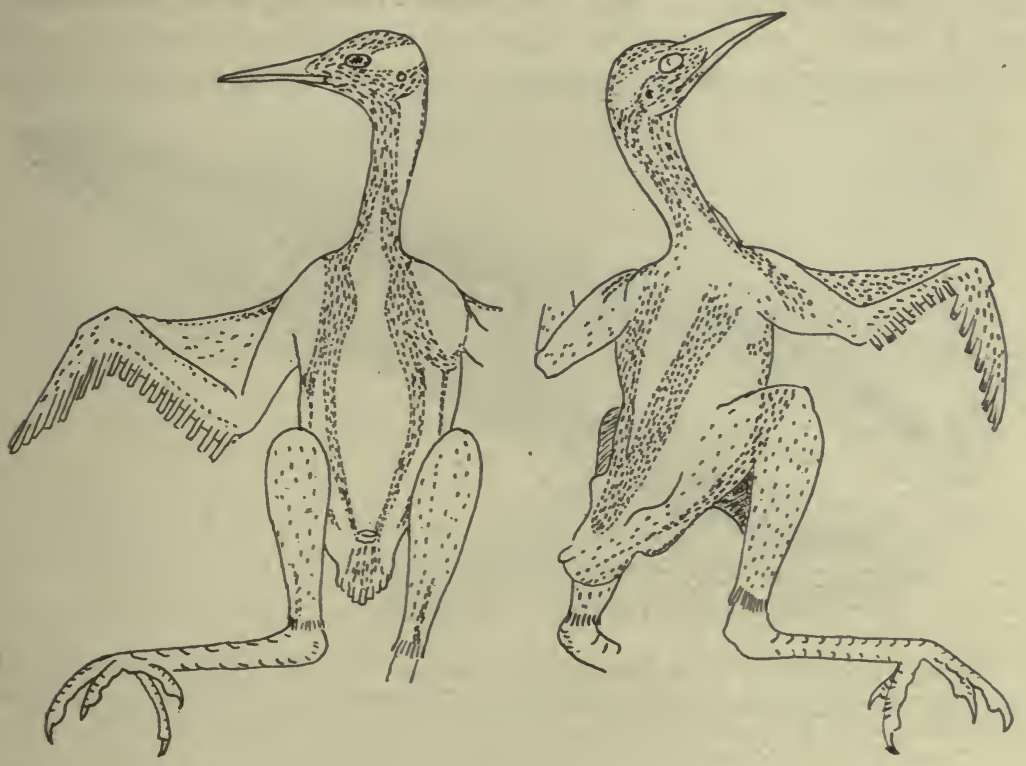

Fig, 23.-Feather tracts of Geococcyx californianus, after Shufeldt.

small amount of loose pith. In the region of the vane the shaft, here called rhachis, is solid, and running the length of its lower surface is a groove, the umbilicus. The vane consists of lateral branches (barbs) on either side, which have, in turn, smaller side branches (barbules), these with small hooks at their sides and tips $(B)$. Interlocking of these hooks gives firmness and continuity to the whole vane. In down feathers the barbs arise directly from the end of the quill, and as hooks are lacking, the barbs do not interlock and no vane is formed. Hair feathers are merely long and slender shafts with no barbs, the simplest, if not the most primitive kind of feather. It is still a question as to 
the primitive type. The oldest fossil bird, Archcopteryx, had well developed contour feathers.

Except in the ostriches, penguins, and toucans, feathers are not distributed everywhere on the surface of the body, but are gathered in feather tracts (pterylæ), separated by apteria in which no contour feathers and but few down or hair feathers occur. These vary in their arrangement in different groups of birds and are of systematic importance (fig. 23).

Complicated as they are, feathers are probably derived from scales, and the section of lizard skin (fig. I7) might well represent an early stage in the development of a feather. A down feather begins as a thickening of the corium, pushing the epidermis before it. By continued growth this forms a long, finger-like papilla,

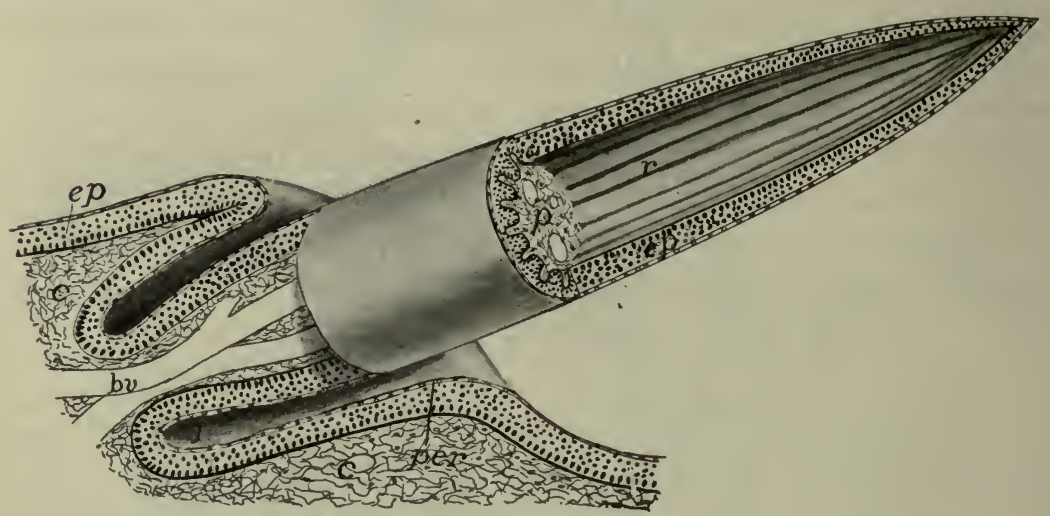

FIG. 24.-Stereogram of developing down feather. $b v$, blood-vessels entering pulp; $c$, corium; $e p$, epidermis; $f$, feather follicle; $p$, pulp (mesenchyme) of developing feather; per, periderm; $r$, rods of epidermis, which later dry, separate, and form the down.

projecting from the skin. The corium extends into the outgrowth, carrying bloodressels with it, while an annular pit, the beginning of the feather follicle, forms around the base of the papilla. Next, the corium or pulp of the distal part of the papilla forms several longitudinal ridges (fig. 24) which gradually increase in height, growing into the epidermis and pressing the Malpighian layer above them against the periderm. As a result the stratum corneum is divided distally into a number of slender rods arising from the base (quill), which at last are only held together by the periderm. Then the pulp retracts, carrying with it the Malpighian layer. With the blood supply removed, the epidermal parts dry rapidly, the periderm ruptures, allowing the rods to separate to form the down.

A contour feather has much the same development, differing in details, for an account of which reference must be made to special papers. The ridges of the corium are no longer longitudinal, but beginning on the dorsal side of the papilla, run obliquely outward and downward (fig. 25) until they meet below. Thus 
there are formed a series of rods set at an acute angle to the undivided dorsal strip, the future shaft. When set free, as before, by the rupture of the periderm, these rods straighten out, forming the vane. In the region of the shaft there are two longitudinal ridges on the ventral side. These gradually roll together, thickening and strengthening the shaft, the groove between them forming the umbilicus. As will be understood, the dorsal and ventral sides of the feather were the outside and inside of the stratum corneum of the papilla.

The corium is thin and consists of irregularly interlaced fibres; it is rich in sense (tactile) organs and smooth muscle fibres, which are largely used in elevating the feathers. The colors of feathers depend in part upon pigment-red, yellow, orange, brown, and black-deposited in them, but the iridescent colors are due to interference spectra.

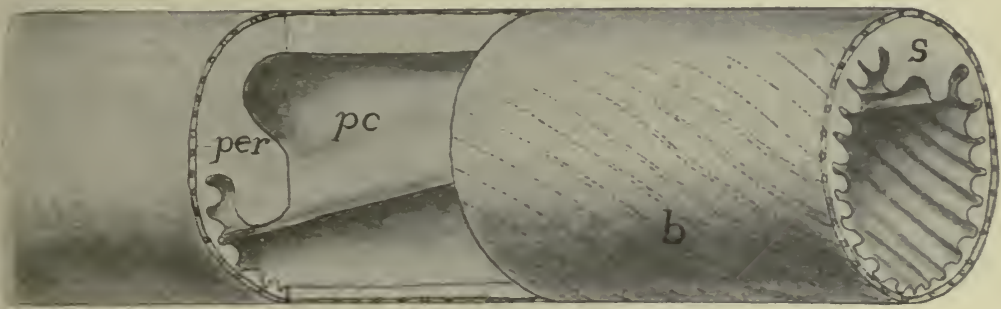

FiG. 25.-Stereogram of part of developing contour feather; compare with fig. 24. $\quad b$ developing barbs; $p c$, pith cavity; per, periderm; $s$, rhachis.

MAMMALS have a skin relatively thicker than have other vertebrates, both layers contributing to the thickness and the whole rather loosely attached to the lower tissues. There are numerous glands, and the hair, abundant in all orders except the whales and sirenians, is found in no other class. Other cuticular structures as horn and claws (p. 27) are widely distributed and scales occur in several forms.

The corium is thick and composed of irregularly interlaced fibres with muscles, blood-vessels, etc. Its outer surface is frequently thrown into papillæ or ridges, especially on the palms and soles, these carrying the epidermis with them. In the thick epidermis several strata may usually be recognized: at the base a thick Malpighian layer; then a thin stratum lucidum in which distinct cells cannot be recognized; and on the outside the stratum corneum. One or more others are sometimes present. As will readily be understood a cell passes through all of these layers before it is worn from the surface of the skin.

Hair.-The epidermis takes the initiative in the formation of hair. It thickens in spots, the thickenings pushing into the corium and each being cupped at the tip, blood-vessels extending into the cup. The basal cells of the ingrowth, thus richly nourished, proliferate rapidly and the 
new cells thus formed are forced outward, forming the hair. While this is going on the ingrowth splits around the hair, forming the follicle, while another ingrowth of the Malpighian layer forms the sebaceous gland which oils the hair.

A section through a hair and its follicle gives the following layers (fig. 26). Around all is the connective-tissue envelope, formed from the corium; next inside is the outer root sheath formed of the Malpighian layer and extending to the cavity of the follicle. Around the root of the hair is the inner root sheath, two cells in thickness, the layers being known as Henle's and Huxley's layers. These do not extend outside the follicle. In the hair itself there is a cortical layer surrounding the central medulla, the hair not being hollow.

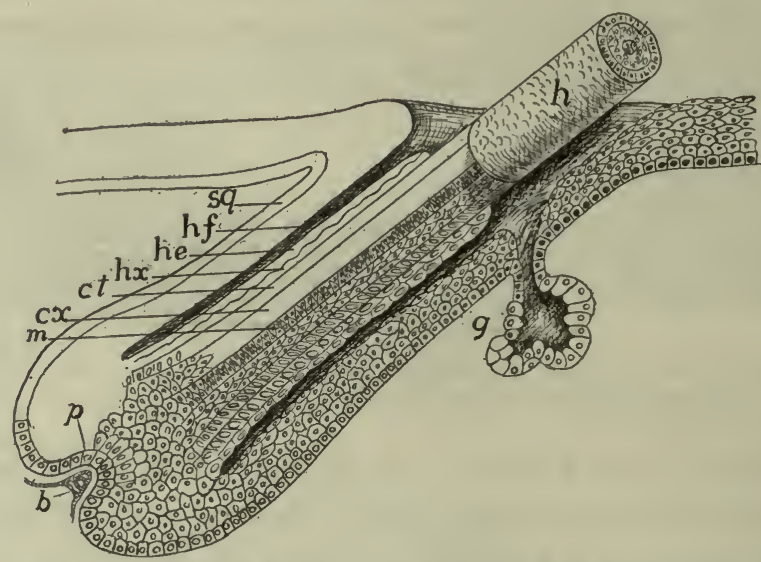

FIG. 26.-Diagram of structure of hair. $\quad b$, blood-vessels; $c t$, cuticle of hair; $c x$, cortex $g$, gland; $h$, hair; $h e$, Henle's layer; $h f$, hair follicle; $h x$, Huxley's layer; $m$, medulla; $p$, papilla; $s g$, stratum germinativum of epidermis.

Hair differs greatly in size, the spines of the porcupines forming one extreme, the prenatal hair (lanugo) of man the other. Hair is shed at intervals. The old hair ceases to grow, separates from its base, and later is pushed out when the root begins again to proliferate. There are smooth muscle fibres connected with the roots of the hairs, their function being to raise the hair from its usual inclined position under influence of the sympathetic system. There are also usually nerves distributed to the base of the hairs, making them to some extent sense organs, a condition which reaches its greatest development in the facial hairs (vibrissæ) of carnivores and the hairs on the wings of bats.

Scales occur in several orders, being usually best developed on the tail and feet. They may be rounded, quadrangular or hexagonal, the square scales being arranged in rings around the part, the others in quincunx. These are closely similar to the cuticular scales of reptiles (p. 26). Recent investigations tend to show that there is a close rela- 
tion between scales and hairs, since in the mammals with scales the hairs are usually arranged in groups of three or five behind each scale (fig. 27); while in those without scales the hairs are frequently grouped in the same manner. The illustration (fig. 28) is interesting as showing the arrangement in man and the possible relation to ancestral

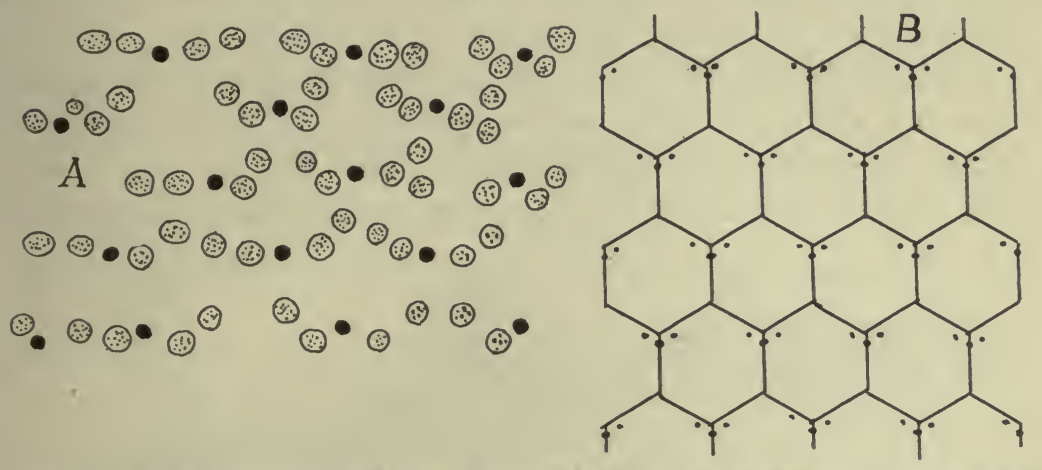

FIG. 27.- $A$, arrangement of the two kinds of hair in Ornithorhynchus; $B$, Arrangement of hair in Ptilocerus lori, with the probable relation of the hair to the ancestral scales; both after Meijere.

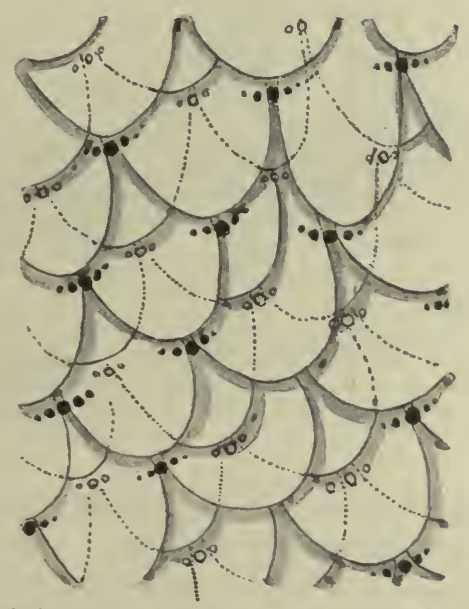

FIG. 28.-Arrangement of the hairs in groups of threes and fives in the human embryo, with the probable ancestral arrangement of the scales; after Stöhr.

scales. The statement is also made that at first the hairs are arranged in longitudinal rows and that the grouping comes later.

The mammalian skin is usually rich in glands which are of two types, tubular and acinous (p. I8). To the first belong the sweat glands, which extend from the Malpighian layer, where they arise, down through 
the corium and then are coiled in order to obtain greater length. The acinous glands are represented by the sebaceous glands in connection with each hair (fig. $26, g$ ), and by the scent glands in the anal or inguinal region of many carnivores, rodents and edentates. Others may occur in very diverse regions as on the face (bats, deer), in the occipital (camel) or temporal region (elephant) or on the legs (swine).

The mammary or milk glands are now known to be modified tubular glands possibly derived from sweat glands. In the monotremes the simplest condition is found, numbers of glands opening into a pair of sacs in the sides of the marsupium, or pouch where the young are kept,

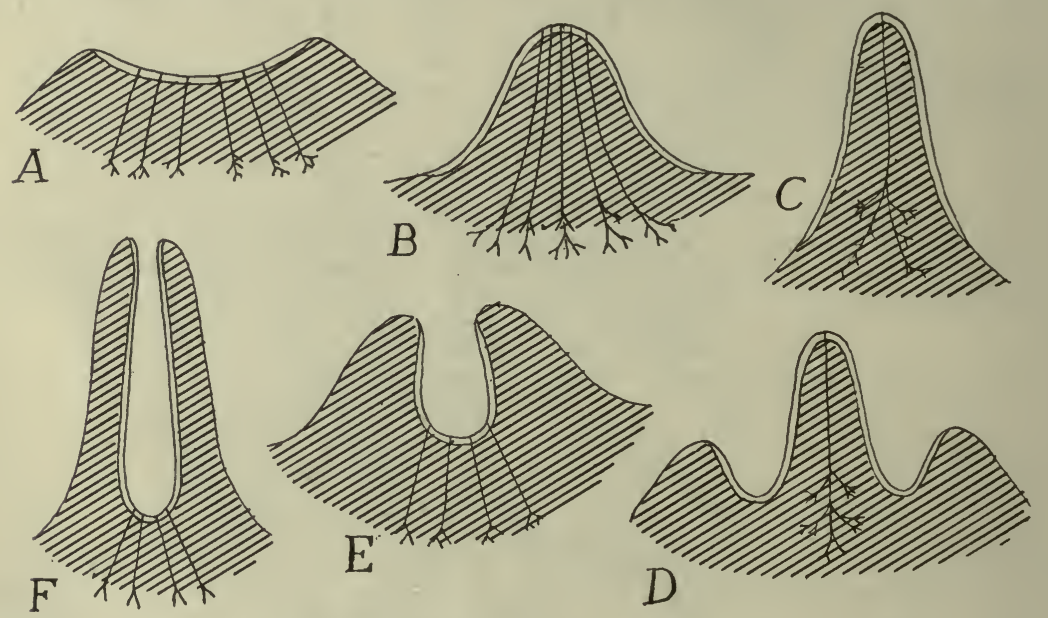

FIG. 29.-Scheme of different kinds of nipples, based on figures by Weber. Single line, ordinary integument, double line, that of primary mammary pocket. $A$, primitive condition, found in Echidna; $B$, human nipple; $D$, Didelphys before lactation; $C$, same at lactation; $E$, embryonic, $F$ adult condition in cow. $B$ and $C$ are true nipples, $F$ a pseudonipple (teat).

on the ventral side of the body. In the marsupials there is a slight nipple developed from the bottom of the pocket. In the higher groups of mammals the first appearance of the milk glands is the formation of a 'milk line,' a ridge on either side of the body from in front back to the inguinal region. This is soon divided into 'milk points' from each of which there is an ingrowth of epidermis into the corium, the intermediate parts of the line disappearing. Each of the points may develop into a definitive mamma, but not all of them come to full development, for the number in the adult is less then in the embryo, varying from a single pair to eleven in Centetes, the number roughly corresponding to 
the number of young at a birth. This method of formation explains the varying position of the mammæ and also the occasional occurrence of more than the normal number (polymastism) in man and other mammals. Each gland is provided with a nipple and of these there are two kinds (fig. 29). In the one the whole surface on which the lacteal ducts empty becomes elevated, in the other the region around the openings of the ducts becomes drawn out into a tube with the ducts opening at the bottom (ungulates).

\section{THE SKELETON.}

The term skeleton as used here is applied to any of the harder parts of the body, developed from the mesoderm and serving for support,

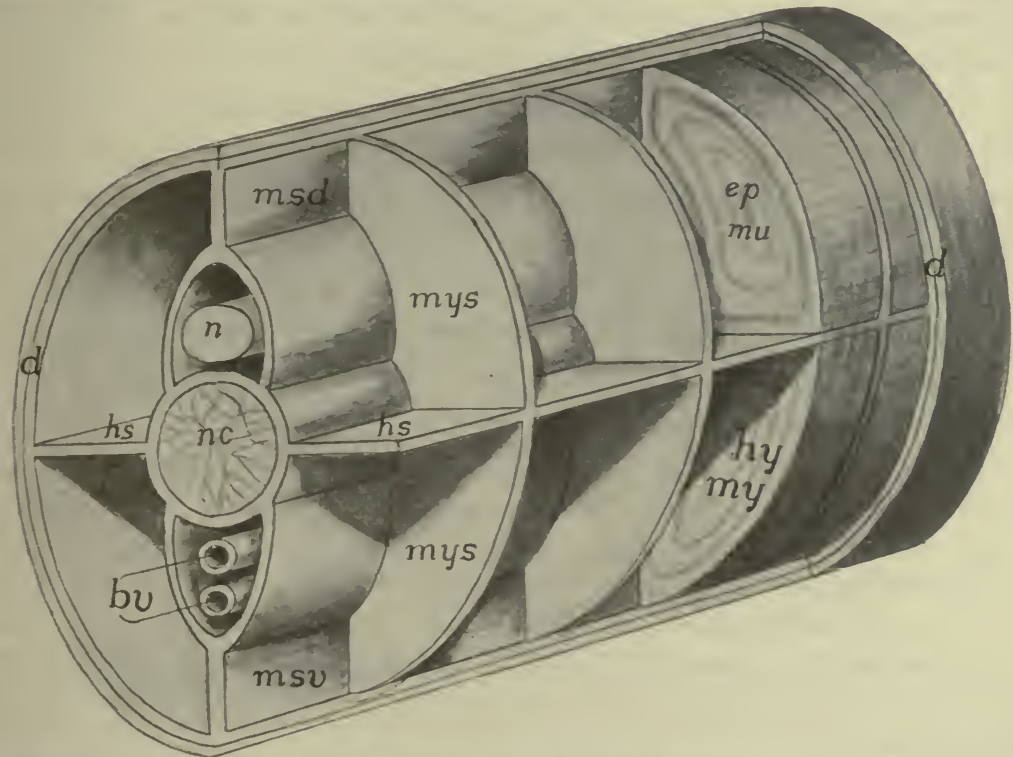

FIG. 30.-Diagram of the skeletogenous tissue in the caudal region of a vertebrate. $b v$, blood-vessels; epmu, epaxial muscles; $h s$, horizontal partition; hymy, hypaxial muscles; $m s d, m s v$, dorsal and ventral median septa; mys, myosepta; $n$, spinal cord; $n c$, notochord.

for the attachment of muscles, for protection and the like. This excludes any purely epidermal hard parts, and these have been included with the integument.

As the skeleton can only develop where there is mesenchyme, the distribution of the chief skeletogenous parts, sometimes called the membranous skeleton, may be given here, continuing the account from page 16 . First is the corium, immediately beneath the epidermis, 
forming an envelope around the internal structures. This connects in the middle line, above and below, with a longitudinal partition which separates the muscle masses of the two sides. This partition splits to pass on either side of the central nervous system and the notochord, and, just beneath the peritoneum, around the viscera. From the median partition sheets of mesenchyme (myosepta) pass vertically between the myotomes to the dermal layer, they being, like the myotomes, metameric. Then there is a horizontal sheet on either side which lies between the epaxial and hypaxial muscles (p. I27). Not all parts of this membranous skeleton develop hard structures, but these are most apt to arise at the intersection of the various planes.

The skeletal structures are divided into the dermal, arising in the outer mesenchymatous envelope, and the endoskeleton, formed in the other parts and lying deeper in the body. The dermal skeleton includes the scales of fishes, the dermal armor of many reptiles and fossil amphibians and the bony scales in the skin of crocodilians and some mammals. In the strict sense the so-called membrane bones of the skull and the cleithrum of fishes and the clavicle and episternum of higher vertebrates should be included here, since they apparently have been derived from dermal ossifications, but convenience of treatment necessitates their consideration with the endoskeleton, with which they are intimately associated.

It is a question whether the dermal or the endoskeleton is the older. The most primitive of the living species, the cyclostomes, have no exoskeleton, but have cartilage developed to some extent. In development, also, cartilage always appears before there is a trace of the exoskeleton. On the other hand, some of the oldest fishes known have a well developed dermal armor, while the best preserved ostracoderms show no trace of an internal skeleton. The external skeleton has probably arisen as a means of protection, the internal as a result of muscular or other strains.

Bones are connected (articulated) with each other in different ways. They may be so articulated that one can move on the other (diarthrosis) or there may be no motion possible (synarthrosis), each with several varieties. Of the immovable joints there may be sutures, where the two bones are connected by the interlocking of saw tooth-like projections, or the two may be united by bony growth (anchylosed) so that the line between the two disappears. In those cases of diarthrodial joints where there is much motion there is usually a closed sac, lined by a synovial membrane between the two bones. This membrane secretes a fluid which lubricates the surfaces. 
Cartilages and bones are covered on their outer surfaces by an envelope of connective tissue, called respectively perichondrium or periosteum. These membranes form the means by which muscles are attached to the bones and by which blood-vessels obtain entrance to them. The periosteum is also a seat of bone formation.

\section{DERMAL SKELETON.}

When present, the dermal skeleton arises by a marked proliferation of cells at definite points in the corium. These cells become specialized (scleroblasts, odontoblasts or osteoblasts) for the deposition of salts of lime plus a varying amount of organic matter (ossein). Upon limy plates formed in this way other parts, also calcareous, may be laid down by the basal surface of the epidermis, so that the whole dermal element may be in part mesenchymatous, in part ectodermal in origin.

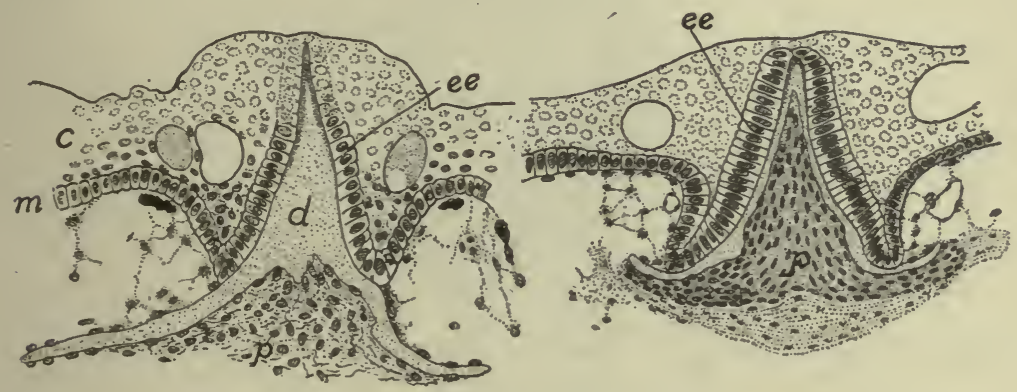

FIG. 3 r.-Cross-sections of developing scale of Acanthias. $c$, stratum corneum; $d$, dentine of scale; $e e$, enamel organ; $m$, stratum Malpighii; $p$, pulp.

It is generally thought that the primitive dermal skeleton resembled that of existing sharks, and that from the hypertrophy or fusion of such scales the so-called membrane bones have arisen. Then the scales of other vertebrates are to be traced back to an elasmobranch ancestry, while teeth are thought to be modified scales. Hence the structure and development of the elasmobranch scale should be understood.

At regular intervals in the skin of a shark there is a multiplication of cells of the corium, each aggregation forming a small papilla which projects above the surrounding corium, carrying with it the basal layer of the epidermis. The surface cells of the papilla and the region around it becomes converted into osteoblasts which secrete calcic 
salts on their outer ends, thus forming a small plate of dentine (p. 24) with a central spine into which the papilla extends. The overlying epidermal cells form an enamel organ, the lower surface of which secretes an even harder layer of enamel ${ }^{1}$ upon the dentine base, this being thickest on the tip of the spine. The mesenchyme in the papilla is the so-called pulp. With continued growth the spine projects through the epidermis, giving the skin of the shark its characteristic rough (shagreen) condition. This is the placoid type of scale.

FISHES.- In the adult elasmobranchs the scales may be large and remote from each other (skates) or small and closely set. In the torpedo scales are lacking, while in the chimæroids they occur only on the claspers, on the frontal horn, and as extreme forms, in a great spine in front of the dorsal fin.

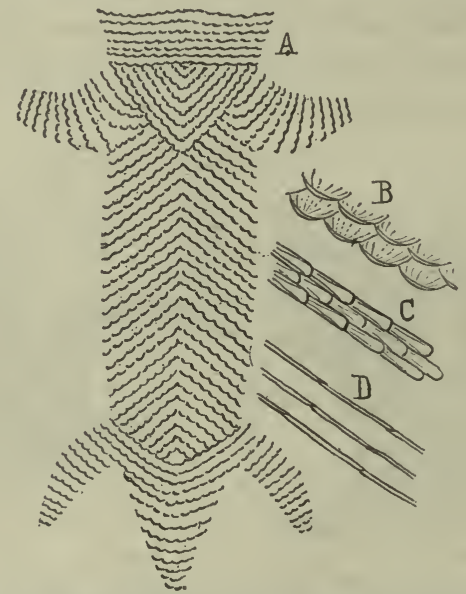

FIG. 32.-Ventral armor of Stegocephals (after Credner-Zittel). A, Branchiosaurus; $B$, detail of same; $C$, detail of Archegosaurus; $D$, of Petrobates.

A few ganoids lack scales (Polyodon), while the sturgeon have minute granules and five rows of large plates along the sides. A mia has scales of the cycloid type, soon to be described. With these exceptions the ganoids have ganoid scales, which are rhomboid in outline and joined to each other like parquetry. They consist of two layers, the lower apparently homologous with the dentine of sharks, except that it is formed in, not on, the corium. The outer layer of ganoin is formed by the corium and consequently cannot be enamel as once was thought.

A few teleosts are scaleless (some eels), but elsewhere scales are formed in pockets in the corium (fig. I8I). At first they lie side by side, but with growth they overlap like shingles. There is only one layer of bone mixed with a large amount of ossein. In cycloid scales the element is circular and is marked with concentric and radiating lines. The ctenoid scales differ in having the posterior edge of

1 There is some question whether this layer is really enamel; the usual statement as to its nature is followed here. 
each scale truncate and this edge and the surface toothed. Cycloid and ctenoid scales intergrade and both kinds may occur on the same fish (many gobiids).

AMPHIBIA.-A dermal skeleton occurs in the recent amphibians only as rows of plates in the cutaneous rings on the bodies of the cæcilians and in the skin of the back of a few exotic toads. In some fossil stegocephalans there was a ventral armor and in others one protecting the whole body. The ventral exoskeleton, sometimes of scales or plates, sometimes long bars, is arranged in oblique rows, and is interesting as probably being the source of the gastralia found in many reptiles (infra). Episternum and clavicle were possibly dermal in these forms, but they will be described in connection with the shoulder girdle. Apparently certain of the gastralia of these fossils were modified into comb-like organs which have been thought to have sexual significance.

REPTILES. - The dermal skeleton is best developed in the turtles of living reptiles, though here it is closely associated with the endoskeleton. The dermal plates form a box for the protection of the body. This consists of a dorsal carapace and a ventral plastron, united to varying extents and each consisting of a number of elements. In the carapace there is a middle line of neural plates (fused with

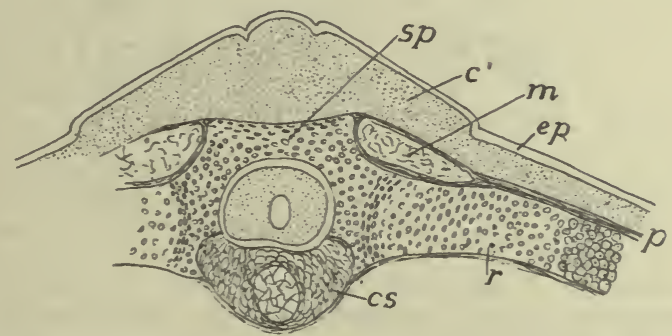

FIG. 33.-Section through developing vertebra, rib and exoskeleton of Chelone imbricata, after Götte. $c$, cutis; $c s$, primitive vertebral body, $e p$, epidermis; $m$, external oblique muscle; $p$, perichondrium; $r$, rib; $s p$, spinal process.

the vertebræ), marginal plates around the margin, and costal plates, fused to the ribs, between neurals and marginals. The plastron (fig. 34 ) usually consists of nine plates, wholly dermal, the names shown in the figure. The three posterior pairs are regarded as the same as the gastralia of other reptiles, the anterior pair as the clavicles, while the unpaired entoplastron is supposed to be homologous with the episternum of other tetrapoda.

Some of the extinct crocodilia were armored with closely applied scales and these have been retained in the existing species in a reduced condition. They also have well developed gastralia. These are of rods dermal bone in the ventral body wall between the true ribs and the pelvis, and so closely resemble ribs that they were called 'abdominal ribs.' They do not meet in the middle line; each, except the first, consists of two distinct parts, and the pairs correspond to the somites in number. In Sphenodon (fig. 35) the gastralia are more numerous than the somites.

In a few lizards there are dermal scales, while the extinct stegosaurs had 
dermal ossicles, sometimes of great size (plates a yard across, spines half a yard long) in the dorsal region.

BIRDS.-Recent birds lack all dermal ossifications, but Archaopteryx had gastralia.

Mammals rarely have dermal bones. They are known in the extinct zeuglodont whales and in several fossil edentates, but in the living species they occur

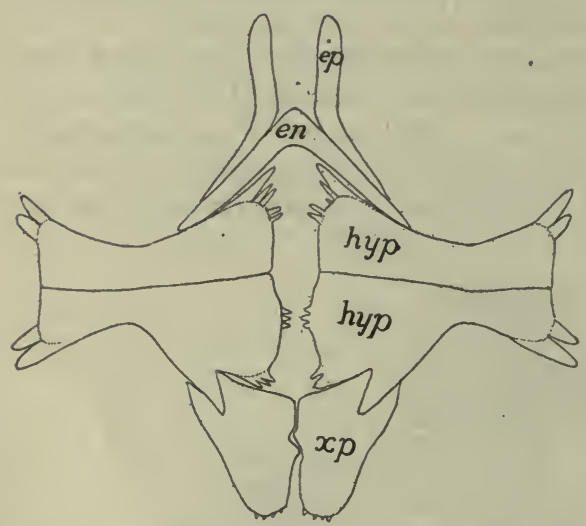

FIG. 34.-Plastron of Trionyx. en, entoplastron; $e p$, epiplastron; $h p p$, hypoplastron; $h y p$, hyoplastron; $x p$, xiphiplastron.

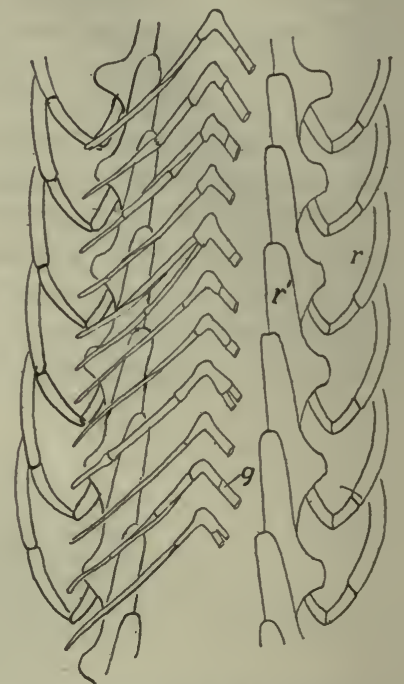

FIG. 35.-Ventral ends of ribs $(r)$ and gastralia $(g)$ of Sphenodon.

only in the armadillos where they form a complete armor above, the plates arranged in transverse rows, some of which are movable on each other. In the extinct glyptodons they formed an inflexible case. It is uncertain whether these are a new acquisition in the edentates or have been inherited from non-mammalian ancestors.

\section{THE ENDOSKELETON.}

The endoskeleton may pass through three stages in its development, including the membranous stage. From this it may pass through a cartilage stage before becoming bone, or it may in part develop directly into bone from membrane, or, lastly, it may never pass beyond the cartilage stage. Thus only the membranous stage is constant. These differences in development are of great importance in tracing homologies between bones in different groups, but the distinction between bones developing directly from membrane (membrane bones) 
and those passing through a cartilage stage (cartilage bones) can only be recognized by following the ontogeny of the element in question.

As stated above, there is much evidence to show that the membrane bones are dermal bones which have sunk to a deeper position and have become secondarily associated with the endoskeleton. This is especially evident in the skulls of some of the lower ganoids. Ossification of cartilage takes place in two ways. In ectochondrostosis the deposit of lime salts begins on the deeper surface of the perichondrium and gradually invades the cartilage. In entochondrostosis the cartilage becomes broken down in the interior, some of the cells becoming modified into osteoblasts, and from these as centres of ossification, the process of bone formation extends in all directions. In ectochondrostosis at least, the centres of ossification may have been derived, phylogenetically, from elements of the dermal skeleton.

In ossification the bone is developed in layers, between which the osteoblasts are arranged. In the elasmobranchs the skeleton is frequently strengthened by deposits of lime, but this calcified cartilage differs from bone.in that the deposits of lime take the form of polygonal plates and there are no lacunæ.

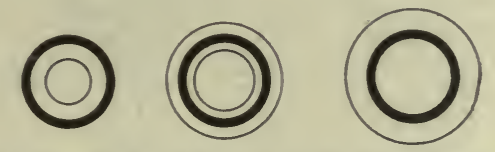

FIG. 36.-Diagram of growth of bone. $A$, from an animal recently fed with madder causing a layer of bone (black) colored by the dye; $B$, later, no madder fed for some time, a deposit of colorless bone on outside of colored layer, internal layer thinner; $C$, still later, outer layer thicker, inner layer absorbed.

Many bones increase in length by the addition of epiphyses at the ends. These are separate ossifications which only unite with the main bone at the time the adult condition is reached. The increase in diameter has some interesting features. In animals fed with madder, the bone formed during the feeding is colored. In this way it is found that the new bone (fig. $36, A$ ) is laid down on the outside of the other, and that with growth ( $B$ and $C$ ), the 'marrow cavity' on the inside is increased in size by the resorption of the bone already formed.

For convenience of treatment the endoskeleton is divided into axial and appendicular portions, the axial consisting of the vertebral column (backbone) and the skull, together with the ribs and sternum which are closely associated with the vertebræ. The appendicular skeleton includes the framework of the limbs and fins and the girdles to which they may be attached.

\section{Axial Skeleton.}

Both the skull and the vertebral column surround and protect the brain and spinal cord, and in this way the skull is an enlarged and 
specialized portion of a continuous axis, but it is not possible to carry the comparison into details. The idea of Oken that the skull is a complex of three or four vertebræ has long been overthrown. The skull differs markedly from the vertebral column in the presence of numerous membrane bones.

\section{Vertebral Column.}

The notochord (p. I2) is the foundation around which the vertebræ and the posterior part of the skull are developed. It is a cylin-

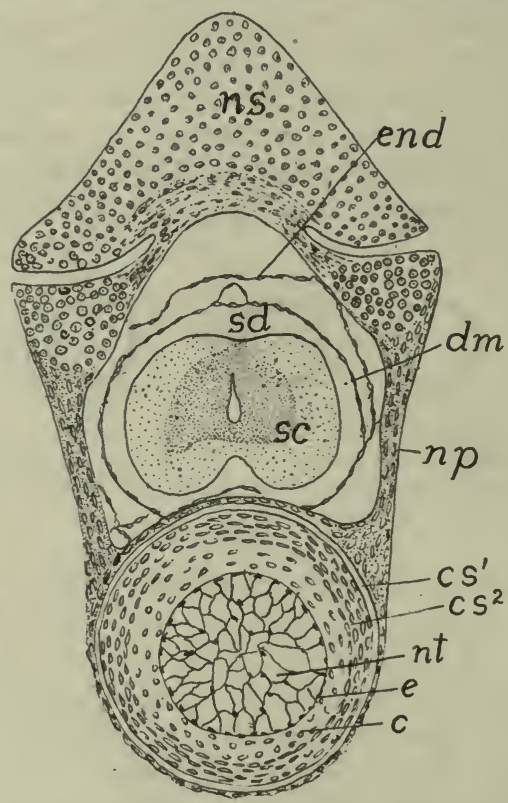

Fig. 37.-Section of developing vertebra of $45 \mathrm{~mm}$. Amblystoma. c, cartilage of inter centrum; $c s^{1}$, outer chorda sheath; $c s^{2}$, inner chorda sheath; $d m$, dura mater; $e$, epithelioid layer of notochord (elastica interna); end, endorhachis, torn from wall of vertebral canal; $n p$, neurapophysis (ossified); $n s$, neural spine of preceding vertebra; $n t$, notochord; $s c$, spinal cord $s d$, subdural space.

drical rod of entodermal origin, without segmentation, ${ }^{1}$ extending from the infundibulum (see brain) to the posterior end of the body. Its cells become vacuolated and at length most of the protoplasm, together with the nuclei, migrate to the surface of the cord, where they appear like an epithelium, which, together with its basal membrane, is called the internal elastic membrane (elastica interna, fig. $37, e$ ).

${ }^{1}$ Segmental undulations occur in the notochords of some mammals, but their significance is not clear. 
Next, mesenchymatous cells, derived from the sclerotomes, form a notochordal sheath, bounded externally by an elastica externa. The mode of formation and the history of the sheath vary in different groups, for accounts of which reference must be made to special papers. Other skeletogenous tissue extends outward from the sheath toward the periphery, as described on a previous page (p. 38 , fig. 30 ) from which the ribs of all vertebrates are developed, the cyclostomes passing but little beyond this membranous condition in the trunk region.

With the appearance of cartilage segmentation is introduced into the skeleton. As cartilage is firm and comparatively unyielding, in

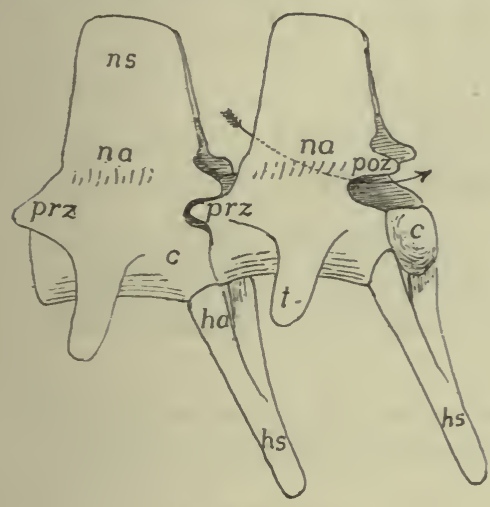

FIG. 38 .

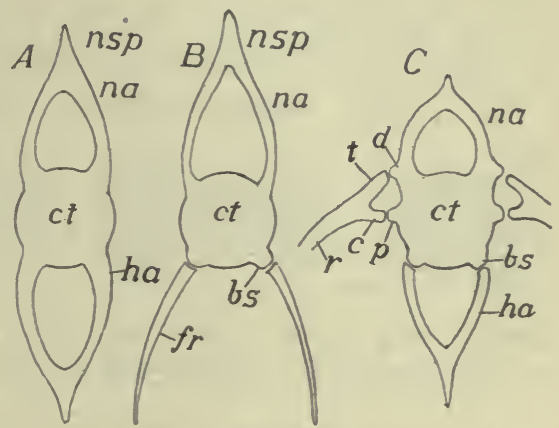

Fig. 39.

FIG. 38.-Two caudal vertebræ of alligator. $c$, centrum; ha, hæmapophysis; $h$, hæmal spine; $n a$, neurapophysis; $n s$, neural spine; poz, prz, post- and prezygapophyses; $t$, transverse process. The arrow passes through the neural arch.

FIG. 39.-Diagrams of $(A$ and $B)$ fish vertebræ and $(C)$ vertebra from higher groups. $b$, basal stumps; $c$, capitular head of rib; $c t$, centrum; $d$, diapophysis; fr, fish rib; ha, hæmal arch; $n a$, neural arch; $p$, parapophysis; $r$, rib; $t$, tubercular head.

order that the trunk may bend, the cartilage becomes divided into separate blocks, which, in order that they may be moved by the muscles connected with them, must alternate with the myotomes. Hence the metamerism of the vertebral column is the result of that of the muscular system.

A typical vertebra, whether of cartilage or bone, consists of several parts, the names of which are necessary for the understanding of the following account. Surrounding the notochord is the body or centrum, developed from the notochordal sheath or from tissue surrounding it. A neural arch, enclosing the spinal cord, extends dorsally from the centrum. It consists of a plate on either side (neurapophysis), the 
arch being completed by a neural spine as a keystone. Ventral to the centrum is a similar hæmal arch, composed, in like manner, of hæmapophyses and hæmal spine, and enclosing, in the caudal region, the caudal artery and vein, farther forward, the cœlom and viscera. This type of vertebra is common in many fishes, and in the tails of some higher forms. In the lowest fishes it is simplified by the omission of parts, while in the higher vertebrates other structures are added. Among these are articular processes (zygapophyses) on the anterior and posterior faces of the neural arch (distinguished by position as pre- and post-zygapophyses) which lock the successive vertebræ together and strengthen the column without interfering with its flexibility (fig. 38 ).
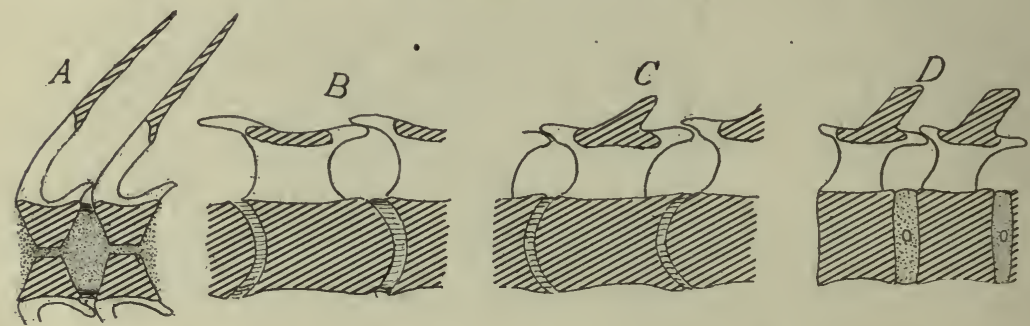

FIG. 40.-Diagrammatic sagittal sections of $(A)$ amphicœlous; $(B)$, procœlus; $(C)$, opistho colous; and $(D)$, amphplatyan vertebræ; the head supposed to be at the left.

In all vertebrates above fishes most of the vertebræ bear transverse processes (pleurapophyses), extending laterally on either side. Of these there are two kinds, a parapophysis arising from the centrum, and a diapophysis projecting from the neural arch. The ribs articulate with the ends of these, as will be explained later. The distinctions are the most marked in the lower vertebrates, but careful comparisons show them in the mammals. Other processes, of less frequent occurrence, will be mentioned below in connection with the groups in which they occur.

The ends of the centra, where they articulate with each other, may take five different shapes. They may be hollow at both ends (amphicœlous); they may fit together with a ball and socket joint, the hollow being sometimes in front (procœlous), sometimes behind (opisthocœlous). In the mammals flat or amphyplatyan conditions are common, while in birds saddle-shaped ends occur (figs. 40, 49).

In the history of vertebræ both comparative anatomy and embryology agree that the process of vertebral formation began with the arches and extended thence 
to the sheath of the notochord. In what must be considered the most primitive condition the arches extend no further than the sheath and nothing comparable to a centrum is found, even when ossification occurs. In the formation of centra two methods of extension of cartilage to the chordal region are known. In the elasmobranchs immigrating cells from the arches break through the elastica externa and distribute themselves through the sheath, converting it into cartilages. In other vertebrates (fig. 43) the immigrating cells extend around the elastica externa so that the sheath eventually comes to lie inside the centrum.

In many fishes and fossil amphibians another element, the intercalare, enters into the composition of the neural arch on either side. The intercalaria lie above and behind the neurapophyses and may expand dorsally so that the arch is completed by them above. The dorsal root of the spinal nerve usually $n$, neural process; $r$, rib; $s$, passes through the intercalare, the ventral

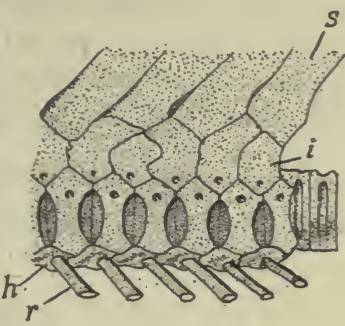

FIG. 4r.-Trunk vertebræ of Rhynchobatus, after Duméril. $h$, hæmal process; $i$, intercalary plate; $i l$, ligament; through the neurapophysis, but both roots may pass between them. Similar intercalaria may occur in the hæmal arch. In the trunk region there may be separate elements of the centra; in each somite a transverse cartilage (hypocentrum) across the under side of the neural sheath, and a pleurocentrum on either side, behind the hypocentrum (fig. 42).
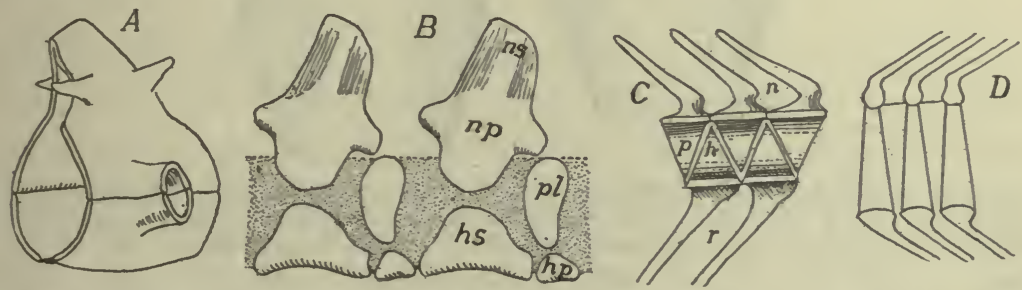

FIG. 42.-Stegocephalan vertebræ, after Zittel and Woodward. $A$, phyllospondylous; $B$, rhachitomous of Chelydrosaurus; $C$, Callopterus; $D$, embolomerous of Eurycormus; $h$, hypocentrum arcuale; $h p$, hypocentrum pleurale; $n p$, neurapophysis; $n s$, neural spine.

Comparisons of different adult vertebræ show that these vertebral elements may combine in different ways, though they have not been recognized in the ontogeny of the higher forms. Apparently the phyllospondylous vertebra of some stegocephals (fig. 42) are formed of hypocentrum and neural arch, both contributing to the hollow transverse process. In others hæmal arch and hypocentrum unite, while the pleurocentra meet and fuse above the notochord. Expansion of these makes the vertebral column look like a series of interposed triangles (fig. ${ }_{42} \mathrm{C}$ ). 
This is the rhachitomous or temnospondylous vertebra. Still farther expansion of hypo- and pleurocentra causes the former to unite with the neural arch, while the two pleurocentra meet below the notochord (fig. $4_{2} D$ ), the result being two rings in each somite, the embolomerous vertebra, which occurs in some stegocephali, some fossil ganoids and in the tail of Amia. Lastly these two rings (often called centrum and intercentrum) may fuse, giving the typical centrum.

The neural and hæmal spines which complete the arches are formed by segmental chondrifications of the interspinous ligament which runs the length of the body above and between the halves of the neural arches.

The vertebræ are outlined at an early stage of the embryo and their number is not subsequently increased. Consequently increase in
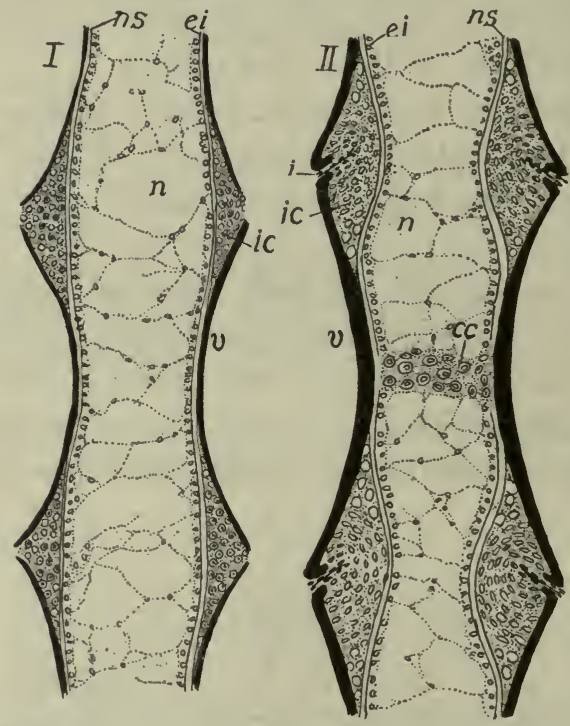

FIG. 43.-Earlier and later stages of development of a vertebra of Amblystoma. cc, cartilage in centre of vertebra; $e i$, elastica interna; $i$, incisure cutting through $i c$, intercentral cartilage; $n$, notochord; $n s$, notochordal sheath; $v$, vertebra (bone) black.

length of the vertebral column can only occur by growth of the vertebræ themselves. When first formed each centrum encircles the notochord and prevents its increase in diameter at this point, while between the centra it can expand. As a result the notochord soon resembles a string of beads (moniliform) with intervertebral enlargements. Then, as additions are made to the centra to increase their length, the new parts must form around the intervertebral enlargements and in this way the ends of the centra become cup-shaped and the amphicœlous condition (fig. $43, I$ ) is produced. In some urodeles this stage is followed by 
the deposition of cartilage in the cups (fig. $43, I I$ ) producing intervertebral constrictions of the cord. As this progresses absorption of the cartilage begins between the ends of the vertebræ (ic) and continues in such a way that the result is a ball of cartilage attached to the hinder vertebra and a corresponding cup in the one in front; in other words. an opisthocœlous condition.

Several regions may be differentiated in the vertebral column, these being the most numerous in the higher groups of vertebrates. These are (I) the cervical, in the neck, with great reduction or even absence of ribs; (2) the thoracic, following the cervical, with distinct ribs; (3)

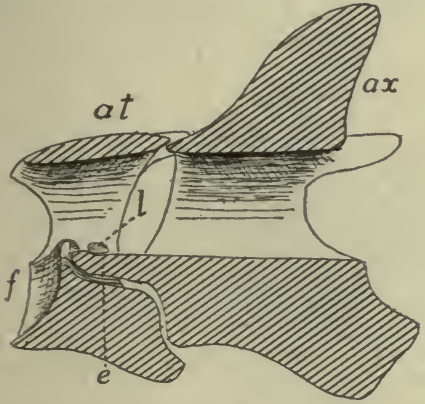

FIG. 44.-Section through atlas $(a t)$ and axis $(a x)$ of fowl, cut surfaces lined. $e$, epistropheus; $f$, facet for articulation with skull; $l$, transverse ligament.

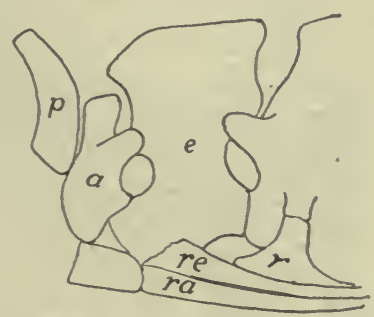

Fig. 45.-Proatlas, atlas and axis of alligator. $a$, atlas; $e$, epistropheus (axis); $p$, proatlas; $r$, rib of third vertebra; $r a, r e$, ribs of altas and epistropheus.

lumbar, without ribs; (4) sacral, including one or more vertebræ with which the pelvis is connected; (5) caudal, the tail, behind the sacrum: Sometimes the ribs extend back to the sacrum so that thoracic and lumbar cannot be distinguished, all being then grouped as dorsal. Then in the fishes and some higher vertebrates (snakes, whales, etc.) sacral vertebræ are not differentiated, and in the fishes there is no line between cervicals and dorsals, so that only trunk or abdominal, and caudal regions can be distinguished, the line being drawn (fishes) at the point where hæmal arches are transformed into ribs.

One or two of the anterior vertebræ are modified in the higher (tetrapodous) vertebrates and have received names. The first, which immediately adjoins the skull, is the atlas. It bears on its anterior face an articular surface which receives the one or two condyles of the cranium. In the amniotes the second vertebra, the axis or epistropheus is also specialized. On the anterior face of its centrum is a pivot (the 
dens or odontoid process) on which the atlas turns. Development shows that this dens is the centrum of the atlas which has separated from its own verfebra and has fused to that of the axis.

In a few reptiles and possibly some mammals a so-called proatlas occurs as a plate or pair of plates (fig. 45) of bone between the atlas and the skull, in the position of a neural arch. It is not certain whether this is the remains of a vertebra which once occupied this position, or is a new formation. Nor has it been settled whether the atlas of the amphibians is homologous with that of mammals.

In cyclostomes, fishes and aquatic urodeles the posterior end of the vertebral column is concerned in the formation of the caudal fin, which presents three modifications. The most primitive is the diphy-

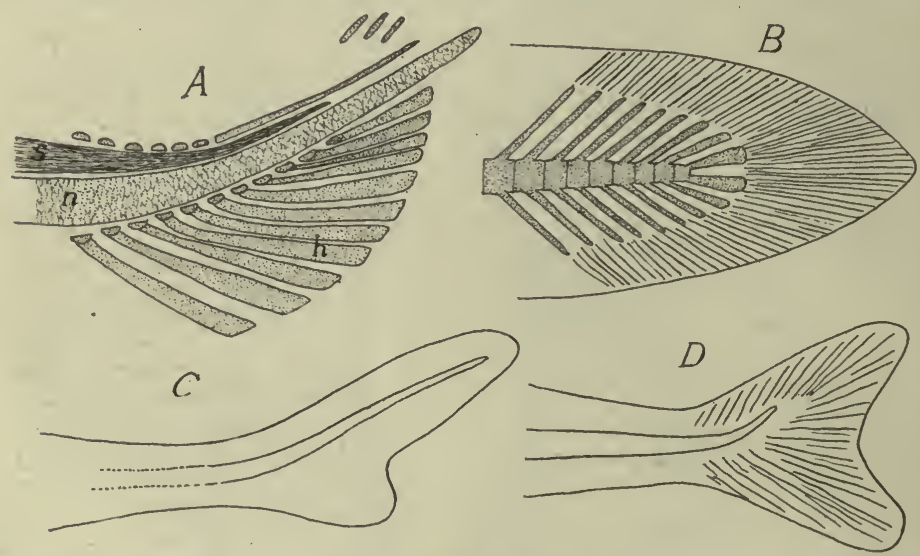

Fig. 46.-Tails of fishes. $A$, young $A$ mia; skeleton (homocercal); $B$, diphycercal; $C$, heterocercal; $D$, homocercal; $h$, hypurals; $n$, notochord; $s$, spinal cord.

cercal tail in which the vertebral column runs straight to the end of the body, the fin being developed svmmetrically above and below it. This is found in the young of all fishes and in the adult cyclostomes, dipnoans, many crossopterygians and urodeles. In the heterocercal tail, which occurs in elasmobranchs and ganoids, the axis bends abruptly upward near the tip, and while retaining the caudal fin of the diphycercal stage, has a second, smaller lobe developed below, giving the whole an unsymmetrical appearance. In the homocercal tail, which occurs in Amia and all teleosts since the cretaceous, there is the same upward bend to the vertebral column, but symmetry is restored externally by the reduction of the neural arches and the development and fusion of the hæmals into larger plates (hypurals), while the lower lobe of the tail grows out to equal the other. 
CYCLOSTOMES have a persistent notochord, increasing in size with the growth of the animal, and lacking constrictions since no centra are developed. In the myxinoids there are neurapophyses and intercalaria deyeloped in the caudal region; in the lampreys they occur in the trunk as well.

FISHES.-In the elasmobranchs the typical vertebræ are developed in cartilage, with intercalaria in connection with the arches. Usually the centra undergo more or less calcification (p. 43), the lime being either deposited in concentric rings around the notochord (cyclospondylous vertebræ) or in radiating plates (asterospondylous). In the trunk region each centrum often bears a pair of transverse processes with short ribs at their extremities. In a few forms (skates, etc.) embolomerism (p. 48) occurs in the tail, and in the holocephali the centra are replaced by numerous rings of cartilage. In skates and in Chimara there is a true joint between the skull and the column, but in the sharks the anterior vertebræ are fused together and to the skull.
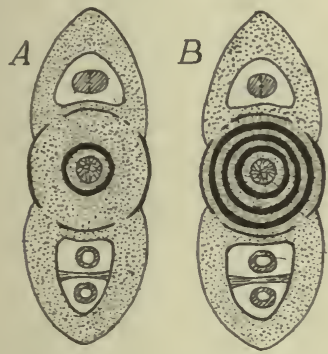

FIG. 47.

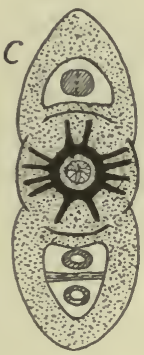

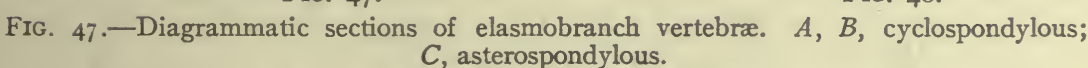

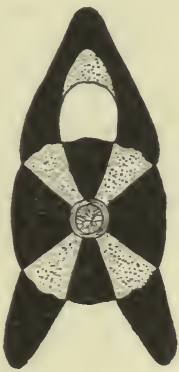

Fig. 48 . FIG. 48.-Cross-section of teleost vertebra; bone, black; cartilage, dotted.

The ganoids vary greatly in vertebral characters, some of the Chondrostei having only cartilage and some of the fossil forms lacked centra. On the other hand, nearly the whole vertebra is ossified in A mia and Lepidosteus, the latter having opisthocœle vertebræ, a condition not reappearing until the amphibians, as all other fishes in which centra are developed have amphicœlous vertebræ.

As the name implies, ossification of vertebræ and other parts is common in teleosts. The arches are almost always ossified, while the centra may be, or those parts directly connected with the arches may remain cartilaginous while the rest ossifies (fig. 48), so that the section presents a radiate figure as in the asterospondylous sharks. Some teleosts have zygapophyses and a few genera have transverse processes on some of the vertebræ.

The dipnoans, so far as ossification of the vertebræ is concerned, are on a par with the cartilaginous ganoids. There are no centra and the notochord grows throughout life.

AMPHIBIA, except the legless forms, have caudal, sacral, trunk, and a single cervical vertebra, the sacrals being single except in a family of extinct anurans. Zygapophyses and both kinds of transverse processes may be present. 
The stegocephals had the greatest range of vertebral structure, rhachitomous, embolomerous, and amphicœlous types occurring, the first two even in the same individual. Phyllospondylous vertebræ (fig. 42) are found only in the fossil Branchiosauridx.

The cæcilians have a very large number (up to 275) of amphicœlous vertebræ in correlation with the snake-like body form. The perennibranchs, derotremes and many salamandrina are amphicœlous; the rest of the urodeles are opisthocœlous.

The anura, as a rule, have procœlous vertebræ, but a few genera have them opisthocœle. All recent species have eight presacral vertebræ, but there were nine in the tertiary forms. A striking feature is the fusion, in the adult, of all of the caudal vertebræ into the well-known rod, the coccyx or urostyle.

REPTILES always have the vertebræ ossified, although remnants of the notochord may persist in the centra, of which all types, amphi-, pro-, opisthocolous and flat occur in the group. In lizards, snakes and dinosaurs the articulation between the successive vertebræ is strengthened by zygantra and zygosphenes, a cavity on one vertebra into which a projection from the next

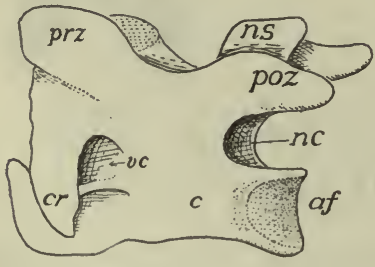

FIG. 49.

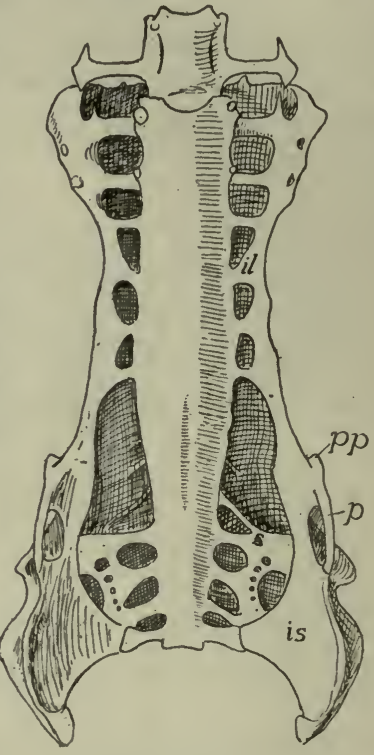

Fig. 50.

FIG. 49.-Cervical vertebra of a bird showing the saddle-shaped articular surface (af) on the centrum, $c$; $c r$, cervical rib; $n c$, neural canal; $n s$, neural spine; poz, prz, post- and prezygapophyses.

FIG. 50.-Central view of synsacrum and pelvis of hawk (Buteo). il, ilium; is, ischium; $p$, pubis; $p p$, pectineal process; $s$, sacral ribs.

fits. In the existing species there are never more than two sacral vertebræ, but the pterosaurs had from three to seven, while in the dinosaurs there might be ten, all being co-ossified when there were more than three.

Little is known of the theriomorph backbone, except that some had persistent notochords, others amphicœlous centra. In the plesiosaurs they were flat, while in the turtles the dorsals are fused and the neural spines are united with the neural plates (p. 4r). The other centra vary. Those of the rhynchocephals and most dinosaurs are flat, while snakes and lizards, except the geckos have them procœlous. In the earliest crocodiles they were amphicœlous, while later they are procœlous or flat, and in the pterodactyls they are procœlous in front, amphicœlous in the tail.

BIRDS usually have saddle-shaped ends to the centra (the atlas procolous). 
Several of the dorsals are usually fused for strength, but the first presacral is free. A characteristic feature is the synsacrum, foreshadowed in the dinosaurs. As the bird stands on two feet and holds the body obliquely, several of the dorsal and caudal vertebræ (up to 20 ) fuse with the sacrals into a common mass, a large proportion also uniting with the pelvis. The true sacrals (three in ostriches, two elsewhere) lie just behind the pits occupied by the kidneys and may be recognized by their lower articulation to the pelvis. A few of the caudals behind the synsacrum are free, as all were in Archceopteryx, but the others in recent birds are united into an upturned bone, the pygostyle.

MAMMALS, except whales where the sacrum is lacking, have all the five vertebral regions differentiated. With four exceptions the cervicals are seven in number (Manatus australis and Cholapus hofmanni, six; Bradypus torquotus, eight; $B$. tridactylus, nine). The dorsals (thoracics plus lumbars) vary between fourteen in armadillos and thirty in $H y r a x$, but usually are nineteen or twenty, the number of thoracics usually increasing at the expense of the lumbars. There are primitively two sacrals, but others may unite until they amount to nine or ten in some edentates. Usually the centra are amphiplatyan, but in the cervicals of ungulates opisthocœle vertebræ are common. It is to be noted that the 'transverse processes' of the cervical vertebræ are, as in birds, composed in part of reduced ribs, as will be shown below.

\section{RIBS.}

Two different structures are included under the common name of rib, both connected at one end with a vertebra, the other supporting the body walls around the viscera. In following forward the hæmal arches in the skeleton of a bony fish (fig. $39, A, B$ ) it is seen that when the
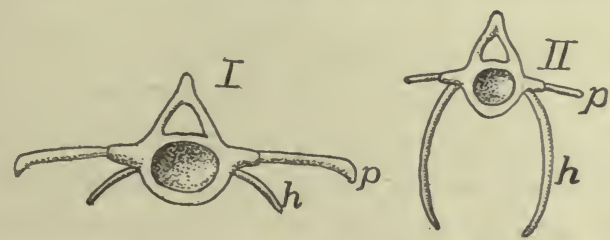

FIG. 5I.-Vertebræ and ribs of $(I)$ anterior and $(I I)$ posterior trunk region of Polypterus, after Gegenbaur. $p$, pleural rib; $h$, hæmapophysial rib.

body cavity is reached the arch becomes incomplete below, the two hæmapophyses separating and coming to lie just beneath the peritoneum in the walls of the cœlom. Above, it is either united directly to the centrum or is jointed to a small process of it. More careful study shows that this fish rib (hæmapophysial rib) lies in the intersection of a myoseptum with the median partition of the skeletogenous tissue (p. 38) and is medial to the hypaxial muscles. In the higher vertebrates the rib is formed in the intersection of 
the myosepta with the horizontal plate, and thus is lateral to the hypaxial muscles and between them and the epaxial series. This is the true or pleural rib. Any vertebra may bear ribs of either kind (including hæmal arches) and the two kinds frequently coexist on the same vertebra in the trunk of salmonids, clupeids and Polypterus, and in the caudal region of urodeles and some reptiles. Their possible occurrence in all parts of the body is explained by the existence of the myosepta and other skeletogenous structures in all regions.

The hæmapophysial ribs end freely below, never being connected with a sternum. In some aberrant fishes they are lacking, while in the ostariophysi they play a part in the 'Weberian apparatus' connecting the swim bladder with the ear (see ear). The teleosts have, in addition, numerous rib-like structures which are not preformed in cartilage (epineurals, epimerals, epipleurals) which are formed in the epaxial or hypaxial regions or in the horizontal partition.
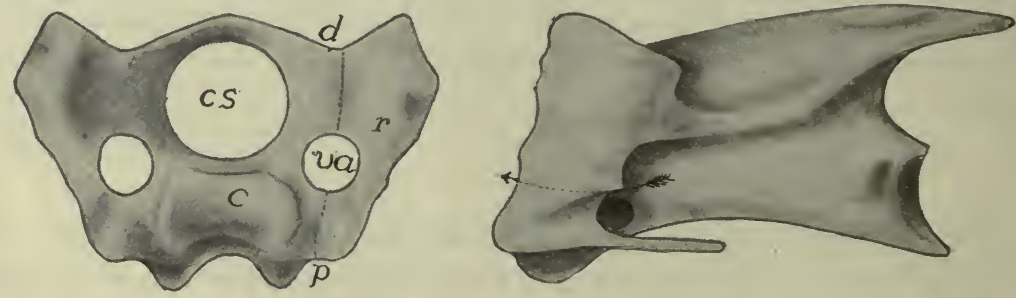

FIG. 52.-Front and side views of cervical vertebra of fowl, showing the cervical rib. $c$, centrum; $c s$, spinal canal; $d$, diapophysis; $p$, parapophysis; $r$, rib; $v a$, vertebrarterial canal; the arrow in the side view passes through the canal.

The typical rib (it is not certain whether this is the primitive form) has two heads for articulation with the vertebra, a capitular head connecting with the parapophysis, a tubercular head joining the diapophysis. Between the two heads and the centrum is a space, the vertebrarterial canal, through which the vertebral artery passes (fig. 39, C.) The true ribs, which are preformed in cartilage, have various extents in the different regions of the body. In the thoracic region, where they have the greatest extension, the ribs have to allow for changes in size of the contained cavity, and hence parts of them are frequently left unossified, or at least they are jointed, the two parts being called vertebral and sternal ribs.

In the cervical region the true ribs are usually greatly reduced and are lacking in the turtles. In many reptiles they clearly show their nature, being short, bicipital and with their heads articulated to dia- and parapophyses (fig. 45). In the birds they may be recognized (fig. 52), their distal ends being bent inward to 
protect the carotid arteries. In the mammals they form the distal part of the 'transverse process' of human anatomy, the vertebrarterial canal and the development revealing their true nature.

The dorsal ribs are very short in amphibians, never extending far from the backbone. They are bicipital in most forms, except the anura where they form small projections on the ends of the transverse

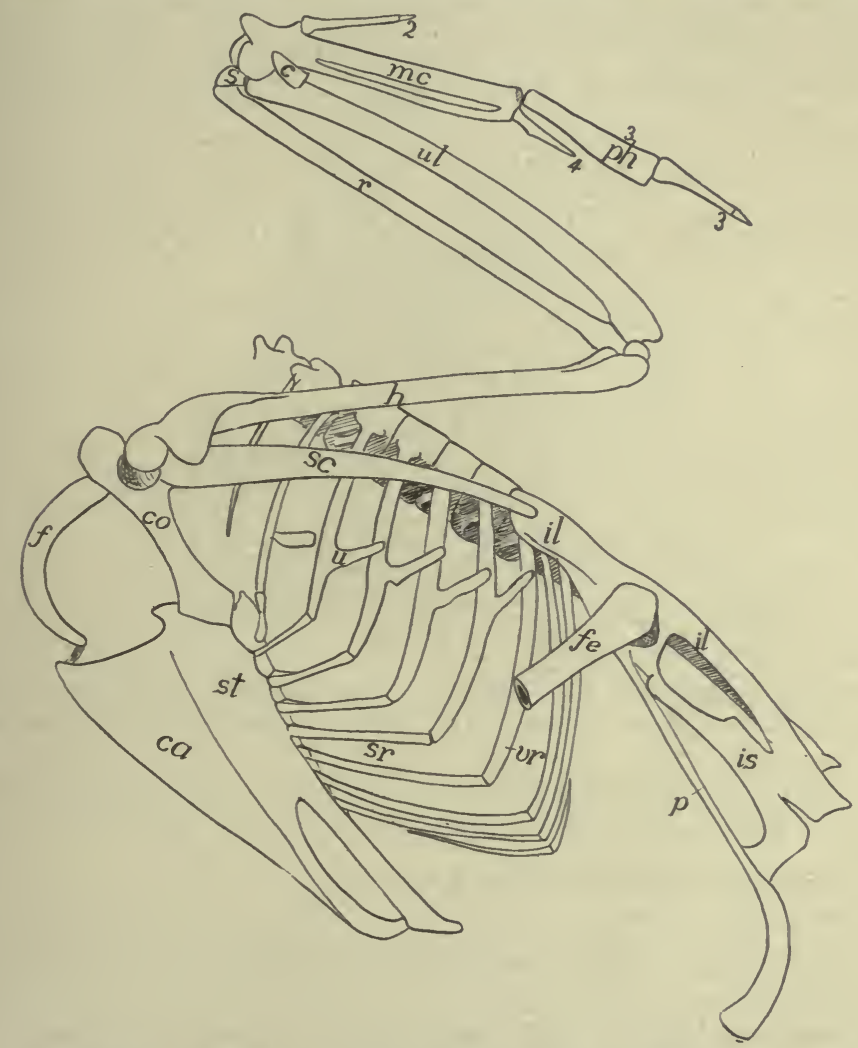

FIG. 53.-Skeleton of trunk of common goose, Anser domesticus. c, cuneiform; $c a$, carina; $c o$, coracoid; $f$, furcula (clavicle); $f e$ femur; $h$, humerus; $i l$, ilium; is, ischium; $m c$, metacarpals; $p$, pubis; $p h$, phalanges; $r$, radius; $s$, scaphoid; $s c$, scapula; $s r$, sternal rib; $s t$, sternum; $u$, uncinate process; $u l$, ulna; $v r$, vertebral rib; $2,3,4$, digits.

processes. In the amphibia the vertebral artery is ventral to the parapophysis. In all other vertebrates with a sternum at least a part of the dorsal ribs reach that structure, encircling the viscera like the hoops of a barrel. Those ribs which do not reach the sternum are called false ribs. In most reptiles and some birds most of the thoracic ribs bear an uncinate process directed upward and backward (fig. 53), overlapping 
the rib behind and strengthening the thorax. In the chelonia the ribs are confined to the dorsal side of the body and are fused to the costal plates (dermal skeleton) to form the carapace. Single- and doubleheaded ribs often occur in the same individual of various groups, and in the mammals the capitular head, instead of articulating with a distinct parapophysis, may rest in a socket formed by two successive vertebræ.

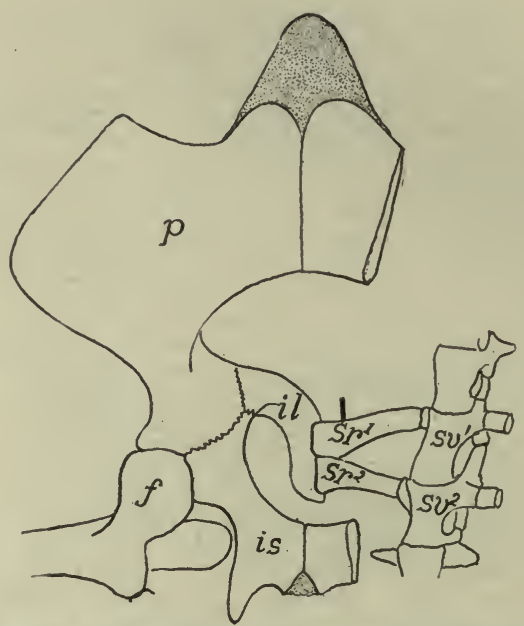

FIG. 54.-Sacral vertebræ, ribs and pelvis of Trionyx, obliquely from below. $f$, head and rochanter of femur; $i l$, ilium; is, ischium; $p$, pubis; $s r$, sacral ribs; $s v$, sacral vertebræ.

The pelvis is never directly united to the sacrum, but sacral ribs intervene. These are distinct in the reptiles (fig. 54), but are fused to the transverse processes in other groups.

\section{The Sternum (Breastbone).}

The sternum includes the skeletal parts on the ventral side of the body, which are closely connected with the shoulder girdle and, except in the amphibia, with the ribs. 'The fact that it occurs only in vertebrates with legs (it is lacking in snakes and cæcilians) shows that it has arisen in adaptation to terrestrial locomotion. In man it consists of three parts, a manubrium in front, a middle piece (gladiolus), and a xiphoid (ensiform) process behind, and these terms have been carried into other groups.

In development the sternum arises in mammals by the formation of a longitudinal bar of cartilage in the linea alba on either side, ventral (medial) to the ends 
of the ribs, eventually connecting them together (fig. 55). With continued growth these bars of the two sides meet and fuse in the median line, forming a median plate, the sternum. Later this separates from the ribs, and with the appearance of bone, becomes a series of separate elements, the sternebræ (fig. 57), alternating with the ribs; by fusion of sternebræ the parts in man arise.

In the amphibia the short ribs never extend to the sternum, but skeletal parts occur near the mid-ventral line in a few forms, which may be ventral ribs as they participate in the formation of the sternum. Nothing is known of a true sternum in the stegocephals. In the urodeles it is a short cartilaginous plate, lying mostly behind the girdle, with its sides grooved to receive the medial ends of the coracoids.

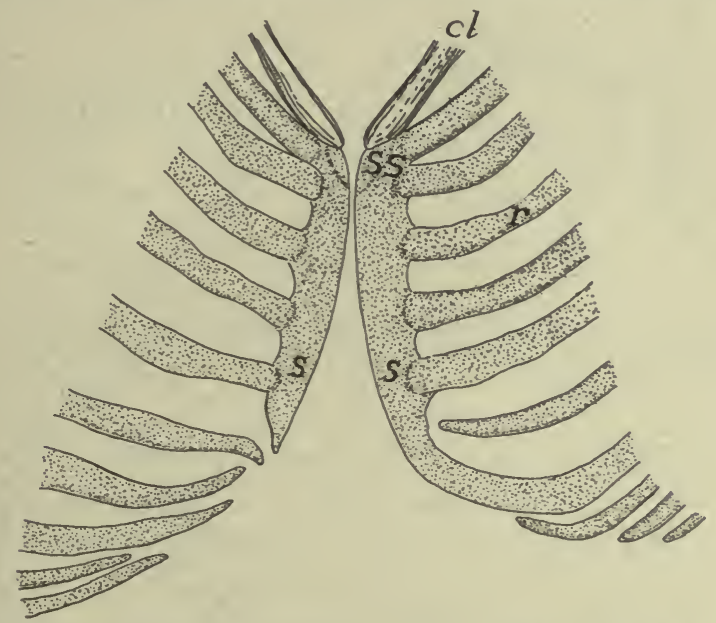

FIG. 55.-Development of sternum in $30 \mathrm{~mm}$. human embryo, after Ruge. cl, lower end of clavicle; $r$, ribs; $s$, two halves of sternum; ss, suprasternalia.

In the toads and their allies (arcifera) it has hardly passed beyond the urodele condition, but the hinder angles are produced into long processes. In the frogs (firmisternia) it consists of a slender thread between the medial ends of the girdles (epicoracoids), but in front it expands into an omosternum, ossified behind; while behind the girdle it forms a broad xiphisternum, the anterior part of which is bone.

In the lizards the sternum is a large rhomboid plate, largely cartilaginous, sometimes perforated with two foramina and joined by a varying number of ribs (fig. 56). In the crocodilia there is an anterior rhombic plate, joined by two pairs of ribs and followed by a second, so-called abdominal sternum, connected with from five to seven pairs of ribs. Ichthyosaurs, plesiosaurs and snakes have no sternum, while it was imperfectly ossified in theriomorphs and dinosaurs.

In the birds (fig. 53) the sternum is ossified and at most is connected with eight pairs of ribs. Behind it may be rounded, perforated, 
notched, or prolonged into one or two long processes. In the ostriches the ventral surface is smooth and this was formerly used as a character separating these birds as a group of ratites, in contrast to all other birds (carinatæ) which either use their wings in flight or in swimming (penguins) and in which there is a necessity for strong wing muscles. For the attachment of these the ventral surface of the sternum is developed into a strong projecting keel (carina). It is to be noted that a similar keel is developed in the bats and pterodactyls.

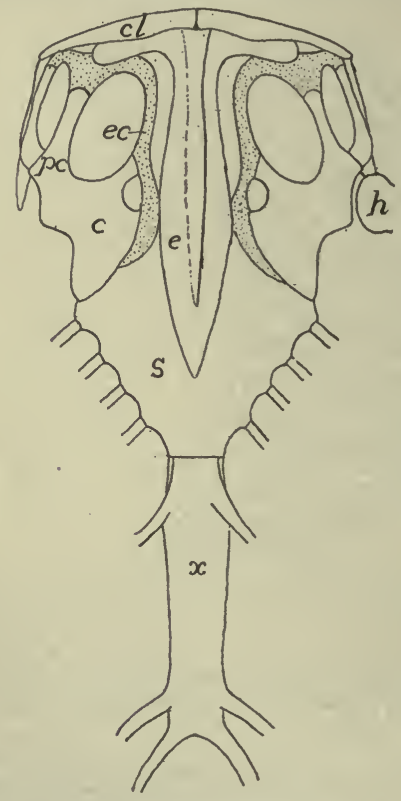

- Fig. 56.-Sternum, etc., of Iguana tuberculata, after Blanchard. $c$, coracoid; $c l$, clavicle; $e$, episternum; $h$, humerus; $p c$, procoracoid; $x$, xiphisternum.

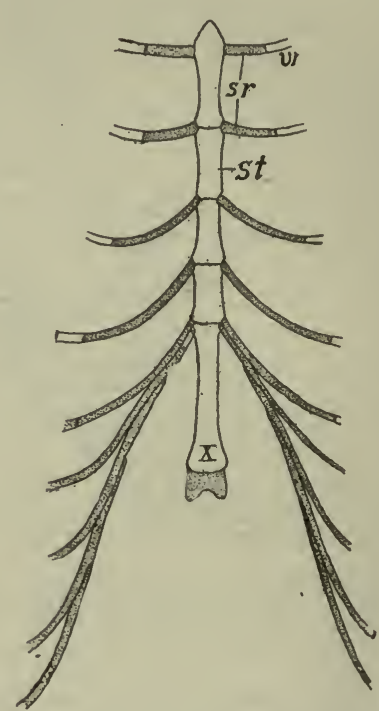

FrG. 57.-Sternum of guinea pig. $s r$, sternal rib; $s t$, sternebræ; vr, vertebral rib, $x$, xiphisternum.

In the mammals the number of ribs connected with the sternum is greater than in the lower classes. The sternebræ may remain distinct throughout life (fig. 57) or, as in man, they may fuse into fewer elements, the xiphoid process being unconnected with the ribs. In the edentates and rodents elements known as ossa suprasternalia and prosternum occasionally occur in front of the sternum, the significance of which is unknown. It is possible that traces of them persist in the higher orders, even in man (fig. 55). 


\section{EPISTER्aum (INTERCLAVICLE).}

In stegocephals and the oldest rhynchocephals there is a median bone on the ventral surface, called the episternum (fig. 58). It is rhomboid in front and may have a long posterior process, the medial ends of the clavicles lying ventral to the broad anterior end. This element is regarded as homologous with a $\mathrm{T}$-shaped membrane bone which occupies a similar position in lizards (fig. $5^{6}$ ) and crocodilians, where it acts as a brace between the shoulders. It arises by two centres
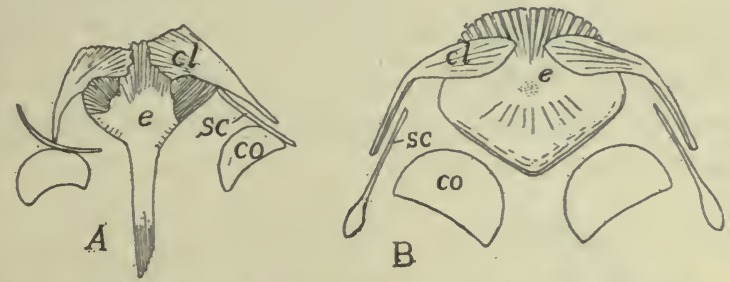

FIG. 58.- Shoulder girdles of $(A)$ Melanerpeton and (B) diagram of Branchiosaurus, after Credner, the determination of elements after Woodward. cl, clavicle; $c o$, coracoid; $e$, episternum; $s$, scapula.

of ossification in membrane and hence cannot be the same as the suprasternalia of mammals. An episternum also occurs in theriomorphs, pythonomorphs, ichthyosaurs, and plesiosaurs, and possibly the entoplastron of the chelonians (fig. 34, p. 42) is the same structure. It has not been recognized in birds, but it reappears in the monotremes among mammals (fig. II3), with nearly the same relations as in the lacertilians.

\section{The SKull.}

The skull is a complex structure and the last word concerning its composition has yet to be said. A century ago Oken pointed out that a series of parts could be distinguished in the mammalian skull, each of which somewhat resemble a vertebra in its general relations, and thus laid a foundation for a 'vertebral theory of the skull' which was farther developed by Owen. Huxley showed that these were superficial resemblances, that the three or four vertebræ they would recognize were nothing of the sort, and that the skull shows no real metamerism except in the occipital region and in the visceral arches.

In its development the skull, like the rest of the skeleton, passes through two, and in the bony vertebrates, three stages: membranous, 
cartilaginous and osseous, and in the early stages there is no trace of segmentation or of vertebræ, the Okenian segments only appearing with the appearance of bone. The skull may be divided into two portions, a cranium, composed of a case for the brain, and sense capsules enclosing the organs of special sense (ears, eyes and nose); and a visceral skeleton, more or less intimately related to the anterior end of the digestive tract.

\section{Development of the Skull.}

Little is known in detail of the development of the membranous skull save that it envelops the brain and sense organs, extends into the visceral region, and that it affords the substance in which the second, or cartilaginous, skull is formed.

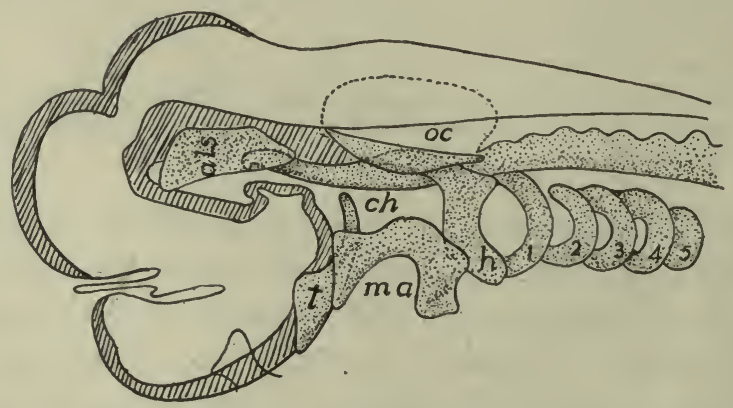

FIG. 59.-Early chondrocranium of Acanthias, after Sewertzoff. (The brain in outline.) $a l s$, alisphenoid cartilage; $c h$, anterior end of notochord; $h$, hyoid arch; ma, mandibular arch, not yet divided into pterygoquadrate and Meckelian; oc, otic capsule; $t$, trabecula; I-5, branchial arches.

The cartilaginous envelope of the brain and sense organs is called the chondrocranium. The notochord extends forward beneath the brain as far as the infundibulum and a horizontal cartilage plate forms on either side of it. These parachordal plates extend laterally as far as the ears, forward as far as the end of the notochord and back to the exit of the tenth nerve. A little later a cartilaginous otic capsule forms around each ear and joins the parachordals, thus forming a trough in which the posterior part of the brain lies, its floor formed of parachordals and notochord (basilar plate) and its sides of the sense capsules.

From this posterior part two cartilages extend forward on either side, forming a somewhat similar trough for the anterior part of the 
brain; the lower of these, the trabeculæ cranii, join the anterior margin of the basal plate while the dorsal bars, the alæ temporales or alisphenoid cartilages are eventually connected with the anterior wall of the otic capsules. In most vertebrates the trabeculæ and alisphenoids develop as a continuum, but in some elasmobranchs they are at first distinct (fig. 59). The two trabeculæ unite in front to form a median ethmoid plate beneath the olfactory lobes, beyond which they diverge as two horns, the cornua trabeculæ, ventral to the nasal organs. The floor of the trough is formed by the ethmoid platein front, while behind it is usually of membrane, but in the elasmobranchs cartilage gradually extends from one trabecula to the other, closing last below the infundibulum and hypophysis, these lying for a time in an opening (fenestra, later fossa hypophyseos), and after the closure, in a pocket in the floor of the chondrocranium, one of the cranial landmarks, the sella turcica.

In the elasmobranchs and amphibians the trabeculæ are widely separated until they reach the ethmoid plate, a condition correlated with the anterior extension of the brain. This is the platybasic chondrocranium. In the other classes the brain does not extend

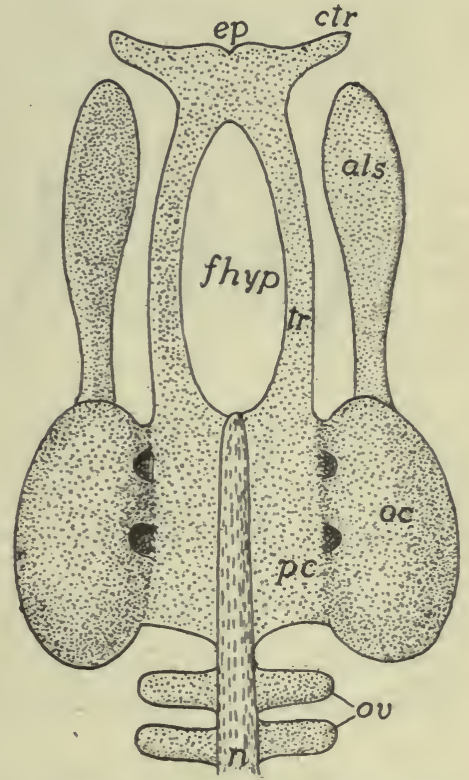

Fig. 60.-Early (platybasic) chondrocranium of an elasmobranch, straightened out. Compare with fig. 59. als, alisphenoid; ctr, cornua trabeculæ; $e p$, ethmoid plate; fhyp fenestra hypophyseos; oc, otic capsule; $o v$, occipital vertebra; $n$, notochord; $p c$, parachordal plate; $t r$, trabeculæ. so far forward and the two trabeculæ meet just in front of the hypophysis (fig. 62) to continue forward as a trabecula communis to the ethmoid region. The trabecula communis is usually compressed between the eyes to a vertical interorbital septum. This represents the tropibasic chondrocranium.

In the more primitive vertebrates the trough is converted into a tube around the brain by the extension of cartilages between the alisphenoid cartilages and the otic capsules of the two sides dorsal to the brain. This roof or tegmen cranii is usually incomplete, having one or more gaps or fontanelles, closed only by membrane. In the higher vertebrates the cartilage roof is at most restricted to a mere arch, the synotic tectum, between the otic capsules of the two sides. Later 
a pair of nasal capsules develop around the olfactory organs. These are usually fenestrated and become united to the cornua, alisphenoids, and ethmoid plate. In a similar way a sclera (sclerotic coat) forms

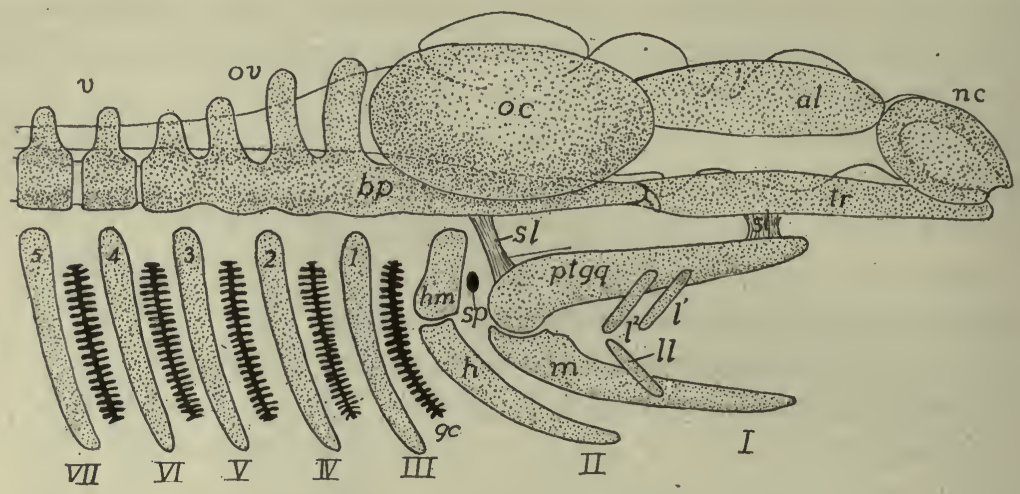

FIG. 6r.-Diagram of early elasmobranch chondrocranium in side view, the brain outlined behind. $a l$, alisphenoid plate; $b p$, basal plate; $g c$, gill clefts; $h$, hyoid; $h m$, hyomandibular; $l$, upper labials; $l l$, lower labials; $n c$, nasal capsule; $o c$, otic capsule; $0 v$, occipital vertebræ; $p t g q$, pterygoquadrate; $s l$, suspensory liga $n e n t s ; s p$, spiracle; $t r$, trabeculæ; $v$, vertebræ; $I-V I I$, visceral arches; I-5 branchial arches.

around each eye, but since the eye must move, this sense capsule never unites with the rest of the cranium. Behind the otic capsules a varying number of (four in some sharks and most teleosts, in others three,

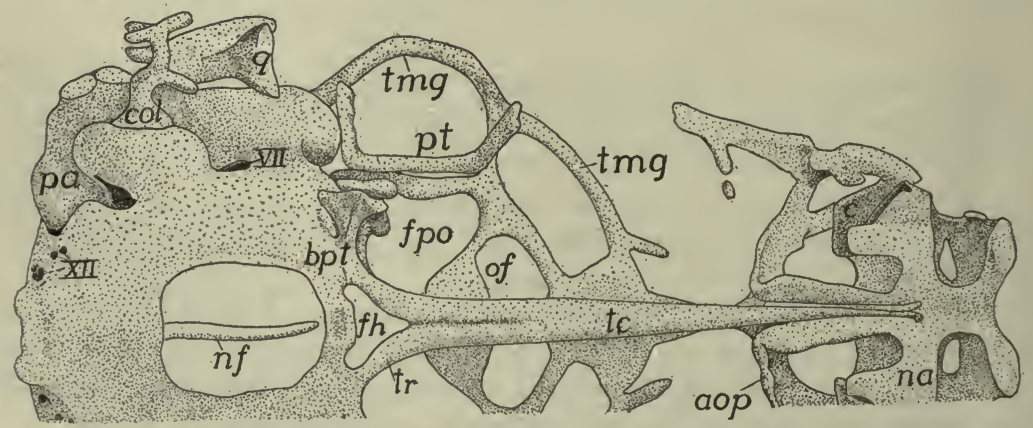

FIG. 62.- Ventral view of (tropibasic) cranium of Lacerta agilis after Gaupp. aop, antorbital plate; $b p t$, basipterygoid process; $c$, entrance to nasal conch; col, columella; $f h$, fenestra hypophyseos; fpo, post-optic foramen; $n a$, nasal capsule; $n f$, notochord; of, optic foramen; $p a$, prominence of posterior ampulla; $p t$, pterygoid; $q$, articular process of quadrate; $t c$, trabecula communis; $t m g$, tænia marginalis; $t r$, trabecula; VII, XII seventh and twelfth nerves.

in amphibia two) occipital vertebræ are developed, which later fuse with the rest of the chondrocranium. They alternate with myotomes and nerves in this region as do the vertebræ of the vertebral column. 
The cartilaginous visceral skeleton arises in the pharyngeal region which is weakened by the presence of the gill clefts. It consists of a series of pairs of bars, the visceral arches (fig. 6I, $I-V I I$ ), lying in the septa between the clefts, the bars of a pair being connected below the pharynx. Each bar, at first, is a continuous structure, but to allow of changes of size in the pharynx, each becomes divided into separate parts, while the arches become connected in the mid-ventral line by unpaired elements, the copulæ. The two anterior arches are specialized and have received special names, the first being the mandibular, the second the hyoid arch, the others, in the region of the functional gills, being called collectively gill or branchial arches. The number of these last varies with the number of gill clefts, there being seven in the primitive sharks, a smaller number in the higher groups, in which, with the loss of branchial respiration, their form and functions may be altered. At first all are clearly in the head region, but by the unequal growth of cranium and pharynx the gill arches are carried back. All of the arches are cartilaginous at first.

The mandibular arch lies in the region of the fifth nerve, behind the mouth and between it and the first visceral cleft or pocket, the spiracle or Eustachian tube. The arch is divided into dorsal and ventral halves (fig. 6I, $I$ ), known respectively as the pterygoquadrate (palatoquadrate $p t g q$ ), and Meckelian cartilages $(m)$. In the elasmobranchs and chondrostei the pterygoquadrate forms the upper jaw, lying parallel to and joined to the cranium by ligaments or (chimæroids) by continuous growth. With the appearance of bone a new upper jaw is formed, as described below, and the pterygoquadrate becomes more or less reduced, and ossifies as two or more bones with greatly modified functions. Meckel's cartilage is the lower jaw of the lower vertebrates, while in the higher it forms the axis around which the membrane bones of the definitive jaw are arranged.

The hyoid arch lies between the spiracle and the first true gill cleft, in the region of the seventh nerve. It divides into an upper element the hyomandibular cartilage (fig. 6r, hm), and a ventral portion, the hyoid proper, which may subdivide into several parts (infra). In the lower elasmobranchs the hyomandibular and the rest of the hyoid arch are closely connected, but in the higher fishes the hyomandibular becomes more separated from the ventral portion and tends to intervene between the mandibular arch and the cranium, becoming a suspensor of the jaws (fig. 63). Still higher it loses its suspensorial functions, 
becomes greatly reduced, and apparently is subsidiary to the sense of hearing (see auditory ossicles), or it may be lost, the matter not being decided. The hyoid proper becomes more or less intimately connected with the arches behind and is largely concerned in affording a support for the tongue.

The branchial arches are all similar to each other in the lower vertebrates, but with the loss of branchial respiration in the higher

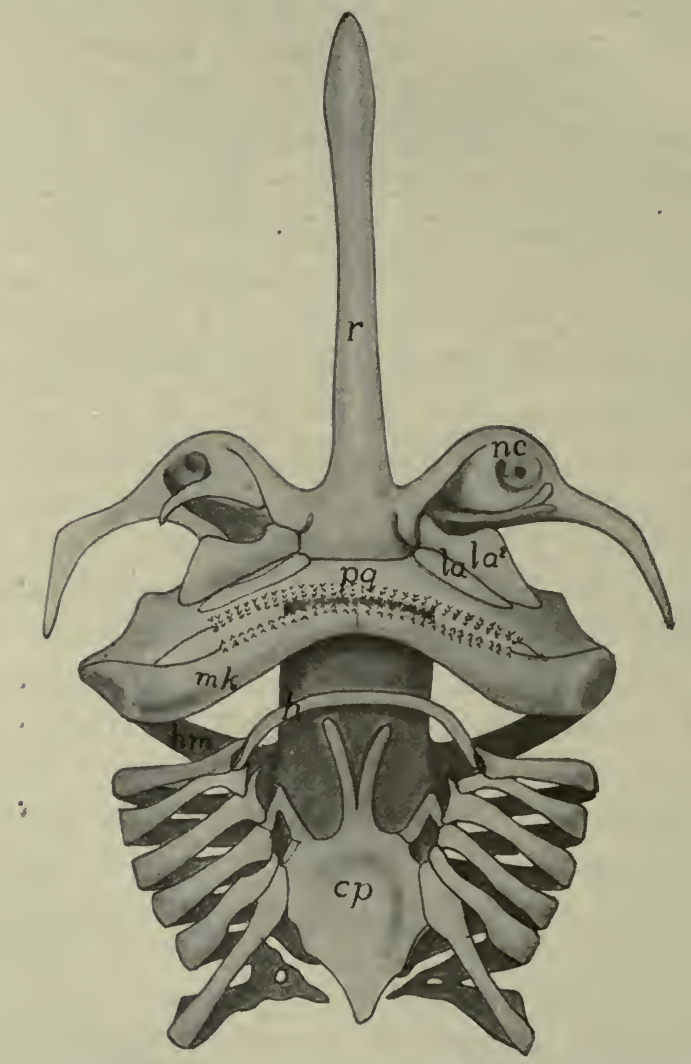

FIG. 63.-Ventral view of cranium and visceral arches of skate (Raia) after Gegenbaur. $c p$, copula; $h$, hyoid; $h m$, hyomandibular; $l a$, upper labials; $m k$, Meckelian cartilage; $n c$, nasal capsule; $p g$, pterygoquadrate; $r$, rostrum.

groups, they tend to become reduced, the reduction beginning behind. Some may entirely disappear, others give rise to the laryngeal cartilages (see respiration) and the first may fuse with the hyoid. The first arch is in the region of the ninth nerve; the others in that supplied by the tenth. 
The elements of the branchial arches have the names, beginning above, pharyngobranchial, epibranchial, ceratobranchial and hypobranchial, the copula being the basibranchials. The elements of the hyoid are correspondingly, epi-, cerato-, and hypohyal. These parts lie in the medial ends of the gill septa, medial to the aortic arches.

Other cartilages, which seem to be of less morphological importance, occur in the same region. Among these are the labial cartilages (fig. $67, l$ ), usually two above and one below, which lie in front (outside) of the cartilages of the mandibular arch of sharks, and in a modified form as high as some of the ganoids. By some they are regarded as remnants of visceral arches of the preoral region. In the branchial
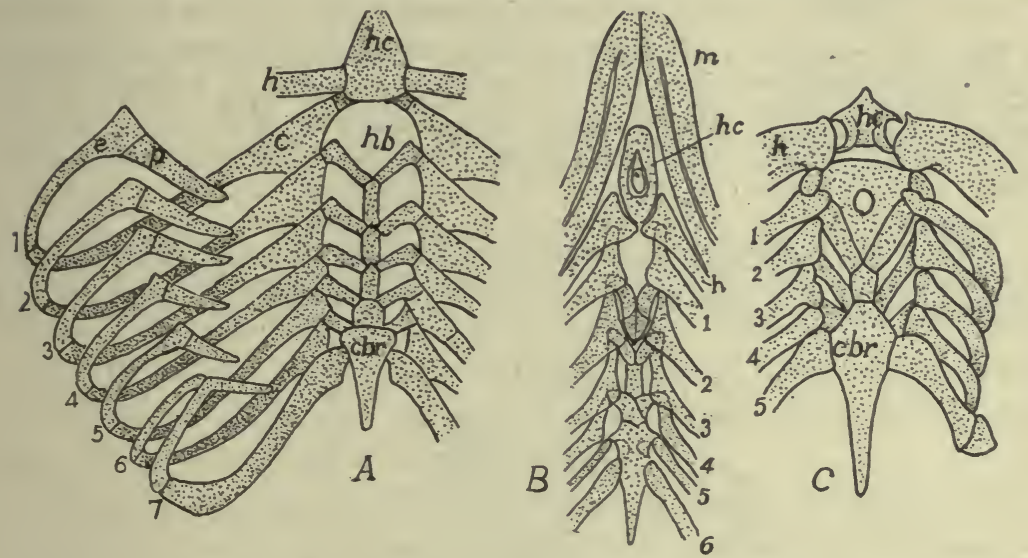

FIG. 64.-Branchial arches of (A) Heptanchus; (B), Chlamydoselache; and (C) Cestracion; $A$ and $C$ after Gegenbaur, $B$ after Garman. $c$, ceratobranchial; $e$, epibranchial; $h$, hyoid; $h b$, hyobranchial; $h c$, hyoid copula; $c b r$, cardiobranchial (posterior copula); $p$, pharyngobranchial; $\mathrm{I}-\boldsymbol{i}$, branchial arches.

region of the elasmobranchs a variable number of extrabranchial cartilages may occur, small bars external and parallel to the upper and lower ends of the gill arches.

The foregoing sketch of the chondrocranium is based on conditions in the gnathostomes, and ignores the peculiarities of the cyclostomes which are summarized below.

In the elasmobranchs and cyclostomes the skull is cartilaginous throughout life, or at most is calcified cartilage, without sharp division into separate elements. In the higher vertebrates the cartilage is supplemented or almost entirely replaced by bone which may be of the two kinds, cartilage bone and membrane bone (p.42), the distinctions between which must constantly be kept in mind in tracing homologies in the different classes. The membrane bones are usually derivatives of the deeper or dentinal layer of scales or teeth which have fused together (fig. 65) and have sunk to a deeper position, coming 
into close connection with the elements derived from the cartilage skull, in some cases replacing considerable of it. The cartilage bones arise by an ossification of the cartilage. Even in the sturgeons the chondrocranium is complete, the membrane bones being superficial and not intimately connected with the deeper parts.

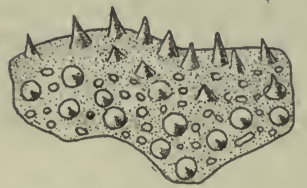

Fig. 65.-Vomer of $25 \mathrm{~mm}$. A mblystoma larva, after Hertwig, showing the bone developed by the fusion of the bases of teeth.

The names of the bones are largely based on the terminology of human anatomy. In many cases what appears as a single bone in the human skull is represented by several bones in the young and in the lower vertebrates. In these cases the bones in the lower forms are usually given names which indicate their relation to the human bones or to the part or region in which they occur. Dermal bones are apparently the older, phylogenetically, but for convenience the cartilage bones are considered first.

The chondrocranium shows several centres of ossification, but only those giving rise to distinct bones are considered here. ${ }^{1}$ The bones of

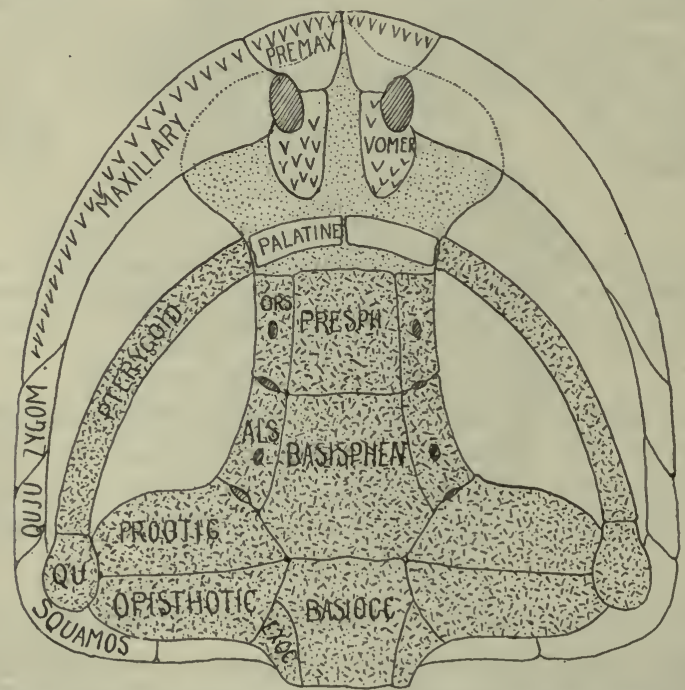

FIG. 66.-Ventral view of schematic skull, chondrocranium dotted, cartilage bones with lines and dots. basioc, basioccipital; basisph, basisphenoid; als, alisphenoid; exoc, exoccipital; ors, orbitosphenoid; presph, presphenoid; premax, premaxilla; qu,quadrate; quju, quadratojugal; squamos, squamosal; zygom, zygomatic; other names in full.

the cartilaginous brain case may be arranged in four groups, beginning behind and called respectively occipitalia, sphenoidalia and ethmoi-

${ }^{1}$ Basi- and presphenoid, for example, arise each from two centres, but in all vertebrates the resulting bones are unpaired. 
dalia, there being two sets of sphenoidalia. The occipitalia arise in the occipital vertebræ and in the basilar plate. Of these there are four (figs. 66, 67): A supraoccipital above, an exoccipital on either side, and a basioccipital below, the latter extending forward into the basilar plate. These four form a ring around a central opening, the foramen magnum, through which the spinal cord connects with the brain.

Just in front of the basioccipital the basilar plate ossifies to form the basisphenoid, which extends forward to the sella turcica, and there is succeeded by the presphenoid, arising from the trabeculæ, and extending forward to the ethmoid plate. On either side a bone, the alisphenoid, ossifies in the cartilage of the same name, and comes into close relation with the basisphenoid. Father in front a second element, the orbitosphenoid, arises in the alisphenoid cartilage and comes into relation to the presphenoid. The alisphenoid bone is just in front of the otic capsule, but there is always a large gap (sphenoidal fissure, foramen lacerum anterior) between it and the orbitosphenoid, through which the third, fourth, and sixth and the ophthalmic branch of the fifth nerve pass, the rest of the fifth nerve passing through the alisphenoid bone. The optic nerve usually perforates the orbitosphenoid, but may pass through a notch in its margin.

The ethmoid plate may ossify into a median mesethmoid bone bounded on either side by an ectethmoid and in some there may be added other bones included among the 'turbinal bones.' The olfactory nerves pass on either side of the mesethmoid, the ectethmoids (below) in the mammals developing as perforated plates (cribiform plate).

A series of otic or petrosal bones is developed in each otic capsule. The most constant of these are a prootic in front, an opisthotic behind, the two usually meeting below (fig. 66), and between them, above, an epiotic, concerning which more evidence is needed. In the teleosts and some other forms the lateral wall of the otic capsule may develop in addition a sphenotic in front and a pterotic behind, the latter overlying the horizontal semicircular canal of the ear. In the higher groups the various otic bones fuse in the adult to a single petrosal bone, which is wedged in between the lateral parts of the basioccipital and basisphenoid.

In the stegocephals, reptiles and birds the sclera often gives rise to a ring of sclerotic bones (fig. 67), which, however, never unite with the other bones of the skull. The nasal capsules often develop a 
lateral ethmoid on the upper wall, and turbinals on the medial and lateral walls.

To place these bones in the terms of human anatomy: the four occipitalia fuse to form the single occipital of man; the six sphenoidalia similarly unite to form the single sphenoid, the alisphenoids forming the greater wings, the orbitosphenoids the lesser wings, while the ethmoidalia fuse to the ethmoid.

In all bony vertebrates the cranial walls are completed dorsally by membrane bones, which in the lower fishes overly the tegmen cranii, while in the higher groups they replace it, the cartilage failing to develop

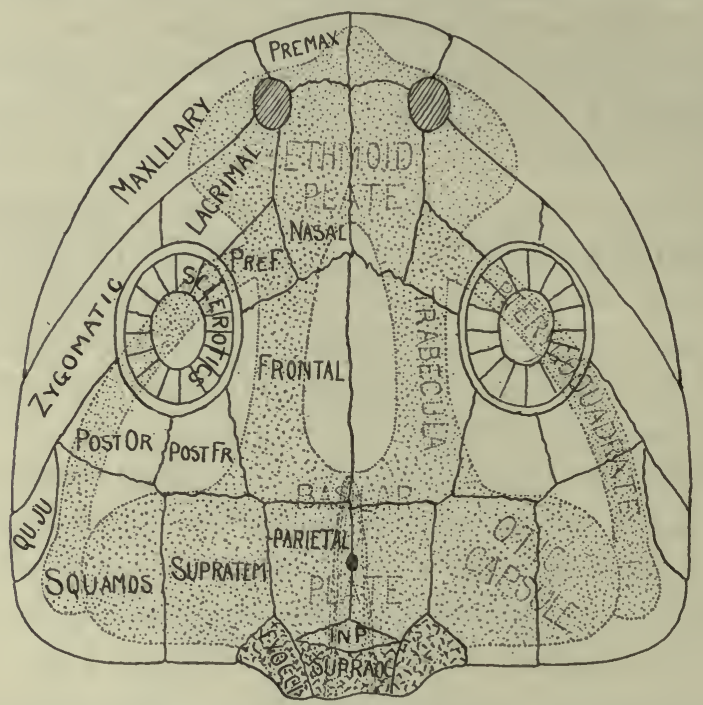

FIG. 67.-Dorsal view of schematic skull, the chondrocranium dotted, cartilage bones with lines and dots. premax, premaxilla; pref, prefrontal; postfr, postfrontal; postor, postorbital; squamos, squamosal; quju, quadratojugal; qu, quadrate; in $p$, interparietal; exoc, exoccipital; supratem, supratemporal; other names in full.

in the roof. The number of these elements varies between wide limits, the following being the most constant.

Beginning in front (fig. 67), there are, on either side of the median line a pair of nasal bones covering the olfactory region; a pair of frontals between the orbits; a pair of parietals at the level of the otic capsules, between which there is frequently a parietal foramen for the connexion of the parietal eye with the brain; and an interparietal, arising from paired centres, between the parietals and the supraoccipital.

In the higher vertebrates (where the interparietal frequently fuses 
with the supraoccipital) these are practically all of the membrane bones in the cranial roof of the adult. In the lower groups there are several other bones, some of which may appear in the development of the higher forms. Thus lateral to each parietal there may be a supratemporal; behind the orbit a postfrontal may articulate with the frontal, and lateral to this, and forming the rest of the posterior wall of the orbit a postorbital. Occasionally the superior (or medial) wall of the orbit is formed by one or more supraorbital bones, which, when present, exclude the frontal from the orbit. The orbit may be bounded in front by a prefrontal bone, adjoining the antero-lateral margin of the frontal, and lateral to this there is usually a lacrimal bone. Less constant are an intertemporal bone dorsal (medial) to the alisphenoid, a pair of postparietal bones between parietals and interparietals and a so-called 'epiotic' above each otic capsule, which, since it is not a cartilage bone and has no relation to the true epiotic, is better called the tabulare.

In the ichthyopsida, and to a less extent in the sauropsida the basilar plate and trabeculæ may fail to ossify. In these cases the floor of the cranium (roof of the mouth) is formed by a membrane bone, the parasphenoid, which lies ventral to the cartilage in the sphenoid region. Farther forward, in the nasal region, are an additional pair of membrane bones, the vomers. Both vomers and parasphenoids frequently bear teeth and their origin by fusion of the bases of teeth is clearly seen in developing amphibia (fig. 65).

Some think the parasphenoid the homologue of the mammalian vomer, calling the vomers of the non-mammals prevomers, their representatives being sought in the 'dumb-bell bone' of the monotremes. More evidence is needed on these points.

With the appearance of bone the mandibular arch undergoes the greatest modifications of all the visceral arches. Its pterygoquadrate half loses its function as the upper jaw and becomes more closely connected with the cranium in front, its median portion disappearing, even as cartilage, and being replaced by a pair of membrane bones, the palatines (fig. 66), which lie between the pre- or parasphenoid and the vomers. The rest of the arch ossifies as two bones on either side, an anterior pterygoid and a posterior quadrate, which now becomes the suspensor of the lower jaw. In the teleosts and reptiles there are a series of pterygoid bones.

A second arch of membrane bones develops outside of the pterygo- 
quadrate to form the functional upper jaw (figs. 66,67 ) in all bony vertebrates. In its fullest development it consists of bones on either side, beginning behind with a squamosal, which overlies the quadrate, and followed by a quadratojugal, a zygomatic (malar or jugal), and a maxillary, which joins the premaxillary, the latter forming the
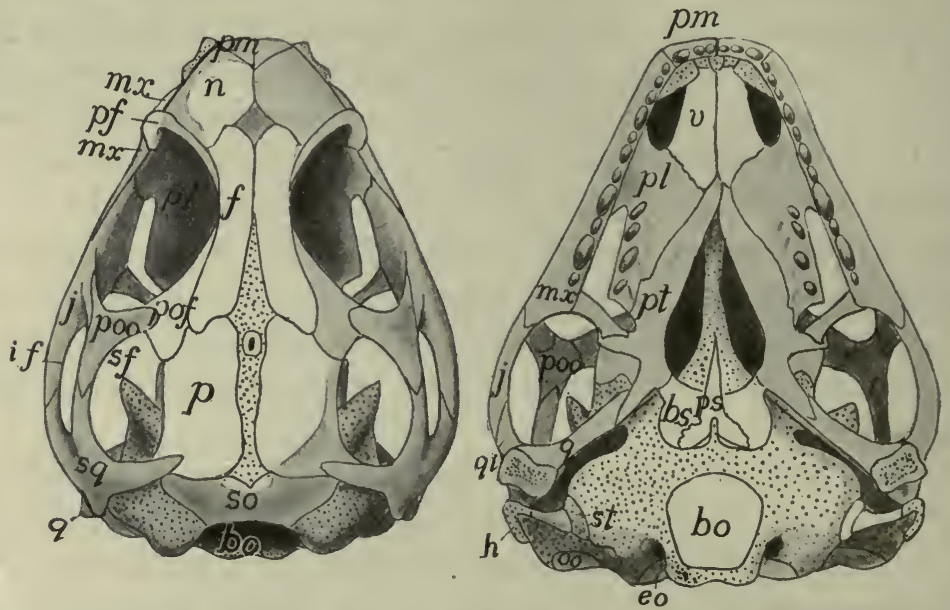

Fig. 68.-Dorsal and ventral views of skull of young Sphenodon, after Howes and Swinnerton. Explanation of letters used in figures of skulls (figs. 68 to ro5) unless otherwise stated. an, angulare; $a o$, antorbital; $a p$, antorbital process; $a r$, articulare; as, alisphenoid; $b$, basale; $b b$, basibranchial; $b h$, basihyal; $b o$, basioccipital; $b s$, basisphenoid; $c \bar{b}$, ceratobranchial; $c h$, ceratohyal; $c l$, columella; $c o$, coronoid; $c p$, copula; $c r$, cranial rib; $c r . e t h$, cribiform plate of ethmoid; $d$, dentary; de, dermal ethmoid; dee, dermal ectethmoid; $e b$, epibranchial; $e e$, ectethmoid; $e h$, epihyal; enp, entopterygoid; eo, exoccipital; ep, ectopterygoid; epo, epiotic; eth, ethmoid; ethpp; perpendicular plate of ethmoid; es, extrascapular; $e x b$, extrabranchial; $f$, frontal; $f p$, frontoparietal; $g$, goniale; $h$, hyoid; $h b$, hypohyal; $h m$, hyomandibular; $h r$, hyoid rays; $i$, incus; if, infratemporal fossa; $i o$, interoperculum; $i p$, interparietal; $j$, jugal; $l$, lacrimal; $l a$, labial; $m d$, mandibular; $m e$, mesethmoid; $m k$, Meckelian; $m l$, malleus; $m m$, mentomeckelian; $m p t$, $m s p t$, mesopterygoid; $m t p$, metapterygoid; $m x$, maxillary; $m x p$, maxillopalatine; $m x t$, maxilloturbinal; $n$, nasal; $n a$, neural arch; $n c$, nasal capsule; $n o$, notochord; $o$, occipital; $o c$, occipital condyle; $o o$, opisthotic; $o p$, operculare; $o s$, orbitosphenoid; ot, otic bones; $p$, parietal; $p d$, predentary; pe, petrosal; $p f$, postfrontal; $p l$, palatine; $p m$, premaxillary; $p o$, preoperculare; $p o o$, postorbital; $p q$, pterygoquadrate; prf, prefrontal; pro, preorbital; prot, prootic; prs, presphenoid; $p s$, parasphenoid; $p t$, pterygoid; ptc, pterygoid cartilage; pto, pterotic; $q$, quadrate; $q j$, quadratojugal; $r$, rostral; $r m$, rostrum; sa, suprangulare; sbo, suborbital; sc, sagittal crest; $s c l$, sclerotic; se, sphenethmoid; $s f$, supratemporal fossa; sh, stylohyal; so, supraoccipital; sop, subopereulare; sor, supraorbital; $s p$, sphenoid; $s p h t$, sphenoturbinal; $s p l$, splenial; $s p o$, sphenotic; $s p t$, supratemporal; $s q$, squamosal; ssc, suprascapular; st, stapes; $s y$, symplectic; $t$, temporal; $t r$, transversum; $t u$, turbinal; $t y$, tympanic; $v$, vomer; $v p$, vomeropalatine.

tip of the jaw and meeting its fellow of the opposite side. Of these only the maxillary and premaxillary bear teeth.

In the lower vertebrates the roof of the skull is continuous, its only openings being those for the nares and the orbits. In the higher 
groups vacuities or fossæ appear in the postero-lateral parts, these being bounded by bars or arcades of bone. At most there may be three of these fossæ. The more lateral of these, the infratemporal fossa (fig. 68), is bounded laterally by the zygomatic and quadratojugal, while on the inner side it is separated from the supratemporal fossa by a squamoso-postorbital arcade. The posttemporal fossa lies between parietal, supratemporal and occipital bones. Occasionally only the infratemporal fossa is present, or, by disappearance of the intervening arcade, infra- and supratemporal fossæ may unite in a single temporal fossa. Lastly, by the breaking down of the zygomaticpostorbital bar, the temporal fossa and the orbit may unite.

One or another of these bones may disappear in some groups, either by fusion or by complete dropping out. Occasionally they may obtain different connexions and relations as in the case of the quadrate in mammals (see ear bones) so that the homologies are traced with difficulty. The complexity is increased by the fusion of membrane bones and cartilage bones and by the union of cranial bones with those of the visceral arches.

In the lower jaw there are no such extensive modifications as in the upper. At most Meckel's cartilage gives rise by ossification to two bones in either half. Behind, at the articulation of the jaw with the quadrate, there is an articular bone, while at the tip, at either side of the union (symphysis) of the two halves of the jaw, there is rarely a mento-Meckelian bone. The rest of

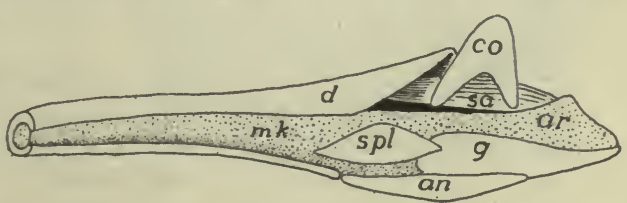

FIG. 69.-Reconstruction of developing jaw of Sceleporus, cartilage dotted; letters as in fig. 68.

Meckel's cartilage forms an axis around which the membrane bones which form the definitive jaw are arranged. These are, at most, as follows: (I) a dentary which surrounds the Meckelian in front and usually bears teeth; (2) a splenial on the inner side, behind the dentary and frequently bearing teeth; (3) an angulare on the lower side, usually extending back to the hind end of the jaw; (4) a suprangulare on the outer posterior part of the jaw; (5) a coronoid on the upper side, affording attachment for the muscles which close the jaws; and (6) a goniale (dermarticulare) on the medial and ventral sides of the articulare, with which it usually fuses. This whole series is present in few vertebrates, dentary, splenial and angulare being the most constant. 
TABLE OF THE PRINCIPAL CRANIAL BONES.

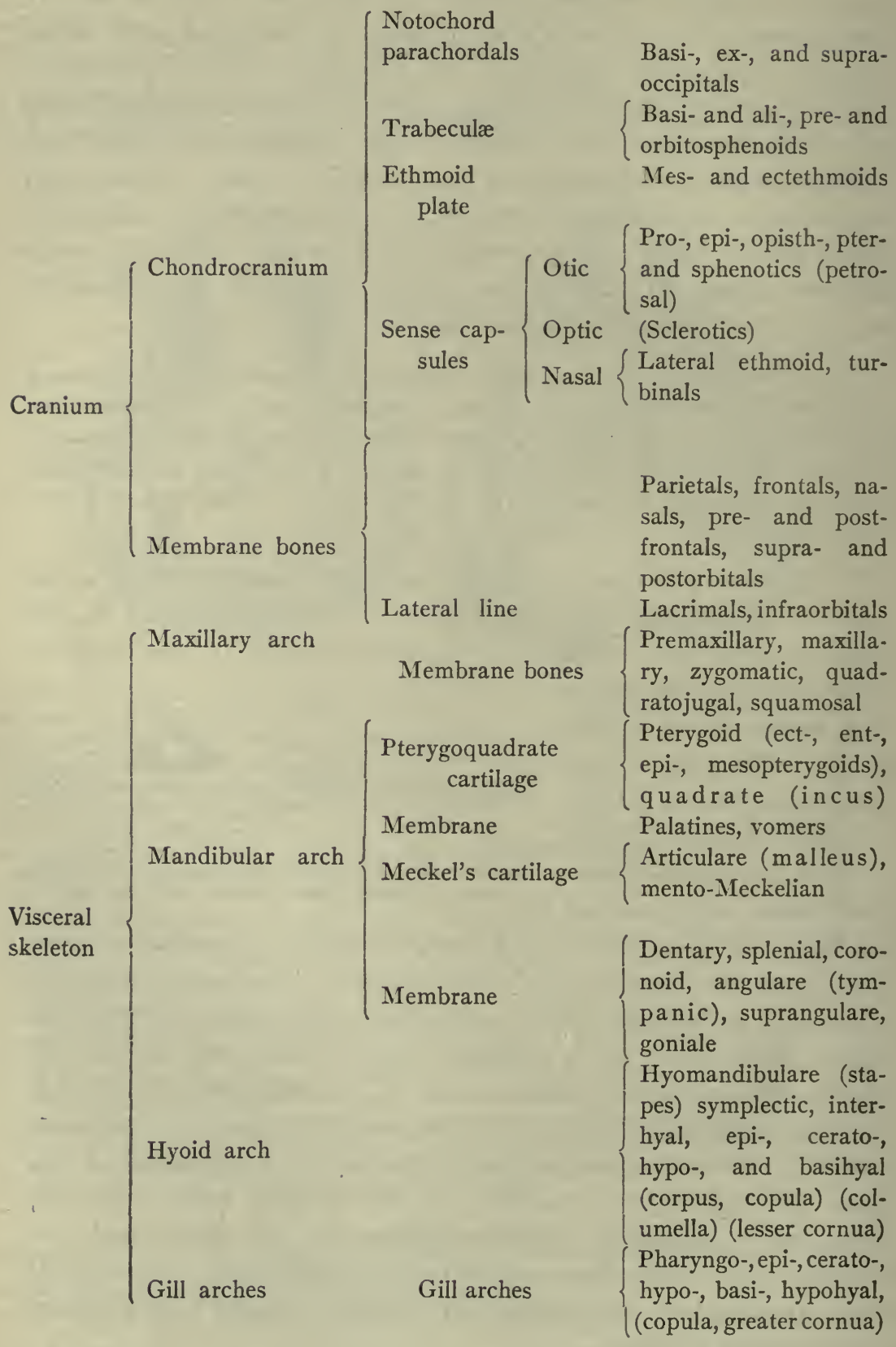


In the hyoid and branchial arches ossification occurs to a greater or less extent, the resulting cartilage bones having the same names as the corresponding cartilages. There are never any membrane bones in this region. In the teleosts the hyomandibular ossifies as two bones, a dorsal hyomandibular and a lower symplectic which connects with the quadrate. There is, however, a considerable amount of union between the various arches in the adults of all tetrapoda, where the branchial respiration is lost and the arches have to assume other functions than the support of gills.

The mode of suspension of the jaws varies. In a few elasmobranchs the pterygoquadrate articulates directly with the cranium (amphistylic); in others it is suspended by ligament and by the interposition of the hyomandibular between the otic capsule and the hinder end of the jaw (hyostylic); while in all groups above the fishes the pterygoquadrate is more or less completely fused with the cranium (autostylic).

The ear bones or ossicula auditus are best treated together here, although their consideration requires the mention of structures not yet described. The ear bones occur only in the tetrapoda; they present several modifications not readily homologized with each other, though they all have

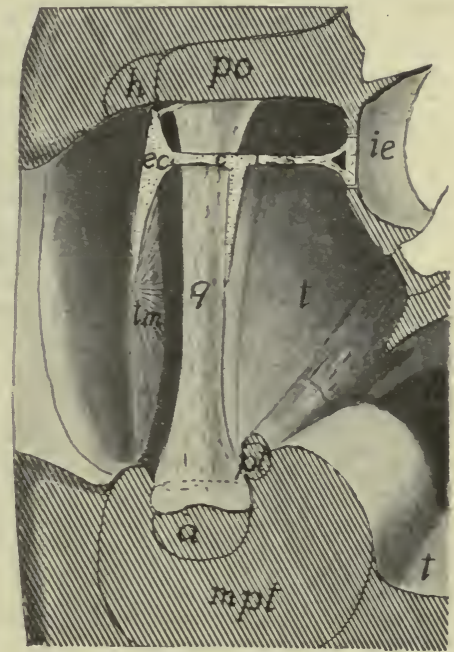

FIs. 70.-Diagram of the middle ear of a lizard, after Versluys. a, articulare; $c$, columella; $e c$, extracolumella; $h$, hyoid; $i e$, inner ear; $m p t$, pterygoid muscle; $o$, oral cavity; po, parotic process; $p t$, pterygoid bone; $s$, stapes; $t$, tympanic cavity; $t m$, tympanic membrane.

the same function of conveying sound waves across the tympanum to the inner ear. In all there is an opening, the fenestra vestibuli (f. ovale) in the lateral wall of the otic capsule, which is occupied by a movable bone, the stapes, of uncertain homologies, but probably representing the hyomandibular of the fishes, which otherwise is lacking in all tetrapoda. This view is the more probable since in some vertebrates the stapes is connected developmentally with the rest of the hyoid arch.

In urodeles and cæcilians a slender process extends from the quadrate across the poorly developed tympanic cavity to articulate with the 
stapes (fig. 82). In the anurans there is no connection of quadrate with stapes, but there is a slender rod, the columella, extending from the tympanic membrane to the stapes. This columella arises behind the tympanic cavity but with growth is included in it, so that in the adult it appears to run directly through it. In the sauropsida the relations are much as in the anura, but when ossification sets in, the columella may form several elements. In development the columella in these forms is directly connected with the hyoid arch.

In the mammals there is

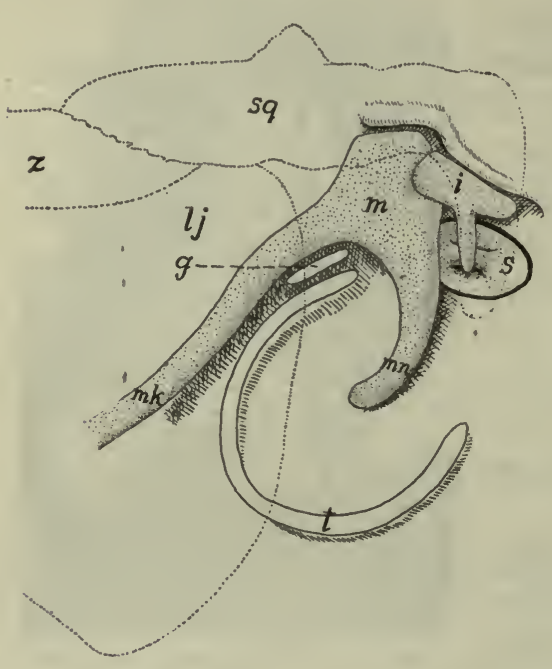

FIG. 7 1.-Diagram of ear bones of embryo pig, the tympanic cavity laid open. $g$, goniale; $i$, incus; $l \cdot j$, lower jaw; $m$, malleus; $m k$, Meckel's cartilage; $m m$, manubrium of malleus; $s$, stapes; $s q$, squamosal; $z$, zygomatic. The outlines of the zygomatic arch and the hind end of the jaw are dotted.

tympani nerve, the columella of the non-mammals lying behind it.

The homologies of these parts seem clear. In development the malleus is the posterior end of Meckel's cartilage, being in the position of the articulare of lower groups. It articulates with the incus, which in turn at first articulates with the wall of the otic capsule, as well as with the stapes, and thus corresponds with the quadrate. The stapes is apparently the same throughout the whole of the tetrapoda. It is to be noted that many paleontologists deny the homologies recognized here, think that in the mammals the quadrate has been lost in the glenoid 
fossa, and find the malleus and incus in the columella. For this they have no evidence except comparisons with certain theriomorph reptiles. The literature, which is extensive, should be consulted for details.

\section{The Skull in the Different Classes.}

CYCLOSTOMES have only the cartilage skull, and this can be homologized only in part with that of other vertebrates; indeed the skulls of the two groups of cyclostomes are not easily compared. The peculiarities are in part due to the development of a suctorial mouth with its necessary framework. The chondrocranium of the Ammocœete stage of Petromyzon is readily understood. Parachordals, otic capsules and trabeculæ (fig. 72) are normal, but a pair of ventral horns are problematical. Their position in front of and below the otic capsule renders doubtful the interpretation of hyoid or quadrate sometimes given them.

The adult Petromyzon has a typical brain trough, roofed by a slender synotic tectum and fibrous tissue and closed in front by the unpaired nasal capsule, bound to the rest by fibrous tissue. The cranium is continued forward by a large plate (mesethmoid?) lying dorsal to the mouth, this part being roofed by two 'dorsal cartilages,' the anterior articulating with the annular cartilage supporting the mouth. A subocular bar extends forward from each otic region and an elongate lingual cartilage extends from the mouth back to the gill region. Several other elements occur,

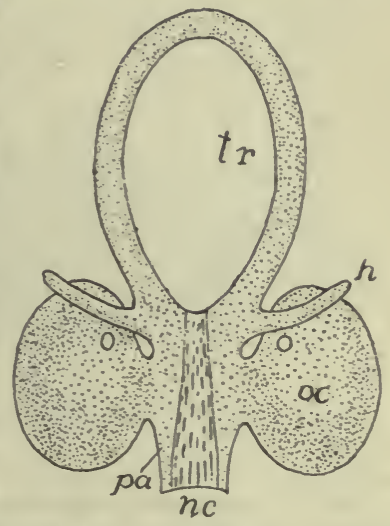

FIG. 72.-Early chondrocranium of Ammocœte stage of Petromyzon, after Schneider. $h$, hyoid; $n c$, notochord; oc, otic capsule; $t r$, trabeculæ. the names and positions of which may be seen from the figures.

The myxinoid skull, the development of which is unknown, is readily interpreted so far as basilar plate, trabeculæ and otic capsules are concerned. The large nasal capsule is continued forward by a latticed framework for the naso-hypophysial canal and a bar (pterygoquadrate) joins the trabecula of either side and in front is continued in a cornual cartilage. The lingual cartilage is enormous (is it the lower jaw as has been suggested?), is divided into three segments and bears a dental plate with teeth at its tip. There are cartilage axes to the tentacles around the mouth.

The branchial skeleton of the lampreys consists of a gill basket of continuous cartilage with fenestræ for the gills and above and below them as well. It cannot be homologized with the branchial skeleton of other vertebrates as it lies immediately beneath the skin and is lateral to gill pouches and aortic arches. It is more easily compared to the extrabranchials (p. 65) of the elasmobranchs. The branchial apparatus of the myxinoids is reduced, consisting of two true gill arches, in front of which is another arch, usually interpreted as a hyoid. 
ELASMOBRANCHS have a nearly typical chondrocranium which is never divided into separate elements and is never ossified. The floor is complete, the hypophysis resting in a sella turcica. Above there is an anterior fontanelle, closed by membrane and a posterior fontanelle may occur. The occipital region typically
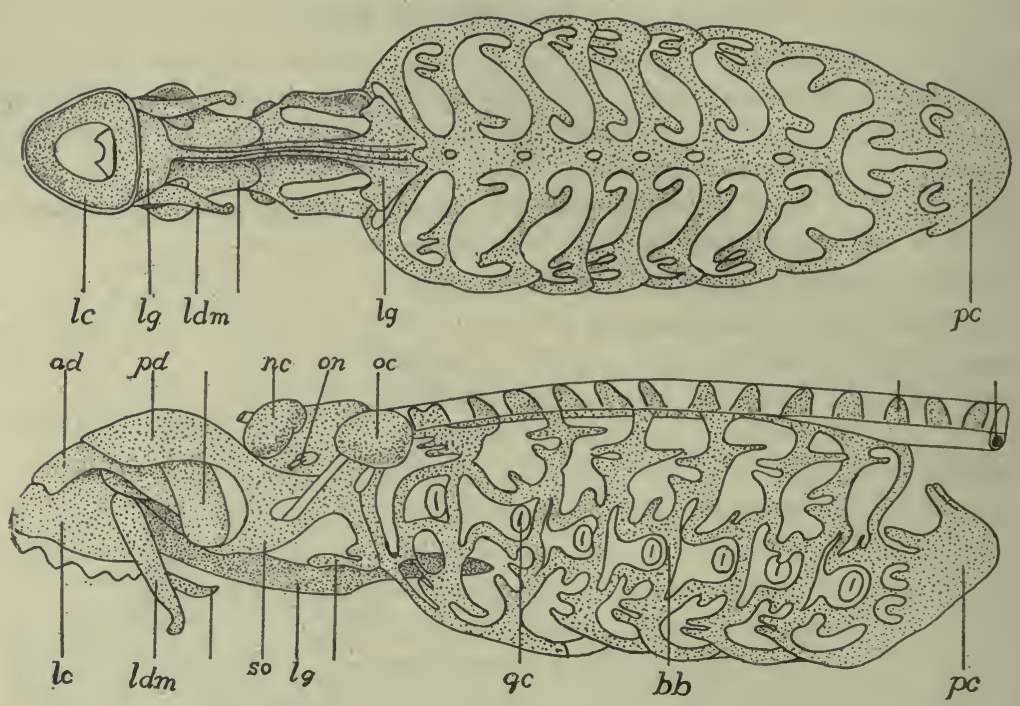

Fig. 73.-Ventral and lateral views of the skull of lamprey (Petromyzon marinus), after Parker. $a d$, anterior dorsal cartilage, $b b$, branchial basket; $g c$, gill cleft; $l c$, labial cartilage; $l d m$, lateral distal mandibular; $l g$, lingual cartilage; $n c$, nasal capsule; oc, otic capsule; $o n$, optic nerve; $p c$, pericardial cartilage; $p d$, posterior dorsal cartilage.

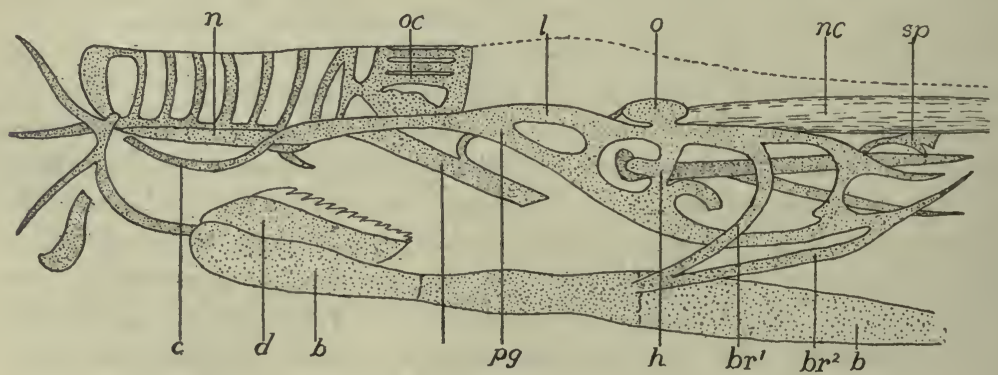

Fig. 74.- Side view of cranium of Bdellostoma, after Ayers and Jackson. $b$, basal plate; $b r$, branchial basket; $c$, cornual cartilage; $d$, dental plate; $h$, hyoid; $l$, lateral labial cartilage; $n$, nasal tube; $n c$, notochord; $o$, otic capsule, oc, olfactory capsule; $p q$, pterygoquadrate bar; $s p$, suprapharyngeal plate.

articulates with the vertebral column by a pair of prominences, the occipital condyles, but in most species this joint is not functional, the skull being immovably united to the backbone. In front the snout is supported by rostral cartilages, usually three in number, but these are frequently fused to a single mass. 
The pterygoquadrate and the Meckelian cartilages bear teeth and form the functional jaws. Most species are hyostylic (p. 73), the pterygoquadrate being supported in front of the orbit by a ethmopalatine ligament on either side; behind by ligament and by the hyomandibular. The Notidanids are amphistylic, the hyomandibular being connected with the rest of the hyoid and not acting as a suspensor of the jaws, but the pterygoquadrate bears a strong process which articulates with the postorbital process of the cranium. A third condition is found in the holocephalans where the pterygoquadrate, free in the young, becomes autostylic by fusion with the cranium.

The variations in the branchial skeleton (figs. 63,64 ) are readily reducible to the typical conditions. In living elasmobranchs the number of gill arches is tive,

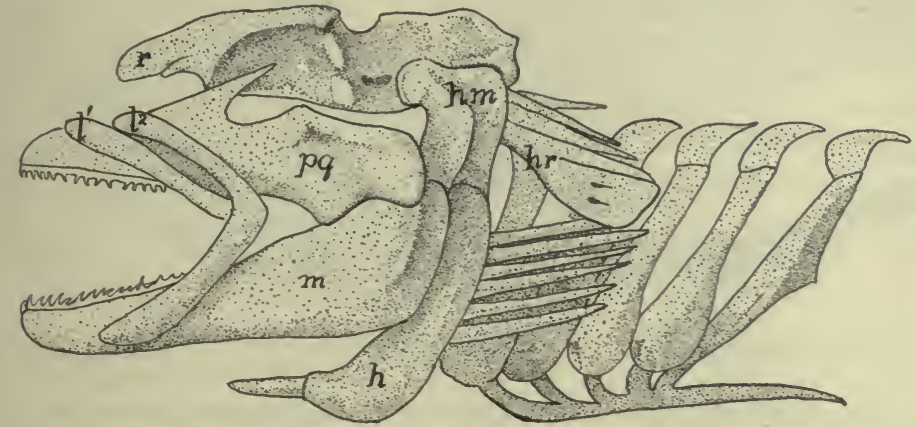

FIG. 75.-Skull of Squatina, after Gegenbaur. $h$, hyoid; $h m$, hyomandibular; $\mathrm{I}^{2} \cdot \mathrm{I}^{1}$, labial cartilages; $m$, Meckel's cartilage; $p q$, pterygoquadrate; $r$, rostrum.

except in Hexanchus and Chlamydoselache (six) and Heptanchus (seven). Hyoid and branchial arches bear numerous branchial rays which support the gills and the gill septa, while smaller cartilages on the inner surface of each arch extend into the gill strainers.

TELEOSTOMES show a wide range of structure of skull, yet the series so intergrade that no sharp lines can be drawn. The chondrocranium persists to a considerable extent, and numerous membrane bones are present, supplementing those of cartilaginous origin. With few exceptions cartilage bones (the four occipitals, orbitoand alisphenoids and prootics are the most constant) are developed, while the inner wall of the otic capsule disappears, so that the cavity is connected with that for the brain. Even more characteristic is the presence of skeletal structures supporting the opercular fold that covers the external openings of the gill slits. This is in part of membrane bones, in part of cartilage or cartilage bones. There are two parts to the opercular fold, a gill cover or operculum above and a branchiostegal membrane below. The latter is supported by branchiostegal rays, comparable to the hyoid branchial rays of the elasmobranchs, while the operculum contains membrane bones, there being, at most, four of these: a preoperculum in front, and behind this in a row from above downward, operculare, suboperculum and interoperculum. The preoperculum, overlies hyomandibular, symplectic and quadrate, and it is possible that the opercular bones have been developed in con- 
nexion with the hyomandibular rays of the elasmobranchs. There are five branchial arches, the last more or less reduced. Often they bear teeth on their inner surfaces, thus acting as accessory chewing organs.

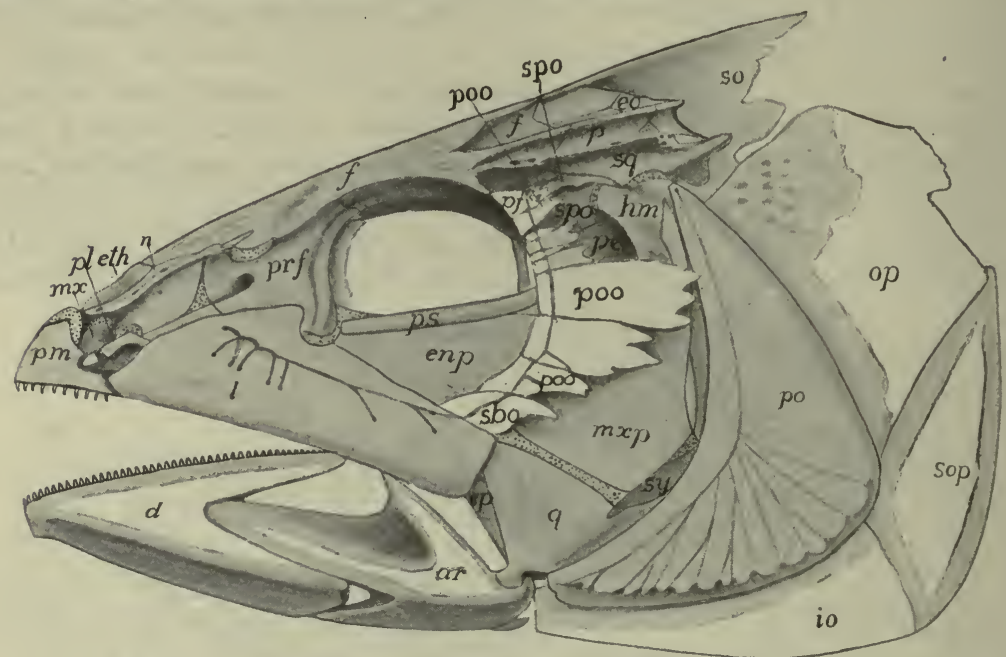

FIg. 76.-Side view of skull of mackerel (Scomber) after Allis. For letters see fig. 68.

The chondrostei, the most shark-like of the GANoIDS, have no cranial cartilage bones. They are also primitive in the great development of the rostral cartilage (enormous in Polyodon), which gives the mouth its ventral position, and in the

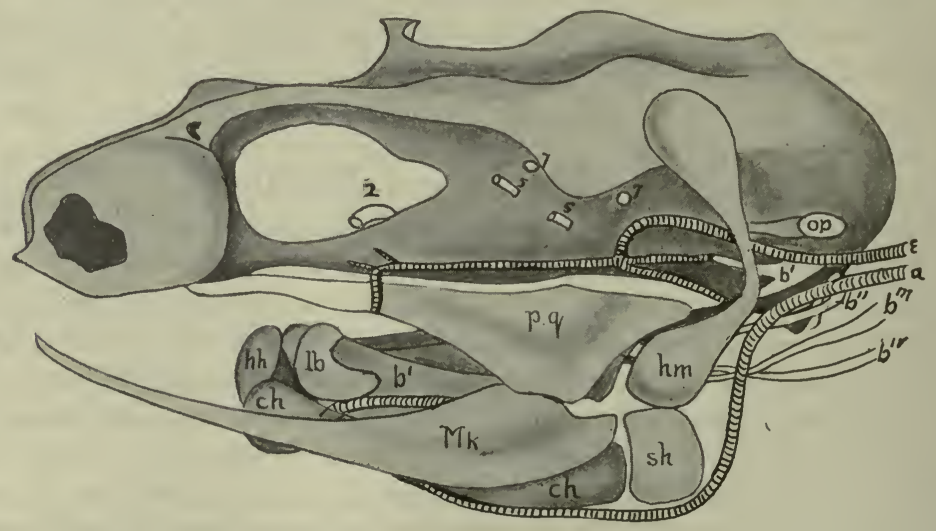

Fig. 77.-Chondrocranium of Polypterus, after Budgett. $a$, afferent artery to external gills; $b^{1}-4$, branchials; $e$, efferent artery from external gills; $l b$, labial cartilage; $2,5,7$, nerve exits; other letters as in fig. 69.

extension of the cranial cavity into the ethmoid region. They have a few bones in the visceral skeleton, while there are numerous membrane bones in the roof of the skull, a few of them readily homologized with those of other vertebrates. 
In other ganoids (holosteans and crossopterygians) the skull is much like that of the teleosts, differing in the extension forward of the cranial cavity. There are

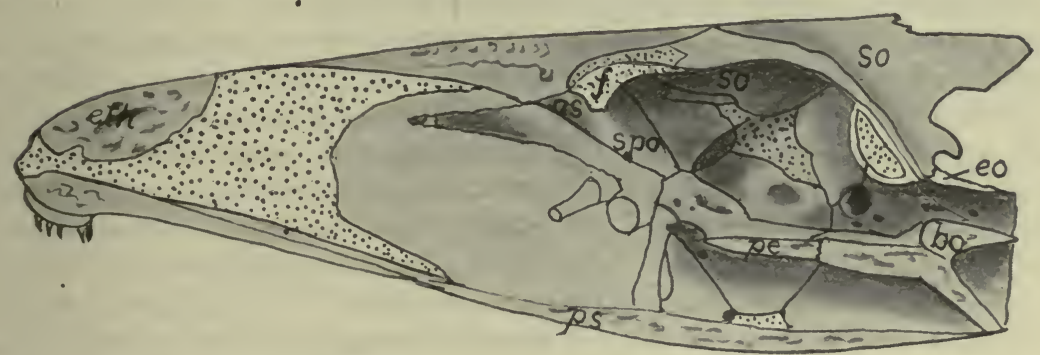

FIG. 78.-Median section of skull of mackerel (Scomber) after Allis. For letters see fig. 68.

one (Amia) or two (Polypterus) gular bones developed between the rami of the lower jaw, and in Polypterus parietals, frontals and nasals fuse with age, and there are numerous small bones in the cranial roof, developed along the lateral line canals. A mia has several splenials in the lower jaw.

TELEOSTS (fig. 76-80) have a considerable range of skull structure. In the lower groups like siluroids and cyprinids, the chondrocranium is largely persistent and the cranial cavity extends into the ethmoid region as in the higher ganoids. In other teleosts the trabeculæ are approximate between the orbits (tropibasic) and develop a thin interorbital septum which limits the anterior ends of the cranial cavity. The cartilage bones are more numerous. All four occipitalia are present, the occipital condyle being formed by basi-and exoccipitals. Basi-, ali-, and orbitophenoids occur, and besides ectethmoids a pair of mesethmoid ossifications. In the otic capsule there are usually pterotic and sphenotic ossifications.

The cranial roof is largely formed by the frontals and parietals, the latter frequently separated by a strong process of the supraoccipital. Several of the cartilage bones are visible from above. The roof of the mouth is formed by the large parasphenoid and the vomers. Premaxillaries (rarely lacking) and maxillaries

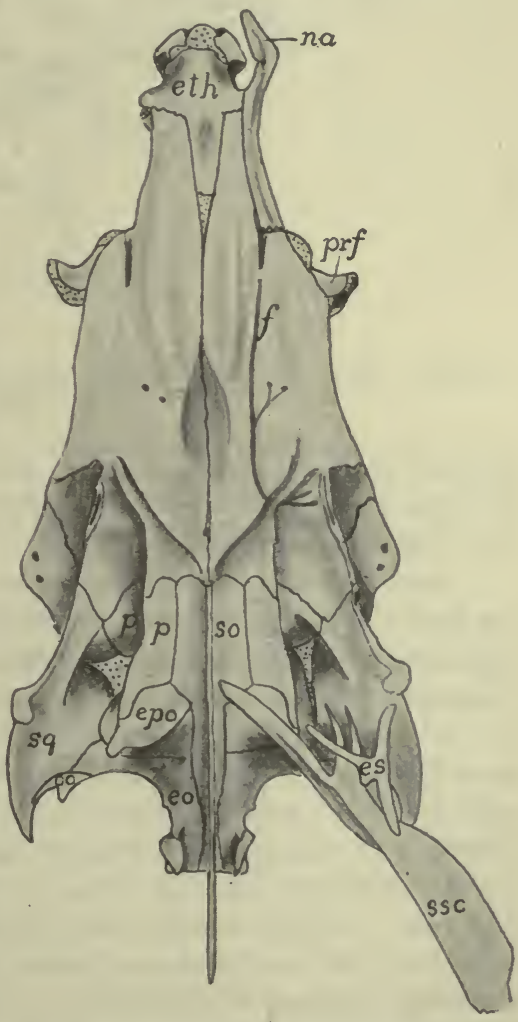

FIG. 79.-Dorsal view of skull of mackform the upper jaw, both usually bearing erel, Scomber, after Allis; letters as in fig. 68 
teeth, but occasionally, by overdevelopment of the premaxillary, the maxillary is excluded from the margin of the jaw.

Instead of the single pterygoid of higher vertebrates there are three bones, an entopterygoid adjoining the palatine, a mesopterygoid (ectopterygoid) which extends back to the quadrate, and a metapterygoid above the quadrate. When the hyomandibular cartilage ossifies it forms a hyomandibular bone from its upper portion and a symplectic (an element not known outside the teleostomes), which supports the quadrate. A small bone, the interhyal, intervenes between the hyomandibular and the rest of the hyoid. The hyoid copula consists of several elements, the anterior, which supports the tongue being called the entoglossal, the posterior, which connects with the branchial arches, the urohyal. The fifth gill arch consists of a single element on either side, the hypopharyngeal bone, which usually bears

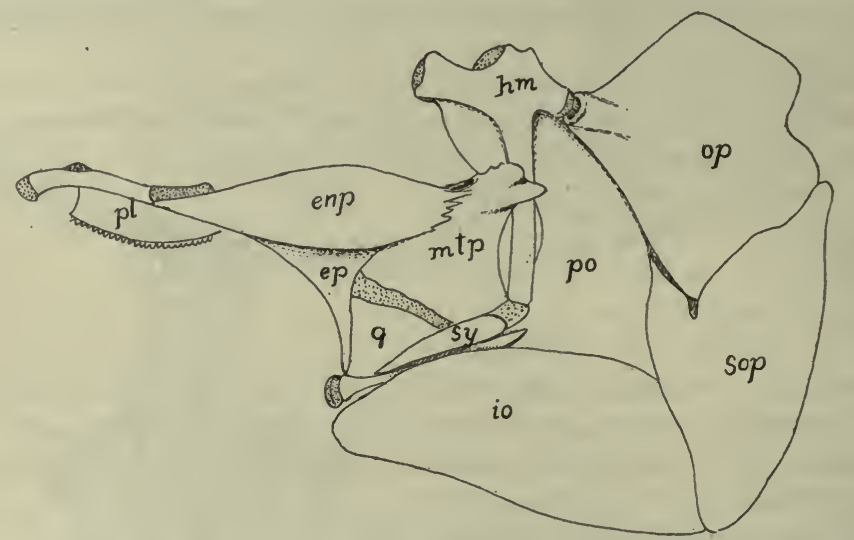

FIG. 8o.-Pterygoids, suspensorium and operculum of mackerel (Scomber) after Allis. For letters see fig. 68.

teeth, the two sides being fused in the plectognaths, forming a pharyngeal jaw. The upper elements of the other arches are frequently expanded, bear teeth, and are called epipharyngeal bones.

DIPNOI.-In the three existing genera the skull is comparatively uniform, but the fossils, beginning in the Devonian, have a wide range of structure. In the former the cavity of the chondrocranium extends to the ethmoid region and the nasal capsules have a second opening, corresponding to the inner nares (choanæ) inside the oral cavity. The pterygoid is fused with the cranium (autostylic) and there are one (Protopterus) or two (Ceratodus) labial cartilages connected with the nasal capsules. In Ceratodus there are no cranial cartilage bones, but in the other genera a plate composed of fused ex- and supraoccipitals occurs.

The membrane bones are few, but their homologies are not always certain. The roof is largely formed by an unpaired bone in the position of frontals and parietals, in front of which is a median bone (supraethmoid or fused nasals) above the nasal capsules. In Ceratodus a bone of uncertain homology occurs on either side of the fronto-parietal, but it is lacking in the others, unless it be represented in Protopterus by a pair of bones which abut against the supraethmoid and overlap 
the fronto-parietals. The otic capsule and quadrate are covered by a squamosal, and the roof of the mouth is formed by a large parasphenoid, in front of which are a pair of palatines. In advance of these last are a pair of large teeth resting directly on cartilage, their bases representing the greatly reduced vomers. The lower jaw has three bones on either side, a small dentary, a larger angulare, and an enormous splenial, which alone bears teeth.

In Ceratodus there is a hyomandibular fused to the cranium behind the exit of the seventh nerve, but elsewhere there is only the hyoid. The operculum has one or two elements (operculare and interoperculum) the free edges of which bear

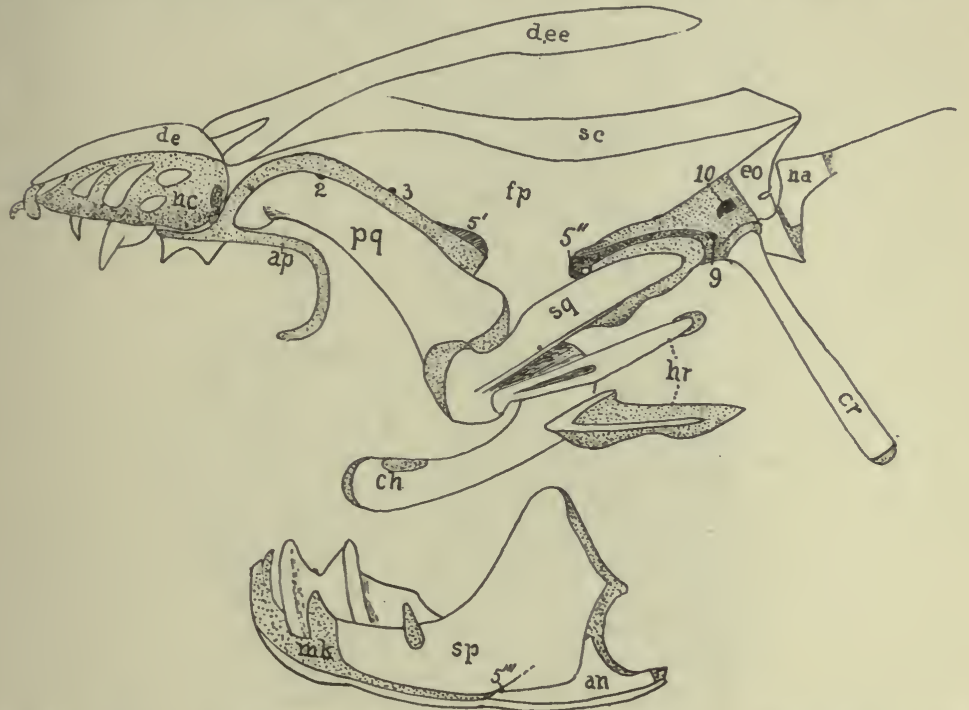

FIG. 81.-Skull of Lepidosiren, after Bridge. an, angulare; $a p$, antorbital process; ch ceratohyal; $c r$, cranial rib; de, dermal ethmoid; dee, dermal ectethmoid; eo, exoccipital; $f p$ frontoparietal; $h r$, hyoidean ribs; $m k$, Meckel's cartilage; $n a$, first neural arch; $n c$, nasal capsule; $n s p$, neural spine; $p q$, pterygoquadrate; $s c$, sagittal crest of frontoparietal: $s p$ splenial; sq, squamosal; I-ro, nerve exits.

cartilaginous rays, and the gill arches are five in Ceratodus, six in the other genera. A peculiar feature of Protopterus and Lepidosiren is the so-called head rib, a slender cartilage bone articulated with the chondrocranium below the occipital plate, and extending backward and downward across the shoulder girdle.

In those extinct Dipnoi which are united with the recent genera to form the order Sirenoidea, the skull is much as in the existing forms, except for the more numerous bones. In the Arthrodira (formerly called placoderms) the cranium is hinged to a large plate which covers the anterior part of the trunk, and the skull is roofed with a few large plates, some of which may be homologired with those of the sirenoids, the others not being readily compared with the bones of other vertebrates. The suggestion has been made that the problematic fossil Palcospondylus resembles, in its skull, the larvæ of the dipnoans, the adults of which were common in the same seas. 
AMPHIBIA.-Several points distinguish the amphibian from other skulls. The chondrocranium is platybasic (p. 6r); except for a small synotic tectum frequently present, it is not roofed by cartilage; the otic capsule has a fenestra vestibuli occupied by the stapes, a development connected with the power of hearing (p. 73); there are two occipital condyles; and the quadrate is immovably united to the cranium by two processes, an otic process, joining the otic capsule, and an 'ascending process' which reaches the upper margin of the trabecula, and which, in many reptiles, often ossifies as the epipterygoid bone.

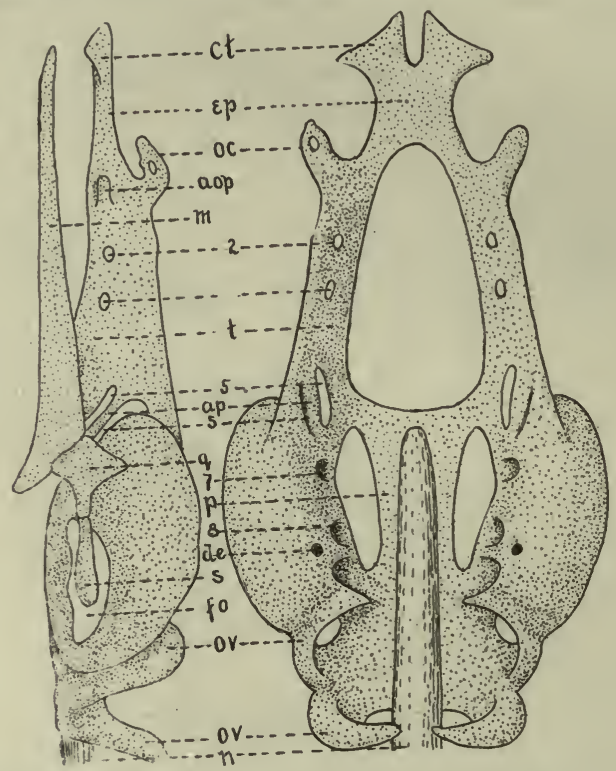

Fig. 82.-Chondrocranium of Amphiuma, lateral and dorsal views. aop, antorbital process; $a p$, ascending process of quadrate (epipterygoid); $c t$, cornua trabeculæ; de, foramen, for ductus endolymphaticus; $e p$, ethmoid plate; $f o$, fenestra vestibuli; $m$, Meckel's cartilage; $n$, notochord; $o c$, olfactory capsule; $o v$, occipital vertebræ; $p$, parachordal; $q$, quadrate; $s$, stapes; $t$, trabecula; $2-8$, nerve exists.

The cartilage cranial bones are few. Usually only exoccipitals are developed in the hinder region, while the rule is a single petrosal (prootic), but occasionally epi-, opisth-, and pterotic occur. There is but a single pterygoid, while basi-, pre-, and alisphenoids are not ossified. The membrane bones in existing amphibians have separated from the integument and have sunk to a deeper position than in fishes, but in the stegocephals the presence of grooves for the lateral line system would indicate a close connexion between skin and bones. In the latter group the membrane bones are numerous, but in existing species they are noticeably reduced. Except in stegocephals and the cæcilians there are large vacuities in both floor and roof of the skull. The lower jaw also has a reduced number of bones, there being at most five including the articulare and the mento-Meckelian.

The most primitive conditions occur in the stegocephals, where, as the name 
indicates, the dorsal surface is covered, leaving only gaps for the eyes and nostrils. In general the account of the skull given on page $67 \mathrm{ff}$ will apply to these forms, and so far as the dorsal surface is concerned little more needs to be said, aside from the fact that the supratemporal is sometimes transversely divided, that an interparietal foramen occurs (indicating the existence of a parietal eye), that the bones called supraoccipital may be interparietal, and that the sclerotics are common. The floor of the cranium is formed by a large parasphenoid, bordered in front by a pair of (usually toothed) palatines, in front of which are the vomers. Of the cartilaginous parts almost nothing is known; a few, clearly larval forms have well developed branchial arches preserved.

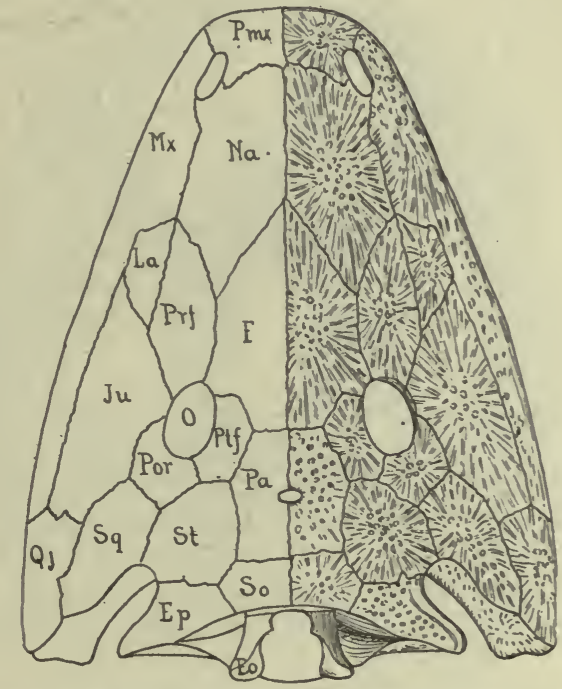

FIG. 83.-Skull of a stegocephalan (Capitosaurus) after Zittell. Letters as in fig. 68.

Of the GyMnophiones (cæcilians) the cartilage skull is known only in Ichthy. $o$ phis; its peculiarities are the reduced parachordals, an ethmoidal nasal septum, a stapes, perforated as in mammals, and alisphenoid and trabecular cartilages more distinct than in most amphibia. Most noticeable of the cartilage bones is the ethmoid, while otics and exoccipitals are fused as are quadrate and pterygoid. The membrane bones form a complete roof to the skull, recalling the stegocephals, but the number of bones is smaller, squamosal, supratemporal, jugal and quadratojugal being absent, while a large prefrontal and a larger postfrontal (usually called squamosal) occur. In the roof of the mouth maxillary and palatine are fused, the vomers distinct, while the united parasphenoid and basioccipital form a large os basale. In the lower jaw there are only dentary and angulare, the latter being produced behind the articulare in a remarkable way.

In the cartilage skull of the URODELES (fig. 82) the pterygoid does not usually reach the anterior part of the skull but projects as a process from the quadrate, which bears, besides the two processes already mentioned (p. 82), a palatobasal 
process joining the otic capsule in front of the otic process. Cartilage bones are few; supra- and basioccipital, alisphenoid and ethmoids are lacking; the otics fuse to a single petrosal; an orbitosphenoid occurs and quadrate and pterygoid are continuous.

The roof of the adult skull is chiefly formed of parietals, frontals and nasals, the latter being frequently separated by processes of the premaxillaries. Each
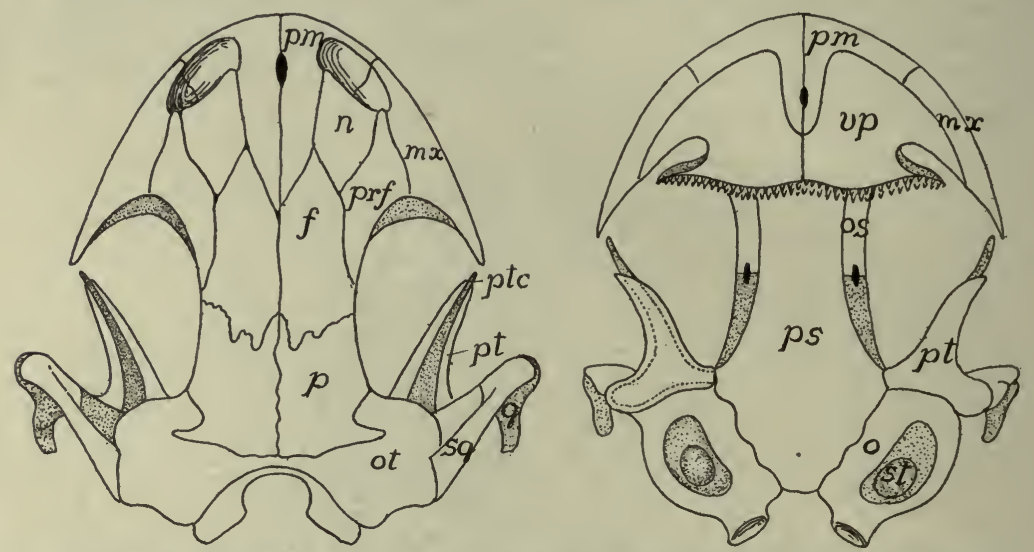

Fig. 84.-Skull of Amblystoma punctatum, after Wiedersheim. Letters as in fig. 68.

frontal has a ventral process which limits the cranial cavity in front; there is usually a prefrontal and a septomaxillary may be developed on the postero-lateral part of the nasal capsule. A supratemporal is always lacking, the squamosal extending up to the parietal. The upper jaw is composed of premaxillaries and (except some perennibranchs, fig. 85) maxillaries; a jugal is always absent and the quadratojugal,

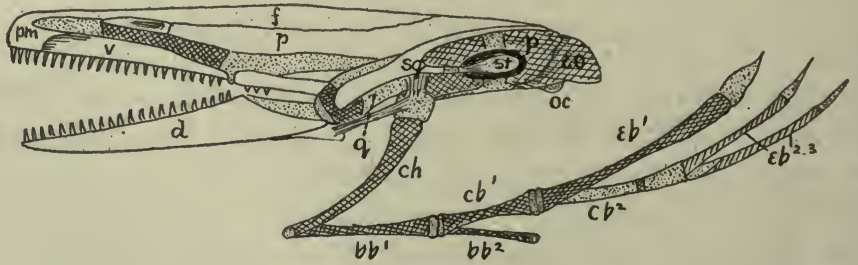

Fig. 85.-Skull of Proteus, after Wiedersheim. For letters see fig. 68.

formed in the larva, fuses with the squamosal. In the roof of the mouth are the large parasphenoid, frequently with teeth, and a pair of vomero-palatines, the choanæ lying behind the vomerine portion, which is farther back than in the dipnoi.

In the lower jaw Meckel's cartilage persists, its hinder end forming the articulare, while in front it is surroundéd by the dentary and splenial, each bearing teeth. In the larvæ the branchial skeleton is nearly typical, there being a hyoid and four gill arches. In the adult, with the loss of aquatic respiration, the posterior arches are 
reduced or even disappear, those remaining being connected by a one or two-jointed copula.

The chondrocranium of the larval ANuRA (Rana, fig. 86) differs considerably from that of other amphibia as well as from the adult conditions. Like all amphibians it is platybasic. The pterygoquadrate has, besides the normal otic and epipterygoid processes, a cranio-quadrate process connected with the nasal region, in front of which is the articulation of the lower jaw. In front of the cornua are a pair of suprarostral cartilages and a similar pair of infrarostrals lie in front of the

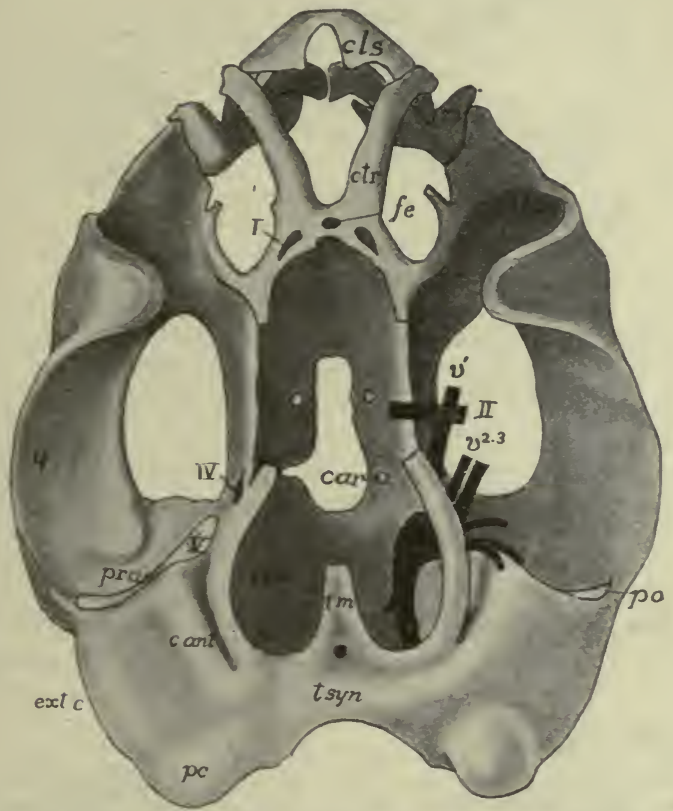

FIG. 86.-Chondrocranium of tadpole of Rana before the metamorphosis; after Gaupp. c., ant, anterior canal; cls, superior labial cartilage; ctr, cornu trabeculæ; car, foramen for carotid; ext. $c$, external canal; $f e$, ethmoid fenestra; $m$, Meckel's cartilage; $p c$, posterior canal; po, otic process of quadrate; pr. as.' ascending process of quadrate; $q$, quadrate; $t m$, tectum medialis; $t t m$, tænia tecti marginalis; $t s y n$, tectum synoticum; $I-V$, nerves and nerve exits.

Meckelian, from which they are apparently derived. These four rostrals form a ring around the suctorial mouth and recall the labial cartilages of the elasmobranchs and the annular cartilage of the cyclostome mouth.

At the time of metamorphosis the changes are great, and as the result is more like the chondrocranium of other amphibia, the larval condition must be regarded as adaptive rather than ancestral. The suprarostrals disappear and the jaw shifts the hinge back to the normal position, this being accompanied by the elongation of Meckel's cartilage, an absorption of the ascending process and a folding of the pterygoquadrate bar. At the same time a pterygoid grows out in front to join an antorbital process from the cranium. A stapes develops and connects 
with the columella, which meets the tympanic membrane. This membrane is stretched on a cartilaginous tympanic annulus, derived from the pterygoquadrate. (Annulus and columella are lacking in those genera, Bombinator, etc., which have no tympanum). There is no connexion between stapes and quadrate.

The chondrocranium largely persists, the only constant cartilage bones being the exoccipitals and prootics. A supraoccipital rarely occurs and basioccipital and

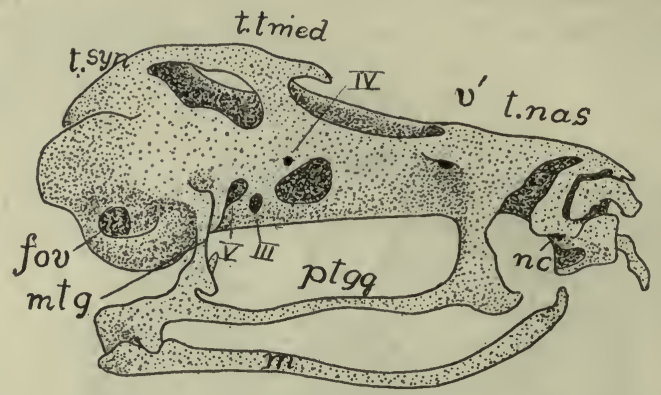

FIG. 87.-Chondrocranium of a frog after metamorphosis, from Gaupp. fov, fenestra ovalis; $m$, Meckel's cartilage; $m t g$, metapterygoid; $n c$, nasal capsule; $p t g q$, pterygoquadrate; tnas, tectum nasalis; $t s y n$, tectum synoticum; $t$ tmed, tænia tecti medialis.

basisphenoid are unknown. In the ethmoid region, except in the aglossa, there is a peculiar bone, the sphenethmoid, which arises as two bones on either side. These fuse, forming a ring ('os en ceinture') around the olfactory nerves and the anterior end of the brain.

The frontals and parietals of a side are fused and often the fronto-parietals are continuous across the middle line. They may extend to the nasals or there may
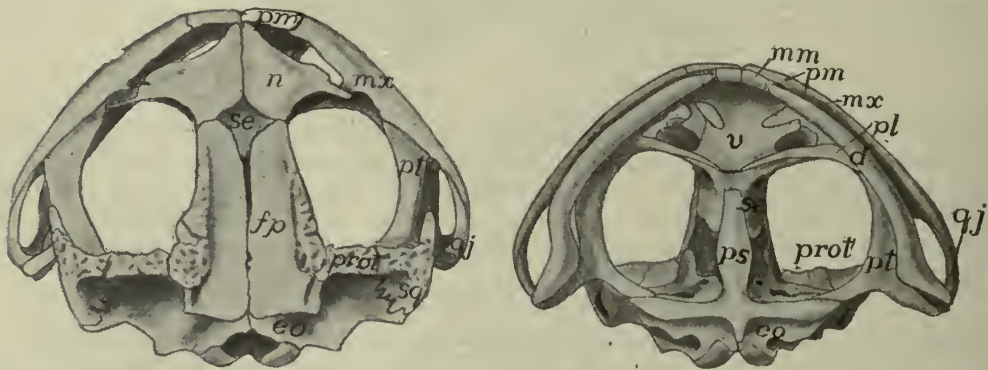

FIG. 88.-Dorsal and ventral views of skull of toad, Bufo americanus. For letters see fig. 68.

be a gap between, leaving the sphenethmoid visible from above. A large squamosal extends above the quadrate, from the otic region to the angle of the jaw. The upper jaw consists of premaxillary and maxillary, and, except in the aglossa, of quadratojugal. The pterygoid cartilage persists, but is overlaid by a membrane bone, also called the pterygoid. Slender palatines, transverse to the axis of the skull, are lacking only in the aglossa, while small vomers are almost always present. The 
floor of the cranium is completed by a I-shaped parasphenoid, which extends to the premaxillaries in the aglossa, elsewhere only to the sphenethmoid.

In the lower jaw there is a mento-Meckelian in front, followed by dentary and angulare, Meckel's cartilage persisting through life. The larval branchial and hyoid arches are typical, there being four gill arches. With the loss of gills the posterior arches disappear, and the broad hyoid plate of the adult has four processes which are new formations.

REPTILES.-The skull of existing reptiles is very different from that of amphibians, but that of many theriomorphs is strikingly like that of the stegocephalans. The principal differences alluded to in the first sentence have arisen by reduction and disappearance of bones appearing in the more primitive types, but aside from these there is little except the parasphenoid to separate the two groups.

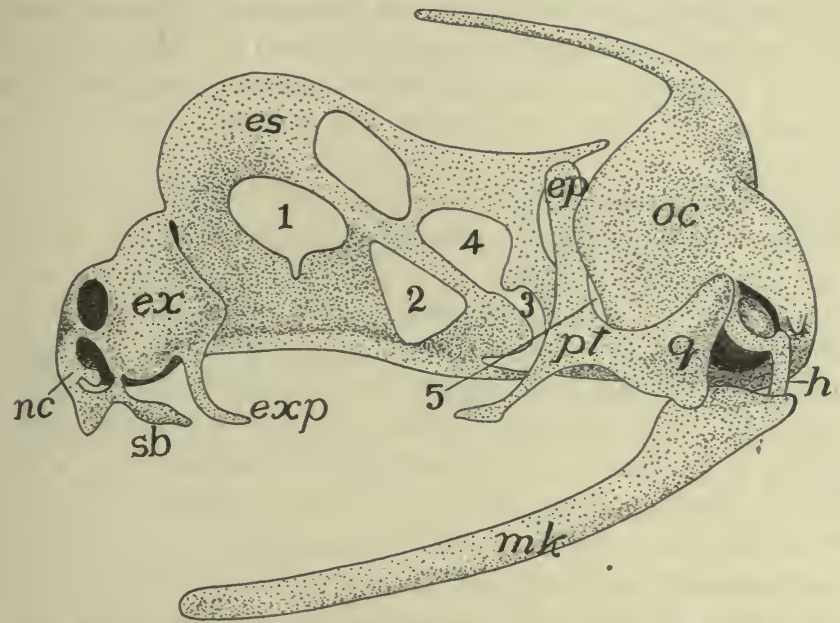

Fig. 89.-Chondrocranium of Sphenodon, stage 'R,' after Howes and Swinnerton. $e p$, epipterygoid; $e s$, ethmosphenoidal plate; ex, extranasal cartilage; exp, extranasal process; $h$, hyoid; $m k$, Meckel's cartilage; $n c$, nasal capsule; $o c$, otic capsule; $p t$, pterygoid; $q$, quadrate; $s b$, subnasal process; $I-5$, exits of nerves.

The chondrocranium is known in but a few forms and these agree with other amniotes in being tropibasic, except in snakes and amphisbænans (see fig. 62). In the adults cartilage largely disappears, except in the ethmoid region, more persisting in Sphenodon (fig. 89) and the lizards than elsewhere. All four occipitalia are ossified, but some may not participate in framing the foramen magnum, the basioccipital being excluded in many chelonians, the supraoccipital in snakes, crocodiles and theriomorphs. There is but a single occipital condyle (except in a few theriomorphs), which is borne on the basioccipital as in the crocodiles, or on this and the exoccipitals as in chelonians and squamata. Basi- and presphenoids are present, orbito- and alisphenoids are but slightly ossified and the ethmoid region is largely cartilaginous. Pro-, epi- and opisthotics are present, the epiotic fusing with the supraoccipital, while the opisthotic in all recent forms except the turtles unites with the exoccipital in the adult.

In all except the squamata, in which it is movable (streptostylic), the quad- 
rate is firmly united to the squamosal and sometimes to other bones (monimostylic). The pterygoids extend forward to the palatines. In the squamata and the ichthyosaurs pterygoids and palatines are widely separated in the middle line, but elsewhere they are closely approximate, the pterygoids even meeting the basisphenoid. In all except chelonians, some dinosaurs and the typhlophida an ectopterygoid (os transversum) extends from pterygoid to maxilla, while in plesiosaurs and most lizards (kionocraniate) ossification of the ascending process of the quadrate forms an epipterygoid bone between the pterygoid and the parietal.

Membrane bones are more numerous than in the amphibians. In many theriomorphs there is a supratemporal fossa between parietal and supratemporal bones and the same is true of plesiosaurs, ichthyosaurs and chelonians. In the rhynchocephals, dinosaurs, pterodactyls and crocodiles there is in addition, an infratemporal fossa, bounded laterally by an arcade in which squamosal, quadratojugal and zygomatic participate in varying degrees. In the lizards the two unite in a single temporal fossa by the disappearance of the upper arcade, and lastly, in the snakes the lower arcade is lost and the fossa becomes a gap in the side of the skull.

Parietals and frontals are usually paired, a parietal foramen being common; pre- and postfrontals usually occur, sometimes excluding the frontal from the orbit. Lacrimals are common and the margins of the upper jaw are formed in front by premaxilla and maxillary, the latter connected with the squamosal, sometimes by jugal and quadratojugal, or the jugal may drop out, or lastly the jaw may end with the maxillary. Several membrane bones may aid in the formation of the roof of the mouth. There is a small parasphenoid in ichthyosaurs, plesiosaurs, many squamata, some rhynchocephals, and rarely in turtles. It is usually associated with the basisphenoid and in ophidia it forms the base of the interorbital septum. The vomers are paired except in the chelonia, and only in Sphenodon of recent species do they bear teeth, and here but one on each bone. The maxillaries usually have broad palatal processes extending toward the middle line, causing the choanæ to open farther back, and in some, these, together with the palatines and pterygoids, form a false palate, ventral to the nasal passages, so that, as in the crocodiles, the choanæ are carried far back in the mouth. In some dinosaurs there is a rostral bone in front of the premaxillæ.

The two halves of the lower jaw are united by ligament in most rhynchocephals, snakes and pythonomorphs; by suture in crocodiles, rhynchocephals and lizards; while they are fused in turtles and pterosaurs. All of the bones mentioned on page $7 \mathrm{I}$ may occur in the lower jaw, usually with distinct sutures, while in crocodiles, theriomorphs and some dinosaurs there are gaps or vacuities in its walls. In many dinosaurs there is a predentary bone at the tip of the jaw. Except in the chelonia and a few isolated forms, both jaws bear teeth, which may be restricted to maxillaries and premaxillaries, or may also occur on palatines, vomers and pterygoids. In their fixation three types are found: acrodont, when fused to the margin of the bone; pleurodont, when fastened to the side of the bone; and thecodont, when implanted in sockets.

The hyoid apparatus is much modified, but is adequately known only in recent 
species. The branchial arches are usually better developed than the hyoid proper, which is cartilaginous in most snakes and is lacking in the crocodiles. In the chelonia (fig. 93) two branchial arches are usually present.

The THERIOMORPHS (fig. 90) have a short, broad skull with parietal foramen; and that of the cotylosaurs was much like that of the stegocephals. In the more differentiated groups the skull recalls that of mammals, especially in the participation of the squamosal in the hinge of the jaw. Lacrimals are occasionally absent, sclerotics sometimes present. The palatal region is known in a few forms. The pterygoids may meet only in front, leaving a vacuity between it and the basisphenoid, or they may meet that bone. The choanæ are in front of the palatines but (theriodonts) may be displaced backward by palatine processes of the maxillaries.

All four occipitalia are developed; the occipital condyle is tripartite, being formed by basi- and exoccipitals, but in Cynognathus the recession of the basioccipital results in a dicondylic condition. The greatest variations occur in the temporal
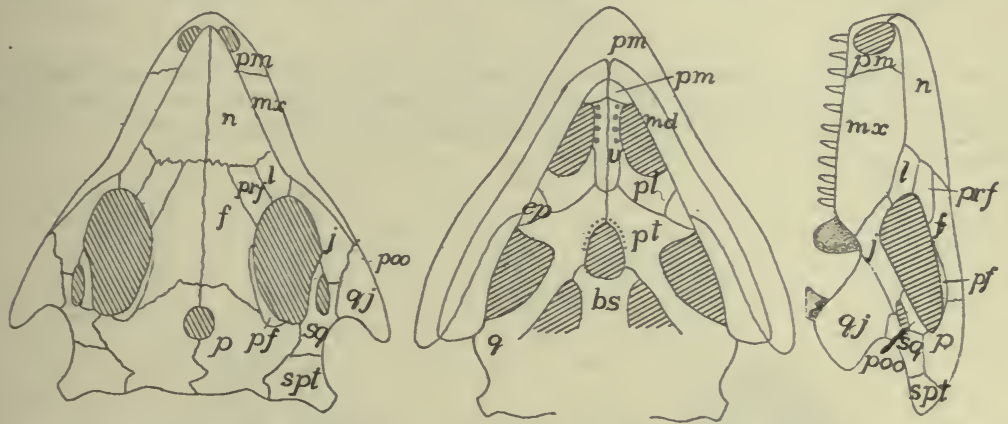

Fig. 90.-Skull of Procolophon, after Woodward. For letters see fig. 6S.

region. In the lower cotylosaurs the cranial roof is without fossæ (Broom doubts the infratemporal fossa of Procolophon). In other theromorphs quadratojugal and supratemporal are lacking, the squamosal meeting the parietal. Placodus has only the supratemporal fossa, but in the majority the upper arcade has disappeared, leaving a large temporal vacuity, much as in mammals.

Little is known of the lower jaw. The bones are sometimes discrete, sometimes extensively fused. The teeth are thecodont, and in the theriodonts are differentiated into incisors, canines and molars, but in the anomodonts teeth are absent, or at most there are a pair of large incisors in the upper jaw.

In the PLESIOSAURS and their allies the skull is about a twelfth of the total length. There is a parietal foramen between the parietals, which have a process for articulation with the squamosal, the supratemporal being absent. The large prefrontals intervene between the frontals and the orbits; lacrimals and usually nasals are absent. The large temporal fossa in bounded externally by the jugal which extends back to the quadrate. The choanæ are in front of the palatines; an os transversum is present and there is frequently a parasphenoid in the interpterygoid vacuity. All have a subtemporal vacuity and there is another in the 

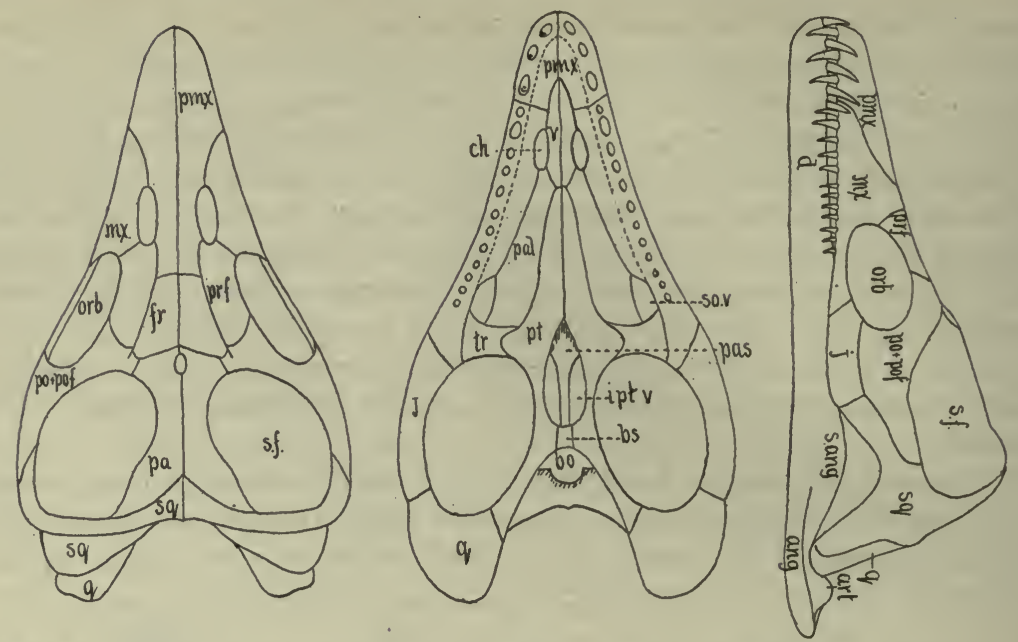

FIG. 9r.-Skull of Plesiosaurus macrocephalus, after Andrews. ang, angulare; art, articulare; $c h$, choana; fr, frontal; orb, orbit; $p a$, parietal; pal, palatine; $p a s_{2}$ parasphenoid; potpof, postorbital and postfrontal; $s f$, supratemporal fossa; $t$, transversum. Other letters as in fig. 68 .
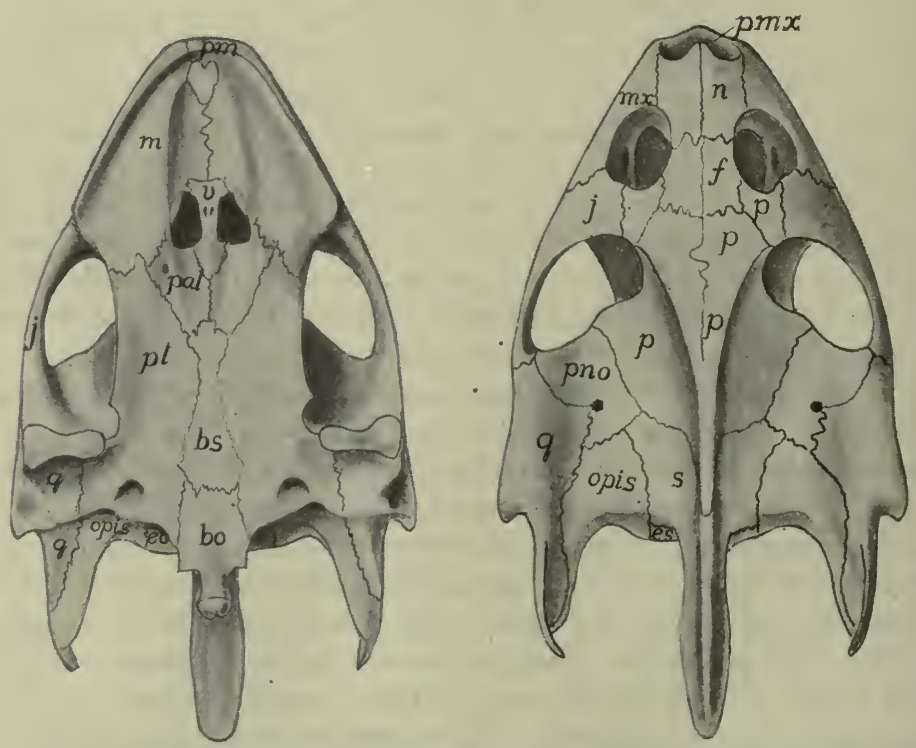

FIG. 92.-Dorsal and ventral views of the skull of turtle, Trionyx ss, exoccipital; $m$, maxillary; $p$, (behind naris), preorbital; pno, postorbital; $s$, supraoccipital; other letters as in fig. 68. 
plesiosaurs in the angle between palatine and transversum. The usual bones are frequently distinct in the lower jaw.

In the Chelonians the cranial cavity extends forward between the eyes and the mesethmoidal cartilage largely persists in the adult. Although the bones are comparatively few, the skull is primitive and can only be derived from that of the cotylosaurs. The bones are firmly united, but the sutures are evident. The basioccipital is usually excluded from the foramen magnum, and it and the exoccipitals participate in the tripartite occipital condyle. The supraoccipital is often prolonged into an occipital spine and is fused with the epiotics. The basisphenoid is present, but pre-, ali- and orbitosphenoids are not ossified, a descending plate of the parietal taking the place of the alisphenoid. The pterygoids meet the

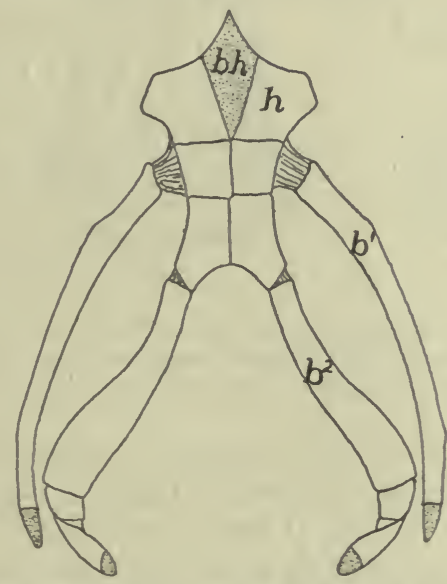

FIG. 93.-Hyoid apparatus of Tryonyx. $b^{1}, b^{2}$, first and second branchial arches; $b h$, basihyal (copula); $h$, reduced hyoid; cartilage dotted.

basisphenoid and may extend to the basioccipital. No ectopterygoid is present. The monimostylic quadrate is large and expanded laterally to support the tympanic membrane, and notched or perforate behind for the columella.

In the most primitive chelonians a complete false roof is formed by the expanded postfrontals, parietals and squamosals. In most of the species the recession of the parietals and squamosals causes a large gap, bounded in front by postfrontal and jugal and exposing the otic bones. Laterally this gap is limited by an arcade of squamosal and quadratojugal, but the latter may be reduced or (Cistudo) absent. In front of the frontals are a pair of bones, which bound the single naris behind. These occupy the position of lacrimals, nasals and prefrontals, and are called by the latter name. The premaxillaries are usually fused; the maxillæ have broad palatal processes and trenchant margins. They, together with the zygomatics, form the lower border of the orbit.

The vomer is a single vertical plate separating the two choanæ. The palatines, which bound the choanæ behind are broad and are firmly united to pterygoids and basisphenoid. A parasphenoid is known only in Dermochelys. In the lower 
jaw the bones are often fused, the two halves being united. Again the bones may be distinct, the splenial being the least constant element. The hyoid apparatus consists of a cartilaginous copula and two pairs of cornua which do not reach the cranium.

ICHTHYOSAURS have a short temporal region but elongate nasals and pre-maxillaries form a long rostrum. There is a large supratemporal fossa and enor-

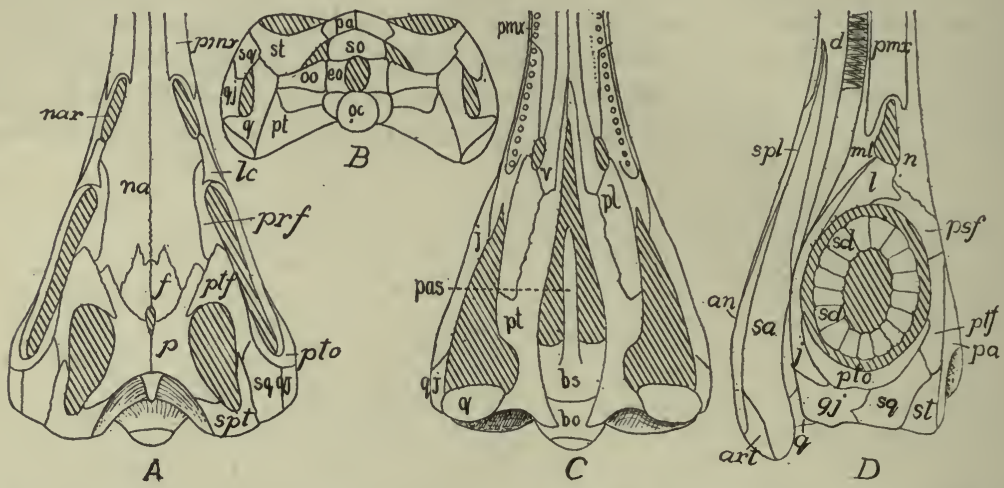

Fig. 94.-Dorsal $(A)$, posterior $(B)$, ventral $(C)$, and lateral $(D)$ views of the skull of Ichthyosaurus longifrons, after Woodward. nar, naris; pas, parasphenoid; $p m x$, pre maxilla; $p t f$, postfrontal; pto, postorbital. Other letters as in fig. 68.

mous orbits, bounded above by pre- and postfrontals, below by an elongate jugal, and containing a sclerotic ring. The nares are just in front of the orbits and the parietal foramen is at the junction of frontals and parietals. All four occipitalia bound the foramen magnum; the basisphenoid is short, the presphenoid long; and the pterygoids are separated in front by the vomers, leaving large pterygoid vacui-
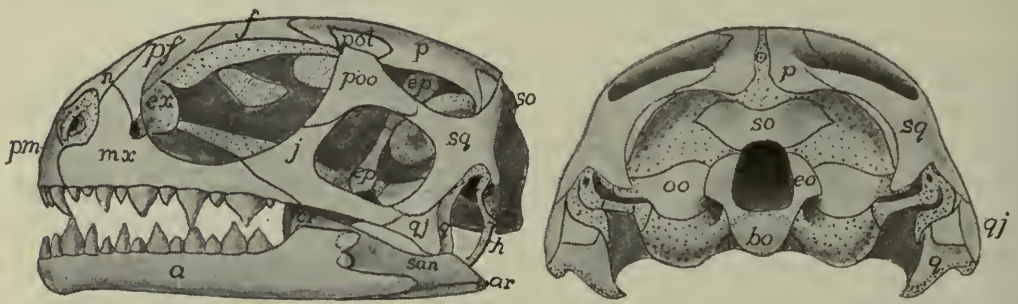

FIG. 95.-Side and posterior views of skull of young Sphenodon, after Howes and Swinnerton. Compare with fig. 69. Cartilage dotted; letters as in fig. 68.

ties. The choanæ are far forward. Teeth (sometimes absent) occur in grooves. The lower jaw has five or six distinct bones, and a rib-like hyoid has been found in some species.

The only living RHynchocepHalian is Sphenodon (Hatteria) of New Zealand. It is lizard-like, but its skull (figs. 68, 95) differs in the three temporal fossæ, the infratemporal arcade being osseous as in no lizard. Then the quadrate is anchylosed to pterygoid, squamosal and quadratojugal. Premaxillæ, maxillæ and 
palatines bear teeth; an epipterygoid is present and the lower margin of the orbit is formed by the maxillary. In the extinct genera the jugal may bound the orbit below (Palaeohatteria), and the vomer may bear teeth.

DINOSAURS have both supra- and infratemporal fossæe and frequently a preorbital vacuity as well. The rostral and predentary bones have been mentioned (p. 88). The palatal region recalls that of Sphenodon, except that the teeth, in grooves or sockets, never occur on the palatines. There are such variations in the skulls that few general statements can be made.

Statements that will apply to all SQUAMATA are few. Except in chamæleons the quadrate is movable, a quadratojugal is lacking, the boundary of the infratemporal fossa being completed by ligament. The external nares are separate, there
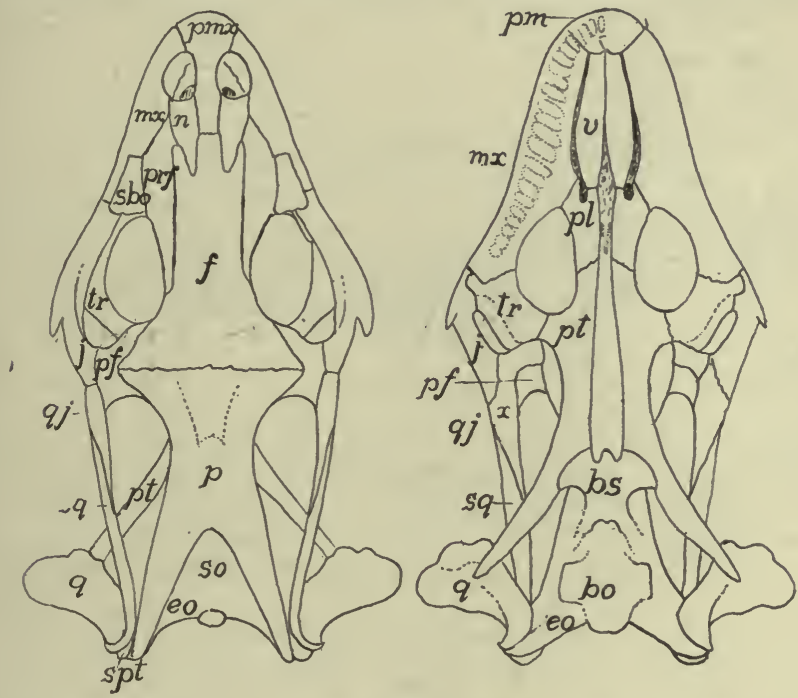

FIG. 96.-Skull of Gerrhonotus imbricatus, after Siebenrock. For letters see fig. 68.

are large vacuities in the floor of the skull and the choanæ are forward. An ectopterygoid occurs except in the typhlopids and all four occipitalia bound the foramen magnum.

The chondrocranium of the LIZARDS (fig. 62), while much like the general type of tropibasic, is very light and is fenestrated to an extent not seen in the ichthyopsids. Among the peculiarities of the adult skull are the fusion of exoccipital and opisthotic to form a 'parotic process' which, together with the squamosal, supports the quadrate. There is a looseness of connexion of the front of the skull with the occipitosphenoidal portion, these parts moving on each other. The hyoid apparatus bears two cornua which either end freely in the neck or may reach the parotic process.

In the PyTHONOMORPHS the striking features are the large supratemporal fossæ, the quadrate recalling that of chelonians; and the joint in the lower jaw, between dentary and angular regions. 
The OpHIDIA (snakes) lack parotic process, parietal foramen, temporal arcades and epipterygoid, and have the squamosal excluded from the cranial wall. The attachment of the visceral skeleton to the cranium is loose, the pterygoid being connected to the other parts by a long bar, consisting of squamosal and quadrate behind and by transversum and palatine in front, features related to the great distensibility of the jaws. In the poisonous serpents the poison fangs are either permanently erect, or they fold back when the mouth is closed. In the latter the fangs are supported on the maxillaries, which are moved by a rod formed of quadrate, pterygoid and ectopterygoid. In the lower jaw distensibility is provided for by the elastic ligament connecting the two halves in front. Some species have remnants of the hyoid apparatus, but occasionally all are lost in the adult.
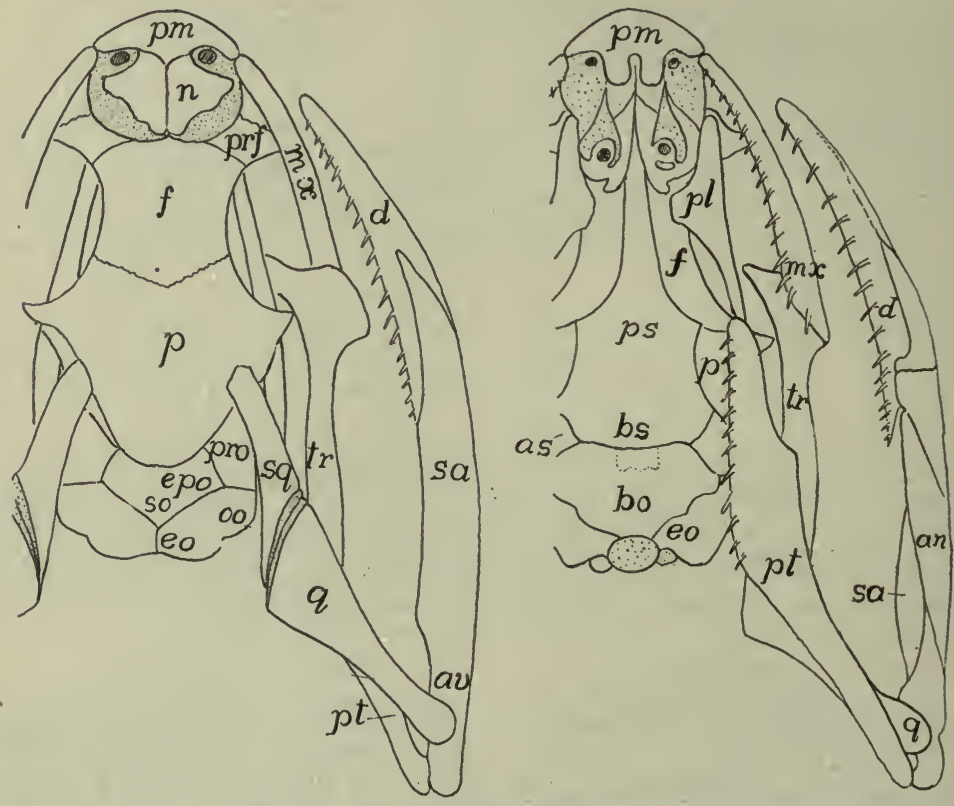

FIG. 97.-Skull of snake, Tropidonotus, after W. K. Parker.

When the whole series of CROcodilia, recent and extinct, is considered the range of variation in the skull is considerable. In all, supra- and infratemporal fossæ are present, the quadrate is immovable, there is more or less of a secondary palate, no parietal foramen, and the thecodont teeth are confined to the margins of the jaws. In the complete series the gradual change of position of the choanæ can be traced from the oldest in which they are beside the vomers; then in the mesosuchia the palatines meet in the middle line, carrying the choanæ back as a single opening behind these bones; while in the recent species the pterygoids have also met, so that the choanæ are between them and the basisphenoid.

Among the recent species the basioccipital is excluded from the foramen magnum, pre- and orbitosphenoids are imperfectly ossified, the nasals are long and the 
premaxillaries short so that the nares are far in front; parietals and usually the frontals are fused in the middle line. There are vacuities in both walls of the lower jaw, which is also pneumatic.

Although there is no relation between the two, the skull of the Pterosaurs is very bird-like in its length and in having its axis at right angles to that of the body, while the elongate premaxillæ form a bird-like beak. The sutures between the bones are largely obliterated in the adult and the brain cavity recalls that of birds. The resemblances are heightened in some by the lack of teeth, in others they are in sockets. Both supra- and infratemporal fossæ are present, as well as a large preorbital vacuity, sometimes united with the naris. Squamosal and quadrate are inclined forward so that the hinge of the jaw is often beneath the orbit. There is no parietal foramen and all of the bones of the jaw are fused, including those of the two halves.

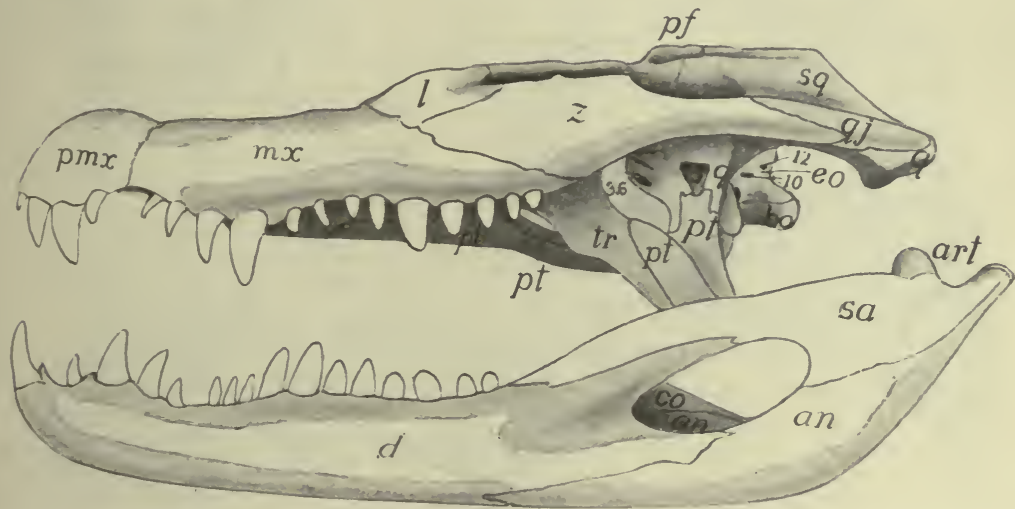

FIG. 98.-Skull of Caiman latirostris, based on a figure by Reynolds; the irregularitesi of the surface omitted. Letters as in fig. 68 .

AVES.-The skull of birds is similar in many respects to that of lizards. The chondrocranium arises as two distinct parts, pre- and perichordal, which, on account of the great head flexure, are at an angle of $100^{\circ}$ to each other, later increased to $160^{\circ}$, which persists through life. There are three (or four?) occipital vertebræ behind the ear, the last being the most prominent, and there is a small synotic tectum. From the first the otic capsules are continuous with the basal plate and the fenestra vestibuli is formed later by resorption of the cartilage. The trabeculæ are at first distinct from each other as well as from the perichordal part; later they fuse in front of the hypophysis to give rise to the base of the interorbital septum. In Tinnunculus the ethmoid plate arises early as an intertrabecular mass, from which, later, the dorsal part of the interorbital septum arises as a backward growth of cartilage. Large alisphenoid cartilages are connected with the otic capsules. The nasal capsules are complicated and later give rise to several centres of ossification. The quadrate is free from the rest (streptostylic) and its pterygoid process, the homologue of the pterygoid cartilage in other groups, is greatly reduced. The other visceral arches are much as in the adult (injra). 
The bones are lighter than those of reptiles and are often pneumatic, that is, are penetrated with canals connected with the respiratory system. The brain cavity is larger than in reptiles; sutures between the bones largely disappear in the adult, and the single occipital condyle (mostly basioccipital) is on the floor of the skull so that the axis of the skull is at right angles to that of the body. There is only a single temporal fossa, bounded laterally by an arcade of jugal and quadratojugal, connecting quadrate and maxillary. There is a preorbital vacuity; and the nares may have the posterior margin rounded (holorhinal) or slit-like (schizorhinal). The premaxillaries are fused and sclerotic bones are common.

A peculiarity of the ventral surface is the union of the anterior part of the

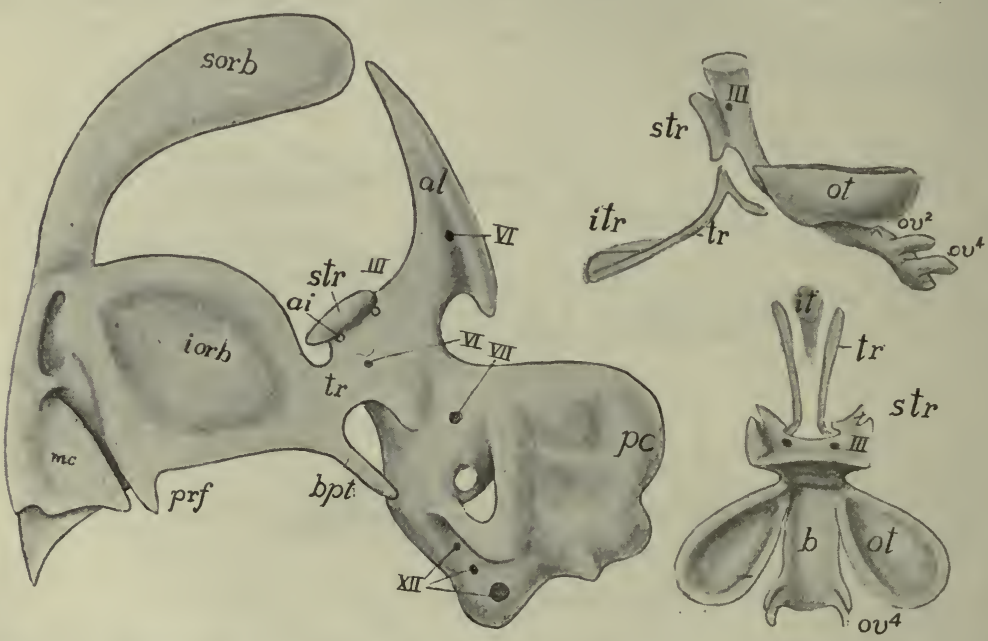

Fig. 99.-Earlier and later stages of skull of bird (Tinnunculus) after Suschkin. al, alisphenoid cartilage; $a i$, foramen for internal ophthalmic artery; $b$, basal plate; $b p t$, basipterygoid; $e c$, external semicircular canal; $h m$, 'hyomandibular;' iorb, interorbital plate; it, intertrabecula; $m c$, middle concha of nose; $o v$, occipital vertebræ; $p c$, posterior semicircular canal; sorb, supraorbital; str, supratrabecula; $t r$, trabecula.

parasphenoid to the basisphenoid to form a 'rostrum sphenoidale' which projects forward in the middle line. The rest of the parasphenoid forms a "basitemporal plate' below the basisphenoid and basioccipital. Dorsal to the rostrum is a small presphenoid (sometimes lacking in the adult) to which the orbitosphenoids are attached as alæ, while the alisphenoids become similar wings to the basisphenoid. Ectethmoids are connected with the mesethmoid; they are sometimes large, appearing ('prefrontals') on the top of the skull. Epi- and ectopterygoids are lacking. The pterygoids, here membrane bones, extend from the quadrates to the palatines, and the two either slide along the rostrum or the vomers intervene. This, together with the hinging of the front part of the skull upon the rest, forms a mechanism by which the upper jaw is raised when the mouth is opened, the temporal arcade aiding in the motion. The vomers may be paired; usually they form a thin vertical plate between the anterior ends of the pterygoids; occasionally they disappear. The choanæ are between the palatines and vomers. Some birds have an 'os uncin- 
atum,' a small bone connecting the lacrimal with the palatine or jugal bar. All of the bones enumerated on page II may appear in the development of the lower jaw.

Teeth occur only in a few fossil birds, where they are implanted in sockets; several species are known to have a dental ridge in the embryo (see Development

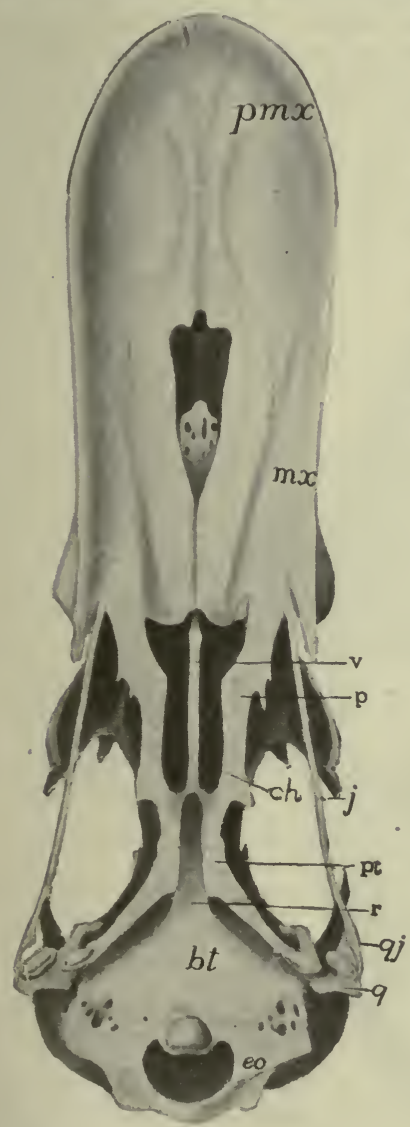

Fig. 100.-Ventral view of skull of a duck; letters as in fig. 68. of Teeth). The hyoid apparatus (fig. ror) consists of a pair of cornua (first branchials) sometimes extremely long, connected by the hyoid copula (os entoglossum), behind which is a second copula (urohyal) while in front of the entoglossum is a 'paraglossal' element with a pair of small cornua.

The palatal structures have considerable importance in classification. All living birds can be arranged in two groups. In the 'dromæognathous' group the palatines and ptery-

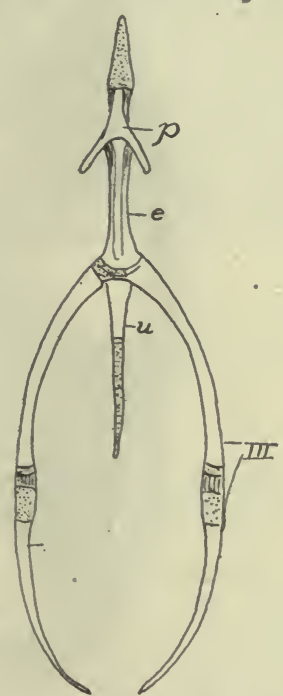

Fig. Ior.-Hyoid of hen, after Parker. $e$, entoglossal; $p$, paraglossal; $u$, urohyal; $I I I$, posterior cornua.

goids do not articulate with the rostrum, the vomers usually intervening. In the 'euornithes' the articulation occurs. The latter are subdivided into the desmognathous forms where the vomer is small or wanting, and the maxillopalatines meet in the middle line; the schizognathous in which the maxillopalatines do not meet the vomer or each other; the ægithognathous, like the last 'except that the vomer is broad and truncate; and the saurognathous with delicate, rod-like vomers and maxillopalatines scarcely extending inwards from the maxillaries. 
The chondrocranium of the MAMMALS has several peculiarities. There are four occipital vertebræ, the last only with a complete vertebral character, all eventually fusing with the synotic tectum. The dorsal part of the otic capsule chondrifies first, owing to the late development of the cochlear part of the ear in the lower half; and the capsules themselves have their axes inclined, so that the exit of the seventh nerve is on the anterior rather than on the lateral face. The trabeculæ soon join the basal plate and from their sellar part an alary process is given off on either side

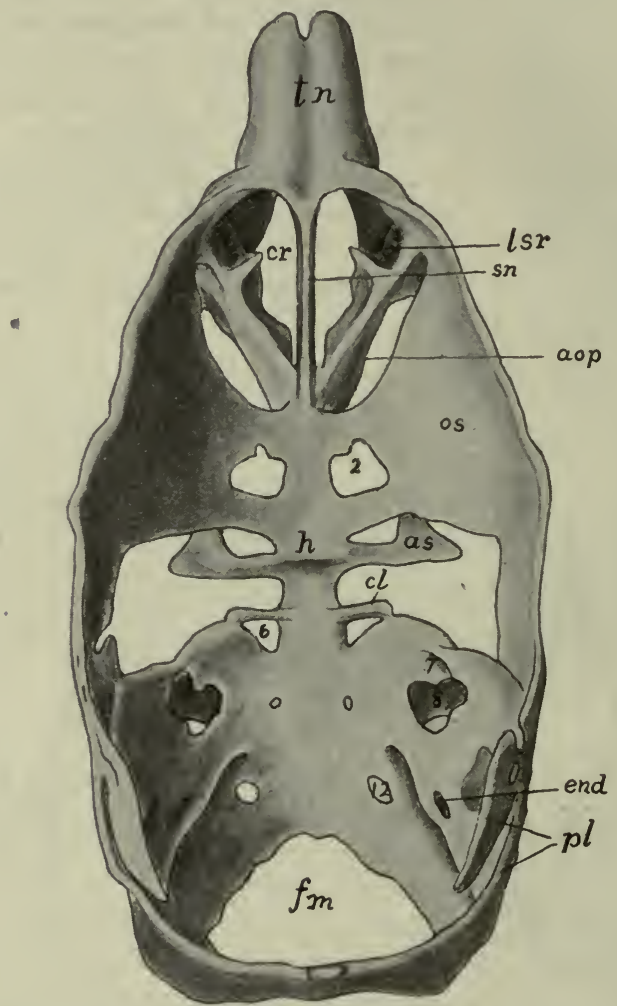

FIG. I02.-Chondrocranium of a pig, after Mead. as, alisphenoid; $c l$, posterior clinoid process; $c r$, fenestra cribrosa; end, foramen for endolymph duct: $f m$, foramen magnum; $h$, fossa hypophyseos; $l s r$, lateral superior recess: os, orbitosphenoid; $p l$, parietal lamina; $s n$, septum nasi; $t n$, tectum nasi; $2-12$, exits of nerves.

which extends upward to join an alisphenoid (ala temporalis) which chondrifies separately, but soon joins the otic capsule above, leaving between them the foramen ovale for the third branch of the fifth nerve, the other branches passing forward over the ala and then between it and the orbitosphenoid (ala orbitalis) through the sphenoidal fissure (foramen lacerum anterior). The ala orbitalis joins the trabecula by two processes, bar and processes sometimes forming a reduced interorbital septum. Later a marginal band (tænia marginalis) extends back from 
the orbitosphenoid to a cartilage plate developed on the otic capsule. The ethmoid parts are complicated, consisting of the two nasal capsules, the septum between them, and, on the inside, coiled turbinal cartilages to support the olfactory membrane.

Some of the visceral arches have been mentioned in speaking of the ear bones (p. 74). The pterygoid cartilage is apparently lacking, and there is nothing that can be interpreted as a quadrate except the incus. Meckel's cartilage extends forward from the incus to the tip of the jaw. In the procartilage stage the hyoid is continuous with the stapes; later it joins the otic capsule behind the fenestra vestibuli, while ventrally it joins its fellow and is connected with the first branchial arch by a median cartilage, probably the copula.

In the adult the so-called facial bones are more closely related to the cranium than in the lower groups, and distinct bones are fewer than in lower vertebrates, the reduction being due in part to actual loss, in part to the fusion of elements

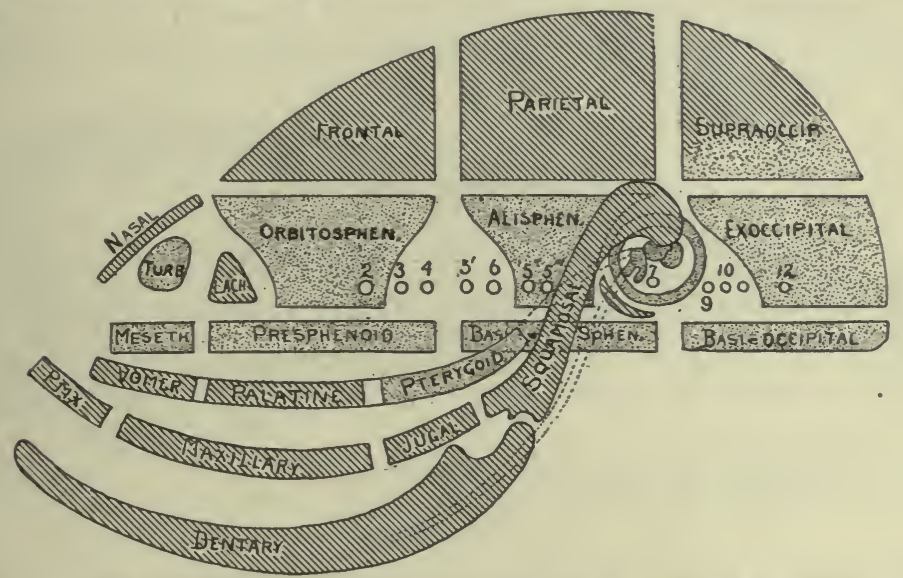

FIG. I03.-Diagram of the bones of the mammalian skull, altered from Flower. Cartilage bones dotted, membrane bones lined; 2-12, nerve exits.

which elsewhere remain distinct. The obliteration of sutures has gone farther in the monotremes and some of the carnivores and apes than elsewhere. Connected with the loss of bones is the absence of the supratemporal arcade, but the infratemporal bar consisting of processes from the squamosal and zygomatic (malar) is always present, bounding the single temporal fossa. This may be separated from the orbit by a bar formed by zygomatic and frontal, or the bar may be incomplete or absent so that orbit and fossa are one.

Usually the bones fuse in such a way that the complexes named on page 66 are readily recognized. The occipitalia are usually united into a single occipital bone, though the sutures between them may persist for some time. The basioccipital forms the so-called basilar process, while the exoccipitals bear the two occipital condyles for articulation with the atlas. The exoccipitals may also bear strong, ventrally directed, paramastoid processes (paroccipital). The membranous interparietal is sometimes distinct, sometimes fused to the supraoccipital, though it may unite with the parietals. 
The sphenoidalia form the sphenoid bone of human anatomy. Basi-and presphenoid form a 'body' from which two pairs of 'wings' arise, the alisphenoids being the greater, the orbitosphenoids the lesser wings. A pair of pterygoid processes are given off from the ventral side of the body and a part of these in some cases persist as distinct pterygoid bones, but apparently are not homologous with the elements of the same name in the lower vertebrates since they are membrane bones. The equivalents of the pterygoids of the non-mammals occur in the monotremes. A second pair of membrane bones, the intertemporals, also belong to the sphenoid complex, fusing at an early date with the dorsal margin of the alisphenoids.

The ethmoid complex consists of a mesethmoid which ossifies in the septum between the nasal organs, and an ectethmoid in the outer wall of each nasal capsule. Mes- and ectethmoids are distinct for a time, the olfactory nerve passing between them. Later bony strands passing between the nerve fibres unite them, producing perforated cribiform plate, characteristic of the mammals. The part of the mesethmoid projecting above the cribiform plates is the cristi galli, below them is

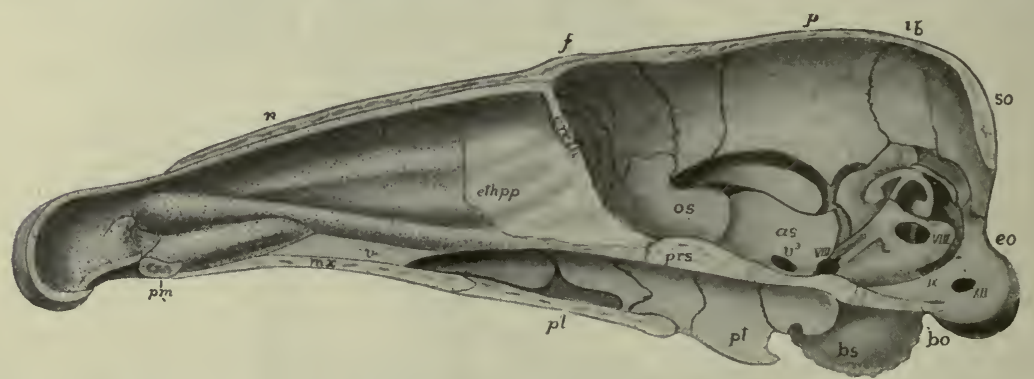

Fig. I04.-Median section of skull of young Erinaceus, after Parker. For letters see fig. 68 .

the perpendicular plate. Two other centres in the lateral wall of each capsule give rise to coiled bones (inferior and sphenoidal turbinal) on which the olfactory membrane is spread, while two other turbinals (superior and middle) arise from the ectethmoid. A few mammals have in addition, a prenasal bone, developed in the septum in front of the mesethmoid.

The temporal complex consists of squamosal, otic bones and tympanic. On the ventral side of the squamosal is the glenoid fossa for the articulation of the lower jaw; in front the bone gives off a zygomatic process for articulation with a similar process of the zygomatic (malar) bone, the two forming the arcade bounding the temporal fossa. The tympanic (apparently the angulare of the lower vertebrates) curves below the auditory meatus, joining the squamosal on either side. In many forms it expands to form a large capsule, the auditory bulla. The otic bones (it is said that there are six centres of ossification in the otic capsule) unite early to form a single petrosal bone, which, in turn (cetaceans excepted) fuses with squamosal to form the temporal bone. Later, the posterior part of the otic region expands to form the mastoid process, while the upper part of the hyoid, fused to the capsule, forms a styloid process.

On account of the great size of the brain some parts of the skull are changed in 
position. Thus the petrosal, instead of forming part of the side wall, is carried to the floor of the brain cavity and the squamosal forms part of the lateral wall. The roof of the brain cavity is largely formed by parietals and frontals. (In some whales, denticetes, the supraoccipital and interparietal extend to the frontal, preventing the parietals from meeting.) The frontals may be distinct or they may fuse. In many ungulates they bear horns or antlers. In cattle, antelopes, sheep and goats (cavicornia) a strong bony process or horn core is developed on each frontal, and this is covered by a cornified epidermis and persists through life. The antlers of the deer differ from horns. Each year there is an outgrowth of bony material, covered by a richly vascular skin, from each frontal bone. This grows with remarkable rapidity, and when its full extent is reached, the skin ('velvet') is lost, leaving the core alone. After about a year resorption takes place at the base so that the antler is soon lost, to be replaced by a similar but larger one in a few weeks.

The nasals lie above and behind the nares. The margin of the upper jaw is formed by premaxillaries followed by the maxillaries which ossify from several centres, difficult to homologize with distinct bones in the lower vertebrates. The inferior turbinals fuse to the inner surfaces of the maxillaries. Premaxillaries and maxillaries may fuse or they may remain distinct. They have broad palatine processes on the oral surface, these meeting in the middle line and forming the anterior part of the hard palate, with frequently one or two incisive foramina for the passage of the nasopalatine nerve between them. The choanæ are usually behind the palatine bones which form the rest of the hard palate, but in some edentates and whales the pterygoids form part of the partition between the narial passages and the mouth cavity.

The ingrowth of the hard palate has forced the vomer from the roof of the mouth to a position just ventral to the anterior part of the cartilage of the nasal septum. In the monotremes there is a 'dumb-bell bone' in front of the vomer (p. 69). A lacrimal bone always occurs at the inner side of the orbit and the zygomatic forms the external wall of that cavity.

The lower jaw articulates directly with the squamosal without the intervention of a quadrate (see ear bones, p. 74). Its halves may unite in front by ligament or by complete anchylosis. It is usually described as consisting of a pair of dentaries, but there are several centres of ossi-

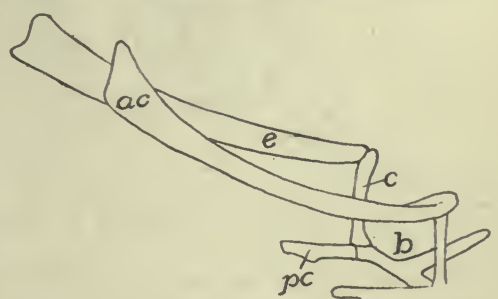

Fig. 105.-Hyoid of rhinoceros (Atelodus). $a c$, anterior cornu; $b$, body; $c$, ceratohyal; $e$, epihyal: $p c$, posterior cornu (thyrohyal).

fication and a splenial and possibly a coronoid may be recognized. The angulare is apparently the tympanic, while the articulare of lower vertebrates is the malleus. A remarkable feature in development is an enormous cartilage at the posterior angle of the jaw, the dorsal side of which forms the condyle for articulation with the glenoid fossa.

The hyoid apparatus varies. As described above, the hyoid is connected above with the otic region, below with the first branchial. The part connected with the 
otic capsule forms the styloid process (p. 100), while the rest may ossify as epi-, cerato-, and hypohyals, or a part may change to a stylohyal ligament, connecting the ventral parts with the skull. The hyoid of the adult consists of the copula forming the body, a part of the hyoid the anterior cornua, while the first branchial arch (of which at most but one or two 'thyrohyal' elements are formed) give rise to the posterior cornua. These are connected by ligament with the greatly modified posterior branchial arches, described in connection with the larynx (see respiratory organs).

\section{Appendicular Skeleton.}

The appendages fall in two categories, the median or azygos (median fins) found only in aquatic vertebrates and the paired appendages, which (cyclostomes excepted) are found in every class, although here and there individual species or genera may lack them. Both kinds have an internal skeleton. Opinions differ as to the origin of these appendages. The two most prominent views are given below.

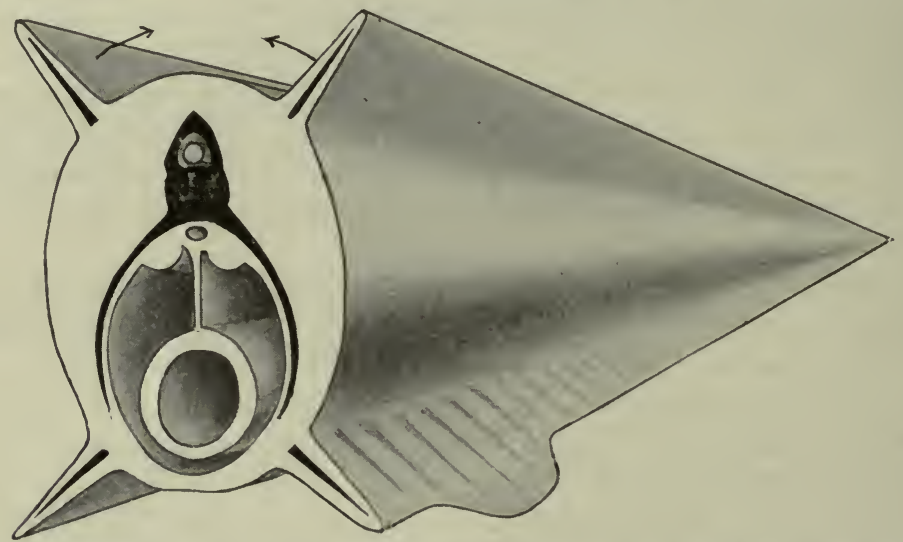

FIG. 106.-Diagram of the origin of median and paired appendages from lateral fin folds.

According to one view the two types have no relation to each other. The paired appendages are derived from gill septa, all traces of which are otherwise lost from these somites. The girdles which support the appendages are modified gill arches, while the skeleton of the appendage itself is derived from the radialia which support the gills, one radial forming an axis, the adjacent radials being arranged on either side of this, and carried outward from the arch by the growth of the septum to form the body of the appendage (fig 122). A somewhat similar view is that the appendage itself is a modification of an external gill, such as is found in larval amphibians.

Another view supposes an ancestor with two pairs of longitudinal folds running the length of the body behind the head, each fold supported by a series of skeletal rods (fig. 106). With farther development the upper folds on either side migrated 
dorsally until the two met and fused in the middle line of the back, thus producing a continuous dorsal fin. The ventral folds migrated downward in the same way, eventually meeting behind the vent, but that opening prevented their meeting farther forward. From the fused part behind the vent the anal and the lower part of the caudal fins were formed, while the paired appendages are differentiations of the preanal parts of the ventral longitudinal folds.

It may be said that in development there is no such double origin of the dorsal fin. In several sharks the paired fins arise from continuous folds, while in the Japanese gold fish the anal fins are frequently paired and the caudal has a double condition below, such as would result from the failure of folds to unite in this region. In criticism of the gill-arch theory it may be said that the supports of the paired appendages arise outside of the body musculature, while the visceral arches (p. 65) are internal.

\section{The Median Appendages.}

The median or azygos appendages always have the form of fins, and may be dorsal, terminal (caudal) or ventral (anal) in position. Primitively, and in many species through life, they are continuous, but usually gaps occur during development so that the fins of the adult are separated by intervals from each other. They occur in practically all fishes, in larval and tailed amphibians, and in isolated groups like the ichthyosaurs and whales. In amphibians and higher groups the median fins have no skeleton, but elsewhere it is of cartilage, bone, or a horny substance (elastoidin), the latter being the most constant and occurring in connection with either of the others.

The simplest skeleton consists of a metameric series of cartilage or osseous bars, each usually divided into a deeper basale and a more distal radiale, the former frequently articulating or alternating with the spinous processes of the vertebræ, while the latter support the fin proper. The elastoidin elements consist of a number of slender rods (actinotrichia), outnumbering the somites, and arising from the corium, immediately below the epidermis. Frequently they are united into bundles (soft fin rays) and may replace the radialia.

\section{Patred Appendages.}

The paired appendages are not, as the gill-arch theory would demand, derived from a single somite, but a varying number of segments participate in their formation. Apparently the simplest fin known is that of the extinct shark, Cladoselache (fig. 107), in which it is a rounded lobe supported by a number of rods, like the radialia in a median fin. These are attached proximally to a few larger plates, the 
basalia, the basalia of the two sides being unconnected with each other. Greater growth of the basalia would result in some of them meeting and fusing in the middle line, thus forming a bar across the ventral side of the body, giving additional support to the fin. Then to compensate for the rigidity, the basals become jointed

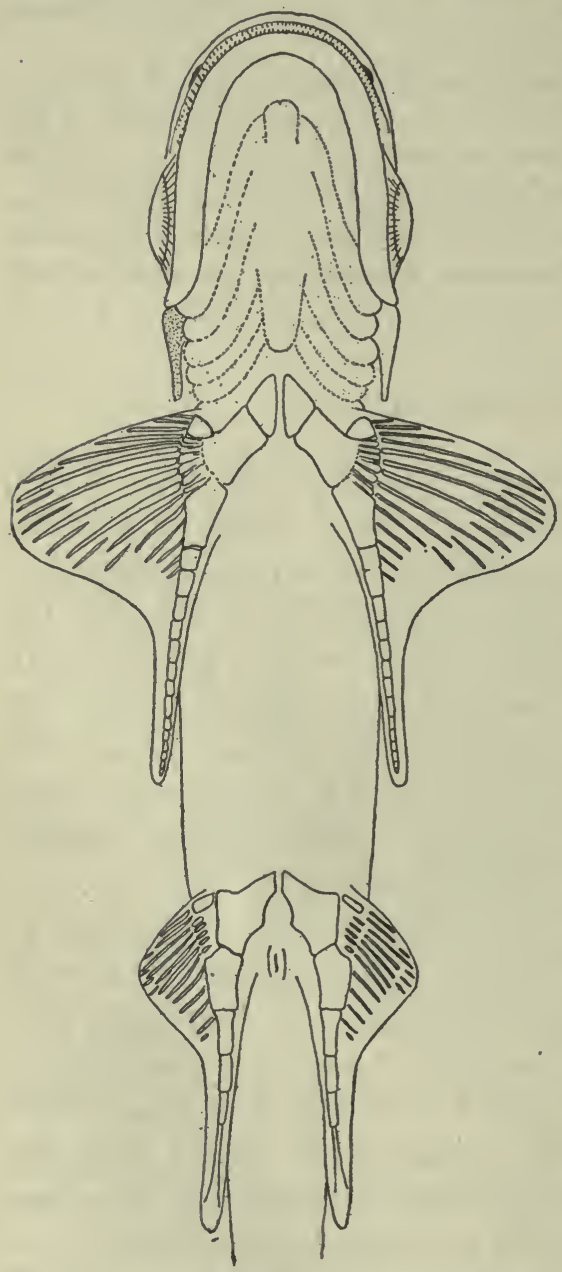

Fig. 107.-Ventral surface of Cladoselache, after Jaeckel. on either side, leaving the medial bar with an articular surface on either side for the reduced basalia. The ventral muscles of the fin would find firm attachment to the bar, while the need for a similar attachment for the dorsal results in an extension of the bar dorsally above the articulation of the limb, thus producing the typical girdle. The derivation of the fin of any fish from that of Cladoselache is easily imagined, but no satisfactory comparison of the fin with the leg has yet been made.

In the appendicular skeleton the internal supports or girdles and the skeleton of the free appendage are to be recognized. Each girdle is an inverted arch crossing the ventral side of the body and extending up on either side above the articulation of the limb. The girdles, as well as the skeleton of the free appendage, are always laid down in cartilage, and in the latter, aside from the actinotrichia, no parts of other than cartilaginous orgin occur. In the girdles mem brane bones may be added as will appear below.

In its typical state each girdle consists of three elements, one dorsal and two ventral, meeting at the point of attachment of the free appendage, all contributing to the socket (glenoid fossa, acetabulum) which receives the basal element of the skeleton of the limb. The limbs themselves are much alike in their general structure, as may be seen from the adjacent diagram. 


\section{The Shoulder Girdle.}

FISHES.--The pectoral or shoulder girdle in the elasmobranchs is more or less U-shaped, the bottom of the arch crossing the ventral surface between the skin and the peritoneal membrane, this ventral portion being known as the coracoid region, which is limited dorsally

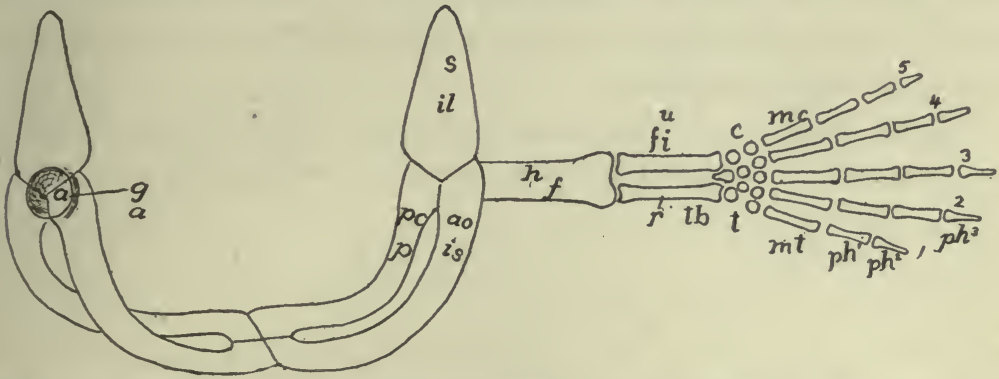

FIG. 108.-Diagram of girdles and appendages from the posterior side; upper letters, fore limb; lower, hind limb. a, acetabulum; $c$, carpus; $c o$, coracoid, $f$, femur; $f i$, fibula; $g$, glenoid fossa; $h$, humerus; $i l$, ilium; is, ischium; $m c$, $m t$, metacarpals, metatarsals; $p$, pubis; $p c$, procoracoid; $p h^{2}-^{3}$, phalanges; $r$, radius; $s$, scapula; $u$, ulna; $1-5$ digits.

by the point of attachment (glenoid fossa) of the fin. Dorsal to the fossa is the scapular region. Not infrequently the dorsal part of the scapular region is segmented off as a separate suprascapula.

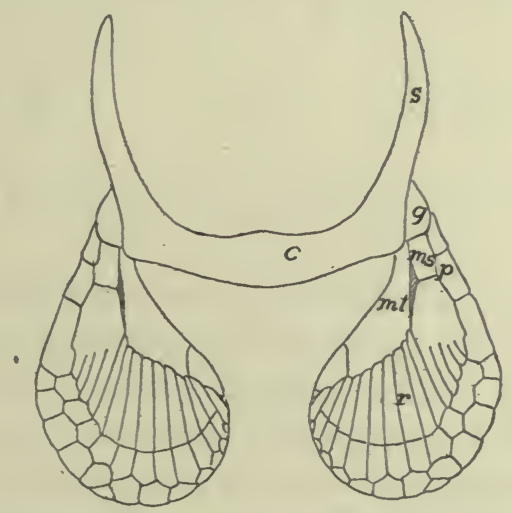

FIG. I09.-Pectoral girdle and cartilaginous fin skeleton of Scyllium. c, coracoid region; $g l$; glenoid surface; $m s$, mesopterygium; $m t$, metapterygium; $p$, propterygium; $r$, radialia: $s$, scapular region.

The girdle is usually free from the axial skeleton, but in the skates (raiæ) the suprascapula articulates with the adjacent vertebræ.

In the simpler teleostomes (some ganoids, dipnoans) the cartilaginous girdle is reinforced by membrane bones derived from the skin. 
Of these there are at least two on either side, a pair of clavicles which overlie the coracoid region and meet in the middle line, and lateral to each clavicle and extending to or above the glenoid fossa, a second bone, the cleithrum. In some ganoids (Polypterus, fig. IIo) the cleithra extend toward the middle line, and a little higher in the scale, meet and take the strains. This assumption of stress by the membrane bones results, in the higher forms, in the separation of the two halves of the cartilaginous girdle.

In the higher ganoids and teleosts the cleithrum has increased greatly, usurping the function of the clavicles, which have consequently

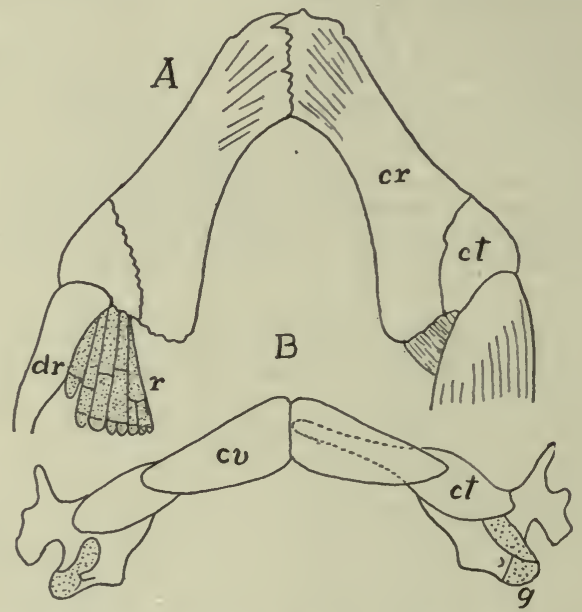

Fig. Iro.-Pectoral girdles of (A) Acipenser and (B) Polypterus, after Gegenbaur. ct, cleithrum; $c v$, clavicula; $d r$, dermal rays; $g$. glenoid surface.

disappeared. Dorsal to the cleithra other membrane bones frequently occur. There may be one or two supracleithra (post- or supratemporals, fig. 79) which connect the girdle with the skull, and occasionally others as postclavicle, infraclavicle, etc. As a result of the great development of the cleithra the cartilaginous girdle has been reduced, but it usually has at least two ossifications on either side, a scapula dorsal to the glenoid fossa and a coracoid in the ventral region, these contributing to the support of the appendage.

AMPHIBIA.-In the stegocephals the cartilage has not been preserved and the bones are variously interpreted (fig. 58). The bone meeting the episternum is the clavicle, and lateral to this is an equally slender bone, usually called scapula, but by some the cleithrum. A 
large round element is called the coracoid. In the recent amphibians we are on firmer ground. The halves of the girdle develop separately, and the cleithrum is lacking. In urodeles the coracoid region has two processes diverging from the glenoid fossa, an anteriorly directed procoracoid and a coracoid proper, directed toward its fellow of the opposite side, the two meeting the sternum behind and overlapping in front. Ossification sets in in the neighborhood of the glenoid fossa, the resulting bone being called the scapula, although it invades the coracoid region, the cartilage dorsal to it being the suprascapula.

In the toads and allied anura (arcifera) the halves of the girdle overlap as in the urodeles, but the procoracoids extend toward the middle line, each being joined to its coracoid by longitudinal cartilage plate, the epicoracoid, leaving a gap between them. With the appearance of bone, scapula and coracoid ossify, while a clavicle of mem-

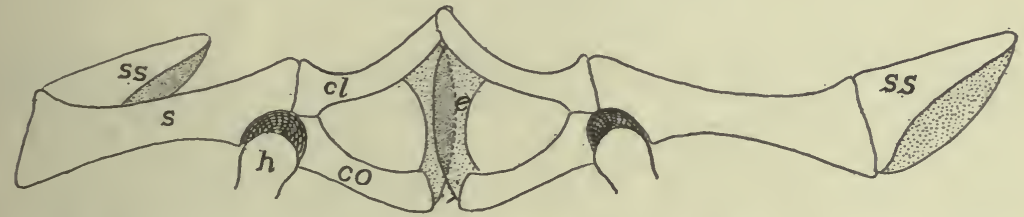

FIG. III.-Arciferous girdle of Ceratophrys ornatus. cl, clavicle; co, coracoid; e, epicoracoid; $h$, head of humerus; $s$, scapula; $s s$, suprascapula; cartilage dotted.

branous origin overlies the procoracoid cartilage. In the frogs (firmisternia) the relations are much the same, except that the epicoracoids, instead of overlapping, abut against each other, and the clavicles nearly or quite replace the procoracoid, while sternum and omosternum join the girdle in front and behind. Girdles are lacking in the gymnophiones.

REPTILES.-With the development of a considerable neck in the reptiles the pectoral girdle is removed farther from the head; it shows considerable differences in the various groups. In the fossil rhynchocephals it is much as in the stegocephals, except that the scapula is large. In the turtles it occupies a peculiar position, being inside the carapace, i.e., internal to the ribs; but this is explained by the development; the girdle arises in front of the ribs and later sinks to the definitive position. Scapula, procoracoid and coracoid are well developed, the medial ends of the latter two being connected by a cartilaginous epicoracoid. Elsewhere in the reptiles the procoracoid tends to reduction, the clavicle taking its place, though it is retained in the lizards in a reduced condition (fig. II2). The clavicle in turn is 
lost in chamæleons and crocodiles, and if present in the chelonians, it is represented by the epiplastron (p. 4I), an element of the carapace. The girdles are greatly reduced in the limbless lizards and have vanished in the ophidians.

In the BIRDS (fig. 53) the scapula is a sword-shaped bar overlying the ribs, while the coracoid extends from its junction with the scapula at the glenoid fossa to the anterior end of the sternum. The clavicles of the two sides are united at their medial or ventral ends to form the well-known furcula (wishbone) which may articulate with the sternum between the two coracoids, or, with diminishing powers of flight, may end freely below.

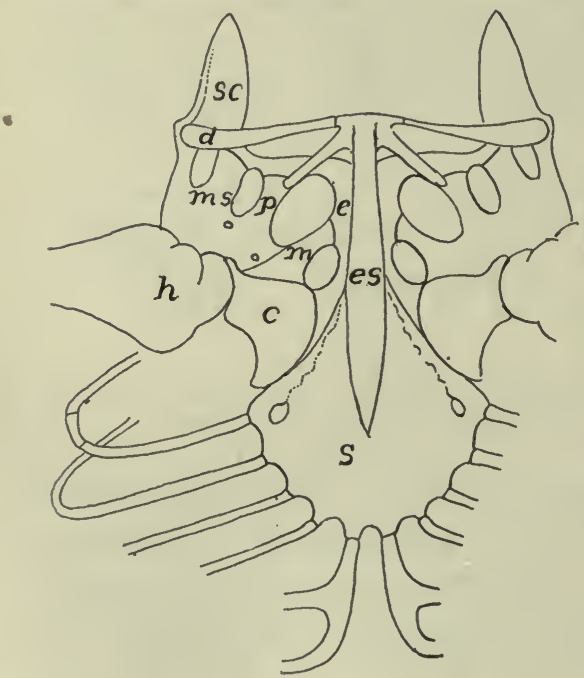

FIG. II2.

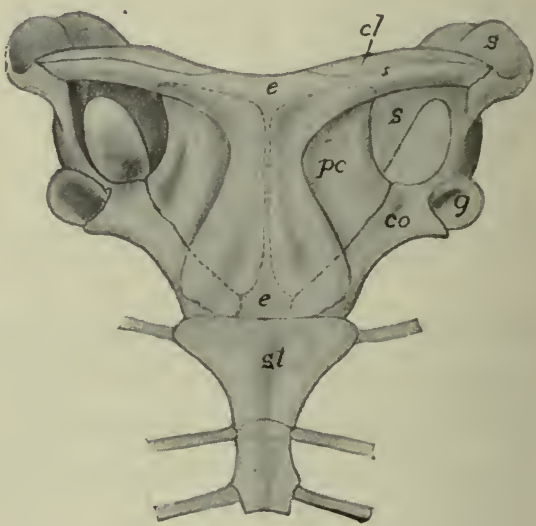

FIG. II 3

FIG. II2.- Sternum and pectoral girdle of Amblyrhynchus, after Steindacher. $c$, coracoid; $c l$, clavicle; $e$, epicoracoid; $e s$, episternum; $h$, humerus; $m$, mesocoracoid; $m s$, mesoscapula; $p$, procoracoid; $s c$, scapula; $s$, sternum.

FIG. Ir 3. - Shoulder girdle of Ornithorhynchus. cl, clavicle; $c o$, coracoid; $e$, episternum; $g$, glenoid fossa; $p c$, procoracoid; $s$, scapula; $s t$, sternum.

MAMMALS.-The shoulder girdle of the monotremes is strikingly like that of lizards, the coracoids acting as a brace between sternum and glenoid fossa, while the resemblance is strengthened by the presence of the episternum. This same large development of the coracoids occurs in the young of some marsupials, but in the adults, as in the rest of the mammals, the coracoid is greatly reduced, persisting only as a small projection, the coracoid process, anchylosed to the ventral end of the 
scapula, where it often forms a part of the glenoid fossa. The scapula is always well developed, and in the placental mammals bears a strong crest (spina scapulæ) on its external surface, terminating ventrally in an acromion process. The clavicle varies with the freedom of motion of the limb. Thus in rodents, insectivores, bats, some marsupials and the higher primates it forms a strong brace between shoulder and sternum. In ungulates, whales, and a few carnivores it has entirely disappeared, while in other mammals it persists as a rudiment without functional value. In development two small elements frequently intervene between the clavicles and the sternum (fig. 55). They are preformed in cartilage but eventually fuse with the sternum. Their homology is very uncertain. They have been called episternalia, suprasternalia, etc.

\section{The Pelvic Girdle (Pelvis).}

In its broader features the pelvis ( $c f$. fig. I08) is much like the shoulder girdle, and in its full development, may be compared, part by part, with the anterior arch. Thus the acetabulum or socket where the appendage is attached, is comparable to the glenoid fossa. Dorsal to this is the ilium in the position of the scapula, while ventral and medial to the acetabulum are, on either side, an os pubis in front, an ischium behind, with a gap (ischio-pubic fenestra) between them, just as between coracoid and procoracoid. An important landmark is the point of passage of the obturator nerve through the pelvis. This may have its own (obturator) foramen, though the pubic portion or the foramen may unite with the fenestra, the condition in the mammals where the common opening is called the obturator foramen.

The phylogenetic history of the pelvis is more clearly indicated than is that of the pectoral girdle, for in many fossils, as well as in the sturgeon, there is little advance over Cladoselache (p. I04). The basalia of a side have fused to a single basal, often perforated for the obturator nerve, and bearing the radialia on its distal surface. The basalia of the two sides have not met, but there is frequently between them a pair of small cartilage plates, possibly the homologues of the epipubis of the tetrapoda (infra). There is no acetabular joint. In the other ganoids and in teleosts there is little advance, aside from ossification of parts, while no epipubic elements occur. A noticeable feature in many acanthopterygians is the forward migration of the pelvic 
fins so that they come to lie in front of the pectorals (the old group of 'jugulares').

The elasmobranchs have a true girdle, but without separate elements as it does not pass beyond the cartilage stage. It consists of a continuous ischio-pubic bar, extending from one acetabulum to the other, and usually prolonged dorsally above the acetabulum by an iliac process.

In all fishes the pelvic girdle is free from the vertebral column, but in the tetrapoda, where the limbs have to support the body weight, the girdle becomes connected with the sacrum by the intervention of one or more sacral ribs ( $p$. 56). In the interpretation of some of the pelvic elements there is some uncertainty.

In the stegocephals ischium and ilium and usually pubis were distinct bones with apparently considerable cartilage between them. In

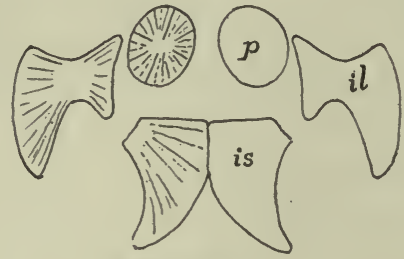

FIG. II4.

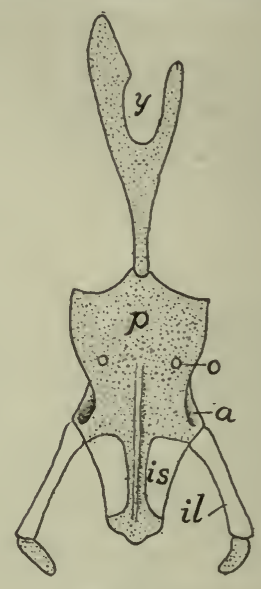

FIG. II5.

FIG. II4.-Pelvis of Discosaurus; after Credner. il, ilium; is, ischium; $p$, pubis.

FIG. I I 5. - Ventral view of pelvis and ypsiloid cartilage of Cryptobranchus, after Wieder sheim. $a$, acetabulum; $i l$, ilium; is, ischium; 0 , obturator foramen; $p$, conjoined pubes; $y$, ypsiloid cartilage.

the urodeles the two ischio-pubic cartilages are usually united in the median line, but the ossifications vary in extent, the pubic region lagging behind the ischium and being at times indistinguishably fused with it. In some cases there is, as in Necturus, an extension of the median cartilage forward in an epipubic process, and frequently a pectineal process from the antero-lateral of each pubis. An interesting feature is furnished by the ypsiloid cartilage (fig. II5) formed independently of the pubis and extending forward in the linea alba through two or three somites. This occurs only in salamanders with functional lungs, where it furnishes attachment for muscles connected with respiration.

In the anura all three pelvic bones are present, and all participate in the formation of the acetabulum. Correlated with the leaping habits 
the ilium is very long and the ischio-pubis is strongly compressed, obturator foramen and ischio-pubic fenestra being absent.

Omitting the extinct rhynchocephals, whose pelvis resembles that of the stegocephals, the reptiles have the pelvic bones more solid and distinct than do the ichthyopsida; the ilium is strong, with its dorsal end frequently expanded; the ischio-pubic fenestra is large; and ischium and pubis are united to their fellows directly, or by the intervention of the epipubic cartilage, or its modification, the ligamentum medium pelvis. As a rule all three bones meet in the acetabulum and there are large prepubic processes, though these are small in the lizards and are lacking in crocodiles.

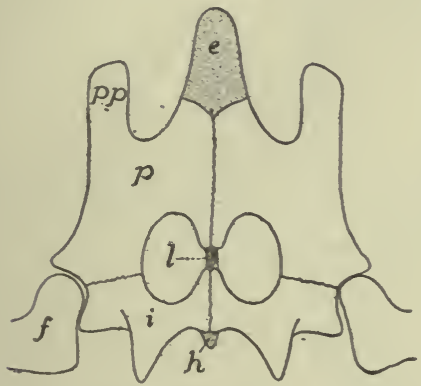

FIG. $x 16$.

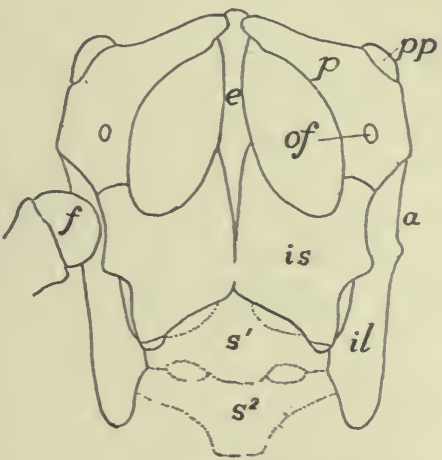

FIG. II7.

FrG. II6.-Pelvis of snapping turtle (Chelydra). from below. e, epipubis; $f$, femur; $h$, hypoischium; $l$, ligamentum medium pelvis; $p$, pubis; $p p$, pectineal process.

FIG. II7.-Pelvis of Iguana tuberculata, after Blanchard. a, acetabulum; $e$, epipubic cartilage; $f$, femur; $i l$, ilium; is, ischium; of, obturator foramen; $p$, pubis; $p p$, prepubis; $s,{ }^{1} s^{2}$, first and second sacral vertebræ.

Many theriomorphs have the pelvic bones fused much as in mammals. In Sphenodon and turtles the epipubic cartilage bounds the fenestra on the median side, and Sphenodon and the plesiosaurs have a separate obturator foramen, but the two are merged in the chelonians. Most lizards have slender pubic bones, perforated by the foramen, and the part of the epipubis between the fenestræ reduced to a ligament, while the posterior part of this, behind the ischium, may ossify as a distinct bone (os cloacæ or hypoischium). In the footless lizards the pelvis is reduced, being represented in the amphisbænans by rudiments of ischium and pubis, while all traces of the pelvis are lost in snakes, except the boas and some opoterodonts. The obturator foramen is very large in the crocodiles, the result of the oblique position of the 
pubes, which do not unite with each other; each is tipped with cartilage (? separate epipubes). All three bones meet at the acetabulm which is perforate in recent species. The lower end of the ilium separates as a distinct bone (pars acetabularis).

The pelvis of the dinosaurs has the same great extension of the ilium forward and back as is seen in the birds and a corresponding increase of the sacrum (p. 53), the result of the partially upright position.

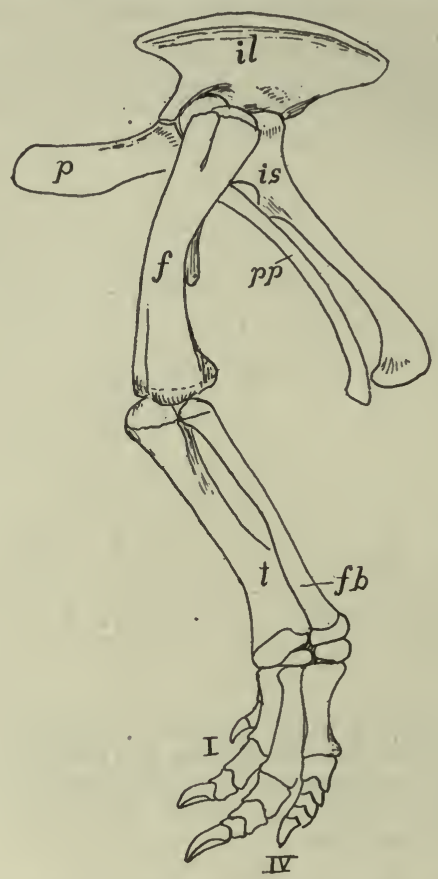

FIG. II8.-Pelvis and hind limb of Camptosaurus, after Marsh. $f$, femur; $f b$, fibula; $i l$, ilium; is, ischium; $p$, pubes; $p p$, postpubis; $t$, tibia; $I-I V$, digits.

The ischia are greatly elongate and are directed backward, being frequently united below. The pubic bones are remarkable in being directed forward and downward and in having strong postpubic processes which are parallel to the ischium. Frequently the ilium gives off an iliac spine near the acetabulum.

The pterodactyls had the same elongate ilium as the dinosaurs, the ischium being fused to it so as to exclude the pubis from the acetabulum, the latter ${ }^{1}$ being usually loosely articulated to the ischium and

${ }^{1}$ This pubis is sometimes regarded as a prepubis, the ischium being called an ischiopubis. 
meeting its fellow in the median line below. The pelvic opening was very small. The pelvic bones of the ichthyosaurs were weak, long and slender, and apparently were imbedded in the muscles.

In recent birds (figs. 50, 53) the pelvic bones are fused. The ilium is greatly elongate and usually fused with the synsacrum (p. 53); ischium

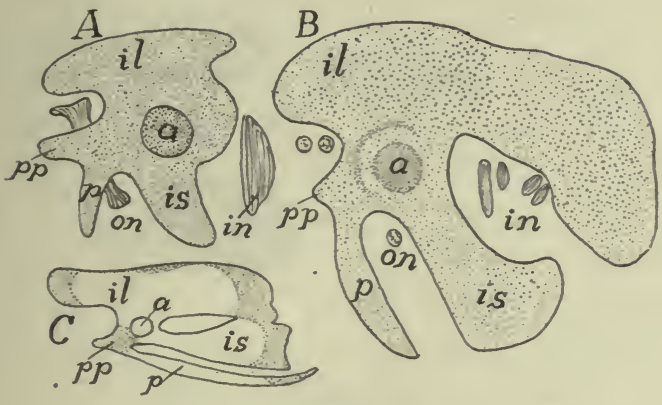

FIG. II9.

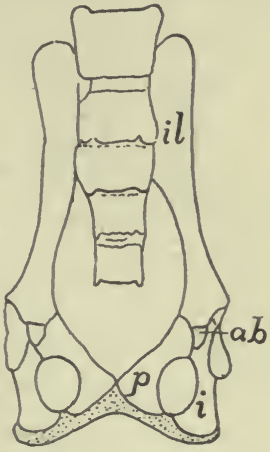

FIG. I20.

FIG. II9.-Development of pelvis of chick, after Miss Johnson. $A$, chick of 6 days. $B$, older; $C, 20$ days; cartilage dotted, bone white. $a$, acetabulum; $i l$, ilium; is, ischium; in, ischiadic nerves; on, obturator nerve; $p$, pubis; $p p$, pectineal process.

FIg. I20.-Pelvis of Galeopithecus, after Leche. $a b$, acetabular bone; $i$, ischium; $i l$, ilium; $p$, pubis; cartilage dotted.

and pubis directed backward. The pubes, lying in the position of the postpubes of the dinosaurs, never meet below except in the ostriches. In the embryo (fig. II9) they are at first directed forward and only attain the final position later. A pectineal process arises from the acetabular region and extends forward, simulating the dinosaur pubis.

In the mammals, obturator foramen and ischio-pubic fenestra are united, the opening being bounded on the medial side by processes from ischium and pubis. All three bones may meet in the acetabulum, but more often the extension of ilium and ischium excludes

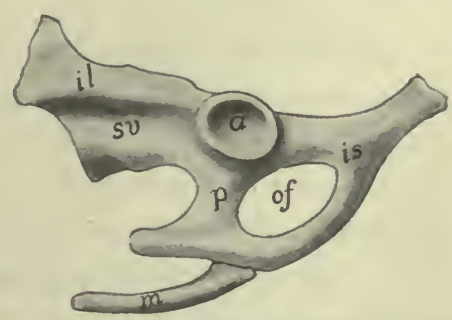

FIG. 121.-Left side of pelvis of duck-bill, Ornithorhynchus, $a$, acetabulum; il, ilium; is ischium; $m$, marsupial bone; of, obturator foramen; $p$, os pubis; sv, sacral vertebra. the pubis from the fossa. A peculiarity is the common occurrence of an additional bone in the formation of the acetabulum (acetabular or cotyloid bone). This lies between ilium and pubic bone and may fuse with any of the elements. In marsupials and monotremes the interpubic car- 
tilage persists for some time, or through life, but elsewhere it disappears and the elements unite by symphysis. The same groups of nonplacental mammals are characterized by the presence of marsupial bones (fig. I2I). These are preformed in cartilage and extend forward from either pubis in the ventral abdominal wall. Their homology is very uncertain; but they are not the ypsiloid of the urodeles.
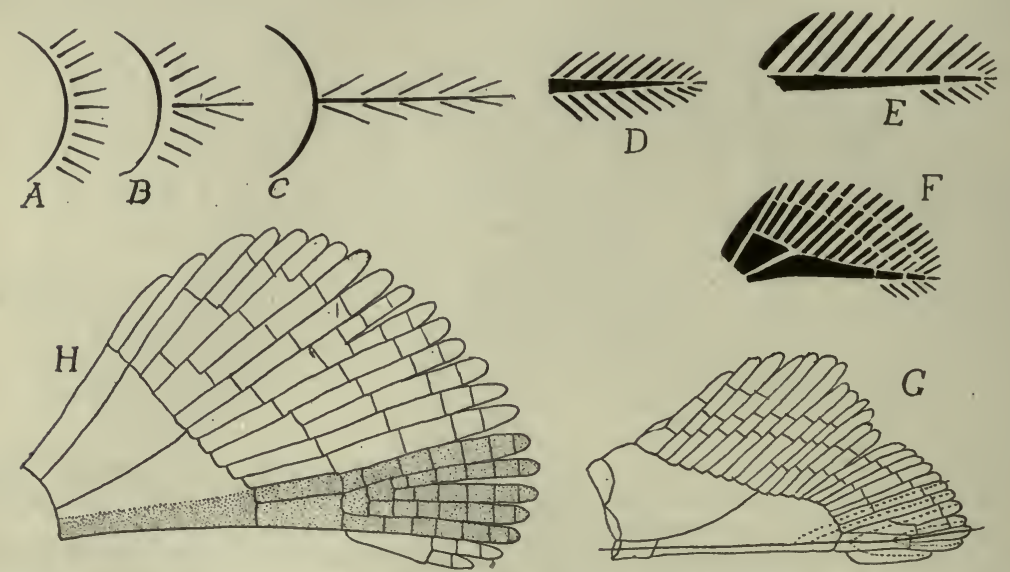

FIG. I22.-Diagrams illustrating theories of origin of appendages. $A, B, C$, origin of biserial appendage $(C)$ from gill arch $(A) ; D$, biserial appendage (archipterygium); $E, F$, evolution of elasmobranch fin; $G$, dotted lines indicate parts involved in origin of leg from fin; $H$, dotted parts show another view of origin of elements of leg.

\section{The Free Appendages.}

These are of two kinds, the paired fins (ichthyopterygia) of the fishes and the legs or their modifications (chiropterygia) found in all classes of tetrapoda. The former is merely a mechanism for altering the position of the body in the water, and requires a small amount of flexibility, being moved as a whole. The assumption of terestrial habits necessitates the support of the body above the ground and its propulsion. Hence the chiropterygium must have a firmer skeleton, with at the same time joints for motion and intrinsic muscles to move the parts on each other. The chiropterygium was undoubtedly derived from the fish fin, but the problem of how the change was made has not been solved. Only paleontology can give the answer.

There are two views as to the origin of the chiropterygium, both based upon the loss of certain parts and the persistence of others in a modified form. One view assumes the persistence of a basal as the framework (humerus or radius) of the 
upper limb. Two proximal radials as that of the next limb segment, while the skeleton of ankle and foot is derived from a corresponding number of distal radials on the anterior side of the fin. The 'archipterygial theory' of Gegenbaur assumes an appendage like that of Ceratodus (the 'archipterygium') as the type from

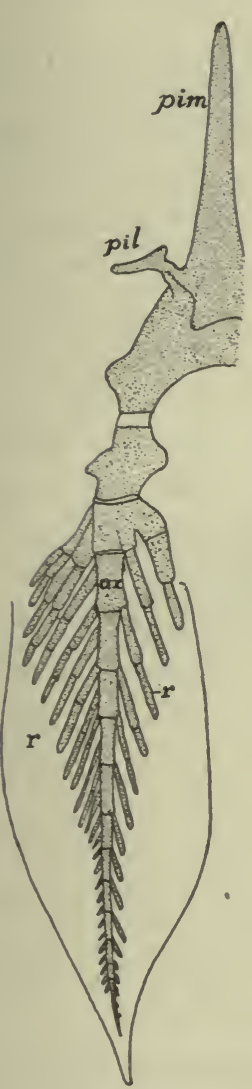

Fig. 123. which all legs and other fins have been derived, by a shortening of the axis and a loss of radials, chiefly on the preaxial side. The two views are illustrated in the adjacent sketches. No known facts of either embryology or paleontology throw any certain light on the matter.

Cladoselache (fig. I07) and the lower ganoids have what is apparently the most primitive type of fin with a large number of basalia which support a large number of radialia. From these, as we go upward in the scale, there is a reduction in the number of basalia, either by disappearance or fusion, while the other parts are variously modified. Thus in recent elasmobranchs the characteristic number of basalia is three in the pectoral, two in the pelvic fin. These are known, from in front backward as the pro-, meso-, and metapterygium, the middle one being absent

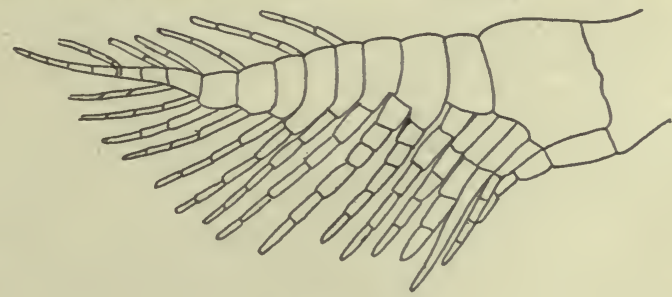

FIG. I24.

FIG. I23.- Pelvic fin and part of girdle of Ceratodus, after Davidoff.a, axial skeleton of fin; pil, iliac process; pim, processus impar; $r$, radialia.

FIG. I24.- Skeleton of pectoral fin of Xenacanthus, after Fritsch.

from the hind limb. The numerous radials are jointed transversely (fig. I09), permitting more flexibility, and these may be arranged entirely on one side of the basalia (uniserial), or the metapterygium may be prolonged as an axis, and while most of the radialia are on the preaxial side, some may occur on the postaxial side (biserial) as seen in the carboniferous shark, Xenacanthus (fig. I24). In the recent species the skeleton of the fin is continued by actinotrichia. 
In the male elasmobranchs the pelvic fin is divided into two lobes, the medial, the so-called clasper (mixipterygium) being the longer and narrower. This is used in copulation and is supported by thespecialized terminal radialia of the metapterygium.

In other ganoids and in teleosts the skeletal parts are more or less ossified, the basalia more numerous than in the higher elasmobranchs and are shortened and more closely associated with the girdles, while

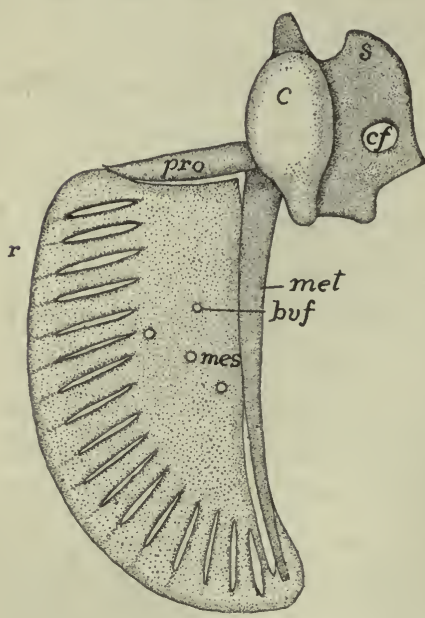

FIG. I25.-Cartilage skeleton of shoulder girdle and left pectoral fin of larval Polypterus, after Budgett, bvf, foramina for blood-vessels; $c$, coracoid; $c f$, coracoid foramen; mes, mesopteryguim; met, metapterygium; pro, protopteryigum; $r$, developing radialia; $s$, scapula. the numerous radii form most of the skeleton of the fin itself. It is not uncommon for the anterior element of the pectoral fin to form a strong defensive spine, not infrequently connected with a poison gland. In some teleosts, e.g., eels, the pelvic fin may be lacking. The fins of the dipnoi are easily understood by comparison with a biserial fin like that of Xenacanthus (fig. 124). The axial part has been elongated and in Ceratodus it bears biscerial radialia, while in Protopterus and Lepidosiren only the axis persists.

Embryology tells little as to the primitive condition of the ichthyopterygium, for in the procartilage stage the condensation of mesenchyme for the skeleton of the fin forms a continuum which later becomes broken into the separate parts (fig. I 25).

The legs (chiropterygia) of all tetrapoda are essentially alike (fig. ro8). Each consists of several regions, comparable in detail with each other. The proximal is the upper arm (brachium) or thigh (femur) containing a single bone, the humerus or femur in the fore and hind limb respectively. The next region, the forearm (antebrachium) or shank (crus), contains two bones, a radius or tibia on the preaxial and an ulna or fibula on the postaxial side. Next follows the podium, the hand (manus) in front, the foot (pes) behind, each consisting of three portions. The basal podial region, the wrist (carpus) or ankle (tarsus) consists of several small bones; the second division (metapodium) is the palm (metacarpus) or instep (metatarsus) and lastly come the fingers or toes (digits), each digit consisting of several bones, 
the phalanges. These separate parts are included in the accompanying table, in which the terms given to the separate elements of the wrist and ankle of man are included.

FORE LIMB (ARM)

HIND LIMB (LEG)

Upper arm (Branchium)

Fore arm (Antebrachium

Basi-
$\begin{gathered}\text { Wodium } \\ \text { Wrist } \\ \text { (Carpus) }\end{gathered}$$\left\{\begin{array}{c}\begin{array}{c}\text { Naviculare } \\ \text { (Scaphoid } \\ \text { Lunatum } \\ \text { Triquetrum } \\ \text { Pisiforme } \\ \text { Multangulu } \\ \text { majus } \\ \text { (Trapezium } \\ \text { Multangulu } \\ \text { minus }\end{array} \\ \text { Palm } \\ \text { (Metapo- } \\ \text { dium) }\end{array}\left\{\begin{array}{r}\text { Trapezoides } \\ \text { Capitatum } \\ \text { Hamatum }\end{array}\right.\right.$

Fingers (Phalanges)
Humerus $=$ Femur

Radius = Tibia

Ulna $=$ Fibula

Radiale $=$ Tibiale

Intermedium $=$ Intermedium

Ulnare $=$ Tibiale

Centrale $^{1+2}=$ Centrale $^{1+2}$

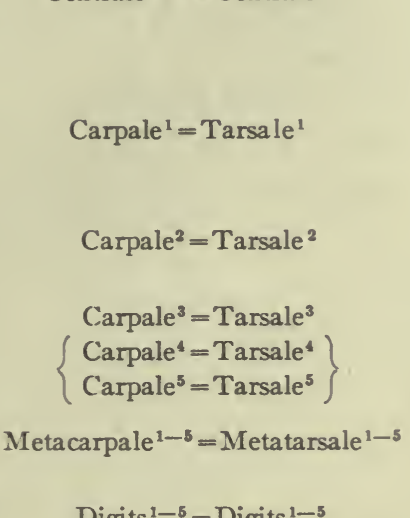

Digits $^{1-5}=$ Digits $^{1-5}$
Thigh

Shank

(Crus)

Astragalus

(Talus)

Calcaneus

Naviculare

pedis

(Scaphoid)

Basipodium

Cuneiform $^{1}$ Ankle (Tarsus)

Cuneiform ${ }^{2}$

Cuneiform ${ }^{3}$

Cuboides

(Metapodium)

Instep

The basal podial region, which is nearly typical in some reptiles, urodeles and man, consists of three rows of bones, a proximal of three bones, a radiale or tibiale on the anterior side, an ulnare or fibulare on the other, and an intermedium between them. The distal row consists of five carpales or tarsales, numbered from the anterior side. The third row is composed of one or two centrales between the other rows. The metapodials and the digits, also numbered from one to five, have, in some cases special names, the thumb (digit I) being the pollex, the corresponding great toe being the hallux, the fifth digit being called minimus.

From this typical condition all forms-legs, arms, wings-are derived by modification, fusion and disappearance of parts. The more distal a part the more variable it is; reduction takes place on the margins of the appendage, the axial portions being the last to disappear. Occasionally in various groups (amphibia, mammals) there occur what 
are interpreted as rudimentary additional digits-prehallux, prepollex, postminimus - but their status is uncertain. There are also certain membrane bones developed in the appendages including the patella (knee-pan) in some reptiles, birds and many mammals, in the tendon that passes over the knee-joint, the fabellæ in the angle of the knee of a few mammals, and the pisiforme in the carpus of man and some other mammals.

In the ancestral limb, as exemplified in the urodeles, the basal joint was directed horizontally at right angles to the axis of the body, but higher in the scale it approaches the sagittal plane and in such a way that the angles of the fore and hind limbs open in opposite directions.

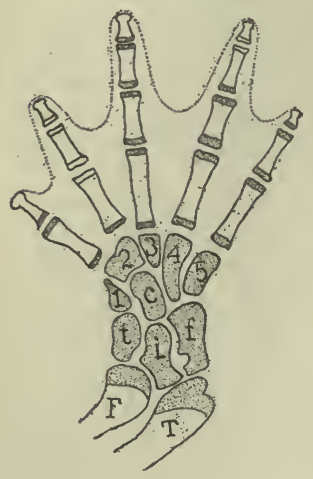

FIG. 126 . Besides there is frequently a torsion of the bones of the forearm (fig. I27) or shank on each other. The lower amphibians have nearly typical legs, although, as in Siren and Amphiuma, they may be greatly reduced, while in some stegocephals and

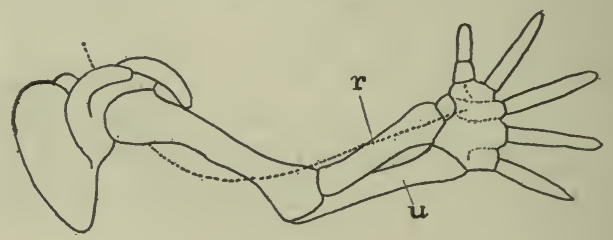

FIG. I27.

Fig. 126.-Tarsus of Geotriton, after Wiedersheim, showing the arrangement of the metapodial elements. $c$, centrale; $f$, fibulare; $F$, fibula, $i$, intermedium; $t$, tibiale; $T$ tibia; $I-5$, tarsales.

FIG. I27.- Torsion in developing human arm, after Braus. $u, r$, ulna and radius; dotted line, course of radial nerve.

the gymnophiones they are entirely lacking. In the anura the radius and ulna or tibia and fibula are frequently fused and the tarsals elongated.

The most marked feature of the reptilian limb is the occurrence of an intratarsal joint, the motion of the foot upon the leg being largely between the two rows of tarsal bones, instead of between tarsus and the bones of the shank (fig. I28). There is also a greater range of form than in the amphibia. Limbs are lacking in snakes and some lizards; on the other hand there is a great increase in the number of phalanges, correlated with a shortening of the proximal bones in the plesiosaurs, which reaches its extreme in the ichthyosaurs where there may be a hundred phalanges in a digit. The wings of the pterodactyls are re- 
markable for the great development of the fifth digit (elongation of the phalanges) as a support for the wing; the other digits are more normal.

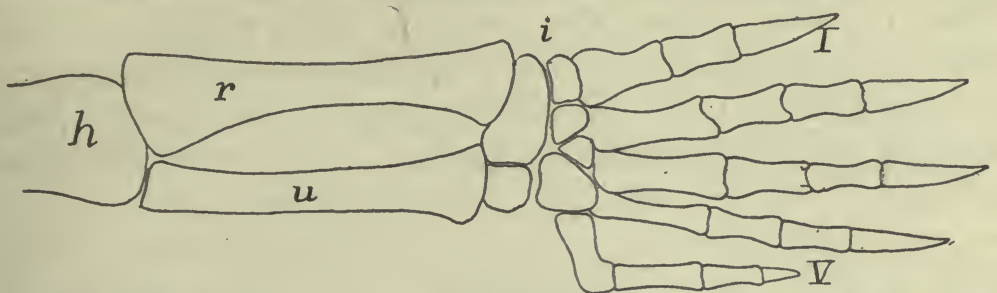

FIG. I28.- Hind leg of snapping turtle (Chelydra) showing intratarsal joint at $i . h$, humerus, $r$, radius; $u$, ulna; $I-V$, digits.

The wings of birds (fig. 55) are even more modified. Until the carpus is reached the structure is approximately normal, but the carpal bones are greatly reduced by fusion, while the metacarpals and digits, extensively modified, number only three. Development shows that the first digit is entirely lost and that the fifth metacarpal, which is present in the embryo, fuses early with the fourth, so that the digital formula is II, III, IV. There is also an extensive fusion of the bones of the tarsus and pes. The ankle-joint is markedly intratarsal, the basal row of tarsal bones fusing with the tibia (the fibula is reduced) to form a 'tibiotarsus,' while the tarsales have united in the same way with the fused metatarsals, forming a 'tarso-metatarsus' (fig. I 29). The toes are rarely more than four in number, the first apparently lacking, and as a rule the number of phalanges increases from two in digit II to five in digit V. Many birds have the toes reduced to

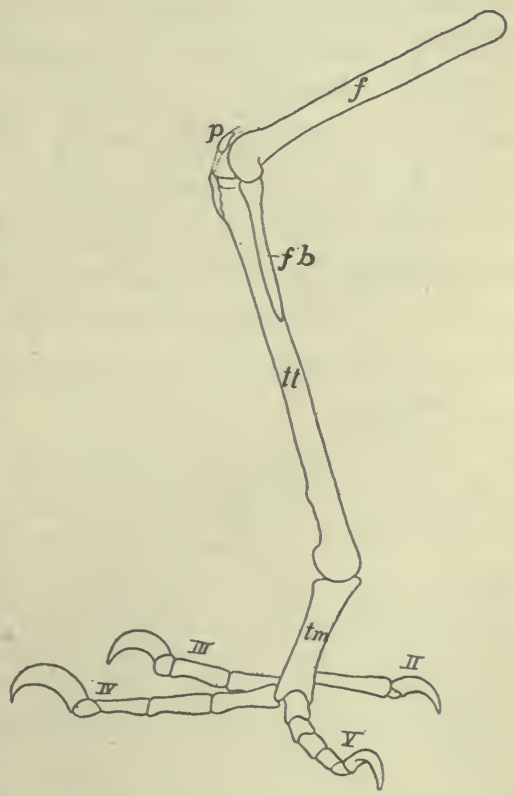

FIG. 129.-Foot of parrot (Psittacus amazonicus), $f$, femur; $f b$, fibula; $p$, patella; $t m$, tarsometatarsus; $t t$, tibiotarsus; $I I-V$, digits. three and in the true ostriches to two.

In the mammals the limbs, especially the fore limbs, exhibit a considerable range of modification. Thus in the primates the skeleton is 
nearly typical, but there is a marked power of rotation of the foot and especially of the hand by the motion of the lower end of the radius around the ulna. There also the appendages may form grasping organs, both features being found to a less extent in several lower groups. In the bats digits II to $\mathrm{V}$ are greatly elongated (either metacarpals or phalanges may be lengthened) to support the wing, the first digit remaining normal. In the whales and sirenians the basal parts of the fore limb are greatly shortened, while there is a multiplication of the phalanges, recalling that of the plesiosaurs. The hind limb is entirely lacking in the sirenians and some of the whales; in other whales there are two vestigial bones (?femur and tibia) imbedded in the muscles of the trunk.

The mammalian humerus is frequently perforated by a (supra- or entepicondylar) foramen passing through the inner lower end, a feature found elsewhere only in some theriomorphs. In many ungulates the ulna is reduced and may be fused with the radius; elsewhere it is well developed. Even where reduced it always bears on its proximal end a strong olecranon process, extending beyond the elbowjoint for the attachment of the extensor muscles of the lower limb. The femur bears a varying number (up to three) of prominences or trochanters for the attachment of muscles. The fibula resembles the ulna in its tendency to reduction. The patella (p. II8) at the kneejoint is analogous to the olecranon process, though it never joins the other bones.

The details of the modification of the feet cannot be described here. The ankle-joint is never intratarsal but always between tarsal and crural bones. There is considerable variety in the extent to which the bones of the feet rest upon the ground. In the plantigrade foot, as in the bear and man, the sole of the foot includes the metapodial bones; in the digitigrade forms, like the dog and cat, the sole includes only the distal phalanges, while in unguligrades (cow, horse) the weight of the body is supported on the hoofs (p. 27) developed on the upper (anterior) surface of the distal phalanges. There is frequently a reduction of the digits, reaching its extreme in the horse where only digit III persists in a functional condition.

\section{THE COEOM (BODY CAVITIES).}

The cœlom includes all of the primitive cavities, right and left, enveloped by the mesothelium (p. Io). With the division of the 
walls into epimere, mesomere and hypomere, the cœlom undergoes a corresponding division. That portion in the epimere is divided into a series of cavities in the myotomes (myocœles), which are eventually obliterated (p. 126); the portions in the mesomere persist only as the lumina of the excretory organs and their ducts, described under the urogenital system; while that part of the original cœlom in the hypomere gives rise to all of the permanent body cavities of the adult.

The hypomeres gradually descend between the ectoderm and the entoderm (fig. I30) until their lower margins meet, ventral to the digestive tract. In this way the latter becomes surrounded by a pair of cavities, the splanchnocœles or body cavities of the adult. Each is bounded by epithelium, the tunica serosa, in which an outer or somatic wall is turned toward the ectoderm, while the inner or splanchnic wall adjoins the alimentary canal. Later, when the muscle plates extend downward (fig. 135), they unite ectoderm and serosa into the outer body wall, the somatopleure, while the invasion of mesenchyme unites the splanchnic serosa with the entoderm into a similar splanchnopleure.

Mesenteries.-As has just been stated the walls of the two cœlomic

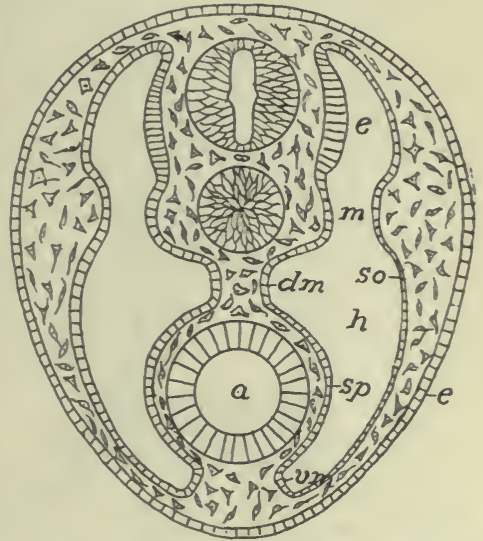

FIG. I30.-Diagram of early mesoderm, showing the zones, $e, h, m m$, epi-, hypo-, and mesomeres, the walls of the colom, $d m, v m$, to form the dorsal and ventral mesenteries. $A$, alimentary canal; $e$, ectoderm; so, $s p$, somatopleure and splanchnopleure. cavities meet below the digestive tract, thus forming a double membrane running lengthwise of the body and binding the alimentary canal to the ventral body wall. This membrane is called the ventral mesentery. In a similar way the splanchnic walls meet above the digestive tract forming a dorsal mesentery. These mesenteries are eventually more than double serosal walls, since mesenchyme comes in between, uniting them and affording a tissue through which blood-vessels, lymphatic vessels and nerves can reach the digestive organs.

For convenience of reference different parts of these mesenteries have received special names, according to the organs supported. The ventral mesentery usually almost entirely disappears, only a small portion persisting in the region of the liver, the mesohepar, which, in the ichthyopsida may carry blood-vessels 
to that organ. The dorsal mesentery is usually more complete, but it is interrupted in various groups. Its regions are called mesogaster, mesentery proper, mesocolon, mesorectum, etc., accordingly as they support stomach, small intestine, colon and rectum. Except in the cyclostomes the alimentary canal is bent on itself and the bends are connected by similar membranes, here called omenta. These also have special names. Thus the gastrohepatic omentum (small omentum) connects stomach and liver; then there are gastrosplenic, doudeno-hepatic omenta, etc., while in mammals there is a great omentum, a double fold of mesogaster and mesocolon which connects the stomach

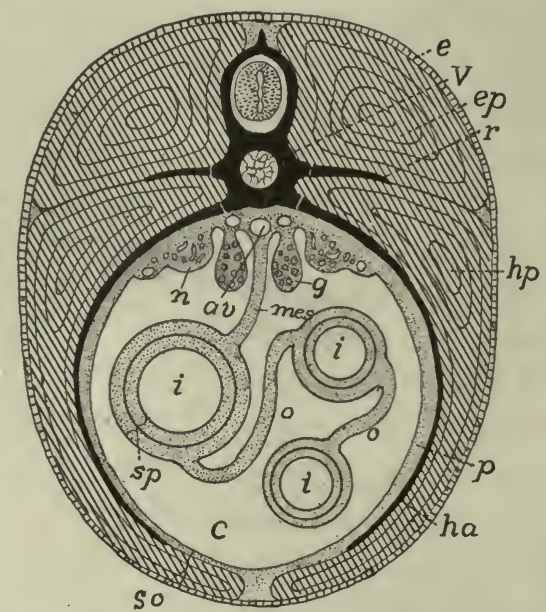

FIG. I3 I. - Diagrammatic section of a vertebrate to show the relation of the body walls, etc. $a v$, aorta; $c$, cœlom; $e$, ectoderm; $e p$, epaxial muscles; $g$, gonads; $h a$, hæmal arch; $h p$, hypaxial muscles; $i$, intestine; mes, mesentery; $n$, nephridium; $o$, omentum; $r$, rib; so, somatopleure; $s p$, splanchnopleure; $v$, vertebra.

with the colon. This forms a large sac, the bursa omentalis, which opens into the rest of the body cavity by a small foramen of Winslow (foramen epiploicum) near the hinder end of the liver.

Homologous structures are formed in connection with other organs. Thus in the formation of the heart there are formed temporary membranes, the mesocardia, connecting it with the walls of the pericardium; while in the mammals a mediastinum, between the two pleural cavities binds the pericardium to the ventral body wall. Frequently the reproductive organs project so far into the body cavity that the serosa meets behind them, forming similar supports, mesovaria for the ovaries, mesorchia for the testes.

The primitive body cavity extends from a point just behind the head back to the vent. It soon becomes divided into two cavities. Just in front of the liver a pair of blood-vessels, the Cuverian ducts, enter the heart from the sides. These arise in the ventral body wall but soon ascend, carrying the serosa before them. In this way they form a 
transverse partition, the septum transversum, attached to the anterior wall of the liver, which cuts off an anterior pericardial cavity, containing the heart, from the posterior part (metacœle) of the body cavity. In many lower vertebrates the septum is not complete, but one or more openings (pericardio-peritoneal canals) connect the pericardium with the metacœle.

In the mammals a second partition, the diaphragm (p. I35), cuts off another pair of (pleural) cavities from the metacœle. Traces of similar structures occur as low as the amphibia; their homology with the mammalian diaphragm is not always certain, but in some cases the
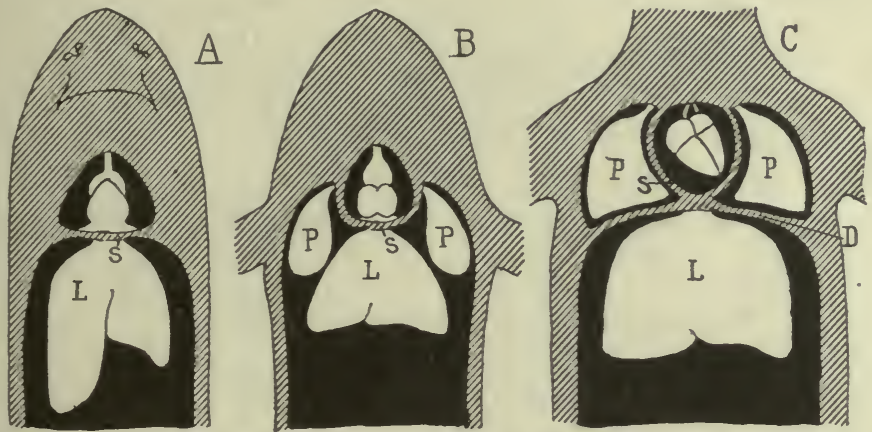

FIG. I32.-Diagram showing the relations of the colomic cavities (black) in $A$, fishes, $B$, amphibians and sauropsida; and $C$, in mammals; $\mathrm{H}$, heart in pericardial coelom; $L$, liver; $P$, lungs in $C$ in pleural cœlom; $S$, septum transversum; $D$, diaphragm.

parts concerned have the same nerve supply. The development of the diaphragm is very complicated and can be stated here only in outline. It involves in part the septum transversum, in part is a new formation. At first a part of the metacœle extends forward, dorsal to the pericardial cavity and alimentary canal, and into this the lungs protrude as they are developed. Then a pair of muscular folds arise from the dorsal surface of the metacœle, posterior to the lungs; these grow downward until they meet the septum adjacent to the attachment of the liver, cutting off a pair of pleural cavities containing the lungs, from the rest of the metacœle, now known as the peritoneal cavity. With increase of the lungs in size the pleural cavities increase, insinuating themselves laterally beween the pericardium and the body wall, and eventually reaching the ventral side, where the two are separated by their two walls, the ventral mediastinum. From the original folds the dorsal muscles of the diaphragm are derived; the ventral come from the rectus muscles of the ventral abdominal wall. The dia- 
phragm undergoes many shiftings of position before reaching its final place.

The tunica serosa lining the various divisions of the splanchnocœle has special names in each. Thus the pericardial and pleural cavities are lined by pericardium and pleura respectively, that portion of the pericardium covering the heart being sometimes called the epicardium. The metacœle or peritoneal cavity is lined by the peritoneum.

The metacœle is not always cut off completely from the external world. In the lower vertebrates the urinary ducts frequently open into the body cavity by the nephrostomes (fig. 133), and in these and even in the mammals the oviducts of the female connect the cavity with the

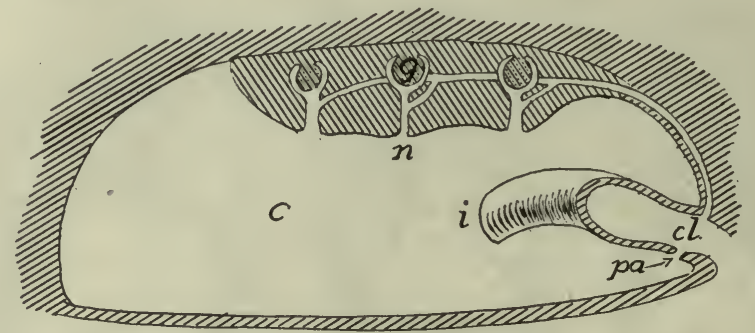

FIG. I33.-Diagram of possible connection of cœlom with the exterior, modified from Bles. $c$, colom; $c l$, cloaca; $g$, glomerulus of kidney; $i$, intestine; $n$, nephrostome; $p a$, porus abdominalis.

exterior. In many fishes there are pori abdominales leading from the metacœle to the outside near the vent. These may be single or paired and are found in cyclostomes, many elasmobranchs and teleosts, ganoids, and dipnoi. None are known in amphibia, birds or mammals, but in turtles and crocodilians so-called peritoneal canals occur, usually ending blindly in chelonians, but emptying into the cloaca in the crocodiles. These may be homologous with the abdominal pores, but only the development can settle the question. In some fishes the pores serve for the escape of the genital products; in other animals their function is uncertain.

\section{THE MUSCULAR SYSTEM.}

Practically all motion in vertebrates is caused by muscles arising from the mesoderm. While other cells may have a certain power of changing shape, the muscle cells possess this in a marked degrec, and so that they may cause the greatest amount of motion in the parts to which they are attached, they are very long, stimulation causing them to contract in length and at the same time to increase in diameter. 
There are two kinds of muscles which differ in origin, histological appearance, physiological action and distribution. The smooth muscles, the appearance of which has been described (p. 20), arise from the mesenchyme and are not under control of the will, but are innervated by the sympathetic nervous system. Their action is much slower than that of the other type. They are found in the skin, in the walls of blood-vessels and of the alimentary canal, and in the urogenital system. Occasionally they occur as isolated fibres, but frequently they form sheets or bands, sometimes of considerable thickness.

In the alimentary tract they are arranged in two layers in the straight parts of the tube, an outer layer of fibres which run longitudinally, and inside this a layer of circular muscles. In enlargements of the tube this regularity is interrupted and the course of the fibres is more irregular. The circular muscles, by their contraction, lessen the diameter of the canal, at the same time causing it to elongate, while the longitudinal fibres shorten it and cause it to increase in diameter. In the blood-vessels there are only circular fibres, the enlargement of the lumen being caused by the internal blood pressure.

The striped muscles are derived from the walls of the cœlom and hence are of mesothelial origin. Excepting those of the heart (to be mentioned below) and some of those at the anterior end of the alimentary canal, they are under control of the will and are supplied by the motor nerves of the brain and spinal cord. They are also able to contract. more rapidly than the smooth muscles. The striped muscles make up the great mass, of the musculature-the 'flesh' - of the body. They occur in the body walls, organs of locomotion, the head, diaphragm and the anterior part of the digestive canal.

The voluntary muscles are derived in part from the somites (myotomes), in part from the lateral plates, the latter furnishing the visceral muscles, including those of the head (except the eye muscles and the sternohyoid and its derivatives in the higher vertebrates) and those of the heart. The heart muscles, the development of which is traced in the account of the circulatory system, differ from the other striped muscles in the uninucleate condition of their short and usually branched cells, while, physiologically, they are involuntary in character.

\section{THE PARIETAL MUSCLES.}

After the myotomes are cut off from the rest of the cœlomic walls (p. I4) each consists of a closed sac, containing a part of the cœlom 
(myocœle) and an inner (splanchnic) and an outer (somatic) wall The cells of the splanchnic wall rapidly increase in number and size, thus tending to obliterate the myocœle. At the same time they become rearranged, so that, instead of forming a cubical or columnar epithelium, they have their long axis parallel to the long axis of the body

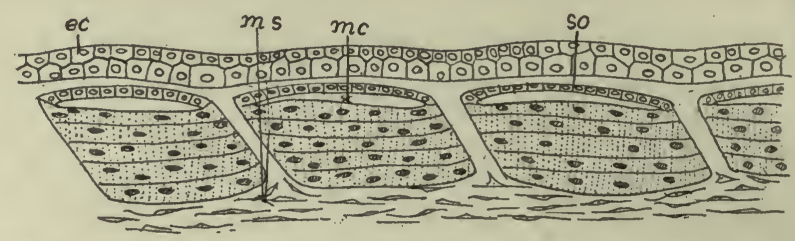

FrG. I34.-Myotomes of Amblystoma developing into muscle fibres. $e c$, ectoderm; $m y$, myocole; $m s$, mesenchyme; so, somatic layer which will form corium.

(fig. I34), each becoming multinucleate. Gradually the mass of the protoplasm becomes converted into contractile substance and the cell is converted into a muscle fibre, the nuclei being in the interior in the lower vertebrates, on the surface of the fibres in the mammals. In this way the splanchnic wall of each myotome is converted into a muscle;

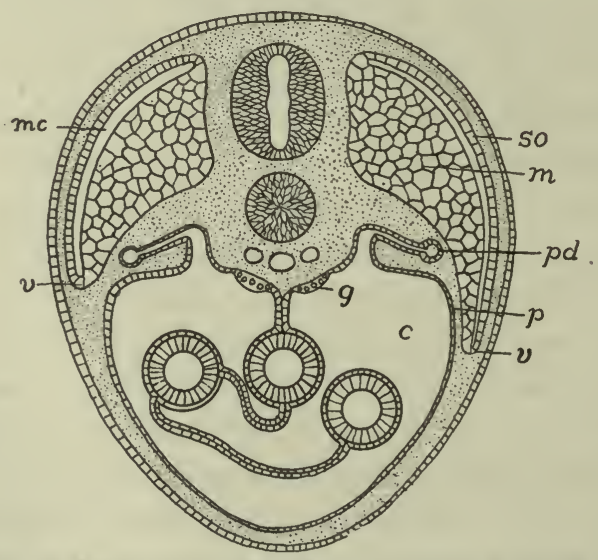

FIG. I35.-Diagram of descending myotomes. $c$, cœlom; $g$, gonad; $m$, splanchnic wall of myotome developing into muscles; $m c$, myocole; $p$, peritoneum; $p d$, pronephric duct; so, somatic wall of myotome; $v$, ventral border of myotome.

hence there are as many pairs of these primitive muscles as there were of myotomes. The somatic wall of the myotome does not participate in the muscle formation, but is gradually changed into mesenchyme and eventually gives rise to the corium of the skin. Mesenchyme also invades the spaces between the successive myotomes, develops into 
fibrous connective tissue, and forms the ligamentous connections (myosepta, myocommata) between the muscles of a side. This primitive condition is readily recognized in the trunk and tail of the lower vertebrates, and even in the adults of the more modified birds and mammals the original segmentation can be traced in the intercostal and rectus abdominis muscles. At first the myotomes lie at about the level of the notochord and spinal cord, but with growth they extend upward and to a greater extent downward, insinuating themselves between the skin and the walls of the cœlom and thus

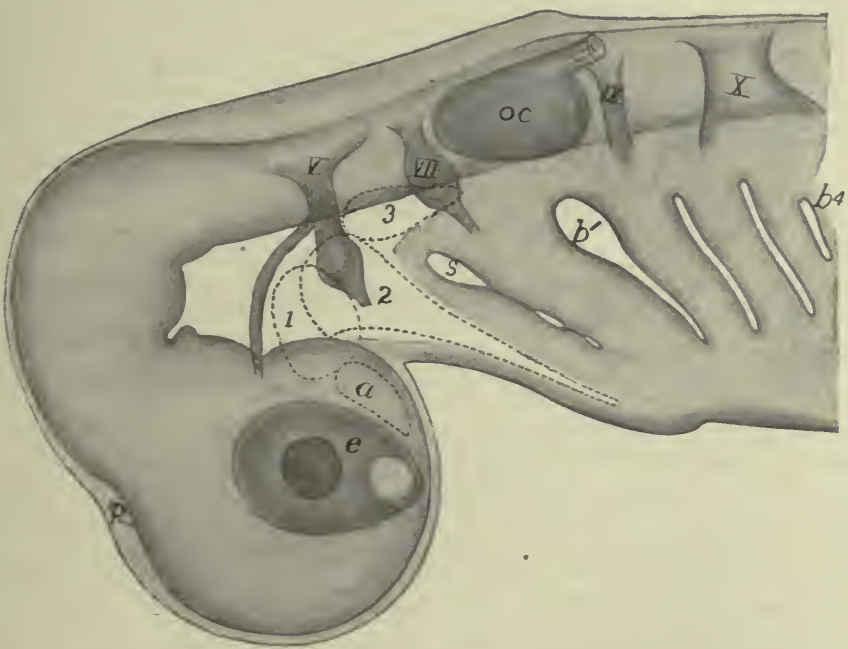

FIG. 136.- - Head of embryo dogfish (A canthias) seen as a transparent object, showing the preotic mesodermal somites, with dotted outlines, as $a, 1,2$, and $3 . b^{2}-b^{4}$, gill clefts, the fifth not yet open; $e$, eye; $o c$, otic capsule; $p$, epiphysial outgrowth; $s$, spiracle; $V$, tri geminal, VII facial-acustic; $I X$, glossopharyngeal; $X$, vagus nerves.

forming part of the somatopleure. The downward growth continues until the muscles of the two sides all but meet in the mid-ventral line, the intervening space being occupied by connective tissue, the linea alba of the adult.

In the fishes the trunk and tail muscles formed in this way become divided horizontally into dorsal and ventral portions; the epaxial and hypaxial muscles, the line of division which follows more or less closely the lateral line, being marked by a partition of connective tissue already mentioned (figs. 30, I3I). These plates of muscle do not retain their flat ends in the adult, but one end becomes conical and fits into a corresponding hollow in the next plate. In the tail of the amphibia 
epaxial and hypaxial muscles are clearly recognizable, but farther forward the hypaxials are greatly reduced, and in the amniotes the reduction is carried so far that the hypaxial muscles, greatly modified, can only be recognized in the cervical and pelvic regions.

In the head the developmental conditions are more complicated than in the trunk, our information being most complete with regard to the ichthyopsida. Here, in the region which develops into the head, ten cœlomic pouches are developed (in amniotes the number is apparently twelve). These are known by number, except that the most anterior, which was not known when the numbers were applied is called $A$. These cœlomic cavities (also known as head cavities) differ from the

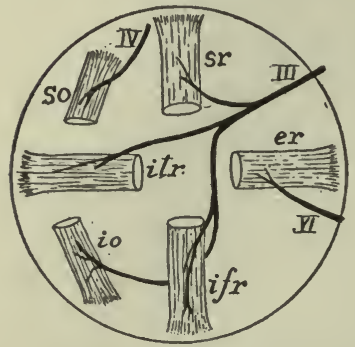

FIG. I37.-Diagram of the eye muscles of the right eye, seen from the medial side. er, external rectus; ifr, inferior rectus; io, inferior oblique; $i t r$, internal rectus; so, superior oblique; $s r$, superior rectus; $I I I$, coulomotor; $I V$, trochlearis; $V I$, abducens nerves. myotomes farther back in having no undivided portion of the cœlom below, corresponding to the hypomeral zone, a difference possibly due to the existence of visceral clefts in this region (fig. I36).

Four of these cavities lie in front of the ear. Of these $A$ disappears completely, its cells joining the mesenchyme, while the other three give rise to the 'eye muscles' which move the eye-ball. Without going into all of the details, I, which lies in front of the mouth, gives rise to the superior oblique muscle; 2 , which lies in the region of the jaws, forms four muscles, the inferior oblique and three of the rectus muscles (in some forms also a retractor bulbi), while 2 , in the hyoid region, develops the external rectus. This method of origin explains the distribution of the eyemuscle nerves to be described later, each nerve supplying only the derivatives of a single myotome. Several of the other head myotomes disappear in development, while the posterior form the so-called hypoglossal musculature (fig. ${ }^{2} 3^{8}$ ).

In the above account there is given merely the origin of the contractile tissue of the muscles. To this other parts of connective tissue are added. Mesenchyme cells invade the masses of muscle fibres, forming envelopes (perimysium) which bind the fibres intobundles (fasciculi) which, in turn, are united by other envelopes, the fascia. These connective-tissue envelopes are extended beyond the contractile tissue and form the cords or tendons by which the muscle is attached to 
other parts. One point of attachment, the origin, is fixed, that to the part to be moved is called the insertion. Tendons may be long and slender, allowing the muscle to lie in or near the trunk, while the part to be moved is in the appendage. Again they may form broad flat sheets (aponeuroses), and these may occur not only at the ends but in the middle of a muscle. Not infrequently parts of tendons may ossify, as in the patella or in the 'drum-stick' of the turkey. Small rounded ossifications of this kind are called sesamoid bones. In a few cases the parietal muscles are without attachment, but form rings which are used to diminish the size of an opening (sphincter muscles).

Muscles vary greatly in shape. They are usually short and flat in the trunk, prismatic or spindle-shaped in the appendages. They may be simple or they may have several 'heads' or points of origin (biceps, triceps, etc.), or several points of insertion as in pinnate or serrate muscles. Again, there may be two or more contractile portions (bellies) in a muscle, separated by a tendon or aponeurosis.

Usually muscles are arranged in antagonistic groups, the action of one being the opposite of its antagonist. Thus there are flexors to bend a limb, extensors to straighten it; elevators to close the jaw, depressors to open it; sphincters working against dilators, etc.

Only a few points in the progressive modifications of the primitive musculature described above can be mentioned here, partly from lack of space, partly from deficient knowledge. There are great difficulties in tracing exact homologies through the different groups of vertebrates, on account of their very different functions in the separate classes and their great variability, even in the same family. The best test of homology is nerve supply, every muscle derived from any one myotome being innervated by branches of the nerve originally connected with the segment, as is beautifully illustrated in the case of the eye muscles as mentioned above. Next in importance are origin and insertion of the muscles, while the work done by the muscles is of little value. Differentiations from the primitive condition may take place in various ways. A single muscle may split into layers or it may divide longitudinally into two or more distinct muscles, or transversely into two successive portions. On the other hand, two muscles, different in origin, may fuse, while with loss of function of a part, its muscles may degenerate or entirely disappear. Muscles may wander far from their point of ontogenetic origin and become connected with parts widely remote, a condition strikingly illustrated in the facial muscles of the 
higher mammals, where nerve supply still shows the original history.

In the ichthyopsida the trunk muscles clearly show their myotomic origin, but even here there are tendencies to division and specialization. The ventral muscles on either side of the body cavity of the amphibia (fig. I40) are divided into a lateral oblique and a medial rectus system, the rectus muscles of the two sides being separated by the linea alba already referred to. The rectus muscles, in turn, become divided into successive groups, a rectus abdominis in the abdominal region, extending from the pelvis to the sternum; a sternohyoid from the

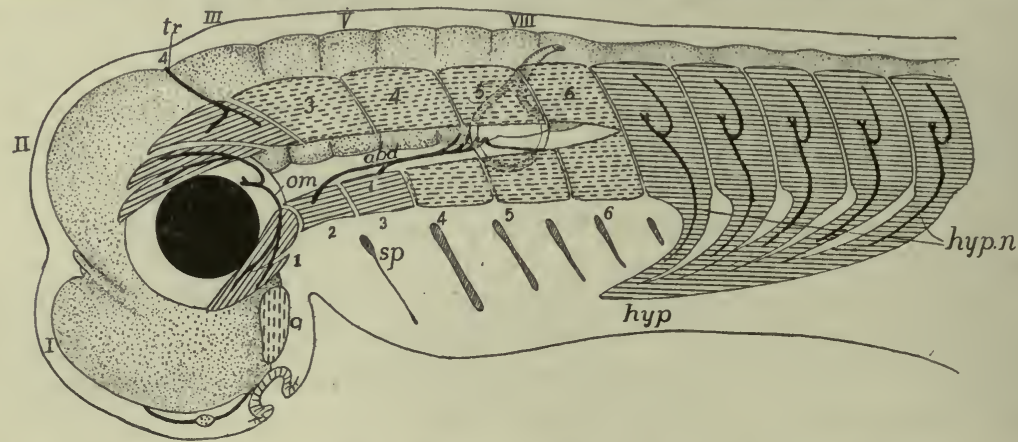

FIG. 138.-Diagram of muscle segments in head of embryo vertebrate, based upon a shark, after Neal. The anterior myotomes tend to divide into dorsal and ventral moieties; persistent myotomes lined, transient with broken lines; central nervous system dotted, nerves black. $a$, premandibular somite; $a b$, abducens; nerve, hyp, hypoglossal musculature; hypm, hypoglossal nerves; om, oculomotor nerve; $s p$, spiracle; $I-6$, first six somites $(4,5,6$, functional in Petromyzon); $I-V I I I$ neuromeres.

sternum to the hyoid bone, and a geniohyoid from the hyoid to the tip of the lower jaw. The oblique region is also divided into three layers (obliques and transversus) characterized by the direction of the fibres. In the higher vertebrates, with the appearance of well developed ribs, the oblique muscles furnish the two layers of intercostal muscles, extending from rib to rib, and in front of the ribs they form the scalene muscles, extending from the ribs along the side of the neck, and the sternocleidomastoid, from the breast bone and clavicle to the skull. In the non-placental mammals a strong pyramidalis muscle extends, ventral to the rectus, from the inner side of the marsupial bones to the sternum, but disappears with these bones.

The dorsal muscles are more conservative, undergo less modification than those just mentioned, and always show, more or less clearly, their metameric nature. They become connected with various parts of the vertebræ and with the ribs, and are correspondingly divided into 
different groups. Thus the spinales connect the spinous processes, the transversales the transverse processes of the successive vertebræ, while the transverso-spinales extend from the transverse process of one vertebra to the spinous process of the next. In the higher vertebrates the anterior spinalis, connecting the first vertebra with the skull, is divided into several rectus capitis muscles. The longissimus dorsi group extends from the pelvis to the head, lying on either side in the angle between spinous and transverse processes. It may be differentiated into separate muscles - a longissimus dorsi proper in the lumbar region, an ileo-costalis inserted on the dorsal part of the ribs, and a longissimus capitis along the side of the neck to the temporal region of the skull.

The muscles which move the appendages are divided into the intrinsic, which are located in the limb itself and have their origin either from the bones of the limb or from the supporting girdle, and the extrinsic, which have their origin on the trunk and are inserted on the girdle or the base of the limb. The latter move the limb as a whole,

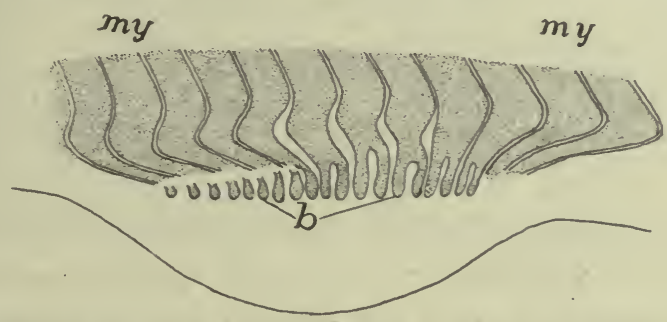

FIG. 139.-Budding of muscles of appendage from myotomes in Pristiurus, after Rabl $b$, muscle buds; $m y$, myotomes.

while the intrinsic bend the limb on itself. As would be expected from the motions of the fins, the intrinsic muscles are hardly noticeable in the fishes, the various movements being accomplished by the extrinsic group. These latter are divided into protractors which draw the member forward; retractors which pull it back against the body; levators which lift it and depressors which pull it down.

In those vertebrates which are sufficiently known the first traces of the development of the musculature of the appendages are the appearance of two buds (fig. I39) from the ventral border of a varying number of myotomes in the region of the developing limb. These buds proliferate cords of cells which soon lose their distinctness and form a blastema from which the intrinsic muscles arise, the definitive muscles being innervated by as many spinal nerves as there are contributing myotomes. The extrinsic muscles arise directly from the myotomes. 
With the development of the paired appendages into organs for the support of the body (tetrapoda) the skeleton of the leg is converted into a series of levers, and the intrinsic muscles are correspondingly differentiated and developed. Details cannot be given here as there are so many modifications, but they may be grouped as flexors, which bend the limb or its parts; extensors which straighten it, and rotators which turn it on its axis. These undergo the most modification in the peripheral regions, the muscles of the upper arm and thigh being more constant in character and position. Even more constant are the extrinsic muscles, which may be grouped as in fishes. Most prominent

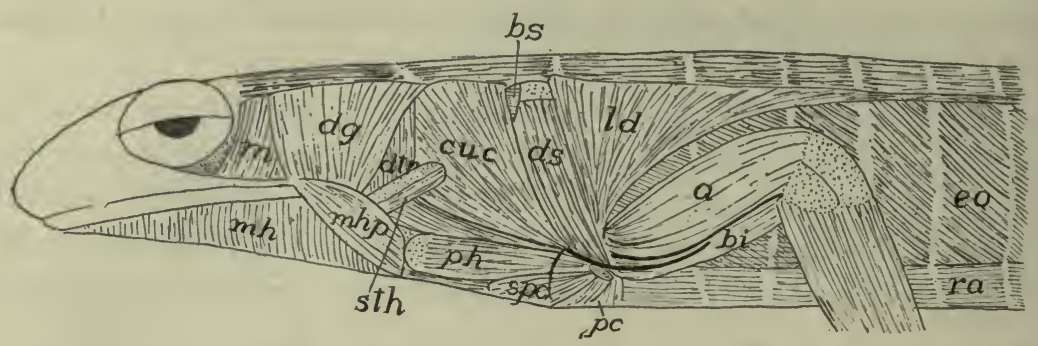

FIG. I40.-Superficial muscles of anterior part of Salamandra maculata, after Fürbringer. $a$, anconeus; $b i$, humero-branchialis inferior (biceps); $b s$, levator scapulæ; cuc, cucularis; $d t r$, dorso-trachealis; $d g$, digastric; $d s$, dorsalis scapulæ; eo, external oblique; $l d$, latissimus dorsi ; $m$, petro-tympano-maxillaris (masseter); $m h$, mylohyoid; $p c$, pectoralis; $p h$, procoraco-humeralis; $r a$, rectus abdominis; $s p c$, supracoracoid.

of the levators of the fore limb are the trapezius and levator scapulæ muscles, while the pectoralis and serratus anterior act as depressors; the sternocleidomastoid and the levator scapulæ anterior act as protractors, the pectoralis minor and the latissimus dorsi are their antagonists. In the pelvic region the extrinsic muscles are less differentiated in function. The pectineus and adductors act as protractors, the pyriformis counteracts them; the limb is drawn toward the middle line by a pubofemoralis, while the gluteus muscle acts as a retractor and elevator.

\section{THE VISCERAL MUSCLES.}

In the gill-bearing vertebrates a special system of muscles is developed in connection with the visceral arches, which have to open and close the visceral clefts, including the mouth. With the loss of the gills some of these muscles are lost while others become changed in function, several retaining their connection with the hyoid. These visceral muscles may be divided into two sets according as they are derived 
from muscles which originally ran in a transverse (circular) or in a longitudinal direction.

To the first category belong the epibranchial muscles, the subspinales and interbasales, which lie in the dorsal part of the branchial region, while the coraco-arcuales are in the ventral or hypobranchial half. The most anterior of the circular group are those which open (digastric or depressor mandibulæ) or close (adductors) the mouth, and the mylohyoid which extends between the two rami of the lower

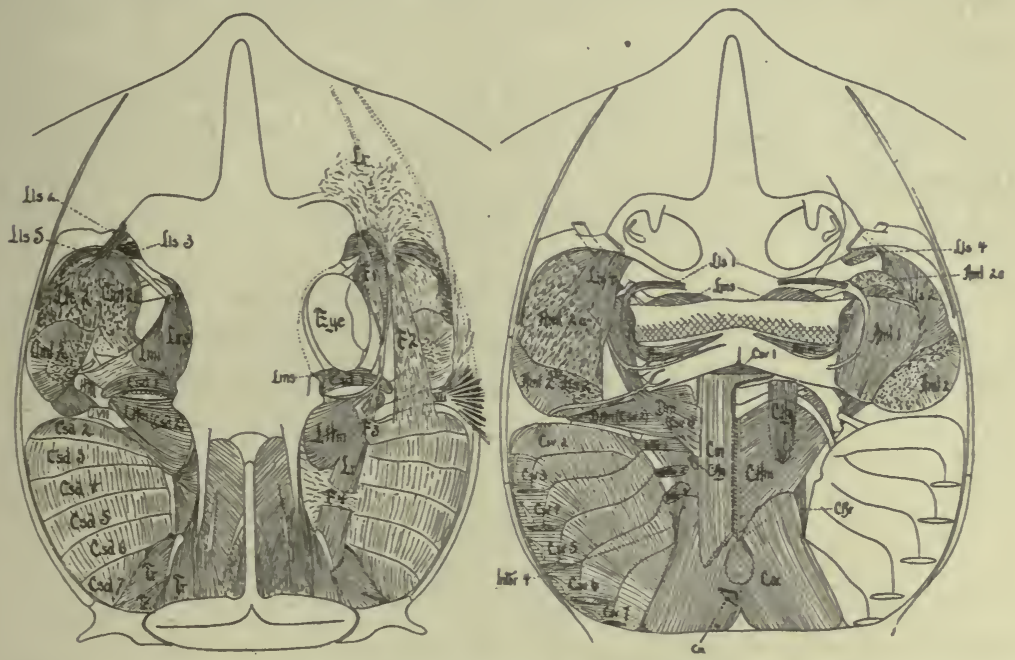

FIG. I4 I.-Dorsal and ventral head muscles of the skate (Raia), after Marion; the dorsal muscles more deeply dissected on the left side, the ventral on the right. $a m b$, lateral mandibular adductors; $a \mathrm{~mm}$, medial mandibular adductors; csd, csv, dorsal and ventral constrictors; $\mathrm{cm}$, coraco-mandibularis; chy, coraco hyoideus; chm, coraco-hyomandibularis; $c b r$, coraco-brachialis; $c a c$, common coraco-arcual; intbr, interbranchials; $l l s$, superior labial levators; $l m i$, levator of lower jaw; $l \mathrm{hm}$, hyomandibular levator; $l \mathrm{r}$, levator of rostrum; $t r$, trapezius; VII, seventh nerve; $d m$, depressor mandibulæ (digastric).

jaw. Usually there are several adductors, known as masseter, temporalis, pterygoideus, accordingly as they have their origin from different parts of the skull. The longitudinal muscles are largely confined to small slips which pass from one arch to the next. In the amphibians these various muscles undergo considerable differentiation, while in the amniotes this is in part carried farther, in part is reduced on account of the loss of branchial respiration and the degeneration of the parts connected with it. Hence the most noticeable of the visceral muscles are those connected with opening and closing the mouth. 


\section{THE DERMAL MUSCLES.}

The muscles already mentioned are connected with the skeleton, but in the higher vertebrates a dermal musculature appears in which the muscles are inserted in the skin, although they are derived from the skeletal muscles. This system is poorly developed in the amphibia, and increases in the reptiles and birds, where it serves to move the scales, scutes and feathers. It is especially noticeable in the snakes, where it is largely concerned in the movement of the scutes in creeping.

The system acquires its greatest development in mammals. In the marsupials, for instance, there is an extensive dermal musculature, the panniculus carnosus, covering a large part of the body and the appendages. It is by means of this that various mammals twitch the

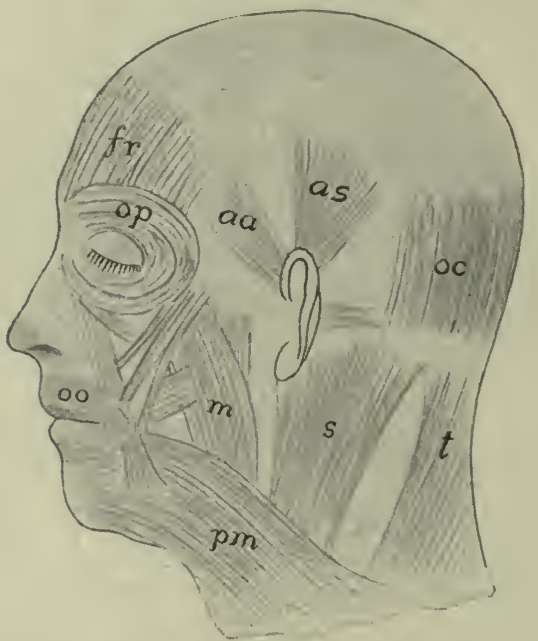

Frg. 142.-Principal dermal muscles of head of man. aa, as, auriculares anterior and superior; $f$, frontalis; $m$, masseter; $o c$, occipitalis; $o o$, orbicularis oris; $o p$, orbicularis palpebrarum; $p m$, platysma myoides; $s$, sternocleidomastoid; $t$, trapezius.

skin to dislodge insects, etc., while armadillos and hedgehogs roll themselves into a ball by means of a part of the layer. In the primates the dermal muscles are restricted to the neck (platysma myoides) and the head, all parts of them being supplied by the facial nerve belonging primitively to the hyoid region. The platysma extends forward from the neck and by growth and division gives rise to the muscles of expression-the orbiculares which close the lips and eyelids, the muscles 
which lift lips, nose and lids and those which move the ears-muscles which as a whole have their highest development in man (fig. 142).

\section{THE DIAPHRAGM.}

The diaphragm -is a transverse voluntary muscle which crosses the body cavity of the mammals just behind the pericardium and lungs. Its muscles are in part derived from those of the back, in part from the rectus muscles of the lower surface. Various attempts have been made to recognize similar muscles in the lower vertebrates, in some cases with considerable success. Its development is outlined in the section on the colom (p. I23). The diaphragm is dome-shaped and is attached to the vertebral column and to the ribs. It is traversed by the œsophagus and the large arterial and venous trunks. In some vertebrates the muscular portion is confined to the margin, the centre being membranous; in others the muscle fibres extend across it. Contraction of the muscles flatten it, thus enlarging the pleural cavities and drawing air into the lungs, thus aiding in respiration. It is supplied by the phrenic nerve.

\section{ELECTRICAL ORGANS.}

It is well known that the contraction of a muscle causes the discharge of a minute amount of electrical energy, so it is not surprising that in certain cases muscles are modified into electrical organs. The known cases occur only in elasmobranchs and teleosts. The discharge is weak in most species, but is strong in Torpedo and Gymnotus. In all but Malapterurus the electrical organs are clearly modified muscles, situated in the head in Torpedo and Astroscopus, in the trunk of Gymnotus, and in the tail of Raia, the nerve supply being correspondingly varied. Thus in Torpedo the seventh, ninth and tenth cranial nerves are concerned, while in Gymnotus and the skates the supply is from the spinal nerves. Malapterurus is peculiar in that the organ is in the integument and has been supposed by some to arise from modified glands. It is more probable that here as elsewhere it is derived from the muscles, as the organ is under control of the will; the development has yet to be studied. This diversity of origin clearly shows that the electrical functions have been separately acquired in the different species.

The organs are composed of a large number of electrical plates 
(electroplaxes) arranged at right angles to the axis of the primitive muscle, each derived, where the history has been traced (Torpeda, Raia), from a primitive muscle cell. In the typical condition each plate consists of an outer electric layer, differentiated into a nervous side and a so-called nutritive side, with a middle striated layer between them, the latter in a few cases being weakly developed or absent. Nervous stimulation is always by motor roots leading to the nervous layer, the connexion corresponding to the nerve-end of a muscle cell. Numbers

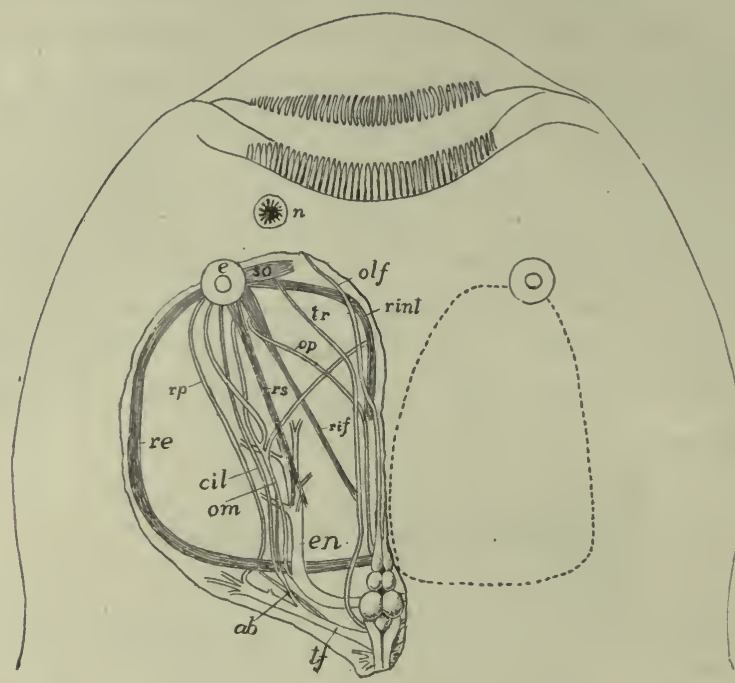

FIG. 143.- Head of Astroscopus y-groecum, after Dahlgren and Silvester. The dotted line on right shows extent of electric organ, on the left the eye-muscles, and nerves as forced out of place by the electric organ. $a b$, abducens; cil, ciliary nerve; $e$, eye; en, electric nerve; $n$, haris; olf, olfactory nerve; om, oculomotor; op, optic nerve; re, rif, rint, rs, external, inferior, internal and superior rectus muscles; $r p$, palatine nerve; so, superior oblique muscle; $t f$, trigeminal-facial nerve.

of these electroplaxes are included in a connective-tissue compartment with a gelatinous substance between them and all with their nervous layer turned in the same direction.

In Torpedo the organ apparently is derived from part of the jaw muscles and the prisms of plates are arranged vertically. In Astroscopus (fig. 143) it is supposed that the tissue comes from one of the eye muscles, while in Gymnotus the ventral trunk muscles are concerned and the columns of electroplaxes are horizontal. In the same fish the discharge is always in the same direction, e.g., in Torpedo from below upward. 


\section{THE NERVOUS SYSTEM.}

Nervous and sensory structures are closely related to each other, - and their distinction in the higher animals is the result of differentiation among cells which were originally both nervoús and sensory in character, and it is in this broader sense that the term nervous structures is used in these introductory paragraphs.

The nervous system primarily has to inform the animal of the conditions, good and bad, in the environment, to correlate this information and to regulate the motions so that advantage may be had of this knowledge. These facts have determined several features of the nervous system. Thus they have determined its origin in the ectoderm, the outer layer of the body, which comes into relation with the external world. Since this information has to be carried to internal parts, conducting tracts or nerves have arisen, while the correlating function has been localized in the body of the cells where incoming and outgoing tracts meet.

Most important of the primitive functions was the determination of the character of the food, which would lead to the greater aggregation of the nervous tissue around the mouth. As we have seen (p. II) the anlage of the central nervous system of the vertebrates occupies such a position.around the blastopore, or mouth of the gastrula, in the form of the neural plate. As the external surface of the body is most exposed to injury, the nervous structures, with the closure of the blastopore, have been protected by removal to a deeper position, through the rolling of the plate into a tube. The closure of the blastopore brings the two halves of the plate into close association with each other, making it a bilateral structure. With bilaterality comes the tendency of one end of the animal to take the lead, resulting in the concentration of nervous and sensory structures at the anterior end, which first comes in contact with foreign objects. In this way a brain has been specialized apart from the rest of the nervous system.

With the appearance of metamerism in the mesothelium and the development of muscles from the myotomes there results a serial repetition of motor nerves going to these, since each muscle must have its own nerve supply, while sensory nerves are the result of the sinking of the neural plate to a deeper position, as the sensory organs must be largely in the skin. 
The close association of sensory and motor nerves in the trunk region of vertebrates is not yet satisfactorily explained. The fact that in Amphioxus the two kinds of nerves are independent of each other throughout their course shows that the vertebrate condition is not primitive.

The infolding of the nervous plate has been described (p. II) and with that stage the present account begins. As the plate is broadest in front, the result is a larger anterior portion of the tube, the brain, while the rest of the tube gives rise to the spinal cord. Brain and cord constitute the central nervous system, while the nerves arising from the brain and cord form the peripheral nervous system.

\section{CENTRAL NERVOUS SYSTEM.}

The two halves of the neural plate are separated by a median band of non-nervous tissue, hence, when it is rolled into a tube, the midventral line-the floor plate-is thinner and differs from the side walls. With the closure of the tube (fig. I44, $A$ ) a similar roof plate appears,

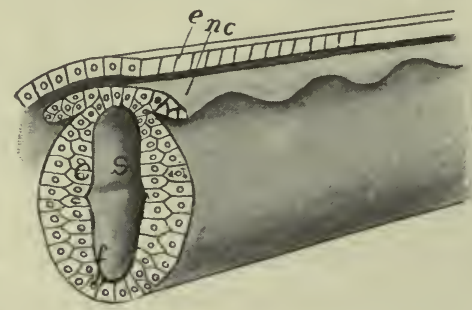

A

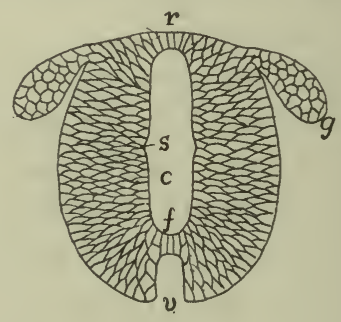

B

FIG. I44.- $A$, diagram of early spinal cord; $B$, later, showing increase in size and consequent ventral fissure. $c$, central canal; $e$, ectoderm; $f$, floor plate; $g$, anlage of spinal ganglion; $n c$, neural crest; $r$, roof plate; $s$, sulcus of Monro; $v$, ventral fissure.

while the lumen of the tube, the central canal, is oval in section, its side walls, consisting of embryonic nervous tissue, being thicker than roof or floor.

From the method of its formation it will be seen that the inner surface of the neural tube is homologous with the outer surface of the general epidermis of the body. The account given above is not exact for cyclostomes, teleosts and some ganoids, where the neural plate forms a keel extending below the surface, in which a central canal appears later, so that the final result is closely similar to the typical condition.

\section{The Spinal Cord.}

From this simple tube the spinal cord of the adult is developed by several modifications. The cells of the side walls proliferate rapidly, 
while those of roof and floor plates do not. As a result the sides soon extend downward on either side beyond the floor plate, thus forming a longitudinal groove, the anterior or ventral fissure of the cord, extending its whole length (fig. I44, B). The roof plate, on the other hand, is at first carried upward by the growth, thus increasing the vertical diameter of the central canal. Then the dorsal portion of the tube closes up-the exact steps are uncertain-and later the tissue along the line of closure is invaded by connective tissue and blood-ressels, the result being the dorsal or posterior fissure of the cord.

Besides the increase in the number of cells, the sides of the cord are modified in other ways. Those cells which line the cavity-floor, roof and sides-retain their epithelial character, never develop nervous structures, and are known as the ependyma. The remaining cells become differentiated in two directions. Some develop processes which surround and support the others, these forming the neuroglia ('glia'), while the others form the true nervous tissue-ganglion or nerve cells. In the primitive condition the primitive nerve cells have no connexion with distant points and hence cannot function. These connexions are established by protoplasmic outgrowths from each cell, these forming the fibres (dendrites or axons). Some of these extend directly outward from the cord as nerves (see below), but others run for a greater or less distance on the external surface of the cord, and since these have medullary sheaths (p. 20) and are consequently white, these tracts constitute the white matter of the cord, in contrast to the gray matter formed by the cell bodies and neuroglia.

In sections of the adult cord the gray matter has something of the shape of the letter $H$, its uprights forming the anterior and posterior horns or cornua, while the cross-bar extends above and below the central canal, from one side to the other. Physiological phenomena and matters of nerve origin lead to the recognition of a lateral cornu on either side, in the lateral prominence of gray matter. Since both dorsal and ventral cornua approach the surface of the cord to connect with the nerve roots described below, they divide the white matter into three tracts on either side, known as the anterior, lateral and posterior columns of the cord, each subdivided in the higher vertebrates into several bundles. As this white matter is composed of nerve fibres, it follows that these columns are the tracts by which nervous impulses are carried to and from the brain, the anterior columns leading from, 
the dorsal to the brain (ascending and descending tracts), while impulses travel in both directions in the lateral columns.

In fishes the cord tapers regularly to the tip, but with the development of legs in the terrestrial vertebrates the cord is considerably enlarged where the nerves to the limbs are given off, the enlargements bearing some ratio to the size of the limb. In the early stages the spinal nerves leave the cord at right angles to its axis. With' growth

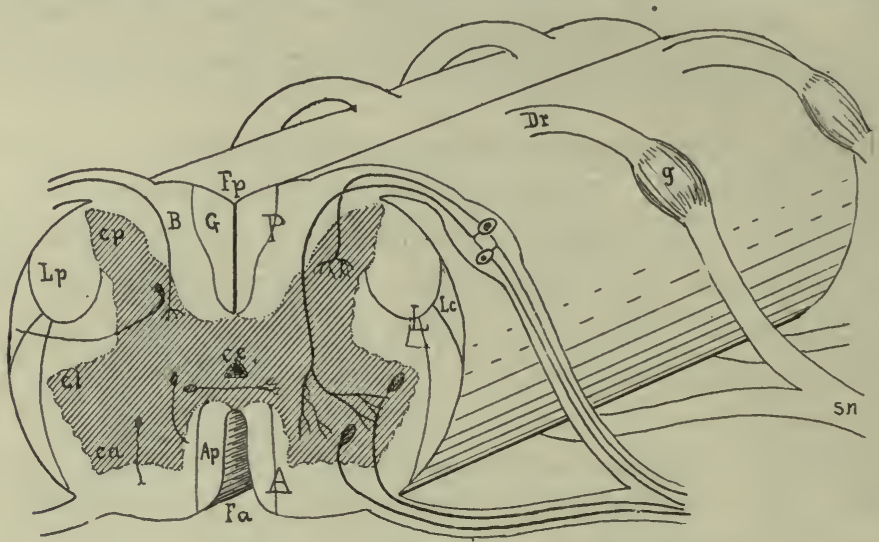

FIG. I45.-Diagram of spinal cord and nerve roots; gray matter shaded. $A, L, P$; anterior, lateral and posterior columns; $A p$, anterior pyramidal tract; $B$, column of Burdach, $c c$, central canal; $c a, c l, c p$, anterior, lateral and posterior cornua; $D r$, dorsal root; $F a, F p$, anterior and posterior fissures; $G$, column of Goll; $g$, ganglion of dorsal root; $l c$, lateral cerebellar tract; $l p$, lateral pyramidal tract; $s n$, spinal nerve.

the angle changes since the peripheral parts increase more in length than does the cord. The result is that the posterior nerves are very oblique and in the hinder part of the spinal canal they form a bundle of parallel nerves, the cauda equina. Another result of the unequal growth may be the drawing out of the hinder end of the cord into a slender non-nervous thread, the filum terminale.

\section{The Brain.}

The spinal cord throws light on the extremely complex brain. Here, as in the cord, there is primitively a tubular structure, with roof, floor and sides, and with nerves connected with it which recall those of the cord. In its development, as stated above, the brain from the first is larger than the cord. It early has three enlargements separated by two constrictions, the third enlargement passing gradually into the cord. These enlargements are called, from in front backward, fore-brain, 
mid-brain and hind-brain, the constriction between mid- and hindbrains being the isthmus. In the sides, as in the cord, two zones may be recognized, dorsal and ventral, separated internally by a groove, the sulcus of Monro, which lies at about the middle of the tube. At the extreme anterior end a small region, the optic recess, is wedged in between the two zones on either side, the end of the tube

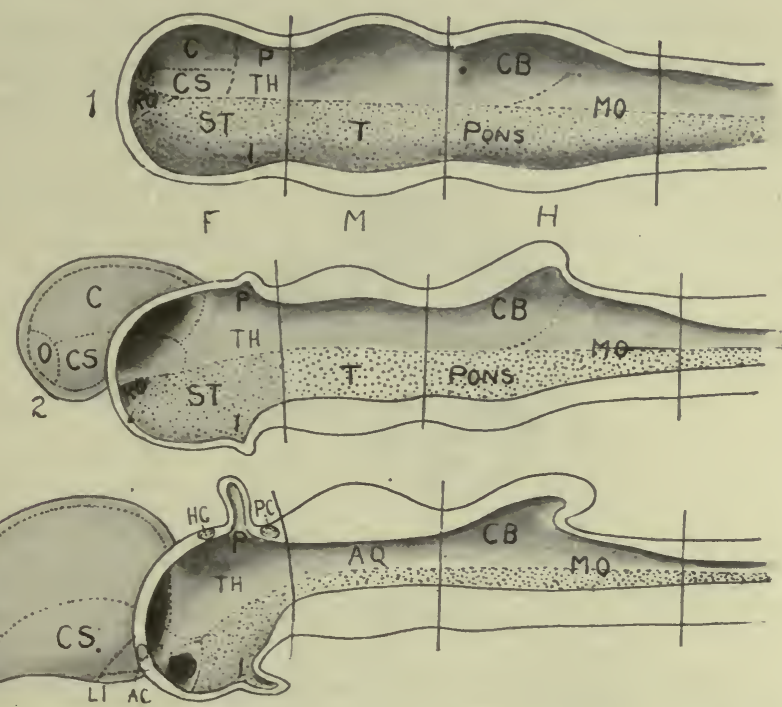

Fig. I46.-Diagrams of (I) primitive brain. (2) an intermediate stage, and ${ }^{\top}(3)$ with the definitive parts. (Compare 3 with fig. I47). $A Q$, aqueduct; $A C$, anterior commissure; $C$, cerebral region; $C B$, cerebellum; $C S$, corpus striatum; $H C$, habenular commissure; $I$, infundibulum; $L T$, lamina terminalis; $M O$, medulla oblongata; $O$, olfactory region; $P$, epiphysial region; $P C$, posterior commissure; $R O$, optic recess; $S T$, subthalamica; $T$, tegmentum; $T H$, thalamus. Dorsal zone plain, ventral zone dotted.

just above the recesses being the lamina terminalis. The most marked modifications in converting the primitive into the adult brain take place in the dorsal zone.

In the fore-brain the anterior part of the dorsal zone on either side forms an outgrowth which rapidly increases in size, the two eventually forming a pair of hollow vesicles, the cerebral hemispheres (telencephalon, prosencephalon) which extend far beyond the lamina terminalis. In the wall of each hemisphere may be recognized a basal ganglionic portion, the corpus striatum, while the rest of the wall is the pallium or mantle. An olfactory lobe (rhinencephalon) grows out from the lower anterior part of each hemisphere to meet 
the olfactory epithelium (see sense organs), and into this a portion of the cavity (ventricle) of the hemisphere may extend (fig. I46).

Considerable differences exist in the olfactory lobes. In some cases they are directly continuous with the hemispheres, but they may be prolonged, each having two portions, a narrower stalk, the tractus olfactorius, and a distal enlargement, the bulbus olfactorius. The true olfactory nerve takes its origin from the end of the bulb or its homologue (for details see cranial nerves).

The ventral zone and posterior part of the dorsal zone of the forebrain, after the differentiation of the telencephalon, forms the thalamencephalon ('twixt-brain, diencephalon). Its sides, the optic

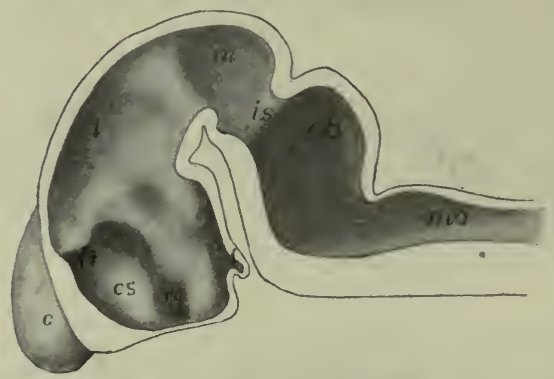

FIG. 147.-Half of model of brain of embryo pig, ${ }_{5} \mathrm{~mm}$. long. (Compare with fig. I 46,3 .) $c$, cerebrum; $c b$, cerebellum; $c s$, corpus striatum; $i$, infundibulum; is, isthmus; $f i$, interventricular foramen; $m$, mesencephalon; mo, medulla oblongata; $t$, thalamus.

thalami, remain without marked modification, but its floor and roof form median outgrowths, corpus pineale, epiphysis, etc., above, infundibulum below-to which reference will be made again later.

In the mid-brain there is little modification except a thickening of the walls forming a pair of prominences, the optic lobes, or corpora bigemina (in mammals two pairs of lobes, corpora quadrigemina) on the dorsal surface. The mid-brain of the adult is also called the mesencephalon (fig. I46).

In the hind-brain the great modifications occur again in the dorsal zone. Its dorsal portion extends itself upward and backward as a broad lobe which tends to arch over the rest of the hind-brain. This outgrowth forms the cerebellum or metencephalon, while the remainder of the hind-brain constitutes the medulla oblongata or myelencephalon (fig. I46).

Thus there arise in the adult brain five regions-telencephalon, thalamencephalon, mesencephalon, metencephalon and myelencephalon -derived from the primitive three. These usually retain in the interior 
the cavity of the primitive three (continuation of the central canal of the spinal cord), but modified in different ways. The cavity in the primitive fore-brain is divided with the outgrowth of the hemispheres into three chambers known at ventricles, a pair of cerebral ventricles in the hemispheres and a third ventricle in the thalamencephalon. The paired ventricles are connected with the third by a pair of narrower passages, the foramina of Monro (for. interventriculares). In the higher vertebrates the cavity of the mid-brain becomes reduced to a narrow tube, the aqueduct (or iter), but in the lower classes (fig. 156) this expands dorsally into a cavity, the epicœle, in the upper part of the optic lobes. The aqueduct terminates behind in the fourth ventricle which lies in the hind-brain, extending forward beneath the cerebellum and gradually diminishing in the medulla to the central canal of the spinal cord. Sometimes there is a prolongation of the fourth ventricle into the cerebellum (metacœle, fig. ${ }_{56} 6$ ).

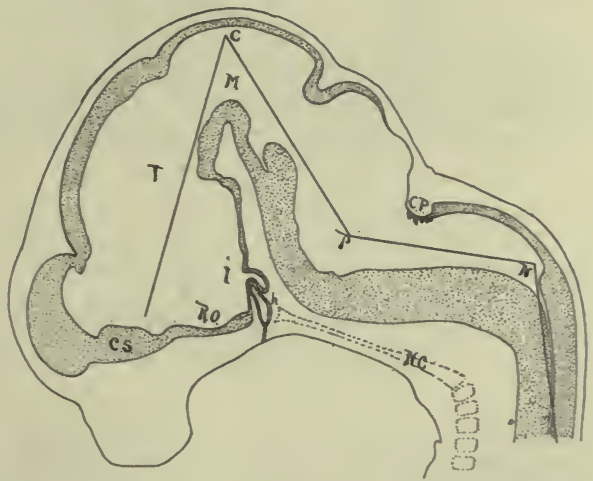

FIG. I 48.-Median section of brain of pig $15.5 \mathrm{~mm}$. long, showing flexures of the brain $C$, principal flexure; $c s$, corpus striatum; $C P$, chorioid plexus of fourth ventricle; $h$, hypophysis; $i$, infundibulum; $M$, mid-brain; $N$, nuchal flexure; $P$, pontal flexure; $R O$, optic recess; $T$, 'twixt-brain.

So far the brain has been treated as if it were a continuation of the spinal cord in a straight line. In reality, by unequal growth in dorsal and ventral zones, it becomes flexed in the vertical plane. In the lower vertebrates, these flexures never attain great prominence and largely disappear in the adult. They are more developed in the higher groups and persist throughout life. Most constant is the primary flexure in the mid-brain, by which the derivatives of the fore-brain are bent downward at a right angle (or more) to the axis of the rest. Second to appear is the nuchal flexure in the hinder part of the medulla ob- 
longata, which also bends in the same direction. The pontal flexure, beneath the cerebellum, bends in the opposite direction and thus tends to counteract the other two. Nuchal and pontal flexures are at best but weakly developed in the ichthyopsida and all are practically obliterated in the adult, but in the amniotes they are increasingly developed and persist through life (fig. I48).

The brain, like the spinal cord, is composed of nerve cells (gray matter) and fibres (white matter), but their arrangement is exceedingly complicated and but the slightest outline of their distribution can be attempted here, in connection with the general account of the regions of the brain.

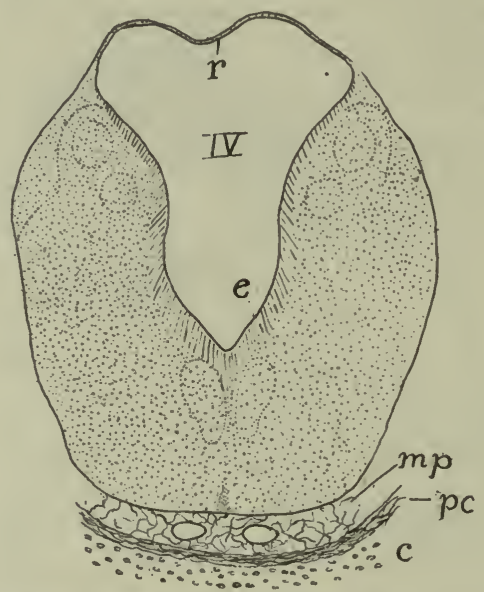

FIG. I49.-Cross-section of medulla of Acanthias embryo, $60 \mathrm{~mm}$. long, showing the greatly broadened roof plate and, below, a bit of the meninx of the nervous system. $c$, cartilage of basal plate; $e$, ependyma; $m p$, meninx primitiva; $p c$, perichondrium (endorhachis); $r$, roof plate.

The myelencephalon is most nearly like the spinal cord of any part of the brain. It is triangular in outline, viewed from above, and is widest anteriorly, due in part to the separation of the side walls by the great development of the roof plate over the fourth ventricle. Bloodvessels press against the roof, carrying parts of it before them into the ventricle, thus forming the chorioid plexus of the fourth ventricle, a means of introducing nourishment into the brain. (Usually in dissections this roof is torn away, leaving a triangular or rhomboid opening into the fourth ventricle-fossa rhomboidea). The floor plate in this region is obliterated by the development of numerous nerve centres - 'nuclei' or ganglia-in the walls, some closely connected with the 
fibre tracts soon to be mentioned, some with nerves arising from this region.

Most noticeable of these ganglia are the olivary bodies (oliva) near the roots of the hypoglossal or first spinal nerves; the nuclei of the cuneate and slender funiculi connected with the posterior columns of the cord; the eminentia medialis in the floor of the fourth ventricle, connected with the anterior and lateral columns; and the tuber acusticum, an enlargement connected with the eighth nerve; its anterior end in the ichthyopsida is specialized as the lobe of the lateral line system

The cerebellum is developed from the dorsal zones and the roof plate, the latter invaded by nerve cells from the sides. In front it dips deeply into the fourth ventricle, its anterior portion being vertical and together with part of the roof of the isthmus, forming the valve of

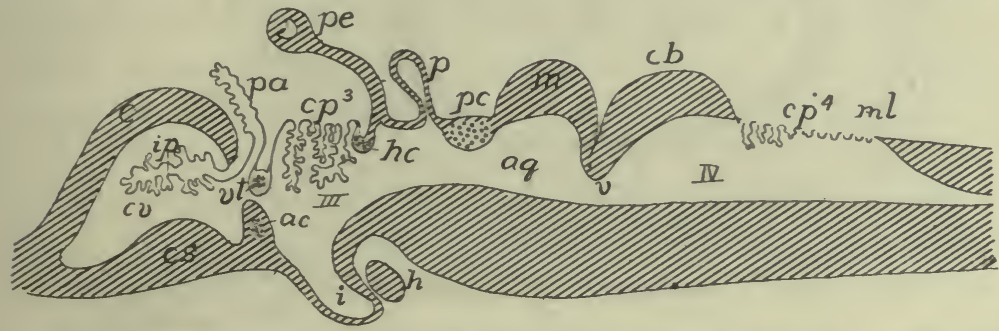

FIG. I50.-Diagrammatic longitudinal section of brain. ac, anterior commissure in lamina terminalis; $a q$, aqueduct; $c$, cerebrum; $c b$, cerebellum; $c p$, chorioid plexus; $c s$, corpus striatum; $c v$, cerebellar ventricle; $h$, hypophysis; $h c$, habenular commissure; ip, inferior chorioid plexus; $m$, mesencephalon; $m l$, myelencephalon; $p$, pinealis; $p a$, paraphysis; $p c$, posterior commissure; pe, parietal eye; $v$, valve of Vieussens; $v t$, velum transversum with aberrant commissure.

Vieussens (velum medullare anterius, fig. I50). In the ichthyopsida and lower reptiles there is no special differentiation of parts in the cerebellum, but in the higher reptiles and in the birds a central portion, the vermis, and a pair of lateral lobes, the flocculi (fig. I6r) occur. In the mammals the cerebellum is still farther enlarged, chiefly by the development of large cerebellar hemispheres between vermis and flocculi, the latter being forced by them to the lower side of the cerebellum. In the walls of each hemisphere, besides others, there is a large nerve centre, the nucleus dentatus, connected with the posterior peduncle of the cerebellum to be mentioned shortly, and with the fibres which go farther forward in the brain.

The mesencephalon is relatively largest in the lower vertebrates, less conspicuous and tending to be covered by cerebrum and cerebellum in the higher groups. On its dorsal surface are the two optic lobes (transversely divided in the mammals) each connected with an optic 
tract leading to the eye of the opposite side. In the lower groups the lobes contain an epicœle (p. I43), but in the higher they are solid, the cavity being reduced to the aqueduct. The floor of the mid-brain is formed of large fibre tracts (see below), the floor plate having been invaded by their fibres.

In the thalamencephalon ('twixt-brain) the lateral walls are thickened, the dorsal zones developing a nerve centre, the optic thalamus,

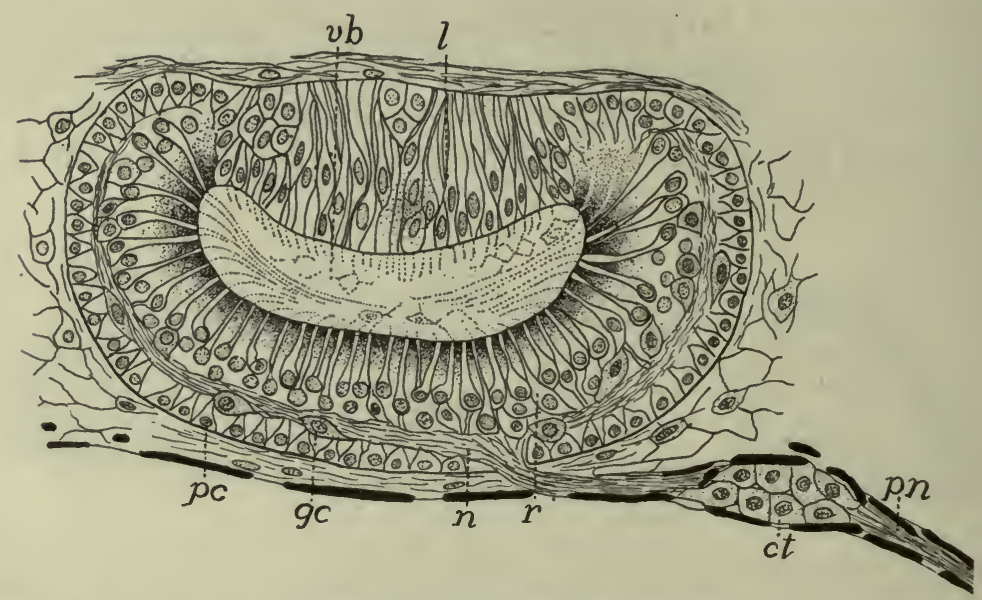

FIG. I5I.-Parietal, eye of Anguis fragilis, after Nowikoff. $c t$, connective tissue cells around nerve; $g c$, ganglion cells; $l$, lens; $n$, nerve fibres; $p n$, parietal nerve; $p c$, pigment cells; $r$, retinal cells; $v b$, vitreous body.

on either side. These are ganglionic and are closely related to the corpora striata. Frequently the thalami of the two sides touch or even unite above, forming the so-called soft commissure (commissura mollis, fig. I52)-really not commissural in character. Still more dorsal is a small habenular ganglion on either side, in front of the pinealis to be described in a moment.

Under the head of epiphysial structures are several parts developed in the roof plate of the primitive fore-brain. At the junction of cerebral hemispheres and twixt-brain (fig. I 50) there is an internal epithelial fold, the velum transversum, depending from the cerebral roof. In front of this an outgrowth, the paraphysis, arises on the top of the brain in nearly all vertebrates. It is non-nervous and apparently is an extra-ventricular chorioid plexus with secretory functions. The other epiphysial structures belong to the 'twixt-brain and consist of a parietal organ and a pinealis. Both arise from the roof between the 
habenular ganglion and the posterior commissure, at the boundary between 'twixt- and mid-brains, sometimes as two distinct structures, sometimes as the result of division of a single outgrowth of the roof. The anterior of these is the parietal organ or eye; the other the pinealis or epiphysis proper. The two vary in development in different vertebrates, the parietal eye being well-marked only in cyclostomes, Amia, teleosts and most lizards (fig. I5I), while the pinealis is almost invariably present.

In its fullest development in lizards and Sphenodon the parietal organ extends as a slender stalk, hollow at first, through the parietal foramen of the skull, expanding beneath the skin to a vesicle, above which the integument is usually thin and transparent, forming a physiological cornea. The distal wall of the vesicle is thickened in the middle, forming a lens, while the cells of the proximal side elongate, each becoming differentiated into a distal, rod-like end and a proximal portion which contains the nucleus and is connected with a nerve fibre. Pigment is deposited between these cells so that the whole forms a retina. An important point, to be better appreciated after the consideration of the paired eyes, is the fact that these parietal eyes are like those of most invertebrates in having no inversion of the retina. How far these eyes are actually functional is not settled. Even in Sphenodon, where it is best developed, experiments have resulted in no decided reactions.

In other vertebrates the parietal organ does not pass outside the skull, and even may not appear transitorily in development. The pinealis to some extent may take its place and often shows, as in certain lizards, traces of a visual structure. In the anura its tip approaches the skin and later is cut off from the brain by the development of the skull, forming the so-called frontal organ, visible from the exterior. Pineal and parietal organs differ in their nerve supply, the parietal being connected with the superior commissure of the 'twixt-brain, the pinealis and its derivatives with the posterior commissure. In the higher vertebrates the epiphysial structures are completely covered by the backward growth of the cerebrum. The large parietal foramina in many extinct reptiles would seem to indicate that they had well developed parietal or pineal organs. The roof of the brain in this region, behind the lamina terminalis, also gives rise to a chorioid plexus like that of the fourth ventricle, a part of which invades the third ventricle and another portion, the inferior plexus, sends branches 
through the foramina interventriculares into the ventricles of the hemispheres, thus providing for a blood supply on the interior of these structures (fig. I50).

The floor of the diencephalon remains thinner behind the optic recess, a portion of it becoming funnel-shaped and pushing out from the ventral surface toward the roof of the mouth. This is the infundibulum which meets an ectodermal diverticulum, the hypophysis. This arises, in the cyclostomes from the ectoderm between the nostril and the mouth; in other vertebrates from the roof of the oral cavity. It retains its connection with the parent epithelium for a time, the point of ingrowth being known as Rathke's pocket. Later the stalk disappears and the infundibulum and hypophysis, closely associated, lie just beneath the brain in the sella turcica on the floor of the skull (p. 6I). In the hypophysis (pituitary body) two parts are distinguished, rich in blood-and lymph-vessels and forming a gland of internal secretion whase action is connected with the fat-storing powers of the animal. The infundibulum may be a simple pit, as in most vertebrates, or its lateral walls may become enlarged and folded, blood-vessels lying in the folds, and the whole forming the so-called saccus vasculosus. The paired eyes are also connected with the 'twixt-brain, both in origin and in the adult; they are described with the other sense organs.

The cerebrum (telencephalon) consists of a pair of hemispheres, separated in front by an intercerebral fissure, slight in fishes, well marked in other vertebrates. Each hemisphere typically contains a ventricle, the walls of which are formed by the corpus striatum below and elsewhere by a thinner portion, the pallium or mantle. To the roof belong the paraphysis and the inferior chorioid plexus, already mentioned. In some vertebrates, like the teleosts, the whole of the pallium remains thin and epithelial throughout life; elsewhere it is invaded to a greater or less extent by nervous matter. In the amphibia and reptiles, where the olfactory lobes are merged in the hemispheres, the medial wall of each hemisphere as far back as the interventricular foramen is called the septum, while the part above the foramen, together with the posterior dorsal and lateral walls, is to be regarded as homologous with a region, long recognized only in mammals, the hippocampus, connected with the olfactory sense. In the mammals a new element, the neopallium, appears in the cerebrum. In the lower groups it is on the outer wall, behind the olfactory tract, and, increasing in extent in the higher 
groups, forces the hippocampus to the medial side of the hemisphere. Other modifications are better understood after a consideration of the commissures of the brain.

The amount of gray matter in the pallium is evidently correlated with the mental powers of the animal, being greatest in the mammals. Here the nerve cells form a layer (cortex) on the surface of the neopallium. Increase in the number of these cells can be accommodated to some extent by increase in the size of the cerebrum, but the extent of this increase is limited, and in the higher mammals the amount of surface is increased by folding, so that the cerebrum is marked externally by numerous fissures or sulci separating convolutions or gyri, as will be mentioned in the paragraphs on the mammalian brain.

In order that the two sides of the body may work in harmony it is necessary that the right and left side of the central nervous system be

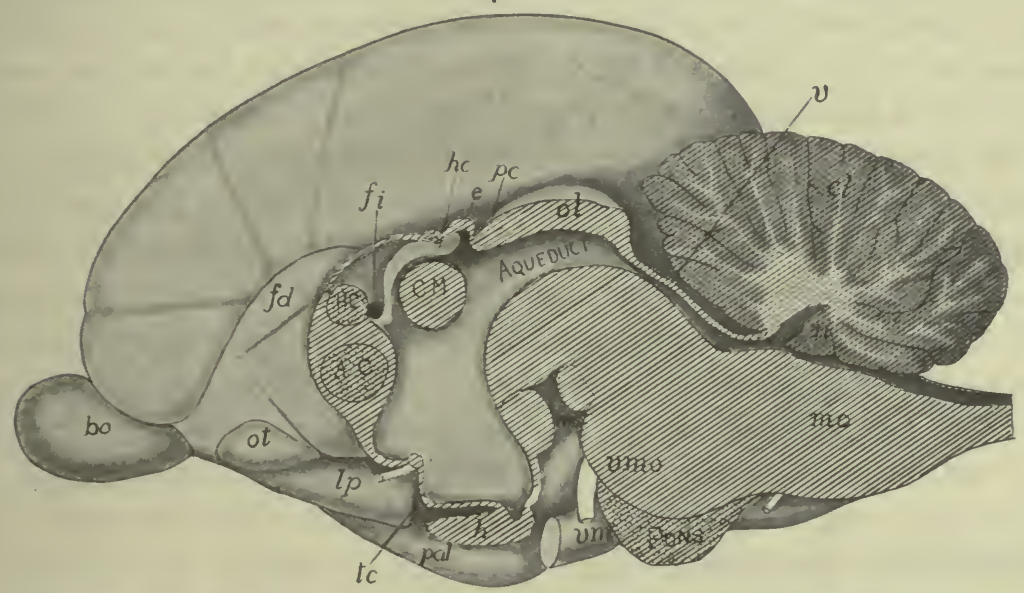

FIG. I52.-Medial plane of brain of Ornithorhynchus, after G. Elliot Smith. ac, anterior commissure; $b o$, bulbus olfactorius; $c m$, commissura mollis; $c l$, cerebellum; $e$, epiphysis; $f d$, fasciculus dentatus; $f i$, interventricular foramen; $h$, hypophysis; $h c$, habenular commissure; $l p$, lobus pyriformis; $m c$, corpus mamillare; $m d$, medulla oblongata; $n$, nodulus; ol, olfactory lobes; ot, olfactory tubercle; pal, pallium; $p c$, posterior commissure; $t c$, tuber cinereum; $v$, velum medullare; vmo, motor root of fifth nerve; $v m$, maxillary of fifth.

connected. This is accomplished in the spinal cord by nerve fibres which pass above and below the central canal from one side to the other. In the brain these commissures are more localized. Then there are longitudinal fibre tracts in the brain, some of which are continuous with the columns of the cord already mentioned. Only a few of these connexions, which are more numerous in the higher than in the lower vertebrates, can be mentioned here.

Most constant and important of the commissures are the following: 
In the lamina terminalis, a little below the interventricular foramen, an anterior commissure, connecting the two hemispheres; a posterior commissure in the roof at the junction of di- and mesencephalon; and a superior or habenular commissure associated with the habenular ganglia and lying between the epiphysial structures and the velum transversum. In the amphibia, with the differentiation of the hippocampal region, a dorsal or hippocampal commissure appears in the lamina terminalis, just dorsal to the anterior commissure, connecting the hippocampi of the two sides. This persists, with slight modifications, through the sauropsida and monotremes, but in the higher mammals it is subdivided into the hippocampal commissure proper and a more anterior portion, the corpus callosum. This corpus callosum is only in part the result of the division, but is more largely formed by new fibres, anterior to the hippocampal portion, connecting the neopallium of the two sides. The result is a broad band (the largest commissure in the brain of man) which invades the intercerebral fissure from behind. In the lower vertebrates a few fibres pass downward from either side of the cerebellum beneath the fibre tracts of the medullary region and so to the other side of the cerebellum. In the mammals these are greatly increased in number, forming a marked projection on the lower surface, the pons (Varolii), the prominence of which is increased by the great development of 'nuclei' in the medullary floor.

The longitudinal tracts are more numerous and more complex. As will be recalled, there are dorsal, lateral and ventral columns in the spinal cord. These extend into the medulla oblongata and there pursue different courses.

Some of the fibres of the dorsal columns end in connection with the nuclei of the medulla (p. I44), while others unite with fibres from the lateral column and with some from the oliva to form an enlargement, the corpus restiforme, and then bend upward (posterior peduncle) to enter the cerebellum. Other fibres from the lateral column, together with some from the dentate nucleus, enter the cerebellum farther in front as the anterior peduncle, those from the dentate nucleus pass forward to the roof of the mid-brain, some terminating in the optic lobes, others continuing to the cerebrum. In this forward course, after leaving the cerebellum, the fibres cross (decussate), those from the right side passing to the left side of the brain farther forward and vice versa. In the dorsal region of the medulla there is a short tractus solitarius (fasciculus communis) derived from fibres from the seventh to tenth nerves and extending no farther forward than the seventh.

In the higher vertebrates there are the crossed and the direct pyramidal tracts on the ventral side of the medulla, the direct being continuations of part of the ventral columns, the crossed of the deeper lateral columns. In the medulla these en- 
large and become somewhat pyramidal, the enlargement being due in part to the decussation of the crossed tracts. The tracts pass forward from the decussation and in the mid-brain region they diverge to pass the hypophysial structures farther in front, the diverging portions being called the crura cerebri. The fibres of the crura enter the corpora striata and in the mammals, the cerebral cortex.

The direct pyramidal tracts have no decussation in the medullary region, but pass to the hemisphere of the same side; the fibres, however, do cross in the spinal cord. Recently attention has been called to Reissner's fibres which occur in all vertebrates, but are relatively largest in fishes. They arise from the roof of the mid-brain, descend to the aqueduct and pass through the fourth ventricle and into the central canal to terminate at various points in the region of the spinal nerves. It has been suggested that they afford a short cut for visual reflexes. Another supposition is that they regulate the flexion of the body.

Of the numerous longitudinal tracts in the anterior part of the brain the fornix must be mentioned. It appears first in the amphibia and is well developed in the mammals. Its fibres are connected in front with the hippocampus, pass downward through the lamina terminalis to the floor of the third ventricle, where they produce a marked swelling (corpus albicans) on either side of the ventral surface of the diencephalon. They ascend from this point to the optic thalami. The passage of the tracts of the fornix through the lamina terminalis and the forward growth of the corpus callosum stretch the lamina into a thin triangular area, the septum pellucidum, and at the same time the callosum causes the lamina to split, the enclosed cavity being called the 'fifth ventricle' though it has no relation, physical or morphological, with the true ventricles of the brain.

\section{ENVELOPES (MENINGES) OF THE CENTRAL NERVOUS SYSTEM.}

Both brain and spinal cord are surrounded by envelopes (meninges) of connective tissue which support and protect them, and also, by carrying blood-vessels, provide for their nourishment. These meninges become more complicated with ascent in the vertebrate series. The canal of the vertebral column and the cavity of the skull are lined with a layer of connective tissue, the endorhachis, which is really the periosteum or perichondrium of the skeletal parts and hence not a true meninx. In the fishes (fig. I49) there is a single envelope, the meninx primitiva, which bears the blood-vessels and lies close upon the spinal cord. Between it and the endorhachis is a perimeningeal space, somewhat broken by strands of tissue passing from meninx to endorhachis, and 
filled, like all meningeal spaces, with an albumen-containing cerebrospinal fluid.

From the urodeles upward there is an increasing division of the meninx primitiva into two layers, a pia mater bearing the bloodvessels and lying close to the cord, and a dura spinalis, separated from the pia by a subdural space, the perimeningeal space now being known as the peridural. In the mammals the pia becomes invaded by cavities separating a delicate arachnoid membrane from its outer surface, so that there is another space, the subarachnoid, in these forms.

There may be slight differences in the region of the brain in the higher groups where the dura presses against and finally unites with the endorhachis, forming the dura mater of human anatomy, thus obliterating the subdural space. In the mammals and to

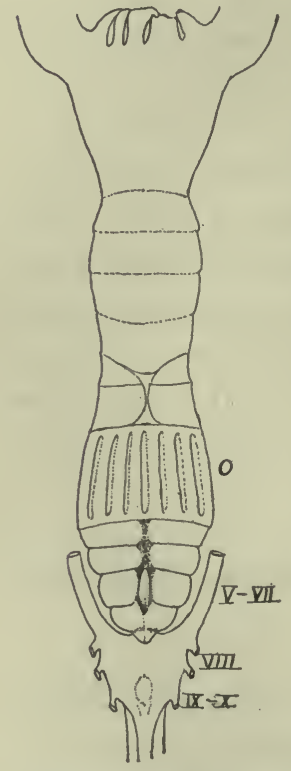

Fig. $153 .-$ Brain of Bdellostoma (Princeton, 2204). 0 , skeleton of olfactory organ, the nerves. brain behind this; $V-X$,

a less extent in birds the dura mater forms two strong folds. One of these is longitudinal and presses in between the two cerebral hemispheres as a firm membrane, the falx cerebri. The other fold, the tentorium, is transverse, and is inserted between cerebrum and cerebellum. It is occasionally ossified and united to the skull.

\section{The Brain in the Separate Classes.}

CYCLOSTOMES.-The brain is very different in the two classes of cyclostomes. All parts lie in the same horizontal plane, the flexures having disappeared, and the whole presents a primitive, almost embryonic appearance. In the lampreys the somewhat slender brain is elongate and its roof is largely epithelial, this extending to the midbrain, of which only the hinder part is nervous in the middle line. The small cerebral hemispheres are largely composed of the corpora striata and the dorsal part of the pallium is purely epithelial, the ventricles being well developed and extending into the olfactory lobes. The optic lobes and the medulla are relatively broad, but the cerebellum is reduced to an inconspicuous fold in front of the fossa rhomboidea.

Authors do not agree regarding the interpretation of some parts of the myxinoid brain. The whole is much broader and shorter than in the other class and is marked dorsally by a groove running the whole length. According to Retzius, the 'twixt-brain of Myxine is invisible from above and the cerebellum is large, completely covering the fossa rhomboidea. The cavities are greatly reduced, the 
aqueduct ending blindly in the mid-brain, in front of which is only the third ventricle, completely cut off from the rest. The brain of Bdellostoma (fig. 153) differs from this in several respects.

ELASMOBRANCHS (figs. 154, I $_{7}$ ) usually have the brain somewhat compact, but in a few it is long and slender. The more striking features are the slight development of the intercerebral fissure, the large hemispheres being lateral expansions just in front of the diencephalon. The optic lobes are large and the large cerebellum overlaps both lobes and the fossa rhomboidea. The olfactory lobes arise from the antero-lateral angle of each hemisphere; their length varies between wide limits. The epithelial roof of the 'twixt-brain is wide and bears a pinealis which often reaches the roof of the skull, but the parietal organ is lacking. The hypophysis and infundibulum are provided with large inferior lobes and a well developed saccus vasculosus. The cerebellum has a longitudinal groove and usually one or more transverse grooves, dividing the upper surface into paired lobes. The medulla differs in the sharks and the skates, being very short in the latter, much longer in the former. In both the corpora restiformia are large folds on either side of the cerebellum, in front of and lateral to the fossa rhomboidea.

In most elasmobranchs the ventricular system is well developed, but in some the paired and third ventricles are not well separated, while in the Myliobatidæ there is no cavity in the cerebrum. There is a large epicœle extending upward from the aqueduct into the optic lobes and a similar cavity usually enters the cerebellum.

TELEOSTOMES.-There is a wide range of form in the brain of ganoids and teleosts. It is usually small in proportion to the size of the animal and is noticeable for the small size of the telencephalon and the usually non-nervous character of the pallium, which in the teleosts is

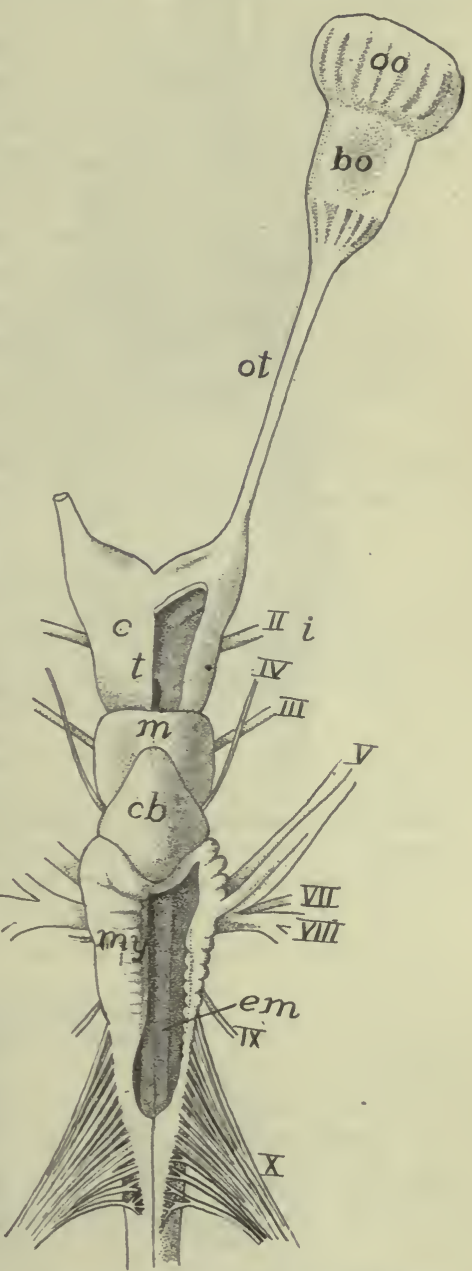

Fig. 154.-Brain of Heptanchus, after Gegenbaur. bo, bulbus olfactorius; $c$, cerebrum; $c b$, cerebellum; em, eminentia teretes; $i$, infundibulum; $m$, mesencephalon; $o$, olfactory organ; ot, olfactory tract; $m y$, myelencephalon; $t$, 'twixt-brain; $I I-X$, cranial nerves. purely epithelial. Consequently the cerebrum consists largely of the corpora striata and the intercerebral fissure is slightly developed. The paired ventricles are small, but they extend into the olfactory lobes. The 'twixt-brain, at a lower level than the rest, has a large infundibulum, saccus 


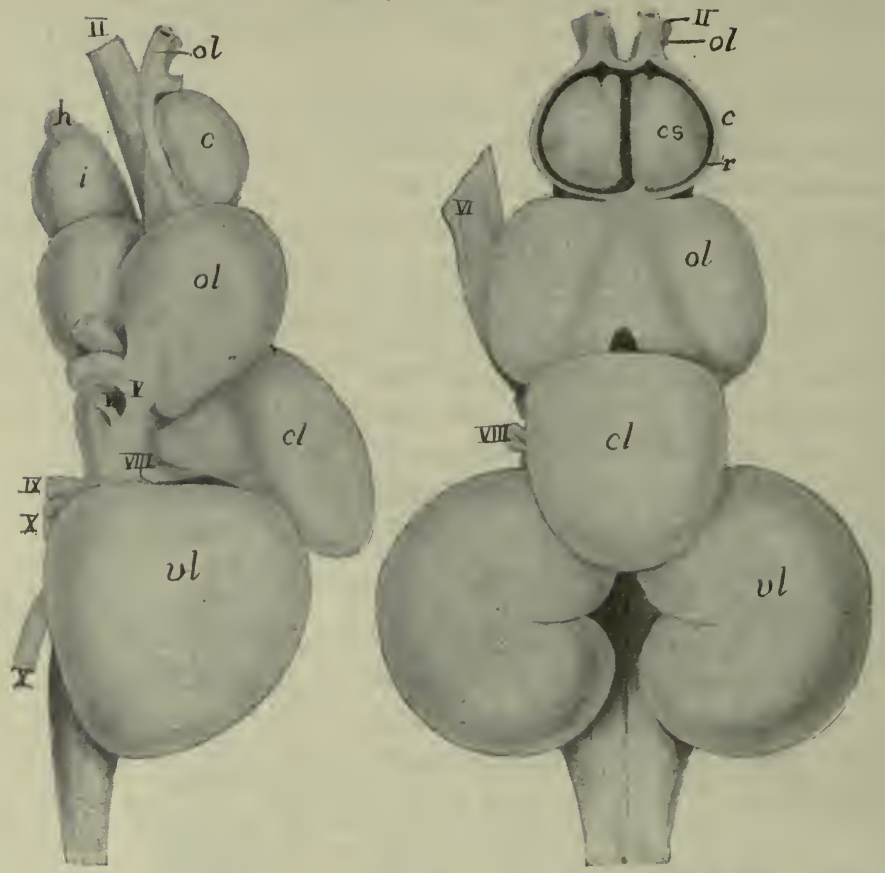

FIG. I55.-Dorsal and side views of brain of buffalo fish (Carpiodes tumidus) after Herrick. $c$, cerebrum; $c l$, cerebellum; $c s$, corpus striatum; $h$, hypophysis; $i$, infundibulum; $o l$, olfactory lobes; $p$, pallium; $v l$, vagus lobes; $I I-X$, nerves.

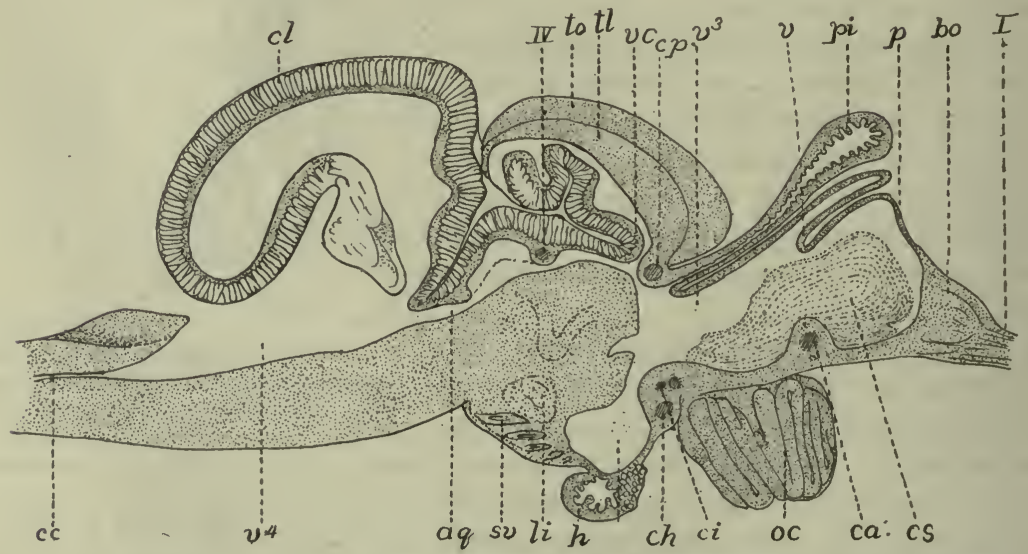

FIG. I56.--Sagittal section of brain of trout, after Rabl-Rückhard. $a q$, aqueduct; bo, bulbus olfactorius; $c a, c h, c i, c p$, anterior, horizontal, inferior and posterior commissures; $c c$, central canal; $c l$, cerebellum; $h$, hypophysis; $i$, infundibulum; oc, optic chiasma; $p$, pallium; $p i$, pinealis; $s v$, saccus vasculosus; $t l$, torus longitudinalis; to, tectum of optic lobes; $v^{3}, v^{4}$ ventricles; $v c$, valvula cerebelli. 
vasculosus and inferior lobes. On its roof is a large pinealis which reaches the skull in a few ganoids. The parietal organ appears in the embryo and soon degenerates; the paraphysis is usually well developed. The optic lobes are large and are usually divided into two hemispheres by a median groove, but this occasionally is scarcely noticeable. The cerebellum is large, much larger than appears from the surface, since a considerable part, the valvula, projects into the ventricle of the mid-brain. In the cerebellar region there is sometimes an enormous development of the lobes of the vagus (fig. I55).

The brain of Polypterus differs from that of other ganoids in several respects. There is no differentiation of cerebral hemispheres; the optic lobes and the cerebellum are moderate, the latter being thin in the median line and the valvula smaller. The medulla oblongata has thin walls and the ventricle is large. The brain has a primitive appearance, but it shows little resemblance to those of the amphibia or of the dipnoi.

DIPNOI.-The brains of Lepidosiren and Protopterus differ considerably from that of Ceratodus. In all the cerebrum is larger than the optic lobes and the

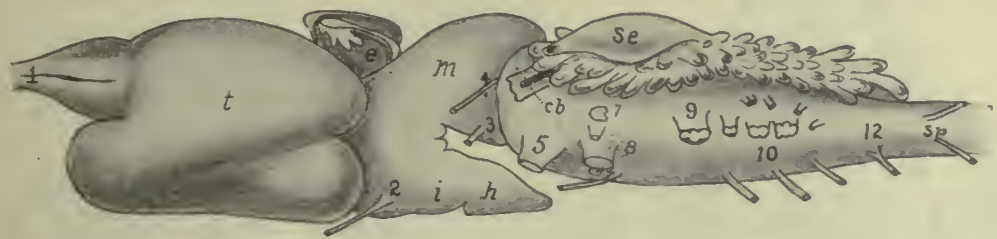

FIG. I57.-Brain of Protopterus, after Burckhardt. $c b$, cerebellum; $e$, epiphysial structures; $h$, hypophysis; $i$, infundibulum; $m$, mid brain; se, saccus endolymphaticus; $s p$, spinal nerves; $t$, cerebrum; $1-12$, cranial nerves.

olfactory bulb is separated from the cerebrum by a long olfactory tract. In $\mathrm{Cer}$ atodus the hemispheres are united above by a part of the chorioid plexus, while internally they are separated from the diencephalon by a well marked velum. The pinealis is long and rests upon a large 'zirbelpolster' developed as an outgrowth of the roof of the third ventricle in front of the superior commissure. The optic lobes are separated into two hemispheres, while the cerebellum is scarcely more than a transverse plate and is, together with the fossa rhomboidea, covered with a complicated chorioid plexus. In Protopterus (fig. 157) the elongate hemispheres are parallel, the pinealis and its 'polster' are smaller and the mid-brain has but a single rounded lobe.

AMPHIBIA.-The parts of the amphibian brain are more distinct from each other than is usual in vertebrates, and, except in the gymnophiones, the flexures have largely disappeared in the adult. There is a deep intercerebral fissure between the hemispheres, but in the anura the two halves of the cerebrum are connected by a transverse band just behind the olfactory lobes. The telencephalon is relatively larger than in fishes, the increase being due to the invasion of the pallium by nervous matter, while the corpora striata are relatively smaller than in other ichthyopsida. In the pallium the inner part is largely composed of nerve cells, the outer layer consisting of nerve fibres.

The diencephalon, broad in the anura, narrower in the urodeles and cæcilians, 
is visible from above. The infundibulum and hypophysis are well developed but the saccus vasculosus and inferior lobes are smaller than in fishes. In the gymnophiones, owing to the pontal flexure the hypophysis is carried back beneath the medulla oblongata. Both paraphysis and pinealis are present, the latter not reach-
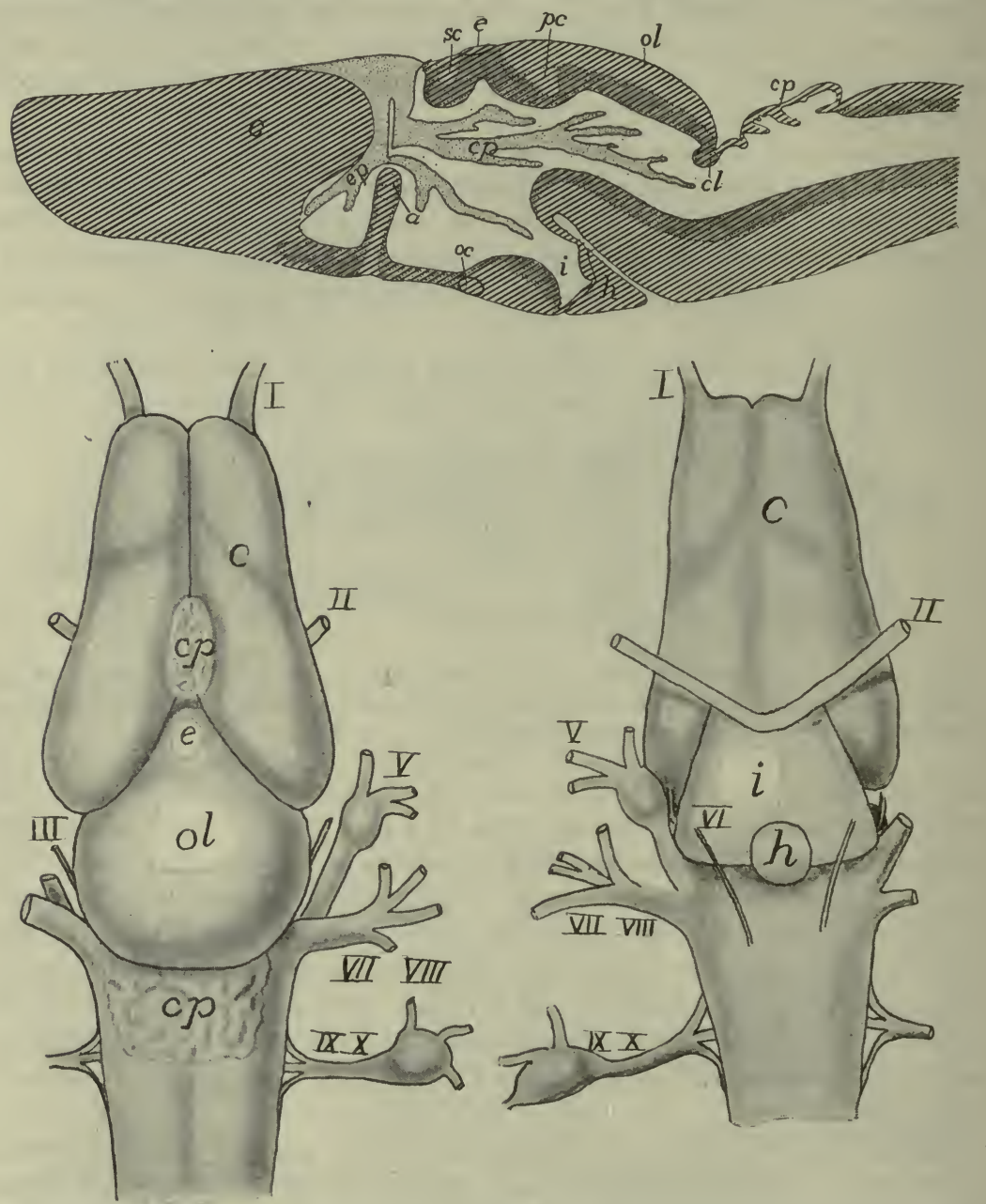

Fig. I 58.-Dorsal and ventral views and sagittal section of brain of Desmognathus, after Fish. $a$, anterior commissure and rudimentary corpus callosum; $c$, cerebrum; $c l$, cerebellum; $e$, epiphysis; $h$, hypophysis; $i$, infundibulum; $o c$, optic chiasma; $o l$, optic lobes; $p$, paraphysis; $p c$, posterior commissure; $c p$, chorioidplexuses; $s c$, superior commissure; $I-X$, nerves.

ing the cranial roof except in the anura, the conditions in this group having already been mentioned (p. 147). The cerebellum is very small, a mere transverse fold on the anterior border of the fossa rhomboidea. The gymnophione brain is noticeable for the pontal flexure already alluded to, which carries the hemispheres so far 
back that they almost touch the sides of the medulla, and for the double roots of the olfactory nerves.

REPTILES.-There is considerable range in the brain of the reptiles, all showing an advance over the amphibians in having the cerebrum larger than the optic lobes; in having, in the pallium, besides the basal layer of gray matter, a distinct cortical layer of nerve cells; the well developed hippocampus; while the olfactory lobes may either be sessile upon the hemispheres or differentiated into tracts and bulbs.

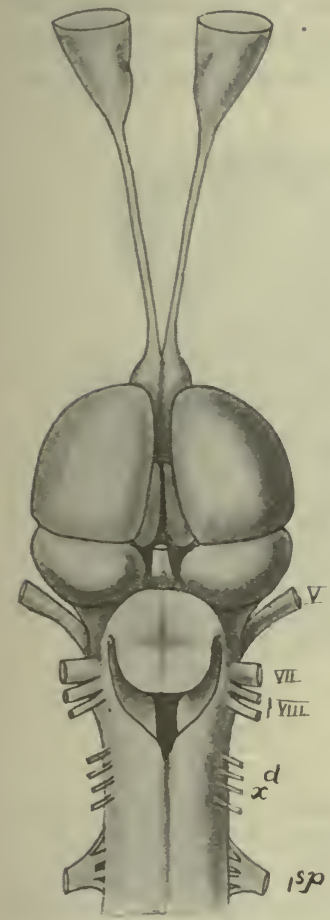

FIG. I59.

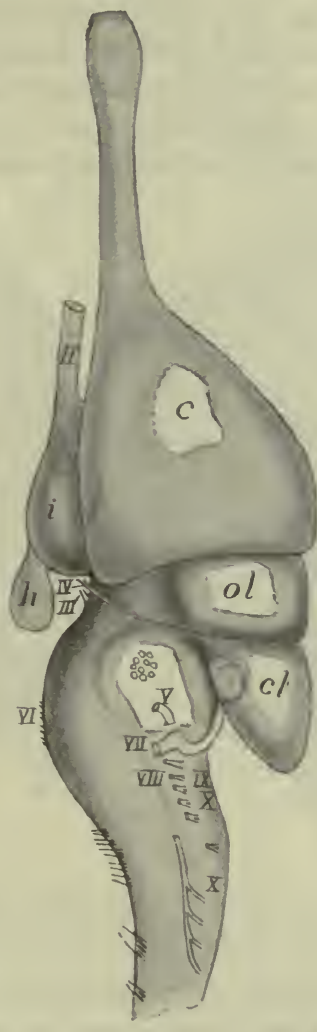

FIG. I60.

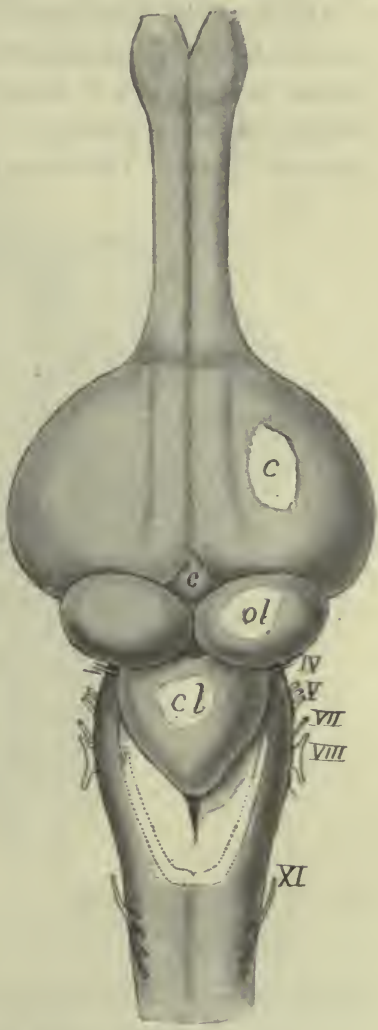

FIG. I59.-Brain of Iguana tuberculata (Princeton, 2293). Compare fig. I72.

FIG. I6o.- Side and dorsal views of brain of young alligator, after Herrick. c, cerebrum; $c l$, cerebellum; $e$, epiphysial structures; $h$, hypophysis; $i$, infundibulum; $o l$, olfactory lobes; $I I-X I I$, cranial nerves.

The greater size of the cerebrum and the large optic lobes result in covering the diencephalon so that it is scarcely visible from above (figs. 159,160 ). Infundibulum and hypophysis are well developed, but the sacci vasculosi are rudimentary and the inferior lobes are inconspicuous. The epiphysial structures reach their highest development in this group. In most species the parietal organ is rudimentary, but in many lizards and especially in Sphenodon it penetrates the roof of the skull and 
forms a well-developed eye (fig. ${ }_{5} \mathrm{I}$ ), lying just beneath the skin and connected with the brain by more or less rudimentary nerves. In some the pinealis also shows eye-like features.

The optic lobes are distinct from each other. The cerebellum is usually small (fig. 159), but in the crocodilia (fig. I $_{5} \mathrm{I}$ ), it attains considerable size. In all reptiles there is a thicker central portion and thinner lateral parts, an approach to the differentiation into vermis and flocculi found in birds. There are no special features in the medulla calling for notice.

AVES. - The bird's brain (fig. I6I) is short, broad and highly specialized. The smooth cerebral hemispheres are large, their size being due more to the enormous corpora striata than to enlargement of the pallium, which is comparatively thin, while the olfactory lobes are very slightly developed, in correlation with the deficient powers of smell. The large cerebellum extends forward between the hinder ends
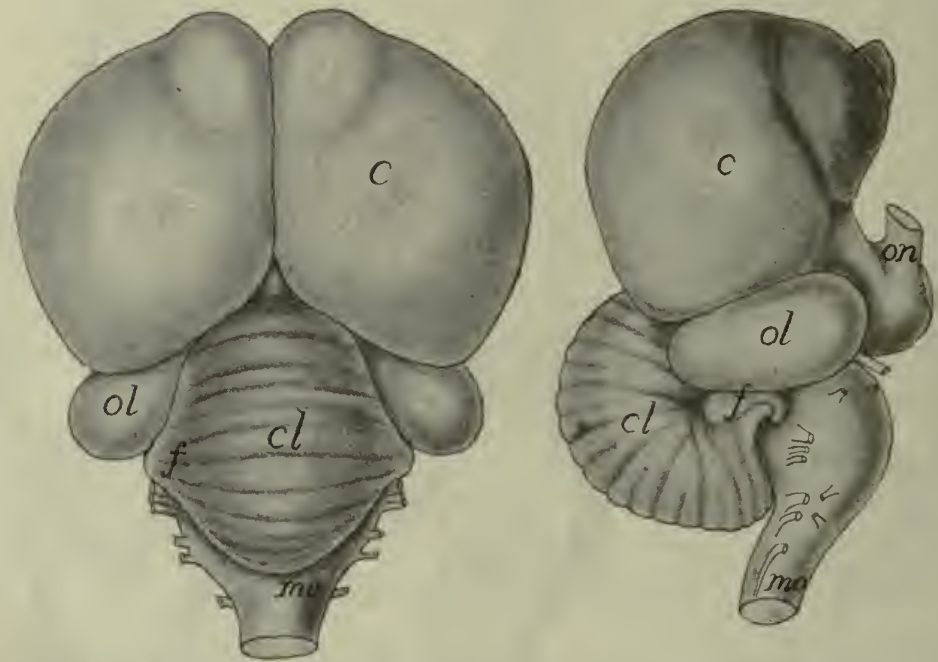

FIG. I6r.-Brain of golden eagle, Aquila chrysatos, after Herrick. c, cerebrum; $c l$, cerebellum; $f$, flocculus; $m o$, medulla oblongata; $o l$, optic lobes; on, optic nerve.

of the cerebrum, thus forcing the optic lobes into a lateral position and completely covering the 'twixt-brain. The epiphysial structures are large but rudimentary in character, the pinealis extending up in the angle between cerebrum and cerebellum. Below, the hypophysis completely hides the infundibulum. The large cerebellum has its median portion transversely furrowed, this constituting the vermis, while the smaller lateral lobes, which vary in extent, form the flocculi. The myelencephalon is very short and the fossa rhomboidea is covered by the cerebellum.

MAMMALS.-The brain in the mammals becomes exceedingly complex. Only the most important features and those of general occurrence will be noted here. Most marked are the large size of the cerebellum and the still greater development of the cerebrum, correlated with the great increase in mental powers. The cere- 
brum covers the di- and mesencephalon, and in the primates even the whole of the cerebellum from above. This increase of the cerebrum is largely an increase of the nervous matter of the pallium, a portion-the neopallium-developing on the lateral side of each hemisphere between the hippocampus and the basal structures (pyriform lobes). This increase in cerebrum is limited in forward and backward growth by the limitations of skull development. Hence it overlaps the olfactory

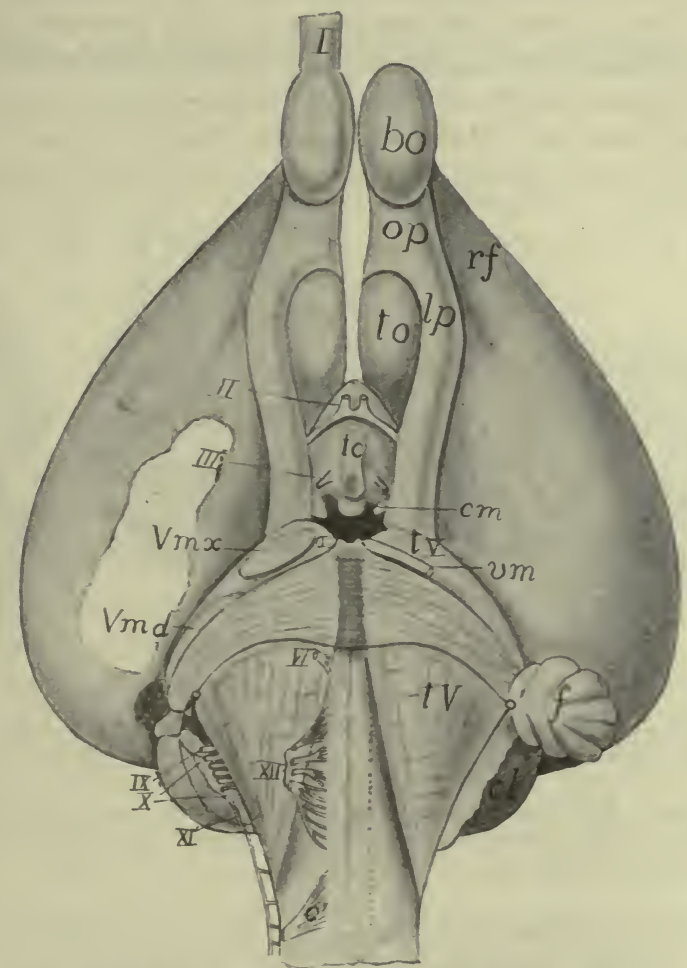

Fig. I62.-Ventral surface of brain of Ornithorhynchus, after G. Elliot Smith. bo, bulbus olfactorius; $c^{1}$, first cervical nerve; $c l$, cerebellum; $c m$, corpus mamillare; $f$, flocculus; $l p$, lobus pyriformis; $o p$, olfactory peduncle; $r f$, rhinal fissure; $t c$, tuber cinereum; to, olfactory tubercle; $t V$, tuberculum quinti; $V m, V m d, V m x$, motor root and maxillaris and mandibularis roots of trigeminal nerve; $I-X I I$, cranial nerves. See also fig. $\mathbf{I}^{2}$.

lobes in front, so that they appear to rise from its ventral surface, while behind it extends backward, then turns downward and lastly extends forward along the sides of the mid- and 'twixt-brains, even overlapping a part of the cerebrum itself. In this way the cerebrum becomes marked off into a series of regions called the frontal lobes in front, the parietal above, the occipital behind, while the reflexed ventral portion of either side makes a temporal lobe.

This folding and overgrowth causes grooves or fissures in the surface of the cerebrum, the most constant being a rhinal fissure between olfactory and frontal lobes, a Sylvian fissure between the temporal lobe and the lower surface of the 
cerebrum against which it is folded. In the bottom of the Sylvian fissure is a part of the side wall of the cerebrum which has received the of insula (island of Riel), while a hippocampal fissure causes the hippocampus to appear as a pronounced swelling on the floor of each ventricle. In the lower mammals these are the only fissures present, the rest of the cerebral surface being smooth. In the higher mammals other grooves (sulci) separating convolutions (gyri) appear. These convolutions increase the extent of cerebral surface and as a consequence they permit of more cortical gray matter upon which mentality depends. The number of gyri increases in the primates and reaches its extreme in man. The folding of the cerebrum also affects the cavities of the cerebrum as well as the course of the fibre tracts, especially of the fornix which becomes greatly bent on itself. In the ventricles distinct regions or 'horns' are recognized, an anterior cornu in

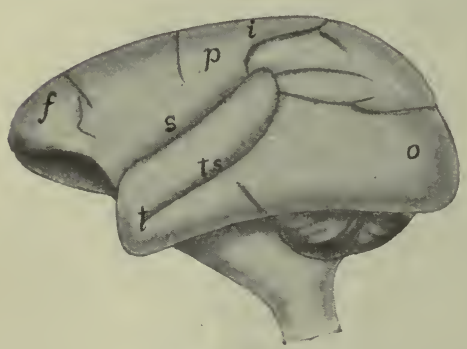

Fig. 163 .

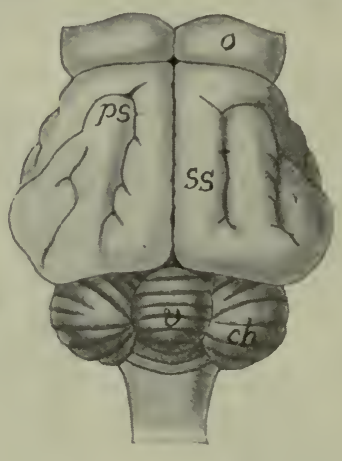

FIG. 164 .

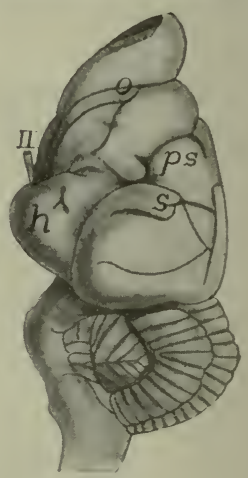
Fig. I63.-Brain of Chrysothryx sciureus, after Weber. $f$, frontal lobe; $i$, interparietal
sure; $o$, occipital lobe; $p$, parietal lobe; $s$, Sylvian fissure; $t$, temporal lobe; $t s$, sulcus fissure; $o$, occipital lobe; $p$, parietal lobe; $s$, Sylvian fissure; $t$, temporal lobe; $t s$, sulcus temporalis.

FIG. I64.-Brain of Manis javanica, after Weber. ch, cerebellar hemispheres; $h$, hippocampal lobe; $o$, olfactory lobe; $p s$, presylvian fissure; $s$, Sylvian fissure; $s s$, sulcus sagittalis; $v$, vermis; $I I$, optic nerve.

the frontal lobe, a posterior in the occipital lobe and an inferior cornu in the temporal lobe. Associated with the cortical gray matter are nerve fibres (comparatively few in the lower, extremely numerous in the higher mammals) which form a corona radiata and connect the cortex with the more posterior regions of the brain. In the non-placental mammals the anterior commissure is very large, forming the chief association tract between the two hemispheres, but in the higher groups the corpus callosum becomes greatly developed and largely replaces it.

The diencephalon is greatly reduced, the hypophysis and infundibulum being small, the latter showing traces of the saccus vasculosus and inferior lobes so prominent in the lower vertebrates. The parietal organ is lacking, but the pinealis is relatively large. It is separated from the roof of the skull by the occipital lobes of the cerebrum. It is connected with the roof of the brain by two bands or peduncles and its cavity contains a quantity of so-called 'brain sand.' A transverse groove divides the optic lobes so that they consist of four lobes (corpora quadrigemina). 
The cerebellum is divided into a median vermis and a pair of lateral portions, each consisting of a large cerebellar hemisphere, ventral (morphologically lateral) to which is a flocculus (fig. 162), homologous to that of the sauropsida. The surface of the hemispheres is convoluted and this results in the arrangement of the white and gray matter in such a way that they have a markedly dendritic appearance (arbor vitæ, fig. 152) when seen in longitudinal section. The pons, characteristic of the mammalian brain, has already been mentioned (p. 150).

\section{THE PERIPHERAL NERVOUS SYSTEM.}

\section{The Spinal Nerves.}

The spinal nerves are metameric structures, connected with the spinal cord by two separate portions or roots which differ greatly from each other in development, structure and function. At the time of the closure of the neural tube a band of cells occurs on either side of the neural plate at the junction of neural and epidermal areas. With the closure of the tube these form two bands, the neural crests, one on either side of the dorsal surface of the cord (fig. I44). By unequal growth each crest soon develops a series of metameric enlargements, the portions of the crest between these gradually disappearing, while the enlargements form the ganglia of the dorsal roots of the nerves. Each of its cells, like those of the cord, sends out processes, one of which grows medially and enters the cord in the region of the posterior cornu, while the other extends peripherally to the skin or viscera, these processes constituting the dorsal root of the nerve, the ganglion forming an enlargement upon it, near its connection with the cord. The other or ventral root is formed by fibres which grow out in a similar way from cells in the ventral horn of the cord itself and leave it between the anterior and lateral columns, to extend to the muscles, glands, etc. As the ganglion cells are inside the cord, there is no ganglion on the ventral root. Except in the cyclostomes the dorsal and ventral roots unite soon after leaving the cord, the combined trunk being a typical spinal nerve (figs. I45, I66).

Physiologically the roots differ in that the dorsal roots are mainly composed of sensory fibres, while the ventral roots contain only motor fibres. That is, on stimulation of the parts to which they are distributed the dorsal roots and their fibres carry nervous impulses to the cord - they are afferent - while the impulses in the ventral roots are carried in the opposite direction by efferent fibres. In their case stimulation arises in the central nervous system and the impulse is carried outward 
to the parts to which the fibres are distributed, causing these to actmuscles to contract, glands to secrete, etc. Hence the ventral roots are called motor roots. Their fibres are without sensory functions, while sensory fibres are equally unable to cause action in any peripheral part (Bell's law).

After a longer or shorter course, each spinal nerve, formed by the union of dorsal and ventral roots, divides into three branches, each of which receives both sensory and motor fibres. These are known as

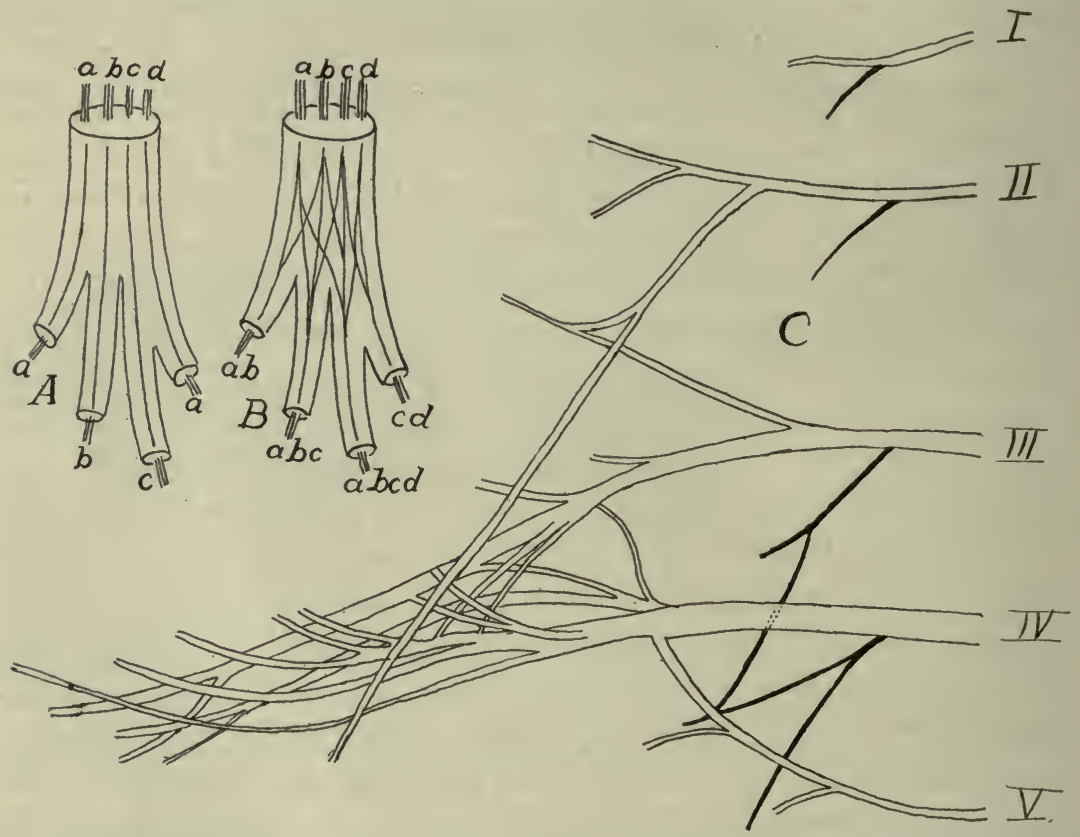

FIG. I65.-A, diagram of collector nerve; $B$, of a nerve plexus, after Braus; $C$, branchial plexus of Salamandra maculata, after Fürbringer.

the ramus dorsalis, ramus ventralis and ramus visceralis or intestinalis. The first goes to the skin and muscles of the dorsal region; the second to those of the sides and ventral parts of the body; while the visceral branch descends to the roof of the cœlom, near the insertion of the mesentery, where it connects with the sympathetic nervous system to be described below (fig. I66).

Recent physiological and histological analysis shows the existence of two groups of nervous elements in both sensory and motor nerves. There are somatic sensory and motor fibres, distributed to the skin and most of the external sense organs and to the voluntary muscles, and 
there are also visceral fibres of both kinds, supplying the viscera (alimentary canal, excretory and reproductive organs) and the circulatory system: The dorsal and ventral rami contain mostly somatic fibres with a few of the visceral type, while the visceral rami are composed of visceral fibres alone. The farther subdivision of these nerves will be considered later.

To the statement that the dorsal roots are purely sensory the exception must be made that in the lower vertebrates some of the visceral motor fibres, arising in the neighborhood of the lateral cornu, pass out from the cord through the dorsal root. In the mammals they are said to leave by the ventral roots like all other motor fibres.

In the regions of the appendages the spinal nerves usually form networks or plexuses, branches of a varying number of ventral rami interlacing in a complicated manner before entering the appendage. Plexuses are poorly developed in the fishes, but here many spinal nerves are united before entering a limb by means of a longitudinal 'collector' nerve, there being no exchange of fibres such as occurs in a plexus. In the amphibia there are two plexuses, a cervico-brachial near the fore limb, and a lumbo-sacral for the hind limb. In the higher groups there may be four plexuses: cervical, brachial, lumbar and sacral, the positions of which are indicated by their names.

\section{The Sympathetic System.}

The function of the sympathetic system is the control of the viscera, various glands, the smooth muscles, and through the latter, of the size of the blood-vessels and the supply of blood to the various parts. The system is connected with the spinal nerves by the visceral rami (rami communicantes) already mentioned. As has just been said, these visceral rami contain both motor and sensory fibres. As these rami extend downward in their development, they carry with them ganglion cells derived from the ganglia of the dorsal roots of the spinal nerves, and these give rise to the sympathetic ganglia. Of these there are three groups. Nearest to the spinal nerves on either side are a series of the sympathetic trunk (chain ganglia), usually connected with each other by a longitudinal sympathetic trunk. Nerves run from these chain ganglia to the prevertebral ganglia, some of which, like the cardiac, pelvic, hypogastric and solar (plexuses) are of considerable size. From these nerves go to the 
peripheral ganglia, situated at various points along the viscera, some at some distance from the sympathetic centres.

In the sympathetic system four kinds of nervous elements are to be distinguished. The original trunk that grows out (the ramus visceralis) consists of motor and sensory fibres. The latter arise from ganglion cells in the ganglia of the dorsal roots. The motor fibres have their cell bodies in the cord at about the level of the lateral cornu, and pass

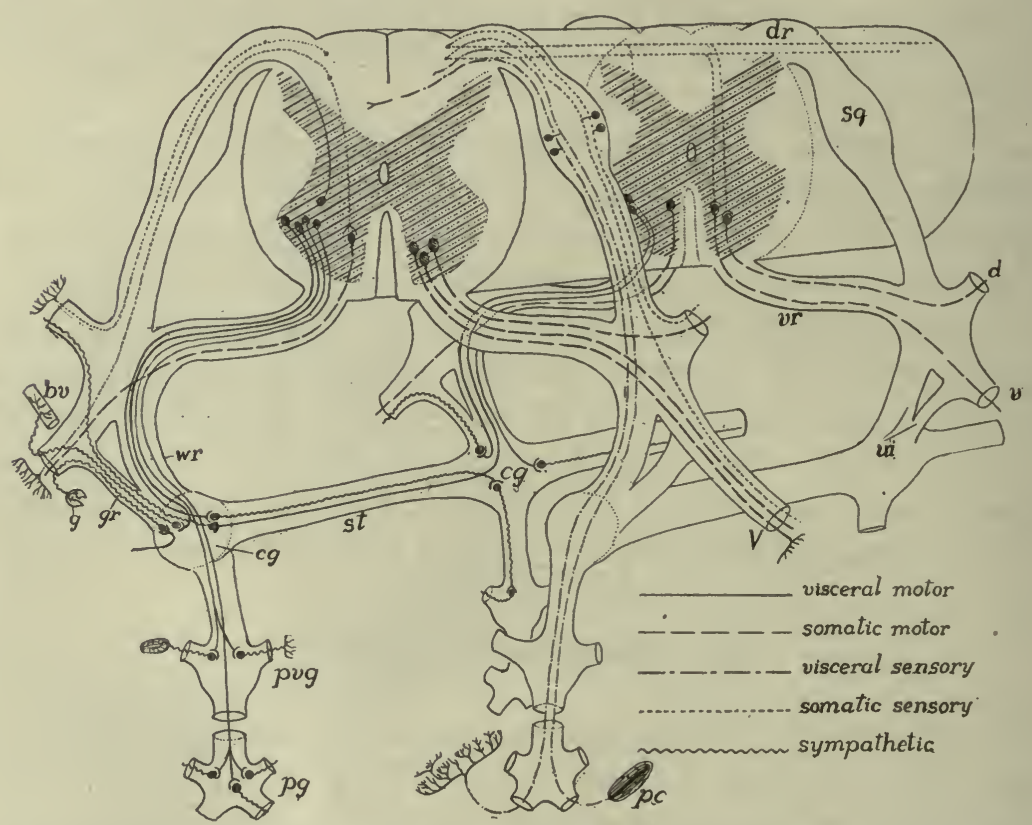

FIG. I66.-Diagram of the relations of the sympathetic system, based on Huber. The character of the different fibres is shown by conventional lines. $b v$, blood-vessel; $c g$, chain ganglion; $d$, dorsal ramus; $d r$, dorsal root; $g$, gland; $g r$, gray ramus; $p g$, peripheral gangiion; pvg, prevertebral ganglion; st, sympathetic trunk; $v$, ventral ramus; vi, visceral ramus; $v r$, ventral root; $w r$, white ramus.

out, in the lower vertebrates by the dorsal, in the mammals by the ventral root. In the sympathetic system itself there are sensory and motor (excitatory) cells, derived from the ganglion cells carried down by the growing nerves. These develop their dendrites and axons, and some of these run up the rami communicantes to the dorsal and ventral rami, and follow along them to the peripheral glands and blood-vessels of the body. Others grow into the various viscera. These purely sympathetic fibers are not medullated and hence are gray in 
color, and form gray rami communicantes for a part of their course to the spinal nerves.

The sympathetic system is best developed in the trunk, but it extends forward into the head, where a series of sympathetic ganglia (ciliary, sphenopalatine, etc.) is connected with the cranial nerves as far forward as the fifth. The sympathetic trunk in this region is usually closely connected with other nerves, but occasionally (Vidian nerve from the sphenopalatine to the facial ganglion, Jacobson's commissure from the seventh to the ninth, fig. I70) it is distinct.

A few words may be added to this general account. In the elasmobranchs there is no sympathetic trunk, this first appearing in the teleosts. The system is more highly developed in the aquatic than in the terrestrial urodeles or in the anura. In the sauropsida the trunk is usually double on either side in the neck region, one branch running through the vertebrarterial canal of the vertebræ. In the mammals the cervical part of the trunk is usually closely associated with the pneumogastric nerve. In the development certain ganglion cells migrate from the developing sympathetic system and pass to various parts of the body, being usually closely associated with the glands of so-called internal secretion-hypophysis, carotid gland, suprarenals, etc. They possess a peculiar affinity for chromic salts and are known as chromaffine cells. Little is known of their function.

\section{The Cranial Nerves.}

The nerves which arise from the brain and pass out through the foramina in the skull are known as the cranial nerves. While in a general way they resemble the spinal nerves, they have been specialized and modified in many respects in correspondence with the specialization of the head itself, some consisting of sensory fibres alone, some of only motor fibres, while others are mixed, that is, contain both kinds of fibres. There can also be recognized somatic and visceral nerves as in the trunk, while the somatic sensory fibres may be arranged in different groups, differing in their connexions inside the brain and in the sense organs to which they are distributed. Thus six different kinds of fibres may occur in the cranial nerves, as follows:

I. The somatic motor, which go to the muscles derived from the myotomes of the head.

2. The visceral motor, distributed to the muscles of the gill region, 


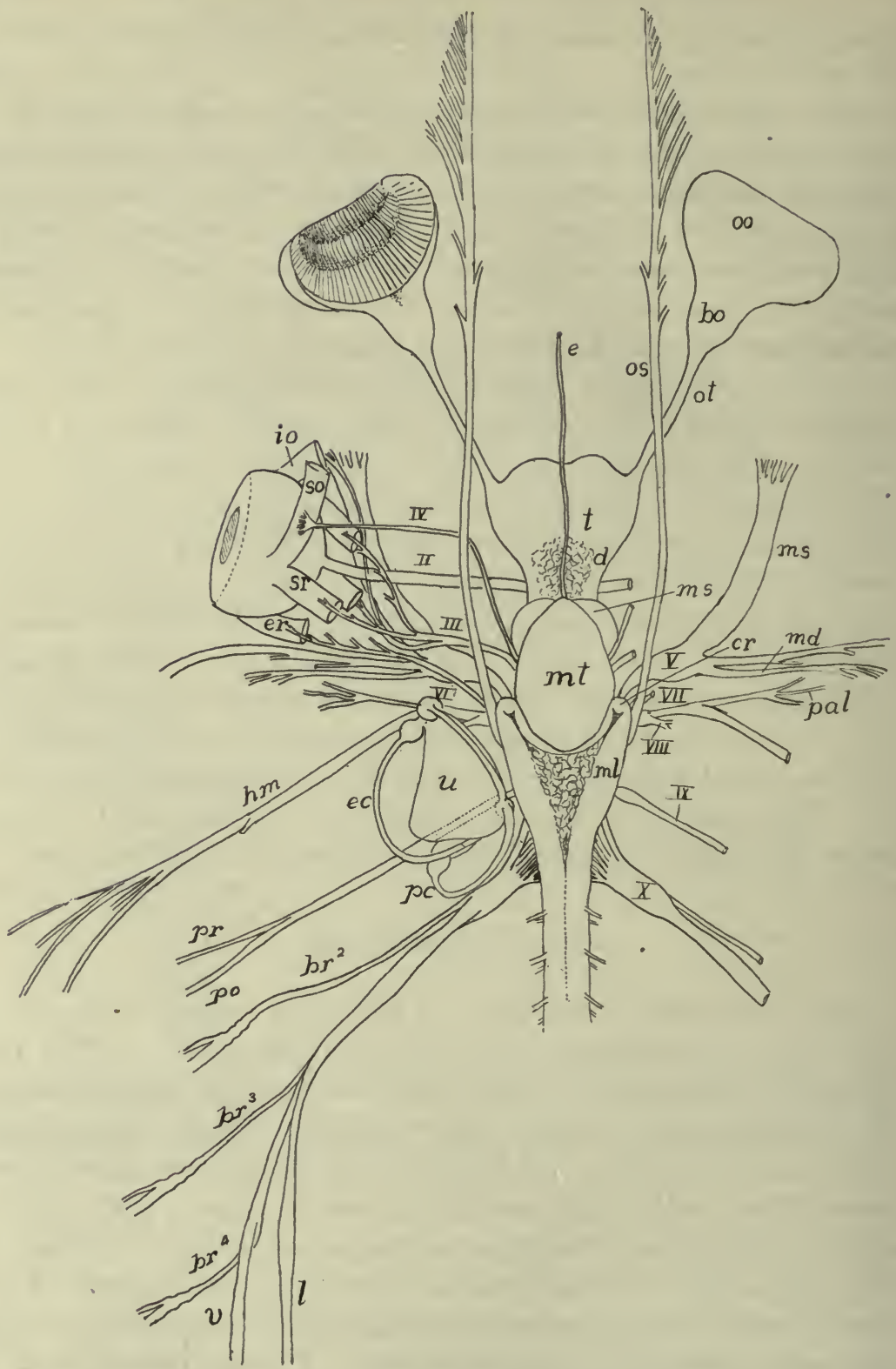

FIG. I67.-Brain and cranial nerves of Carcharias littoralis (Princeton 310 ), natural size. $b o$, olfactory bulb; $b r^{1}-4$, branchial nerves; $c r$, corpus restiforme; $d$, diencephalon; $e$, epiphysis; $e c$, external canal of ear; $e r$, external rectus; $e o$, external oblique; $h m$, hyomandibular nerve; $l$, lateralis nerve; $m d$, mandibularis nerve; $m s$, mesencephalon, also, maxillaris superior; oo, olfactory organ; os, ophthalmicus superficialis nerve; ot, olfactory tract: pal, palatine nerve; $p c$, posterior canal; po, post-trematic branch; $p r$, pretrematic branch; so, superior oblique; $s r$, superior rectus; $t$, telencephalon; $u$, utriculus; $v$, visceral branch of $\mathrm{X}$; $I-X$, cranial nerves. 
and their homologues in the higher vertebrates, arising from the lateral plate region of the embryo.

3. The visceral sensory nerves are connected inside the brain with the communis tract of the medulla (fascicularis solitarius of human anatomy), while they terminate in special taste organs, usually within the mouth, but in many teleostomes distributed on the sides of the body as well.

4. The general cutaneous sensory nerves, corresponding to the somatic sensory of the trunk. Internally they are connected with the dorsal horns of the spinal cord and the homologous parts of the myelencephalon, while distally they terminate either as free nerves or in special tactile organs in the skin.

5. The acustico-lateralis nerves, the centre of which is in the cerebellum and in the tuberculum acusticum of the myelencephalon. Distally the fibres terminate in peculiar collections of sense cells known as sense hillocks or neuromasts occurring in the inner ear and in the lateral line organs of the ichthyopsida.

6. The nerves of special sense (olfactory and optic).

The first four of these groups occur in the spinal nerves; the last two are confined to the head. While each spinal nerve contains all four components, the same is not true of most of the cranial nerves, some having but a single kind of fibre. On this and other accounts it is necessary to review each nerve in some detail. In the lower vertebrates (ichthyopsida) there are ten of these cranial nerves; in the amniotes there are twelve. These are known by both name and number.

I. The Olfactory Nerve differs considerably in the various groups of vertebrates. The term strictly includes only the fibres extending between the olfactory lobe of the brain and the olfactory epithelium, the fibres terminating in the rhinencephalon by dendrites which, interlacing with dendrites of cerebral neurons, form oval bodies, the glomeruli. The olfactory nerve differs from all others in that it arises from cells of the epidermis. In some vertebrates (elasmobranchs, some teleosts, ganoids, snakes, some lizards, fig. $168, A$ ), the nerve proper is very short, while the olfactory lobe is developed into an elongate structure in which separate regions may be distinguished, a part of the lobe remaining in connexion with the cerebrum, next a narrower stalk, the tractus, and lastly a larger bulbus olfactorius, containing the glomeruli, close to the nasal organ. In other vertebrates (some teleosts, amphibia, some lizards, turtles, fig. $168, B$ ) the nerve is more 
elongate and the lobe is not differentiated into bulb and tract. The nerve in all forms consists solely of special sensory fibres, and its apparent origin from either the tip or the ventral surface of the cerebrum

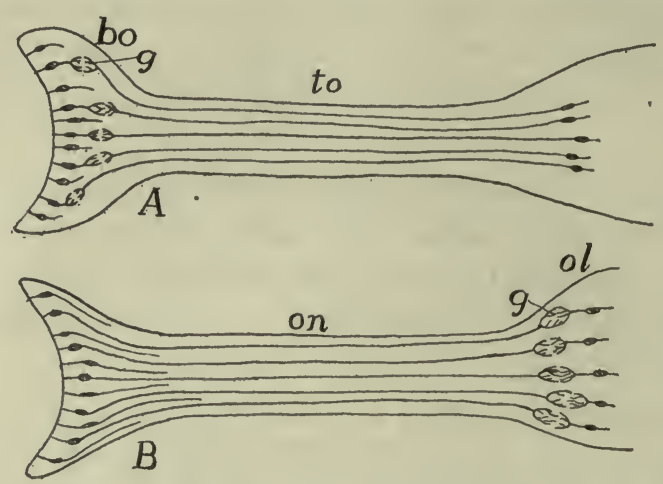

FIG. 168.-Diagrams of the different kinds of olfactory bulb, tract, and nerve. bo, olfactory bulb; $g$, glomeruli; ol, olfactory lobe; on, olfactory nerve; to, olfactory tract.

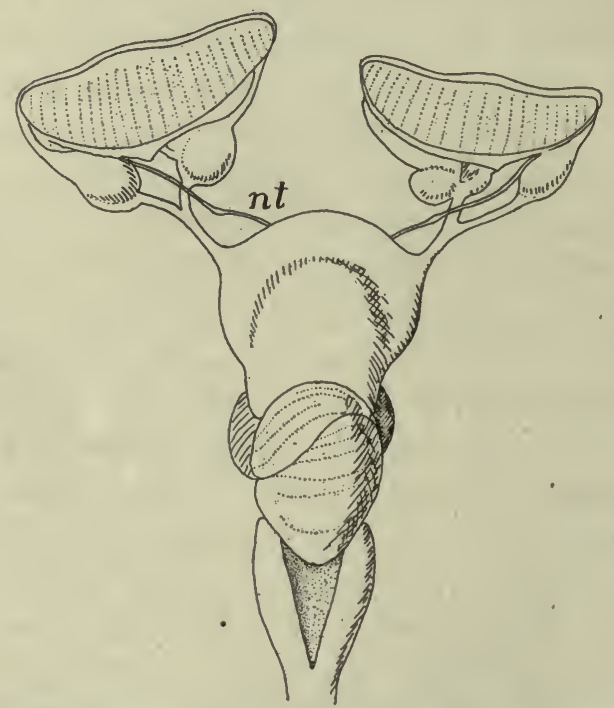

FIG. I69.-Brain and olfactory and (nt) terminalis nerves of Raia, after Locy.

is to be explained by the varying development of the hemispheres as given above (p. I 59 ).

In some fishes (several elasmobranchs, dipnoi, Amia) a small nerve arises dorsally (some elasmobranchs) or ventrally from the cerebrum, has a distinct ganglion and, following somewhat closely the 
olfactory nerve, is distributed to the olfactory epithelium. Apparently the same nerve occurs in the human embryo and it may be looked for elsewhere. It is called the terminalis nerve and probably belongs to the general cutaneous system.

II. The Optic Nerve arises from the floor of the diencephalon and extends to the eye where it spreads over the inner surface of the retina. Together with the olfactory nerve it is usually stated to differ from the other cranial nerves in being an outgrowth from the brain. In its history, which is closely connected with that of the eye, there is first formed the optic stalk with the optic vesicle at its tip (see eye for details). The stalk grows out from the recessus opticus and hence is clearly dorsal in position. Soon after the involution of the optic cup, nerve cells are proliferated from the distal surface of the retina, which pass through the chorioid fissure and along the groove on the ventral side of the optic stalk. These fibres and not the cells of the stalk form the definitive optic nerve of the adult, and the cells from which they arise form the optic ganglion, which, to a certain extent, is comparable to the ganglion of a dorsal root. This view also lessens the differences between the optic and other cranial nerves, a view which was natural before the history of the nerve was known and when it was thought that the stalk itself was transformed into the nerve.

The nerve fibres, in their centripetal growth, do not stop on reaching the diencephalon, but continue across its ventral surface and become connected with the opposite side of the brain. There is thus a crossing or chiasma of the optic nerves, that from the left eye going to the right side of the brain and vice versa. In most vertebrates the chiasma is plainly seen from the surface, but in cyclostomes and dipnoans it may occur in the substance of the brain itself. In the lower vertebrates the chiasma is complete and the nerves from the two sides may simply overlap or they may interlace with varying degrees of complexity. In the mammals, on the other hand, the chiasma can be analyzed only by microscopic methods, so intimately are the fibres interwoven, while here some of the fibres ('lateral fibres'), instead of crossing, enter the corresponding side of the brain. The internal connections of the optic nerves are not with the 'twixt-brain, but the fibres, after passing the chiasma, grow dorsally and posteriorly and become connected with the dorsal part of the mid-brain, hence called the optic lobes.

There has been described in the embryo elasmobranch, under the name thalamic nerve a small strand arising between the di- and mesencephalon. It disap- 
pears without leaving a trace, unless it contribute to the ciliary ganglion. Its status as a nerve is very uncertain.

The Eye Muscle Nerves (fig. I37).- The III (oculomotorius), IV (trochlearis) and VI (abducens) nerves are distributed to the muscles which control the movements of the eye and hence are treated together. The oculomotor supplies the superior, inferior and internal rectus and inferior oblique muscles; the trochlearis goes to the superior oblique, while the abducens innervates the external rectus muscle.

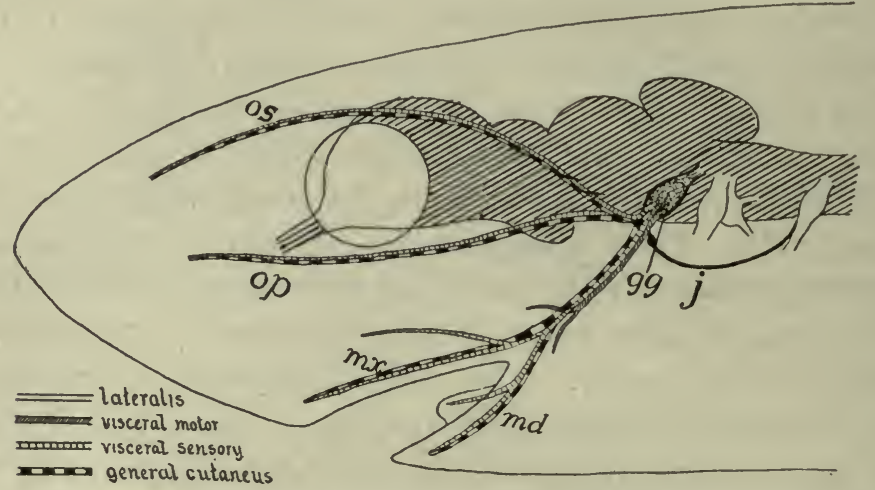

FIG. I70.-Diagram of branches and components of the fifth or trigeminal nerve in a shark. $g g$, Gasserian ganglion; $j$, Jacobson's commissure, connecting with glossopharyngeal; $m d$, mandibularis nerve; $m x$, maxillaris nerve; $o p$, os, ophthalmicus profundus and superficialis nerves.

These peculiarities of distribution are explained by the development of the muscles (p. r28), the derivatives of each somite having a common nerve supply. The oculomotor nerve springs from the ventral surface of the mid-brain, the fourth from the dorsal surface at the hinder margin of the mesencephalon, while the sixth comes from the ventral surface of the myelencephalon. Inside the brain the trochlearis is traced to its nucleus in a ventral position.

In the majority of vertebrates these nerves are readily traced from the brain to the muscles they supply, but not infrequently the abducens (lacking in Petromyzon) is united proximally with the fifth nerve, while in a few forms the trochlearis has not been recognized, and it is said that in the adult Bdellostoma all eye-muscle nerves are lacking. The ciliary ganglion is closely associated with the oculomotor nerve. All three eye-muscle nerves belong to the somatic motor group.

V. The Trigeminal, one of the largest of the cranial nerves, arises 
from the anterio-lateral angle of the myencephalon, and its fibres pass almost immediately into the semilunar (Gasserian) ganglion, which may lie either within or without the skull. In the higher vertebrates the nerve divides beyond the ganglion into three main trunksophthalmic, maxillary, and mandibular-whence the name. In the lower vertebrates the maxillary and mandibular pursue a common course for some distance before separating.

In the fishes the ophthalmic is represented by two branches, an ophthalmicus superficialis (not to be confused with the similarly named branch of the seventh with which it is closely associated) and an ophthalmicus profundus, which passes between the eye muscles on its way to the tip of the head. Both are purely sensory; in most vertebrates general cutaneous, but in the teleosts they, together with the maxillary, supply also the taste organs (visceral sensory) of the surface of the head. The superficialis innervates the skin above and in front of the eye; the profundus goes to the eyelids, conjunctiva, snout and the mucous membrane of the nose, passing through the ciliary ganglion in its course. In the urodeles, where the maxillaris is reduced, the profundus supplies its region.

The maxillaris, with components similar to those of the ophthalmic, runs beneath the eye, passing the sphenopalatine ganglion (p. I65) in its course, supplying much the same territory as the ophthalmic and, in addition, the roof of the palate and the teeth of the upper jaw.

The mandibularis ramus is a mixed nerve. The motor components (visceral) innervate the muscles of the jaws, some muscles of the floor of the mouth and in mammals the tensor tympani muscle. The sensory component (general cutaneous) divides into two parts, the lingualis going to the tongue and the mandibularis to the skin of the lower jaw, chin and lower lip, and to the lower teeth. In mammals there is a weak auricularis superficialis nerve arising from the mandibularis and going to the temporal region and to the conch of the ear.

Two ganglia of the sympathetic system are associated with the trigeminal: the otic ganglion near the exit from the skull and the submaxillary where the lingualis bends to enter the tongue. From the otic a trunk (Jacobson's commissure, p. 165) runs back to connect with the ninth nerve.

The fifth nerve is usually compared to a post-otic nerve (vide infra) in that the mouth is regarded as the homologue of a pair of gill clefts, the maxillary being the pre- and the mandibularis the post-trematic nerves (see nerve IX, below). The homologies of the ophthalmicus are less certain. Some facts seem to point 
to the fifth being a compound nerve, this branch being the remnant of a somite otherwise lost. Others would view the ophthalmic as the representative of the dorsal ramus of a spinal nerve.

VII. The Facial Nerve, the hindmost of the preotic nerves, differs greatly in the branchiate and the pulmonate vertebrates. In all there is a close association with the eighth nerve, and in the anura, some teleosts and ganoids, and in the holocephals the fifth and the seventh are so closely related that their ganglia are fused.

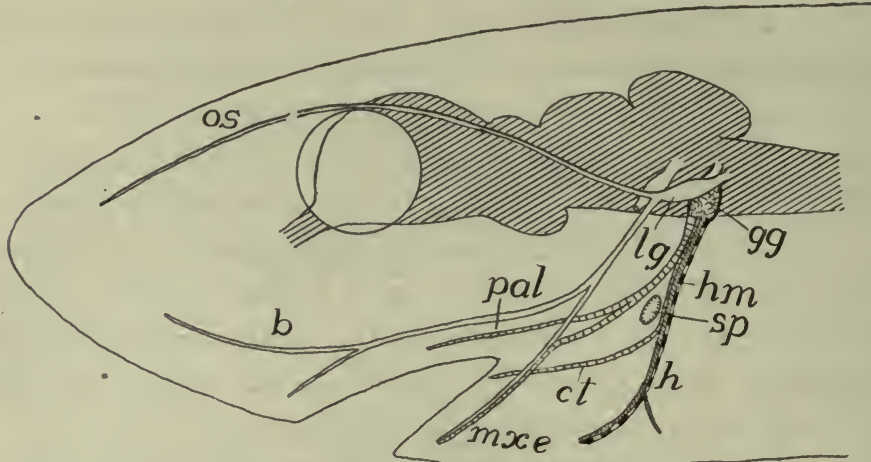

FIG. I7I.-Dagram of seventh (facial) nerve; for components see fig. I70. $b$, buccalis nerve; $c t$, chorda tympani; $g g$, geniculate ganglion; $h$, hyoid nerve; $h m$, hyomandibular nerve; $l g$, lateralis ganglion; $m x e$, maxillaris externus nerve; os, ophthalmicus superficialis nerve; pal, palatine nerve; $s p$, spiracle.

In the aquatic ichthyopsida the several roots by which the seventh nerve leaves the medulla unite in a compound ganglion, the upper element being the ganglion of the lateralis component, the lower the geniculate, the true ganglion of the seventh nerve. Beyond the ganglion the nerve divides into five trunks, as follows:

$A$. The ophthalmicus superficialis, which runs forward near the dorsal surface of the head; $B$. the buccalis, which courses nearly parallel to the maxillaris of the trigeminal and is often bound up with it; $C$. the mandibularis externus, which usually divides into two branches, usually follows much the same course as the mandibularis trigemini, and supplies the lower jaw and the spiracular and hyoid region; $D$. the palatinus which goes to the mucous membrane of the oral cavity, $E$. the hyoideus (usually united with the mandibularis for some distance as a hyomandibular nerve), which goes ventrally and supplies the mucosa of the mouth and the muscles of the hyoid region. In cases, like many elasmobranchs, where a spiracle is present, the hyomandib- 
ularis passes behind it and hence is a post-trematic ramus. In some cases a small twig bends down from the palatine and represents the pretrematic branch.

Three of these-ophthalmicus superficialis. buccalis and mandibularis externus-belong to the lateralis system, which is unrepresented in the spinal nerves. This has its own ganglion, which may unite with geniculate or semilunar, and it supplies the lateral line system of the head (see sense organs). The superficial ophthalmic innervates the supraorbital line of these organs, and in the elasmobranchs, breaks up distally to go to the modified organs (ampullæ of Savi and Lorenzini) at the tip of the snout. In the same way the buccalis supplies the infraorbital line and the mandibularis externus those of the lower jaw and the hyoid and spiracular regions.

As there are no myotomic muscles in the region supplied by the facial nerve, there are no somatic motor components The general cutaneous elements run in the hyoideus to the skin of the hyoid region, but in other vertebrates this territory is supplied by branches of the fifth, which spread to the operculum and to the dorsal surface of the head. The visceral motor components occur in the hyoid nerve and, in the aquatic forms, they supply the muscles of the hyoid region and the posterior belly of the depressor mandibulæ. In the mammals, with the development of the muscles of expression (p. I34), the same branch (known in human anatomy as the main branch of the facial) has a much greater extension, the result of the migration of the muscles from the hyoid region to their definitive position.

The geniculate ganglion belongs to the visceral sensory system, the fibres of which run in the hyoid and palatine nerves to reach the sense organs in the oral cavity and in the spiracular gill when this is present. In those fishes where there are taste organs on the outer surface of the body there is a 'nerve of Weber' (ramus lateralis accessorius) which goes to the dorsal surface of the head and then to back, fins and tail, wherever the gustatory organs occur. It is frequently accompanied by fibres of the tenth nerve. In the mammals the visceral sensory fibres occur in the main trunk of the seventh, in the great superficial petrosal and in the chorda tympani nerves. This last is a post-trematic nerve which passes through the middle ear and thence on the medial side of the lower jaw to join the lingualis.

In the adult anura and in the amniotes, where gills and lateral line organs are lacking, the facialis undergoes a corresponding reduction, 
the lateralis nerves being lost, while, as stated above, the motor portions are increased in the mammals, in correlation with the greater development of the facial muscles.

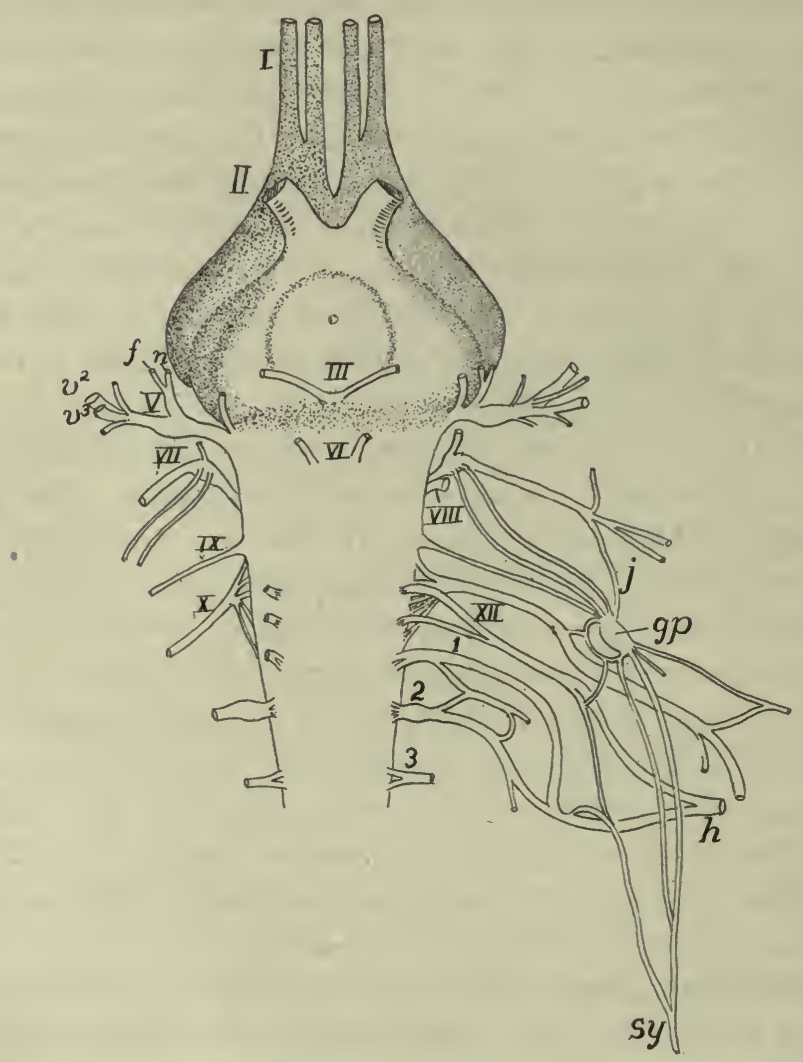

FIG. I72.- Ventral view of brain and cranial nerves of Iguana, after Fischer. I-XII, cranial nerves; $I-3$, first three cervical nerves; $g p$, petrosal ganglion; $i$, Jacobson's commissure; $h$, hypoglossal; $n$, nasalis ramus of $\mathrm{V} ; r f$, ramus frontalis of $\mathrm{V}$; $s y$, sympathetic.

VIII. The Acustic (Auditory) Nerve is closely associated with the seventh, but microscopic analysis shows that it has its own roots and ganglion. It is purely sensory, its branches going to the sensory areas of the inner ear. Its connections inside the brain and the development of the ear itself (see sense organs) show that the nerve belongs to the lateralis system, the ear being a group of modified lateral line organs. Beyond the ganglion the nerve divides into a vestibular branch, supplying the utriculus and semicircular canals, and a cochlear branch, going to the lagena and to its homologue in the mammals, the cochlea. 
IX. The Glossopharyngeal, the first of the post-otic nerves, has its typical development in the branchiate vertebrates. Its roots, both motor and sensory, pass into the petrosal ganglion, beyond which a dorsal ramus is given off to the top of the head, while the main trunk, passing outward and backward, leaves the skull, either by its own foramen (most branchiates) or together with the tenth nerve (anura and amniotes). It divides, just above the first gill cleft, into pre- and posttrematic nerves, which run in the anterior and posterior walls of the cleft to the ventral wall of the pharynx, the pretrematic giving off a nerve to the mucous membrane of the palate. Ninth and tenth nerves

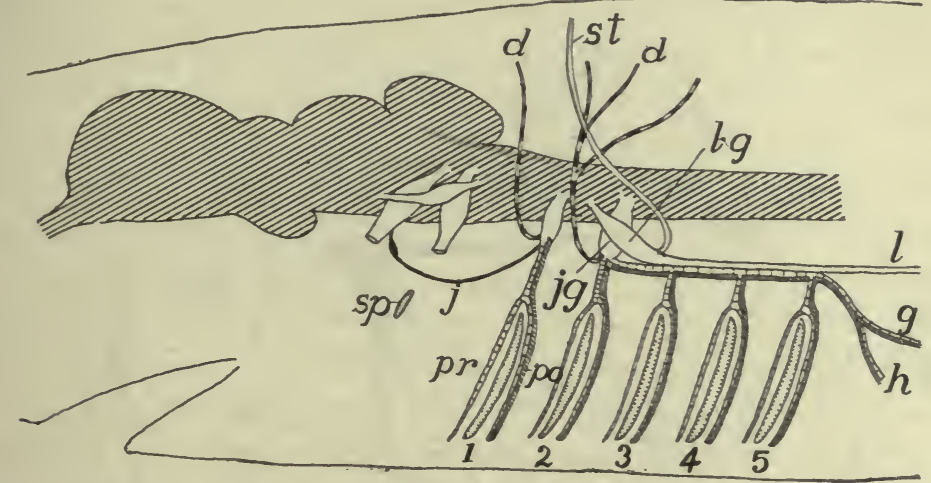

FIG. I73.-Diagram of ninth (glossopharyngeal) and tenth (vagus) nerves of a shark; for components see fig. I70. $d$, dorsal ramus; $g$, gastric nerve; $h$, to heart; $j$. Jacobson's commissure; $l$, lateralis nerve; $l g$, lateralis ganglion; $p o, p r$, post- and pretrematic branches; $s p$, spiracle; $s t$, to supratemporal lateral line organs.

are usually closely associated (their ganglia may fuse), while ninth and fifth are frequently connected by Jacobson's commissure and the palatine branch may connect with the geniculate ganglion. The glossopharyngeal may contain three kinds of components, the somatic motor fibres being absent because of the failure of the myotomic muscles to develop. The general cutaneous is usually represented by the dorsal ramus alone, but in Petromyzon its fibres reach the ventral skin through the post-trematic nerve. The visceral sensory fibres reach the taste organs by way of the pharyngeal and lingual nerves, while the visceral motor elements go to the muscles of the gill region by way of the posttrematic ramus.

$\mathrm{X}$. The Vagus is a complex of nerves, each similar to the ninth, with the addition, in the branchiates, of lateralis components, and supplying in them the remaining gill clefts. Numerous rootlets pass from 
the medulla to the ganglion jugularis, beyond which the dorsal rami arise and then the main trunk runs backward, giving off as many branchial nerves as there are gill clefts, each with an epibranchial ganglion and each dividing into pre- and post-trematic rami. To this extent the tenth is a polymeric nerve with coalesced proximal portions.

Near the last cleft the main trunk divides into two nerves. One of these, the ramus lateralis, continues back, just beneath the skin, to innervate the lateral line organs of the trunk and tail. The other, the

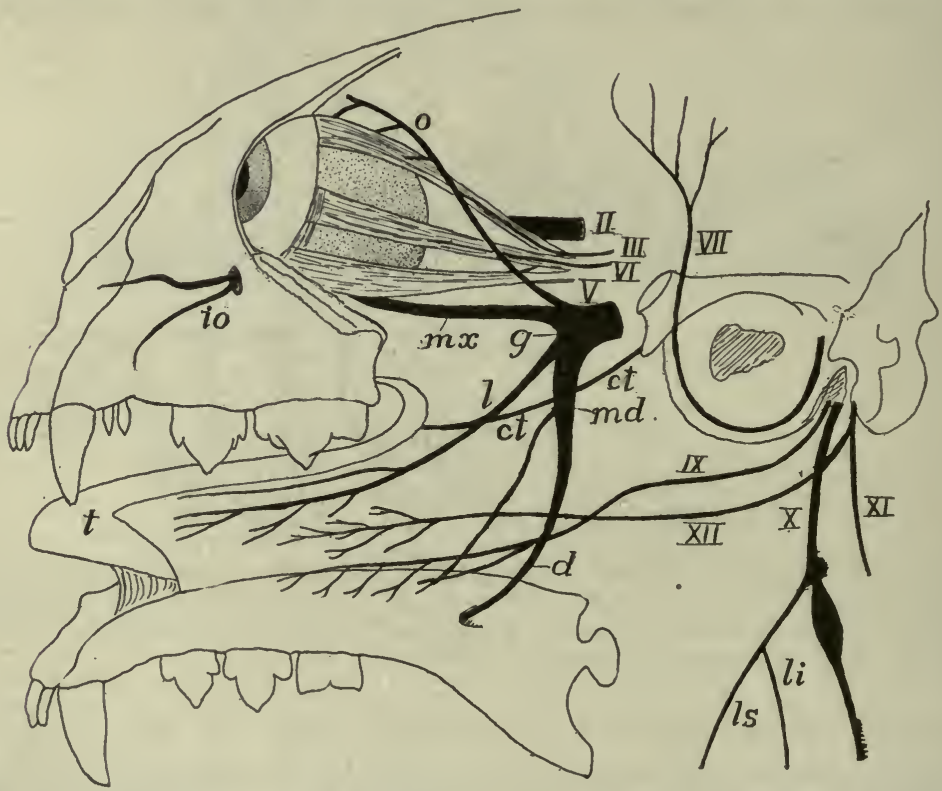

FIG. I74.-Diagram of cranial nerves of a cat, the lower jaw reflected, after Mivart. $I I-X I I$, cranial nerves; $c t$, chorda tympani; $d$, dentary nerve; $g$, Gasserian ganglion; $i o$, infraorbital nerve; $l$, lingual nerve; $l i, l s$, laryngeus inferior and superior; $m d$, mandibularis nerve; $m x$, maxillaris nerve; $o$, ophthalmic nerve; $t$, tongue.

ramus intestinalis, goes inward and backward to supply the œsophagus, stomach, heart and other viscera (in air-breathing vertebrates the lungs also, whence the name pneumogastric nerve). In the dorsal rami and the branchial nerves the components are about the same as in the ninth nerve. The most caudal of the motor roots of the vagus furnish visceral motor fibres which go to some of the muscles connected with the pectoral arch and appendages, while others pass, by way of the intestinalis, to the viscera. In the same way visceral sensory fibres go through the same nerve to the taste buds of the pharynx, and in the 
higher vertebrates the same components occur in the pharyngeal, laryngeal, œsophageal, and gastric branches of the intestinalis. The distribution of the vagus shows that the parts supplied are to be regarded as morphologically derived from the head, though (heart, lungs and stomach) they may be far removed from it in the adult.

Although details have been mentioned, some differences between air- and water-breathing vertebrates may be summarized. The lateral line organs are associated with an aquatic life, occurring in the branchiate forms, even of the amphibia. With the assumption of a pulmonate respiration the lateral line organs are lost and with them go the lateralis elements of the seventh and tenth nerves. In the amniotes neither the organs nor the nerves appear, even in development. Also the loss of gills, and the closure of the clefts results in a modification of the nerves of the ventral regions.

XI. The Accessory Nerve appears as a distinct nerve in the amniotes, though traces of it appear in the ichthyopsida where the posterior roots of the vagus furnish fibres which go to muscles in the pectoral region. In the amniotes the number of these roots is increased (up to seven in mammals), the additions being made to the posterior end of the series. The fibres run forward between the dorsal and ventral roots of the cervical nerves and unite to form a trunk, distinct from the vagus, which bends back to supply muscles connected with the pectoral arch. The components of this accessory nerve belong to the visceral motor system, and the explanation of muscles connected with locomotion being supplied by visceral nerves is not easy.

XII. The Hypoglossal Nerve of the adult contains only somatic motor fibres, but in the young of several forms, both amniote and ichthyopsidan, two or more ganglionated roots are formed which soon disappear. The roots of the nerve lie at the junction of brain and spinal cord, and hence the nerve lies outside the skull in the lower, inside it in the higher forms. The nerve contributes to the innervation of the tongue, the trunk and the brachial plexus in the lower vertebrates, while in the higher groups it is more restricted to the tongue and the sternohyoid muscle.

\section{THE SENSORY ORGANS.}

The sensory organs are to receive information from without and to transform it into stimuli to be carried by the nerves to the ganglia, usually those of the central nervous system. This information varies 
in character and the organs consequently differ in structure according to the impressions they are to receive.

With very few exceptions the characteristic portions of the organs, the sensory cells, arise from the ectoderm, but accessory parts, chiefly of mesodermal origin, may be so abundant as to form the bulk of the organ. In some cases the organs may remain in connexion with the surface of the body (the parent ectoderm) throughout life, but frequently they sink to a deeper position and become surrounded with a protective sense capsule, while those connected with the sympathetic system may be scattered throughout almost the entire body.

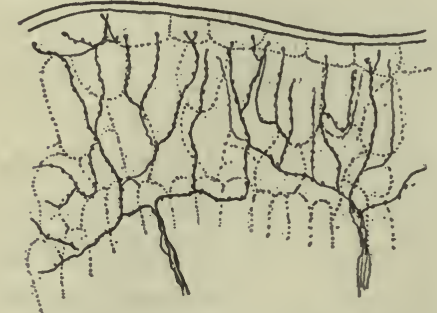

Fig. 175.-Free nerve terminations in the skin of Salamandra, freely after Retzius.

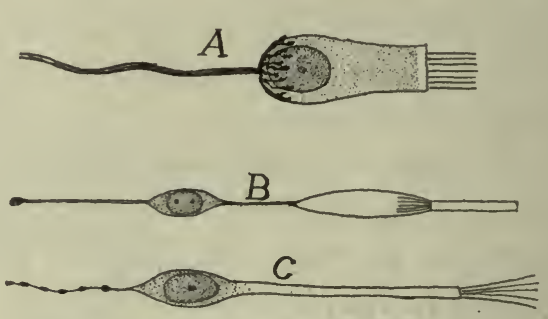

Fig. I76.-Sensory cells, after Fürbringer. $a$, crista cell of ear; $b$, rod cell of eye; $c$, olfactory cell.

The recipient structures may be of two kinds. In the one (fig. I75) the ends of the nerve receive the impressions from without, often aided by various accessory structures. In the other there are specialized sense cells (fig. I76), the peripheral ends of which bear different kinds of cuticular percipient parts-hairs, bristles, rods, cones, etc.-while the basal ends of the cells are connected with the terminations of nerve cells which act as the conducting elements. The distinction between the two is one of convenience rather than one of physiological or morphological importance, for the 'nerves' of the first are in reality but the prolongations of sensory cells.

\section{Nerve-end Apparatus.}

In many cases-skin, alimentary tract, muscles, etc. - the ends of the sensory nerves lose their medullary sheath and break up into fine fibrillæ which terminate, without special accessory structures, among the cells of the tissue to which they are distributed (free nerve terminations). On the other hand, there are numerous end organs, espe- 
cially among the terrestrial vertebrates, in which accessory parts are present. For details of these reference must be made to histological text-books; only a mention of some of the kinds can be made here.

In the simple tactile corpuscle the nerve terminates with a cup in which is seated a lenticular tactile cell (fig. I77, $A$ ). Somewhat allied are Grandry's (Merkel's) corpuscles in which two or more tactile cells are enclosed in a connective tissue sheath, while the nerve, losing its medullary sheath as it reaches the capsule, expands into plates which are inserted between each two tactile cells (fig. I77, B).

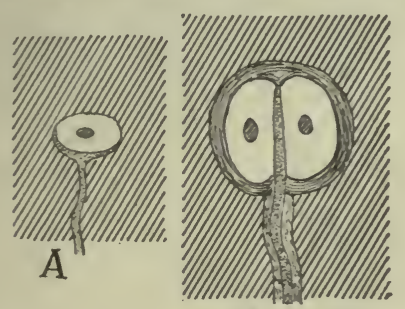

$B$

FIG. I77.- $A$, tactile corpuscle; $B$, Grandry's corpuscle.

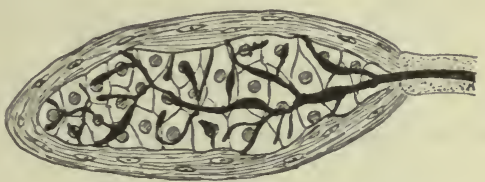

FIG. I78.-Vater-Pacinian corpuscle.

In another series of sensory structures the end of the nerve is clubshaped and is surrounded by a connective-tissue sheath, either simple (cylindrical corpuscles), or in Pacini's (Vater's, fig. I78) and Herbst's corpuscles, the sheath is formed of layers of cells, recalling the coats of an onion, while immediately around the club is a layer of cubical cells. Still another variant is found in Krausse's (corpusculum bulboideum) and Meissner's corpuscles, where the nerve, on entering the corpuscle, breaks up into numerous branches which surround an axial core of large cells.

It is impossible at present to state with certainty the function of each of these and other nerve-end apparatuses and to say which are connected with the different senses-tactile, pressure, pain, heat and cold, muscular, etc.- -which are commonly confused under the term 'touch.'

\section{Lateral Line Organs.}

The lateral line organs occur only in the ichthyopsida and here only during the branchiate stages. They arise as thickenings of the ectoderm on either side of the head in the neighborhood of the ear. From here the thickenings extend in definite lines which determine the 
series of organs in the adult. At points on these lines the sensory areas are developed by the differentiation of two kind of cells, the supporting cells which extend through the epidermis from the corium to the free surface, and the sensory cells which reach from the surface only part way to the base. The latter are pear-shaped and bear cuticular hairs or bristles on their free ends (fig. I79), while the deeper ends are embraced by the non-medullated fibrils of the lateralis system of nerves, which follow the lines of organs, and in development keep pace with their extension. These sensory areas are the nerve hillocks or neuromasts already referred to.

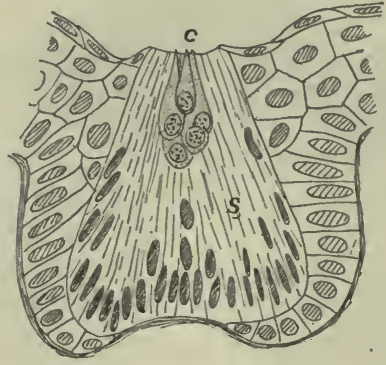

FIG. 179 .

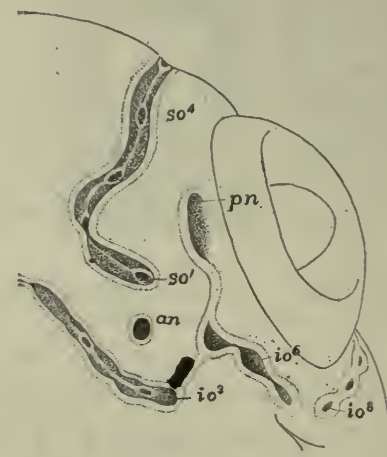

FIG. I80.

FIG. I79.--Sense organ of lateral line of Diemyctylus (aquatic form) freely after Kingsbury, $C$, cone cells; $s$, spindle cells.

FIG. 180.-Developing lateral line organ on one side of head of $A$ mia, showing method of closure of grooves to canals, after Allis. an, anterior naris; $i o$, so, infra- and supraorbital lines; $p n$, posterior naris.

In the cyclostomes and aquatic amphibia each sensory patch sinks into a separate pit (fig. I79), but in all other itchhyopsida the lines of organs sink in the same way, the patches being connected by grooves. In Chimara these grooves remain open, but in all others they are closed except at certain points where pores connect the canals formed by the closed grooves with the exterior. In this way the sensory areas come to lie in canals beneath the surface, water obtaining access to them through the pores. In many teleosts (fig. I8I) the pores pass through notches or openings in the scales, while on the head the canals themselves frequently run through some of the cranial bones.

Of considerable morphological importance, especially in connection with the morphology of the ear, are the facts that the sensory areas multiply by elongation, followed by division, and that the pores themselves increase in the same way 
(fig. I80); the pore elongates and then its margins meet in the middle, thus producing two pores. There has been much discussion as to the development of the lateralis nerves, especially that of the trunk, some thinking that it increases by additions from the ectoderm of the skin. It appears more probable that all of its material is derived from the nerve and that there are no additions from other sources.

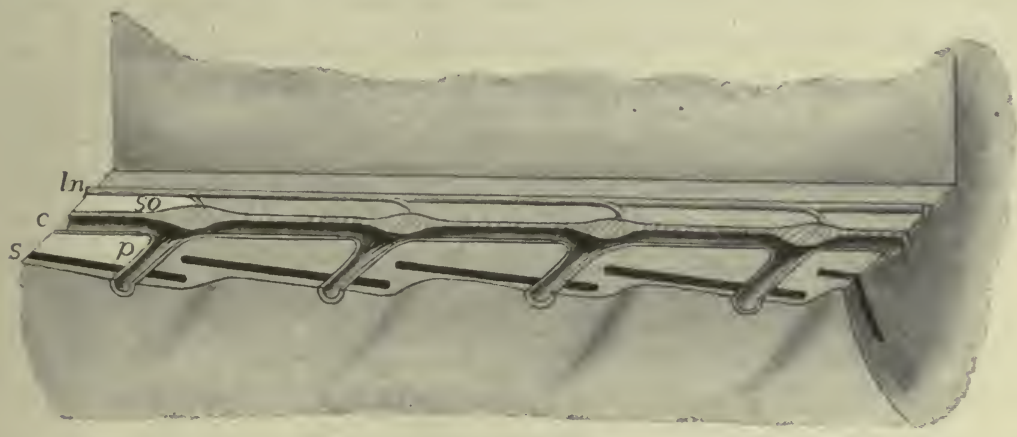

FIG. I8r.-Stereogram of lateral line organs of a fish. $c$, lateral line canal; $l n$, lateralis nerve; $p$, pores connecting with the exterior; $s$, scales in skin; so, sense organs of lateral line.

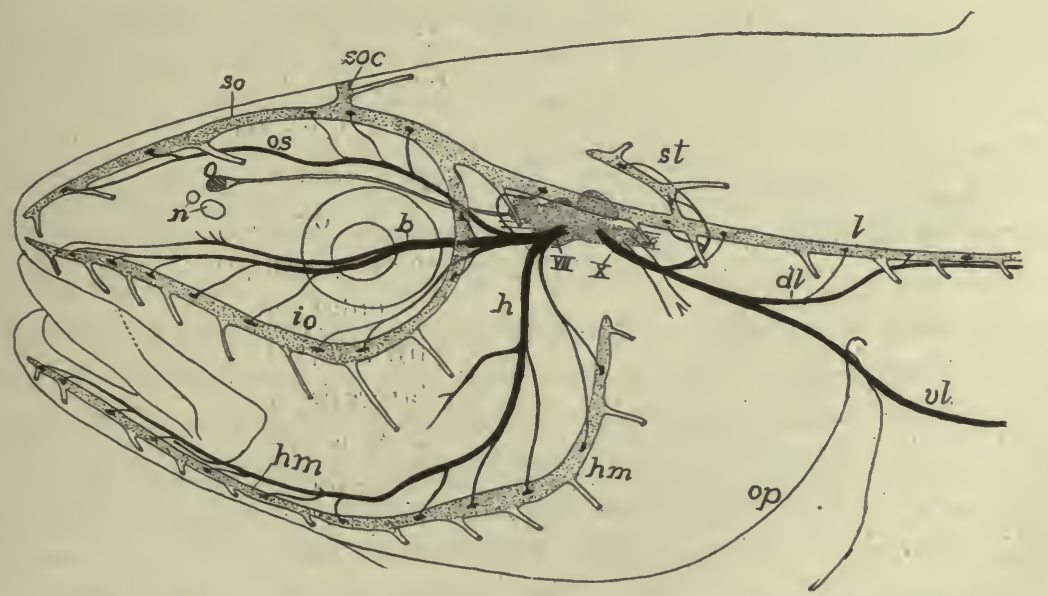

FIG. 182.-Head of pollack, showing lateral line canals and nerves of the lateralis system, after Cole. Lateralis nerves black, canals and brain dotted. $b$, buccalis ramus of VII nerve; $d l$, dorsal ramus of lateralis of $\mathrm{X}$ nerve; $h$, hyomandibularis nerve; $h m$, hyomandibular line of organs; $i o$, infraorbital line; $l$, lateral line canal; $n$, nares; $o$, olfactory lobe; $o p$, operculum; os, ophthalmicus superficialis nerve; soc, commissure connecting lines of the two sides; so, supraorbital line of organs; st, supratemporal part of lateral line; $v l$, ventral ramus of lateralis of $\mathrm{X}$ nerve; $x$, visceralis part of $\mathrm{X}$ nerve.

The distribution of these organs and their canals varies considerably. The most constant lines are the following (fig. I82): A supraorbital line running forward from the region of the ear, above the eye, to the 
tip of the snout and innervated by the ophthalmicus superficialis branch of the seventh nerve; an infraorbital line running in the same way beneath the eye and supplied by the buccalis nerve; a hyomandibular line extending along the lower jaw (and the operculum when present), and innervated by the mandibularis externus; and lastly the lateral line proper (sometimes double) which runs back on either side to the tail and is supplied by the lateralis of the tenth nerve. Frequently the systems of the two sides are connected by a supratemporal line extending across the hinder part of the skull, from one side to the other.

The lateral line organs appear in the larvæ of all amphibia, but on the assumption of a terrestrial life they sink beneath the skin and usually degenerate, all traces of them and the lateralis nerves being lost in the adult. In a few cases (Triton, Amblystoma, etc.) they are said not to be entirely lost, but to reappear at the surface when the animals return to the water for oviposition. Various functions have been assigned to the lateral line organs. Since they contain much mucus they were long called slime organs. Then they were recognized as sensory and a 'sixth sense' was attributed to them. Recently it has been made very probable that they are to recognize vibrations of a slow rate in the water and thus, among other things, to determine currents, etc.

Closely allied to the lateral line organs in nerve supply are the ampullæ of Savi and Lorenzini which occur on the head of elasmobranchs. Each consists of a long tube, opening by a pore at the surface of the skin and ending with a chambered enlargement, the ampulla, at the deeper end. The tube is filled with a crystal mucus and the ampulla is embraced by fibres of the lateralis nerve. The organs have been supposed to be connected with a pressure sense. The statement is made that when they are removed the fish is unable to sink; this may throw some light on their functions.

\section{The Auditory Organs.}

Both in character of innervation and in certain peculiarities of development the sensory parts of the vertebrate ears are closely related to the lateral line organs. In their most complete expression three parts are recognized in the auditory organs, the outer, middle and inner ears. Of these the last is the essential portion and occurs in all vertebrates, the middle ear first appearing as such in the amphibia 
and the outer ear, more or less completely developed, is found only in the amniotes.

The Inner Ear arises as a circular area of thickened ectoderm on either side of the head, between the seventh and ninth nerves (fig. I36). This soon becomes cup-shaped and then the cup closes in to form an auditory vesicle (fig. I83), the cavity of which is connected with the exterior by a slender tube, the endolymph duct, the result of incomplete

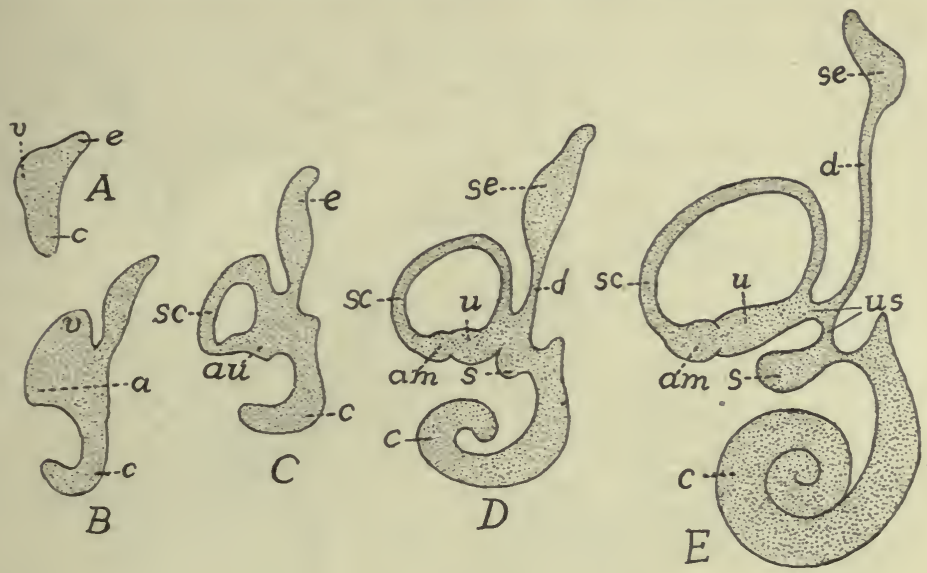

Fig. I83.-Diagram of developing human labyrinth from 6 to $30 \mathrm{~mm}$. long, after Streeter. $a$, ampulla; $c$, cochlear region and cochlea; $a u$, ampullo-utricular region; $d$, endolymph duct; $e$, endolymph region; $s c$, semicircular canal; se, endolymph sac; $s$, sacculus: $u$, utriculus; $u s$, utriculo-saccular canal; $v$, vestibule.

closure. As one portion of the medial wall of the vesicle develops an area of sensory epithelium like that of the lateral line system, this stage may be compared to an isolated canal organ with a single pore.

In the amphibia and some of the ganoids, where there is a two-layered ectoderm from the early stages, there is never an open auditory cup. The lower, so-called nervous layer of the ectoderm is alone concerned in the formation of the auditory vesicle, while the outer layer extends as an unbroken sheet across the cup. In the elasmobranchs the endolymph duct opens to the exterior throughout life, the external pores being recognizable on the top of the head. Elsewhere they later lose their external openings, and the distal end of each usually expands into an enlargement, the sacculus endolymphaticus; but in the amphibia the ducts of the two sides may unite dorsal to the brain, while other parts may branch and grow in a root-like manner, in the canal of the spinal cord, sending diverticula (frog) into the so-called calcareous glands, which surround the basal parts of the spinal nerves.

The next stage in the auditory vesicle is its differentiation by a constriction into two chambers, an upper vestibulum or utriculus 
and a lower sacculus (fig. I83), the two connected by a narrow sacculo-utricular canal. The sensory area becomes divided between the two, but the endolymph duct is connected with the sacculus alone. The anterior, posterior and lateral walls of the utriculus now produce flattened outgrowths, the lateral in the horizontal, the others in vertical planes, and parts of the sensory areas extend into each. Next, the walls of these diverticula become pinched together so that each pocket

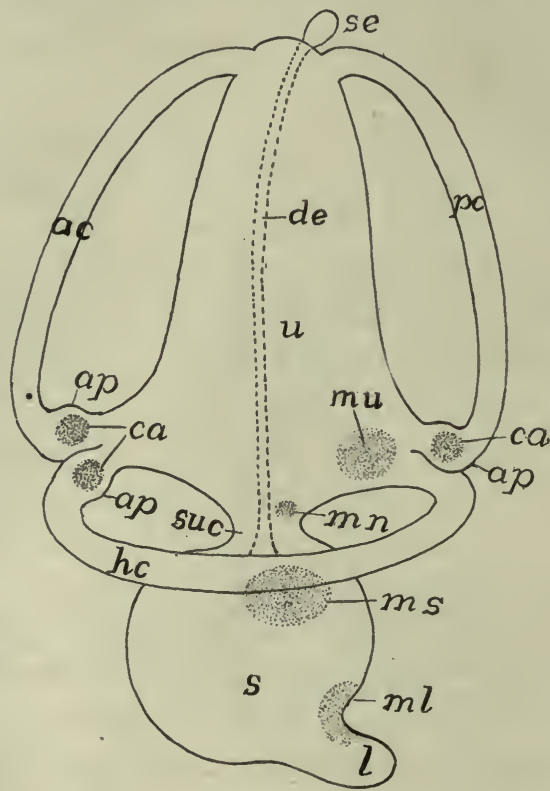

FIG. I84.-Diagram of the membranous labyrinth of a vertebrate, the sensory areas dotted. $a c$, anterior semicircular canal; $a p$, ampullæ; $c a$, cristæ acusticæ in the ampullæ; $d e$, ductus endolymphaticus; $h c$, horizontal (external) canal; $l$, lagena; $m l, m n, m s, m u$, maculæ of lagena (neglecta, sacculi and utriculi); pc, posterior semicircular canal; $s$, sacculus; se, saccus endolymphaticus; suc, sacculo-utricuar canal; $u$, utriculus.

is converted into a tube or canal, open at either end into the utriculus, and hence approximately semicircular in outline. In one end of each of these semicircular canals there is a patch of sensory epithelium and the wall expands around this into an ampulla, the ampullæ of the anterior and external canals being side by side, that of the posterior canal at its lower end.

In the lower ichthyopsida there is little differentiation in the sacculus, but in the higher a pocket, the lagena, is given off from its posterior side, a portion of the sensory epithelium extending into it. With in- 
creasing powers of hearing the lagena becomes greatly elongate, until in the mammals it acquires a peculiar development and is known as the scala media, the structure and relations of which are described below.

In the cyclostomes utriculus and sacculus are not differentiated. In the myxinoids there is but a single semicircular canal, with, however, an ampulla at either end. In the lampreys there are two canals, both in the vertical plane, and each with an ampulla at its lower end.

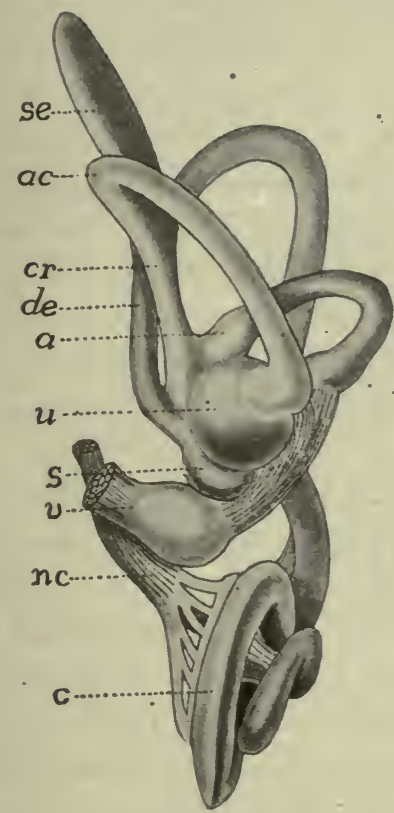

Fig. 185 .

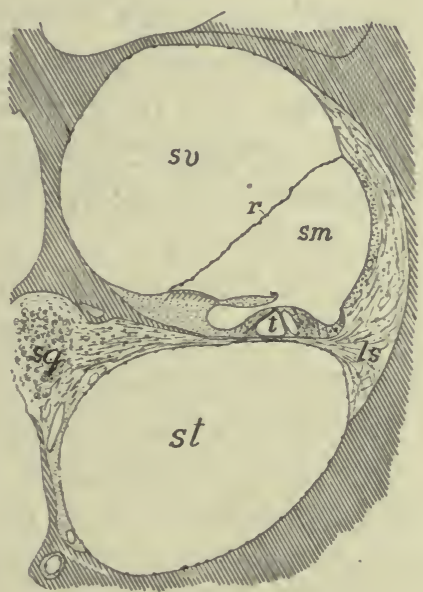

FIG. I86.

Fic. 185:-Labyrinth of human embryo, $30 \mathrm{~mm}$. long, after Streeter. $a$, ampulla; $a c$, anterior canal; $c$, cochlea; $c r$, crus; de, endolymph canal; $n c$, cochlear nerve; $s$, sacculus; se, endolymph sac; $u$, utriculus; $v$, vestibular nerve.

Frg. 186. - Section through one of the coils of cochlea of guinea pig, after Schneider. Bone lined; $l s$, spiral ligament; $r$, Reissner's membrane; $s g$, spiral ganglion; $s m, s t$, $s v$, scalæ media (ductus cochlearis), tympani and vestibuli.

These parts of the internal ear form the membranous labyrinth. With the formation of canals, lagena, etc., the sensory epithelium divides into separate areas (fig. I84), some of which (maculæ acusticæ) have sensory cells with short hairs or bristles, while others (cristæ acusticæ), characteristic of the ampullæ, have cells with longer hairs. The membranous labyrinth is filled with a fluid, the endolymph, in which are solid particles, the otoliths. These are usually microscopic crystals of calcium carbonate which give the endolymph 
a milky appearance, but in the teleosts the lime is aggregated into one or more 'ear stones' of considerable size.

With the appearance of cartilage the membranous labyrinth becomes enclosed in a protecting otic capsule (p. 60), which usually follows pretty closely the divisions and canals of the epithelial parts, thus forming the skeletal labyrinth, separated from the membranous labyrinth by a slight gap filled with fluid (the perilymph). When ossification occurs the skeletal labyrinth is converted into the several otic bones. Sometimes the perilymph space is separated from the brain cavity by membrane alone, but usually firmer structures intervene, interrupted only by foramina for the passage of nerves and bloodvessels, for the endolymph duct and for a similar perilymph duct which extends downward. On the other hand, in all vertebrates in which the middle ear is developed the lateral part of the skeletal wall has two openings into the middle ear. The lower of these (fig. I88), the fenestra tympani (f. rotunda), is closed by membrane. In the upper (fenestra ovale or vestibuli) the membrane supports a small bone, the stapes (p. 73).

One part of this compound skeletal and membranous labyrinth of the mammals becomes very complicated. The lagena becomes greatly elongated and in order to accommodate its length it is coiled in a spiral, its sides reaching the walls of the skeletal labyrinth on either side. In this way the perilymph space is divided into two spiral tubes (fig. I86), called scalæ, from their resemblance to spiral stairways. The upper of these is the scala vestibuli, the lower the scala tympani, while the scala media is formed by the lagena. This whole part of the inner ear is the cochlea, so-called from its resemblance to a spiral shell.

The sense organ of the scala media is very specialized and is known as the organ of Corti (fig. I87). In general it may be said that the scala diminishes in width from base to apex of the cochlea, and is accompanied in its coils by a branch (cochlear) of the acustic nerve. The sensory structures consist of hair cells and Deiter's cells, regularly arranged, and a series of pillar cells, inclined to each other like the rafters of a roof, in an A-like manner (fig. 187). As the A's diminish in width from base to apex of the cochlea, this part has been thought to play a part in the recognition of pitch. There is also a cuticular structure, the membrana tectoria, which extends from the medial wall out over the hair cells, and this may be the intermediate organ of stimulation 
and may have to do with the recognition of sound waves of different rapidity. It has recently been shown that the membrana tectoria is connected with the hairs of the hair cells. The fact that in birds, where pitch is certainly recognized, there is no organ of Corti, renders all speculation doubtful.

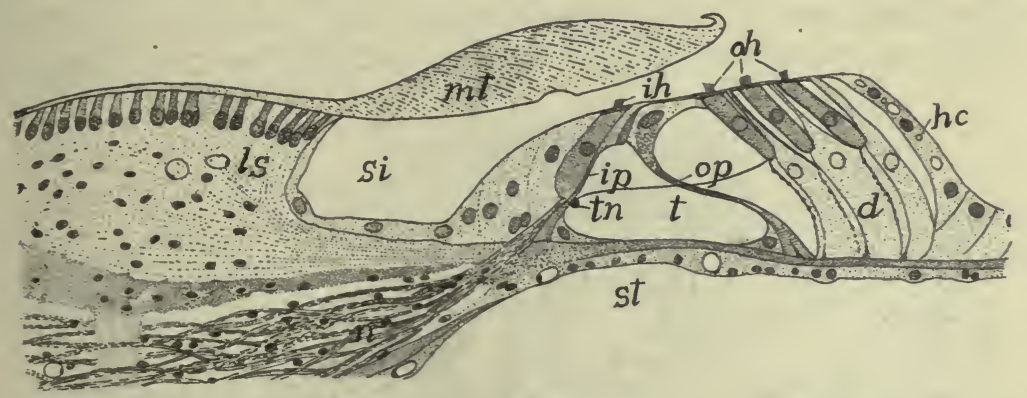

FIG. I87.-Organ of Corti of guinea pig, after Schneider. $d$, Deiter's cells; $h c$, Henson's cells; $i h$, inner hair cells; $i p$, inner pillar cells; $l s$, limbus spiralis; $m t$, membrana tectoria; $n$, nerve fibres; oh, outer hair cells; $o p$, outer pillar cells; si, inner sulcus; $s t$, scala tympani; $t$, tunnel; $t n$, tunnel nerve.

The Middle Ear or tympanum first appears in the anura. It consists of a cavity (cavum tympani) in front of and below the otic capsule, connected by a slender duct, the Eustachian tube, with the pharynx. Externally it is separated from the outer world by a thin partition, the tympanic membrane, from which a chain of bones, the ossicula auditus (p. 73), extends across the cavity to the fenestra ovale, and serves to transmit the sound waves to the inner ear. The tympanic cavity is the homologue of the spiracular cleft of the elasmobranchs (see respiration), which never breaks through. The tympanic membrane, covered externally with ectoderm, on the inner surface with entoderm, represents the imperforate wall of the cleft, while the Eustachian tube is the narrowed internal end of the spiracle. The chain of ear bones has already been described. It is to be noted that the chain consists of columella and stapes in anura and sauropsida, while in the mammals columella is replaced by incus and malleus. In the urodeles and gymnophiones, where no tympanic cavity is developed, the quadrate articulates with the stapes.

The External Ear.-In the anura and in many reptiles the tympanic membrane is flush with the surface of the head, but in other reptiles and in birds it is at the bottom of a canal, the external auditory meatus, the simplest expression of an external ear. In the mammals 
(whales, sirenians and some seals are exceptions) an external conch is developed behind the meatus to collect the sound waves and to direct them to the inner parts. In some birds the feathers are arranged around the meatus so as to play the same part. The conch is strengthened by cartilage and is moved by muscles (fig. I42). There is evidence which points to the conch being homologous with either the operculum of fishes or with the first external gill of amphibians.

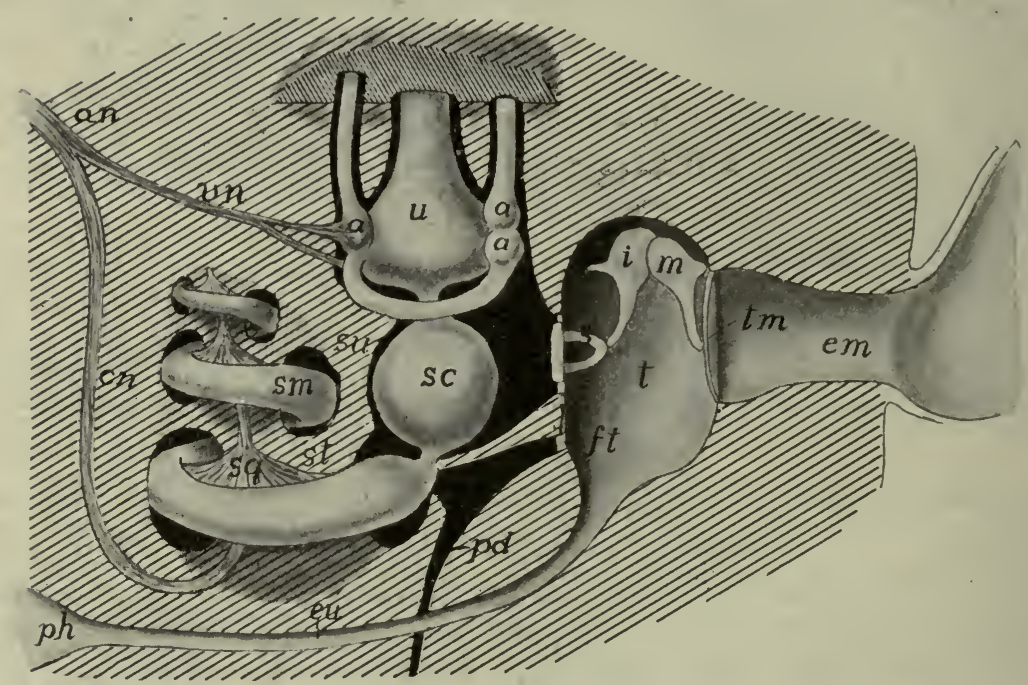

FIG. I88.-Diagram of mammalian ear. $a$, ampullæ of semicircular canals; an, acustic nerve; $c n$, cochlear nerve; em, external auditory meatus; $e u$, Eustachian tube; $f t$, fenestra tympani; $i$, incus; $m$, malleus; $p$, perilymph space (black); $p d$, perilymph duct; $p h$, pharynx; $s$, stapes; $s c$, sacculus; $s m$, $s t$, sv, scalæ media, tympani et vestibuli; $s g$, spiral ganglion; $t$, tympanic cavity; $t m$, tympanic membrane; $u$, utriculus; $v$, vestibular nerve.

Functions.- The vertebrate ear is primarily an organ of equilibration by which the animal recognizes all changes of position. Though the purposes of the various parts are not accurately known, the following conclusions seem warranted. Every movement of the head affects the endolymph and the contained otoliths, causing them to move (by gravity or by momentum, or by both) over the cristæ acusticæ in the ampullæ and thus to stimulate the sense cells and nerves. The position of the semicircular canals in approximately the three dimensions of space would seem to afford a means for the recognition of the directions and amounts of the components of any motion. The maculæ, and especially that of the lagena, are probably concerned in the recognition of sound. In the fishes the lagena is poorly developed, 
and while some fishes have been proved to hear, others have given negative results. With the terrestrial vertebrates the sound percipient functions of the ear are beyond a doubt, while they still retain their equilibrational use. The sound waves strike the tympanic membrane, are carried across the middle ear by the auditory ossicles, and set the perilymph in motion and thus affect the parts of the membranous labyrinth.

\section{Organs of Taste.}

The sense of taste is resident in groups of cells known as taste buds. These differ morphologically from the lateral line organs in having each sensory cell extend the depth of the bud, ending at the basal membrane, while the majority of the supporting cells are on the outer side of the bud. Each sense cell bears a short, bristle-like percipient structure on its free end, while the basal end is embraced by the fibrillæ of the nerve. According to the accounts of the development the taste buds are derived from the entoderm, the only case apparently established for the origin of sense organs except from the ectoderm. In the higher vertebrates the organs are restricted to the cavity of the mouth where (mammals) they occur on the tongue, especially on and near the circumvallate papillæ, on the soft palate and on the epiglottis. In the fishes the distribution is much wider, for they are found in the pharynx, on the gills, and in many species on the surface of the body, even upon the tail. The barbels about the mouth of many forms are richly supplied with these organs.

The taste organs are supplied by different nerves. Apparently those of mammals are supplied by the chorda tympani and the lingual branch of the ninth nerve. In the fishes those of the pharyngeal region are supplied by the post-trematic branches of the glossopharyngeal and vagus; those of the mouth by the palatine and mandibular branch of the seventh; while those on the head of teleostomes are supplied by the ophthalmic and maxillary branches of the fifth; and those of the trunk by the nerve of Weber (p. I73), formed by fibres from the seventh and sometimes of the tenth nerves.

\section{Olfactory Organs.}

While the senses of smell and taste are closely associated physiologically, being what might be called the chemical senses, the organs con- 
cerned differ considerably in structure and relations. The olfactory epithelium is always restricted to one or two patches at the anterior end of the head and differs from the taste buds in histological structure. Both sensory and supporting cells of the olfactory organs are variously constituted. The supporting cells are the stouter, some being ciliated, some muciparous at their free ends. The sense cells (fig. $7_{7} 6, C$ ) are thread-like or rod-like, being greatly expanded around the spherical nucleus, while the basal end of each contracts to a nerve fibre which extends back to the olfactory tract (p. I68), where the dendrites, interlacing with those of the olfactory lobe, form the glomeruli. In the higher vertebrates a third kind of cells, the basal cells, occur at the base of the olfactory epithelium.

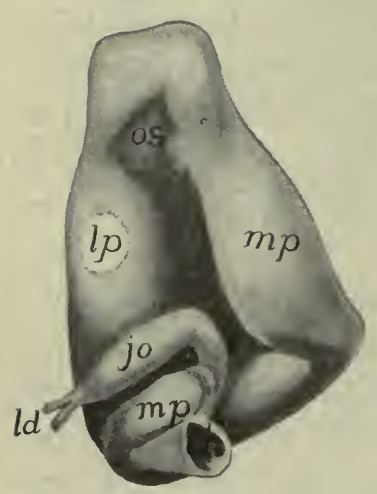

FIG. 189.-Nasal organ of cæcilian (Epicrium), after Sarasins. ch, choana; jo, organ of Jacobson; $l d$, lacrimal duct; $l p$, lateral cavity; $m p$, middle passage; os, olfactory sac.

The olfactory epithelium arises as part of the surface ectoderm of the top of the head, but with growth it changes its position. For protection it sinks beneath the surface as an olfactory sac, connected with the external world by (usually) a pair of openings, the external nares. The growth of the dorsal side of the head carries the nares toward the tip of the snout and, in the elasmobranchs, to the ventral side of the head.

The accessory parts of the olfactory organs are the skeletal nasal capsules (p. 62 ), which are always present; in the tetrapodous forms glands to keep the epithelium moist, and the organ of Jacobson. The involution of the nasal sacs necessitates some mechanism for bringing the external medium (water or air) to the sensory cells. These will be described in connection with the several groups below. The organ of Jacobson is a kind of accessory olfactory organ, first appearing in the amphibia, supplied by the first and fifth nerves and apparently serving to test the character of the food while in the mouth. The position of the organ near the internal nostrils lends probability to this view of the function.

The cyclostomes differ markedly from the other vertebrates in their olfactory organs. The unpaired area of olfactory epithelium develops in the region of the anterior neuropore (p. I2) and becomes involved with the involution for the hypophysis (fig. I90) so that there is but a single external opening, serving for both 
olfactory organ and hypophysis. Hence cyclostomes, having but a single nostril, are called monorhinal, in comparison with all other vertebrates which have two nostrils (amphirhinal). The median opening or naris of the cyclostomes connects with a naro-hypophysial duct, on the upper, posterior wall of which is the olfactory sac, formed of pairs of lateral folds (fig. IgI) covered with the olfactory

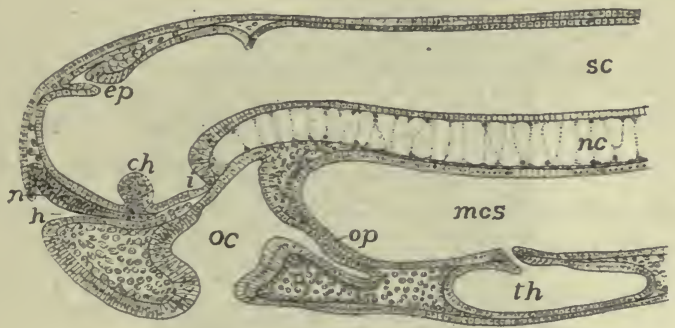

FIG. I90.-Longitudinal section of head of I9 day Petromyzon embrgyo. ch, optic chiasma; $e p$, epiphysial outgrowth; $h$, hypophysial ingrowth; mes, mesenteron; $n$, nasal epithelium; $n c$, notochord; $o c$, oral cavity; $o p$, oral plate; sc, canal of spinal cord; th, thyreoid.

epithelium and supplied by a pair of olfactory nerves. The lower part of the duct, now purely hypophysial, descends to the hypophysis on the ventral side of the brain, where it either ends blindly (petromyzons) or opens into the dorsal part of the oral cavity (myxinoids). In the latter group the olfactory organ is surrounded by a complicated nasal capsule of enormous size (fig. 153).

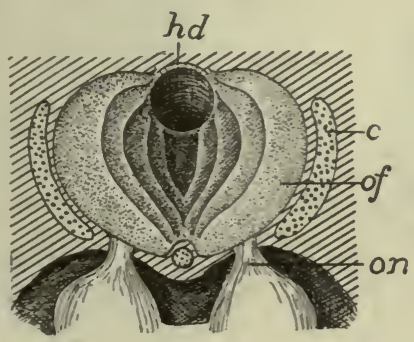

FIG. I9I

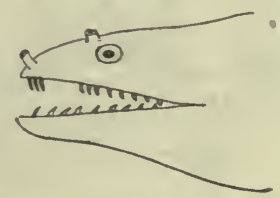

FIG. I92.

FIG. 191.-Nario-hypophysial region of Petromyzon, from above. c cartilage of nasal capsule; $h d$, hypophysial duct; of, folds of olfactory membrane; on, olfactory nerve.

FIG. 192.- Head of Murana, after Jordan and Evermann, showing double nostrils.

All other vertebrates have paired olfactory areas and paired nostrils (nares) are developed in connection with them, and they have at no time any relation to the hypophysis. The mechanism for bringing the water or air to be tested to the olfactory surface differs accordingly as the animals are air or water breathers. In all fishes, with the exception of the dipnoi, the sensory surface is at the bottom of a pit with no connection with the alimentary canal. In the elasmobranchs, in 
order that water may flow more readily through this pit, a fold is developed on one side of each naris, which practically divides it into two. In many teleosts there is an actual division of each primitive nostril into two, which may be at some distance from each other,

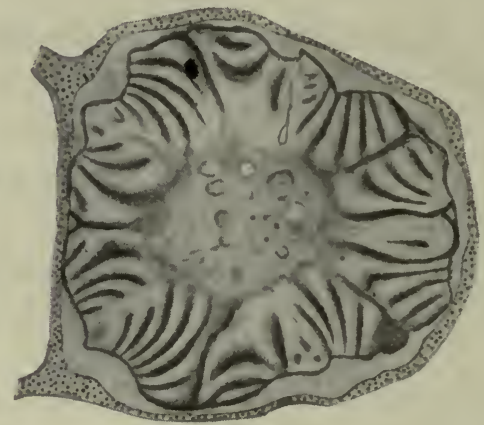

FIG. I93.- Section through the nasal labyrinth of Polypterus. The nerve runs through the centre.

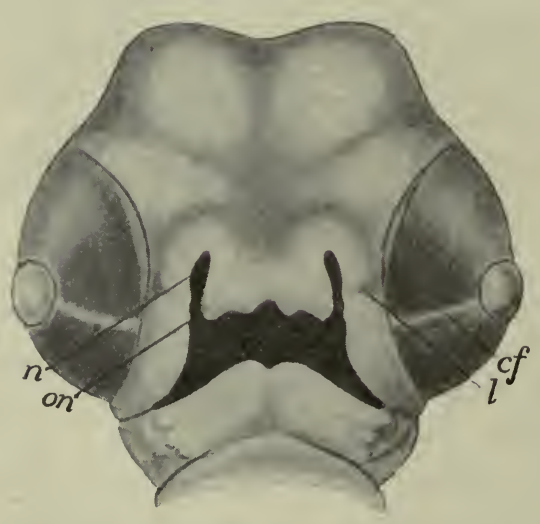

Frg. I94:

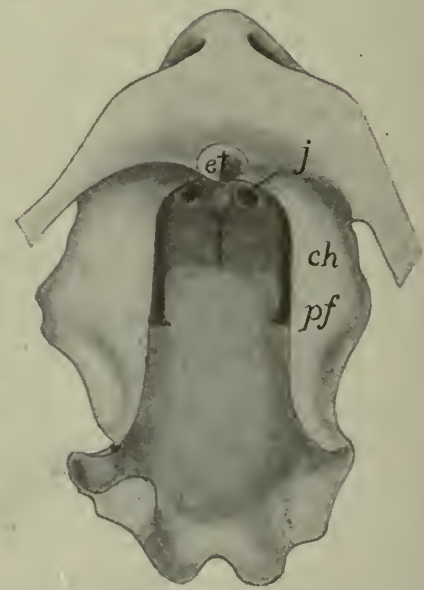

Fig. I95.

FrG. 194.- Head of chick of $5 \frac{1}{2}$ days, showing development of oro-nasal canal after Keibel. $c f$, chorioid fissure; $l$, thickening for lacrimal duct; $n$, nasal pit; on, oronasal groove.

FIG. I95.-Model of mouth of Echidna embryo, after Seydel, showing method of ingrowth of palatal folds $(p f)$ to cut off secondary nasal passages. ch, primitive choanæ; $e$, egg tooth; $j$, opening of Jacobson's organ.

often at the ends of prominent tubes (fig. 192). Inside the nasal capsule the olfactory epithelium is variously folded in order to increase the sensory surface, often forming a labyrinth of considerable complexity (fig. I93). 
In air-breathing vertebrates, beginning with the dipnoi, a means is developed for drawing air over the sensory surface, the first traces of which are seen in the elasmobranchs. These frequently have an oro-nasal groove, leading from each naris to the angle of the mouth. In some species this groove is practically converted into a tube by the meeting of the walls below. Beginning with the dipnoi and continuing with the amphibia and amniotes (fig. r94) a similar groove is formed on either side before the formation of skeletal parts. This closes in, the edges of each groove uniting, so that a tube or duct is formed, leading from the naris into the oral cavity, where an internal naris or choana occurs. Later maxillary and premaxillary bones arise ventral to the narial passage, so that the ducts appear to run through the skull. The position of the choanæ varies considerably, being just inside the jaws in the amphibia and lower reptiles, farther back in the higher reptiles and the birds and mammals, the nasal passages being cut off from the roof of the primitive mouth by the ingrowth of the palatal processes of the maxillary bones and higher, by similar extensions of the palatines, and in some cases, of the pterygoids (fig. I95).

Incomplete closure of the oronasal groove results in the deformity known as 'hare-lip' externally, while 'cleft palate' is the result of failure of palatines, and sometimes of maxillaries to meet below the nasal passages.

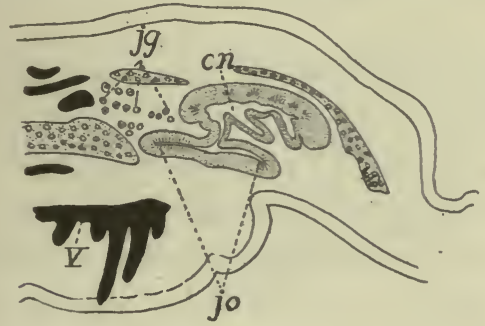

Fig. $x 96$.

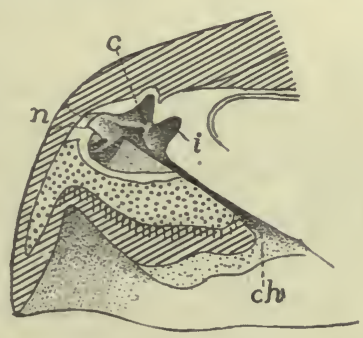

FIG. I97.

Fig. I96.-Section through the nasal region of Siren, after Seydel. cn, nasal cavity, $j g$; Jacobson's gland; $j o$, organ of Jacobson; $v$, vomer.

FIG. 197.-Section of nose of Chelonia cauana, after Gegenbaur. $c$, concha; ch, choana; $i$, inner olfactory groove; $n$, projection of naris between dotted lines.

In the dipnoi the olfactory membrane forms a few large folds on the dorsal side of the respiratory duct formed from the oronasal tube. In the amphibia the sensory surface has a similar position on the upper medial surface (fig. I96), with frequently a lateral pocket lined with sensory epithelium, the beginnings of an organ of Jacobson. In the same group glands (inner and outer Jacobson's glands) occur for 
moistening the olfactory epithelium. Usually there is little complication of the olfactory surface, but in a few urodeles (Plethodon) there is a projection from the lateral wall, the first indication of the conchæ which acquire such development in the higher groups. There is frequently a differentiation of the nasal passage into a ventral respiratory duct lined with ordinary and a more dorsal olfactory duct lined with sensory epithelium. In the lower urodeles the diverticulum representing the organ of Jacobson is on the medial side of the nasal cavity; a little higher it is ventral, while in the highest urodeles it has rotated to the lateral side. It may be noted that some of the amphibia have smooth muscles to close the external nares.

Aside from the varying position of the choanæ the changes from amphibia to reptiles in the olfactory organs are comparatively slight.

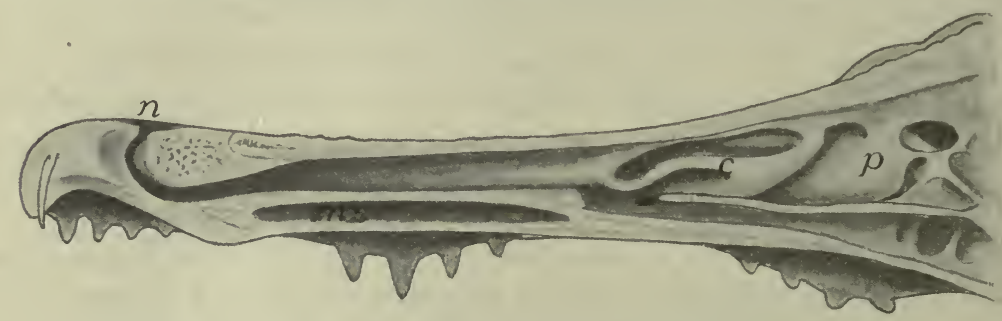

FIG. I98.- Longitudinal section of nasal region of alligator, after Gegenbaur. $c$, concha; $m s$, maxillary sinus; $n$, naris; $p$, pseudoconcha.

The olfactory region becomes more distinct from the respiratory tract and the latter shows a tendency to be differentiated into an anterior atrium or vestibule, a middle area connected with the olfactory region, and a posterior naso-pharyngeal duct between the basis cranii and the roof of the mouth. This latter duct varies in length accordingly as the choanæ are anterior or posterior in position, the extreme being reached in the crocodiles, where by ingrowth of palatines and pterygoids, the internal nares are carried back nearly to the hinder end of the skull. A single concha, supported by bone, is developed in the lateral wall of the reptilian nose. It is weak in the turtles (fig. 197), but is larger elsewhere, and in the crocodiles (fig. I98) it becomes divided in front, while a 'pseudoconch' (its homology with the superior concha of birds is uncertain) is developed above and behind the true concha. Jacobson's organ occurs only in the squamata, where it forms a simple pocket in the primitive position, ventral and medial to the nasal cavity, near the nasal septum. 
There are three folds developed on the wall of each nasal cavity in birds, an anterior and inferior concha vestibuli, a middle and a superior fold, the middle supported by the maxillo-turbinal, the superior by the naso-turbinal bones. The vestibular conch lacks olfactory epithelium at all times, while it disappears from the middle one after hatching,
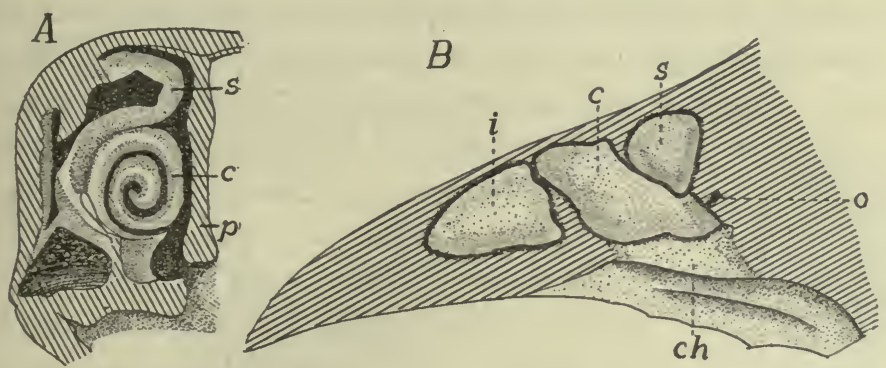

FIG. 199.-Olfactory region of hen in longitudinal and transverse section, after Gegenbaur. $c$, middle concha; $c h$, choana; $i$, inferior (anterior) concha; 0 , connection of air cavity of head; $p$, septum of nose; $s$, superior concha.

leaving the upper conch as the sole seat of smell in the adult, which corresponds with the limited sense of smell in these animals. Jacobson's organ is never developed in the adult, though traces of it appear in the embryos.

With the great increase of the sense of smell in the mammals the

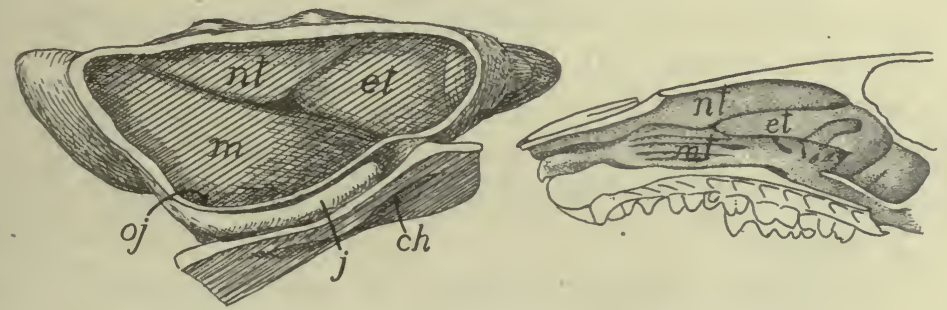

FIG. 200.

FIG. 20I.

FIG. 200.-Model of the nasal cavity of a rabbit embryo, $13 \frac{1}{2} \mathrm{~mm}$. head length, after Peter. ch, choana; $e t$, first ethmoturbinal; $j$, organ of Jacobson; $o j$, opening of same; $m t$, maxilloturbinal; $n t$, nasoturbinal.

FIG. 20r.-Nasal cavity of Erinaceus, after Paulli, showing the foldings of the maxilloturbinals $(m t)$ and the nasoturbinals $(n t)$.

nasal labyrinth undergoes a corresponding complication, and is farther characterized by the great length of the naso-pharyngeal duct, and by the position of the olfactory area below a part of the brain cavity. The folds of the labyrinth may be supported by processes, more or less complicated, of three bones or cartilages, the ethmo-turbinals, the naso- 
turbinals and the maxillo-turbinals (fig. 200), the purpose of these folds being to increase the amount of sensory surface, while the skeletal supports keep the folds from touching each other. With diminution of the powers of smell the folds are correspondingly reduced, even to a loss of the turbination of the bones concerned.

The maxillo-turbinals and naso-turbinals arise from the lateral wall of the nasal cavity (the former as a distinct turbinal bone), the ethmo-

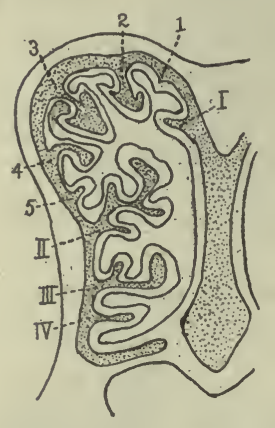

FIG. 202.-Section through the nasal cavity of fa new born dog, after Paulli, $I-I V$, entoturbinals; $x-5$, first to fifth ectoturbinals. turbinals as outgrowths from the ethmoid bone, appearing first at the upper hinder part of the septal wall and extending to the lateral wall. The result is that the ethmo-turbinal tends to insinuate itself between the hinder ends of the other two (figs. 200, 20I). Each of these may be subdivided, with corresponding subdivision of the epithelial covering, and in the case of the ethmo-turbinals the subdivisions may be of varying heights (fig. 202), the ecto- and entoturbinals. The nasoturbinals often disappear in the adult, while the epithelium of the maxilloturbinals is not sensory in character, this part of the nose being apparently to warm and moisten the air in its passage to the lungs.

The homologies of the various parts of the nasal labyrinth in different amniotes are thus stated (Peter).

I. Concha of the anterior epthelium: concha vestibuli (birds).

II. Conchæ of the primitive sensory epithelium:

I. Arising from the lateral wall (conchæ laterales).

A. Anterior:

a. Primary, ventral: concha of reptiles; middle concha of birds; maxillo-turbinals of mammals.

b. Secondary, dorsal: Upper or posterior of birds; nasoturbinals of mammals (? pseudoconch of crocodiles).

B. Arising from the posterior part: conchæ obtectæ of mammals.

2. Arising from the primitively median wall: ethmo-turbinals of mammals, numbered from in front backward.

Jacobson's organ (vomero-nasal organ) is laid down in the embryo of most mammals as a groove or pocket on the lower medial side of each nasal cavity, opening in rodents and in man near the duct of 
Stenson's gland; in other mammals, so far as known, its duct becomes cut off from the nasal cavity and opens in to the naso-palatal canal. Its medial wall is covered with sensory epithelium, supplied by a branch of the olfactory nerve. In the primates the organ is more or less degenerate in the adult.

There are two kinds of glands in the nasal cavity, the smaller and scattered Bowman's glands and the larger Stenson's gland lying in the lateral ventral wall and opening into the vestibule. There are usually several sinuses in the bones of the skull, connected with the

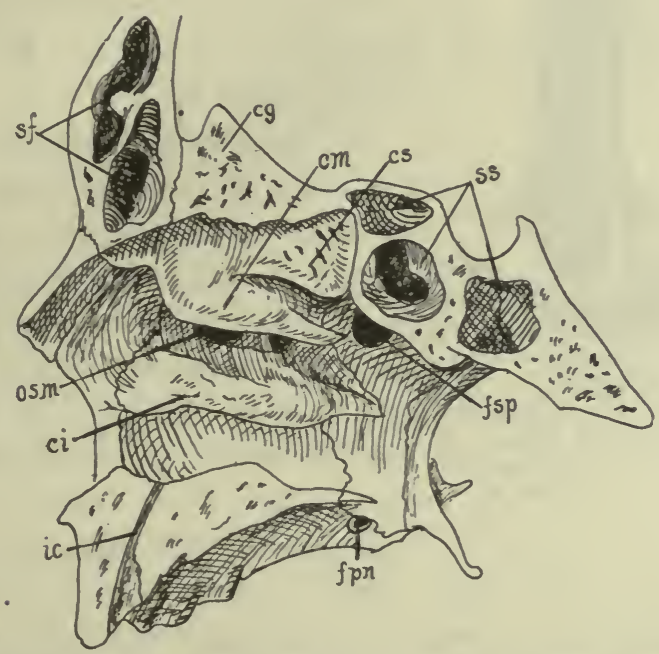

Fig. 203.- Lateral wall of nasal cavity of man, after Corning. cg, crista galli; ci, cm, $c s$, inferior, middle and superior conchæ; $f p m$, foramen palatinum majus; $f s p$, sphenopalatine foramen; $i c$, incisive canal; osm, opening of maxillary sinus; $s f$, frontal sinus; $s s$, sphenoidal sinus.

nasal cavities by foramina. Chief of these are the maxillary sinuses (antra of Highmore), the frontal and sphenoidal sinuses in the corresponding bones, the relations of which may be seen in fig. 203. Others may occur in other bones of the face.

Mammals are characterized by an external fleshy nose, supported by the nasal bones and by cartilages, developed in part from the ethmoid cartilage of the embryo, in part from paired cartilages, a new acquisition of the mammals. Beyond these skeletal parts is the fleshy portion which may form a proboscis of considerable size (swine, elephant shrew, elephant). 
In most mammals the sense of smell is well developed, but is comparatively slight in the seals, whalebone whales and in the primates, while it is completely lost in most of the toothed whales where even the olfactory nerve may disappear.

\section{The Eyes.}

The sensory part of the eyes comes from the ectoderm of the neural plate, and in several embryos the regions which are thus destined may

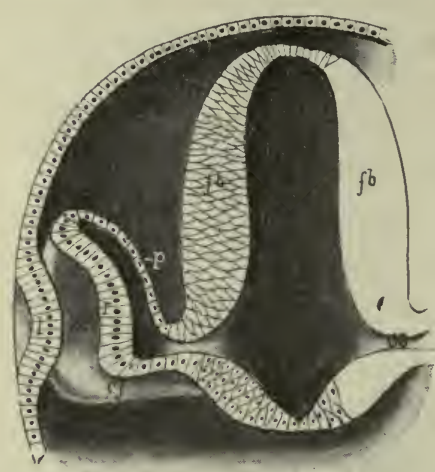

Fig. 204.-Stereogram of developing eye. $c f$, chorioid fissure; $f b$, cut wall of fore-brain; $l$, anlage of lens; oc, optic cup; os, optic stalk; $p$, layer for pigmented epithelium; $r$, retinal layer.

cup (fig. 204). There thus results a differentiation of parts in the optic outgrowth and a partial obliteration of the cavity of the vesicle. The distal wall which forms the inside of the cup is called the retinal
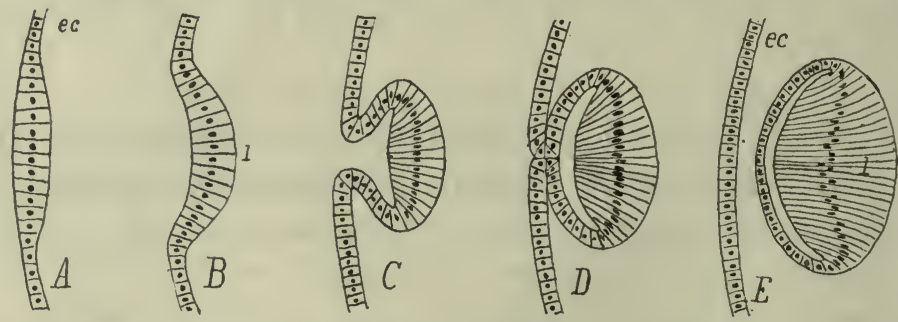

FIG. 205.-Sections of successive stages in the development of the lens of the eye from the first thickening of the ectoderm $(e c)$ to the complete separation ot the lens, $l$.

layer; the outer wall the pigment layer, in anticipation of their development into the corresponding parts of the adult.

The involution of the retina is not easily described, but may be 
understood from figure 204. It occurs on the lower distal side so that the cup is not complete but is interrupted by a deep notch, the chorioid fissure, below, and this is extended as a groove on the ventral side of the optic stalk. Later the fissure closes (fig. I94), but not until some of the changes described below have occurred.

Opposite the distal part of each optic vesicle the ectoderm of the side of the head thickens, then becomes invaginated (fig. 205), the mouth of the invagination closes, and the hollow ball thus formed is cut off from the rest of the ectoderm and sinks into the mouth of the optic cup, where it forms the lens of the eye. From the first the cells of the two sides of the lens differ in size, those of the outer wall being cubical, those of the other being elongate, while the cavity is a narrow cleit. Later the cavity is obliterated, while the lens is increased in size by the addition of new cells, like the coats of an onion, by budding from the equatorial zone of the lens.

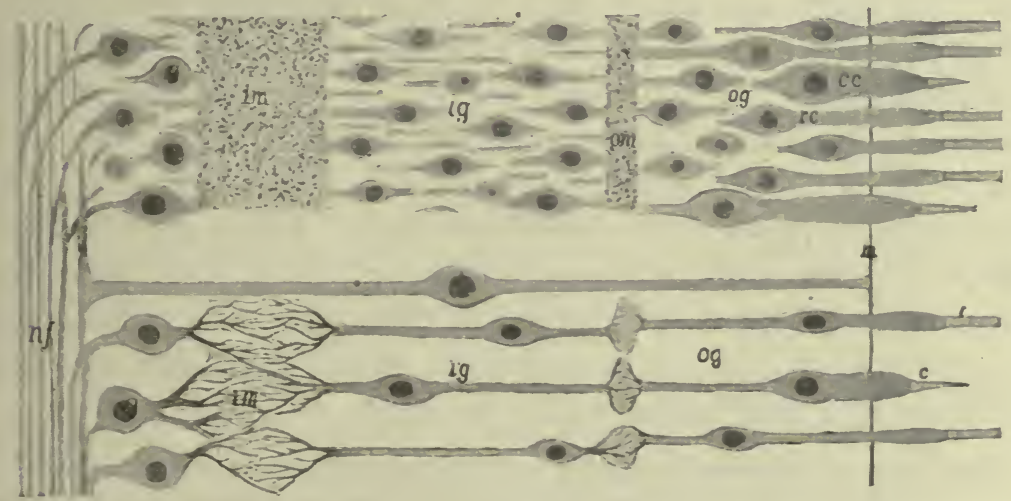

Fig. 206.-Mammalian retina; above the general appearance, below the diagrammatic relations; the lens toward the left. $c$, cone; $c c$, cone cell; $g$, ganglion cells; $i g$, inner granular layer; $i m$, inner molecular layer; $m$, basal membrane; $n f$, nerve fibres; $o g$, outer granular layer; om, outer molecular layer; $r$, rod; $r c$, rod cell.

The Retina consists of several layers which constitute the ganglion and the sensory cells, the latter being on the outer surface, i.e., that which is turned away from the lens. Each sensory cell bears on its outer end the percipient structure, rod or cone, which has given these the name of rod and cone cells. These rods and cones project through the basal membrane which encloses the retina into the pigment layer to be described shortly. The bodies of the cells with their nuclei are inside the basal membrane, where they form the so- 
called outer granular (nuclear) layer, separated by an outer 'molecular' (reticular) layer of interlacing dendrites from the inner granular layer. This is ganglionic in character and is connected by the inner molecular layer with the rest of the ganglionic layer which lines the inside of the retinal cup.

In order to understand the latter layer and the relations of the optic nerve, an account of the development is necessary. At first the retinal layer is comparatively thin, but it increases in thickness, in part by a multiplication of cells, in part by their increase in length and the development of the dendrites of the molecular layers. Each cell of the inner layer (the one turned toward the lens) also develops an axon which runs over the free surface of the cells to the chorioid fissure, passes through this and along the ventral groove of the optic stalk to the diencephalon.

As will readily be understood, it is these fibres and not the optic stalk which form the optic nerve (p. I69). When the chorioid fissure closes, the nerve appears to leave through the centre of the retina, and as this part contains no sense cells, the point of exit constitutes the 'blind spot' of physiological works. Besides the cells already mentioned the retina contains supporting or radial cells, like other sense organs or like the brain itself (neuroglia). These extend through from the nerve fibres to the basal membrane. Either rods or cones may be absent in isolated groups of vertebrates. Usually there is a spot, the macula lutea (yellow spot) or fovea centralis at the centre of the retina where vision is most distinct. Here the rod and cone cells are shorter and more crowded than elsewhere.

Here may be mentioned a point of morphological importance. It will be recalled (p. r 38 ) that the ependymal surface of the brain corresponds to the external surface of the ectoderm of the rest of the body. Therefore, as a glance at fig. 204 will show, the rods and cones are on the primitively outer and the ganglion cells and nerve fibres are on the deeper surface of the ectoderm. Hence rods and cones correspond to the percipient cuticular structures of other sensory organs like the lateral line, taste buds and the like. Before it can affect the sensory cells the light has to traverse the whole of the retina and then the nervous impulses have to pass back through the same layers to reach the optic nerve. This constitutes an 'inverted eye' and, with the exception of a few molluscs, it is unknown, except in the vertebrates. A comparison with the parietal eye of reptiles (fig. $\mathrm{I}_{5} \mathrm{r}$ ) is very instructive.

The cavity between lens and retina is filled with a semisolid vitreous body, the origin of which is in dispute. In mammals blood-vessels 
and mesenchymatous cells enter the optic cup through the chorioid fissure before its closure. Some suppose that the vitreous body arises from a modification of these cells, some regard it as an exudate from the blood-vessels, and others think it a retinal secretion. The fact that the blood-vessels mentioned do not occur in birds is of interest in this connection. In mammals, when the chorioid fissure closes, the vessels appear to enter through the centre of the optic nerve (central retinal artery and vein-fig. 207). In the early stages the retinal artery

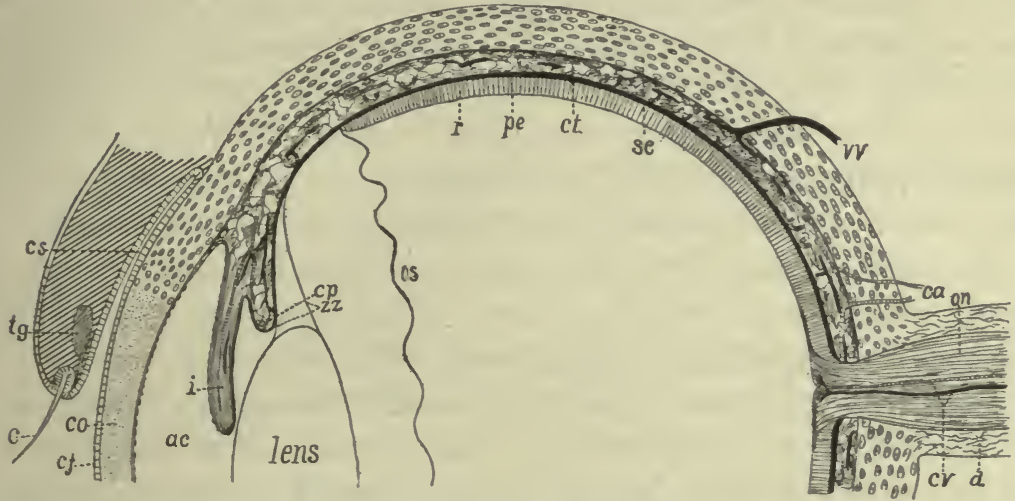

FIG. 207.-Diagrammatic section of half a mammalian eye. $a$; anterior chambcr; $c a$, ciliary arteries; $c$, eyelash (cilium); $c j$, conjunctiva; $c o$, cornea; $c p$, ciliary process; $c r$, central retinal artery and vein; $c s$, conjunctival sac; $c t$, chorioid tunic; $d$, dura of optic nerve; $i$, iris; on, optic nerve; os, ora serrata; $p c$, posterior chamber; $p e$, pigmented epithelium; $r$, retina; sc, sclera; $t g$, tarsal gland; $v v$, vorticose vein; $c c$, zonula zinii.

divides inside the cup, one branch (hyaloid artery) going through the vitreous body to the neighborhood of the lens, the other being distributed over the inner surface of the retina. Later the hyaloid artery disappears, while retinal arteries are rare except in mammals.

The outer wall of the optic cup forms the pigmented epithelium of the eye, developing a large amount of black pigment which eventually surrounds and isolates the rods and cones, so that each can be affected only by the light which falls directly upon it. As will readily be understood the side of the pigment layer away from the retina corresponds to the deeper surface of the skin and so comes into relation with the connective tissue. From this is developed the envelopes of the eye-tunica vasculosa, sclera, etc.

Surrounding the retina and pigmented epithelium and extending forward over the lateral parts of the lens is the tunica vasculosa, in which two parts are recognized, the iris and the chorioid. The 
whole is richly vascular, and the chorioid, supplied by the ciliary arteries which enter at the side, is the chief source of nourishment for the rod and cone cells. To the vascular part certain other portions are added in some groups. Thus just outside the blood-vessels there may be a large lymph space, and outside of this, in most fishes and some amphibia and turtles, there is an argenteal layer containing calcic crystals which give the layer a whitish appearance. On the other hand, the side toward the retina frequently develops a somewhat similar tapetum lucidum, with a metallic lustre, which reflects light strongly and is the cause of the apparent shining at night of the eyes of many selachians and some other fishes and carnivore mammals. In a few teleostomes (those with a pseudobranch) there is a so-called chorioid gland just oustide the vascular layer, near the entrance of the optic nerve. It partakes of the nature of a rete mirabile.

The chorioid extends as far forward as does the retina, when its anterior edge is produced into a circular ciliary process, which is best developed in the amniotes, though appearing here and there in the ich thyopsida. This process is muscular (ciliary muscles) at its base and is connected at its margin with the delicate capsule surrounding the lens by a double fenestrated membrane, the zonula ciliaris (Zinnii). By the action of the muscles the lens is moved toward or away from the retina, while variations in tension may slightly alter its shape, thus changing its focal point (accommodation of the eye).

Beyond the ciliary process the vascular tunic continues in front of the lens as the iris, a circular curtain with a central opening, the pupil. Pigment in the posterior layer (uvea) of the iris renders it opaque, while in many fishes the outer surface is silvery owing to the continuation of the argentea into this region. The rest of the iris is muscular, the muscles increasing in extent from the lower to the higher forms. They are arranged in two groups. The circular muscles (sphincter pupillæ), by their contraction, diminish the size of the pupil; the radial (dilator pupillæ) are antagonistic and effect an enlargement of the opening in the iris. In the sauropsida these iridial muscles are cross banded, in amphibia and mammals of the smooth variety.

Surrounding all of the structures of the eye so far described is the sense capsule, which differs from all other sense capsules (p. 62) in not being connected with the rest of the skull, as a result of its necessity for movement. In the capsule two parts are distinguished, the sclera which covers the proximal side of the eye, and the cornea, 
perfectly transparent, through which light passes to reach the lens. The cornea, covered externally by the conjunctiva, the modified epidermis of the front of the eye, consists of connective tissue; the sclera is usually white. In most of the lower vertebrates and in the monotremes it is partly or wholly cartilaginous, but in other mammls and in the lampreys it consists of fibrous tissue. In the stegocephals and in many reptiles and birds portions of the sclera ossify as a ring of sclerotic bones (p. 67).

Sclerotic bones are lacking in snakes, plesiosaurs and crocodiles. In the sturgeon and many teleosts two or more dermal bones develop upon the sclera, but neither these nor the calcifications to be found in some sharks and teleosts are to be confused with true sclerotics.

Between cornea and lens is a cavity which is partially divided by the iris into anterior and posterior chambers which connect with each other through the pupil. These are filled with a refracting fluid, the aqueous humor.

The parts so far described form the eye-ball (bulbus oculi) which is more or less freely movable in its socket in the side of the head. It is moved by the six muscles (p. I 28 ) which are constantly present. Others may occur here and there. Thus in the amphibia a distinct muscle (retractor bulbi) is developed from the external rectus to pull the ball back into the socket, while portions of the jaw muscles may be set apart as elevators and depressors of the ball. In the elasmobranchs a cartilaginous rod, the optic pedicel, extends from the ball to the skull. This is replaced in the teleosts by a fibrous band, the tenaculum, but its equivalent is not found in the higher groups.

Among the accessory parts of the eye are the lids, of which there may be three, the upper and the lower lids so familiar in the higher vertebrates and the third lid, the nictitating membrane, a transparent sheet which may be drawn horizontally across the front of the eye from the inner (anterior) angle of the eye or from beneath the lower lid. All three lids are folds of the skin. The upper and lower are poorly developed in the ichthyopsida, but appear in the amniotes. They are lined on the side next the eye by a continuation of the conjunctiva, which continues beyond the edge of the lid as the epidermis. The nictitating membrane appears in some sharks, again in the amphibia, and receives its highest development in the sauropsida, while in the mammals it is reduced to a rudimentary fold, the plica semilunaris, at the inner angle of the eye. 
There are no glands connected with the eyes in cyclostomes or fishes, but in the urodeles a series of glands is developed from the conjunctival lining of the lower lid. In the amphibia they show little differentiation, but in all sauropsida (glands are lacking from a few reptiles-crocodile tears are non-existent) they become divided into two groups. One becomes aggregated near the inner angle and forms what is known as Harder's glands (glandula membrana nictitans); the others migrate toward the outer angle of the eye and constitute the true lacrimal or tear gland. In the mammals the migration continues until the gland comes to lie beneath the upper lid, where it shows its multiple nature by the numbers of ducts by which it pours its secretions into the conjunctival sac. In most mammals Harder's gland degenerates. The tears secreted by the glands pass over the conjunctiva and are collected at the inner angle of the eye, where they are drained by the lacrimal duct into the cavity of the nose. This duct is formed as a thickening of the epidermis, which later becomes perforated. It follows the course of an earlier groove (fig. I94) leading from the orbit to the nasal invagination and which was formerly thought to form the duct.

The eyes of the cyclostomes are degenerate. In the larval (Ammocotes) stage of Petromyzon the eye is buried under a thick skin, but this thins out in the adult. In the myxinoids the lens and eye muscles are lacking, and iris, cornea and sclera are not differentiated.

Fishes have eyes with a very flattened cornea, a spherical lens and very long retinal rods. A peculiar feature in many fishes is the falciform process, a vascular and muscular structure which enters the retinal cup through the chorioid fissure and extends to the lens where it bears an expansion, the campanula Halleri. The whole is supposed to act as a means of accommodation, there being no ciliary muscles. In most fishes the eyes are so placed on the sides of the head that there must be monocular vision. In the flat fishes (Heterosomata) one of the eyes migrates during development, so that both eyes come to lie on one side of the head.

Most sauropsida are characterized by the development of a process from the inner retinal surface which reaches its extreme in the pecten of the birds. In the reptiles it is a small conical process arising from the point of entrance of the optic nerve, but in the birds this expands distally into a quadrangular plate, folded like a fan, to which various functions have been ascribed. It has been recently shown to be rich in sense cells. The shape of the eye of the bird is peculiar, but is not easily described. It consists of a hemispherical posterior part, followed by a conical portion, and this surmounted by a hemispherical corneal region, the whole being somewhat telescopic in shape. The whole is very large in proportion to the size of the animal.

The pecten is said to be outlined in the fotal stages of some mammals. The 
pupil of the mammals is not always circular, but is a vertical slit in the cats, a horizontal opening in the whales, many ungulates, etc. During development the lids fuse for a time, separating in some cases, only after birth. The edges of the lids are fringed with short hairs, the eye-lashes or cilia, and internal to these are the ducts of sebaceous glands (tarsal or Meiobomian glands), the glands themselves being in the substance of the lids. The whales have an enormously thick sclera which, here as elsewhere, appears as a continuation of the dural sheath of the optic nerve.

\section{THE DIGESTIVE ORGANS.}

Few articles of food, as they come to a vertebrate, are in shape to be taken immediately into the organism and to be used, without modification, as a source of energy or as material for the construction of new tissue or the repair of old. They have to be altered so that they are soluble and so able to pass by osmosis into the blood-vessels (proteids, carbohydrates), or they must be broken up (hydrocarbons) so as to be taken up by the absorbtive vessels (lacteals) of the lymphatic system. These changes in the food, which are the result of the action of the secretions of the digestive glands, constitute the process of digestion. The digestive tract or alimentary canal, where these changes take place, also has to provide for the passage of the digested food into the blood-ressels, to be carried by them to all parts of the body. It is therefore richly supplied with blood- and lymph-vessels.

The alimentary canal, which is complete (i.e., has both mouth and vent), is largely entodermal in origin, but small portions at either end are derived from the ectoderm. The entodermal portion, the mesenteron, consists of the wall of the archenteron (p. I2) after the separation of the notochord, the mesothelium, and a few less prominent structures. The ectodermal parts are a stomodeum at the cephalic end and a proctodeum behind.

In the early stages of all vertebrates the mouth is lacking, the cephalic end of the archenteron abutting directly against the ectoderm of the ventral side of the head, so that an oral (pharyngeal) plate is formed, consisting of both ectoderm and entoderm. Next this plate is pushed inward, either as a pocket (fig. I90) or as a solid plug, carrying the entoderm before it. This ingrowth constitutes the stomodeum, and the site of its ingrowth forms the mouth opening of the adult. Later the oral plate breaks through, placing the stomodeum and mesenteron in communication. 
In the majority of vertebrates the blastopore closes behind, so that

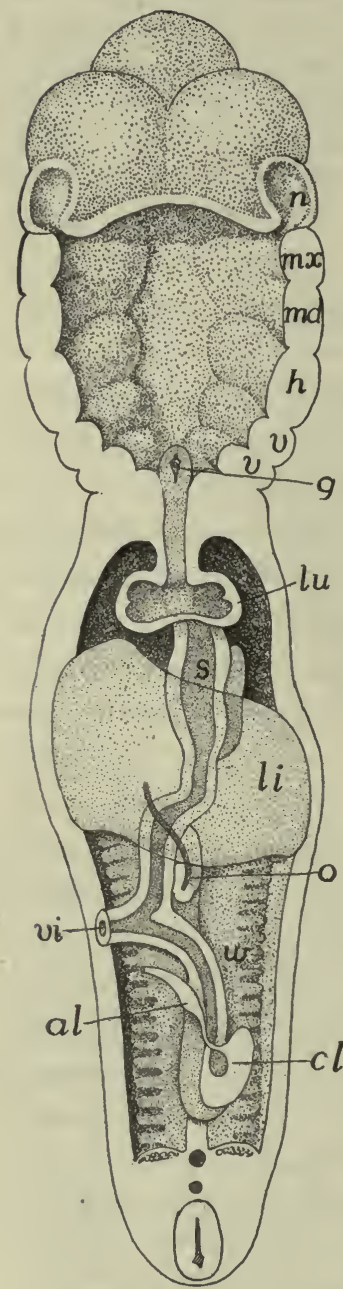

F I G. 208.-Reconstruction of alimentary canal of human embryo, after His. $a l$, allantois stalk; $c l$, cloaca; $g$, glottis; $h$, hyoid arch; $l i$, liver; $l u$, lung; $m d, m x$, mandibular and maxillary arches; $n$, nasal pit; $o$, omphalomesaraic vein; $s$, stomach; $v$, visceral arches; $v i$, vitelline stalk; w, Wolffian body. the anus is a new formation, although it arises in the line of closure. In the amniotes this opening is preceded by the formation of a pocket, the proctodeum, similar to the stomodeum, and opening later into the mesenteron in the same way. In the adult it is impossible to find any lines separating the three regions, stomodeum, mesenteron and proctodeum.

The proctodeum lies wholly behind the entrance of the urogenital ducts into the cloaca. The ectoderm of the stomodeum extends inward as far as the posterior teeth, following the outline of the jaws. On the dorsal side of the oral cavity two pits persist for some time, the limits of ectoderm and entoderm passing between them. The posterior of these, Seessel's pocket, is of unknown significance. The other, Rathke's pocket (fig. 253), lies just in front of the oral plate. It marks the point of invagination of the hypophysis (p. 148) and remains open for a time as the hypophysial duct (fig. I48).

In some teleosts, where the stomodeal ingrowth is slight, the mouth appears at first as a pair of perforations in the oral plate, these later coalescing to form the permanent mouth. This condition lends plausibility to the view that the vertebrate mouth has arisen from the coalescence of a pair of gill clefts.

Except in the higher mammals the entodermal part of the alimentary canal contains a large amount of food yolk in the early stages. In the sauropsida this is so abundant that the whole cannot be contained in the body walls, and hence it causes the ventral side of the canal to protrude as a yolk-sac, which is gradually absorbed with the digestion and removal of the yolk by the blood-vessels.

The first differentiation in the mesenteron is the development of a ventral diverticulum, the anlage of the liver, which arises just caudal to the head. This divides the alimentary canal into pre- and post- 
hepatic portions (fig. 209). From the anterior of these is formed part of the cavity of the mouth with the salivary glands, the pharynx, œsophagus, stomach, and duodenum; the post-hepatic portion gives rise to large and small intestines, rectum and cloaca, as well as to the urinary bladder. Of these parts the pharynx will be considered in connection with the respiratory organs, the bladder with the urogenital system. Mouth and pharynx belong primitively to the head, but by unequal growth the pharynx may be carried apparently to some distance behind the brain and other characteristically cephalic structures.

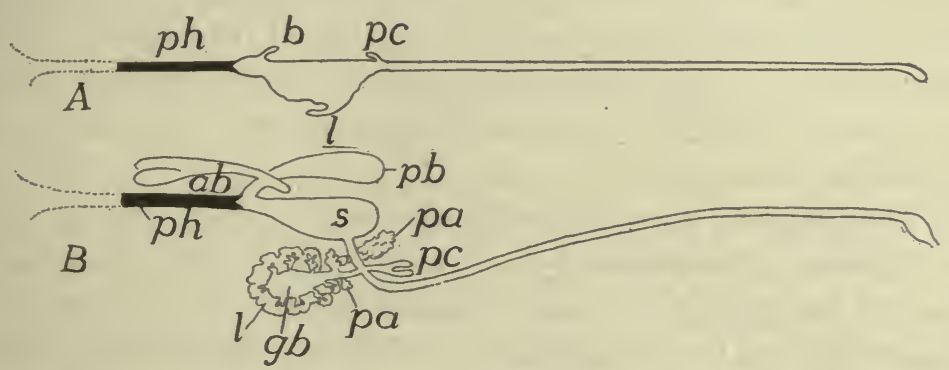

FIG. 209.-Diagrams of the alimentary canal in embryos of 6 and 8 days of Gymnarchus niloticus, after Assheton. $a b$, air bladder; $b$, early diverticulum for air bladder; $g b$, gall bladder; $l$, liver; $p a$, pancreas; $p b$, posterior part of air bladder; $p c$, pyloric cæca; $p h$, pharynx; s, stomach.

In the following account stress is laid upon the epithelial lining (entoderm), the characteristic tissue of the digestive tract, but it must not be forgotten that the wall contains other tissues of mesenchymatous origin. That part of the canal which runs through the body cavity has the following layers. The lining epithelium is supported by a layer of connective tissue, containing the capillary absorbtive vessels; outside of this are two layers of smooth (involuntary) muscles, the inner with the fibres running in a circular, the other in a longitudinal direction. By the action of these antagonistic muscles the peristalsis or movement of the digestive tract is effected, by which the food undergoing digestion is churned and thoroughly mixed with the digestive fluids, and all parts of it are brought into contact with the absorbtive surfaces. The outer surface of stomach, intestine and associated glands is covered with the serous coat, the lining of the peritoneal cavity, but this is lacking from those parts (pharynx, œsophagus, etc.) which are outside the region of the cœlom. 


\section{THE ORAL CAVITY.}

The cavity of the mouth is limited anteriorly by the line of the stomodeal involution and extends back to the pharynx. It is lined in part by ectoderm, in part by entoderm, the line between the two, as stated above, not being recognizable in the adult. In the amphibia the lining is ciliated, the cilia extending back to the stomach. In the cyclostomes the oral cavity is funnel-shaped, with a circular or quadrangular opening supported by a cartilaginous ring and has the name of oral hood. It is permanently open, there being no jaws capable of closure (see skeleton, p. 73) thus furnishing a marked contrast to all other vertebrates in which there are jaws and which are consequently known as gnathostomes. (Development gives little support to the view that the cyclostome tongue is the homologue of the lower jaw of the gnathostomes.)

In development the mouth arises on the ventral side of the head, some distance from the anterior end of the body. This position is retained throughout life in most elasmobranchs and in the sturgeons; but elsewhere, by the development of the bony upper jaw in front of the pterygoquadrate (p. 69) and the concomitant extension of Meckel's cartilage, the mouth opening is gradually transferred to the anterior end and becomes terminal.

In most lower gnathostomes (the holocephali and other isolated forms are exceptions) the mouth opening is bounded by folds of epithelium which meet when the mouth is closed. Usually these folds are soft and are supported below by connective tissue, but in birds, turtles and monotremes they are cornified. It is only in the mammals that true lips occur. These are fleshy folds around the mouth and their development in this group is correlated with the presence of the dermal facial muscles (p. I34), by which they are moved. With the development of lips there is formed a space between lips and teeth, the vestibule of the mouth, which sometimes (e. g., some rodents) forms cheek pouches, lined with hair, of considerable size.

\section{Teeth.}

The primitive function of the teeth was apparently to hold the prey taken into the mouth and this is their sole use in many forms. In other species they have become efficient organs for the comminution of food, either by cutting or by crushing it. 
There are two types of teeth, much alike in function, but differing markedly in structure and development and without genetic relationships. The typical vertebrate teeth are comparable to placoid scales; they arise as a calcareous secretion at the junction of ectoderm and mesenchyme and are a product of both layers. The other type contains purely cuticular teeth, formed by a cornification of the epithelium and have their analogues in many invertebrates.

True Teeth.-The ability to form scales is characteristic of the skin of many vertebrates. The primitive type of these scales is the placoid (p. 40), consisting of a basal portion of dentine capped with enamel and the apex projecting through the integument as a spine. When invaginated to form the stomodeum the skin retains this capacity of forming hard structures and hence any portion of the stomodeal walls may secrete scale-like plates. In fact, in the teeth of some elasmobranchs (Raia, Mustelus, Trygon, etc.) the placoid scale can be recognized with scarcely a modification. In the ichthyopsida teeth may form anywhere in the oral cavity where there are skeletal parts - cartilage or bone- to support them. Thus they may occur, not only on the margins of the jaws, but on vomers, palatines and parasphenoid, and in some teleosts on the tongue, where they are attached to the hyoid. In the amniotes (some squamata excepted) teeth occur only on the margins of the jaws. Teeth are lacking, here and there, in various families of vertebrates as well as from all turtles and living birds, but some extinct birds had teeth. In the embryos of both chelonians and aves the dental ridge is formed (vide infra), but it soon completely disappears.

In the development of a tooth, as of a placoid scale, there is first a thickening of the ectoderm, the basal layer of which pushes into the cutis, and at the same time the mesenchyme cells of the latter layer multiply beneath the centre of the ectodermal ingrowth, pushing it outward, so that the basal layer forms a cup with the opening toward the deeper tissues (fig. 210). The mesenchyme within the cup forms the dental papilla, while the ectoderm cells lining the cup form the enamel organ. With farther development the outer cells of the papilla are converted into odontoblasts, so-called from their function of forming a bone-like substance, the dentine or ivory of the tooth. This, in accordance with the method of its formation by secretion from the ends of the odontoblasts, has a prismatic structure. The basal surface of the enamel organ secretes a denser substance, the enamel, which lies like 
a cap, firmly united to the top and sides of the dentine. By continued additions to the deeper portions of the dentine the tooth is gradually forced up through the epithelium so that its tip or crown comes into position for use (eruption of the tooth).

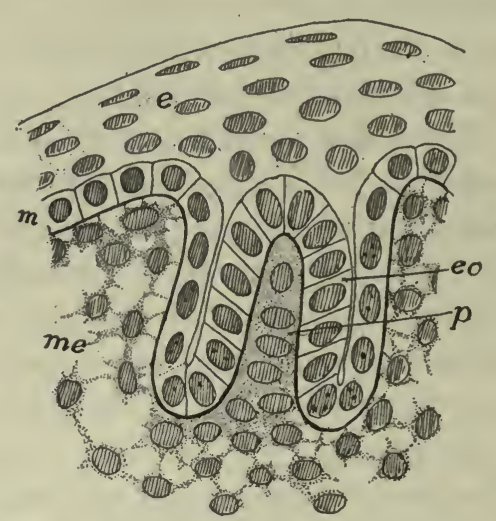

FIG. 210.-Section of developing tooth germ of Amblystoma. $e$, epidermis; $e o$, enamel organ; $m$, Malpighian layer; $m e$, mesenchyme; $p$, pulp of tooth.

In the lower vertebrates there may be a separate invagination of the ectoderm for each tooth, but in the mammals there is a continuous ingrowth, the dental ridge (fig. 2Ir) along the margin of the jaw. Later this becomes differentiated into separate enamel organs and dental papillæ, the separate teeth developing much as

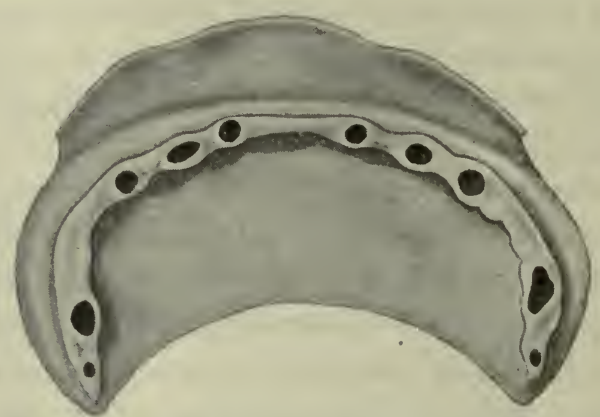

FIG. 2II.-Model of ectodermal parts of jaw of human embryo $40 \mathrm{~mm}$. long, after Röse, showing the dental ridge with the enamel organs for the first teeth.

in other groups. From the posterior side of this dental ridge there arises a continuous projection, the dental shelf (fig. 212) which later gives rise to the enamel organs for the second or permanent dentition (infra).

The dental papilla persists throughout life as the pulp of the tooth, continuing to occupy the space (pulp cavity) in which it first appeared. 
Nerves (branches of the trigeminal) and blood-vessels enter the cavity through the base of the tooth. Usually, when the tooth is fully formed, the odontoblasts cease to act, but exceptionally, even in mammals (tusks of elephants, incisors of rodents) they function through life and the tooth continues to grow. In the mammals an additional layer of modified bone, the cement, is formed around the root of the tooth and may extend on to the crown.

Just as the scales are arranged in quincunx on the surface of the body, so are the teeth in the mouths of skates and some other elasmo-

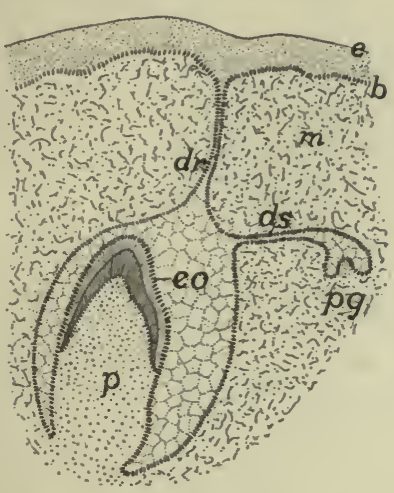

FIG. 2 I2.

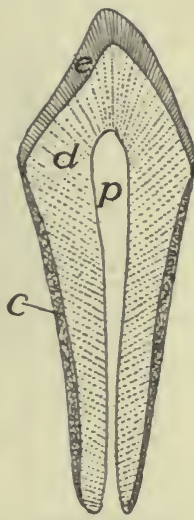

FIG. $2 I_{3}$.

FIG. 212.-Diagram of germs of milk and permanent dentitions in a mammal, based on Röse. $b$, basal layer of $e$, ectoderm; $d r$, dental ridge; $d s$, dental shelf; $e o$, enamel organ of milk tooth; $m$, mesenchyme; $p$, pulp of milk tooth; $p g$, germ of permanent tooth.

FIG. 2 13. -Diagrammatic section of incisor tooth. $c$, cement; $d$, dentine; $e$, enamel; $p$, pulp cavity.

branchs, where they form a tessellated pavement above and below, the teeth being flattened and used for crushing the molluscs on which these animals feed. More commonly the teeth are flattened in the anteroposterior direction and have sharp cutting edges. In such cases, as a rule, only the anterior row of teeth is functional, the others lying folded down behind, ready to come into use when one of the first row is lost.

Most vertebrates have a succession of teeth (polyphyodont dentition) and the elasmobranchs show how this has come about. The second arises on the (morphologically) posterior side of the first and so on. In the non-mammalian classes the number of such dentitions is indefinite (polyphyodont), but in the great majority of mammals there are two, the first or milk dentition and the second or permanent dentition (diphyodont condition). 
In a few mammals only one dentition has been retained (monophyodont); among these may be mentioned the monotremes, sirenians and cetacea. In the marsupial Myrrecobius, where the permanent dentition is greatly reduced, and in some of the insectivores and rodents, a prelacteal dentition has been observed in the embryo, while Röse has described traces of a prelacteal and a post-permanent dentition in man. In a number of mammals (guinea pigs, many bats, etc.) the milk dentition is lost before birth.

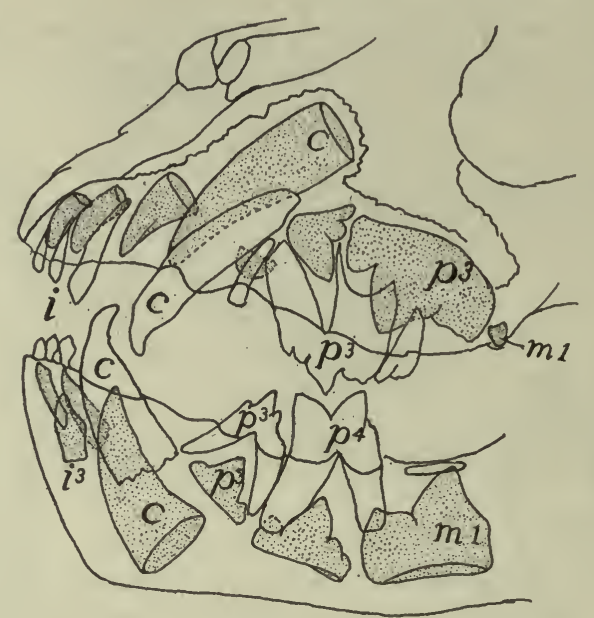

FIG. 2I4.-Jaws of a six month lion, after Weber. Milk teeth white, permanent dotted. $i$, incisors; $c$, canines; $m$, molars; $p$, premolars.

Only a few fishes (adult Acipenser, Coregonus, etc.) lack teeth, while in most they extend to the lining bones of the mouth and in some to the hyoid and branchial arches (pharyngeal bones). Usually they are conical, but they may be flattened and pavement-like or even form large plates, apparently by the coalescence of numbers of primitive teeth (dipnoi). In the amphibians the teeth are not so widely distributed in the mouth, occurring on the margins of the jaws and on the palatines and vomers, rarely on the parasphenoid, while they are entirely lacking in Bufo and Pipa.

Among the reptiles the turtles and some of the pterodactyls are toothless; most of the others have the teeth confined to the margin of the jaws, though they occur on the palatines and pterygoids in the snakes and lizards, and rarely (Sphenodon) on the vomer. While the conical shape prevails, the teeth present a great variety of forms, some of the theriomorphs. closely simulating the mammals in their heterodont dentition. The teeth may be anchylosed to the summit of the jaws 
(acrodont); applied to their inner side (pleurodont, fig. 97, d); or have their roots implanted in grooves or sockets or alveoli (thecodont). Mention must also be made of the poison fangs of certain serpents. These are specialized teeth borne on the maxillary bones and are either permanently erect (proteroglypha) or the bone may turn, as on a pivot, so that when the mouth is closed the teeth lie along the roof of the mouth, but when it is opened, they are brought into position for striking the prey (vipers, rattlesnakes-solenoglypha). Correlated with the fixed or movable condition is a modification in the teeth themselves. In the proteroglypha a groove runs along the anterior side of the fang by

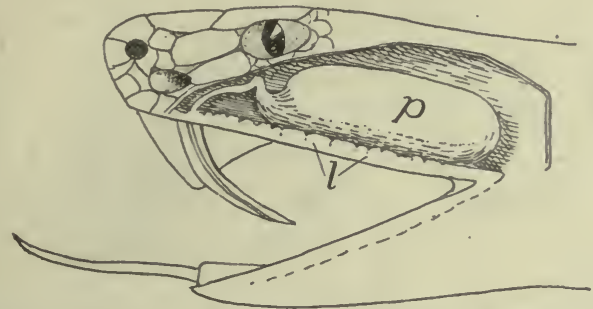

FIG. 215.-Poison gland and fang of rattlesnake, Crotalus horridus. $p$, poison gland; $l$, labial glands.

(Princeton 1404)

which the poison is conducted from the poison gland into the wound. In the solenoglypha the groove is rolled into a tube with openings near the base and apex of the tooth (fig. 2I5). In these solenoglyphous snakes only a pair of fangs are functional at a time, but there are reserve teeth which can come into use on the loss of the first.

The greatest variation is found in the teeth of mammals, the heterodont dentition being the rule. Four kinds of teeth are recognized. These are the incisors in the premaxillary bones, followed by a single canine at the anterior end of each maxillary bone. This resembles the incisors and differs from the other maxillary teeth in its conical shape and single root. Behind the canines come the premolars (the bicuspids of the dentists) which have two roots and complicated crowns and appear in both milk and permanent dentitions. Lastly are the molars, like the premolars in form, with several roots, but appearing only in the permanent dentition: The corresponding teeth in the lower jaw have the same names.

In a few mammals, like the whales, all of the teeth are of a simple conical shape, but in the majority the crown of the molars is marked by projections-cones, tubercles, crests, etc.-which are variously 
arranged. When the teeth are adapted for cutting they are called secodont (cats, fig. 2I4); for crushing, bunodont (man); when marked by transverse ridges, lophodont (elephants); when there are longitudinal crests, more or less crescentic in outline, they are selenodont (horse, fig. 2I6).

In the triconodont tooth there are three prominences in the crown arranged in a straight line, parallel to the axis of the jaw. The middle and more prominent of these in the upper jaw is the protocone, with a smaller paracone in front and a metacone behind. In the lower jaw the corresponding terms are proto-, para-, and metaconid. In
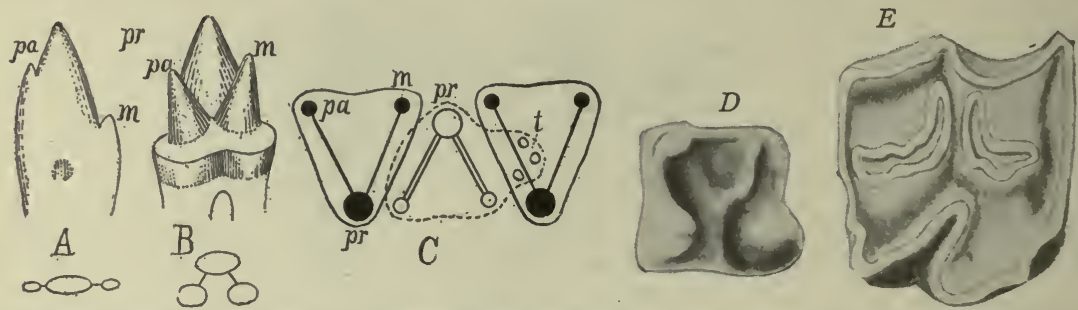

FIG. 2 16. - A, triconodont tooth of Dromatherium; $B$, tritubercular tooth of Spalacotherium; $C$, interlocking of upper (dark) and lower (light) tritubercular molar teeth (after Osborn); $D$, molar of Erinaceus; $E$, of horse (selenodont type); $c$, cingulum; $m$, metacone (metaconid); $p$, paracone (paraconid); $p r$, protocone (protoconid); $t$, talon.

a tritubercular tooth the three cones are arranged in a triangle, in such a way that they alternate in the two jaws, the protocone being on the inner side, the protoconid on the outer. Tritubercular teeth may have a lower projection (talon) on the hinder side. When this develops into a prominent tubercle (hypocone, hypoconid) the tooth becomes quadritubercular. Then crests or lophs may develop, connecting the cones, so that the crown becomes ridged rather than tubercular.

In the homodont dentition the number of teeth may be very large, varying from 100 to 200 . With the heterodont dentition the number is smaller, the full dentition in the placental mammals including 44 teeth. From this number reductions may occur by the loss of teeth of any kind. The number of teeth and of those of each kind is important in systematic work, and a dental formula has been devised to express this. As the number of teeth in the two sides of each jaw is the same, only one side is represented in the formula, while the teeth of the upper and lower jaws are represented as fractions. The number of incisors, canines, premolars and molars of man are represented by

$$
\mathrm{i} \frac{2}{2}, \mathrm{c} \frac{\mathrm{r}}{\mathrm{r}}, \mathrm{pm} \frac{2}{2}, \mathrm{~m} \frac{3}{3} \text {; that of the opossum by } \mathrm{i} \frac{5}{4}, \mathrm{c} \frac{\mathrm{I}}{\mathrm{r}}, \mathrm{pm} \frac{3}{3}, \mathrm{~m} \frac{4}{4} \text {. }
$$


Not infrequently the enamel is lacking from the teeth of mammals, as in whales, dugongs and edentates, or it may be restricted to one side of a tooth, as in the incisors of rodents. Sexual differentiations occasionally occur in mammals, certain teeth (usually canines or incisors, more rarely premolars) being better developed in the males than in the females of the same species.

There are two views as to the way in which the complicated molars of the mammals have arisen. Both start with the conical tooth as the primitive condition. One theory is that the fusion of such simple teeth is sufficient to account for the multiplication of roots and tubercles in all of their varying forms (figs. 217,218 ).

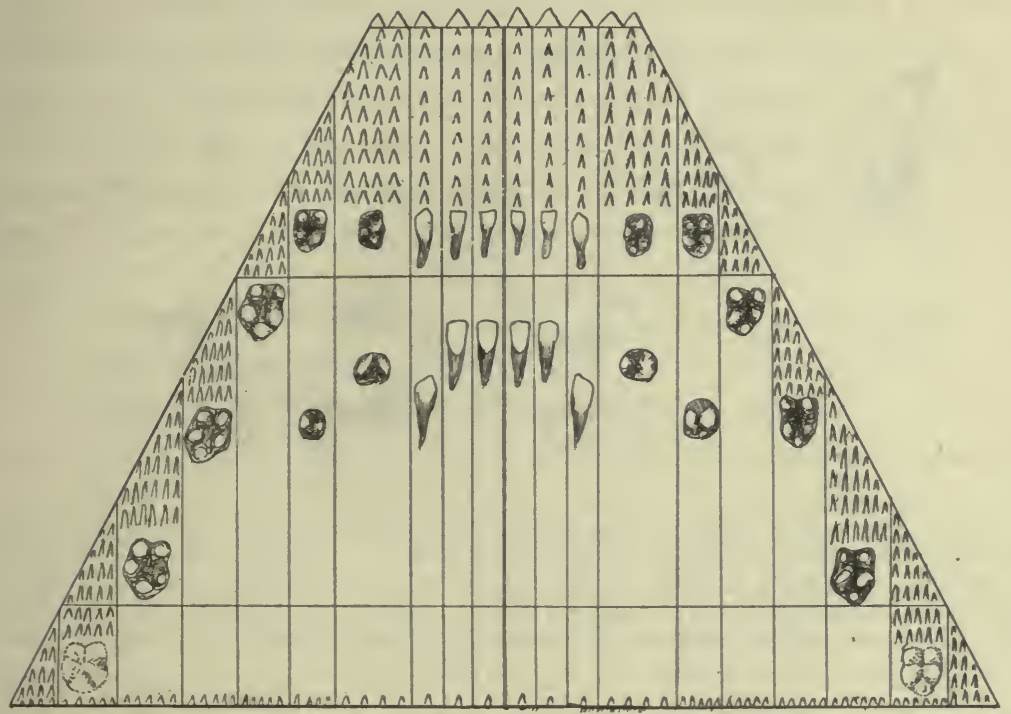

FIG. 217.-Diagram of the relation of the human teeth to the primitive dentition, after Röse.

The other hypothesis is that parts have been developed on the primitive cone, giving, first, the triconodont shape. Next these three cones have been shifted to the tritubercular position; and later other parts-hypocone, lophs, etc.-have been added and these have been modified in different directions. Each view has much in its favor. Embryology is not at all decisive, while paleontology favors the latter view.

Epidermal Teeth occur in cyclostomes and in larval amphibia and in embryonic monotremes. In the cyclostomes they are cones of cornified epithelium covering an underlying core of the integument; they are differently arranged in the lampreys and myxinoids. In the latter they are few, there being a single tooth on the 'palate' and two chevron-shaped rows on the tongue. In the lampreys nearly the whole inner surface of the oral hood is lined with these teeth of varying shape, 
and there are a varying number upon the tongue. These teeth are used as a means of fastening the animals to their prey, and those of the myxinoid tongue are used for boring into the fishes on which these animals feed.

In the larval anura (the larval Siren is said to resemble them) the edges of the jaws are armed with cornified papillæ, serving as teeth, the arrangement of which varies in different genera. They are frequently aggregated in dental plates, used in scraping the algæ from submerged objects. They are not related to the teeth of cyclostomes.

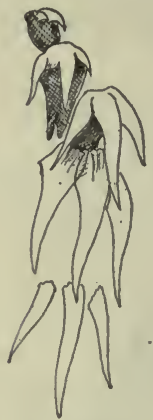

FIG. 218 .

In the embryo monotreme teeth are formed as in other mammals, of a multituberculate type, with a normal enamel organ (fig. 219), but these are lost before birth. During their eruption the adjacent epidermis becomes cornified, gradually extends beneath
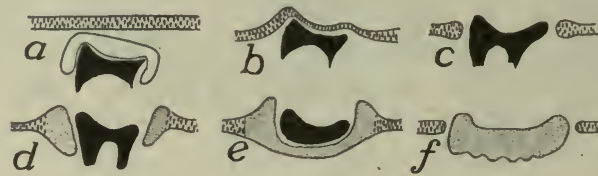

FIG. 2 I9.

FIG. 2 I8.-Teeth of Chlamydoselache (after Röse), showing a triconodont tooth arising from the fusion of three simple teeth.

FIG. 2 I9.-Diagram of development of teeth in Ornithorhynchus, after Thomas and Poulton. $a$, tooth covered with enamel organ, beneath oral epithelium; $b$, just before eruption; $c$, tooth erupted; $d$, edges of epithelium cornified; $e$, horny plate formed, contains the tooth; $f$, tooth lost, plate separated from its surroundings.

each tooth and after the loss of the true tooth this forms a horny plate, used, like those of many birds, in holding and crushing the food.

In this connection mention may be made of the baleen or 'whalebone' of the balenid whales. This takes the form of large plates of horny material, attached in series to the margins of the upper jaw, so that with their fringed ends and edges they serve as strainers to extract the plankton (minute floating life) from the sea. This baleen is formed by the agglutination of enormously developed cornified papillæ.

Egg Teeth.-In the embryos of certain lizards and snakes one of the median teeth of the first dentition of the premaxillary region projects from the mouth and is used for the rupture of the egg shell, thus allowing the escape of the young. In the turtles, Sphenodon, crocodiles, birds, and monotremes an egg tooth is formed on the upper surface of the beak which is used for the same purpose. However, it differs greatly as it is but a thickening, often calcified, of the epidermis (Fig. I95): 


\section{The Tongue.}

The tongue as it occurs in its more primitive condition in the fishes is merely a fleshy fold developed from the floor of the mouth between the hyoid and mandibular arches, the hyoid frequently extending into and supporting it. It is incapable of motion, except as moved by the supporting skeleton, for it lacks intrinsic muscles. It is sensory, having both tactile and gustatory functions. It is often papillose, and in a few teleosts it bears teeth (p. 209).

The tongue in the cyclostomes is considerably different. Here it is thick and fleshy and is supported by a cartilaginous skeleton (p. 75) and is moved by appropriate protractor and retractor muscles at the base, developed from the postotic myotomes and innervated by the hypoglossal nerve. With its terminal armament of epidermal teeth it serves as the boring organ with which the myxinoids obtain entrance into their prey, while in the lampreys it serves as a rasping organ and also as part of the sucking apparatus.

In the amphibia there is a greater range of structure. In a few anura (aglossa) the tongue is practically absent; in the perennibranchs it is scarcely more advanced than in the fishes, but elsewhere it contains intrinsic muscles and is extremely mobile. It consists of a small basal portion corresponding to the tongue of the fish, to which is added a large glandular part arising between the copula and the lower jaw. This secretes the slime, so useful in capturing the prey. In the anura the tongue is attached at the margin of the jaw, its free end, when at rest, being folded back on the floor of the mouth. In urodeles the base of attachment is more extensive and embraces the anterior margin of the tongue and part of the ventral surface as well. The supporting skeleton (fig. 85) consists of the median portion (copula) with usually two pairs of cornua, largely formed from the ventral ends of the hyoid and first branchial arches (see p. 64).

The reptilian tongue includes not only the parts found in the amphibia (the fold above the basihyal), but also a median growth; the tuberculum impar, arising between the basihyal and the lower jaw, and also a pair of lateral folds lying above the first visceral arch (Lacerta). In the turtles and crocodiles the tongue lies on the floor of the mouth and is not protrusible. In the squamata it can be extended from the mouth, and in snakes and many lizards there is a sheath into which it is withdrawn. In many snakes the tongue is two-pointed at the 
tip; in the lizards its shape varies greatly, the differences being used in classifying these animals. In the reptiles (fig. 220) with retractile tongue the hyoid apparatus extends into

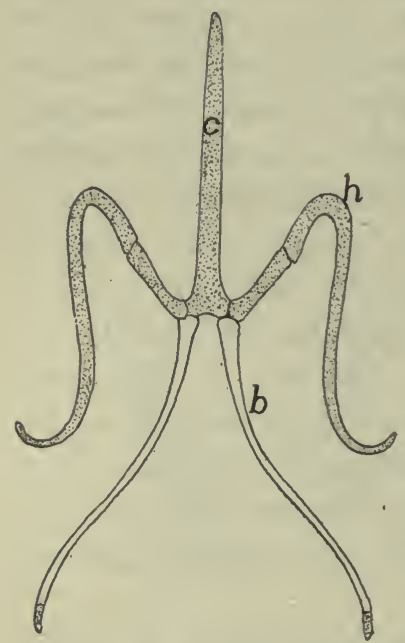
the tongue, its unpaired anterior portion being called the os entoglossum (copula or basihyal), while the two cornua (usually. hyoid and first branchial) afford attachment for the retractor muscles. In addition to the usual lingual nerve (glossopharyngeal) the tongue also receives a lingual twig from the mandibular branch of the fifth nerve.

In birds the tongue has lost the lateral parts of the reptilian tongue and with this the trigeminal branch. It contains no intrinsic muscles. In its form itvaries greatly; but usually it is slender and is covered with retrorse papillæ. Its skeleton is also reFig. 220.-Hyoid apparatus of duced (fig. IOI) and consists of an os en-
eloderma, after Cope. $b$, first toglossum, bearing in front a pair of eleHeloderma, after Cope. b, first toglossum, bearing in front a pair of ele-
branchial; $c$, copula; $h$, hyoid. pair of cornua (first branchials) and in the median line behind, a urohyal portion. This skeleton has a marked development in the woodpeckers, where the cornua curve around the base of the skull
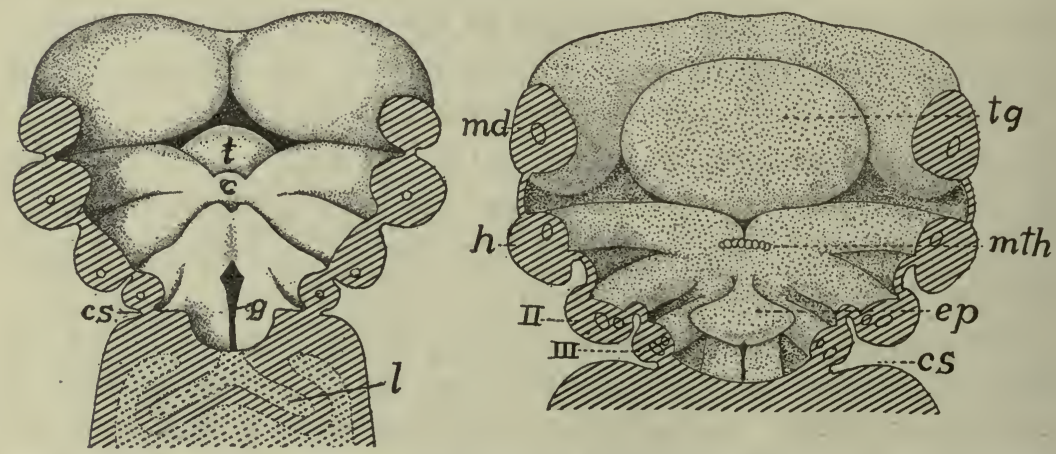

FIG. 221.-Two stages in developing tongue and pharyngeal floor of man, after His. $c$, copula (basihyal element); $c s$, cervical sinus; $e p$, epiglottis; $g$, glottis; $h$, hyoid arch; $m$, mandibular arch; $m t h$, median anlage of thyreoid; $t$, tuberculum impar; $t g$, tongue.

and over its dorsal side to the neighborhood of the nostril, a condition correlated with the use of the tongue in these animals. 
In the whales the tongue has little power of motion, but elsewhere in the mammals it is very mobile, reaching the extreme in the ant-eaters. This mobility is largely due to the extensive intrinsic musculature. The tongue is developed from the tuberculum impar, which furnishes the larger anterior part (fig. 22 I), the rest arising from the fleshy ridges above the hyoid arch. In the adult the line between these parts is largely obliterated, but it lies near the line of circumvallate papillæ (p. I8g) and the foramen cæcum, a blind tube connected with the development of the thyreoid gland. Arising in this way from the tubercle and the lateral suprahyoid parts, the tongue of the amphibia is

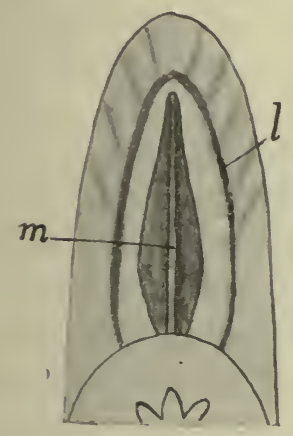

FIG. 222.

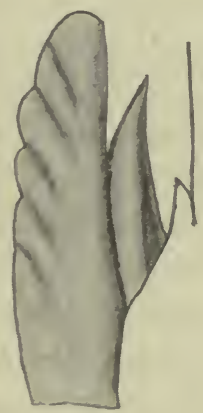

22.

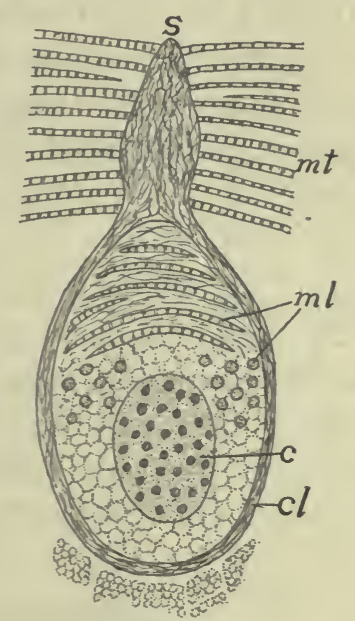

FiG. 223.

FIG. 222.- Ventral and side views of tongue of Stenops gracilis, after Weber. l, lateral margin of sublingua; $m$, plica mediana.

FIG. 223.- Section through lyssa of late dog embryo, after Nussbaum. ce, cartilage of lyssa, $c l$, capsule of lyssa; $m$, muscles of tongue; $m l$, longitudinal and transverse muscles of lyssa; $s$, septum of tongue.

unrepresented in that of most mammals, unless it be in the sublingua, a fleshy fold developed beneath the functional tongue in the marsupials and lemurs (fig. 222). Traces of this are to be found in other mammals, even in man, as folds (plicæ fimbriatæ) beneath the tongue. In some cases (Stenops) this sublingua is supported by a cartilage which is regarded as an entoglossal part. Others think that the tongue of the lower vertebrates is represented in the mammalian tongue and regard the lyssa as the os entoglossum. The lyssa is a vermiform structure of cartilage, muscle and connective tissue (fig. 223) lying ventral to the septum of the tongue.

The tongue varies considerably in shape in the different mammalian orders, but the differences are of little morphological importance. 
The dorsal surface is usually covered with a soft epithelium, developed into papillæ of varying shapes, some being sensory in character, and some are occasionally (monotremes, felidæ) cornified.

The skeleton of the mammalian tongue (hyoid apparatus) varies considerably. In its most complete development it consists of a body (copula of the hyoid and first branchial) in the median line, which bears two pairs of cornua. The anterior pair (lesser horns of human anatomy) are usually elongate, and consist of a series of ossicles (p. IOI) connecting the body with the otic region of the skull. The second pair (greater cornua of man) are occasionally absent. In man the greater part of the anterior cornua is represented by the stylohyoid ligament, the proximal portion being fused to the skull as the styloid process.

\section{Oral Glands.}

In the cyclostomes there is a large, so-called 'salivary gland' of unknown function, opening into the mouth on either side below the tongue. With this exception, glands are lacking from the mouths of aquatic ichthyopsida. With the assumption of pulmonate respiration and more terrestrial habits, the mouth is no longer constantly bathed -

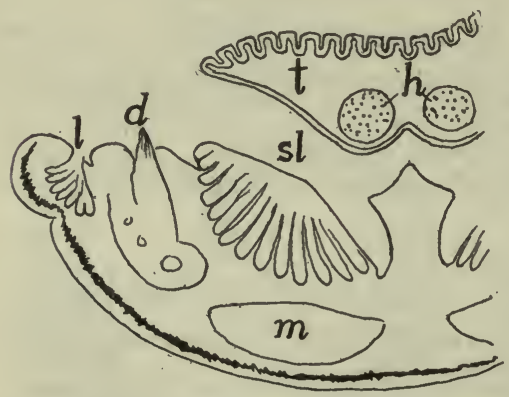

FIG. 224.-Transverse section of tongue and lower jaw of Lacerta, after Gegenbaur. $d$, tooth; $h$, hyoid cartilage; $l$, labial glands; $m$, muscles; sl, sublingual gland; $t$, tongue. with water and so glands appear, increasing in number and complexity in the higher forms. The secretion of these glands aids in moistening the food, and not infrequently it is adhesive and is used in capturing the prey. In the mammals true salivary glands appear. The saliva secreted by them contains not only mucus, but also a digestive ferment (ptyalin) which changes starch into sugar. The names of the various oral glands (labial, buccal, lingual, retrolingual, etc.) are roughly indicative of their position.

In the terrestrial amphibia, snakes (fig. 2I5) and lizards there are labial glands, opening at the bases of the teeth, and an intermaxillary or internasal gland in the septum between the nasal cavities, as well as palatal glands near the choanæ (the internasal gland is lacking 
in the cæcilians). Many reptiles also have a sublingual gland on either side (fig. 224). In many snakes a pair of the labial glands are greatly developed and have migrated into the zygomatic ligament, where they have become modified into the well-known poison glands (fig. 215), the ducts of which connect with the poison fangs (p. 213). In the only known poisonous lizards (Heloderma) the sublingual glands furnish the poison. Oral glands are poorly developed in the sea turtles and the crocodilians.

m Birds lack the labial and internasal glands, but they have numerous other glands opening separately into the roof of the mouth (fig. 225) as well as anterior and posterior sublinguals and frequently an 'angle gland' at the angle of the mouth, which may be the last remnant of the labial glands of the other Sauropsida.

Besides numerous smaller glands (labials, buccals, linguals, palatines) imbedded in the mucous membrane and opening separately into the mammalian mouth, the salivary glands, though absent from the cetacea, form a distinguishing feature of the group. These salivary glands are usually in the neighborhood of the mouth, but one or more of them may be carried back into the neck (fig. 226), but in all cases the homologies are decided by the openings of the ducts. The salivary glands include the sub-

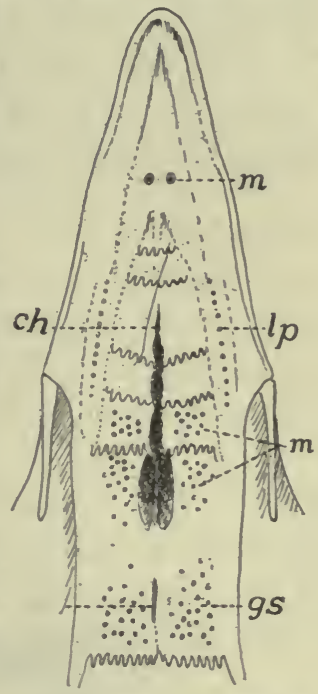

Fic. 225.-Palatal surface of hen, after Heidrich. $c h$, anterior end of choana; gs, openings of sphenopterygoid glands; in, infundibular opening; $l p, m p$, openings of lateral and medial palatine glands; $m$, opening of gl. maxillaris monostomatica. maxillary and sublingual of the lower groups, and in addition the parotid gland, apparently a development within the class. The submaxillary normally lies in the lower jaw beneath the mylohyoid muscle, and its duct (Wharton's duct) opens near the lower incisor teeth. Near this is frequently a retrolingual gland, its duct opening near the former. The sublingual gland occurs between the tongue and the alveolar margin of the lower jaw and usually empties by numerous duct. The parotid gland has its normal position near the ear and its ducts (Stenon's duct) pours the secretion out near the molars of the upper jaw. Other oral glands are occasionally present, like the molar glands of ungulates and the orbital glands of dogs, both of which have ducts leading into the mouth. 


\section{PHARYNX.}

The pharynx is the division of the alimentary canal intervening between the cavity of the mouth and the œsophagus and is characterized by being at once alimentary and respiratory. From its walls are developed the gill clefts and lungs as well as a number of derivatives of these, and it also receives the internal openings of the nasal passages. Hence it is best described in connection with the respiratory system.

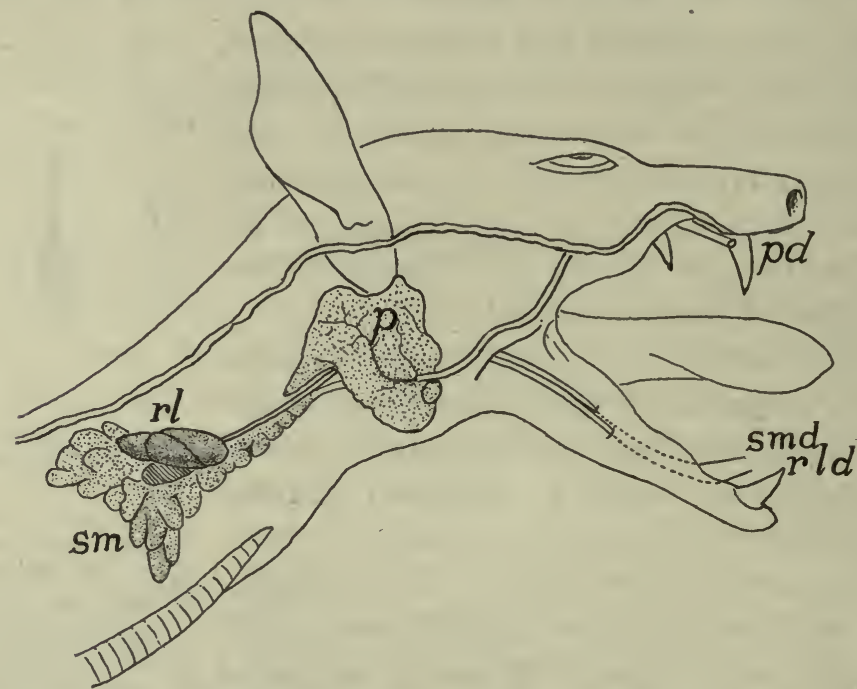

FIG. 226.-Salivary glands of fruit bat, Pteropus conspicillatus (Princeton, 2065). $p, p d$, parotid gland and duct; $r l, r l d$, retrolingual gland and duct; $s m, s m d$, submaxillary gland and duct.

\section{THE CESOPHAGUS.}

That part of the digestive tract between the pharynx and the entrance of the bile duct (fig. 209) develops into œsophagus, stomach and that part of the intestine known as the duodenum. Stomach and duodenum are separated by the pyloric valve described below, but it is difficult to draw a clear line between œsophagus and stomach. In general it may be said that the œsophagus is the tract immediately succeeding the pharynx, lying in front of the body cavity and thus lacking a serous coat; that it is smaller than the stomach, and that there are no digestive glands in its walls; but all of these statements have exceptions. 
The œsophagus varies in length with the length of the neck of the animal, being short in the ichthyopsida, longer in the reptiles, and reaching its extreme in the birds. In some its internal lining epithelium is smooth, but more commonly it bears longitudinal folds, while in the

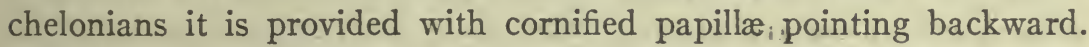
Outside of the epithelium its walls contain muscles, those at the cephalic end being striped and these may extend back, in some instances, even on to the stomach. They are apparently derivatives of the pharyngeal region. Usually the œsophagus is of the same diameter throughout, but frequently in birds it has a marked dilatation, the ingluvies or crop. This may be an expansion of one side of the tube, or, as in pigeons, it may consist of a median and a pair of lateral chambers. The extreme of development of the crop occurs in Opisthocomus, where the organ is extremely muscular and has numerous longitudinal folds.

The crop, which is usually supported by the furcula, may be either a reservoir for food, or it may be a glandular organ, its secretions serving to moisten the food or even to initiate its digestion. In the pigeons at the breeding season the secretion is a milky fluid and is used in feeding the young.

\section{THE STOMACH.}

The stomach is apparently a new acquisition in the vertebrates, possibly arising as a place for the storage of food. This view is supported by several facts. In the embryo vertebrate and in the adult of Amphioxus the duct from the liver immediately follows the pharynx, opening just behind the last gill cleft; while the innervation from the tenth nerve shows that both stomach and œsophagus are parts of the pharynx greatly drawn out (fig. 209).

The pylorus, which limits the stomach behind, is a fold of the lining mucous membrane projecting into the interior and reinforced by a circular (sphincter) muscle, which by its contraction, closes the tube so that no food can pass from the stomach until it is properly acted upon by the gastric fluids. The anterior end of the stomach is not so well marked. Usually it is differentiated from the œsophagus by its greater diameter, but in some of the fishes (fig. 227, a) there is no distinction in size. The stomach lies in the cœlom and hence is covered externally by the serous membrane (peritoneum), but the 
œsophagus usually extends a short distance into the body cavity and then its lower end has the same coat.

The true stomach is characterized by the presence of glands, developed from the mucous layer and emptying into the lumen. Of these glands there are at most (mammals) three kinds: cardiac, near the-entrance of the œsophagus, which secrete an albuminoid fluid;

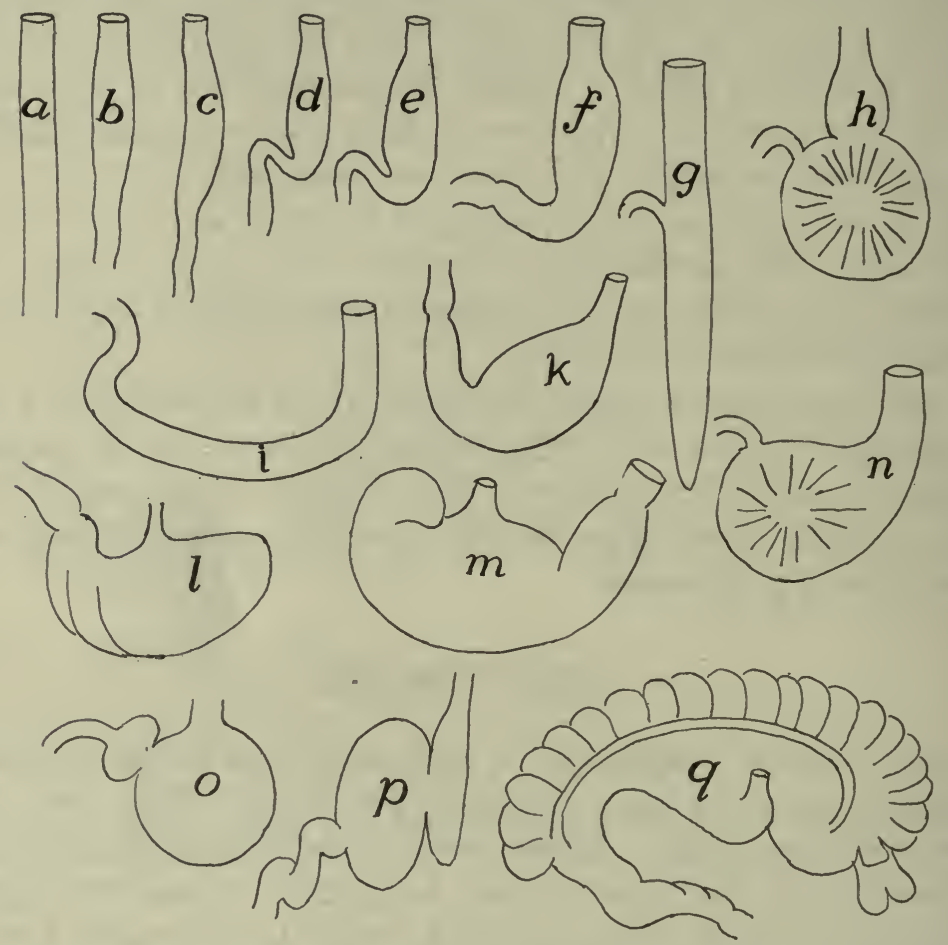

FIG. 227.-Different shapes of stomachs, mostly after Nuhn (Keibel). a, Belone; $b$, Proteus; c, Tropidonotus natrix; $d$, Gobius; $e$, shark; $f$, Phoca vitulina; $g$, Polypterus; $h$, Fulica atra; $i$, Testudo grceca; $k$, land tortoise; $l$, rabbit; $m$, pig; $n$, owl; $o$, crocodile; $p$, Delphinus; $q$, Halmaturus.

pyloric, near the pylorus, which form mucus; and the most characteristic, the fundus glands, which secrete a digestive ferment, pepsin. (For the structure of these glands reference should be made to histological text-books.) Tested by glands, many vertebrates (dipnoi, cyprinoids) lack a true stomach, while the sturgeons have the gastric glands extending into the œsophagus. On the other hand, a part of the enlargement called the stomach in mammals often includes a part of the osophagus (fig. 228, $A, E$ ). 
The shape of the stomach is to some extent dependent upon the shape of the body. In the elongate species it lies in the axis of the trunk, especially in the lower vertebrates (fig. 227,a), but with increase in the body width it becomes more transverse. This involves a bending and a torsion of the tube, always to the right, and results in two faces or 'curvatures,' a lesser or anterior, and a greater or posterior, the greater curvature often expanding into a so-called fundus region. The end of the stomach which connects with the œsophagus is nearest the heart and hence is called the cardiac end.

In the fishes the stomach may be either straight or saccular, often assuming the form of a blind sac (fig. 227, $g$ ). The line between œsophagus and stomach is not well marked, as the œsophageal folds may continue into the stomach. The teleosts exhibit the greatest variety in shape, in correlation to the differences in food. All gastric glands are lacking in the cyprinoids, while Amia has both cardiac and pyloric glands, and, like many teleosts, the stomach is ciliated. In the amphibians and reptiles the distinctions between osophagus and stomach are more marked, most in the crocodiles. In the amphibians the ciliation of the mouth is continued into the stomach.

In the birds there is a differentiation of the gastric region into two regions, an anterior glandular stomach or proventriculus, and a posterior muscular gizzard. The proventricular glands secrete a digestive fluid, and the food, mixed with this, is passed on to the gizzard. The walls of the latter have their muscles developed into a pair of discs with tendinous centres, while the glands of the gizzard form a secretion which hardens into a horny (keratoid) lining, sometimes developing into tubercular structures, of great use in grinding the food, thus in part making good the absence of teeth. In the grain-eating birds small pebbles are taken into the gizzard and are used in triturating the food. (In the fossil pterodactyls small clusters of stones are sometimes found in such a position as to lead to the supposition that these reptiles also had a gizzard.) The gizzard is best developed in the grain-eating birds and is weakest in the birds of prey. In one species of pigeon part of the wall of the gizzard is ossified.

The mammalian stomach shows the greatest range of form (figs. $227,228)$ and the greatest development of different kind of glands. It may be a simple sac or it may be subdivided into a series of chambers. It may be almost wholly œsophageal in character (Ornithorhynchus, fig. 228, A). Occasionally the cardiac glands may be absent. It may be a simple sac, longitudinal or transverse in position, or it may be 


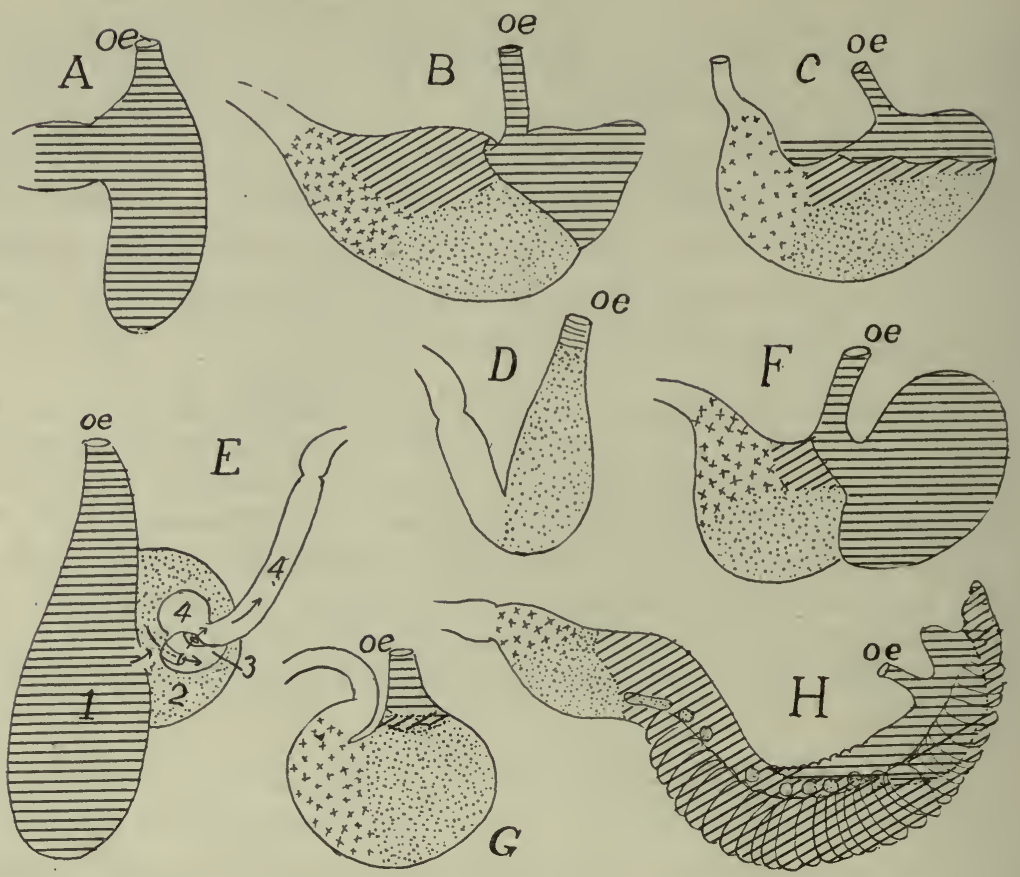

FIG. 228.-Outlines of the stomachs of various mammals (various authors), after Oppel, to show the distribution of the different glandular regions. Horizontal lines, œsophageal; oblique, cardiac; dots, fundus; crosses, pyloric; $A$, Ornithorhynchus; $B$, gray rat; $C$, tapir; $D$, seal; $E$, whale (Lagenorhynchus); $F$, mouse; $G, \operatorname{dog} ; H$, kangaroo (Macropus).

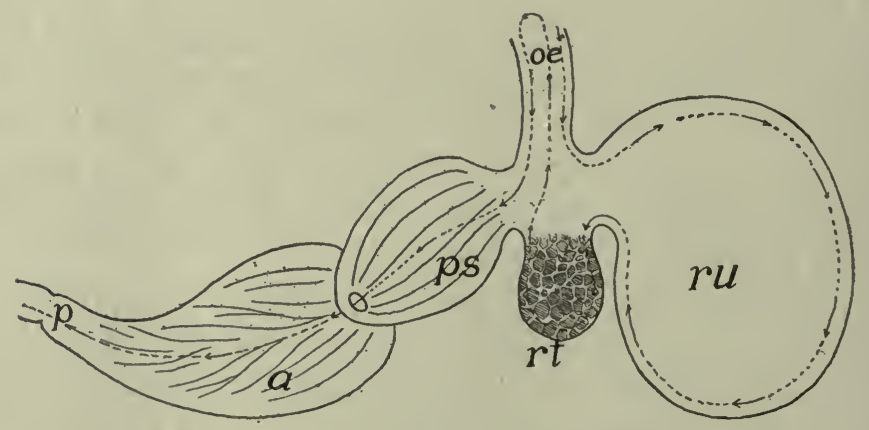

FIG. 229.-Diagram of ruminant stomach, the dotted line showing the course of the food. $a$, abomasum; oe, œsophagus; $p$, pylorus; $f s$, psalterium (omasus, manyplies); $t r$, reticulum (honeycomb); $r u$, rumen (paunch). 
divided into chambers, the division reaching its extreme in the ruminants (fig. 229) and the cetacea (fig. 228, E) where four compartments can be recognized. In the ruminants two of these, the rumen or paunch and the reticulum or honey-comb are expansions of the œsophagus and serve as reservoirs for food before its complete mastication, after which it follows the course of the dotted lines to the psalterium, omasus or manyplies and the abomasus or rennet stomach for gastric digestion.

\section{INTESTINE.}

The remainder of the pre-hepatic portion of the alimentary canal, the duodenum, extending from the pylorus to the entrance of the bile duct, is considered as part of the intestine. It is especially noticeable

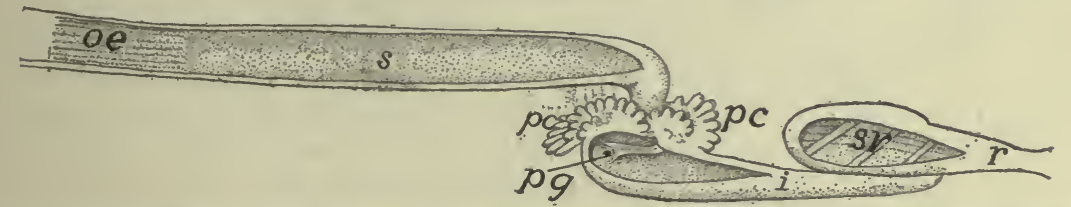

FIG. 230.-Digestive tube of garpike, Lepidosteus (after Gegenbaur). i, small intestine; $o e$, œsophagus; $p c$, pyloric cæca; $p g$, pylorus; $r$, rectum; $s$, stomach; $s v$, spiral valve.

in many ganoids and teleosts (figs. 230, 233) where it may bear from one to two hundred blind digestive tubes, the pyloric cæca. The same region in a few elasmobranchs may have a pair of these cæca or (Galeus) it may be expanded into a pouch ('bursa Entiana').

The post-hepatic intestine is the seat of most of the digestive processes and of absorption of the products of digestion. Here the food, coming from the stomach, is mixed with the bile from the liver and with the pancreatic juice and with the secretions of numerous small glands in the intestinal wall. The increase of surface needed for adequate digestion and absorption is provided in several ways. There may be an elongation of the tube which results in its becoming coiled in the body cavity; the mucous lining may develop folds, both longitudinal and circular; or the folds may break up into numerous minute, fingerlike processes (villi) which give the surface a velvety appearance. The food undergoing digestion is moved back and forth (peristaltic motion) by the antagonistic action of the muscles of the intestinal wall (p. 207), bringing all of it in contact with the absorbtive surface. 
The length of the intestine is roughly related to the food, being longer in the plant-eating than in the carnivorous species. This is strikingly shown in the frogs, where the tadpole (larva) has a very long intestine, correlated with the vegetable food, while the adult flesh-eating frog has a canal hardly longer than that of the tadpole of half the size.

In the intestine there are two divisions, an anterior small intestine and a posterior large intestine, terms adapted from the digestive tract of man, though not always appropriate in the lower groups. The line between the two may be marked externally by the development of

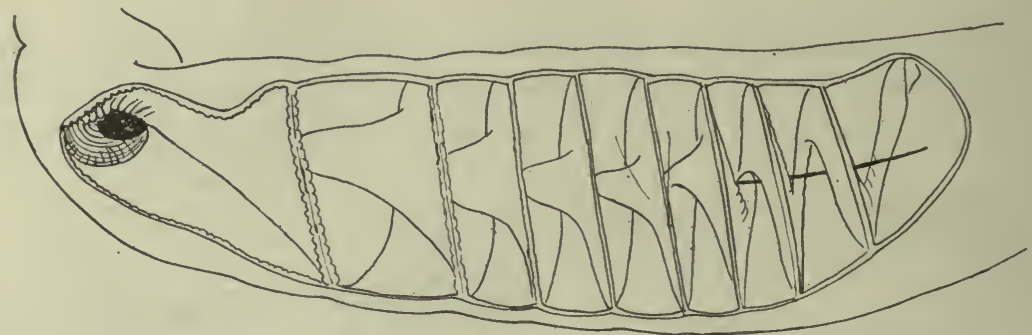

FIG. 23I.-Spiral valve of Raia, after Mayer.

one or two blind pouches or cæca at their junction or by a circular fold or a pair of internal folds of the lining, constituting an ileo-colic (ileo-cæcal) valve, both valve and cæca coexisting in many cases. Both large and small intestines may be subdivided, chiefly by differ-

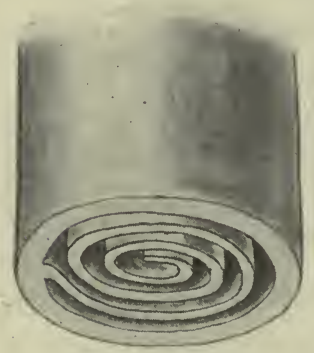

FIG. 232.-Diagram of spiral valve of Carcharias. ences in their walls. Thus in the small intestine there may be recognized in different groups a jejunum, a spiral valve region and an ileum, while the large intestine may furnish a colon, a rectum and a cloaca.

In the cyclostomes but two regions occur, the intestine and the rectum, differentiated externally by the larger size of the latter. In the petromyzonts there is an internal fold of the intestine which pursues a slightly spiral course, constituting a spiral valve, a structure which reaches its highest development in the elasmobranchs.

In the elasmobranchs the intestine is nearly straight, but its differentiation has proceeded farther. At the junction of small and large intestine is a dorsal blind sac, the rectal gland. Its function is un- 
known, but it apparently corresponds to the cæca of the higher groups. In the 'small' intestine is the spiral valve which has two forms, both leading to increase of surface. In most species a fold, carrying bloodand lymph-vessels, arises in a spiral line from the wall of the tube, and its free edge projects into the lumen like a spiral stairway (fig. 23I). In a few forms (Carchariidæ, Galeocerdo) the line of origin of the fold is straight and its free margin is coiled like a roll of paper (fig. 232). In the large intestine rectum and cloaca are recognized, the cloaca being that part which receives the ends of the excretory and reproductive ducts and thus is both digestive and urogenital in character.

Ganoids and dipnoi (figs. 230, 233) also have the intestine nearly straight and a spiral valve, least developed in Lepidosteus. In the teleosts the canal may be straight (fig. 227) or may make more or fewer coils, the predaceous species being simplest, while in the mullet (Mugil) there may be $\mathrm{I}_{3}$ or $\mathrm{I} 4$ turns. In the teleosts the line between small and large intestine is often marked by an ileo-colic valve and a few species have a cæcum or rectal gland. A spiral valve rarely occurs in teleosts and a cloaca is never found. In a few teleosts, in correlation with the translation of the ventral fins, the anus may lie in front of the pectoral girdle.

The intestine is straight in the cæcilians, has a few coils in the perennibranchs and more in the salamanders, while the anura have a greatly convoluted intestine. (Reference has already been made to the differences between the intestines of the larval and adult frogs (p. 228). The line between small and large intestine is frequently marked in the amphibians by an ileo-colic valve and in a few forms (Rana, Salamandra) there is a rudimentary cæcum.

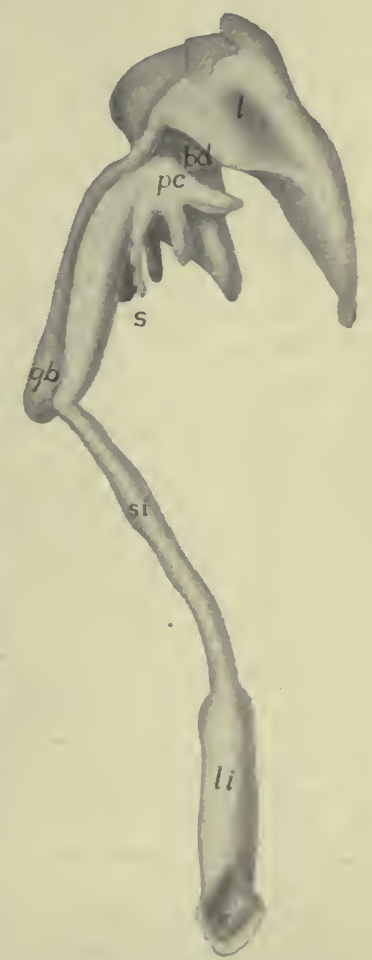

FiG. 233.-Digestive tract of scup (Stenostomus chrysops -Princeton 296). $\quad b d$, bile duct; $g b$, gall bladder; $l$, liver; $l i$, large intestine; $p c$, pyloric cæca; si, small intestine. The rectum is larger than the rest of the intestine and a cloaca is always present in the amphibia.

The reptiles have the intestine coiled (nearly straight in amphisbænans) and usually of about the same diameter throughout. Small and large intestine are separated by an ileo-colic valve, and except in crocodiles a cæcum is usually present, while a cloaca constantly occurs. The spirally twisted coprolites of the ichthyosaurs have been supposed to indicate the existence of a spiral valve, but since in other groups the fæces are formed in the rectum, this is not conclusive. 
The intestine is longer in the birds than in the reptiles, but there is considerable difference in the group in this respect. The great increase comes in the colon which is coiled in different ways, which may be reduced to seven plans or combinations of loops and spirals (fig. 234). In a few forms (woodpeckers, parrots, etc.) there

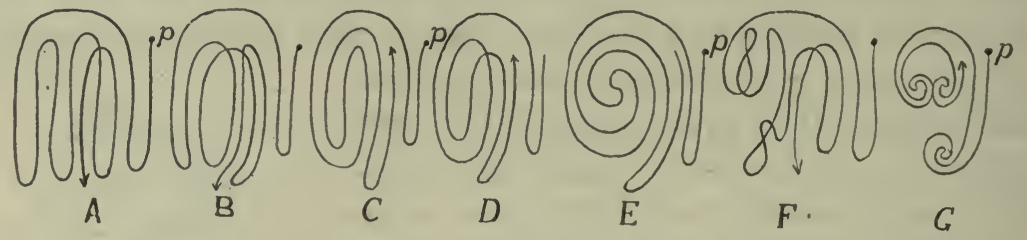

FIG. 234.-Types of coiling of the intestines of birds, after Gadow. $A$, isocœelous; $B$, anticœlous; $C$, antipericœlous; $D$, isopericœlous; $E$, cyclocœlous; $F$, plagiocœlous; $G$, telogyrous; $p$, pylorus.

is no cæcum, but usually the junction of large and small intestine is marked by one or two cæca (fig. 235). In some cases these cæca are lined with villi, or portions may be ciliated, while the very large cæcum of the ostrich is spirally coiled. Many birds have a pocket, the bursa Fabricii, of unknown functions, developed from the

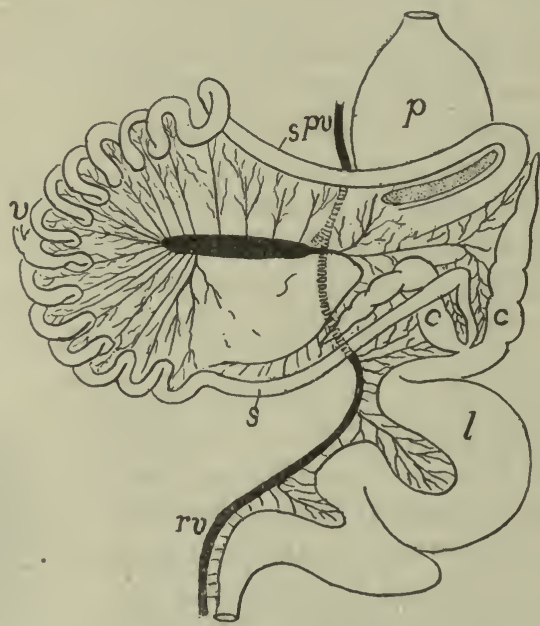

Fig. 235.-Alimentary canal of Chauna, after Mitchell. $c$, cæca; $l$, large intestine; $p$ proventriculus; $p v$, portal vein; $r v$, rectal vein; $s$, small intestine; $v$, remnant of vitelline duct.

dorsal part of the cloaca. It arises from the ectodermal (proctodeal) portion and extends forward, dorsal to the rectum (fig. 236). In some cases it degenerates in the adult.

The limits of large and small intestine in the mammals are usually marked by an ileo-colic valve and a single cæcum, but there are two cæca in some edentates, while some edentates, bats, carnivorous mammals and many whales lack either cæcum or valve. The cæcum is larger in the herbivorous forms and frequently 
there is a relation between the development of cæcum and stomach. The cæcum becomes enormous in certain rodents and marsupials (sometimes longer than the body) and plays an important part in digestion, being sometimes lobulated or furnished with internal folds, those of the rabbits being arranged in a spiral manner. In man and the anthropoids and some other forms, as is well known, the distal part of the cæcum degenerates to a rudiment, the vermiform appendix, which tends to become obliterated with increasing age.

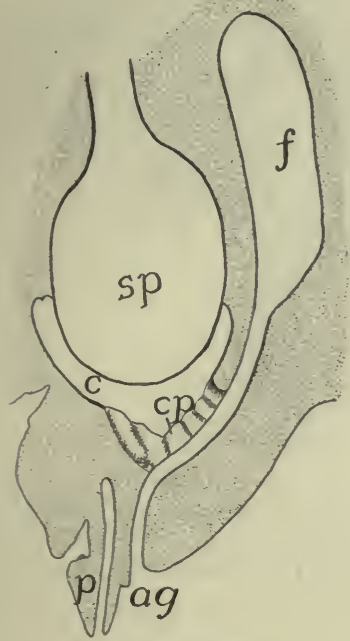

Fig. 236.

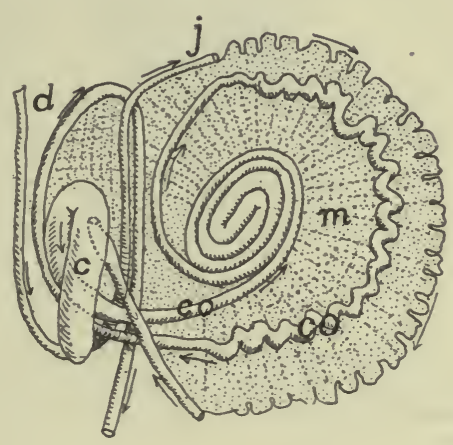

Fig. 237.

FIG. 236.-Diagrammatic longitudinal section of the cloacal region of a duck embryo at the twenty-second day of incubation, after Poindyer. $a g$, anal groove; $c$, cloaca; $c p$, cloacal plate; $f$, bursa Fabricii; $p$, phallus, with cæcal duct; $s p$, stercoral pouch of rectum.

FIG. 237.- Semidiagrammatic course of intestine of new-born deer Cervus canadensis, after Weber. $c$, cæcum; $d$, duodenum; $c o$, colon; $\jmath$, jejunum; $m$, mesentery.

Both small intestine and colon are at first straight, but with growth they become longer, involving convolutions varying in pattern and extent in different groups, the patterns of the colon being of some systematic value. The full history has been worked out only for man, two stages being represented in figure 238 . The genus Hyrax is remarkable for a pair of cæcal diverticula arising from the colon (fig. 239). In the monotremes the rectum terminates in a cloaca as in the sauropsida, and the same condition occurs in the young of all higher mammalia. In the later stages, however, the urogenital and digestive openings become separated by the formation of a perineal fold between the two.

\section{THE LIVER (HEPAR).}

The liver, the largest gland in the body, has several functions. It secretes the bile (gall) and forms several internal products such as glycogen, urea and uric acid, of great importance in the animal economy. 


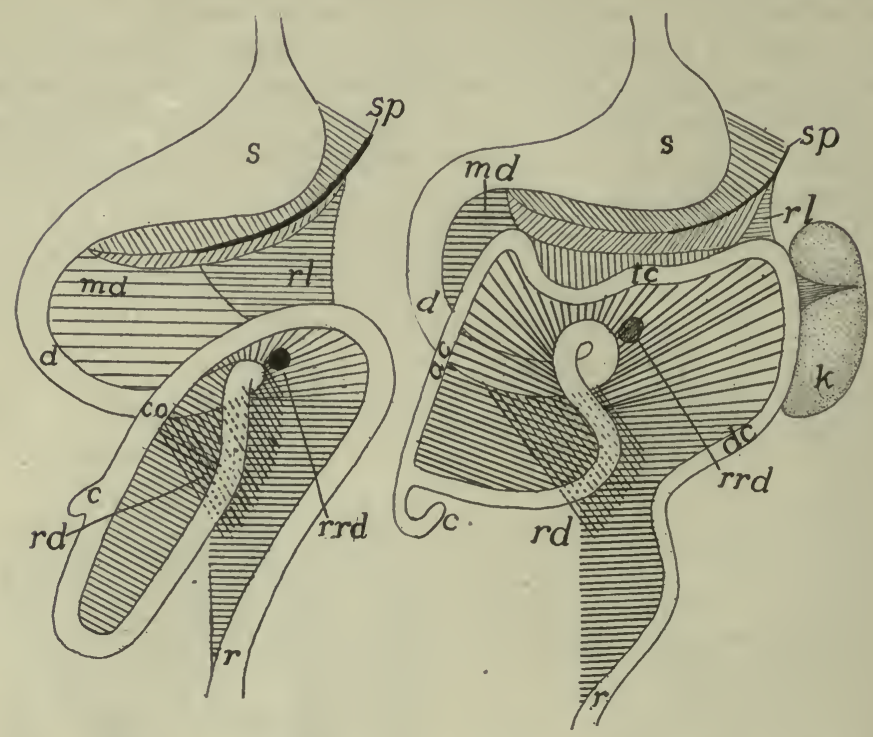

FIG. 238.-Scheme of alimentary canal and mesenteries in human embryos, 30 and 50 mm. long, after Klaatsch. $c$, cæcum; $c o$, colon; $d$, duodenum; $k$, kidney; $r$, rectum; $r d$, recto-duodenal ligament; $r l$, recto-lienal ligament; $r r d$, recto-duodenal recess; $s$, stomach; so, spleen.

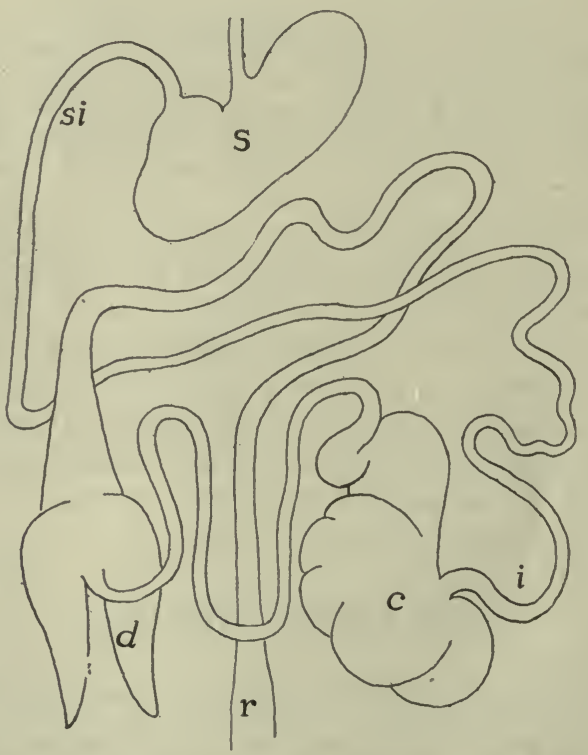

Fig. 239.-Alimentary canal of Hyrax capensis after Flower. $c$, cæcum; $d$, blind diverticula of colon; $i$, ileum; $r$, rectum; $s$, stomach; si, small intestine. 
The bile is passed to the intestine by the bile duct (choledochal or hepatic duct), but the other products are carried away by the blood (internal secretion).

The anlage of the liver is a ventral diverticulum from the archenteron (p. 206), which grows forward from its point of origin, branches again and again, the ultimate branches forming the glandular part of the organ, the proximal parts of the outgrowth giving rise to the bile duct (ocasionally multiple) which empties into the intestine. As a result of this method of formation the liver is to be regarded as a compound tubular gland, the lumens of the tubules forming the gall capillaries which eventually empty into the duct. This tubular condition is readily recognized in the ichthyopsida, but it is masked in the amniotes and especially in the mammals, in part by the anastomosis of the tubules, in part by the interrelation of the bile and blood-vessels.

With development the liver grows cephalad from its point of origin, but this forward growth is limited by the presence of the blood-vessels which develop the sinus venosus and the hepatic veins and also contribute to the septum transversum (hepatic veins-see circulation), and so its later increase must cause it to grow in the opposite direction. As it increases in size there is an immigration of mesenchyme between the lobules and with these the

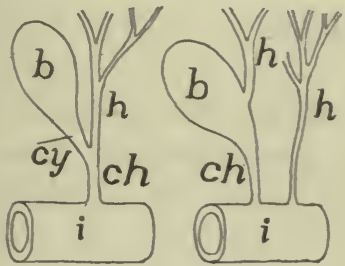

FIG. 240.

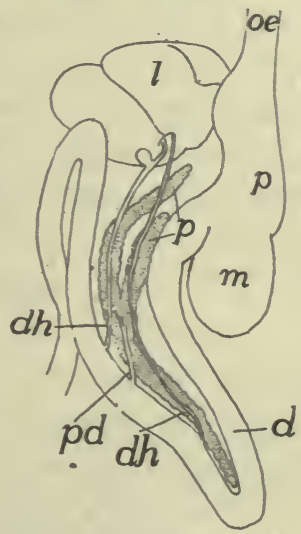

FIG. 24I.

FrG. 240.-Diagram of two types of bile ducts. $b$, gall bladder; ch, choledochar duct; $h$, hepatic ducts; $i$, intestine.

FIG. 24I.-Liver and pancreas of American ostrich (Rhea) after Gegenbaur. d, duodenum; $d h$, bile ducts; $l$, liver; oe, œesophagus; $p$, pancreas; $p d$, pancreatic duct; $s$, stomach.

blood-vessels enter. At the same time the liver grows away from the alimentary canal, carrying the peritoneum before it so that it receives an outer serous coat.

Usually the bile duct (when there are several ducts only one is concerned) forms a lateral diverticulum, the gall bladder, which serves as a reservoir for the bile. This is usually placed on the dorsal side of the 
liver, but it may be immersed in the substance of the gland. In some cases, even in mammals, the gall bladder may be lacking. When a gall bladder is present, three regions may be recognized in the bile ducts. Those parts which lead from the liver to the connexion with the bladder are called hepatic ducts; these are met by the cystic duct leading from the bladder, and the common duct, formed by the two and which empties into the intestine is the choledochal duct (fig. 240). The shape of the gland is in part determined by the shape of the body, being long in elongate species, sometimes consisting of two consecutive lobes. Another modifying factor is the shape and size of the adjacent organs, stomach, etc. Usually the liver is divided into right and left halves, these corresponding to the first division of the anlage, but these halves are hardly indicated in some of the teleosts. Frequently, and especially in mammals, the halves become subdivided into lobes of varying size, which are arranged in various ways. The.liver is relatively larger in the ichthyopsida than in the amniotes, but the cyclostomes have a small liver, that of the myxinoids being in two parts. It is larger, too, in the flesh-eating than in the herbivorous species. The blood supply, chiefly through the portal vein and to a less extent by the hepatic artery (see circulation) is very large. The color of the gland is very variable, especially in teleosts, where it may be brown, yellow, purple, green and even vermilion.

\section{THE PANCREAS.}

The second largest of the digestive glands, the pancreas, secretes digestive ferments of great strength (trypsin, steapsin, amylopsin), which digest both proteids and carbohydrates. In some respects it resembles the salivary glands and so compensates in part for the absence of them in the lower vertebrates (p. 220). The pancreas arises by diverticula from the wall of the intestine close to the liver. There are usually three of these diverticula, one dorsal and two ventral, the ventral soon uniting (fig. 242), but in the sharks there is only a single dorsal, diverticulum, while in the sturgeon there are two dorsal and two ventral. In a general way these develop much like the liver, the distal portions of the divisions forming the glands, which are of the acinous type; the proximal portions form the ducts. Of these ducts all may persist; all but one may disappear, while in the lampreys all may be lost. In many mammals two ducts persist, the ventral forming the 
main pancreatic duct (Wirsung's duct), the dorsal, the accessory or Santorini's duct. The ducts may remain distinct; they may unite before entering the intestine or one of them may unite with the bile duct.

For a long time it was supposed that a pancreas was lacking in certain vertebrates (some teleosts, dipnoi, cyclostomes), but recent studies have shown its presence in many of these. In the case of some

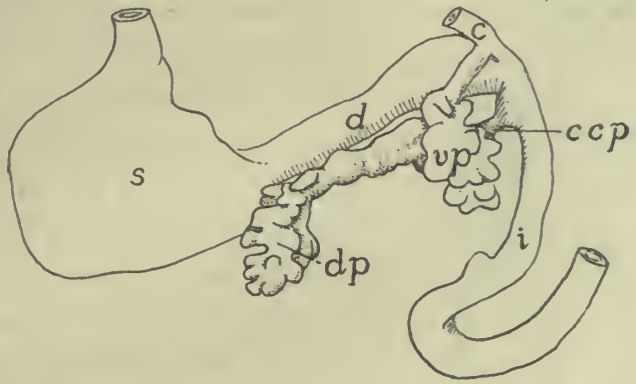

Fig. 242.-Diagram of developing pancreas of cat, after Thyng. $c$, ductus coledochus; $d$, duodenum; $d p$, dorsal pancreas; $d d p$, its duct; $i$, small intestine; $s$, stomach; $v p$, ventral pancreas.

teleosts it occurs as a slender tube in the mesentery; in the dipnoi it is outside of the muscles in the intestinal wall, while in the cyclostomes it is partly concealed at the insertion of the spiral valve, partly (myxinoids) in the liver. In these forms, owing to the complete disappearance of the duct it becomes a gland of internal secretion. The pancreas may be elongate, compact, or sometimes extremely lobulated. Usually (fig. 24I) it lies in a loop of the duodenum. From certain peculiarities of structure the queston has arisen as to whether two distinct structures are included in the pancreas.

\section{THE RESPIRATORY ORGANS.}

The respiratory organs have for their purpose the exchange of gases between the blood and the surrounding medium-water or aircarbonic dioxide being given off and oxygen being absorbed by the circulating fluid. In order that the exchange be readily effected it is necessary that the organs be richly vascular, that the walls between the blood and the surrounding medium be extremely thin so as to permit rapid osmosis, and that the osmotic surface be as great as possible. Further, there must be an adequate mechanism for passing the oxygencontaining medium over the respiratory surfaces. 
In the vertebrates the organs of respiration are developed in more or Mess intimate connection with the cephalic portion of the digestive tract, just behind the cavity of the mouth. This part of the alimentary

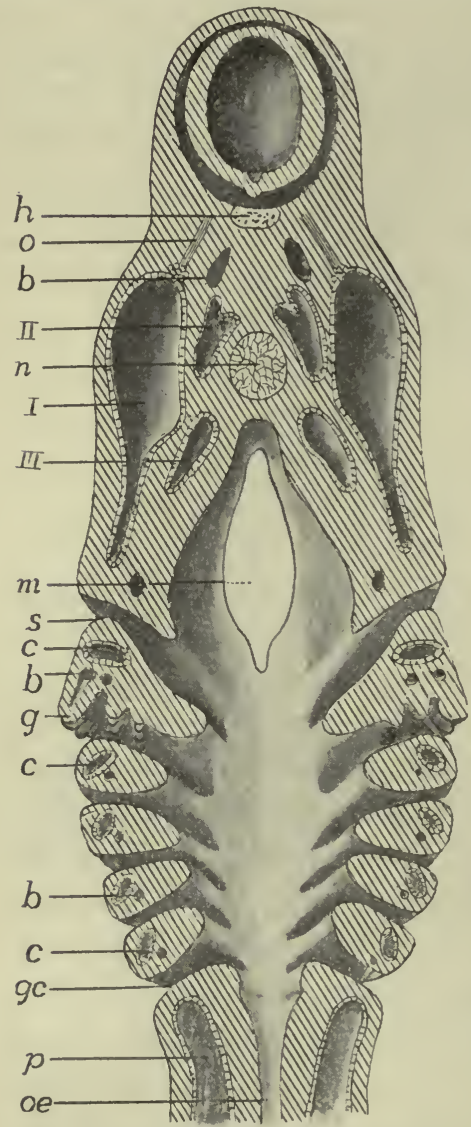

FIG. 243.-Pharyngeal region of a young Acanthias embryo. b, bloodvessels; $c$, colomic cavities of gill arches; $g$, developing gills; $g c$, gill clefts; $h$, hypophysis; $m$, mouth; $n$, notochord; $o$, oculomotor nerve; oe, œesophagus; $p$, peritoneal cavity; $s$, spiracular cleft; $I-I I I$, first to third head cavities. canal, which thus serves for the passage of food and for the performance of respiratory functions is called the pharynx. The organs themselves may take the form of gills or branchiæ, adapted for aquatic respiration, or of lungs (pulmones) fitted for breathing air. In this connection must be considered the cases of certain fishes, amphibia, and turtles where respiration is effected in part by the skin, the pharyngeal epithelium, or the digestive tract. There are also a number of other structures-air bladder, thymus and thyreoid glands, etc., which are derived from the pharynx, though they are without respiratory functions.

\section{GILLS OR BRANCHIA.}

The typical gills or branchiæ are developed on the walls of some of the visceral clefts (gill or branchial clefts) which are formed in the sides of the pharynx. These clefts arise as paired pouches or grooves of the entoderm of the pharynx (fig. 208). They extend laterally, pushing aside the mesoderm, until they reach the ectoderm, ectoderm and entoderm then fusing to a plate. This in most cases becomes perforated, so that the cavity of the pharynx is connected with the exterior by a series of openings (fig. 243), the clefts developing in succession from the cephalic end backward.

, These visceral pouches develop in all vertebrates, but in the mammals only a few or even none of them break through to the exterior. In 
the adult amniotes the pouches may completely disappear without leaving a trace, aside from the Eustachian tube (p. I87) and the thymus glands to be mentioned below. The number of clefts or pouches varies between considerable limits. The largest number in any true vertebrate (there are more in Amphioxus and the enteropneusts) is fourteen pairs in some specimens of Bdellostoma. In other cyclostomes there are seven, eight to seven in the notidanid sharks, six in other elasmobranchs, five or six in teleostomes, amphibia and reptiles and five in mammals. In this numbering the oral cleft is not included, although there is some evidence that the mouth has arisen by the coalesence of a pair of gill clefts (p. 206).

The serial repetition of the visceral clefts does not strictly correspond to the other segmentation of the body, their number and position being at variance with those of the myotomes. There is a branchiomerism or serial repetition of the gill clefts, apparently distinct from the true metamerism of the head. The appearance of these clefts or pouches and the relation of aortic and branchial arches in the amniotes, where gills are never developed, can best be explained by the assumption that these forms have descended from branchiate ancestors.

Between each two successive gill clefts there is an interbranchial septum, covered externally with ectoderm, internally with entoderm, and with an axis of mesoderm, the latter in the earlier stages carrying with it a diverticulum of the cœlom (fig. 243, c). Later blood-vessels (aortic arches) and skeletal elements (visceral arches, p. 63), are developed in each septum, the visceral arches appearing on the splanchnic side of the cœlom and hence not being comparable to ribs or girdles.

In the cyclostomes and fishes the gills are developed from the anterior and posterior walls of the typical interbranchial septa. They were long regarded as of entodermal origin, but in recent years considerable doubt has been thrown on this, at least for the fishes, and there is some evidence for their ectodermal origin. The matter cannot yet be regarded as settled. These gills are either filamentous or lamellate outgrowths of epithelium, each carrying a loop of a bloodvessel. Thus each typical cleft is bounded in front and behind by gill plates or filaments (fig. 246), those on a side constituting a demibranch, the two demibranchs of a septum constituting a gill, while a cleft is bounded by demibranchs belonging to two gills. In the young elasmobranchs and in the young of a few teleosts (before birth) the gill filaments protrude from the clefts as long threads, but later they are withdrawn. 
In the cyclostomes and notidanid sharks the first cleft (between the mandibular and hyoid arches) bears gills like the rest, but elsewhere it differs. In most elasmobranchs and in a few ganoids (Acipenser,
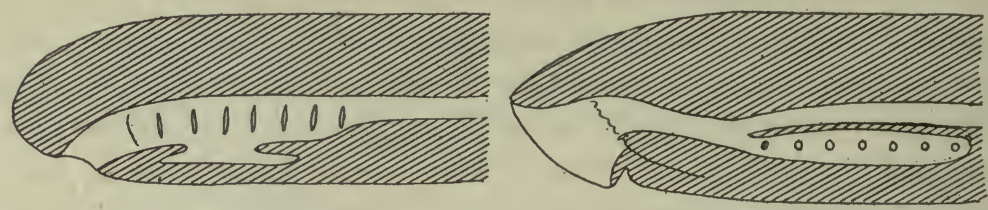

FiG. 244.-Diagram of relations of cesophagus and respiratory tracts in (A) Myxine and Ammocœtes, and (B) Petromyzon, b, bronchus; $o e$, œsophagus; $t$, thyreoid gland.

Polyodon, Polypterus) it becomes reduced in size in the adult, the closure beginning ventrally (fig. I 36 ) so that the persistent part of the opening is on the upper side of the head. This opening is called the

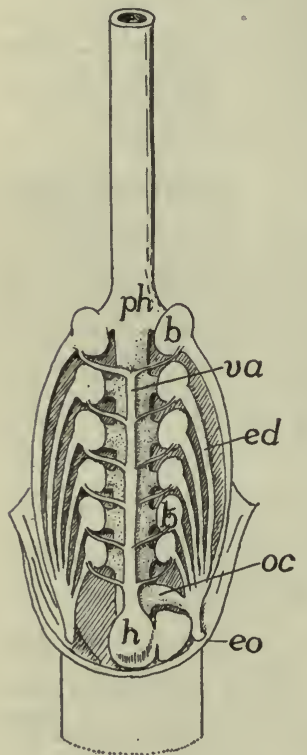

FIG. $245 \cdot-\mathrm{Gi} 11$ pouches and blood-vessels of Myxine, after Müller. $b$, gill pouches; $e d$, efferent ducts; $e o$, external gill opening; $h$, heart; oe, œsophageo-c u ta n e o us duct; $p h$, pharynx. spiracle. In other vertebrates, including the chimæroid sharks and many true sharks, the spiracle is closed in the adult, but in the anura and the amniotes its inner portion persists as the Eustachian tube and the tympanic cavity of the ear (p. $18 \dot{7}$ ).

Usually the series of gills begins with the demibranch on the caudal side of the hyoid arch, while none ever appears on the caudal side of the last cleft. In the teleosts the series of gills is still further reduced, the reduction reaching its extreme in Amphipnous, where there are no demibranchs on the first and fourth branchial arches and only one on the second.

In the cyclostomes the gill clefts occur at a considerable distance behind the mouth, partly the result of the great development of the lingual apparatus. In the larvæ of Petromyzon (Ammocœes) the seven gill clefts are nearly typical, the gill extending inward nearly to the pharyngeal wall, each cleft having a short efferent duct leading to the exterior, and the œsophagus beginning at the hinder end of the pharynx (fig. 244, $A$ ). In the metamorphosis to the adult the œsophagus grows forward, dorsal to the gill clefts, to the cephalic end of the pharynx, thus cutting off a ventral respiratory tube, the so-called bronchus (fig. $244, B)$. At the same time the gill-bearing region of each cleft becomes separated 
from the bronchus by the development of a short afferent duct, while the demibranchs come to lie in oval pouches (much as in Myxine, fig. 245), in allusion to which the cyclostomes are sometimes called marsipobranchs (pouched gills).

In the myxinoids the tract between the mouth opening and the pharynx is more elongated and the pharyngeal region (fig. 244, $A$ ) is not differentiated into œsophagus and bronchus, as in the adult lampreys. In Myxine there are six pairs of gills; in Bdellostoma the number ranges from seven to fourteen, varying even on the two sides of our Pacific species, $B$. dombeyi. In the petromyzons and in
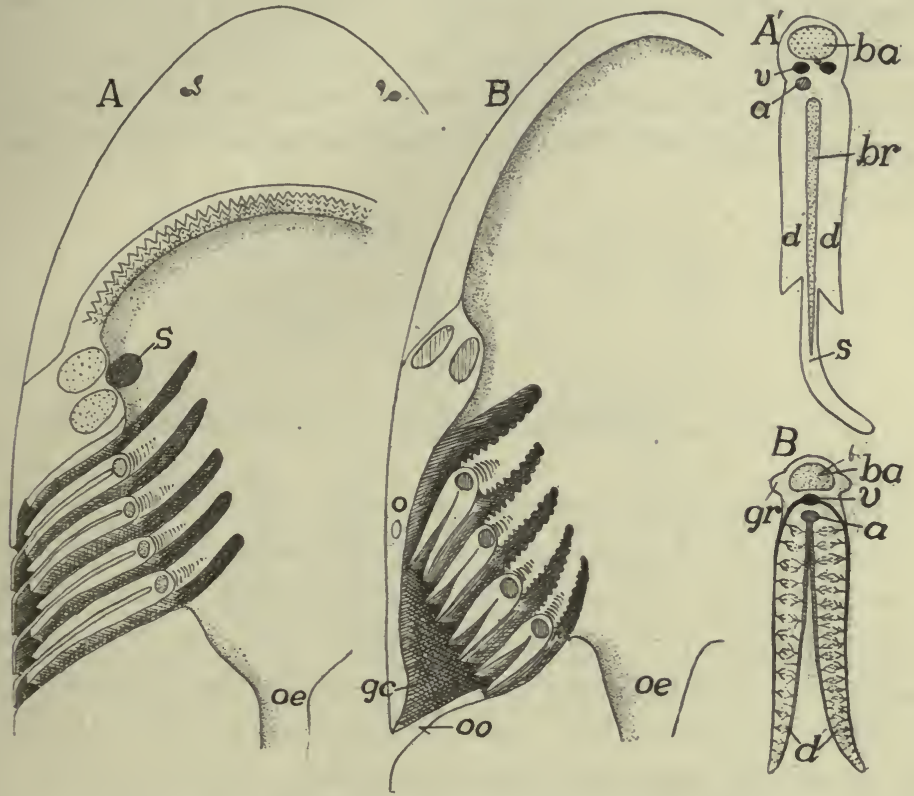

FIG. 246.-Diagram of gill clefts in $(A)$ elasmobranchs and $(B)$ teleosts. $A^{\prime}$ and $B^{\prime}$, a single gill of each. $a$, artery; $b r$, branchial ray; $d$, demibranchs; $g c$, gill chamber; $g r$, gill raker; $o$, operculum; oe, œsophagus; $o 0$, opercular opening; $s$, spiracle; $v$, veins.

Bdellostoma the efferent ducts of the gill pouches open separately to the exterior; in Myxine (fig. 245) they unite into a common duct on either side, the left also receiving an osophago-cutaneous duct, behind the last gill. This duct, which leads from the œsophagus to the exterior, resembles a gill cleft, but lacks gills. A similar duct occurs in the same position in Bdellostoma.

In the fishes there are two types of gills and associated structures. In the elasmobranchs (the chimæroids excepted) the interbranchial septum is greatly developed (fig. $246, A^{\prime}$ ), extending some distance laterally beyond the gill folds so that the distal part of the cleft forms an excurrent canal. This prolongation of the septum extends to the exterior and then turns backward, thus protecting the delicate gills from 
injury (fig. $246, A$ ). In other fishes the posterior margin of the hyoid septum grows back as a broad fold over the clefts behind, thus forming a gill cover or operculum (fig. $246, B, o$ ), enclosing an extrabranchial or atrial chamber into which all of the clefts empty and which in turn opens to the exterior by a single slit (oo) behind the operculum. This opercular opening is usually broad, but it is reduced to a circular opening on either side in a few teleosts, while in the symbranchii the openings of the two sides are united to a single one in the mid-ventral line. Correlated with this protection of the gills by the operculum is the reduction of the interbranchial septum (fig. $246, B^{\prime}$ ), which forms only a slender bar, from which the demibranchs project far into the gill chamber.

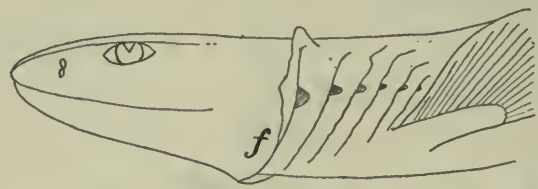

FIG. 247.-Head of Chlamydoselache, after Garman; $f$, opercular fold.

Usually the two opercular folds are continuous beneath the pharynx, which points to the beginnings of an operculum in the shark, Chlamydoselache (fig. 247). In the chimæroids the operculum is farther developed and is supported by cartilaginous rays. In the teleostomes two parts may be recognized in the operculum, the operculum or gill cover proper, supported by a series of large bones (p. 77), and a more ventral part, the branchiostegal membrane, which is very flexible and has a skeleton of slender (branchiostegal) rays, connected with the hyoid.

In the sea horses and pipe fishes (lophobranchs) the gills form small rounded tufts. In the labyrinthine fishes there is a complicated bony structure in the branchial chamber, covered by a folded membrane which is used in aerial respiration. In the young crossopterygians (Polypterus, Calamoichthys) bipinnate external gills persist for some time. In Amphipnous, just referred to, a sac opening between the hyoid and the first branchial arch is developed on either side of the head. Its walls are very vascular thin vessels being connected with both the branchial arteries and the dorsal aorta.

The gills are so placed that there can be an almost continuous stream of water over them, thus bringing the oxygen needed by the blood. As a rule, this water is drawn in through the mouth by the enlargement of the oral cavity, and by its contraction is forced out through the clefts. 
In the myxinoids the œsophago-cutaneous duct is supposed to act as the incurrent opening when these animals burrow into fishes. In the lampreys the water is said to pass both in and out through the gill clefts when these animals are attached to some object. In at least some of the elasmobranchs water passes in through the spiracle which regularly opens and closes.

Many, if not all of the teleosts have breathing valves. There are two pairs of these, an anterior pair attached to the margins of the jaws, which permit the ingress of the water but prevent its outflow. The other pair is formed by the branchiostegal membrane, which closes the opercular opening and only allows the water to pass out. The action of both pairs can be easily seen from fig. 248 .

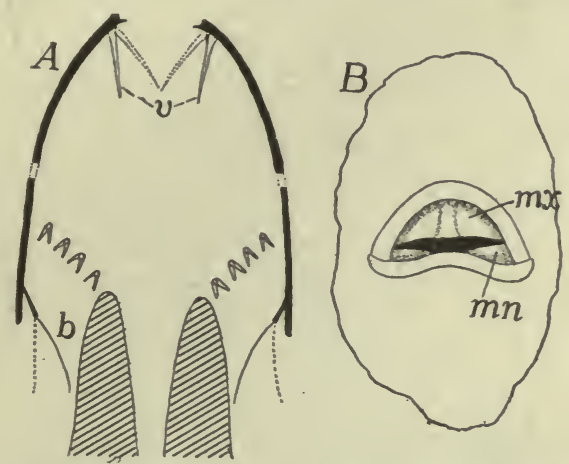

FIG. 248.-Breathing valves of teleosts, after Dahlgren. $A$, schematic figure, the anterior half in the vertical, the posterior in the horizontal plane; $B$, mouth of sunfish (Eupomotis); $b$, branchiostegal valve; $m n, m x$, mandibular and maxillary valves; $v$, oral valves.

In certain fishes with an operculum (Acipenser, Lepidosteus, many teleosts) a gill is developed as a series of lamellæ on the inner surface of the operculum. This opercular gill has respiratory functions. The pseudobranchs are homologous with the true gills. They are developed in some elasmobranchs as vertical folds on the anterior wall of the spiracular cleft, occurring in some cases, even where the spiracle is closed externally. They, however, receive arterial blood and so cannot be respiratory in function. The blood, still arterial in character, passes from them to the chorioid coat of the eye and in some cases to the brain. From their position they must be interpreted as the demibranch of the posterior side of the mandibular arch.

Pseudobranchs are common in teleosts, usually lying on the medial side of the hyomandibular bone. When free, they are gill-like in appearance, but in some species (fig. 249) they are covered by muscles and connective tissue, when they have a blood-red, glandular appearance. Pseudobranchs also occur in Lepidosteus, most sturgeons and Ceratodus; they are lacking in Amia and Protopterus. Polyp terus and Polyodon have opercular gills. 
In the amphibia the gill clefts are formed in the same way as in the fishes, but the first and fifth never break through, and all are usually closed in the adult, the exceptions being in the perennibranchs and derotremes where from one to three clefts remain open through life. In the urodeles and cæcilians there is a reduced operculum which never becomes prominent, being merely a fold of the integument in front of the gill area. In the larval anura it is well developed, though skeletal

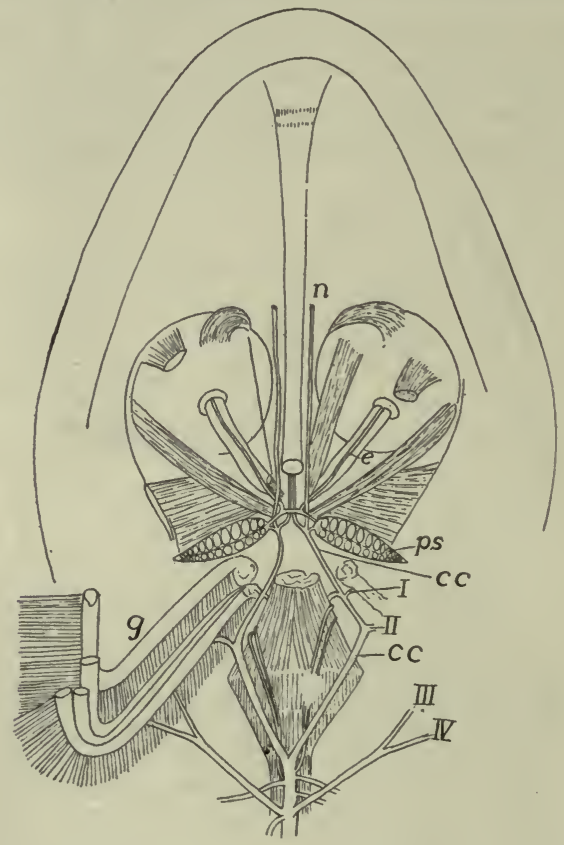

FIG. 249.-Dissection of pseudobranchs $(\dot{p} s)$ and cephalic circle in pike (Esox), after Maurer. $c c$, cephalic circle $e$, vessels to eyes; $g$, gills; $n$, vessels to palate and nose; $I-I V$, efferent branchial arteries.

supports are lacking, as in all amphibia. Before the time of metamorphosis it grows backward over the gills, gill clefts, and the anlagen of the fore limbs, and fuses with the sides of the body behind the latter. In this way these parts are enclosed in an extrabranchial or atrial chamber, the chambers of the two sides being in communication below. During larval life the branchial chambers usually communicate with the exterior by a single excurrent pore, usually on the left side, but in the larval aglossa right and left excurrent pores are found.

The gills of the amphibia are certainly of ectodermal origin ( $c f . \mathrm{p}$. 237). First to appear are the external gills, covered with ciliated epi- 
thelium. Three pairs of these usually arise, before the gill clefts break through, on the outer surface of the third, fourth and fifth arches, and they are supplied by the corresponding (aortic) arches of the blood system. They are without any skeletal support and are of ${ }_{0}$ varying form -pectinate, bipinnate, dendritic, etc. (fig. 250) - and in one species

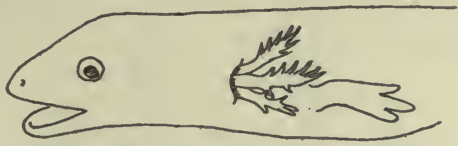

FIG. 250.-External gills of young Amphiuma, partially covered by opercular fold.

of cæcilians, where but a single pair occurs, they are large leaf-like lobes. When the gill clefts break through there is an ingrowth of ectoderm into each cleft, from which (except in perennibranchs) gill filaments are developed on the sides of the septa, so that for a time there may be both external and internal gills (fig. 25I, right side). In the

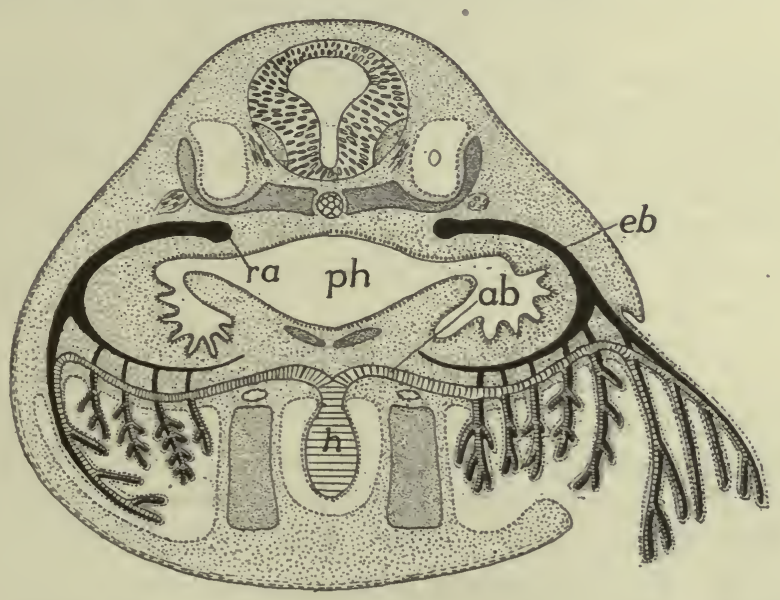

FIG. 25I.-Diagram of the relations of external and internal gills in the anuran tadpole, after Maurer. $a b, e b$, afferent and efferent branchial arteries; $h$, heart; $o$, ear cavity; $p h$; pharynx; ra, radix aortæ.

perennibranchs the external gills persist through life (they are said to be absorbed and reformed in Siren), but in other urodeles and in cæcilians they are absorbed at the time of metamorphosis. In the anura (fig. 25I), as the operculum grows back over the clefts, the external gills, which are so prominent in the earlier stages, become folded into the extrabranchial chamber, where they are gradually reduced, while 
those belonging to the cleft become the functional organs, the water taken in through the mouth passing over them in its way to the exterior via the extrabranchial chamber. Then, with the completion of the metamorphosis, the lungs become functional, the gill clefts are closed and the gills absorbed, the legs are developed and the anterior pair released from the extrabranchial chamber, the tail is absorbed, and the tadpole (larva) becomes the adult.

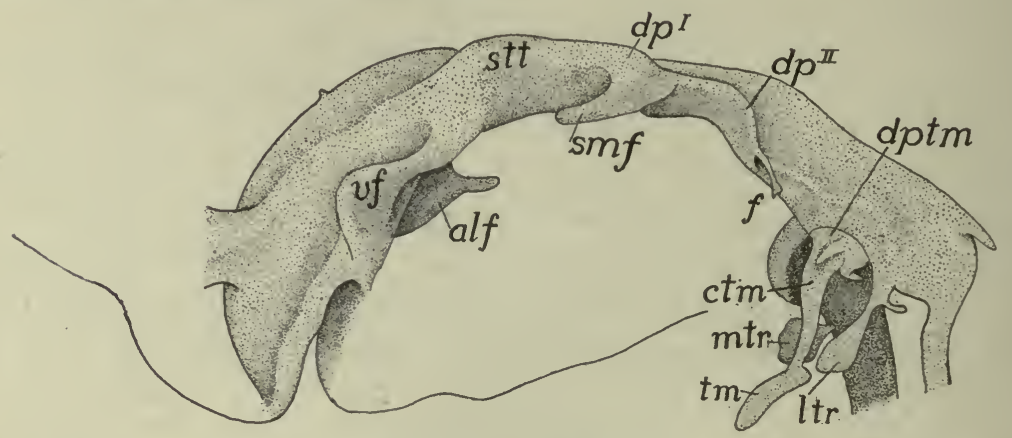

FIG. 252.-Cast of oropharyngeal region of pig embryo, $17 \mathrm{~mm}$. long, after Fox. alf, alveo-lingual fold; ctm, cervical cord of thymus; $d p^{1}, d p^{2}$, dorsal apex of first and second pharyngeal pouches; $d p t m$, dorsal plate of thymus; $f$, filiform appendix of second pouch; $t l r$, lateral thyreoid; stt, sulcus tubo-tympanicus; $t m$, thymus; $v f$, vestibular fold of mouth.

Little is known of the gills in the stegocephals, but the presence of well developed branchial arches in the larvæ of some species (p. 83) would imply the existence of functional gills.

For some time it was thought that the fish gills were of entodermal origin, and those of the amphibia were derived from the ectoderm. Hence the conclusion was that the two had no genetic connexion, the gills of the amphibia being a new acquisition, developed within the group or arising from the external gills of some form like Polypterus. Lately the doubts thrown upon the entodermal origin of the gills of fishes (p. 237) render it possible that all vertebrate gills are homologous.

Gills are never developed in the amniotes, but in the embryos the paired visceral pouches are formed (figs. 208, 252) - five in the sauropsida, four in mammals - in the same way as in the fish-like forms. Few, if any, of them break through to the exterior, although their position is indicated by grooves on the outside of the neck. The process of obliteration of these external grooves is interesting. The anterior arches enlarge and slide back over the posterior, so that at least the external branchial grooves lie in the wall of a pocket, the cervical sinus, on either side of the neck (fig. 253). Later a process of the anterior (hyoid) arch extends over and closes the sinus, a process re- 
calling the history in the anura. Internally the entodermal branchial pouches, with the exception of the first, disappear, but the first persists as the tympanic cavity and Eustachian tube described in connexion with the ear.

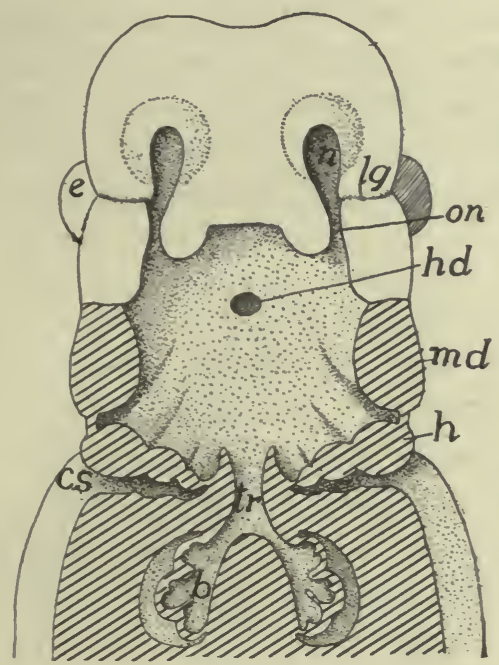

Fig. 253.-Head of human embryo with pharyngeal floor removed, after Hertwig. Cut surfaces lined. Compare with fig. $22 \mathrm{I}$. cs, cervical sinus; $e$, eye; $h$, hyoid arch; $h d$, hypophysial duct (Rathke's pocket); $l$, lung; $l g$, lacrimal duct; $n$, naris; $m d$, mandible; on, oronasal groove; $t r$, trachea.

\section{Pharyngeal Derivatives.}

Several structures arise in the pharyngeal region-some developed from gill clefts, some from other parts-which, while not respiratory in character, naturally come for mention here.

Among these are the thymus glands. These arise from the entodermal epithelium at the dorsal angle of a varying number of visceral clefts (elasmobranchs, clefts $2-6$ and possibly the spiracle; teleosts and cæcilians, 2-6; urodeles, I-5, I and 2 degenerating; anura, I and 2 , the latter only persisting; amniotes 3 and 4).

The organ which results has varying positions and shapes in the different groups. It becomes richly vascular, and by the intrusion of connective tissue, assumes an acinous form. In Myxine a number of lobules behind the gill region have been regarded as a thymus, but now are interpreted as pronenephric. In some cases (fishes, etc.) the thymus retains its primitive position dorsal to the gill clefts (usually above the 
fourth in teleostomes), and it maintains its branchiomeric character in snakes and gymnophiones. It may lie above and behind the angle of the jaw (most amphibians), close to the carotid arteries (most sauropsida), sometimes extending along the neck (crocodiles and birds). In the young mammals the thymus (sold in the markets as 'throat sweetbreads'), which arises from a single pair of clefts, is largely behind the sternum, extending forward along the neck. Later it gradually grows smaller, the extreme development being reached in man between the fourteenth and sixteenth years, but retaining its functional structure

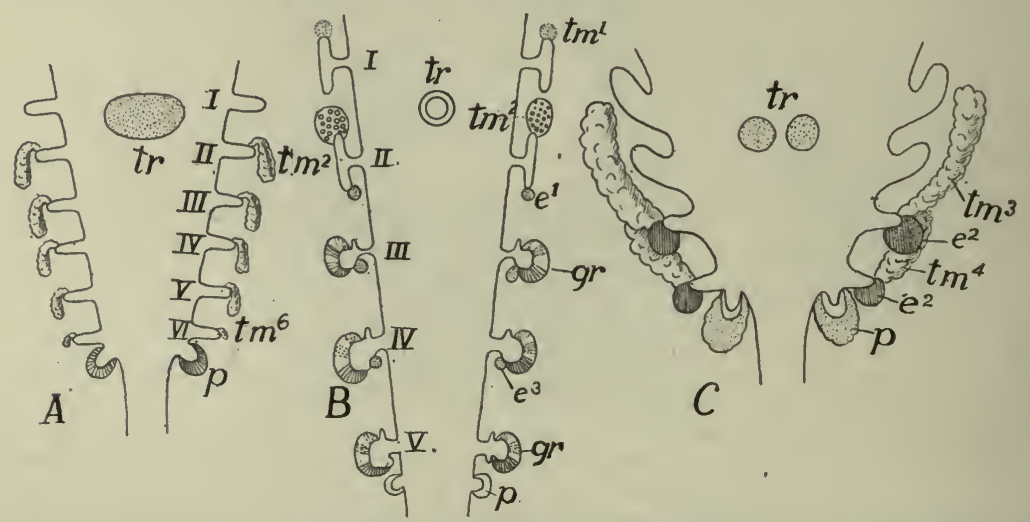

FIG. 254.-Schemes of the origin of several pharyngeal derivatives in $(A)$ Raia, $(B)$ anuran and $(C)$ chick, after Verdun. $c d$, carotid gland; $e$, epithelial body; $g r$, gill remnants; $p$, postbranchial body; $t m$, thymus; $t r$, thyreoid; $I-V I$, gill pouches or clefts.

until middle life. The function of the thymus glands is as yet unknown; though leucocytes are abundant in them, they are not lymphoidal in character.

Other structures arising in the pharynx, either from the gill clefts or from the pharyngeal walls, are the 'epithelial bodies,' post-branchial bodies, suprapericardial bodies, gill remnants, etc., concerning which little is known. The carotid glands of the same region are referred to elsewhere.

The thyreoid gland cannot be dismissed in such a summary manner. This is a ductless gland in the pharyngeal region of all vertebrates, ventral to the alimentary tract. In the lower vertebrates it arises as an unpaired pocket in the floor of the pharynx (fig. 254), this retaining its connexion with the parent tube in the ammocœte stage of the lamprey (fig. I90), but at the time of metamorphosis it loses its duct (as is early the case in all other vertebrates) and eventu- 
ally becomes follicular. In most vertebrates, the anlage, after separation, forms a network of epithelial tubes before becoming follicular. Usually it exhibits a marked bilaterality, and in amphibia and birds it becomes divided into two glands.

In the elasmobranchs the thyreoid lies between the end of the ventral aorta and the symphysis of the lower jaw; in teleosts the groups of follicles lie around the ventral aorta, extending out on the anterior aortic arches. In the urodeles the gland lies just behind the second arch and in the anura on the hinder margin of the thyreoid process of the hyoid plate. In reptiles it is ventral to the trachea (at about its middle in lizards, nearer its division in other groups), while in the birds the two glands occur at the base of the bronchi. In the mammals it is usually near the larynx, and while generally two-lobed, it is here and there (monotremes, some marsupials, lemurs, etc.) paired.

Like the other ductless glands, the thyreoid supplies the blood with substances necessary to the well-being of the organism, in the case of mammals at least, an iodine-containing albumen. Degeneration or extirpation of the thyreoid result in cerebral trouble. In the ancestral vertebrate the thyreoid apparently had to do with some part of the digestive work, as is shown by its late connexion with the pharynx in the ammocœte.

In the pharynx and at the entrance of the mouth into the pharyngeal cavity (isthmus of the fauces) occur certain lymphatic structures called tonsils, concerning which our knowledge is yet very deficient. One account says they arise from inwandering epithelial cells, the other maintains that they are formed from the sub-epithelial mesoderm. Two different groups of organs are included under this name, the true tonsils at the isthmus of the fauces, and the pharyngeal tonsils. The latter may be represented by lymphoid structures in the floor or roof of the pharynx of urodeles and anura. They are well developed in reptiles and birds, occurring in the latter behind the choanæ. In mammals they are inconstant structures. The true tonsils of mammals lie one on either side of the isthmus. Both types of tonsils consist of an adenoid ground substance containing numerous lymph cells, and become follicular after birth.

\section{THE SWIM BLADDER.}

While the air or swim bladder (pneumatocyst) is not respiratory, it is included here from its possible connexion with the lungs. It 
occurs only in teleostomes, and while found in most species (frequently absent from bottom-feeding forms-pleuronectids, etc.), it is lacking here and there, even among species classed as physostomous (Loricaria, etc.). In the young of a few sharks (e.g., Scyllium) there is a pouch on the dorsal side of the œsophagus which suggests the possible origin of the organ.

The swim bladder lies dorsal to the alimentary tract, outside of the peritoneum (which frequently covers only its ventral surface) immedi-

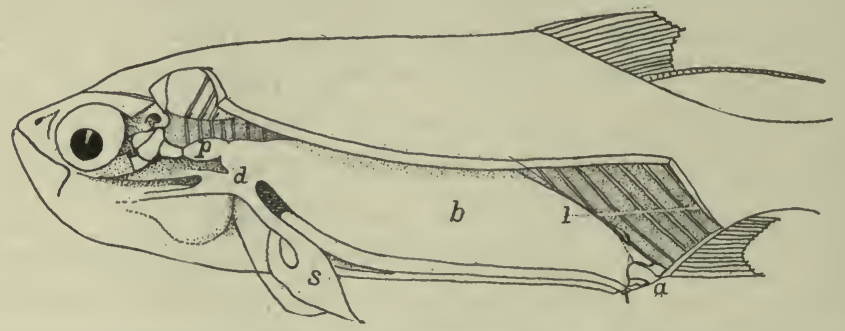

FIG. 255.-Air bladder of Megalops cyprinoides, after de Beaufort. $a$, anus; $b$, air bladder; $d$, pneumatic dust leading from the œsophagus; $l$, ligament; $p$, anterior part of bladder extending to skull.

ately below the vertebræ and excretory organs (mesonephroi). In some instances it extends the whole length of the body cavity and (clupeids) may even send diverticula into the head. In other species it may be much shorter. In development it arises as a diverticulum of the alimentary canal (fig. 209), and in the ganoids and one group of teleosts (physostomi) it is connected with the digestive tract throughout

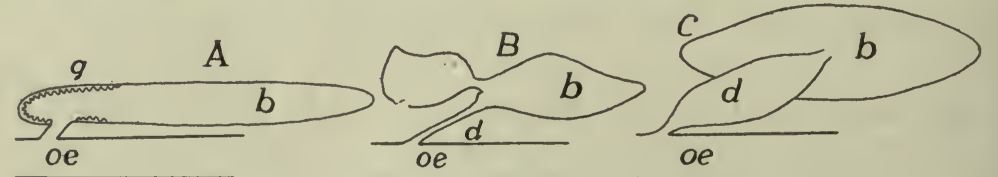

FIG. 256.-Swim-bladders of physostomous fishes; $\overline{A \text {, pickerel (Esox) }} ; B$, carp (Cypri$n u s)$; and $C$, eel (Anguilla) after Tracy. $\quad b$, swim-bladder; $d$, duct; $g$, red gland; oe, œesophagus.

life by the pneumatic duct. This usually empties into the œsophagus, but it may connect with the stomach. In most teleosts, however, the duct becomes closed at an early date and the bladder loses its connexion with the digestive tract (physoclisti).

The swim bladder is usually unpaired (paired in most ganoids) and may be simple or divided into two (rarely three) connecting sacs (fig. 256). It is usually regular in outline, but diverticula of all kinds are 
common, the form being most varied in the physoclistous species. Internally the walls may be smooth and the cavity simple, or it may be subdivided by septa (fig. 257), or, as in Amia and Lepidosteus, it may be alveolar, recalling the condition in the lungs of higher vertebrates. The walls sometimes contain striated muscle, and in some siluroids and cyprinoids they are more or less calcified, partly by the inclusion of processes from the vertebræ.

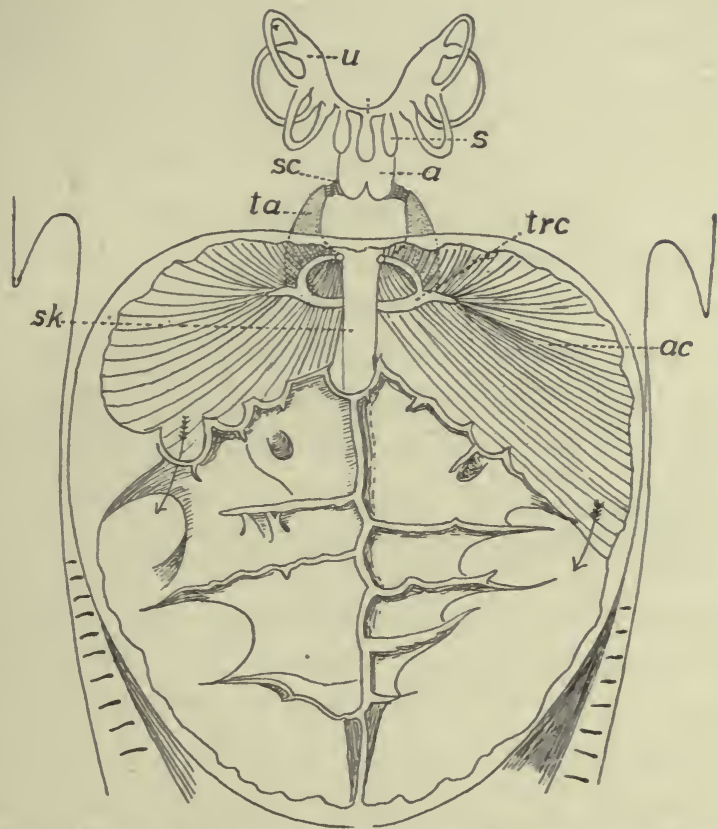

FIG. 257.-Ventral view of opened air bladder and Weberian apparatus of Macrones, combined from Bridge and Haddon. a, atrial cavity; $a c$, anterior chamber of air bladder, the arrows showing the connexion with the posterior chamber; de, endolymph duct; $s$, sacculus; sc, scaphium; sk, subvertebral keel; $\operatorname{tra}, \operatorname{trc}$, anterior and crescentic processes of tripos; $u$, utriculus.

The blood supply is arterial, coming from either the aorta or the cœliac axis, in some instances different portions receiving blood from both. In the walls the arteries break up into networks of minute vessels ('rete mirabile'), these frequently making 'red spots' on the inner surface. From the retia the blood passes to the body veins, (postcardinal, hepatic or vertebral). In the ganoids and phystomous species, especially those with a wide pneumatic duct, the gases contained in the swim bladder may be obtained directly from the air or water, but in the physoclists this is impossible and the red spots may be the place of its 
secretion and possibly of its absorption, the probability being increased by the greater abundance of the spots in species with closed ducts.

While the pneumatic duct usually connects with the dorsal side of the alimentary canal, it enters the left side in Erythrinus, and in the mid-ventral line in Polypterus and in Calamoichthys. In Polypterus the bladder arises from the ventral side and there are paired swim bladders, the right being the longer. The blood in this genus comes from the efferent branchial arteries and hence is arterial.

The swim bladder is supposed to have hydrostatic functions, aiding in the recognition of differences of pressure due to changes in depth. In the clupeids the air bladder sends a diverticulum into the head, there giving a branch to each ear. In some physostomes (siluroids, cyprinids, gymnonoti) parts of the anterior vertebræ are modified into a chain of bones - the Weberian apparatus - adapted to convey differences of bladder pressure to the internal ears. One pair of bones is connected with the dorsal wall of the air bladder, a second with a diverticulum (sinus impar) of the internal ear, while others are intercalated between these extremes (fig. 257). Changes in the distention of the bladder are thus conveyed to the inner ear and probably affect the sense organs.

\section{LUNGS AND AIR DUCTS.}

Lungs arise as a diverticulum from the ventral side of the pharynx, immediately behind the last gill pouch. The diverticulum divides almost as soon as outlined into right and left halves, each the anlage of the corresponding lung. As development proceeds, the two grow in a caudal direction into the trunk, carrying the peritoneum with them as they protrude into the cœlom, so that they eventually have an entodermal lining, derived from the epithelium of the pharynx; an outer serous layer of peritoneum, with mesenchyme carrying blood- and lymphvessels, nerve and smooth-muscle fibres between the two. In this development two parts are differentiated, the lungs, the actual seat of the exchange of gases, and the air ducts leading from the pharynx to them. The ducts may consist of an anterior unpaired portion, the wind-pipe or trachea, connecting with the pharynx, and usually dividing at its lower or posterior end into two tubes, the bronchi, leading to the two lungs. In most air-breathing vertebrates the anterior part of the trachea is specialized and forms a larynx. In addition to these parts, the mechanism by which air is drawn into and expelled from the lungs forms a part of the respiratory apparatus. 


\section{THE AIR DUCTS.}

The opening from the pharynx into the air ducts is known as the glottis, usually an elongate slit capable of being closed and opened by appropriate muscles. This is immediately succeeded by the ducts, which, except in the dipnoi, are more or less differentiated into regions and have skeletal supports in their walls.

In the dipnoi the glottis is either in the mid-ventral line (Protopterus) or a little to one side (Lepidosiren, Ceratodus) and the air duct passes up on the right side of the œsophagus to reach the lungs which are dorsal to the alimentary canal. The tube is without skeletal supports and connects directly with both lungs without any division into bronchi.

Larynx.-The beginnings of the larynx are seen in the amphibia, where in the lower types (Necturus) a pair of cartilages are developed on the sides of the glottis, in the position of a reduced visceral arch, each cartilage extending posteriorly a short distance along the air ducts. In other genera of urodeles the anterior end of each lateral cartilage separates from the rest as an arytenoid, the first of the laryngeal cartilages, imbedded in the walls of the glottis. The rest of the lateral cartilages may remain entire (fig. 258) or they may separate into a number of pieces, extending along the lateral walls of the trachea and bronchi. Usually the anterior pair of these pieces fuse in the mid-ventral line, thus forming the second (cricoid) element of the pharyngeal framework. These parts are moved by antagonistic muscles. One set of these, extending to

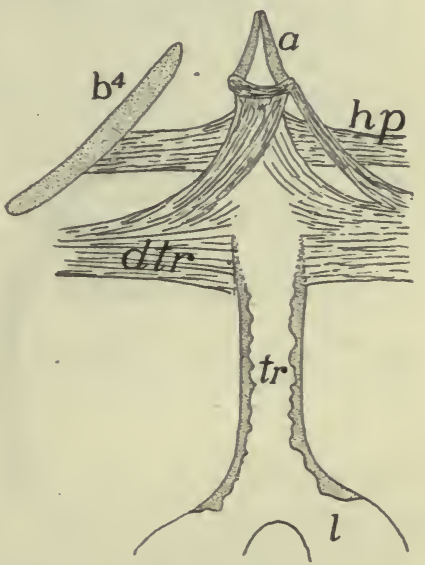

FIG. 258.-Trachea, etc., of Amphiuma, after Wilder. $a$, ary tenoid cartilages; $b^{4}$, fourth branchial arch; dtr, dilatator tracheæ, muscle; $h p$, hyopharyngeus muscle; $t r$, trachea with cartilages in its walls. the persistent branchial arches, serves as dilatators of the glottis; the others, connected with the laryngeal cartilages themselves, constrict the opening. In the anura the cricoid is converted into a ring, with the arytenoid hinged within and anterior to it, the whole larynx moving anteriorly to a position between the hinder processes of the hyoid plate. Inside of the short larynx thus framed by these cartilages are a pair of folds of the laryngeal lining, the vocal cords, extending parallel to 
the margins of the glottis. These may be tightened or relaxed, and by their vibration of their edges under influence of the breath the voice is produced.

The larynx is scarcely more developed in reptiles. The cricoid is usually an incomplete ring, to which the arytenoids are attached, and the whole is placed just ventral to the median part of the hyoid, with which it is closely associated (fig. 259). In several reptiles there is a fold of the mucous membrane just in front of the glottis which is supposed to represent the beginnings of an epiglottis (infra), while in geckos and chameleons a pair of folds, running dorso-ventrally in the larynx, serve as vocal cords. The larynx is also rudimentary in the birds, its place as a vocal organ being taken by the syrinx to be described below, in connexion with the trachea. The arytenoids are frequently ossified in birds.

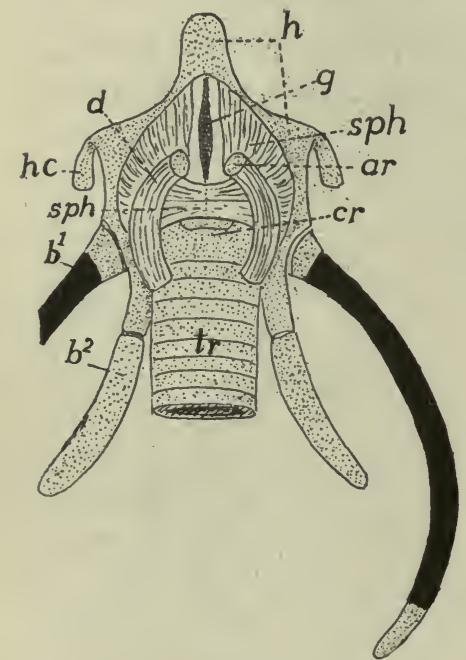

FiG. 259 .

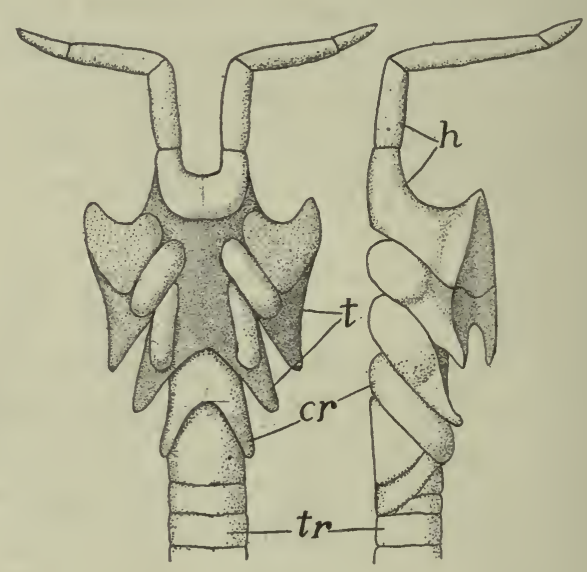

FIG. 260 .

FIG. 259.- Laryngeal apparatus of Chelone, after Goppert. $\quad a$, arytenoid; $b^{1}{ }^{2}$, first and second branchial arches; $c r$, cricoid; $d$, dilator laryngis muscle; $g$, glottis; $h$, hyoid; $h c$, hyoid cornua; $s p h$, sphincter laryngis; $t r$, trachea; cartilage dotted, bone black.

Fig. 260.-Ventral and side views of monotreme larynx, after Gegenbaur. c, cricoid; $h$, hyoid; $t h$, thyreoid; $t r$, trachea.

In the mammals the larynx reaches its highest development. Its framework is formed by the arytenoid and cricoid cartilages, homologous with those of the lower groups, and in addition, a thyreoid cartilage (or cartilages) on the dorsal side anterior to the arytenoids and cricoids. The origin of the thyreoid is best seen in the monotremes where the hyoid apparatus enters into close relations with the larynx (fig. 260), while the second and third branchial cartilages form two plates, the lateral elements of the thyreoid on either side, the median 
element of the hyoid forming a copula. In the higher mammals the association of hyoid and larynx is not so intimate, even in the embryo, but the thyreoid shows its double origin in its development.

In the higher mammals the thyreoid cartilage forms a half ring on the ventral side of the anterior end of the larynx, its anterior dorsal angles being produced into cornua connected by ligament with the hyoid (fig. 26I). Dorsal to the thyreoid is the glottis with the arytenoids in its walls. Posterior to it is the ring-shaped cricoid, following which is the trachea. Anterior to the glottis is a fold of the mucous
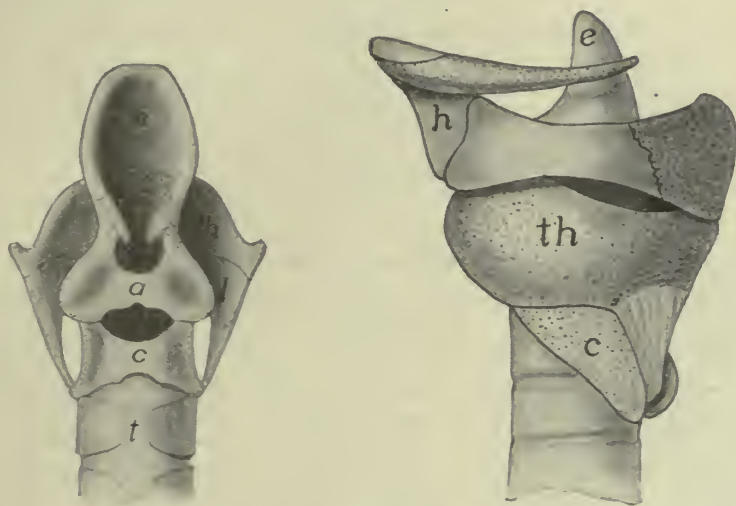

FIG. 261.-Dorsal and side views of larynx of opossum, Didelphys virginianus (Princeton I739) cartilages dotted. $a$, arytenoid; $c$, cricoid; $e$, epiglottis; $g$, glottis; $h$, hyoid; $t$, trachea; th, thyreoid.

membrane of the pharynx, the epiglottis, supported by an internal cartilage (possibly the fourth branchial arch) which articulates with the anterior margin of the thyreoid. The epiglottis usually stands erect, leaving the glottis open for respiration, but during deglutition it folds back over the glottis, thus preventing the entrance of food into the trachea.

Internally the cavity of the larynx bears a vocal cord on either side. These are folds of the mucous membrane, extending from the thyreoid to the arytenoids, and by movements of these latter cartilages they can be tightened or relaxed, thus altering the pitch of the note caused by their vibration. Anterior to these cords is a pocket, the laryngeal ventricle (sinus of Morgagni) on either side, small in most mammals, but developed in the anthropoid apes to large vocal sacs (in some there is a median vocal sac in addition), which act as resonators, adding to the strength of the voice. 
In the whales and young marsupials the larynx is prolonged so that it projects into the choana behind the soft palate. In the whales (fig. 262) this is an adaptation to the manner of taking food from the water and breathing at the same time. In the young marsupials the milk is forced into the mouth by the muscles of the mam$m æ$ of the mother and this arrangement prevents strangulation.

Trachea.--In the tetrapoda the trachea is strengthened by the formation of cartilage in its walls, the beginnings of which are seen in the urodeles where the fifth branchial arch gives rise to these elements (p. 25I). Their arrangement varies considerably in the urodeles

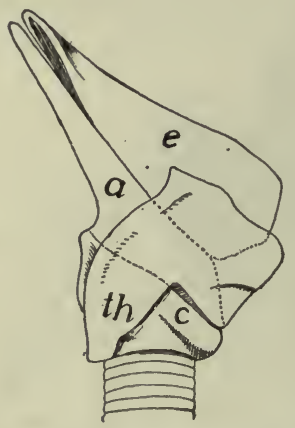

FIG. 262.-Larynx of Xiphius cavirostris (after Gegenbaur) from side showing the prolongation of epiglottis $(e)$ and arytenoid (e) which project into the choana; $c$, cricoid; th, thyreoid. and cæcilians, being sometimes scattered pieces, sometimes regularly arranged and even united in the lateral walls (fig. 258). Corresponding to the posterior position of the lungs the trachea is long in these groups, but in the anura it can scarcely be said to exist, the lungs succeeding almost immediately to the larynx.

In the reptiles the trachea varies in length, being shortest in lizards (except amphisbænas), longer in snakes, tortoises and crocodiles, dividing into bronchi at varying distances from the lungs. It is frequently bent in turtles. In many reptiles the cartilage rings of the trachea are incomplete, but in Sphenodon, lizards and some snakes some cartilages (usually the more anterior) form complete rings, the others being completed dorsally by membrane. In snakes the successive rings are often united, especially on the sides.

The trachea is greatly elongate in birds in correlation with the length of the neck and the position of the lungs within the thorax. The rings, which are usually complete, are frequently ossified. The trachea is occasionally (male ducks, etc.) widened in the middle and in various groups becomes greatly convoluted so that its length from the glottis to the lungs exceeds that of the neck. In some these convolutions occur beneath the integument of the thorax; in some between the sternum and the muscles; and in the cranes and swans within the keel of the sternum.

The larynx is never the organ of voice in the birds, its place being taken by a somewhat similar structure, the syrinx, at the division of the trachea into the bronchi. The sound-producing elements are 
membranes which vibrate by the passage of air, as do the vocal cords of mammals. Most common is the broncho-tracheal syrinx, in which the last rings of the trachea are united to form a resonating chamber, the tympanum, while folds of membrane, internal and external tympanic membranes (not to be confused with the similarly named structure in the ear, p. I87), extend into the cavity from the median and lateral wall of each bronchus. In some cases there is also an internal skeletal element (pessulus) which bears a semilunar membrane on its lower surface. In many birds this type of syrinx is often asymmetrical (fig. 263) and is expanded into a (usually) bony resonating vesicle. In the tracheal type of syrinx the lateral port ons of the last tracheal rings disappear and the membrane which closes the gap forms the vibratile part. In the bronchial syrinx the membranes occur between two successive rings of each bronchus, each ring being concave toward its fellow. By a shortening of the bronchial wall these membranes are forced as folds into the tube. In all types of syrinx there are muscles attached to trachea and bronchi, which, by moving these parts, alter the tension of the folds, thus changing the note.

In the mammals the trachea is elongate (shortest in the whales and sirenians, dividing in the latter immediately behind the cricoid into the two

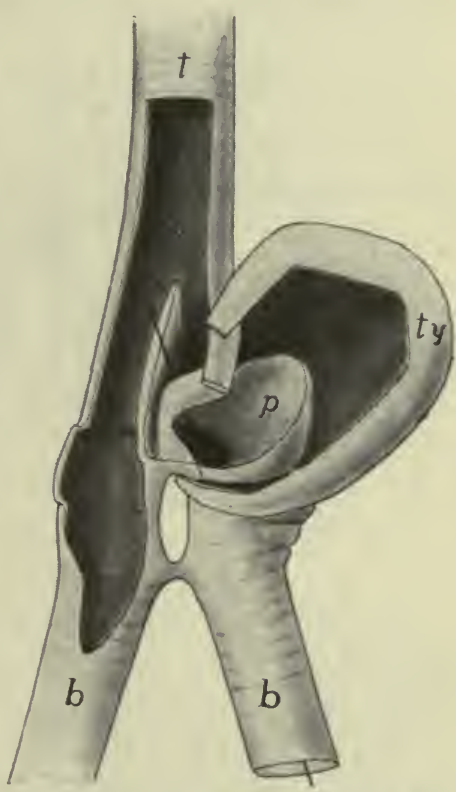

FIG. 263.-Syrinx of canvas-back duck, Aythya, laid open (Princeton 9r5). $b$, bronchi; $p$, pessulus; $t$, trachea; $t y$, tympanum. bronchi), and the cartilage rings are usually incomplete dorsally, the gaps being closed by membrane. This structure allows the tube to remain open under ordinary conditions and yet allows it to give when food is passing down the œsophagus, just dorsal to it. In the cetacea and sirenia the tracheal cartilages are sometimes spirally arranged.

\section{Lungs.}

The morphology of the lungs may be understood by following their development in the mammals and then describing their modifications 
in the various classes of vertebrates. As stated above the lungs arise as a diverticulum (fig. $264, A$ ) on the ventral side of the pharynx which quickly divides into two sacs, the anlagen of the two lungs. These are gradually pushed posteriorly toward the body cavity, still retaining their connexion with the pharynx by the air duct, and each consisting of an enlarged terminal vesicle connected by a slender portion (the beginning of the primary bronchus) with the undivided tracheal portion. With continued growth each terminal vesicle divides again and again, the result being a number of rounded vesicles connected with the primary bronchi by slender tubes, the secondary bronchi (fig. 264, B).

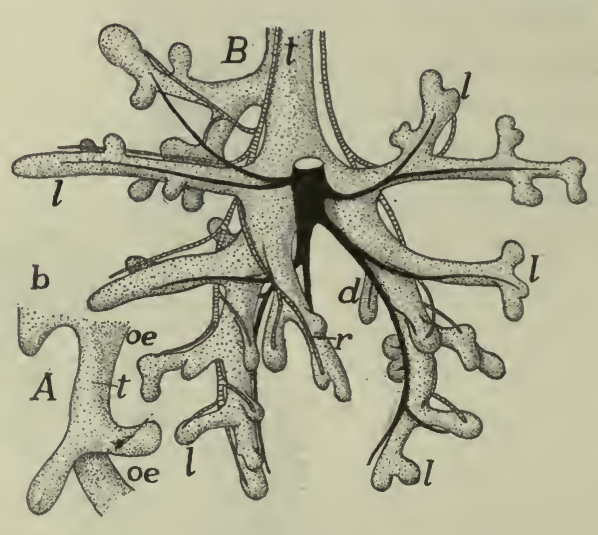

FIG. 264 .

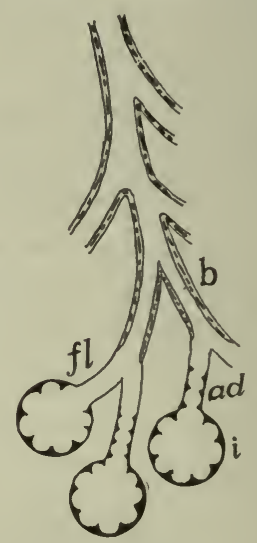

Fig. 265.

Fig. 264. - Two stages in the development of the lung of the pig, ventral views, after Flint. $A$, pig $5 \mathrm{~mm}$. long; $B, 18.5 \mathrm{~mm}$. long. $b$, gill pouch; $d, l$, $v$, dorsal, lateral and ventral bronchi; oe, œsophagus; $t$, trachea.

FIG. 265.-Scheme of mammalian lung structure. $a d$, alveolar duct; $b$, bronchus; $f l$, bronchiole; $i$, infundibulum lined with alveoli.

By a continuation of this process tertiary and other bronchi are outlined, and also slender tubes, the bronchioles, to be described later, which connect the terminal vesicles with the ultimate bronchi. Next, the inner wall of each vesicle becomes divided into small chambers, the alveoli, the whole vesicle now being known as an infundibulum. The result of these many divisions is an enormous amount of internal respiratory surface without great increase in the size of the whole organ. It is to be noticed that in this subdivision the entodermal lining takes the initiative, the outer (serous) surface showing but slight signs of the internal modifications.

Each infundibulum has its own duct which, when smooth internally, is called a bronchiole, when lined with alveoli, an alveolar duct. 
The alveoli of infundibulum and duct are lined with squamous epithelium, and in the walls is an extensive network of capillary bloodvessels. The lining cells of the bronchioles are cubical and those of the bronchi ciliated columnar. There are no skeletal elements in the bronchioles, but the bronchi have small cartilages in the walls, these exhibiting a tendency in the larger tubes to approximate the rings or semi-rings of the trachea.

In their backward growth into the cœlomic region the lungs either insinuate themselves dorsal to the lining of the dorsal side of the body cavity (dipnoi and a few scattered forms) so that only their ventral surface has a serous coat; or they grow out as free structures, covered on all sides by the cœlomic epithelium, and are bound to the dorsal wall by a mesenterial-like fold of varying extent. This outer coat of epithelium has received the name of pleura, the term being extended in the case of the mammals to include the whole lining of the pleural cavity, separated from the rest of the cœlom by the diaphragm (p. I35).

DIPNOI, - In Ceratodus there is a single lung sac; Protopterus and Lepodosiren have paired lungs, the two being united in front at the entrance of the air-duct. In all three the inner surface is divided more or less regularly into groups of alveoli, separated by more prominent partitions. The pulmonary arteries arise from the last efferent branchial artery of either side, and hence the blood supply, under normal conditions, is arterial and the lungs cannot act as respiratory organs. In times of drought (Protopterus)

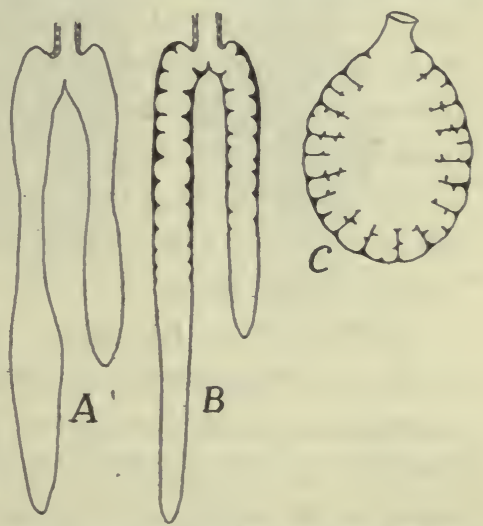

FIG. 266.-Different types of amphibian lungs. $A, N$ ecturus, without alveoli; $B$, alveoli in the proximal portion; $C$, frog, alveoli throughout. or of foul water (Ceratodus) the gills no longer function and the pulmonary arteries bring venous blood to the lungs.

AMPHIBIA.- In the lower urodeles the two lungs are elongate (the left the longer) and are united at their bases, true bronchi being absent. Internally they may be entirely smooth as in Necturus, or there may be alveoli in the basal portion (fig. 266), the whole representing a terminal vesicle either connected directly with the trachea $(A)$ or by the intervention of an alveolar duct $(B)$. In the cæcilians the left lung is very short; the other elongates, with alveoli developed throughout. In the frogs (fig. 266, C) the two lungs are distinct, and their walls are divided into 
a series of sacs or infundibula lined with alveoli. The infundibula open into a central chamber, which, since it is ciliated and has numerous glands in its walls, may be compared to a bronchiole. In the toads and aglossa the alveoli are more extensively developed in correlation with the more terrestrial habits.

It has recently been shown that a number of terrestrial urodeles are lungless in all stages of development, and that no traces of larynx or trachea occur, even after the gills are absorbed. In these species there is a great development of capillaries in the skin and in the walls of the mouth and pharynx, the respiratory functions being transferred to these parts. In the frogs the skin is also respiratory and it is largely supplied by the cutaneous arteries which arise from the same arch as the pulmonary arteries.

In the amphibia the air ducts enter the anterior end of the lungs, but in the amniotes the lungs extend anteriorly to the entrance of the bronchi which is on the medial side. This change is in part the result of the transfer of the heart into the thorax, the position of the pulmonary arteries forcing the bronchi toward the centre of the lungs. In the amniotes, also, the ducts are characterized by the presence of cartilage in their walls, so that they are true bronchi. These bronchi may also extend inside of the lungs, often dividing into secondary and tertiary bronchi inside them.

REPTILES.-In many reptiles (snakes, amphisbænans, many skinks) the lungs are asymmetrical (left usually larger in snakes, right in lizards) and exceptionally one may be absent in snakes. The internal structure shows considerable variation. The simplest conditions are found in the snakes and in Sphenodon (fig. 267), where the lungs consist of a single sac lined with infundibula in the basal portion (snakes) or throughout (Sphenodon). In the lizards (fig. 268) one or more partitions or septa extend from the distal wall of the lung nearly to the entrance of the bronchus, thus dividing the lung into chambers lined with alveoli; while a part of the bronchus may extend (main bronchus, fig. $268, B$ ) to the extremity of the lung. In the chameleons the septa do not reach the distal wall so that the chambers communicate here as well as at the proximal side, the result being that the bronchus enters a cavity, the atrium, which connects with the chambers separated by the septa, and these in turn open into a terminal vesicle, a condition recalling the parabronchi of the birds, soon to be described. This resemblance is heightened by the development in these same lizards of long, thin-walled sacs from the posterior part of the lung which extend among 
the viscera, even into the pelvic region. These air sacs, which are used to inflate the body, foreshadow the similarly named structures in birds. In the higher lizards (Varanus, fig. $268, B$ ) and the turtles and crocodiles there is no atrium, the bronchus, on entering the lung, breaking up into several tubes. As these connect with smaller tubes which lead to the infundibula, the whole lung has a spongy texture.

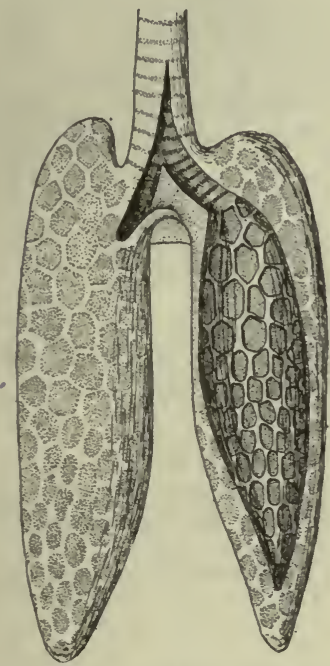

Fig. 267 .

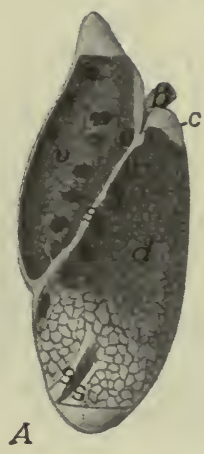

FIG. 268.

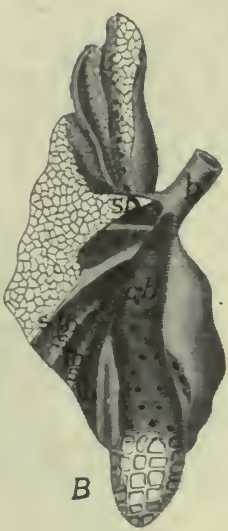

Fig. 267.-Lungs of Sphenodon, after Gegenbaur; the left lung opened to show the alveoli.;

Fig. 268.-A, left lung of Iguana; B, right lung of Varanus, after Meckel. $\quad b$, bronchus $c$, connection between dorsal and ventral chambers; $c b$, chief bronchus; $d$, dorsal chamber; $\iota b$, lateral bronchi; $s$, septa; $s b$, secondary bronchus; $v$, ventral chamber.

BIRDS.- In the birds the lungs are closely united to the ribs and vertebral column and hence undergo less considerable changes of shape than those of other groups. Each bronchus enters the mesoventral surface of the lung, immediately expanding into a sac, the atrium or ventricle, and then continues as a main trunk, the mesobronchus, near the ventral side of the organ (fig. 269). In this course it gives rise to the secondary bronchi (usually eight lateral ectobronchi and from five to six dorsal entobronchi) and these in turn connect with very numerous small tubes, the lung pipes or parabronchi. These run approximately parallel to each other and connect with another bronchus at the other end. Each parabronchus bears a number of elongate diverticula radiately arranged (fig. 270), these having a narrower basal portion and being branched and lobulated distally. The 


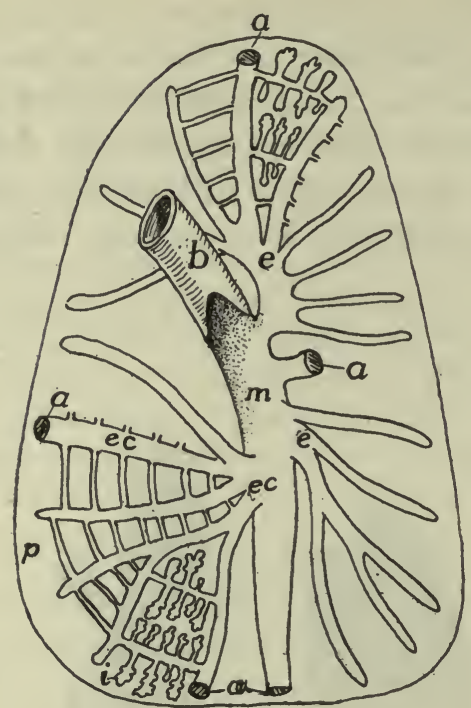

Fig. 269.
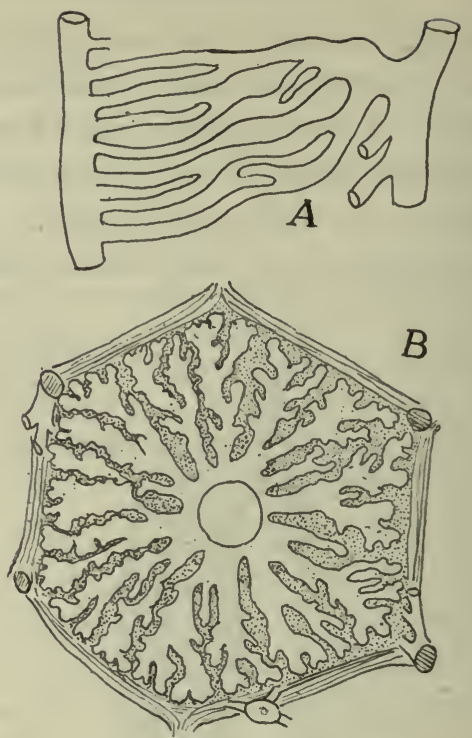

FIG. 270.

Fig. 269.-Diagram of structure of bird's lung. $a$, connexions of bronchi with air sacs; $b$, bronchus; $e$, entobronchi; $e c$, ectobronchi; $i$, infundibula; $m$, mesobronchus; $p$, parabronchi.

FIG. 270.- $A$, lung pipes of bird from a corrosion preparation; $B$, section of lung pipe with radiating infundibula, after Schulze.

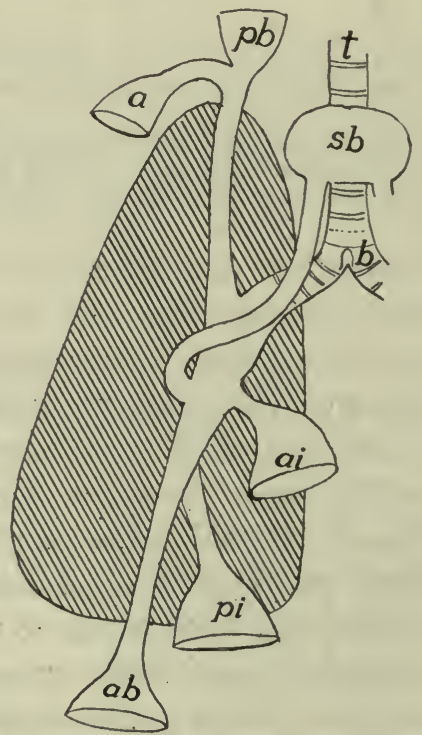

FIG. 271.-Diagram of the relations of the chief air sacs in a bird, lung tissue shaded. $a$, axillary sac; $a b$, abdominal sac; $a i$, anterior intermediate sac; $b$, bronchus; $p b$, prebronchial sac; $p i$, posterior intermediate; $s b$, subbronchial sac; $t$, trachea. 
parabronchi are to be compared to bronchioles, the diverticula to infundibula.

The mesobronchus and usually four other bronchi do not stop at the lung wall, but are continued as thin walled vesicles, the air sacs,

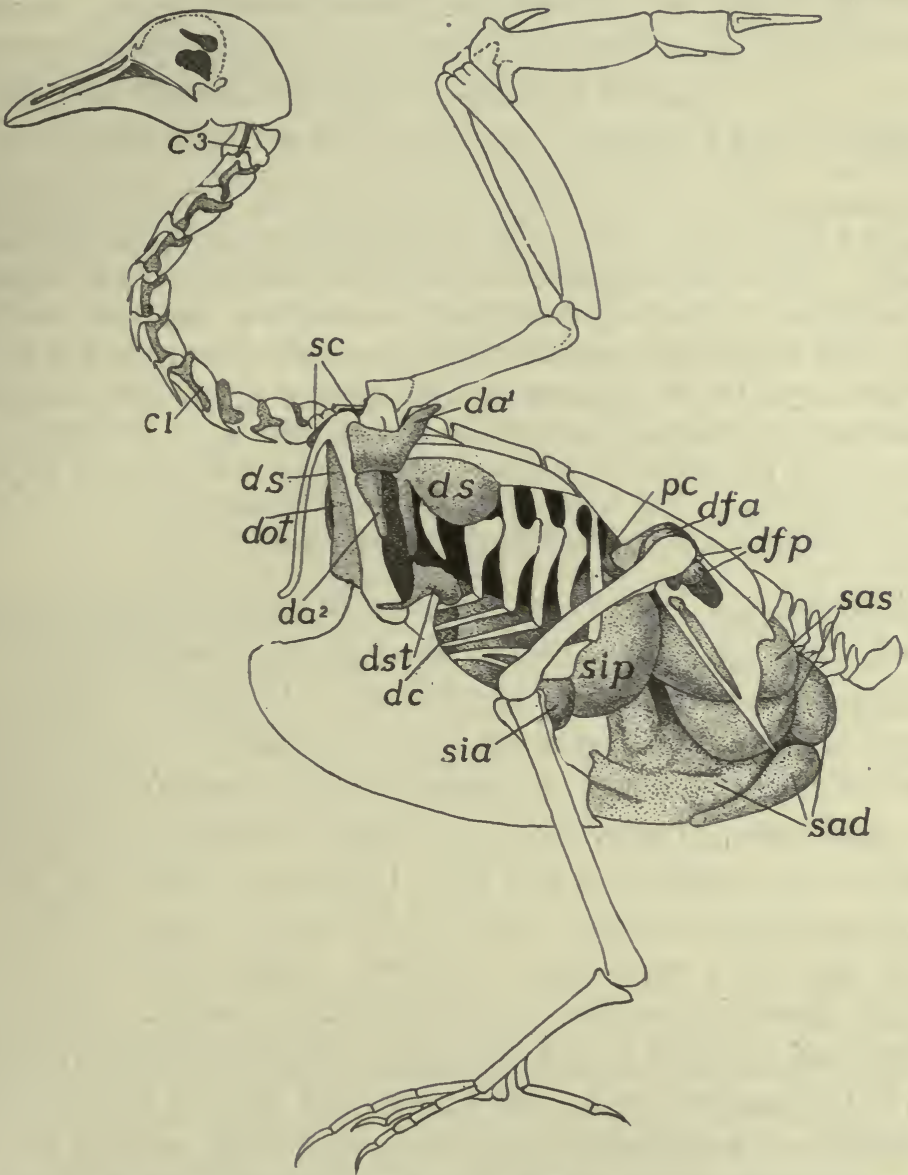

Fig. 272.-Air sacs of pigeon, after Bruno Muller. $c^{1}, c^{3}$, intertransverse canal; $d a^{1}, d a^{2}$, axillary diverticulum and its ventral outgrowth; $d c$, diverticulum costale; $d f a$, $d f p$, divert. femorale anterior et posterior; dot, divert. œsophago-tracheale; $d s$, div. subscapulare; $d s t$, div. sternale; $p c$, preacetabular canal; sad, sas, saccus abdominalis dexter et sinister; sc, saccus cervicalis; sia, sip, saccus intermedius, anterior et posterior.

structures peculiar to birds (and in a slight extent to chameleons) and occurring in all recent species. Each sac (figs. 27I, 272) has received several names. The sub-bronchial, anterior to the furcula, is usually unpaired. The cervical, lateral to the first, lies at the base of the 
neck, and gives off a branch which forms an axillary sac in the axillary region. Other sacs lie in the abdomen, lateral to the viscera, and are called the anterior intermediate, posterior intermediate and abdominal, the latter extending into the pelvis. From these air sacs slender diverticula, not shown in the figures, extend among the viscera and into certain of the bones. The pelvis, humerus, coracoid, sternum and ribs most frequently contain prolongations of the air sacs-are pneumatic-less frequently the femur, furcula and scapula.

The functions of the air sacs are not certainly known. The fact that the walls are supplied with blood by branches from the aorta negatives the idea that they are respiratory. It has been suggested that they are concerned with the maintenance of the equilibrium of the body during flight and that they also lessen the specific gravity of the body. More plausible is the view that by the motion of the parts about them they aid in the inspiration and expiration of air, especially during flight, thus allowing the thoracic framework to remain rigid as an attachment of the muscles, and at the same time causing the air to pass twice over the respiratory surfaces of the lungs. The bones of the fossil bird Archecaopteryx were not pneumatic but those of some of the dinosaurian reptiles were.

MAMMALS.-The general structure of the mammalian lung was outlined above ( $\mathrm{p} .25^{6}$ ). The external shape is largely due to the position in the pleural cavity, where it has to fit itself around the pericardium, while it is flattened or truncate behind as a result of the presence of the diaphragm. In a number of mammals (cetacea, sirenia, horse, rhinoceros, Hyrax, etc.) both lungs are undivided, but usually one or both are subdivided into lobes (the larger number in the right lung), there being as many as five or six lobes in some species. Internally there is a main bronchus from which dorsal and ventral secondary bronchi arise, the ventral being the stronger. The bronchi are supported and kept open by cartilages, rings in the larger, scattered pieces in the smaller trunks. Frequently the bronchi are grouped as eparterial and hyparterial (fig. 264), accordingly as they lie above or below the pulmonary artery, but the distinction has little morphological value. Eparterial bronchi may be lacking or there may be one or two in each lung.

The phylogenetic history of the lungs is uncertain, one view being that they have arisen from the air bladder of the fishes, the other being that they are modified gill pouches, which, instead of growing laterally and fusing with the ectoderm, have extended caudally and have encroached upon the coelom. In favor of the former view are the double condition of the bladder in some ganoids, with alveolar walls like those of the lungs of higher vertebrates, and the peculiarities of the pneu- 
matic duct and the blood supply in Polypterus. On the other hand the dorsal position of the opening of the duct into the œsophagus and the arterial supply from the aorta in fishes are difficult to reconcile with the conditions obtaining in the tetrapoda. Favoring the gill-pouch theory are the following facts. The lungs are paired outgrowths from the pharynx immediately behind the last gill cleft; the blood supply can readily be derived from the branchiate condition; while the skeletal supports of the larynx have the appearance of rudimentary visceral arches, and the muscles of the region are modified from those of the gill arches.

The mechanisms by which air is caused to enter the lungs (inspiration) or is expelled from them (expiration) differ considerably in the various classes. In the amphibia air is drawn into the mouth via the nares by depressing the floor of the oral cavity. Then, the nares being closed by small muscles, the contraction of the mylohyoid muscle forces the air into the lungs. Expiration is affected in part by the elasticity of the lungs, in part by the muscles of the body wall. In most reptiles the position of the ribs is altered by the action of the intercostal muscles, thus altering the size of the pleuro-peritoneal cavity, to accommodate which air is drawn into and expelled from the lungs. It is difficult to understand how inspiration is effected in the chelonia, but transverse muscles run ventral to the lungs, and these by their contraction, expel the air. In the birds the lungs are attached to the ribs and vertebræ, so that any motion of the latter necessitates a change in shape and size of the lungs. In addition the air sacs, as noted above, may play a part in the movement of the air.

In the mammals the ribs are hinged at an oblique angle to the vertebral column, the angle being changed accordingly as the intercostal muscles are contracted or relaxed, and thus the size of the thoracic cavity is increased or dimininshed. Then the diaphragm (p. I35) also plays an important part in this alteration in size. This transverse muscle forms a complete partition between pleural and peritoneal cavities, projecting into the former like a dome when relaxed. When it contracts it flattens, thus increasing the size of the pleural cavity and drawing air in through the trachea. The abdominal muscles also have their effect. Expiration is caused in part by the action of the intercostal and abdominal muscles, in part by the elastic tissue and smooth muscles in the lungs themselves.

\section{ACCESSORY RESPIRATORY STRUCTURES.}

Allusion has already been made to the pharyngeal and dermal respiration of the amphibia (p. 258). There are several fishes in which 
the hinder part of the alimentary tract is also respiratory. Thus in Cobitis water is drawn in and expelled from the anus, and the posterior half of the digestive canal is richly vascular and is the seat of considerable respiration.

Before hatching or birth the lungs of the amniotes are unable to function, while a certain amount of oxygen is necessary for the development and the carbon dioxide formed must be carried away. This respiratory function is assumed by the allantois. The allantois is a ventral diverticulum from the hinder part of the alimentary canal, which during fœtal or embryonic life, acquires a relatively enormous development. It extends beyond the body limits and in reptiles and birds comes into close relations with the porous egg shell, while in the mammals it plays an important part in the formation of the placenta. In all these the allantois is extremely vascular, developing a rich network of blood-vessels close to the shell (sauropsida and monotremes) or to the walls of the maternal uterus, (mammals) which serves for the rather limited exchange of gases necessary for the young. After free life begins the allantois is either absorbed (sauropsida) or is lost with the rest of the placenta (mammals), only the basal part persisting as the urinary bladder, described in connection with the urogenital system.

\section{ORGANS OF CIRCULATION.}

The functions of the circulation are two-fold: to carry food and oxygen to the tissues and organs of the body and to remove the waste from them. In addition it has been made probable that every activity of the body results in the formation of peculiar substances - activatorswhich have fixed and definite effects upon the various organs. These activators pass into the blood and form the stimulus which may cause other organs or cells, remote from the place where the activator is formed, to act. This subject is a new one and much may be expected from it in the future.

The structures concerned in the circulation are two fluids, the blood and the lymph; and the vessels (vascular system) in which the fluids circulate, certain parts of the vessels being specialized (hearts) for the propulsion of the blood and lymph. A blood heart occurs in all vertebrates in connexion with the blood circulation; most vertebrates have lymph hearts in connexion with the lymph vessels, but in the higher groups the flow of the lymph is due to the blood pressure and also to the motion of the parts through which the lymph vessels course. 


\section{BLOOD AND LYMPH.}

The two circulating fluids, blood and lymph, are much alike. Each consists of a fluid portion, the plasma, in which float numerous solid particles, the corpuscles. The plasma is colorless or slightly yellow and can be separated by clotting into a solid part, fibrin, and a fluid, the serum, which is, under ordinary circumstances, incapable of clotting again. The lymph plasma contains less of the fibrin-forming substances (fibrinogen) than does the blood plasma. The composition of the plasma is very complex. Besides water it contains proteids, extractives, salts, and a number of lessknown substances, internal secretions, enzymes, etc. The plasma can also absorb a considerable amount of carbon dioxide. It serves to carry nourishment to the tissues and takes away from them the waste of metabolism.

The corpuscles are of three kinds, erythrocytes, leucocytes and blood plates. Only the leucocytes occur in the lymph while the blood contains all three.

The erythrocytes, or red corpuscles give the blood its color. They have fixed outlines and are flattened oval discs in the nonmammals and the camels, circular biconcave discs in the other mammals, and in all except the mammals they are nucleated throughout their existence. They owe their color to an iron-containing proteid, hæmoglobin, which readily combines with oxygen and carbon dioxide and as readily gives up these gases in places where they are scanty. This renders the erythrocytes the respiratory elements of the blood.

It has recently been stated that the erythrocytes of the mammals are hatshaped, (hollow cones) while inside the blood-vessels and that they assume the biconcave shape after leaving them. This account has been disputed.

The size of the erythrocytes varies in different vertebrates, being the largest in the amphibia (Amphiuma) and smallest in the vertebrates (musk deer). A few measurements are giving here in microns ( $0.00 \mathrm{Im}$.). Where two dimensions are given they are the length and breadth of the oval corpuscles. Musk deer, $2.5 \mu$; man, $7.7 \mu$; hen, $7 \times 12 \mu$; carp, $9 \times 15 \mu$; frog, $16 \times 25 \mu$; Necturus,

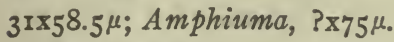

In the higher vertebrates the red corpuscles arise by division of giant cells (erythroblasts) in the red bone marrow, but in the young and at times of great depletion of the blood new red corpuscles may be formed in the spleen and the liver. At first all are nucleated but in the mammals the nucleus is soon lost.

The leucocytes or white corpuscles (divided accordingly as they 
occur in blood or lymph into leucocytes and lymphocytes) are very variable in shape (amœboid) and may be uni- or polynucleate. By their amœboid motions they are able to pass through the endothelial walls of the capillaries and to pass among the cells of the different tissues, hence they are often called wandering cells. They have the power of ingesting foreign bodies which renders them of value in combating pathogenic organisms; and they also aid in the absorbtion of fats and peptones.

The blood plates are very little known. Their size is less than that of the red corpuscles and they rapidly degenerate when drawn from the vessels. They are circular or elliptical in outline.

\section{THE BLOOD-VASCULAR SYSTEM.}

The blood-vessels include the arteries, which carry the blood from the heart to all parts of the body; the veins, which bring it back, and the

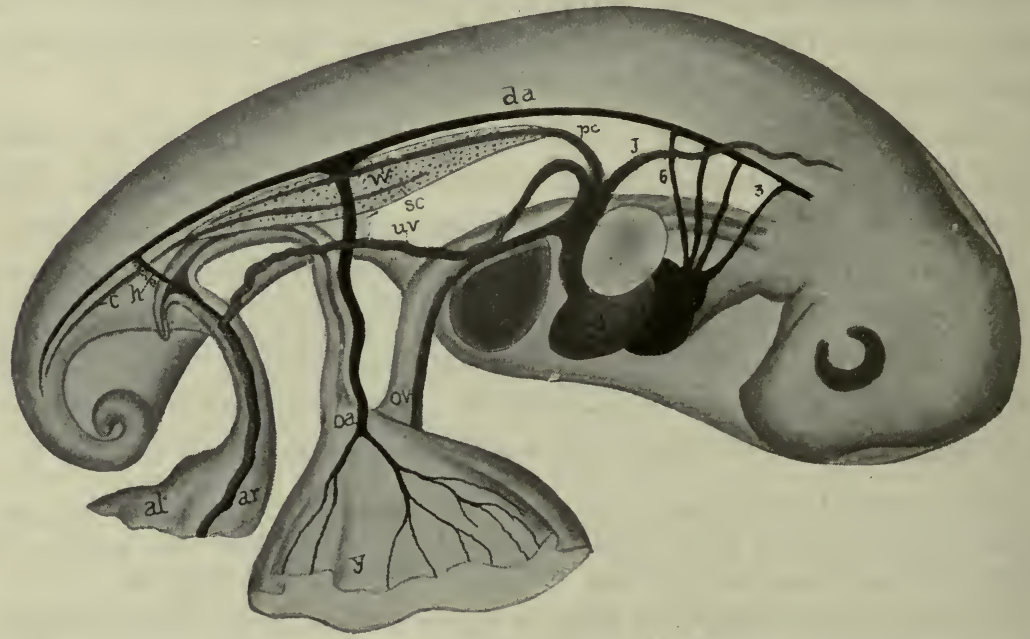

FIG. 273.-Embryonic circulation of snapping turtle, Chelydra, showing relations of allantois, after Agassiz and Clarke. a, right auricle; al. allantois; $a v$, allantoic vessels; $c$, caudal vein; $d a$, dorsal aorta; $h$, hypogastric artery; $j$, jugular; $l$, liver; $o a, o v$, omphalomesenteric artery and vein; $p c$, post-cardinal; sc, subcardinal vein; $u v$, umbilical vein; $w$, Wolffian body; $y$, yolk sac.

capillaries which connect the ends of the arteries and veins, for the system is closed, and there is a complete circulation.

Since all transfer of gases and nourishment takes place through the capillaries, these vessels have extremely thin walls, consisting of a single layer of squamous epithelium, the so-called intima. Usually, as 
the name implies, the capillaries are very small in diameter, but attention has recently been called to the sinusoids, vessels with similar walls but larger in diameter, which are noticeable in some developing organs, especially the liver. Here also must be mentioned the retia mirabilia, places where an artery or vein suddenly breaks up into a network of small vessels (often capillary) which unite again, as in the glomeruli of the kidney, to form a vessel as large as before. In the lymph nodes there are similar networks of the lymph vessels.

Arteries and veins (fig. 274) are larger than the capillaries and they have their walls strengthened outside of the intima by layers of smooth

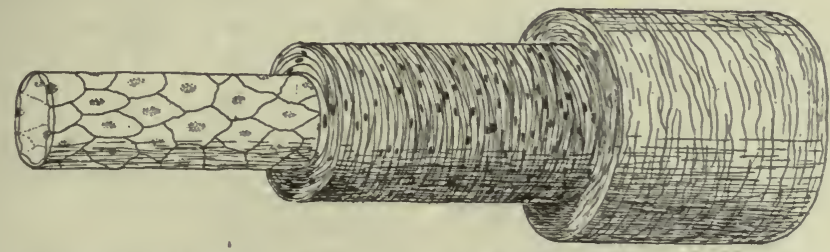

FIG. 274--Diagram of artery or vein. At the left the intima alone; covered in the middle by the muscularis, and at the right with the adventitia added.

muscle fibres (muscle wall) and connective tissue, mostly elastic (adventitial wall). Since the arteries are subjected to greater pressure than the veins their walls are relatively much thicker, but in other respects the two are much alike, except that valves to prevent the backflow of the blood, may occur in the veins, especially those that are vertical in the normal position of the animal (legs).

It has been suggested, with much plausibility, that the main blood-vessels are the remnants of the segmentation cavity, which elsewhere has been obliterated by the increase of the mesoderm. As will be recalled (p. I2I) the mesothelium grows toward the middle line above and below the digestive tract, thus tending to narrow the segmentation cavity in these regions into two longitudinal tubes. The epimeral part of the mesothelium divides into somites, and of course the segmentation cavity extends between these, and as these somites grow downward, these lateral extensions of the segmentation cavity are carried ventrally, so that at last they form a series of pairs of transverse vessels connecting the longitudinal trunks, thus forming the vessels of the somatic wall. Other tubes, connecting the dorsal and ventral trunks, would form between the two walls of the mesentery and between the splanchnic mesoderm and the entoderm, thus outlining the vessels of the alimentary tract.

Even more speculative is the suggestion that the original circulation was lymphoidal and that the blood circulation is a specialization of a part of this, the definitive lymph vessels being the unmodified part of the primitive system of vessels. 
An appreciation of this probable ancestral condition makes the actual structures more easily understood. In development much of this phylogenetic history has been lost, while other parts have been masked by the development of additional vessels. Many vessels, which theoretically should arise as spaces between other tissues, are actually formed as solid cords of cells, which are later canalized and converted into tubes. Again, separate vessels of the embryo may fuse during development into a single vessel of the adult.

The chief features of the theoretically primitive condition may be summarized here (fig. 275). A dorsal tube carries the blood toward the tail. From this transverse vessels-right and left, somatic and splanchnic-arise, which connect with two ventral longitudinal tubes,

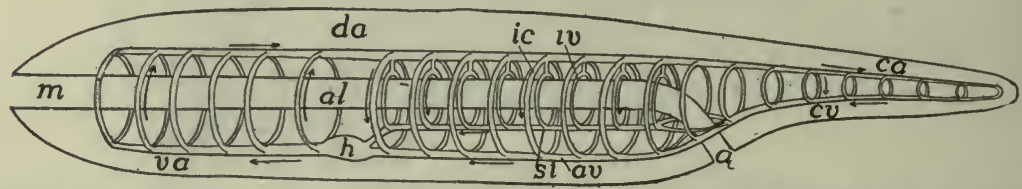

FrG. 275.-Diagram of the primitive vertebrate circulation. $a$, anus; al, alimentary canal; $a v$, abdominal vein; $c a, c v$, caudal artery and vein; $d a$, dorsal aorta; $h$, heart; $i c$, intercostal (somatic) transverse vessels; $i v$, intestinal vessels; $m$, mouth; si, subintestinal vein; $v a$, ventral aorta.

one in the wall of the alimentary tract and extending forward to its junction with the second which runs in the ventral body wall, a single tube coursing from the point of union to the anterior end of the body. In Amphioxus various parts of this system develop muscular walls and act as pumping organs. In the vertebrates, so far as the blood system is concerned, there is a single pumping organ, the heart (the portal heart of the myxinoids may be ignored in this general statement). The heart arises in the ventral tube beneath the pharynx and anterior to the junction of the two tubes. It marks the line of division of the transverse tubes into ascending and descending, those in front of the heart carrying the blood upward while those behind return it to the ventral vessels which carry it forward. The transverse vessels are not continuous, but capillaries intervene between their dorsal and ventral moieties.

\section{The Embryonic Circulation.}

In all vertebrates a series of blood-vessels is laid down in the early stages, forming a framework around which the rest of the circulation is 
arranged. Hence these parts are first described, the additions and modifications being taken up later.

\section{The Heart.}

The heart, the central organ for the propulsion of the blood, lies in a sac, the pericardium, a part of the cœlom, which is ventral to the pharynx or œsophagus and is partially filled with a serum, the per-

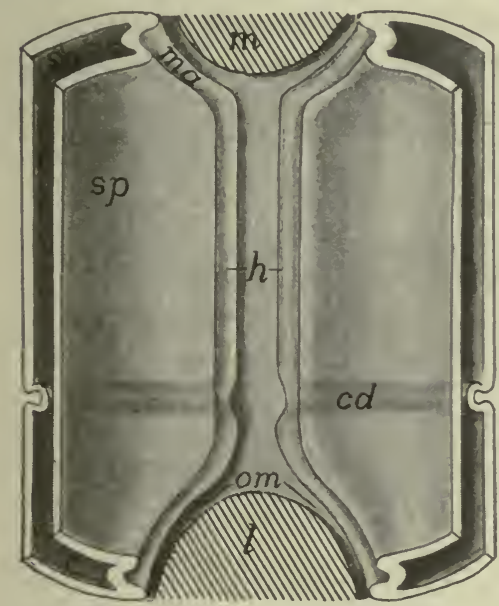

Fig. 276.

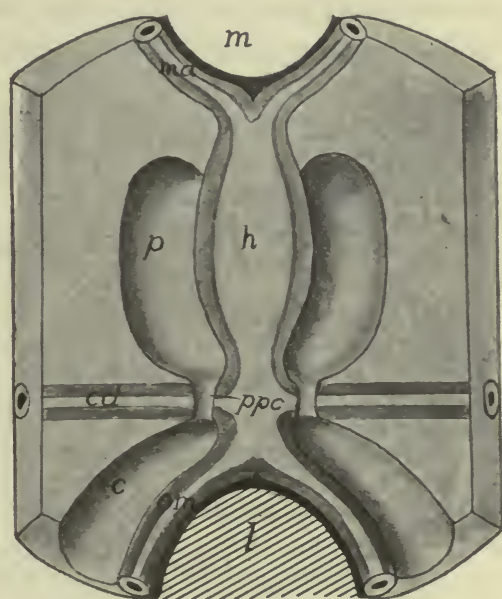

FIG. 277 .

FIG. 276.-Diagram of the formation of the heart tube, showing the descending mesothelial plates from above. $c$, cœlom; $c d$, first appearance of the Cuvierian ducts; $h$, grooves to form heart and ventral aorta; $l$, liver; $m$, mouth; $m a$, mandibular artery; om, omphalomesenteric veins; so, $s p$, somatic and splanchnic walls of colom.

FIG. 277.-Early stage of the heart; the descending plates of fig. 276 have met, forming the heart and ventral aorta. $c$, peritoneal cœlom; $p$, pericardial cœlom; $p p c$, pericardioperitoneal canals; other letters as in fig. 276 .

icardial fluid. In the heart we have to consider its epithelial lining (endocardium), its muscular walls (myocardium) and its covering epithelium and connective tissue (epicardium).

The development of the heart is simplest in the vertebrates with relatively small yolk. It is more modified in the elasmobranchs, where the head is early completed below, and is most modified in the large yolked eggs of the sauropsida and in the mammals where the yolk sac is large, though the yolk is small. The following account is based upon the development in the amphibia:

From just behind the point where the first or spiracular gill cleft is to form, backward to the region just in front of the anlage of the 
iver the hypomeral portions (lateral plates) of the cœlomic walls grow ventrally beneath the alimentary canal, in much the same way as farther back (p. $12 \mathrm{I}$ ). In these descending plates splanchnic, mesenterial and somatic walls, as well as the cœlomic cavity can be recognized. As they descend, cells which have received the name of vascular cells appear between the cœlomic walls and the entoderm. The origin of these has been in dispute, but the present evidence favors their origin from the mesothelium. Some of these vascular cells are more dorsal and aid in the formation of the dorsal blood-vessels, while the ventral (fig. $278, A$ ) contribute to the heart and the ventral trunks.
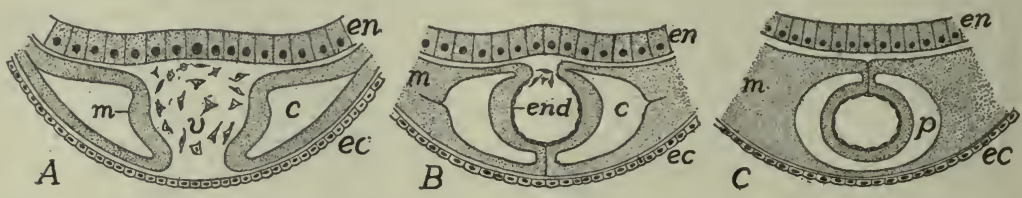

FIG. 278.-Diagrammatic cross sections of developing heart. Compare with figs. 276 and 277. In $A$ the descending mesothelial plates have nearly met, a number of vascular cells between them. In $B$ the plates have met ventrally, forming the ventral mesocardium; most of vascular cells utilized in forming the endocardium. In $C$ the plates have met dorsally, with the resulting dorsal mesocardium; the ventral mesocardium has disappeared, placing the two cœlomic cavities, now the pericardium, in communication. $c$, colom; ec, ectoderm; en, entoderm; end, endocardium; $m$, edges of descending mesothelium; $p$, pericardium; $v$, vascular cells.

The descent of the lateral plates continues until their lower edges meet just dorsal to the ventral ectoderm and the ventral parts of the mesenterial regions of the two sides fuse to a vertical plate, the ventral mesocardium (fig. $278, B$ ), above which is a groove in which the ventral vascular cells lie. Next, the edges of the plates crowd in above the groove and meet to form a dorsal mesocardium, the result being that groove is converted into a tube. The mesocardia disappear early, the ventral usually being lost before the dorsal is formed (fig. 278 , $C)$. The walls of the tube, which are to form the muscular and epicardial walls of the heart, are called the myoepicardial mantle. ${ }^{1}$ The vascular cells, which are enclosed in this mantle, gradually arrange themselves as a continuous sheet, the endocardium, which lines the future heart.

With the disappearance of the mesocardia the cœlomic spaces on the two sides communicate with each other so that the myoepicardial mantle lies free on all sides in a cœlomic sac, being bound to the walls only at the two ends. This cavity or sac is the pericardial cavity,

${ }^{1}$ The fact that the heart muscles arise from this layer-mesothelial and yet not myotomic -partly explains the differences between cardiac and other muscle. 
the extent of which is decreased by the fusion laterally of the somatic and splanchnic walls (fig. 277).

In front of and behind this tube the descending lateral plates are kept from meeting in the middle line by the projections for the mouth and liver (fig. 276). Vascular cells, however, are formed in these regions and these furnish the lining of tubes on either side, arising in the edges of the lateral plates. These tubes consequently diverge from the myoepicardium in front and behind and form the first stages of the vessels connected with the heart, the anterior pair giving rise to the mandibular arteries, the posterior to the omphalomesenteric veins. At about the same time a transverse tube appears on either side, which connects with the heart tube, just in front of the division into omphalomesenterics (fig. 276). These transverse vessels continue laterally between the lateral plate and the ectoderm, forming the venous trunks known as the ducts of Cuvier (trunci transversi), the other relations of which will be described later. The cœlom on either side of the heart is restricted behind by the ridge formed by the Cuvierian ducts (fig. 277); with growth this interruption grows larger, the result being a transverse partition, the septum transversum, which bounds the pericardial cavity behind and separates it from the rest of the colom, the peritoneal cavity. At first this septum is incomplete, and in the elasmobranchs it never closes dorsally to the omphalomesenterics, but leaves two openings, the pericardio-peritoneal canals (fig. 277). Elsewhere the pericardial and peritoneal cavities are entirely separate in the adult.

In teleosts and amniotes, where the early embryo is closely appressed to the very large yolk sac, the development of the heart is modified. At first the pharynx is not complete below but communicates ventrally with the yolk. Hence the two hypomeres are prevented, for a time, from meeting ventrally. Each, however, is accompanied by its vascular cells; its edge becomes grooved and the grooves are rolled into a pair of tubes, lined with endocardium, so that for a time the anlage of the heart consists of two vessels, each connected in front and behind with its own mandibular artery and omphalomesenteric vein, and is surrounded with its pericardial sac. Later the two tubes approach and fuse, with the formation of mesocardia as before: these latter soon disappearing, leaving the whole much as in the small yolked forms.

In the early stages the pericardium is relatively large, but it does not keep pace with the growth of the other parts, until finally in the adult it is only large enough to accommodate the changes in size and shape 
of the heart, due to its alternating enlargement (diastole) and contraction (systole).

While the mesocardia are present the cardiac tube is a straight canal, lying in the pericardial sac and connected with its walls in front and behind. With their disappearance the tube increases in length more rapidly than the pericardium, the result beng the flexure of the tube on itself, something like the letter $\propto$, the flexures being largely in the vertical plane. At the middle point of the flexure the tube remains small, forming the atrio-ventricular canal, but in front of and behind this the walls become thickened and the lumen enlarged. The posterior and dorsal of the chambers thus formed becomes the atrium (auricle), the ventral and anterior the ventricle of the heart.

The atrium is bounded posteriorly by a constriction, behind which the tube expands into another chamber, the sinus venosus, which extends back to the posterior wall of the pericardium and receives the ducts of Cuvier and the omphalomesenteric veins. The ventricle, also, does not reach the anterior wall of the pericardium, but the anterior part of the heart tube forms a smaller trunk, the truncus arteriosus, while from the pericardium to the mandibular arteries is an arterial vessel, the ventral aorta.

Muscles, as stated above, are developed in the wall of the heart, but to an unequal extent in the different parts, being scanty in the sinus venosus, and most abundant in the ventricle. Folds or valves of the endocardium appear in places at an early date and are so arranged that they permit the blood to flow forward but prevent any backflow. In the base of the truncus these valves take the form of pockets on the walls, there being several $(3-5)$ rows with several valves in a row in the elasmobranchs (fig. 287, $A$ ) and ganoids. This valvular part of the truncus is called the conus arteriosus. In other vertebrates the conus is reduced to a single row of valves.

Valves also occur in the atrio-ventricular canal (fig. 279) but here the pocket-like condition is impossible. The folds extend from the canal into the ventricle and are prevented from folding back into the atrium, under the heavy ventricular pressure, by ligaments-chordæ tendineæ-which extend from the edges of the valves to the opposite wall of the ventricle, and are kept taut during systole by short muscles (columnæ carnea) at the base. Other valves, more simple in character, occur around the opening from the sinus into the atrium and, in some vertebrates, where the hepatic veins empty into the sinus. 
In many fishes the conus arteriosus is followed by a strongly muscular region, the bulbus arteriosus (fig. $287, B$ ) which has muscles like those of the heart (p. I25), while the truncus in front of this has smooth muscles, like the rest of the blood-vessels. Hence conus and bulbus are to be regarded as a part of the heart, while the region in front is a part of ventral aorta to be described below.

When first formed, the heart lies close behind the mandibular artery (first aortic arch to be described below), but as other vessels are formed it is forced farther back into a position, in the lower vertebrates, ventral to and a little behind the pharynx, but in the adult tetrapoda it is carried back, as a result of unequal growth even into the thorax, the extreme of migration being seen in the giraffe and the long-necked birds.

Although all of the blood of the body passes through the heart at short intervals, this is not sufficient for the nourishment of that organ. Therefore its muscles are usually supplied with blood

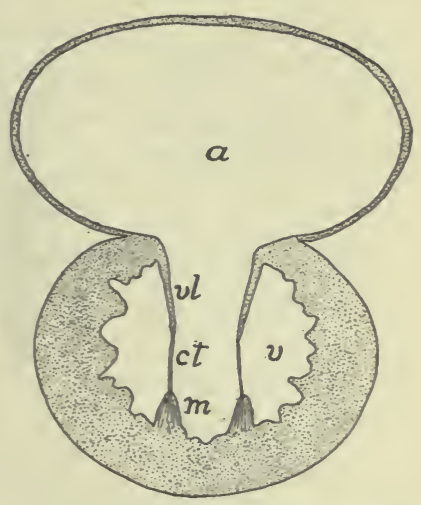

FrG. 279.-Diagrammatic cross section of heart showing atrioventricular valves; $a$, atrium; $c t$, chorda tendinea; $m$, muscula papillosa; $v$, ventricle; $v l$, atrio-ventricular valves. through coronary arteries which arise from the aortic arches and run back along the truncus arteriosus to reach the atrium and ventricle.

\section{The Arteries.}

Aorta and Aortic Arches.--The ventral aorta is the trunk in front of the pericardium, extending from the truncus arteriosus to the mandibular artery (first aortic arch). It runs, not through a cavity, but between muscles and through connective tissue. The mandibular arteries continue dorsally on either side of the pharynx until they reach its dorsal surface. With development, the ventral aorta elongates and at the same time other aortic arches arise between the mandibular arteries and the pericardium, these extending dorsally until they meet the backward prolongations of the first, thus forming a pair of longitudinal tubes, dorsal to the alimentary tract, the radices aortæ.

The number of pairs of aortic arches varies with the number of gill clefts, the vessels coursing between the clefts. The number of arches 
is greatest in the myxinoids, where the number of clefts varies (p. 239); seven or eight in the notidanid sharks; and, as recent investigations tend to show, probably six in the embryos of all other vertebrates. The history of these arches differs greatly in the different classes (fig. 280), there usually being a reduction in number by the more or less complete
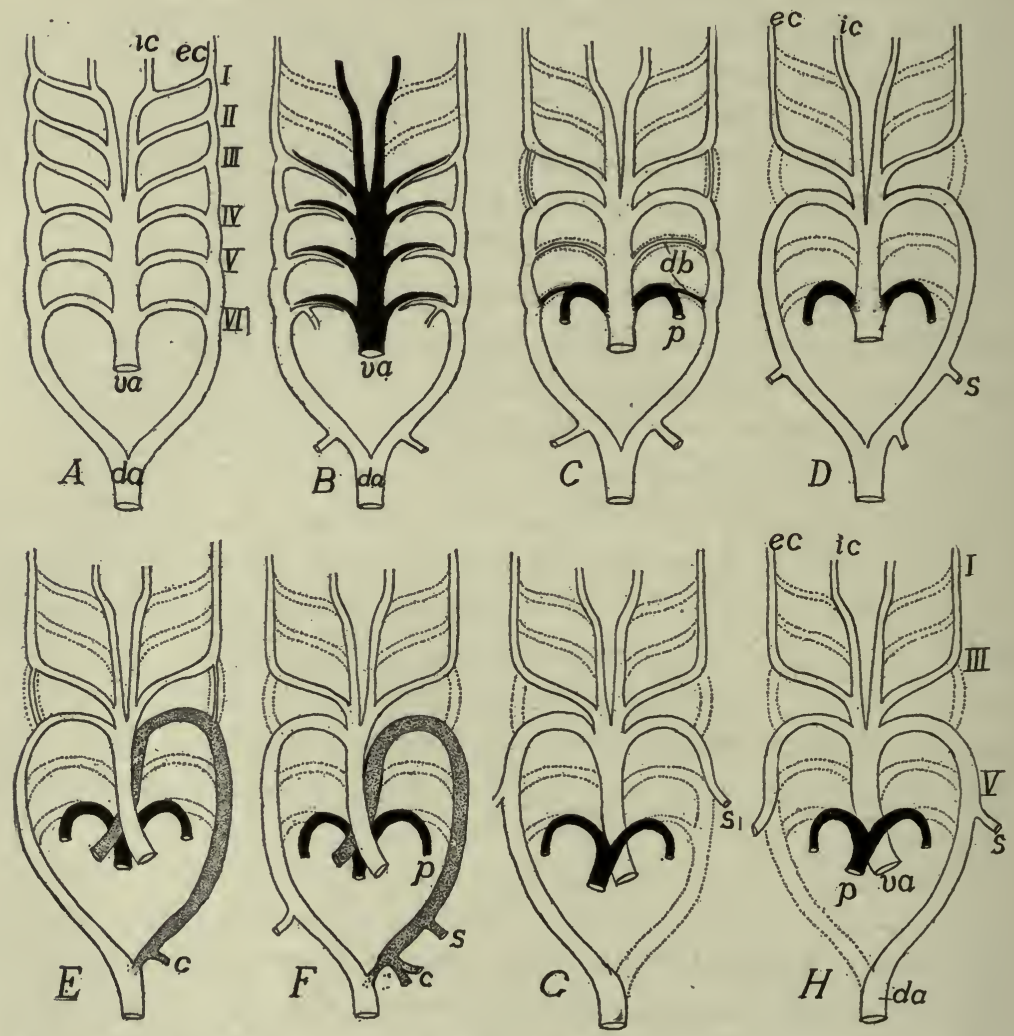

FIG. 280.-Modifications of the aortic arches in different vertebrates, after Boas. $A$, primitive scheme; $B$, dipnoan; $C$, urodele; $D$, frog; $E$, snake; $F$, lizard; $G$, bird; $H$, mammal. $c$, cœliac artery; $d a$, dorsal aorta; $d b$, ductus Botallii; $e c$, $i c$, external and internal carotids; $p$, pulmonary artery; $s$, subclavian; $v a$, ventral aorta. Vessels carrying venous blood black, those which disappear, dotted.

abortion of one or more pairs as well as a modification of those that persist, accompanying changes in the respiratory system.

With the development of gills (ichthyopsida) each aortic arch becomes divided into two portions, an afferent branchial artery convey ing blood from the ventral aorta to the gills and an efferent branchial artery (sometimes called a branchial vein) carrying it from the gills 
to the radix aortæ (fig. 28r). These two vessels parallel each other for a part of their course and are connected with each other by numerous capillary loops which run through the gill filaments. In passing through the gills the blood loses its carbon dioxide and takes up oxygen, and thus becomes converted from venous to arterial blood. In the amniotes afferent and efferent branchial arteries are never differentiated, the aortic arches being continuous from ventral aorta to the radices aortæ.

The first of these arches (the mandibular arteries) never forms afferent and efferent portions since no gills are ever developed in their region. From each half of this arch an artery, the external carotid,

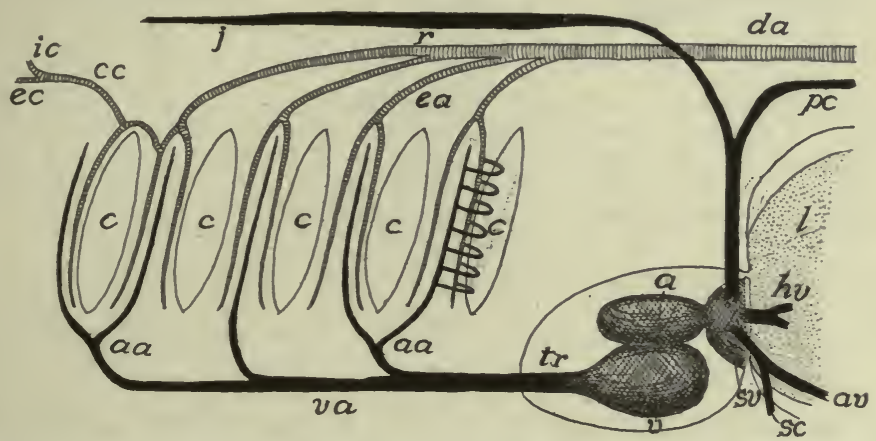

FIG. 281.-Scheme of branchial circulation in elasmobranchs. $a$, atrium; $a a$, afferent branchial arteries; $a v$, abdominal vein; $c$, gill clefts; $c c$, common carotid; $d a$, dorsal aorta; $e a$, efferent branchial arteries; $h v$, hepatic vein; $i c$, internal carotid; $e c$, external carotid artery; $i$, jugular vein; $l$, liver; $p c$, postcardinal vein; $s c$, subclavian vein; $s v$, sinus venosus; $t r$, truncus arteriosus.

extends forward to supply the lower and a part of a upper jaw, while an internal carotid artery forms an extension forward of each radix and supplies the brain and face. Later their relations are such that the carotids appear to arise from the first of the functional arches.

The radices aortæ of the two sides meet and fuse behind the last aortic arch, forming a single tube, the dorsal aorta, which runs in the middle line, dorsal to the alimentary tract, to the end of the body. The fusion may also extend forward from the last aortic arch, involving the whole of the radices.

From the dorsal aorta segmental arteries extend laterally between the somites, these forming the upper halves of the transverse somatic vessels alluded to on page 268 . To these the name of intercostal arteries, derived from human anatomy, is given. Ventral to them the aorta also gives off other arteries (nephridial arteries) to the excre- 
tory organs. Other arteries, arising from the dorsal aorta, run ventrally into the mesenterial structures and supply the alimentary canal and other viscera. Two pairs of these, the omphalomesenteric (omphalomesaraic) and the hypogastric arteries, may be mentioned at present. The first of these arise in the trunk region, pass on either side of the intestine, and finally empty on the lower side of the body into the om-

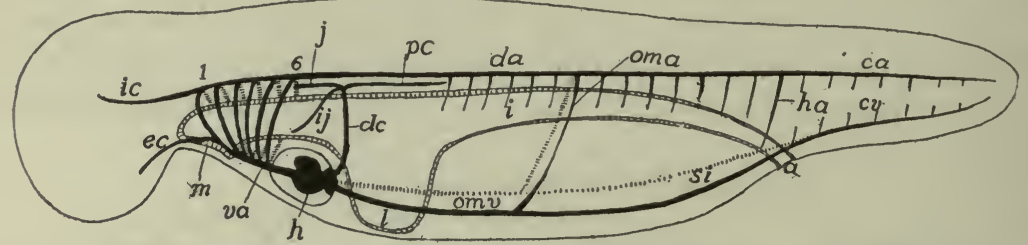

FIG. 282.-Diagram of the circulation in an early stage of a small yolked vertebrate (amphibian). $\quad a$, anus; $c a, c v$, caudal artery and vein; $d a$, dorsal aorta; $d c$, Cuverian duct; $e c$, external carotid; $h$, heart; $h a$, hypogastric artery; $i$, intestine; $i c$, internal carotid; $i j$, inferior jugular; $j$, superior jugular; $l$, liver; $m$, mouth; oma, omv, omphalomesenteric artery and vein; $p c$, postcardinal vein; si, subintestinal vein; $1-6$, aortic arches.

phalomesenteric veins, soon to be described. The hypogastric arteries arise from the dorsal aorta at the junction of trunk and tail and pass on either side of the intestine, to meet posterior continuations of the omphalomesenteric veins, here known as the subintestinal veins. Behind the origin of the hypogastric arteries the dorsal aorta is called the caudal artery (figs. 275, 282).

\section{VEINS.}

Behind the pericardium the edges of the descending lateral plates (p. 270) are kept from meeting by the anlage of the liver (figs. 276, 277). The edges of the plates become grooved just as in front and each groove becomes rolled into a tube, lined with vascular cells, so that two vessels, the omphalomesenteric veins, extend backward from the heart, around the liver, to meet the omphalomesenteric arteries already described: Behind the connection of the omphalomesenteric arteries and veins the pair of vessels continue back, ventral to the alimentary canal as the subintestinal veins, until just behind the anus they fuse into a median tube, the caudal vein, which extends the length of the tail.

The two subintestinal veins soon fuse to a single median vessel (fig. $283, B$ ) save for a loop around the anus connecting it with the caudal vein. The right omphalomesenteric vein disappears except for a short distance between the sinus venosus and the liver, leaving the left as the 
trunk connecting the posterior parts with the heart, this passing along the left side of the liver (fig. $283, B$ ).

Portal Circulation.-As the liver develops from the simple sac it is at first, into the compound tubular condition (p. 233), the left omphalomesenteric breaks up into a sort of rete mirabile of sinusoids, which ramify among the liver tubules, finally connecting with both omphalomesenterics on the anterior side of the liver (fig. 283, B). As the liver increases in size the network of sinusoids increases in complexity, supplying all of the tubules. For a time the left omphalomesenteric
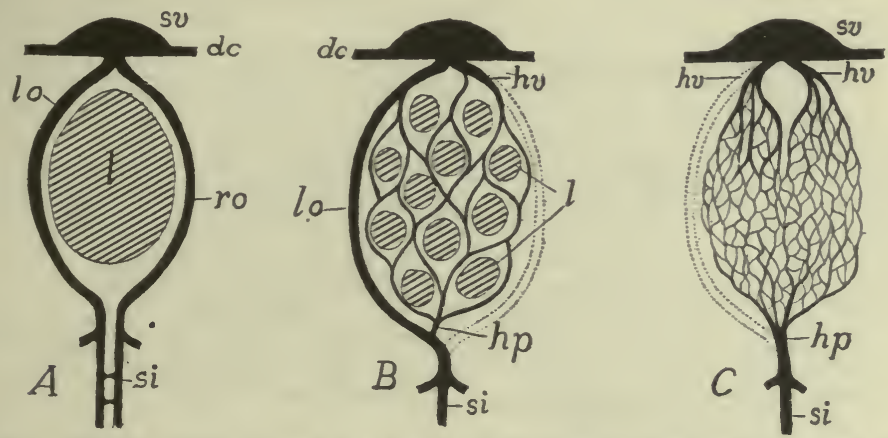

FIG. 283.-Three stages in the development of the hepatic portal system. $A$, primitive; $B$, liver tubules beginning to develop, right omphalomesenteric interrupted; $C$, definitive condition, liver not indicated. $d c$, Cuverian ducts, $h p$, hepatic portal vein; $h v$, hepatic vein; $l$, liver; $l o, r o$, left and right omphalomesenteric veins; si, subintestinal veins; $s v$, sinus venosus.

retains its primitive importance on the side of the liver and is known as the ductus venosus (Arantii), but soon this preeminence is lost and all blood coming from behind passes through the network of capillaries in the liver before it enters the heart (fig. 283, C). Such a capillary circulation occurring in the course of a vein is known as a portal system, and this one occurring in the liver is the hepatic portal circulation. It consists of the vessels bringing the blood to the liver (portal vein) - a part of the original omphalomesenteric - the capillary vessels and the bases of both omphalomesenterics, now known as the hepatic veins, which convey the blood from the. liver to the heart.

In eggs with a large yolk (elasmobranchs, sauropsida) the presence of this large food supply exercises a modifying influence on these ventral veins (fig. 284). From the junction of the omphalomesenteric and the subintestinal veins a pair of large vitelline veins run out into the yolk sac, over the yolk, and play a large part in the transfer of material to the growing embryo. The distal parts of these reins follow the margin of the yolk sac, forming a tube (sinus terminalis) into which 
smaller veins empty. Blood is brought to the yolk by the omphalomesenteric arteries, which are also distributed to the yolk sac, dividing up distally into a network of capillaries connecting distally with the vitelline veins. By these the blood is carried to the liver and through the portal circulation to the heart. In the mammals a similar vitelline circulation is developed, but as the yolk sac contains no yolk, it is of minor importance.

In the amniotes an outgrowth, the allantois (p. $3^{\mathrm{I}} 8$ ), arises as a diverticulum from the hinder end of the alimentary canal, increases in extent, growing downward and carrying the ventral body wall before it. Branches of the hypogastric arteries, known as the allantoic arteries, extend into it and are connected by capillaries

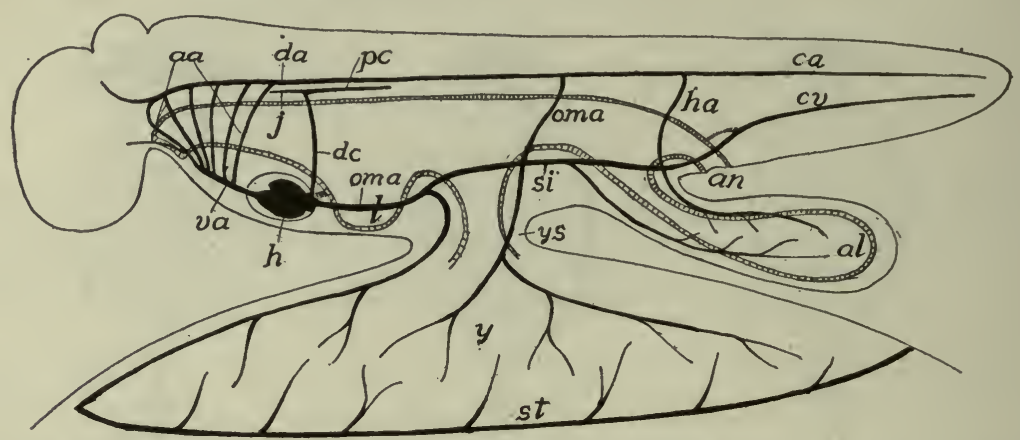

FIG. 284.-Diagram of embryonic circulation in a large-yolked vertebrate; compare with fig. 282. $a a$, aortic arches; $a l$, allantois; $a n$, anus; $c a, c v$, caudal artery and vein; $d a$, dorsal aorta; $d c$, Cuverian duct; $h$, heart; $h a$, hypogastric (allantoic) artery; $i$, jugular vein; $l$, liver; oma, omv, omphalomesenteric artery and vein; $p c$, postcardinal vein; si, subintestinal vein; st, sinus terminalis; $v a$, ventral aorta; $y$, yolk; $y s$, yolk stalk.

with umbilical veins which arise from the subintestinal vein behind the vitelline veins. There thus is formed an allantoic circulation which is both respiratory and nutritive in character. In the reptiles both of the umbilical veins persist through the fotal life (only one shown in fig. 273), but in birds and mammals one aborts, leaving the other as the efferent vessel of the allantois. With the end of fœtal life (at hatching or at birth) both the vitelline and the allantoic circulations disappear, leaving only inconspicuous rudiments.

The entrance of the Cuverian ducts into the heart was mentioned on page 27I. These ducts are a pair of transverse vessels which enter the sinus venosus, one from either side, and, together with the hepatic veins, mark the posterior limit of the heart. Each develops outside of the somatic wall of the hypomere and extends dorsally until it reaches the level of the top of the colom (fig. 282). In this course, in the fishes, each receives an inferior jugular vein which comes from the head, bringing back blood from the muscles of the lateral and ventral branchial regions. At its dorsal end each Cuverian duct divides into 
the two cardinal veins, an anterior cardinal (superior jugular) and a postcardinal vein (fig. 285 ), which belong to the dorsal half of the body. The superior jugular comes from the head, dorsal to the gill clefts and brings blood from the more dorsal regions. Since the inferior jugulars are found only in fishes and salamanders, the anterior cardinal is usually called simply the jugular and that usage will be followed here.

The postcardinals are closely related in development to the nephric system, and keep pace with its development backward, so that they eventually reach the loop which the caudal and subintestinal vein

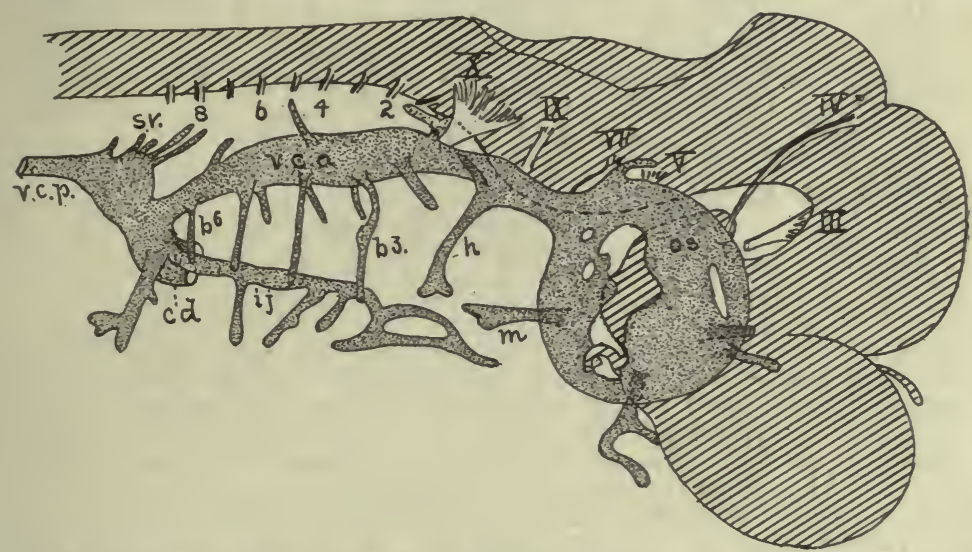

FIG. 285.-Developing anterior veins of Scyllium embryo, $26 \mathrm{~mm}$. long; after Grosser. $b{ }^{1-6}$, veins of the visceral arches; $c d$, Cuverian duct; $h$, vein of hyoid arch; $i j$, inferior jugular; $m$, vein of mandibular arch; os, orbital sinus; $s v$, segmental veins; vca, vcp, pre- and post-cavas; $I I I-X$, cranial nerves; $2-8$, spinal nerves.

makes in passing around the anus. They run just above the dorsal side of the cœlom and dorsal to the nephridial arteries (p. 275). They are preeminently the blood-drainage system of the early excretory organs and they retain that function throughout life in the lower vertebrates.

Closely associated with the postcardinals are the subcardinals. As the mesonephroi (see Excretory Organs) reach the hinder end of the cœlom, the caudal vein loses its primitive connection with the subintestinal vein and becomes connected with a pair of vessels, the subcardinal veins, which develop between the mesonephroi and ventral to the nephridial arteries (fig. 286, B). The blood from the tail now goes through the subcardinals and from them into the excretory organs, passing through a system of capillaries, to be gathered again in the postcardinals 
and by them to be returned to the heart. Here, then, there is another portal system (p. 277), the first renal-portal system, which may be modified later as will be described below.

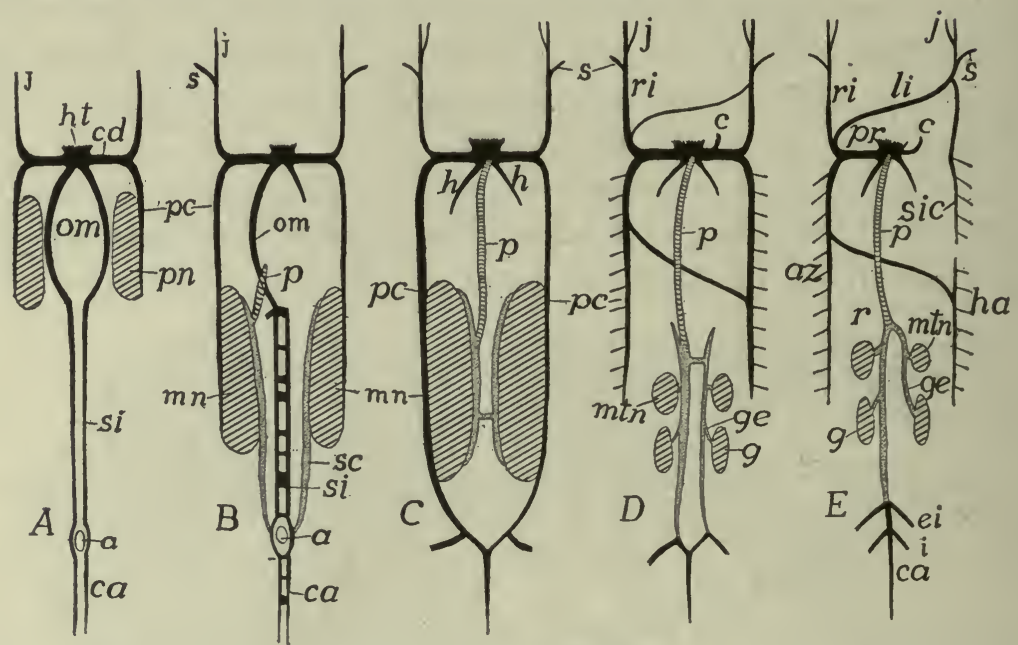

FIG. 286.-Scheme of development of the principal veins. $a$, anus; $a z$, azygos major; $c$, coronary vein; $c a$, caudal vein; $c d$, Cuvierian duct; $e i$, external iliac; $g$, gonads; $g e$, genital (spermatic, ovarian) vein; $h$, hepatic veins; $h t$, heart; $i$, ischiadic; $j$, jugular; $l i$, left innominate; $m n, m t n$, meso- and metanephroi; om, omphalomesenterics; $p$, postca va; $p c$, postcardinal; $p n$, pronephros; $p r$, precava $r$, renal; $r i$, right innominate; $s$, subclavian; sc, subcardinal; si, subintestinal; sic, superior intercostal.

In $A$ the early condition with paired omphalomesenterics and subintestinals, the postcardinals extending back as far as the pronephroi. $B$, mesonephroi developed and with them the subcardinals and the beginning of the postcava; one omphalomesenteric lost and subintestinals and caudals beginning to fuse; the intestinal vessels omitted in the later figures. $C$, postcava has joined sinus and postcardinals have reached caudals; $D$, amniote, appearance of metanephroi (true kidneys) with obsolescence of mesonephroi; the postcardinals lose connexion with caudal, their place being taken by the backward extension of the subcardinals; formation of cross connexions between jugulars and between postcardinals of the two sides. $E$, breaking up of postcardinals and disappearance of left Cuvierian duct, the other being called the precava.

Postcaval elements crosslined, subcardinal, dotted, other veins black.

\section{The Definitive Circulation.}

It is impossible here to follow in detail the development of all parts of the circulatory system, or even to mention all of the vessels in all of the groups. All that can be attempted is an account of the more important parts and their modifications, with here and there references to their history which will render their peculiarities more intelligible. Most of the major trunks are now known to appear at first as lines of vascular cells, similar to and arising in the same way as those described in connexion with the heart (p. 27 I), and it seems possible that 
the intima of all of the blood-vessels is in genetic relations to such lines of cells. It should be remembered that the vascular system is extremely variable, even within the limits of the species.

\section{The Heart.}

The heart, as it was left on page 273 , was a venous or branchial heart, in that all of the blood which enters it is venous blood and is all pumped directly to the gills to lose its carbon dioxide and to take up oxygen, before being distributed to the various parts of the body.
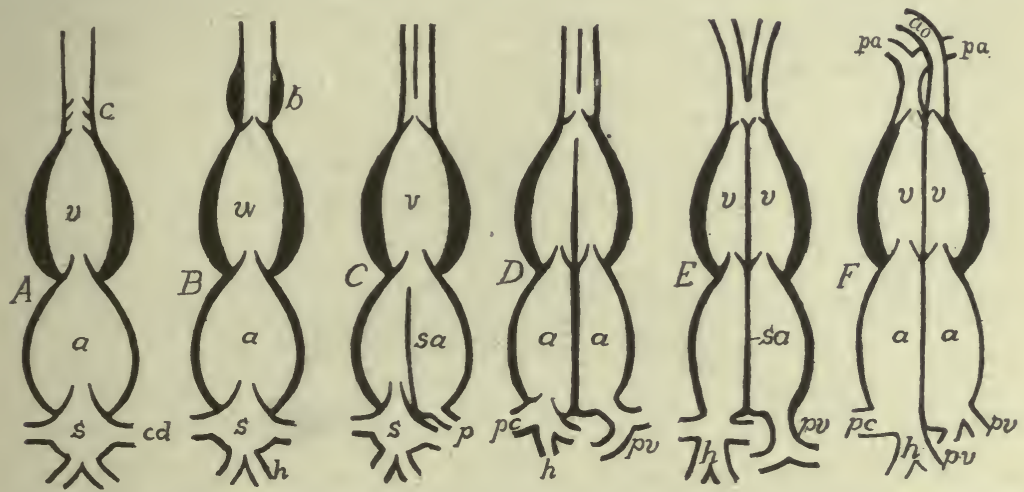

FIG. 287.-Different stages in the differentiation of the parts of the heart. $A$, elasmo. branch; $B$, teleosts; $C$, amphibia; $D$, lower reptiles; $E$, alligator; $F$, birds and mammals$a$, atrium; $a o$, aorta; $b$, bulbus arteriosus; $c$, conus; $c d$, Cuvierian duct; $h$, hepatic veins; $p a$, pulmonary artery; $p c$, pre- and postcaval veins; $p v$, pulmonary vein; $p a$, pulmonary artery; $s$, sinus venosus; sa, septum atriorum.

In its course through the body it passes but once through the heart in order to make the complete circuit. Such, in general, is the heart in the cyclostomes and fishes (fig. $287, A, B$ ).

When, however, lungs are formed (dipnoi and amphibia) to share in the respiratory processes, the heart begins to divide into arterial or systemic, and venous or respiratory halves. This division is brought about by the formation of a septum or partition in the atrium, partially or completely dividing the chamber, the pulmonary vein (infra) opening into the left half, which thus becomes arterial, while the sinus, with its veins, is connected with the right alone (fig. $287, C$ ).

Still higher in the scale the partition or septum extends through the atrio-ventricular canal, dividing its valves into two groups (tricuspid valves on the right side, mitral on the left) and partially dividing the ventricle (most reptiles fig. $287, D$ ). In the crocodilia (fig. $287, E$ ) 
the division of the ventricle is completed by the extension of the septum to the anterior end, but there is an opening (foramen Pannizæ) between the two sides of the aortic trunk, so that some admixture of arterial and venous blood can occur. In the birds and mammals (fig. $287, F$ ) there is complete internal separation of the two sides of the heart, though externally it shows but slight signs of the division. As a result of this division blood must pass twice through the heart (once through the venous, once through the arterial half) in order to make a complete circuit of the body. Venous blood enters the right atrium, passes to the right ventricle, by which it is forced to the lungs (pulmonary or respiratory circulation). Returning to the heart by the pulmonary veins, it passes through the left atrium and ventricle and thence through the systemic circulation, by which all parts of the body are supplied. Details of the modifications of the heart in the different classes of vertebrates are given at the end of this chapter.

\section{Aortic Arches.}

As was said above, the typical number of aortic arches is six pairs, this number being but rarely exceeded. In all groups except cyclostomes and fishes they undergo considerable modification, and in the fishes they are frequently more or less reduced in correlation with the reduction of the gills (p. 238). The modifications may be outlined as they occur in the successive pairs of arches.

In many fishes and all tetrapoda the first arch on either side disappears beyond the point where the external carotid arises, while, correlated with the reduction of the spiracular gill, the second pair of arches is partially or completely lost in the adult. The third pair is always persistent and through them flows the blood for the internal carotids and, in the fishes, gymnophiona and a few urodeles (fig. 280, $C)$ and reptiles, $(E)$ blood for the radices aortæ as well. In all other tetrapoda the radix disappears between the third and fourth arches (fig. $280, D$ ) and consequently here the third arch is purely carotid in character. When this occurs the portion of the ventral aorta between the third and fourth arches carries blood for the carotids alone and hence forms a common carotid trunk, usually divided into right and left common carotid arteries.

The fourth pair of arches are the systemic trunks in all tetrapoda, 
carrying blood from the ventral to the dorsal aortæ, while the fifth, reduced in size, perform a similar function in a few urodeles (fig. 280, C), but elsewhere they entirely disappear. The fourth arches show a differentiation between the two sides in many reptiles. That on the left side becomes separated from the rest of the ventral aorta (fig. 280, E, F) and has its own trunk connecting with the right side of the partially divided ventricle, and, as will be understood from the relations of the heart (p. 28I), it may carry a mixture of arterial and venous blood. From the dorsal side, this blood of the left fourth arch is largely distributed to the digestive tract, the cœliac axis arising from its radix, while the part connecting it with the dorsal aorta is reduced in size. The right arch and the carotids are connected with the left side of the
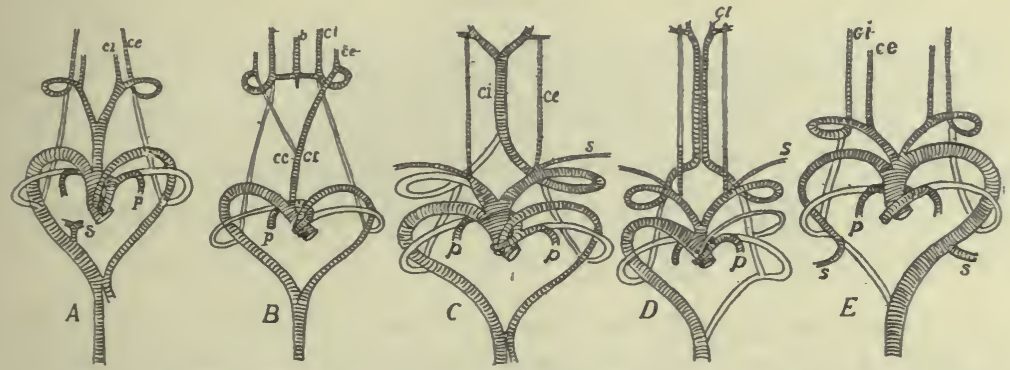

FIG. 288.-Aortic arches of amniotes, after Hochstetter. A, Varanus; $B$, snake; $C$, alligator; $D$, bird; $E$, mammal. $b$, basilar artery; $c c$, common carotid; $c i, c e$, internal and external carotids; $d a$, dorsal aorta; $p$, pulmonary; $s$, subclavian.

heart and hence are purely arterial, the arch forming the main trunk connecting the heart with the dorsal aorta. In the birds (fig. 280, $G$ ) the radix of the left side of the adult disappears distal to the origin of the subclavian artery, so that this arch supplies only the fore limb of that side, while the right arch is purely aortic in character. In the mammals (fig. 280, $H$ ) these relations are exactly reversed, the right arch being subclavian, the left supplying the dorsal aorta and the subclavian of that side.

With the development of lungs (dipnoi, tetrapoda) a pair of pulmonary arteries are developed from the sixth pair of arches on the ventral side of the pharynx. These grow back into the lungs, while the rest of the arch, dorsal to their origin, becomes reduced to a small vessel the ductus arteriosus (d. Botallii) in some urodeles, and persists occasionally vestigially in higher vertebrates. Elsewhere it entirely disappears. In the dipnoi and amphibia, where the ventricle remains 
undivided, the pulmonary arteries are connected with the same trunk (ventral aorta) as are the other aortic arches (fig. 280, $C, D$ ). In the amniotes $(E, F, G, H)$ with partial or complete division of the ventricle, the truncus and the ventral aorta are divided in such a manner that derivatives of the sixth arch are connected with the right side of the heart, while the rest of the ventral aorta, save for the exception noted in the reptiles above, receives its blood from the left side of the heart.

In connexion with the almost complete obliteration of the fifth arch, and in most pulmonate vertebrates, the separation of the sixth from the rest, it is interesting to note that in the lower vertebrates (elasmobranchs) there is already a differentiation of these two arches from the rest of the series (fig. 28I).

\section{Arteries.}

The dorsal aorta arises from the fusion of two primitive trunks running approximately parallel to the notochord, and extends as a median vessel, usually lying just dorsal to the origin of the mesentery, from the point of union of the radices back nearly to the posterior end of the body.

In human anatomy the different parts of the aortic vessels have names different from those adopted here. The persistent portion of the ventral aorta is called the ascending aorta, the persistent fourth arch is the arch of the aorta, and the adjacent part of the dorsal aorta is the descending aorta. The rest of the dorsal aorta is divided into the thoracic and abdominal aortæ, accordingly as they lie in the regions of the corresponding cavities. These terms are inapplicable in comparative anatomy.

The arteries arising from the dorsal aorta may be grouped under the two categories, visceral and somatic (p. 268). To the former belong the vessels running through the mesenterial-like structures (mesenteries, omenta, mesorchium, etc.) to supply the digestive tract and the excretory and reproductive organs. In the primitive condition those going to the alimentary canal are numerous but they do not show a metameric character. In the majority of vertebrates they become united into a smaller number of main trunks from which branches go to the various regions. The principal of these trunks are the following: There is usually present a cœliac artery, arising from the radix or from the dorsal aorta near it, and dividing in the mesogaster into gastric, splenic and hepatic arteries, distributed to stomach, spleen and liver. The superior mesenteric artery is connected in develop- 
ment with the omphalomesenteric arteries (p. 276) and goes to the anterior part of the intestine; while frequently an inferior mesenteric artery is distributed to the posterior part of the digestive tract. The superior mesenteric may fuse with the cœliac to form the cœliac axis while not infrequently other mesenteric arteries may be developed.

The hypogastric arteries, already mentioned, need further notice. These primitively connect the dorsal aorta with the subintestinal vein in the neighborhood of the anus, and later give off vessels to the region of the rectum. When, as in all classes, from the amphibia upward, a urinary bladder is developed from the rectal (cloacal) region, the

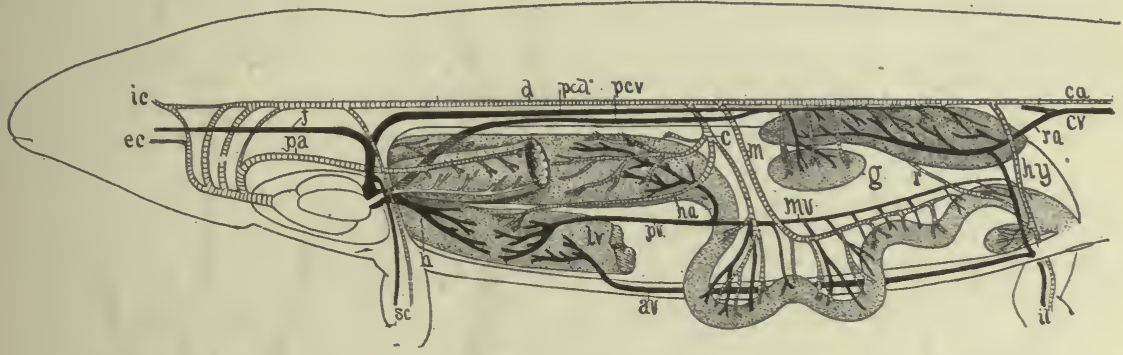

FIG. 289.-Diagram of vertebrate circulation based on a urodele. Arteries crosslined; veins black except the pulmonary vein, white. $a v$, abdominal vein; $a$, coeliac artery; $c a, c v$, caudal artery and vein; $d$, dorsal aorta; $e c$, external carotid; $g$, gonad; $h$, hepatic vein; $h a$, hepatic artery; $h y$, hypogastric artery; $i c$, internal carotid; $i l$, iliac artery and vein; $j$, jugular; $l v$, liver; $m, m v$, mesenteric artery and vein; $p a$, pulmonary artery; $p c d$, postcardinal; $p c v$, postcava; $p v$, hepatic portal vein; $r$, rectal artery; $r a$, renal advehent vein; sc, subclavian artery and vein.

hypogastrics form its blood supply, these vessels being the vesical arteries. In the amniotes the distal end of the anlage of the bladder forms a fœtal structure known as the allantois, described in another section (p. 3I8), and parts of the vesical arteries are carried out as allantoic arteries (fig. 273), into the new formation. Since these pass through the umbilicus, they are also known as the umbilical arteries. Later, when the umbilicus disappears, the allantoic arteries are lost and only the rectal and vesical arteries remain of the hypogastric trunks.

The arteries going to the excretory and reproductive organs are paired and, in the more primitive vertebrates show a marked metamerism. They are best described in details along with the urogenital structures in a subsequent section. It may be mentioned here that the metamerism is well shown in the nephridial or renal arteries going to 
the pro- and mesonephroi, while there is usually but a single pair of renal arteries to supply the metanephroi (true kidneys) of the amniotes. The arteries to the gonads may be included under the single head of genital arteries, though they are usually subdivided into the spermatic and ovarian arteries according to the sex. Like the nephridial, the genital arteries are more numerous in the lower and are reduced in number in the higher forms.

The somatic arteries are more numerous and are metamerically arranged. In the

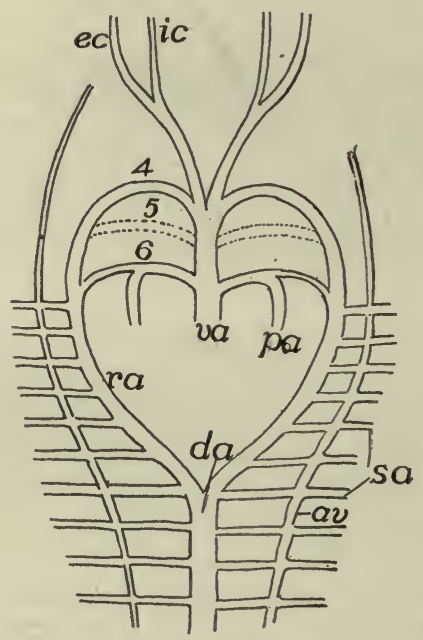

FIG. 290.

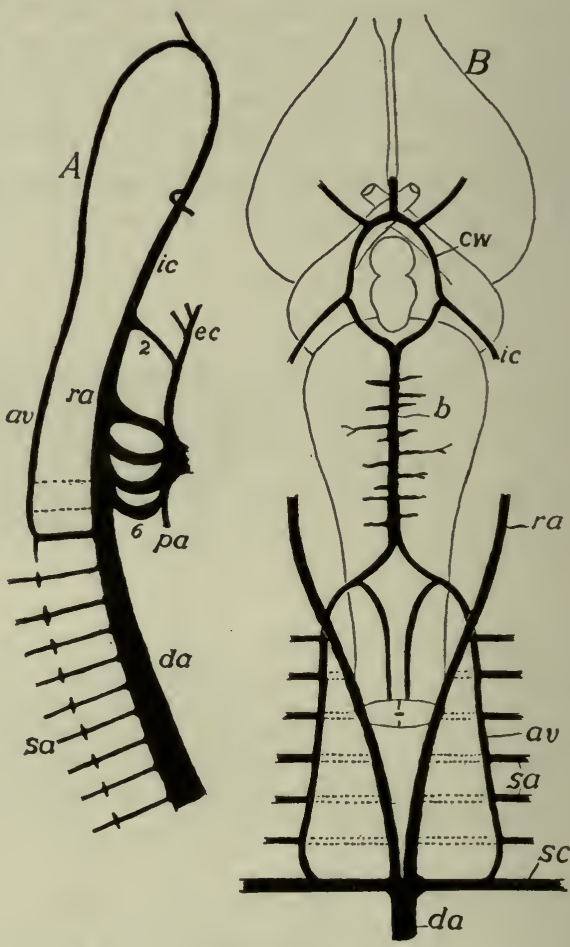

FIG. 29 .

FIG. 290.-Diagram of early relations of vertebral arteries in an amniote. $a v$, vertebral artery; $d a$, dorsal aorta; $e c, i c$, external and internal carotids; $p a$, pulmonary artery; $r a$, radix aortæ; $s a$, subclavian.

FIG. 29r.- $A$, side view of developing anterior arteries of Lacerta, after van Bemmeln; the vertebral artery not developed hehind; $B$, ventral view of the relations of the arteries at the base of the vertebrate brain. $a v$, vertebral artery; $b$, basilar artery; $c w$, circle of Willis; $d a$, dorsal aorta; $e c, i c$, external and internal carotids; $p a$, pulmonary artery; ra, radix aortæ; $s a$, segmental arteries; sc, subclavian; $2-6$, aortic arches.

early stages they are given off in pairs from the radices and the dorsal aorta, an artery on either side, extending laterally between each two successive myotomes (fig. 275). Many of these remain in a slightly modified condition and are called intercostal arteries (including lumbar and sacral arteries, etc., according to position). These usually become connected on either side (fig. 290), near their 
origin, by a longitudinal vessel, the vertebral artery, which, in the higher vertebrates, runs through the vertebraterial canal (p. 54) of the vertebræ.

In the region of the aortic roots, after the formation of the vertebral artery, all of the segmental arteries except the last of the series lose their connexion with the radix and henceforth are supplied by way of the posterior segmental and the vertebral (fig. 29I). Anteriorly the vertebral arteries pass to the ventral side of the spinal cord (or medulla oblongata) dividing there into two branches, one of which, joining its fellow of the opposite side, runs back beneath the spinal cord as a spinal artery, while the anterior branches unite in the same way to form a basilar artery, running forward beneath the medulla (fig. 29I, $B)$. At the point just behind the

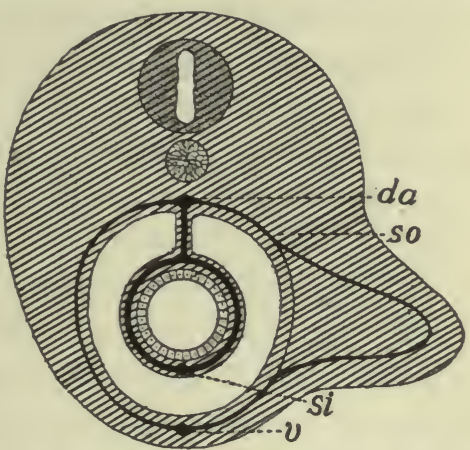

FIG. 292.-Diagram of origin of blood supply of vertebrate appendage. $v$, abdominal vein; da, dorsal aorta; si, subintestinal vein; so, somatic (segmental) vascular arch.

hypophysis the basilar divides, one-half passing on either side of that structure and receiving the internal carotid of that side. The trunks thus formed unite in front in the region of the optic chiasma. There is thus formed an arterial ring, the circle of Willis, round the hypophysis.
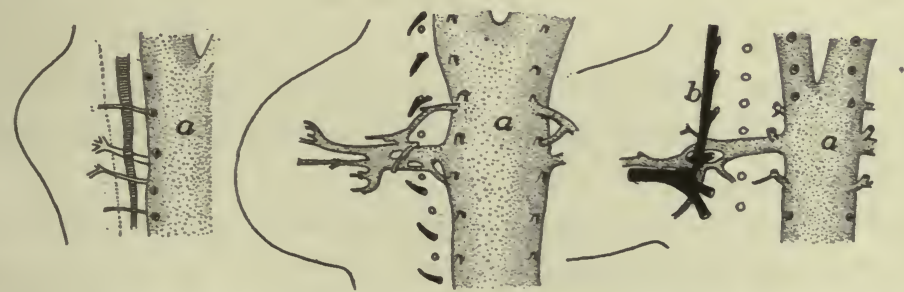

FIG. 293. - Three stages in the development of the arteries of the forelimb of the white mouse, after Göppert. $A, 8$ days; $B, 9$ days; $C$, ro days; $a$, aorta; $b$, brachial plexus. -(The vessels are extremely variable, not agreeing even on the two sides of a single individual.)

As the limbs grow out, segmental arteries, corresponding in number to the somites concerned in the appendages, grow out into the member. Distally these arteries become connected with each other and with the veins of the limb by a network of small vessels. By enlargement of 
parts of these main trunks and of the connecting network, and the partial or complete atrophy of other portions the definitive circulation of the limb is established. This explains the numerous variations in the blood supply of the limbs, both in the distal parts and in the origin of the main trunks, which may arise from the dorsal aorta or from the radices as far forward as the third aortic arch.

The main trunk of the fore limb may have different names in different parts of its course. It is the subclavian artery as it leaves the dorsal aorta, the axillary as it enters the limb, and the brachial in the upper arm. It divides near the elbow into radial and ulnar arteries, which run near the corresponding bones into the podium.

There are some additional elements of complexity in the development of the arteries of the hind leg. As in front several somatic vessels are concerned and there is the same formation of a capillary network. Two of the arteries attain special prominence. In front is the epigastric artery, which descends from the aorta to the ventral side of the body and runs forward to supply the lower portion of the myotomes, becoming connected at first with the epigastric veins, although later they may anastomose with the hinder ends of the cutaneous arteries (infra). When the hind limb grows out, the epigastric sends a branch, the external iliac or femoral artery, into its anterior side. As the leg increases in size this may surpass the parent epigastric in size, the latter now appearing as a side branch.

The second pair of somatic arteries are the sciatic (ischiadic) arteries. These descend into the posterior side of the leg, the name changing at the angle of the knee to popliteal artery, and farther down it divides into peroneal and anterior and posterior tibial arteries, the peroneal supplying the calf of the leg, the others continuing into the foot.

The arrangement of vessels thus outlined is characteristic of the lower tetrapoda where the femoral artery is small. It is also characteristic of the 'embryos of the mammals, but in the latter, before birth, the femoral artery grows down, joins the popliteal, and thus becomes the chief supply of the limb. These trunks and the hypogastric do not always remain distinct, but may fuse in different ways at the base. Epigastric and hypogastric arteries are distinct in many reptiles and in birds, but elsewhere they fuse to form the common iliac artery, so called since the proximal portion of the femoral is often called the external, the hypogastric the internal iliac artery. The sciatic, too, 
may remain distinct or it may fuse with the others at the base, and then its independent portion appears as a branch of the common iliac artery.

The dorsal aorta, which continues into the tail, is called the caudal artery behind the point where the sciatics (common iliacs) arise.

A cutaneus artery, arising from either the subclavian or the pulmonary artery of either side (both conditions occur in the amphibia), runs backward in the skin of the trunk, and may extend back and unite with the epigastric artery. When, as in the amphibia, these arise from the pulmonary they contain venous blood and the skin acts as a subsidiary respiratory organ (p. 258).

\section{VEINS.}

The position and development of the chief longitudinal venous trunks have already been outlined. Both these and other veins yet to be mentioned frequently undergo shiftings of position and other modifications during growth, but before describing these changes some other vessels must be described.

With the development of the limbs corresponding veins arise (fig. 294), a subclavian vein for each fore limb, a common iliac for the hind leg, these bringing the blood from the appendage to the trunk. In the young each subclavian empties into the postcardinal of the same side, but in the adult the opening may shift to the Cuvierian duct. The common iliac vein likewise empties into a vein, the epigastric or lateral abdominal, which runs forward in the body wall to connect with either the postcardinal or the duct of Cuvier (fig. 294, A). This condition obtains throughout life in some elasmobranchs, but higher in the scale the iliac vein, while retaining its connexion with the epigastric, grows toward the middle line and joins the postcardinal of the same side, a condition which is permanent in amphibia and reptiles (fig. 294, B, C), where blood coming from the hind limb has two routes to the heart.

The epigastric veins of the two sides may fuse in the median line in front (amphibia, some reptiles, birds), forming an anterior abdominal vein (fig. $294, C$ ) which reaches the heart by passing through the remains of the ventral mesentery (ligamentum teres) to the liver and thence forward. A similar anterior abdominal vein has been described in Echidna but is unknown elsewhere in the mammals. 
In the fishes the vessels of the appendages are but slightly developed, there being a subclavian vein entering the Cuvierian duct, and occasionally a brachial vein which may empty into the sinus venosus. In the amphibia a cutaneus magnus vein (fig. 302), coming from the skin of the trunk, may enter the subclavian, while in all tetrapoda the subclavian, after leaving the limb, receives a superficial cephalic and an axillary vein, the latter changing its name in the appendage to the
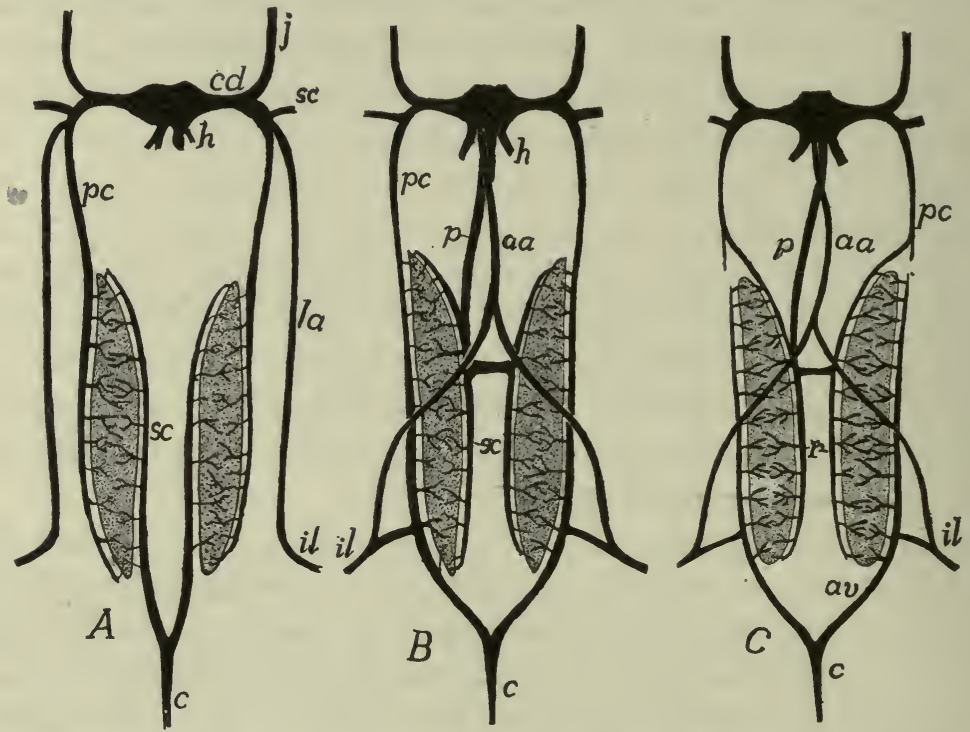

FIG. 294.- - Relations and modifications of the post- and subcardinal, abdominal and postcaval veins in different stages ot the amphibia. In $A$ the veins (il) from the hind limb return directly to the heart by the lateral abdominal veins $(l a)$, while the blood from the tail (c) passes by way of the subcardinals ( $s c$ ) through the mesonephroi to the postcardinals $(p c)$. In $B$ the lateral abdominals have united in front to form the anterior abdominal vein $(a a)$; the iliacs have sent a branch to the postcardinals, which have grown back to join the caudals, while the subcardinals have lost their connexion with the caudal and have acquired one with the postcava $(p)$, a backward growth from the sinus venosus. In $C$ the postcardinals have been interrupted, the posterior half of each now forming an advehent vein while the subcardinals, as in $B$, form the revehent veins $(r)$.

brachial vein. In the hind limb the common iliac vein is formed by the union of the femoral and sciatic (ischiadic) veins, as well as the hypogastric (internal iliac) vein already referred to.

In the classes above fishes (dipnoi, amphibia and amniotes) a new vein, the postcava (vena cava inferior) appears. This arises in part from scattered spaces, in part as a diverticulum of the sinus venosus and the hepatic veins, and grows backward, dorsal to the liver, until it meets and fuses with the right subcardinal vein (fig. 295), a 
portion of which now forms a new trunk, carrying blood from the posterior part of the body to the heart (figs. 294, 295).

With the appearance of the postcava changes are introduced in the embryonic renal portal circulation ( p. 280) which may be summarized as follows: The subcardinals lose their connexion with the caudal vein and become connected with each other by transverse vessels (interrenal veins) while parts of the postcardinals adjacent to the nephridial organs separate from the parts in front, while they grow backward
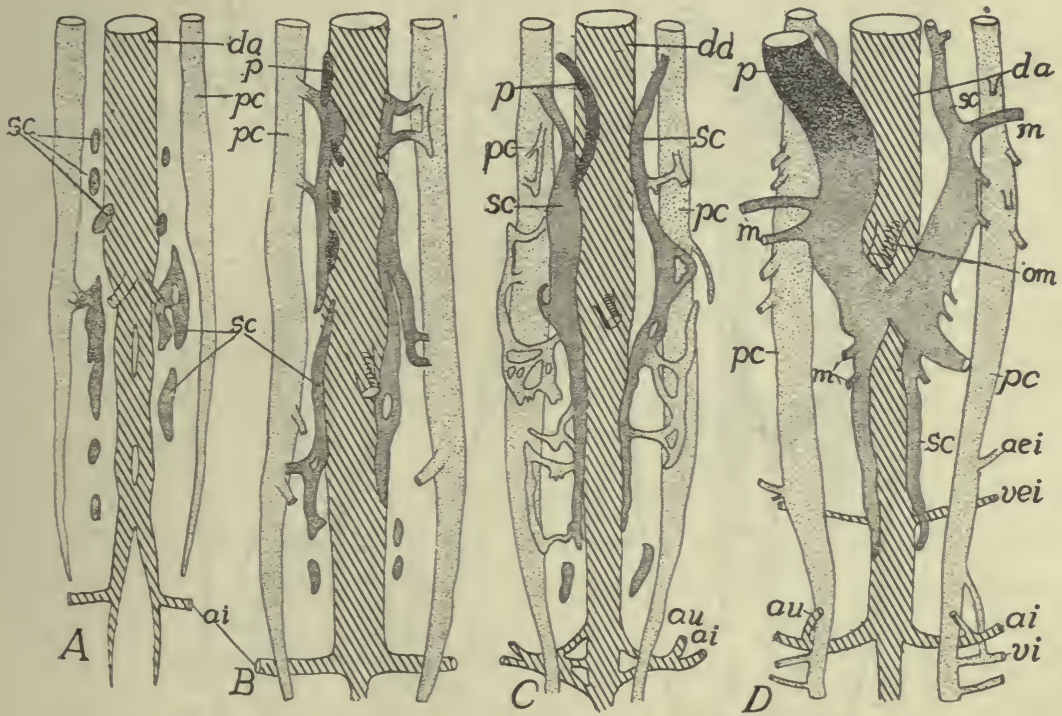

FIG. 295.-Development of postcaval system in birds ( $A, B$, sparrow; $C, D$, chick), schematized after A. M. Miller. In $A$ the postcardinals have extended nearly to the pelvic region and the subcardinals are appearing as isolated spaces. In $B$ the subcardinal spaces are uniting and the capillary system connecting with the postcardinals is developing, while the postcava is arising. In $C$ the postcava has united with the subcardinal of the right side. ai, ischiadic artery; aie, external iliac artery; au, umbilical (hypogastric) artery; $d a$, dorsal aorta; $m$, mesonephric veins; om, omphalomesenteric artery; $p$, postcava and its anlagen; $s c$, subcardinal and its elements; vei, external iliac vein; vi, ischiadic vein.

and connect with the caudal vein (fig. 295). These posterior parts of the postcardinals now become the advehent veins of a second renal portal system, bringing blood from the tail and hind limbs to the excretory organs (mesonephroi). The subcardinals of the two sides usually fuse in the middle line, a process initiated by the appearance of the interrenal veins, and now act as a revehent vessel, carrying blood from the excretory organs to the postcava and the anterior 
portion of the postcardinals which have joined the anterior ends of the subcardinals (fig. 294, C). The changes in the postcardinals and the renal portal system of mammals will be described below.

In Ceratodus (dipnoi, fig. 296, $A$ ) there are some differences from the above account. Thus the anterior portion of the right postcardinal (not shown in the figure) loses its connexion with the vessels behind and acts as a vertebral vein, taking the blood from the intercostal veins of that side back to the heart. The
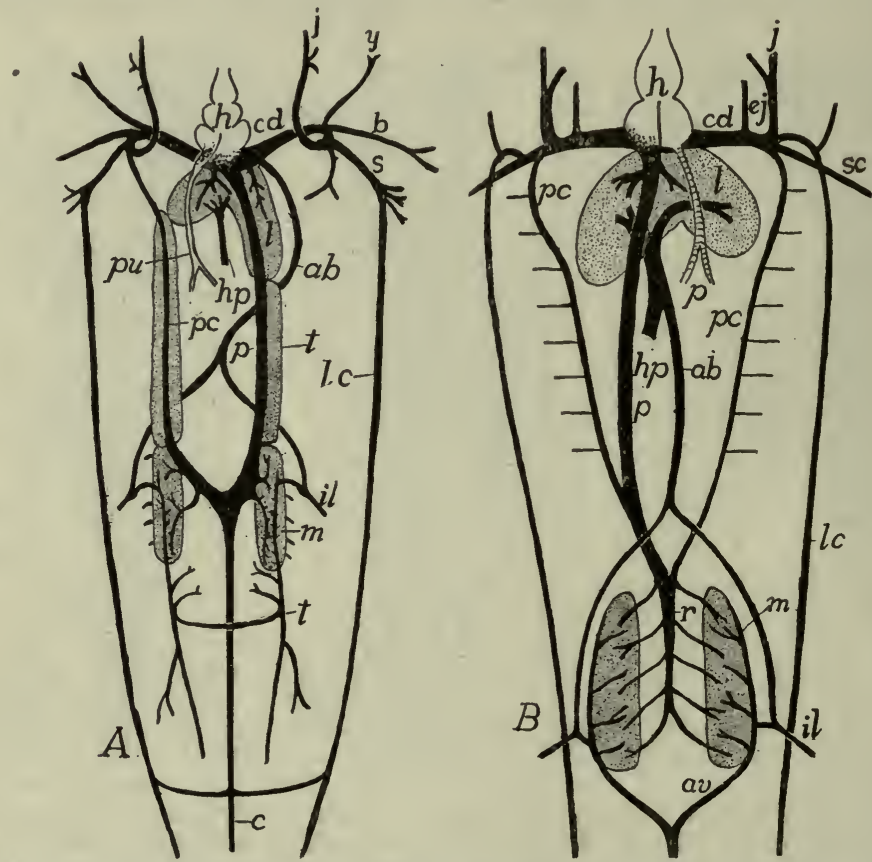

FIG. 296. - $A$, venous system of Ceratodus, dorsal view, after Spencer; $B$, of a urodele, ventral view. $a b$, abdominal vein; $a v$, venæ advehentes; $b$, brachial; $c$, caudal; $c d$, Cuvierian duct; $e j$, external jugular; $h$, heart; $h p$, hepatic portal; $i j$, inferior jugular; $j$, jugular; $i l$, iliac; $l$, liver; $l c$, lateral cutaneus; $m$, mesonephros; $p$, postcava; $p c$, postcardinal; $r$, venæ revehentes; $s$, subclavian; $t$, testes.

caudal and the subcardinals form a continuous trunk, the revehent vessels forming side branches. The posterior portions of the postcardinals grow back into the tail as paired vessels, forming no connexion with the caudal vein. In Protopterus the vertebral vein is lacking, the subcardinals are not fused behind while the advehent veins are connected with the caudal.

The development of lungs brings about the appearance of one or more pairs of pulmonary veins which bring the (arterial) blood from these organs to the heart. These arise as an outgrowth from the 
left atrial portion of the heart, dividing farther back to reach the two lungs. At no time do the pulmonary veins connect with the sinus venosus, but they. always empty into the left atrium (fig. 285).

\section{The Fœtal Circulation.}

Some features of the fotal circulation of the amniotes have already been alluded to, but the whole may be summarized here. In the amniotes, with the development of a large yolk sac and of the allantois, the vessels on the ventral side of the body become correspondingly modified. The processes involved may be readily understood from a comparison of figs. 282 and 284 . The yolk sac is to be regarded as a diverticulum of the intestine while the allantois is a similar outgrowth from the urinary bladder, itself a process of the alimentary canal. These outgrowths naturally carry with them the bloodvessels distributed to the parts from which they arise. Hence the omphalomesenteric artery and the vitelline veins (derivatives of the omphalomesenteric veins) extend out ever the yolk, increasing in number as well as in extent of their branches as the yolk sac spreads over the yolk.

In the same way the hypogastric arteries are carried out with the allantois, these portions being called the allantoic or umbilical arteries, the blood being carried back to the trunk by a single allantoic vein. These two kinds of vessels-arteries and veins-are connected in the distal part of the allantois by a rich network of capillary vessels. It is by these that the allantois is able (p. 264) to act in the sauropsida as an organ of respiration. In the mammals, by means of osmosis through the placenta, it is not only respiratory, exchanging gases with the uterine walls (there is no exchange of blood with the mother), but they serve as recipients of nourishment by the passage of plasma from the maternal tissues.

From the foregoing statements it will be seen that in the sauropsida five vessels-three arteries and two veins-pass out through the umbilicus to the fœtal adnexa, but in the mammals, where the yolk is wanting and the yolk sac reduced and transitory in character, the omphalomesenteric artery and the vitelline vein disappear early, leaving but three vessels in the umbilical cord. In the elasmobranchs, where there is a large yolk sac but no allantois, only the yolk sac circulation is found. 


\section{Circulation in the Separate Classes.}

CYCLOSTOMES present marked differences in the circulation of the two groups, the petromyzons being nearly normal, the myxinoids decidedly aberrant. The aortic arches vary in number with the number of gill pouches (p. 239). In the myxinoids the common carotid is connected with all of the efferent branchials by a

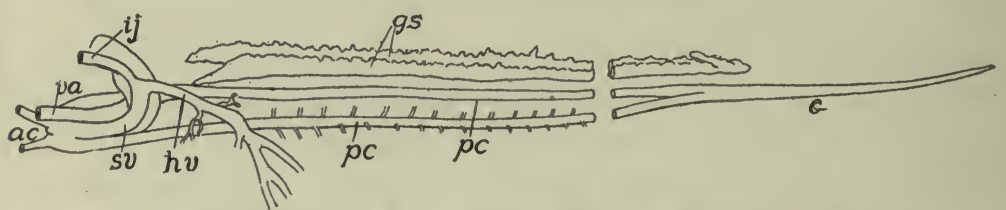

FIG. 297.-Oblique ventral view of venous system of Petromyzon, drawn from a corrosion preparation (Princeton, 669); ac, precardinal; $c$, caudal; $g s$, genital sinus; $h v$, hepatic vein; $i j$, inferior jugular; $p c$, postcardinal; $s v$, sinus venosus; $v a$, ventral aorta.

trunk running parallel to the body axis, just dorsal to the gill pouches. The intersegmental arteries of the dorsal region are irregular, sometimes alternating, sometimes appearing in pairs on the two sides of the median line. In the myxinoids (fig. 297) the subcardinals are united behind, the postcardinals in front, these latter uniting with the single inferior jugular of the left side to form the unpaired. Cuverian duct, the presence of which renders the sinus venosus asymmetrical and

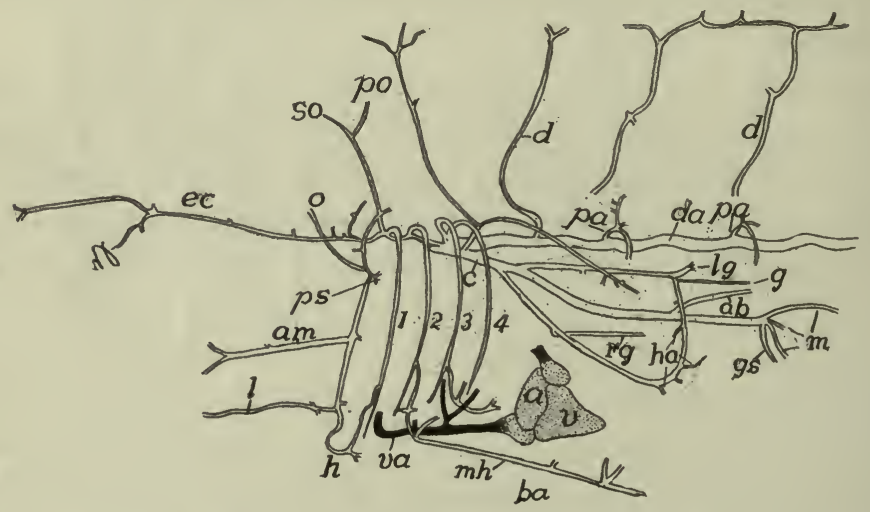

FrG. 298.-Anterior arterial vessels of the tile fish (Lopholatilus), after Silvester. $a$, auricle; $a b$, to air bladder; $a m$, to angle of mouth; $c$, coeliac axis; $d$, dorsal arteries; $d a$, dorsal aorta; $e c$, external carotid; $g$, genital artery; $g s$, gastrosplenic; $h$, hyoid artery; $h a$, hepatic; $l$, lingual; $l g$, left gastric; $m$, mesenteric; $m h$, middle hypobranchial; $o$, oph thalmic; $p a$, parietal; po, postorbital; $p s$, pseudobranch; $r g$, right genital; so, supraorbital; $v$, ventricle; va, ventral aorta.

forces the hepatic veins to empty into the right side. The hepatic portal receives a vein from the head, and then passes back to a contractile portal heart, just before it enters the liver.

FISHES. - In the fishes, the dipnoi excepted, the circulation corresponds rather closely in its main features with the primitive condition described above. The 
heart is purely venous and the only peculiarities to be mentioned are the following: In the elasmobranchs and ganoids the valves of the conus are arranged in several $(3-8)$ rows, but in the teleosts (Butyrinus excepted) they are reduced to a single row, apparently corresponding to the first of the lower forms. In the latter group the bulbus is especially well developed. The aortic arches correspond in number to the functional gill slits-six or seven in the notidanid sharks, five in other elasmobranchs and at most four in ganoids and teleosts. Paired inferior jugulars are usually present, but they are lacking in Polypterus, while in Lepidosteus and many teleosts they are united into a single trunk emptying directly into the sinus venosus. Epigastric veins are usually present and paired but are absent from many bony fishes.

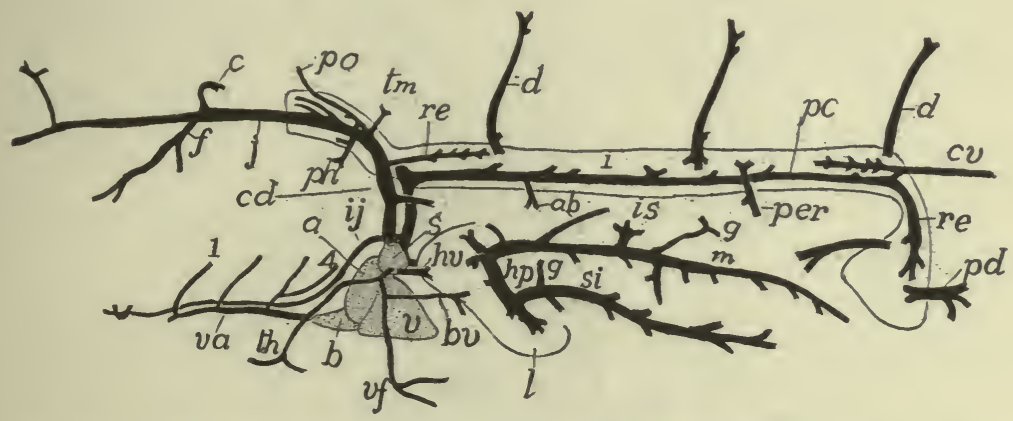

FIG. 299.-Anterior venous system and heart of Lopholatilus, after Silvester. $\quad a$, auricle $a b$, veins from air bladder; $b$, bulbus; $b v$, brachial vein; $c$, cerebral vein; $c d$, Cuvierian duct; $c v$, caudal vein; $d$, dorsal branches of parietal veins; $f$, facial vein; $g$, gastric veins; $h p$, hepatic portal; $h v$, hepatic veins; $i j$, inferior jugular; $i n$, is, veins from intestine and spleen; $l$, liver; $p c$, postcardinal; $p d$, postcloacal; per, peritoneal; $p h$, pharyngeal; $p o$, postorbital; $r e$, anterior revehentes; $s$, sinus venosus; si, veins from stomach and intestine; th, thyreoid; $t m$, thymus; $v$, ventricle; $v a$, ventral aorta; $v f$, vein from ventral fin; $w$, outline of Wolffian body.

DIPNOI.-In this group the atrium, in correlation with the development of lungs, becomes partially divided as described above. No true atrio-ventricular valves occur, their place being taken by a strong ridge which, in systole, closes the canal and at the same time partially divides the ventricle into arterial and venous halves. The conus has eight rows of valves and in Ceratodus the truncus shows the beginning of a division (completed in Protopterus) separating the arterial from the venous arches. For veins, see fig. 296.

AMPHIBIA. - In the amphibia the division of the atrium by a septum atriorum into right (venous) and left (arterial) halves is carried farther. This septum is fenestrate in urodeles and gymnophiones, entire in anura, but in none is it carried clear to the atrio-ventricular wall. In systole the edge of the septum is forced forward, completely separating the two atria. No corresponding septum is developed in the ventricle, but numerous muscular bands extending through its cavity tend to prevent the mingling of arterial and venous blood. In Proteus, Cryptobranchus and the cæcilians the bulbus is simple but in the other urodeles and the anura a spiral septum (possibly representing fused valves) is developed in it, separating it 
into two tubes. This is continued in the anterior part of the truncus by a horizontal septum (short in urodeles, longer in anura) separating aortic and pulmonary trunks, the former subdivided in a similar way a little farther forward into carotid and aortic portions.

In the early larvæ of the amphibia each fully developed aortic arch except the last extends into the gills, but as the branchiæ begin to be absorbed, a small vessel connecting the afferent and efferent arteries at the base of each gill enlarges and

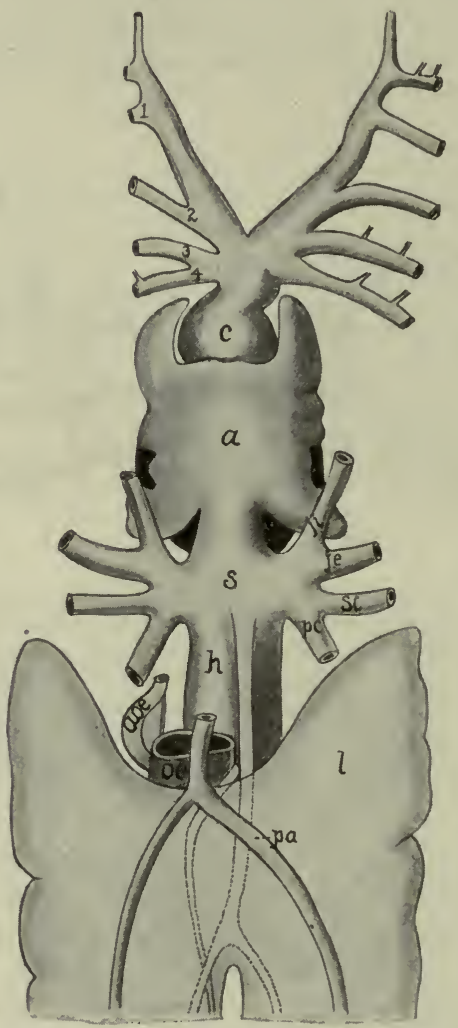

FIG. 300.- Heart and adjacent parts of Protopterus, after Röse a, atrium; aoe, osophageal artery; $l$, air bladder (lung); $c$, conus; $h$, hepatic vein; $j i$, $i s$, superior and inferior jugular veins; $o e$, œsophagus; $p a$, pulmonary artery; $p c$, postcardinal vein; $p h$, pharyngeal artery; $s$, sinus venosus; sc, subclavian vein; $1-4$, afferent branchial (aortic) arteries.

becomes the path of the main blood stream and a part of the arch of the adult (fig. 304). Of these four arches-3, 4, 5, and 6 of the primitive scheme-the fifth is lost in the adults of all except a few urodeles and cæcilians. The fourth connects with the dorsal aorta and the sixth with the pulmonary arteries. These last, which often have a ductus Botallii, are noticeable for the large cutaneus arteries-anterior and posterior-which arise from them and which play an important part in respira- 
tion. Connected with the carotid arteries are the carotid glands (fig. 304). In the larval stage each consists of a network of blood-vessels-a rete mirabilebetween the afferent branchial and the carotid artery, but in the adult this degener-

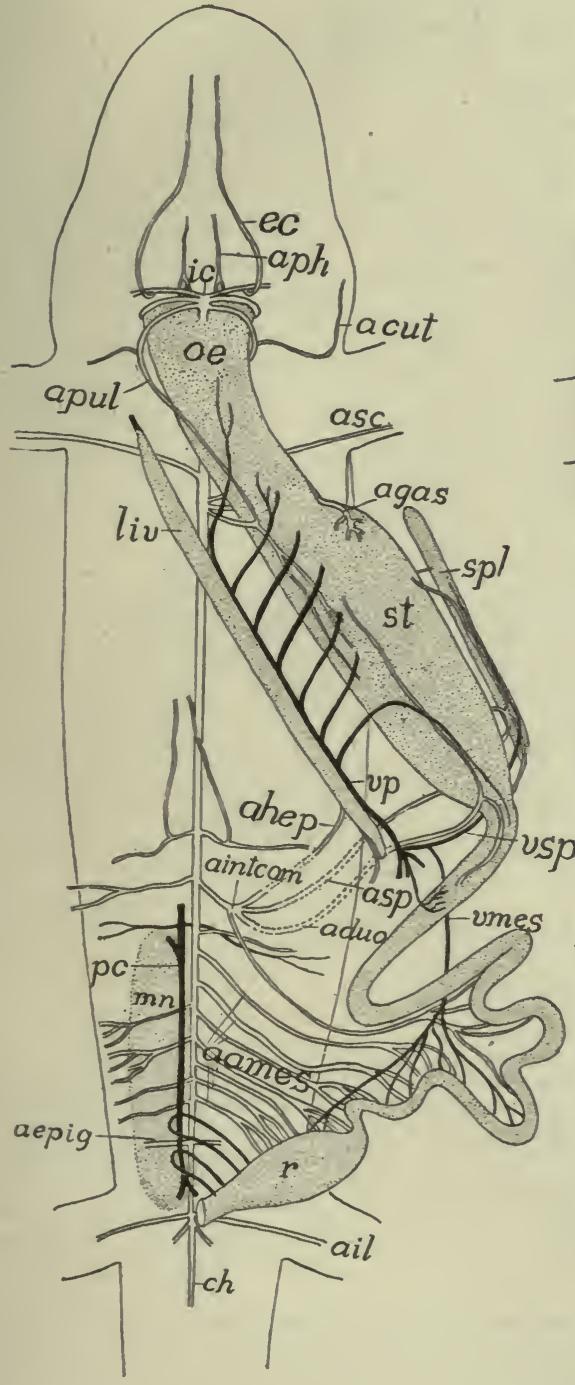

FIG. 3or.

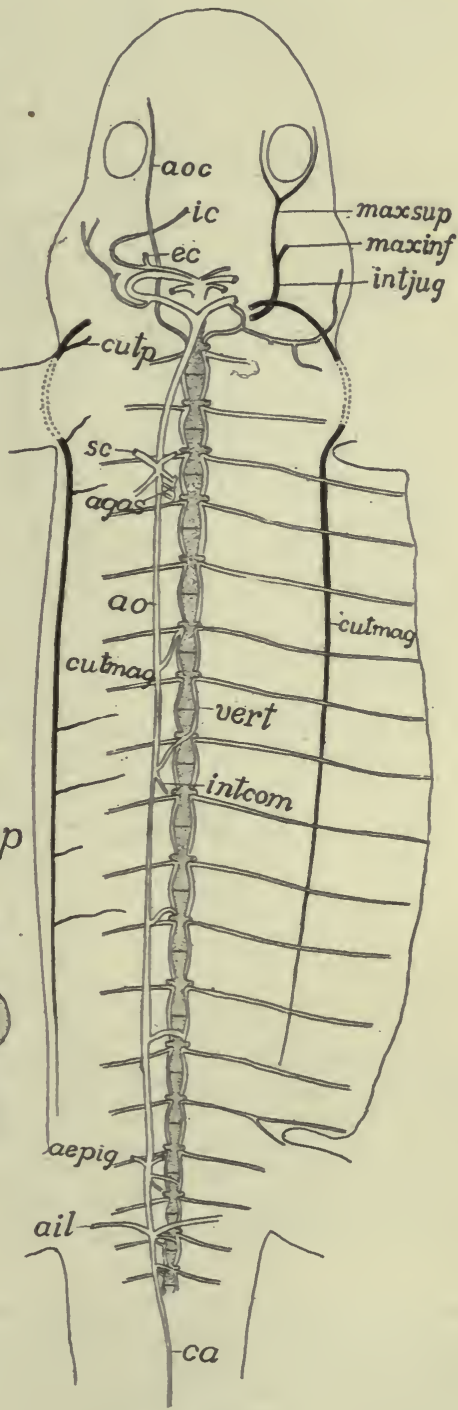

FIG. 302 .

ates into a small muscular organ containing sympathetic cells ( $\left.\dot{\mathrm{p}} . \mathbf{\sigma}_{5}\right)$, at the base of the carotid.

The postcava is well developed and the epigastric veins unite to form an anterior 


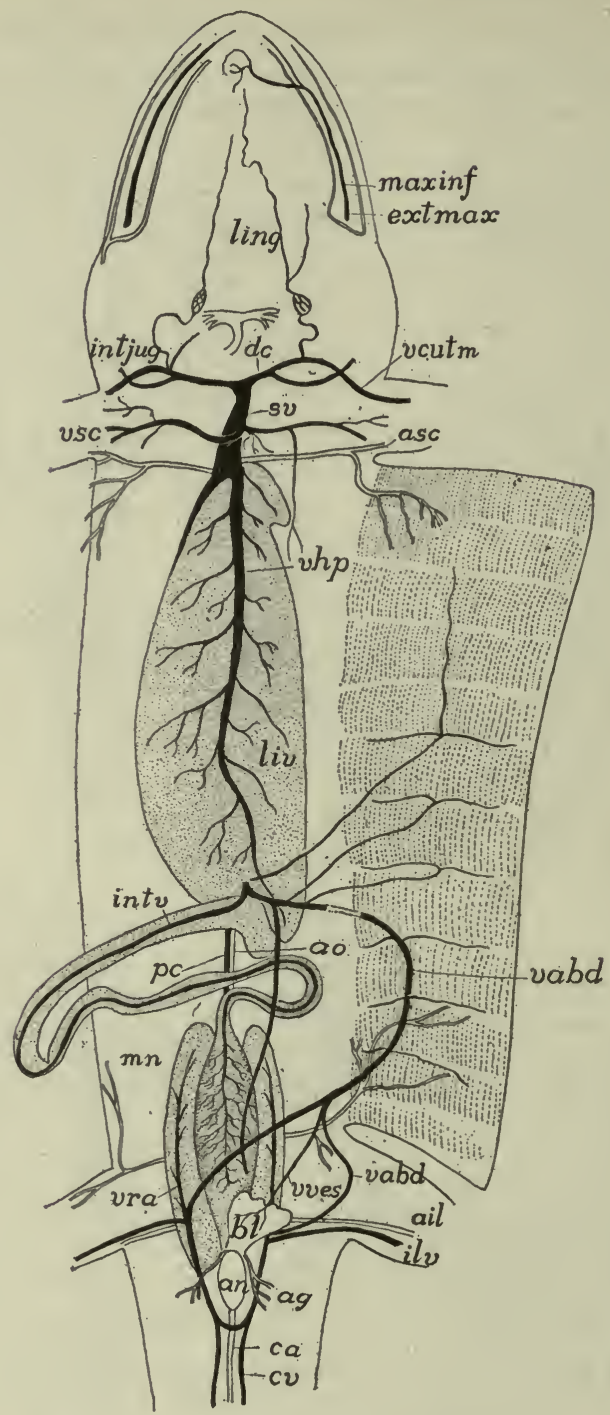

FIG. 303 .

FIGS. 301, 302, 303.-Circulatory system of Desmognathus fuscus after Miss Seelye; fig. 301 , superficial vessels; fig. 302, deeper vessels; fig. 303 , vessels of the dorsal body wall; all from the ventral surface. aames, mesenteric arteries; acut, cutaneus artery; aduo, duodenal artery; aepig, epigastric artery; ag, artery to anal gland; agas, gastric arteries; ahep, hepatic artery; ail, iliac artery; ainicom, communis intestinal artery; ao, aorta; aoc, ocular artery; $a p h$, pharyngeal artery; an, anus; apul, pulmonary artery; asc, subclavian artery; $a s p$, splenic artery; $b l$, urinary bladder; $c a$, caudal artery; cutmag, cutaneus major vein; cutp, cutaneus parva vein; cv, caudal vein; $e c$, external carotid; extmax, external maxillary; ic, internal carotid; ilv, iliac vein; intcom, common intestinal; intjug, internal jugular; intv, intestinal vein; ling, lingual; liv, liver; $\operatorname{maxinf,~} \operatorname{maxsup}$, inferior and superior maxillaries; $m n$, mesonephros; $\alpha$, œsophagus; $p c$, postcava; $r$, rectum; $s p l$, spleen; $s t$, stomach; $s v$, sinus venosus; $v a b d$, abdominal vein; vcut, cutaneus vein; vhp, hepatic vein; vert, vertebral artery; vmes, mesenteric vein; $v p$, portal vein; vra, vena renalis advehentis: vsp, splenic vein; vves, vein from bladder. 
abdominal vein (fig. 294), while the blood from the hind limbs may return to the heart through either the anterior abdominal or the renal portal system.

In the lungless salamanders (p. 258) the heart and blood-vessels show corresponding modifications. There is no septum atriorum and the pulmonary arteries and veins fail to develop. The cutaneus arteries and the smaller vessels supplying the pharyngeal region are greatly enlarged, respiration taking place through the skin and the mucous membrane of the throat.

The action of the anuran heart may be outlined here. The two atria contract at the same time, forcing arterial and venous blood into the ventricle, but it is kept from mixing by the muscular bands already alluded to. At the systole of the ventricle the venous blood, which is nearest the truncus, is first forced forward. This takes the most direct course through the wide and shorter pulmonary arteries, which are prac-

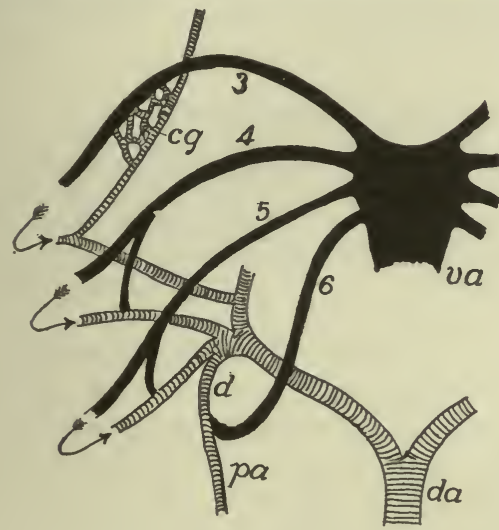

FIG. 304 .

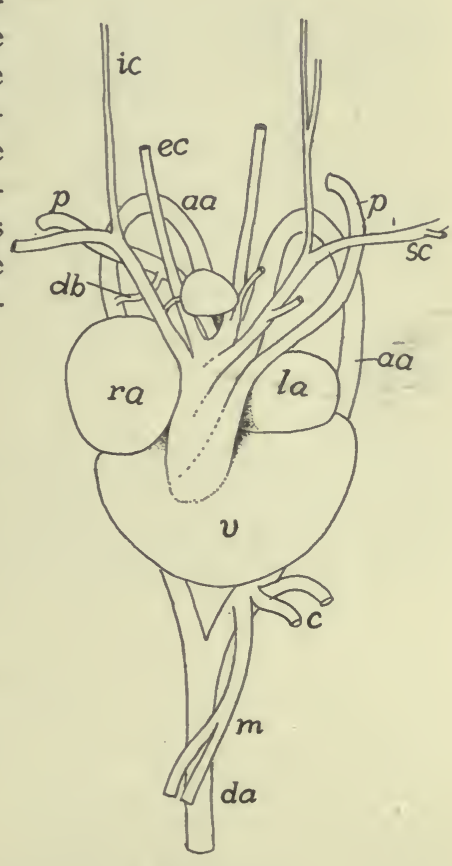

Fig. 305 .

FIG. 304.-Diagram of the aortic arches in amphibia. Arterial blood cross lined, venous black. The gill circulation omitted, its course indicated by arrows; the permanent circulation after the absorption of gills shown. $c g$, carotid gland; $d a$, dorsal aorta; $d$, ductus Botalli; $p a$, pulmonary artery; va, ventral aorta; $3-6$, aortic arches.

FIG. 305.-Heart of snapping turtle, Chelydra serpentina (Princeton, 479). aa, aortic arch; $c$, coliac artery; $d a$, dorsal aorta; $d b$, Botall's duct; $e c$, $i c$, external and internal carotids; $l a$, left auricle; $p$, pulmonary artery; $r a$, right auricle; $s c$, subclavian artery; $v$, ventricle; $m$, mesenteric artery.

tically empty at the time. The next portion of the blood, containing both arterial and venous, follows the next easiest course through the aortic arches, while the last to leave the ventricle, consisting of pure arterial blood, can only go into the carotids, where the resistance is greater on account of the small size of the vessels and the obstacles presented by the carotid glands.

REPTILES. - In the reptiles the division of the heart (fig. 287 ) is carried still farther and the sinus venosus tends to be merged in the right atrium. The atrial septum is complete and is continued forward as a ventricular septum, partially 
(Sphenodon, turtles, squamata) or completely (crocodiles) separating the two ventricles. The peculiar relations of the aortic arches have been mentioned (p. 283). Correlated with the differences between the aortic (fourth) arches of the two sides in the majority of reptiles are certain features in the origin of the arteries. Thus both of the subclavian arteries (lacking in snakes) arise from the right radix, while the left gives rise to the cœliac artery. In many reptiles the anterior parts of the postcardinals are replaced by vertebral veins. The renal portal system is developed in the embryo and persists (much as in the amphibia) to a greater or less extent in the adult. Usually paired anterior abdominal veins are present.

BIRDS.- The peculiarities of the heart and aortic arches were mentioned on page 283. Birds have the same reduction of the postcardinals as is found in reptiles. The renal portal system is formed in the embryo, but the only blood received by the adult kidney comes through renal arteries like those of mammals. The iliac veins extend to the postcava and lose all connexion with the anterior abdominal veins. The paired epigastric veins persist only in front.

MAMMALS.-In the mammals the four chambers of the heart are completely separated and the sinus venosus has been completely merged in the right atriumt The persistent left fourth aortic arch forms the sole connexion between the hear.

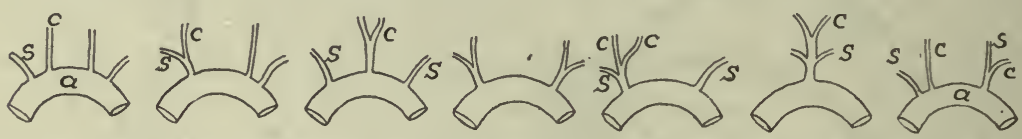

Frg. 306.-Modifications of the origin of the carotid and subclavian arteries in mammals.

and the dorsal aorta and from it arise the carotid and subclavian arteries, the arrangement of these representing almost every possible condition (fig. 306). In the lower groups (e.g., rodents) both Cuvierian ducts persist, but in the higher orders a cross connexion (the innominate vein) arises between the trunks formed from the jugulars and subclavian veins of the two sides (fig. 308) so that the blood from the left side of the head, neck and fore limb joins that of the left side in a common trunk, the precava (anterior vena cava) which enters the right atrium. With this development the left Cuvierian duct, as such, disappears.

The renal portal system has but a transitory existence in the embryo (best developed in the monotremes) and early disappears with the degeneration of the Wolffian bodies (mesonephroi). As these organs disappear a part of the capillary system of the Wolffian bodies enlarges and forms a main trunk connecting the postcava with the posterior parts of the postcardinal veins (fig. $307, C$ ) which bring the blood from the tail, the iliacs and the permanent kidneys. With farther development $(D, E)$ the left postcardinal is largely lost (except the part connecting with the suprarenal and gonad of that side) and all the blood from the posterior part of the body is returned by the right postcardinal and the postcava, which appear (fig. $308, A)$ as if they arose from a union of the iliac veins. Correlated with these changes in the venous system and the impossibility of venous blood entering the excretory organs, there is developed a renal artery from the aorta for each of the permanent kidneys. 

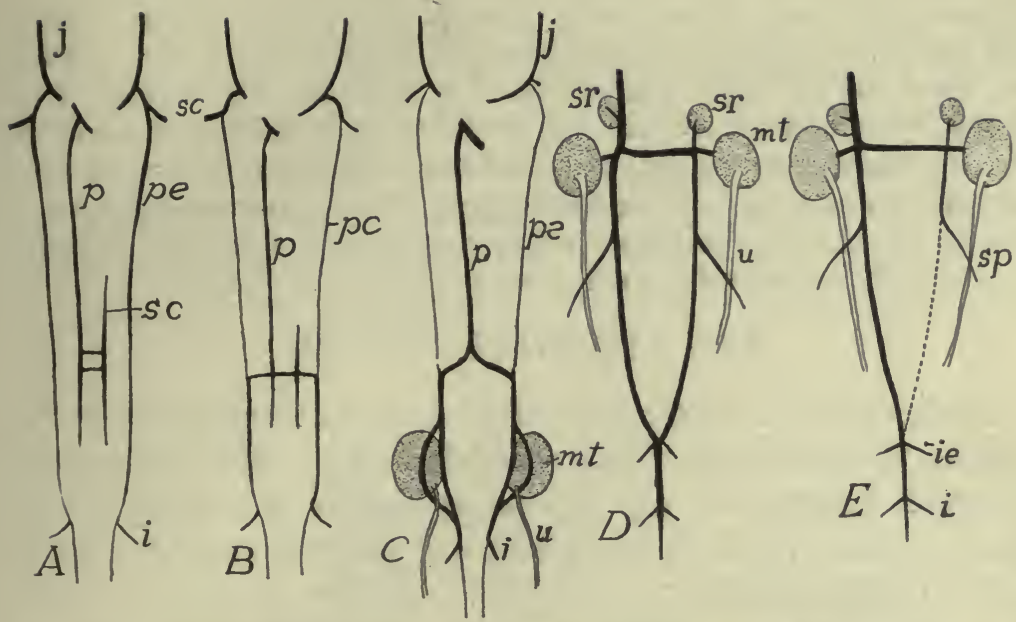

FrG. 307.-Development of posterior veins of rabbit, after Hochstetter. $C$ and $D$ represent only the hinder part of the whole shown in $A$ to $C$. In $B$ the veins for the postcavalsubcardinal system have tapped the postcardinal veins, which in $C$ have lost their connection with the anterior part and empty now through the postcava exclusively. In $E$ the left posterior postcardinal is entirely lost. $i$, ischiadic vein; $i$, external iliac; $i$, jugular; $m t$, metanephros (kidney); $p$, postcava; $p c$, postcardinal; $s$, subclavian; sc, subcardinal: $s r$, suprarenal; $u$, ureter.

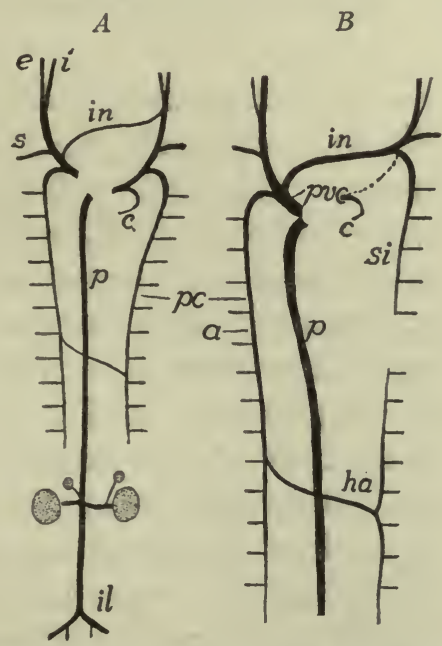

FIG. 308.-Development of the anterior veins of a mammal. $A$, earlier stage, to be compared with fig. $307 C$; $B$, definitive condition of adult. $a$, azygos; $c$, coronary; $e, i$, external and internal jugular; $h a$, hemiazygos; $i l$, iliac; in, innominate; $p$, postcava; $p c$ postcardinal; prc, precava (superior vena cava); si, superior intercostal veins. 
The anterior parts of both postcardinals have separated from the posterior por tion and receive only blood coming from the intercostal veins (fig. 308). A cross vessel now connects the posterior parts of the postcardinals of the two sides, after which the left vessel separates into two portions. The anterior of these (fig. $308, B$ ) connects with the heart by way of the jugular and innominate vein and forms the superior intercostal vein of human anatomy. The rest of the left postcardinal is now known as the hemiazygos vein and it returns blood from the trunk by way of a cross connexiop and the anterior part of the right postcardinal (now called the azygos vein), to the precava and so to the heart.

\section{THE LYMPHATIC SYSTEM.}

The lymphatic system consists of (I) a series of lymph vessels which penetrate all parts of the body; (2) of pulsating portions of these vessels, the lymph hearts; and (3) peculiar aggregates of connective tissue, leucocytes and lymph vessels which are grouped under the general head of lymph glands.

There are different views as to the morphology of the blood and lymph systems. According to one (Marcus) the lymph vessels were primitively connected with the cœlom and have only secondarily come into relations with the blood-vascular system. Others think that both blood and lymph vessels have arisen from extracœlomic spaces, from which, by modification and specialization, the two systems have been differentiated. The fact that in many invertebrates there is but a single system, best compared with the lymph system of the vertebrates, and that, even in the crustacea, lymphatic and blood systems are but partially differentiated, is of interest in this connexion.

The lymph vessels are, in part, capillary in character with walls of endothelium alone. The larger ducts and the still larger sinuses are strengthened by smooth muscle fibres and by elastic and fibrous tissue. The capillaries have numerous anastomoses, but the vessels are said to terminate blindly, while, at least in the higher vertebrates, some may connect with the cœlom by minute openings (stomata) in the peritoneal lining. The larger vessels have valves at intervals to prevent backflow of the lymph, these often giving the vessels a lobulated appearance. Proximally the vessels open at two or more points into the veins. The fluid portion of the lymph is derived in part by osmose from the walls of the blood capillaries, in part from the alimentary canal.

The development of the lymph vessels has been traced mainly in birds and mammals (chiefly in the latter), with fewer observations on amphibia and other classes. Many points remain to be worked out, there being considerable differences in the various accounts. Apparently the process in its main features is as follows: 
Near the junction of pre- and postcardinals on either side numerous small diverticula are given off from the lateral side of these veins (fig. $309, A)$. These diverticula unite with each other, forming small tubes parallel to the parent vessels and united to them for a time at numerous points where the budding took place. Later these connexions are lost and the tubes are separated from the veins (fig. 309, $B$ ) forming an anterior cephalic duct, extending forward, parallel to the jugular vein; an ulnar lymphatic duct destined to grow into the fore limb; and, a little later, a thoracic duct grows back, parallel to the
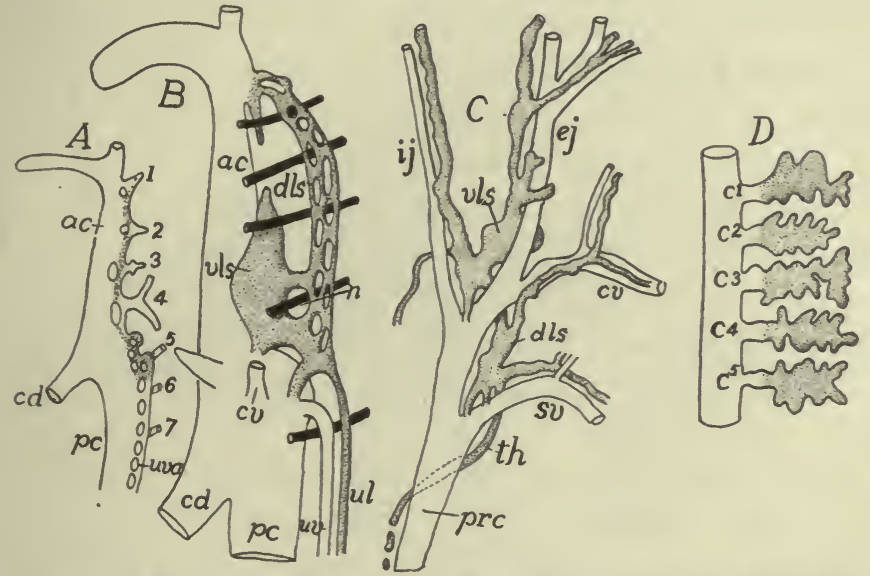

Fig. 309.-Early development of the lymph vessels in the cat, after McClure and Huntington. $A$, in $6.5 \mathrm{~mm}$. embryo; $B$, in 10.5 $\mathrm{mm}$. embryo; $C$, definitive stage; $D$, diagram of developing diverticula of chick which are to form lymph heart, based on Sala. $a c$, anterior cardinal vein; $c^{1} \iota^{5}$, coccygeal veins; $c d$, Cuverian duct; $c v$, cephalic vein; $d l s$, dorsal veno-lymphatic sinus; $e j, i j$, external and internal jugulars; prc, precava; $t$, thoracic duct; $u l$, primitive ulnar lymphatic; $u v a$, anlage of ulnar vein; vls, ventral veno-lymphatic sinus; $1-7$, segmental vessels; lymphatic-forming tissue stippled.

postcardinal vein. All of these vessels are united near their point of origin by a large sinus, the jugular lymph sac (fig. 309, C). Later the lymph sac reestablishes communication at one or two points in the subclavian-jugular region with the vein.

The conditions at the posterior part of the body are less certainly known (fig. $309, D$ ). In this region a cistern of chyle (a mesenterial lymph sac) and a posterior lymph sac develop in close connexion with the postcava in the region of the nephridial organs, and it is possible that a portion of the thoracic duct grows forward from the cistern of chyle, while other vessels grow into other regions. Later the primitive trunks thus outlined give off branches which gradually ex- 
tend into all parts of the body, but of their development little is known. Anastomoses occur between the vessels of the two sides of the body and not infrequently the thoracic duct of one side shows more or less degeneration, resulting in a lack of symmetry in the adult.

Not enough is known of the distribution of the lymphatic trunks to render broad generalizations possible, but it may be said that the system is most extensively developed in the subcutaneous tissue, in the corresponding envelopes (meninges) of the central nervous system, in the intermuscular connective tissue, in the walls of the alimentary canal, and, as a network, in close connexion with the blood-vessels of the body.

The lymph hearts are enlarged and contractile portions of the lymph vessels, provided with valves to prevent backflow of the fluid (fig. 310). Usually these contract by means of the intrinsic muscles of the walls, but in some urodeles ( $\mathrm{Am}$ blystoma) there is an unpaired lymph heart beneath the truncus arteriosus which enlarges and contracts with the systole and diastole of the blood heart.

As was intimated above there is a constant osmosis of fluid from the blood capillaries into the surrounding tissues. This finally passes into the distal capillaries of the lymph system, while in the walls of the alimentary canal there are, in addition, the results of the digestive processes

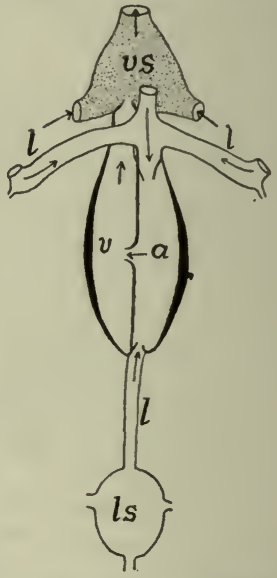

Fig. 3ro.-Scheme of caudal lymph heart of teleost, after Favaro. $a$, a trium; $l$, lymph vessels; $l s$, lymph sinus; $v$, ventricle; $v s$, venous sinus of caudal vein. added to the fluid in the lymph vessels. As this latter portion has a milky appearance, due to the contained fat, it is called chyle and the lymphatics which contain it are called lacteals and chyle ducts. All of these additions to the contents of the lymph vessels make a current in the larger lymph trunks, and finally the whole of the lymph is returned to the veins by the several connexions already mentioned. In addition to the propelling force of the lymph hearts and the pressure due to absorption and osmosis, the lymph is also carried along by the motions of the parts in which the vessels ramify, their pressure being supplemented by the action of the valves.

In those fishes which have been accurately studied the lymph system is well developed and opens into the veins in the cardiac and caudal regions. The vessels are especially developed in the tail, where (myxinoids, teleosts) lymph hearts occur. 
There is also a large lymph sinus in the scapular region into which the trunks from head and body empty. Frequently there is also a large caudal sinus (physostomes) connected with a lymph heart (fig. 310 ) which forces the lymph into the caudal vein.

The urodeles have the thoracic ducts united behind but separate in front, a cephalic trunk emptying into each, and each duct opening into the corresponding subclavian vein, while a series of from fourteen to twenty lymph hêarts occur in connexion with the trunk accompanying the lateral line. The anura are noticeable for the complete disappearance of the thoracic ducts, their place being taken by a

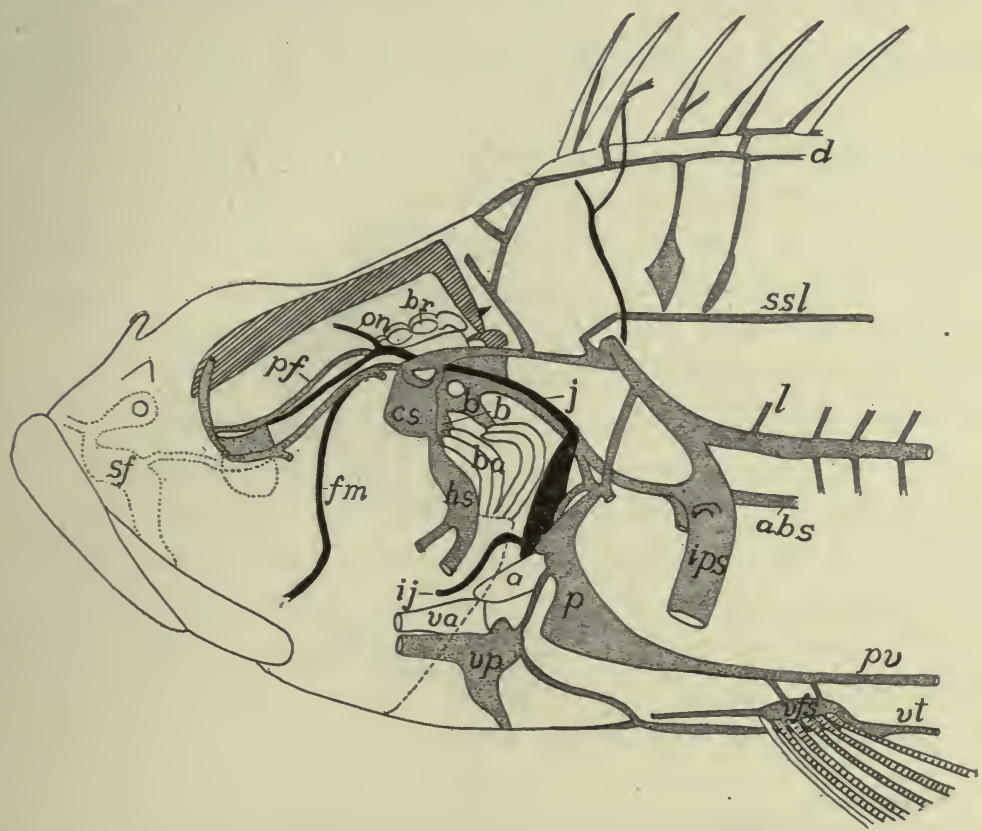

FIG. 3II.-Deeper anterior lymphatics (stippled) of Scorpenichthys, after Allen. $a$, auricle; $a b s$, abdominal sinus; $b$, brachial sinus; $b r$, brain; $c s$, cephalic sinus; $d$, dorsal trunk; $f m$, facialis-mandibularis vein; $h s$, hyoid sinus; $i j$, inferior jugular vein; $i p s$, inner pectoral fin sinus; $j$, jugular vein; $l$, lateral trunk; on, orbito-nasal vein; $p$, pericardial sinus; $p f$, profundus facialis lateral trunk; pv, profundus ventral trunk; $s f$, superficial lateral trunk; $s s l$, superior spinal longitudinal trunk; $v$, ventricle; $v a$, ventral aorta; $v f s$, ventral fin sinus; $v p$, ventral pericardial sinus; $v t$, ventral abdominal trunk.

pair of trunks between the dorsal myotomes and those of the lateral body wall. They have also enormous subcutaneous lymph spaces, separated from each other by narrow partitions. It is the presence of these large spaces that makes the skinning of a frog such an easy matter. Two pairs of lymph hearts are present, one pair in the neighborhood of the extremity of the urostyle, the other between the transverse processes of the third and fourth vertebræ. In the cæcilians there is a pair of lymph hearts for each segment of the trunk.

Reptiles have two cephalic lymph trunks and one (lizards) or two thoracic 
ducts, the one of the lizards being divided in front so as to empty into either subclavian vein. There is a single lymph heart at the junction of trunk and tail. In the birds both thoracic ducts occur and there is a pair of lymph hearts present in the young in the position occupied by the single heart of the reptiles.

In the mammals the primitively paired thoracic ducts are sometime retained throughout life, but usually only one persists. This begins at the cistern of chyle in the lumbar region and empties into the left brachiocephalic vein near the entrance of the single cephalic duct. The thoracic duct receives the lymph vessels from the limbs and those (lacteals) from the alimentary canal. In those cases where there

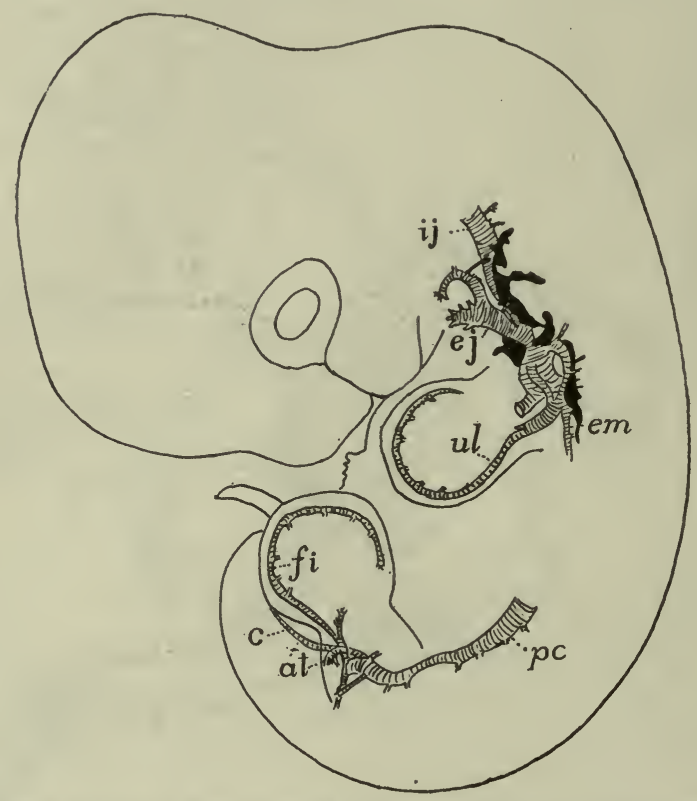

FIG. 312.-Early lymph system (black) of to mm. rabbit embryo, after F. T. Lewis. at, anterior tibial; $c$, caudal; $f i$, primitive fibular; $e j, i j$, external and internal jugular; $e m$, external mammary; $p c$, postcardinal; $u l$, primitive ulnar veins.

is but a single thoracic duct in front, its representative on the right side is a much smaller vessel connected with the right side of the venous system. No lymph hearts are known in the mammals. The jugular lymph sacs of the embryo have been regarded as such, but the absence of valves and muscles in the walls renders such an interpretation doubtful.

Lymph Glands.--In connexion with the lymph vessels are numerous structures included under the heads of lymph glands, lymph nodules and blood-lymph glands. These are most abundant in the walls of the cœlom (mesenteries) and of the digestive tract, although they may be found at remote points. They consist of aggregates of 
adenoid tissue (reticular connective tissue crowded with leucocytes). Well-known among these structures are the so-called fat bodies (corpora adiposa) connected with the gonads of the amphibia, and the 'hibernating glands' of some rodents and insectivores, which consist of richly vascularized masses of fat. In the lymph nodules this adenoid tissue is enmeshed in a rete mirabile of lymph vessels. In the blood-lymph glands there is a somewhat similar relation to bloodvessels as well, for the details of which reference must be made to histological text-books. These lymph structures, which occur at various points of the body, are apparently places for the formation of leucocytes (lymphocytes).

The spleen, attached to the mesentery near the stomach and pancreas, is intermediate in some respects between lymph and bloodlymph glands and is the largest lymph structure in vertebrates. It is developed in the walls of the alimentary canal and is said to have an entodermal origin. Later it separates from the stomach and assumes its definitive position. It serves, apparently, as a place for the disintegration of the red blood corpuscles in addition to functioning as a leucocyte-forming organ.

The tonsils (p. 247) belong to the category of adenoid glands. There are two kinds of these, the pharyngeal and the palatine tonsils, the latter occurring between the inner ends of the Eustachian tubes of amniotes, the palatine (best developed in mammals) are paired structures on either side of the pillars of the fauces. Other tonsil-like structures occur at different points of the floor and roof of the mouth of the tetrapoda.

\section{THE UROGENITAL SYSTEM.}

In several phyla of the animal kingdom there is an intimate relation between the reproductive and excretory organs, the ducts of the latter serving either to carry the products of the gonads directly to the exterior or acting as brood organs where a portion of the development of the egg takes place. This close association of the two systems is especially marked in most vertebrates and hence this section is headed Urogenital System, because of the difficulty of treating the two components separately.

The urinary or excretory organs have for their purpose the elimination of the nitrogenous waste (and occasionally other products) from 
the system. They are paired organs which consist of glandular portions, the nephridia. (kidneys), and their ducts. The reproductive organs include the gonads or sexual 'glands,' which (ovaries) produce the eggs or (testes) the spermatozoa, and the passages by which these products are carried to the external world. To these are frequently to be added accessory reproductive structures by which, in certain cases, the sperm is transferred to the female.

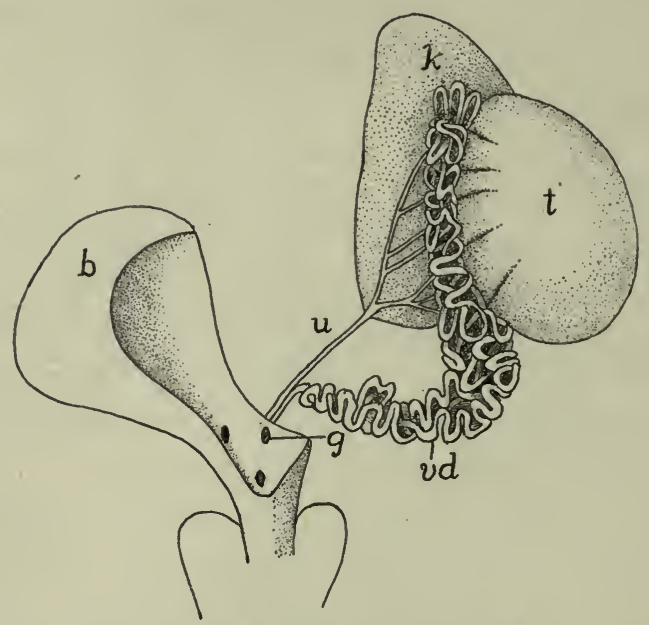

FIG. 313.-Urogenital organs of Emys europea, after Bojanus. b, urinary bladder; $g$, opening of vas deferens into the urogenital sinus; $k$, kidney; $t$, testis; $u$, ureter; $v d$, vas deferens.

\section{THE EXCRETORY ORGANS.}

The nephridia consist of a series of excretory tubules, specialized in different ways, and of the ducts into which the tubules empty. As the function of the nephridia is the elimination of the nitrogenous waste (uric acid, urea, etc.) which accumulates in the blood, they have an abundant blood supply, entirely derived, in the younger stages of all vertebrates and in the adults of the higher groups from the dorsal aorta, while in the later developmental stages and in the adults of most anamniotes the aortic blood is supplemented by blood coming from the tail and hind limbs by way of the caudal and iliac veins (fig. 303).

In its extreme development one of the excretory tubules may consist of the following parts (fig. $3^{14}$ ): At the proximal end the tubule opens into the cœlom (metacœle) by a ciliated funnel, the nephro- 
stome; the cilia, which may continue for some distance along the inside of the tubule, serving to create a current which carries the cœlomic fluid into the tubule and thence outward. Farther along the tubule expands into a Malpighian or renal corpuscle (fig. 315). This consists of a vesicle (Bowman's capsule), one side of which

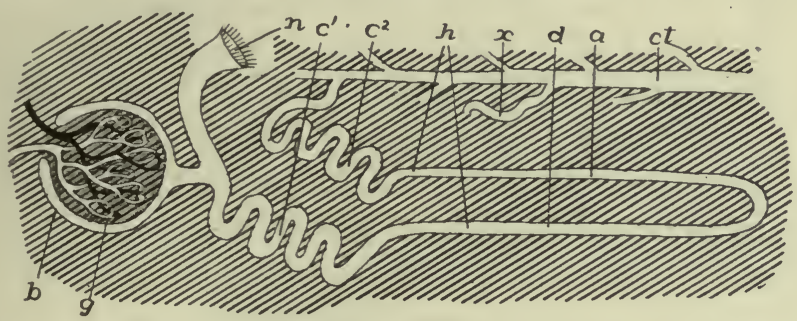

FIG. 3I4.-Diagram of conventionalized excretory tubule. $a$, ascending limb of Henle's loop; $b$, Bowman's capsule of Malpighian body; $c^{2}-c^{2}$, first and second convoluted tubules; $c t$, collecting tubule; $d$, descending limb of Henle's loop; $g$, glomerulus of Malpighian body; with artery and vein; $h$, Henle's loop; $n$, nephrostome opening into colom; $x$, entrance of other tubules into collecting duct.

projects into the other, nearly filling the cavity. This inturned portion is the glomerulus. It consists of a network of capillary blood-vessels, supplied by an artery and drained by a vein. Beyond the connexion of the Malpighian body the tubule becomes contorted or convoluted and its cells are strongly glandular in character. This first convoluted tubule is succeeded by a nearly straight tract, folded once on itself into

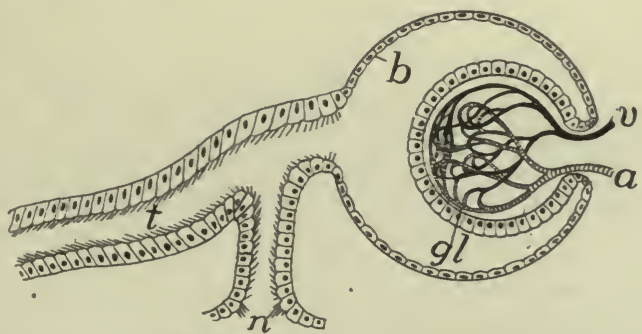

FIG. 315.-Diagram of renal (Malpighian) corpuscle. a, artery; $b$, Bowman's capsule; $g l$, glomerulus; $n$, nephrostome; $t$, nephridial tubule; $v$, vein.

the descending and ascending limbs of Henle's loop. Next follows the second convoluted tubule, which passes by means of a short connecting tubule into a non-glandular collecting tubule into which several other systems of excretory tubules enter, and which leads more or less directly into the urinary duct which conveys the waste from the excretory organ to the exterior. 
One or another of these typical parts may be lacking in certain groups. Thus in the amniotes the nephrostomes are never formed, though they occur in most ichthyopsida. In the pronephros the Malpighian corpuscle is rudimentary or lacking at all stages while there is no differentiation of convoluted tubules and Henle's loop.

The function of the various parts of the nephridial tubule is in outline as follows: Theoretically it would appear that in the primitive condition the nitrogenous waste, which is elaborated in the liver, collected in the cœlom and, together with the cœlomic fluid, was passed outward through the nephrostomes and the tubules, which acted merely as ducts. Higher in the scale the parts become more differentiated and specialized. The renal corpuscles form a filtering apparatus by which water is passed from the blood-vessels of the glomerulus into the tubules near their beginning, and this serves to carry out the urea, uric acid, etc., secreted by the glandular portions of the walls of the tubules (convoluted tubules, ascending limb of Henle's loop).

In development there may be three successsive series of nephridial structures, the higher number occurring only in the amniotes. These are known as the pronephros (head kidney), mesonephros (Wolffian body), and the metanephros (permanent kidney of the amniotes). All three are closely related in development and structure but are distinguished by differences in origin and in the final details. Three views are held as to their relations one to another. According to one they are parts of an originally continuous excretory organ (holonephros) which extended the length of the body cavity. This has become broken up into the separate parts which differ merely in time of development and function, with minor modifications in details. A second view is that they are three separate organs, while a third regards them as superimposed structures which occasionally overlap (birds, gymnophiona) and thus are not, strictly speaking, homologous but rather homodynamous. The first view has the most in its support, but for convenience the three structures are kept distinct here. All arise from the mesomeric somites or from the Wolffian ridge which appears on either side of the median line where the mesomeres separate from the rest of the wall of the body cavity, the mesomeric cells furnishing the nephrogenous tissue from which the definitive organs develop.

Pronephros. - The pronephros is the first to appear in development. As will be recalled (p. I4) the mesomere, like the epimere, 
becomes segmented, and later, when the epimere separates to form the myotome, the dorsal end of each mesomere becomes closed, the whole then forming a sac, opening below into the ventral, undivided cœlom (metacœle). A varying number of these nephrotomes (as they are called) lying a little behind the head are concerned in the
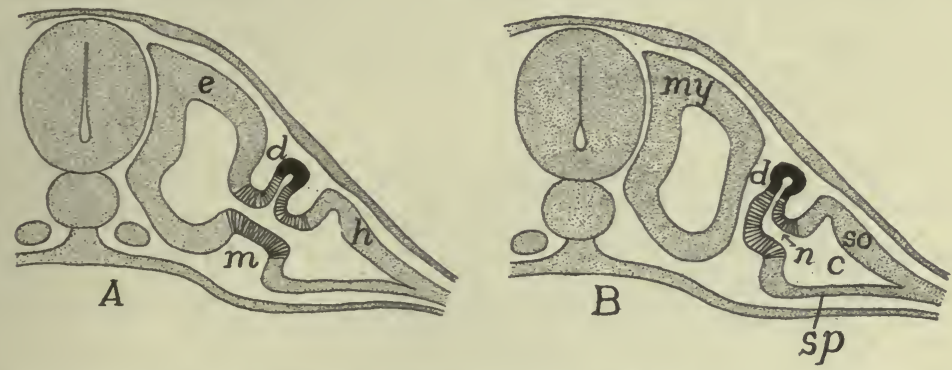

FIG. 316.-Scheme of origin of pronephric tubules after Felix. $A$, earlier, $B$, later stage. $c$, colom; $d$, pronephric tubule and duct; $e$, epimere; $h$, hypomere; $m$, mesomere (lined); $n$, nephrostome; $m y$, myotome; so, $s p$, somato- and splanchnopleure.

formation of the pronephros (two in most urodeles and amniotes; three in.lampreys, anura, some sharks and some amniotes; four or five in some sharks and Lepidosteus; seven or eight in skates; eight to eleven in Amia; and a dozen in some cæcilians; while it is claimed that the whole series of nephridial tubules of Bdellostoma is pronephric). The somatic wall of these nephrotomes (fig. 3r6) grow out toward

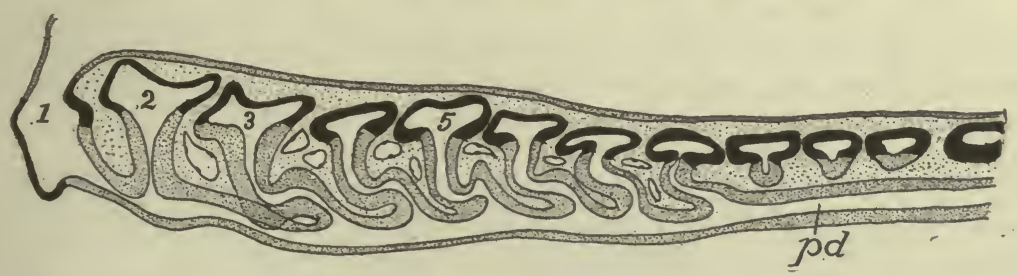

FIG. 317.-Reconstruction from longitudinal sections of pronephros of Hypogecphis (cæcilian), after Brauer. Pronephric duct ( $p d)$ and primary pronephric tubules light; the rest of the somites (nephrotomes) black; glomeruli between tubules 2-8. The three trunk somites in front of I develop no tubules.

the ectoderm, thus forming slender pronephric tubules (or solid cords which later become canalized), the proximal end of each communicating freely with the metacœle by way of the cavity of the nephrotome, the opening of the latter into the metacœle being the nephrostome. As will be understood, these tubules, like the nephrotomes, are metameric in character, equalling the somites in number. The distal ends 
grow outward until they are just beneath the ectoderm, when they bend toward the posterior end of the body, the anterior tubules fusing with those behind. From the junction a tube, the pronephric or archinephric duct, gradually grows backward just beneath the ectoderm (figs. $3 \mathrm{I} 7,3 \mathrm{I} 8$ ) until it reaches the posterior end of the metacœle, when it fuses with the hinder end of the digestive tract (cloaca) or with the ectoderm in the vicinity of the anus. An opening now breaks through, thus putting the colom indirectly in communication with the outer world.

At first the pronephric duct lies closely below the ectoderm and is almost equally near the lining of the metacœle. As the myotomes grow downward they come to lie between the ducts and the ectoderm so that eventually the ducts are just beneath the lining of the definitive body cavity.

There has been considerable dispute as to the origin of the cells which form the pronephric duct. They were long thought to be solely of mesothelial character, arising by proliferation from the tube itself. Then it was noticed that the backward-growing tube fused at its tip with the ectoderm and it was thought that there was an actual contribution of ectodermal cells at this point. This view received considerable support from its agreement with certain theoretical views. The matter is not yet decided. The writer is convinced, from the study of perfectly preserved material in which cell boundaries are clearly shown, that in the sharks (Acanthias) which were thought most strongly to support the view of ectodermal contribution, that the whole duct is of mesothelial origin.

In the teleosts the dorsal end of the nephrotome grows out to form the pronephric tubule, to which both somatic and splanchnic walls thus contribute. In the amphibia the nephrotome is not distinctly separated from the lateral plates (hypomere) and the pronephric tubules are formed from the common area.

The pronephros is functional for a time in the embryos of some lower vertebrates; in other groups it is a rudimentary and transitory structure, save for its participation in the oviducts and the ostium tubæ abdominale (see below). When functional it takes the nitrogenous waste from the body cavity, while its filtering apparatus consists either of separate glomeruli (one for each tubule) or the glomeruli of the separate somites may run together, forming a glomus. These glomeruli or the glomus of the pronephros do not project into a Bowman's capsule, but lie immediately above the dorsal wall of the cœlom, between the mesentery and the nephrostomes (fig. 318), pushing the epithelium before them. Later, as in the cæcilians, they and the nephrostomes may be enclosed in a cavity cut off from the cœlom, 
so that the whole resembles a renal corpuscle, but is different in origin. In either case the exuding fluid passes into the metacœle from which it is drawn by the cilia of the nephrostomes and passed into the tubules.

The blood is brought to the glomus or glomeruli by short segmental arteries arising from the dorsal aorta (fig. 318) and, after passing through the capillaries, it is carried away by the postcardinal veins of the corresponding side to the heart, these veins keeping pace in their backward development with the development of the nephridial tubules.

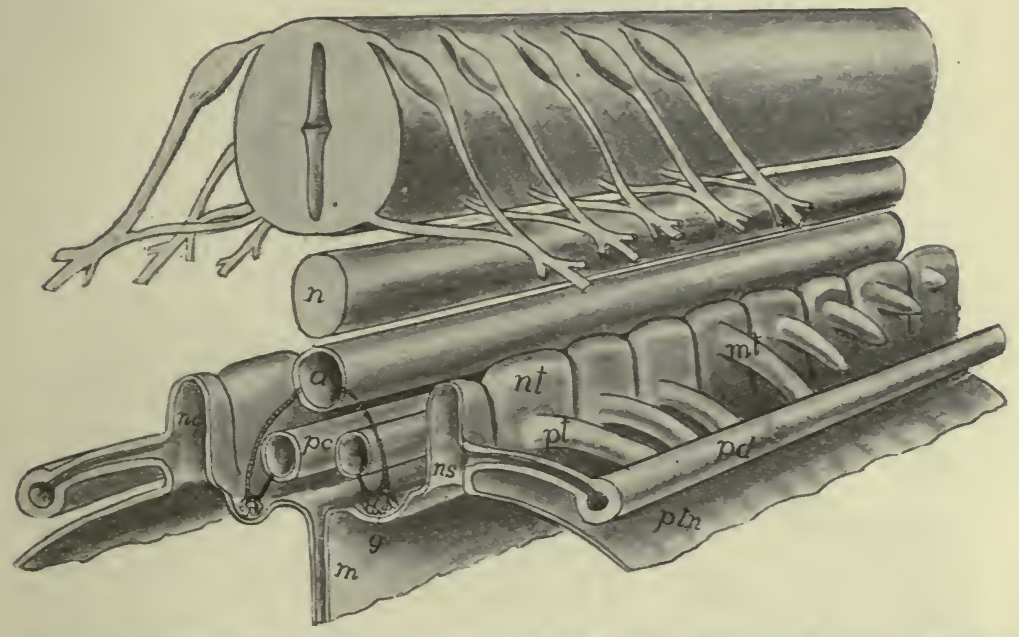

FIG. 3 I8.- Stereogram of developing pro- and mesonephros. $a$, aorta; $g$, glomus or glomerulus; $m$, mesentery; $m t$, mesonephric tubule; $n$, notochord; $n c$, cavity of $(n t)$ nephrotome; $n s$, nephrostome; $p c$, postcardinal vein; $p d$, pronephric duct; $p t$, pronephric tubule; ptm, peritoneal membrane.

There is much that goes to show that the pronephros formerly had a much greater extension than at present, including a larger number of somites. It has, however, been replaced in the adults of all vertebrates (with the possible exception of Bdellostoma) by the mesonephros, and later, in the amniotes, by the metanephros as described below.

Mesonephros.-The mesonephros or Wolffian body is the second excretory organ to arise. It arises after the pronephros and its duct are formed, by the development of a series of mesonephric tubules, which grow out from the nephrotomes behind those concerned in the formation of the pronephros. These tubules extend laterally until they meet and fuse with the pronephric duct, which now acts as the excretory canal of the new gland. In some cases the point of origin 
of the mesonephric tubules is clearly dorsal to that of the pronephric tubules (fig. 3 I 8 ), and in some cases (birds, cæcilians) pro- and mesonephric tubules have been described as arising from the same nephrotome, one above the other. In most ichthyopsida the opening of the nephrotome into the metacœle forms the nephrostome, but in the amniotes this opening is closed before the tubules are formed and consequently nephrostomes are lacking in the latter group.

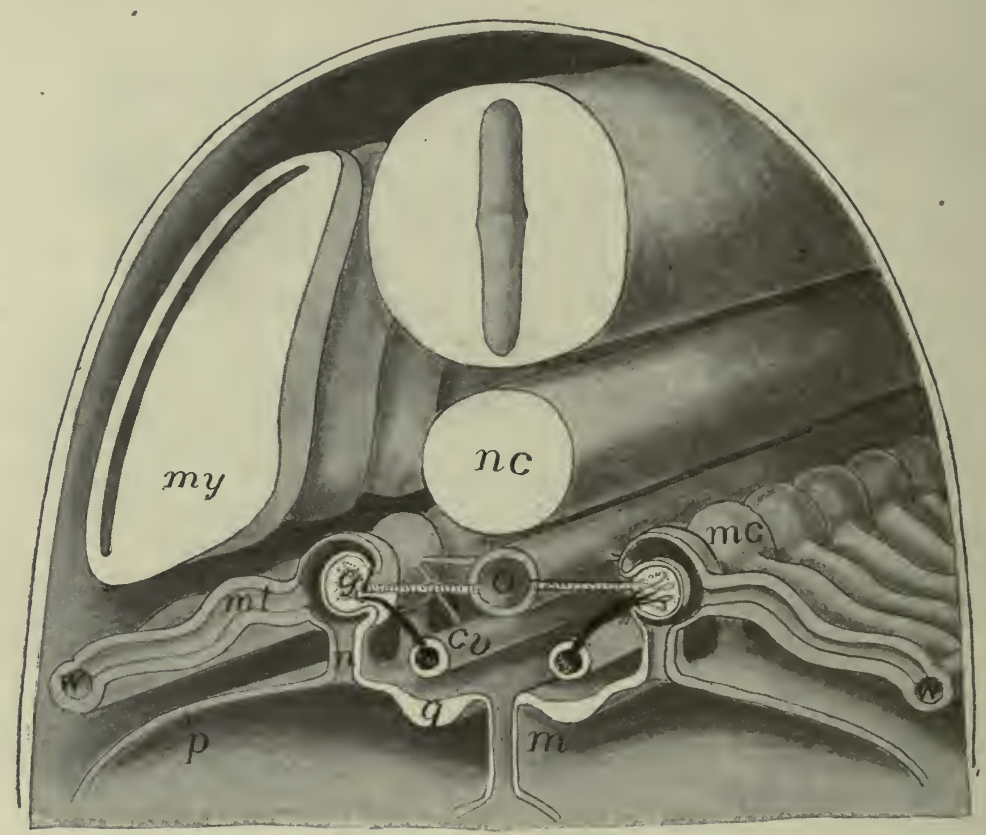

FIG. 3rg.-Stereogram of mesonephros. $a$, aorta; $c v$, postcardinal vein; $g$, genital ridge; $g l$, glomerulus; $m$, mesentery; $m c$, Malpighian corpuscle; $m t$, mesonephric tubules; $m y$, myotome; $n$, nephrostome; $n c$, notochord; $p$, peritoneal lining; $w$, Wolffian duct.

Segmental arteries grow out from the aorta to the splanchnic wall of each nephrotome, forming there a network of capillaries at a higher level than the pronephric glomeruli (fig. 3I9). The glomerulus thus formed presses the wall before it, while the rest of the nephrotome closes around it as a Bowman's capsule, the whole forming a Malpighian body (in some rodents the glomeruli are rudimentary or absent). In most ichthyopsida the Malpighian body is connected on one side with the metacœle by the nephrostome, and on the other with the mesonephric tubule. 
Thus at first the mesonephros is a metameric structure, extending over a much larger number of somites than does the pronephros and reaching nearly to the posterior limits of the metacœle. As the development of the embryo proceeds the number of tubules increases by budding in a manner not readily described (fig. 320 ). These tubules unite with the distal ends of those first formed, so that the distal part of these form collecting tubules. Each of these secondary tubules forms its own Malpighian body and all of the tubules elongate, become convoluted, and the mesonephros loses its primitive metameric character.

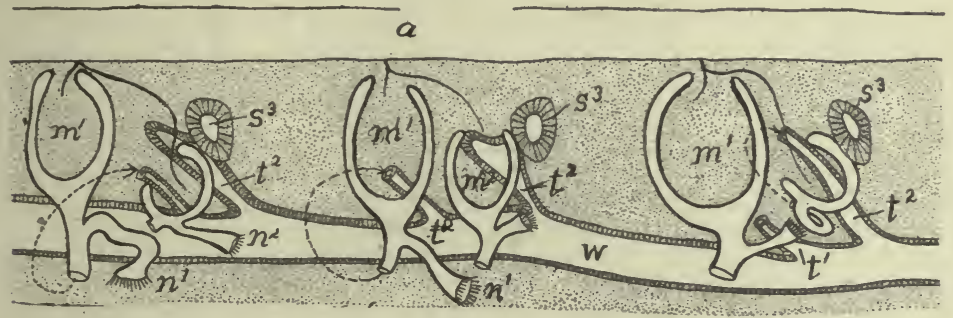

FIG. 320.-Reconstruction of three somites of the Wolffian body (mesonephros) of Hypogeophis, after Brauer. $a$, aorta; $m^{1}-m^{2}$, primary and secondary Malpighian bodies; $n^{1}-n^{2}$, corresponding nephrostomes; $s$, tertiary segments of mesonephros; $t^{1}-t^{2}$, primary and secondary mesonephric tubules; w, Wolffian duct.

At the same time changes are introduced into the mesonephric circulation. The veins emerging from the renal corpuscles extend out into the region of the tubules, each breaking up there into a second system of capillaries which envelop the tubules before returning the blood to the postcardinal vein. The subcardinal vein (p. 279) brings the blood from the caudal region (and usually from the hind limbs) to the Wolffian body and this is also returned via the postcardinals to the heart. (For details of the modifications of the mesonephric circulation see pages 290-292.)

The Mesonephric Ducts.-The conditions in the elasmobranchs have been regarded as very primitive. In them (and to some extent in some of the amphibia), when the mesonephros develops, the pronephric duct divides longitudinally from its hinder end as far forward as the anterior end of the Wolffian body. Of the two ducts thus formed (fig. 32I, $A$ ), one, the Wolffian (Leydig's) duct, remains connected with the tubules of the mesonephros and forms its excretory canal. The other, the Muillerian duct, is similarly related to the 
pronephros and its derivatives, and in the female forms the tube (oviduct) by which the eggs are carried to the exterior. In other amphibia and in the amniotes the pronephric duct does not divide, but remains solely in the service of the mesonephros and forms the Wolffian duct, while the oviduct arises in another manner, to be described in connexion with the reproductive organs. In the teleosts also there is no division of the pronephric duct.
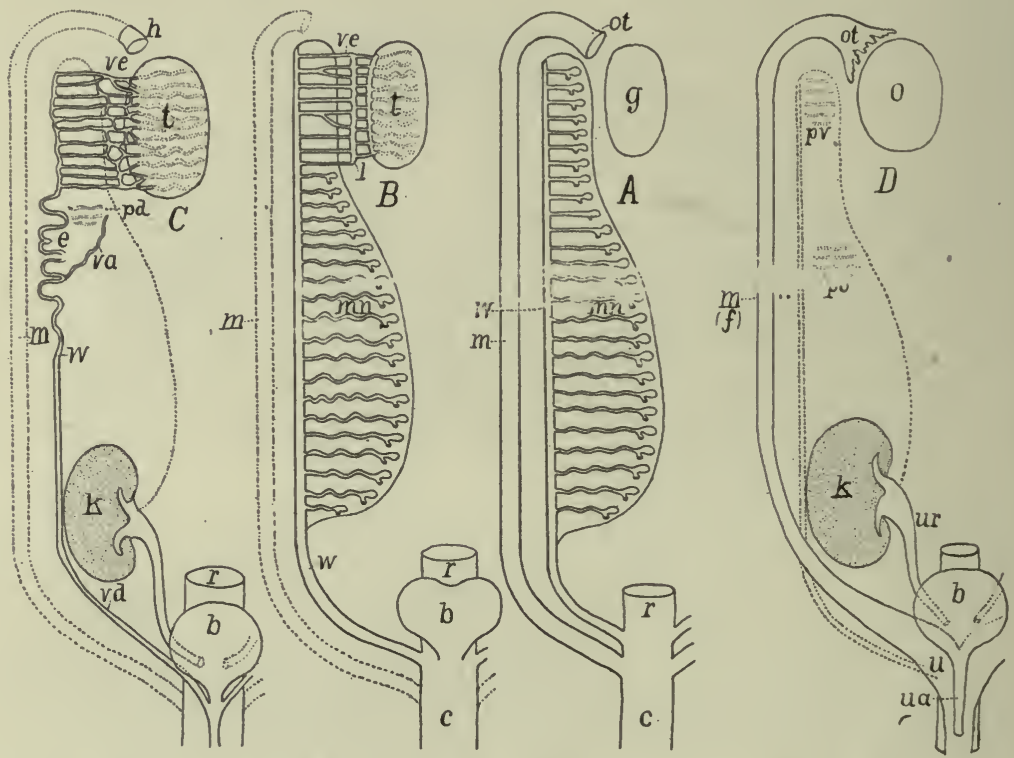

FIG. 32 r.-Diagrams of urogenital structures in $(A)$ indifferent and in female elasmobranchs and amphibians; $(B)$ male elasmobranchs and amphibians; $(C)$ male amniote (mammal); $(D)$ female amniote (mammal). $b$, urinary bladder; $c$, cloaca; $e$, epididymis; $k$, kidney (metanephros); $f$, Fallopian tube; $g$, gonad; $h$, 'stalked hydatid'; $l$, longitudinal tubule; $m$, Müllerian duci (oviduct), rudimentary in $B$ and $C$; $m n$, mesonephros; $o$, ovary; ot, ostium tubæ abdominale; $p d$, paradidymis; $p o$, paroöphoron; $p v$, parovarium; $r$, rectum; $t$, testis; $u$, uterus; $u a$, urethra; $u r$, ureter; $v a$, vas aberrans; $v d$, vas deferens; $v e$, vasa efferentia; $w$, Wolffian duct, urinary in $A$, urogenital in $B$, genital in $C$ and rudimentary in $D$.

Metanephros. - The mesonephros is functional in the embryos of all vertebrates and throughout life in the ichthyopsida. It also functions for a short time after birth in certain reptiles (lizards) and in the lowest mammals (Echidna, opossum). It becomes replaced in the adults of all amniotes by the mesonephroi, the only structures to which the name kidneys is strictly applicable. Each metanephros arises behind the mesonephros of the same side. From the dorsal hinder end of the Wolffian duct, near its entrance into the cloaca, a tube, the 

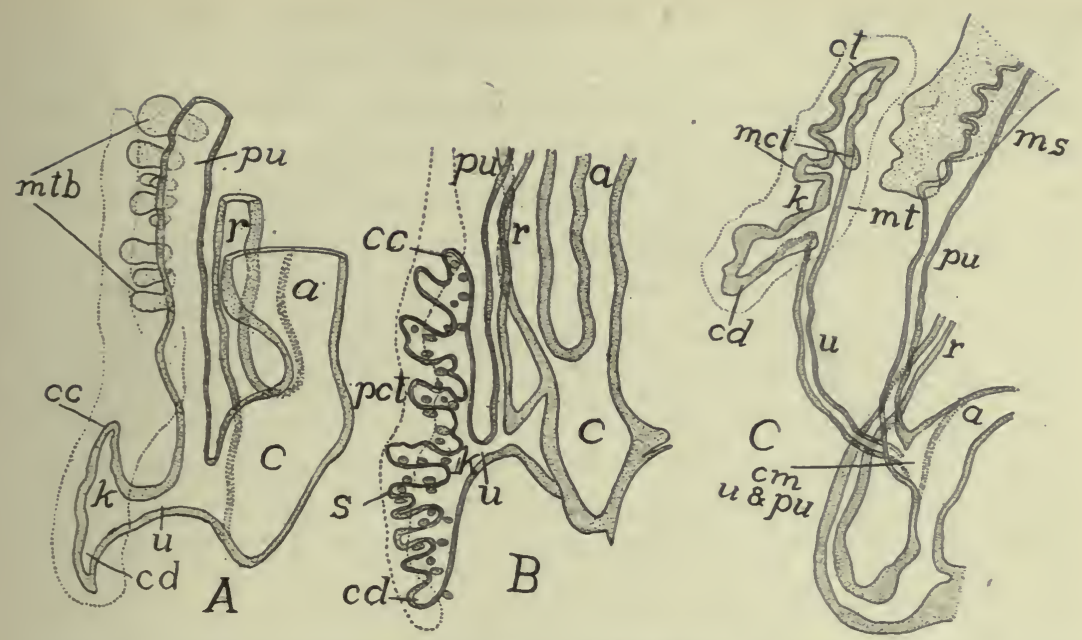

FIG. 322.-Profile reconstructions of lizard (Lacerta agilis) $(A)$ I6 mm. long; (B) $20 \mathrm{~mm}$. long; and $(C)$ human embryo II $5 \mathrm{~mm}$. long, after Schreiner. a, allantois stalk; $c$, cloaca; $c c$, cranial collecting tubule; $c d$, caudal collecting tubule; $k$, permanent kidney (metanephros); $m c t$, median collecting tubule; $m t$, metanephric (nephrogenous) tisssue; mtb, mesonephric tubules; pct, primary collecting tubule; $p u$, Wolffian duct (primitive ureter); $r$, rectum; $s$, secondary collecting tubule; $u$, ureter; $c m, u$ and $p u$, common portion of primitive and permanent ureters.
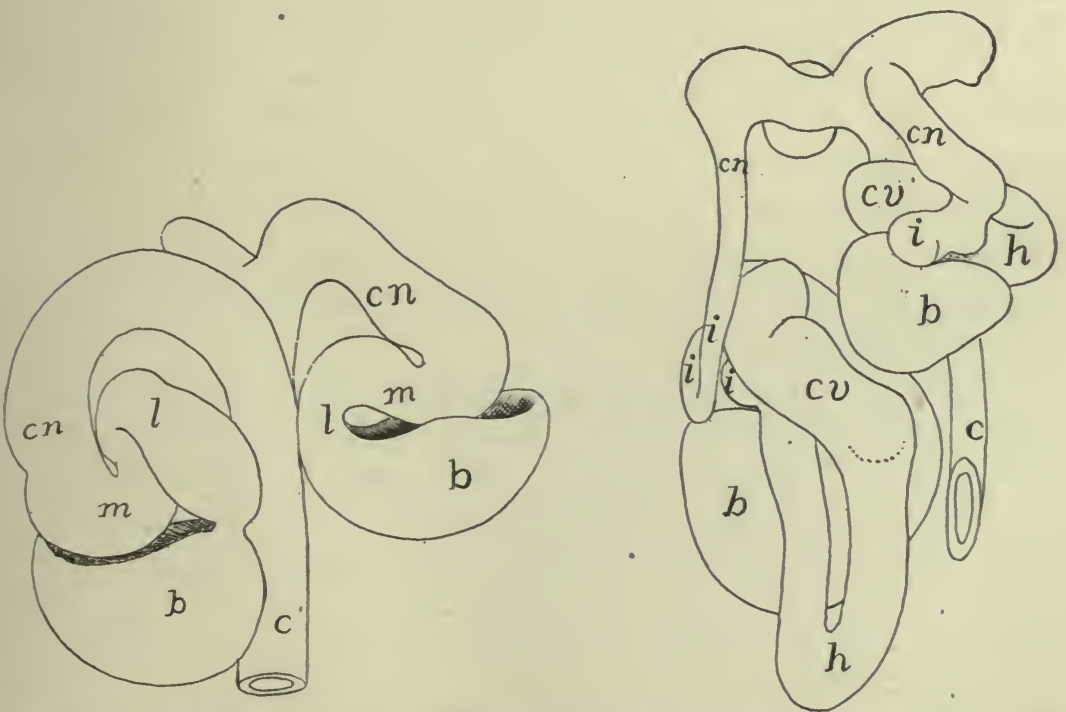

FIG. 323.-Models of two stages in the development of tubules of kidney (metanephros) of man, after Stoerk. b, Bowman's capsule; $c$, collecting tubule; $c n$, connecting tubule; $c v$, convoluted tubule; $h$, Henle's loop; $i$, intercalary tubule; $l$, lower arch; $m$, middle piece. 
ureter (fig. $322, k$ ) grows forward, parallel to the parent duct, into the tissue posterior and dorsal to the mesonephros. This nephrogenous tissue is apparently serially homologous with that from which the mesonephric tubules have arisen, but all traces of metamerism have disappeared from it. In this nephrogenous tissue the anterior end of the ureter gives off a varying number of branches (fig. 322), each of which expands at its tip, thus forming a primary renal vesicle, and a little later the place where the branches and the ureter unite expands, the enlargement forming the pelvis of the definitive kidney. The cells of the nephrogenous tissue form a number of aggregates around each primary vesicle; each aggregate soon becomes hollow, and develops into an S-shaped tubule (fig. 323 , left), one end of which joins the primary renal vesicle, while a glomerulus arises at the other end, but no nephrostomes are formed. Later there is a great multiplication of these tubules and an extension of the capillary system of the glomeruli around them, much as in the mesonephros. The differentiation of each tubule into convoluted, collecting and Henle's regions occurs early (fig. 323 , right).

Urinary Bladder.-At or near the hinder ends of the excretory ducts there is frequently a reservoir for the urine, the urinary bladder or urocyst. Of these there may be three kinds. In most fishes the bladder arises by a fusion of the hinder ends of the Wolffian ducts plus a part derived from the hinder end of the digestive tract (cloaca), the Wolffian ducts emptying into it and the whole opening to the exterior, usually dorsal and posterior to the anus. In the dipnoi there is a diverticulum from the dorsal wall of the cloaca, anterior to the openings of the Wolffian ducts. This is usually called the urinary bladder (fig. $325, D$ ), but it may be homologous with the rectal gland of the elasmobranchs.

The third type, the allantoic bladder, occurs in all tetrapoda. This arises as a ventral diverticulum from the cloaca. In the amphibia the whole of the outgrowth forms the bladder and its walls are supplied by the hypogastric arteries. In the amniotes the proximal portion alone is converted into the urinary bladder, while the more distal portion, in the embryo becomes the respiratory organ of the growing young, the allantois. This part extends far beyond the body wall, carrying with it branches of the hypogastric arteries (allantoic arteries), and in the mammals forms a part of the placenta. The allantois becomes reduced in the later stages and at the beginning of 
free life is entirely absorbed or is lost with the placenta. In the amphibia the urine finds its way into the urinary bladder via the cloaca, as the urinary ducts (Wolffian ducts) do not open into it. In those amniotes in which a bladder is present the ureters open into it, and the urine is conveyed to the exterior by a single tube, the urethra. In many sauropsida there is no urinary bladder, though the allantois is formed in development.

There is great difficulty in comparing the excretory system of the vertebrates with anything known in the invertebrates. In general the nephridial tubules may be compared with those of the annelids. Both have nephrostomes opening into the cœlom, convoluted tubules, enveloped in a network of capillary blood-vessels, but in the annelid each tubule opens separately to the exterior in the somite behind that in which the nephrostome lies, while in the vertebrate the series of tubules empty into a common duct. When it was thought ( $\mathrm{p} 3^{\mathrm{r} 2}$ ) that the ectoderm contributed to the pronephric duct, the homologies appeared easy. The duct was originally a groove on the outer surface into which the separate tubules opened. Then the groove was rolled into a tube which continued backward to the vicinity of the anus By the downgrowth of the myotomes the duct became cut off from its primitive position and came to lie just outside the peritoneal lining When, however, it is considered that in all probability the pronephric duct is formed solely from the mesoderm the homology falls to the ground and an explanation is still a desideratum.

\section{THE REPRODUCTIVE ORGANS.}

The tissue which is to form the ovaries and testes early forms a pair of genital ridges, one on either side of the mesentery and between it and the Wolffian ridge (fig. 3 I9). At one time it was thought that the anlage of the gonad was segmental in character and 'gonotomes,' comparable to nephrotomes and myotomes, were described. It has since been shown that no metamerism exists and that the primary germ cells, which alone characterize the gonads, arise in several groups of vertebrates (possibly in all) from the entoderm, which is never metameric. At about the time of the differentiation of the somites they migrate through the developing mesoderm to their definitive position in the epithelium of the genital ridges, the primitive or primordial ova (whether to form eggs or sperm) being recognizable from their size and their reaction to microscopic stains (fig. 324,0 ). In the adults of many vertebrates the gonads at maturity project far into the cœlom and are often suspended by a fold of peritoneum which is called a mesorchium in the male, a mesoarium in the female. 
Ovaries.-In the ovarian epithelium the primitive ova multiply, and the products, accompanied by some of the epithelial cells, sink into the deeper stroma of connective tissue, thus forming ovarial cords each containing a number of ova. Then the cords break up and each egg becomes surrounded with a layer of epithelial cells, the whole forming a Graafian follicle, the follicle cells supplying nourishment to the contained ovum. In the higher vertebrates there is a great increase in the number of follicle cells, which become arranged in several layers. Then a split arises in the follicle, the cavity becoming

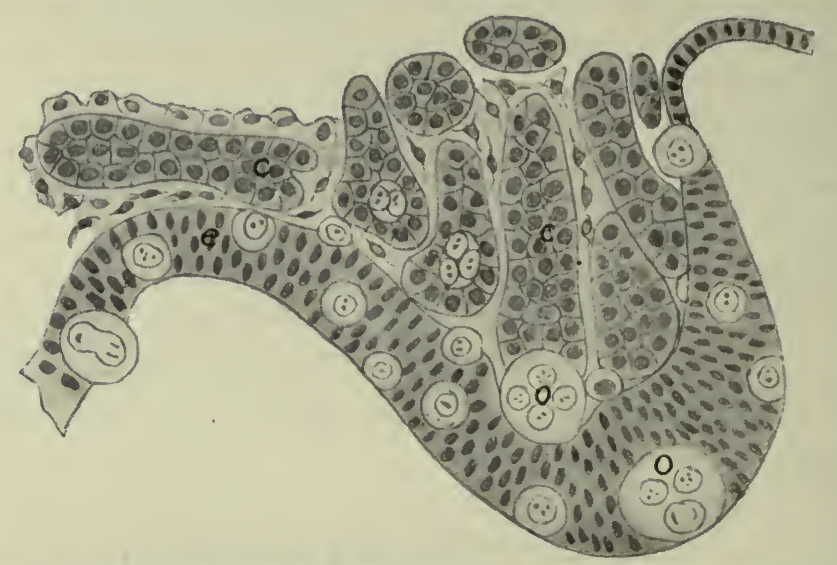

Fig. 324.-Section of genital ridge of chick of five days' incubation, after Semon. $e$, epithelium of ridge (cœlomic wall); $c$, medullary cords; $o$, primordial ova.

filled with a follicular liquor, while the ovum, surrounded by several layers of cells, adheres to one side of the cavity, this part being called the discus proligerus.

When the eggs have attained their full size and the proper time has arrived some of the follicles migrate to the surface of the ovary, then the follicles rupture and the contained ova escape into the colom. Their history from this point will be outlined in connection with the genital ducts. Each ruptured follicle (at least in elasmobranchs, amphibians and amniotes leaves a scar on the surface of the ovarythe corpus luteum-characterized by the presence of peculiar ('lutein') cells.

Testes.-In the gonads of the male (testes) there is a somewhat similar insinking of the primordial ova and epithelial cells into the stroma of the genital ridge, but, instead of breaking up into separate follicles, each sexual cord develops a lumen and becomes converted 
into a seminiferous tubule, in the walls of which both the epithelial cells and the primordial ova are recognizable, as well as a third kind of cell, called Sertoli's cell, concerning which accounts are somewhat at variance, some regarding them as derivatives of the epithelial cells, others as coming from the primitive germ cells. They play no part in the actual formation of the spermatozoa, but act rather as nutritive or 'nurse cells' for the developing spermatozoa. For the differentiation of the germ cells into spermatozoa reference must be made to the text-books of embryology and histology. In most vertebrates the testes continue in the position where they first appear, but in most mammals they eventually descend to a position outside of the body cavity and are enclosed in a special pouch, the scrotum. This descent of the testes is described in connection with the reproductive organs of the mammals, below.

\section{THE REPRODUCTIVE DUCTS.}

The reproductive products formed in the gonads have to be carried to the exterior, either as spermatozoa, or as eggs or young in different stages of development, the ducts in the male being called vasa deferentia, those of the female being oviducts. The former are usually the Wolffian ducts, the latter may be either the Müllerian ducts or tubes developed for the special purpose, or lastly, the abdominal pores.

Male Ducts.-In elasmobranchs, amphibia and amniotes the Wolffian ducts (fig. 32I) serve as the outlet for the sperm. While the seminiferous tubules are developing, there occurs a proliferation of cells from the wall of the Bowman's capsules in the anterior end of the mesonephros. These medullary cords extend through the adjacent connective tissue and into the genital ridge where they come into close connexion with the developing seminiferous tubules (fig. 324). When the latter acquire their lumen the medullary cords also become canalized, so that both form a continuous transverse tubule (vas efferens) leading from the genital cells to the Malpighian corpuscles, and thence by the mesonephric tubules to the Wolffian duct (fig. $325, A$ ). These vasa efferentia become connected by a longitudinal canal before entering the Wolffian body, while usually there is another longitudinal canal connecting them in the body of the testis (fig. $32 \mathrm{r}, \mathrm{B}$ ). Usually this connexion of testis and Wolffian body takes place at the anterior end of the mesonephros, but in some dipnoi 
the posterior end of the mesonephros alone is involved. This is frequently accompanied by a degeneration of the glomeruli of the tubules concerned, so that this part of the mesonephros loses its excretory character and becomes subsidiary to reproduction. With this formation of vasa efferentia the sperm never enters the cœlom except as this is represented in the cavities of the mesonephric tubules.

As a farther result the anterior end of the Wolffian duct becomes purely reproductive in the male and is usually greatly coiled, this portion being called the epididymis. In the amniotes, where the hinder portion of the mesonephros is supplanted by the true kidney (metanephros), the whole Wolffian duct is a sperm duct (vas deferens) in the male, while in the female it largely or completely degenerates. In the amphibia and elasmobranchs the hinder end of the duct is both reproductive and excretory in the male; in the female it is purely excretory.

In the ichthyopsida, other than elasmobranchs and amphibia, the sperm is carried to the exterior in other ways, and there is no connexion of the testes with the excretory organs. In the cyclostomes the sperm escapes from the testes into the cœlom and then is passed to the exterior by way of the abdominal pores (p. I24) which in the lampreys open into a cavity (sinus urogenitalis) which also receives the hinder ends of the Wolffian ducts. In the myxinoids the pores are united and open to the exterior behind the anus and between it and the urinary openings.

The conditions found in the sturgeons (fig. $325, A$ ) and in Polypterus give a possible explanation to the aberrant structures of the teleosts. In the first group can be made out the vasa efferentia and the two longitudinal canals connecting them, these extending the whole length of the testis. In Polypterus (fig. $325, C$ ) the connexion between the testis and mesonephros is confined to the hinder portion of organs, the anterior vasa efferentia and the longitudinal canal disappearing in front, the longitudinal testicular canal taking the sperm from the anterior end of the testis and carrying it farther back for passage through the mesonephros. Here the anterior end of the Wolffian duct is purely excretory. A farther concentration of the efferent functions to the last vas efferens would give, with a few other modifications, the conditions of the teleosts (fig. $325, B$ ). In all of this group there is no connexion of testes with mesonephroi. The seminiferous tubules are connected by a longitudinal canal (apparently 
the longitudinal testicular canal of other vertebrates) which runs in the membrane (mesorchium). supporting the testis, back to the external opening, which is either directly to the exterior between the urinary opening and the anus (fig. 328 ) or into a urogenital sinus (fig. $32 \mathrm{I}, B$ ).

This view is farther supported by the relations in the dipnoi. In Ceratodus there are numerous vasa efferentia which extend from the testis into the mesonephros. In Lepidosiren the efferent ductules are
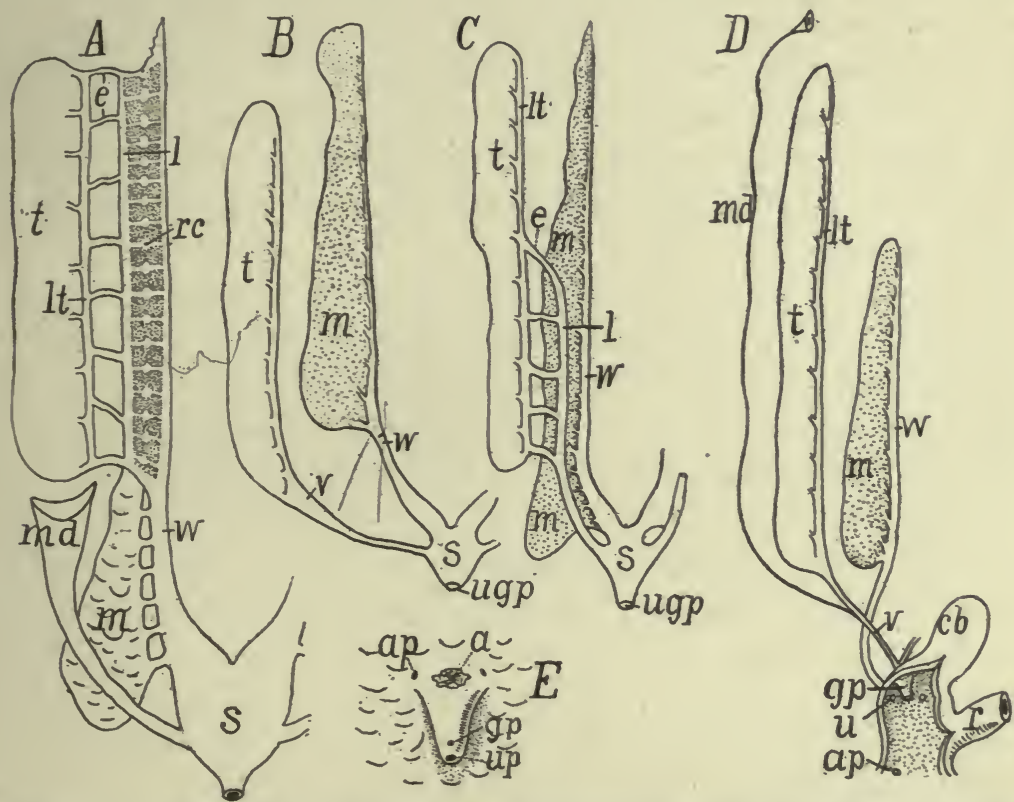

Frg. 325.-Diagrams of urogenital organs of male fishes, after Goodrich. $A$, Acipenser (Lepidosteus and Amia similar, but lack the oviduct); $B$, teleosts; $C$, Polypterus; $D$, Protopterus; $E$, urogenital openings of female salmon. $a$, anus; $a p$, abdominal pore; $c b$, cloacal ('urinary') bladder; $e$, vasa efferentia; $g p$, genital pore (papilla); $m$, mesonephros; $m d$, Müllerian(?) duct; $r$, rectum; $r c$, renal corpuscle; $s$, urogenital sinus; $t$, testis; $u$, $u p$, urinary pore; $u g p$, urogenital pore; $v$, vas deferens; $w$, Wolffian duct.

fewer in number and they arise from a posterior degenerate portion of the testis, while in Protopterus (fig. $325, D$ ) there is but a single vas efferens on either side and this passes through the posterior end of the Wolffian body.

Oviducts.-In the elasmobranchs the Müllerian duct, which, as described above, arises by a splitting of the pronephric duct, serves as the oviduct. After separation from the Wolffian duct this opens in front into the cœlom by means of the pronephric tubules and their 
nephrostomes. Then these flow together, forming a large opening, the ostium tubæ abdominale, on either side (in elasmobranchs the ostia of the two sides are usually united ventral to the liver) through which the eggs, which pass from the ovary into the cœlom are carried into the oviduct.

In some amphibia (Salamandra) the pronephric tubules and nephrostomes take a part in the formation of the ostium tubæ and the beginning of the oviduct, while in Amblystoma the ostium develops in close connection with the pronephric nephrostomes. Here, as in all other tetrapoda, the rest of the oviduct arises by the formation of a groove of the peritoneal membrane close beside the Wolffian duct. This becomes rolled into a tube, the Müllerian duct. In the amniotes the anterior end of the groove does not close, but remains open as the ostium tubæ (fig. 321, $A$ ).

Usually the condition in the elasmobranchs has been regarded as the primitive one, a supposition which renders it difficult to homologize the Müllerian ducts (oviducts) of elasmobranchs with those of other forms. Still, when the adult conditions are considered-similar ostia, similarity of position, and of external openings-it is hardly possible to believe them as merely analogous, as examples of convergence. The facts in the amphibia, referred to in the preceding paragraph are additional evidence of homology. If, however, it be assumed that the more common type of development, by the infolding of cœlomic epithelium, be the primitive condition, the difficulties are less, though not entirely solved. Then, if it be that the homologous tissue in the elasmobranchs was at first included in the tissue of the pronephric duct and that the splitting is a secondary operation to separate parts which elsewhere are always distinct, the similarities are more apparent.

In the females, as in the males, of cyclostomes and teleosts the reproductive ducts are not easily brought into harmony with those of other vertebrates, and an answer to all questions cannot be had until the development of the parts has been studied in more forms, and especially the ganoids and dipnoi. In the cyclostomes the eggs are shed from the ovaries into the cœlom and are thence passed outward through the abdominal pores.

In the teleosts there are several conditions. The ovaries may be simple and solid bands or saccular in character with an internal lumen (fig. $326, E$ ). In the first the eggs pass into the cœlom and thence 
to the exterior by abdominal pores or by oviducts of varying lengths (fig. $326, F$ ). Concerning the nature of these ducts there is uncertainty. They may be true Müllerian ducts or new formations within the group. The fact that similar tubes occur, with permanently open ostia in both sexes of the sturgeons (fig. 325), and that these open
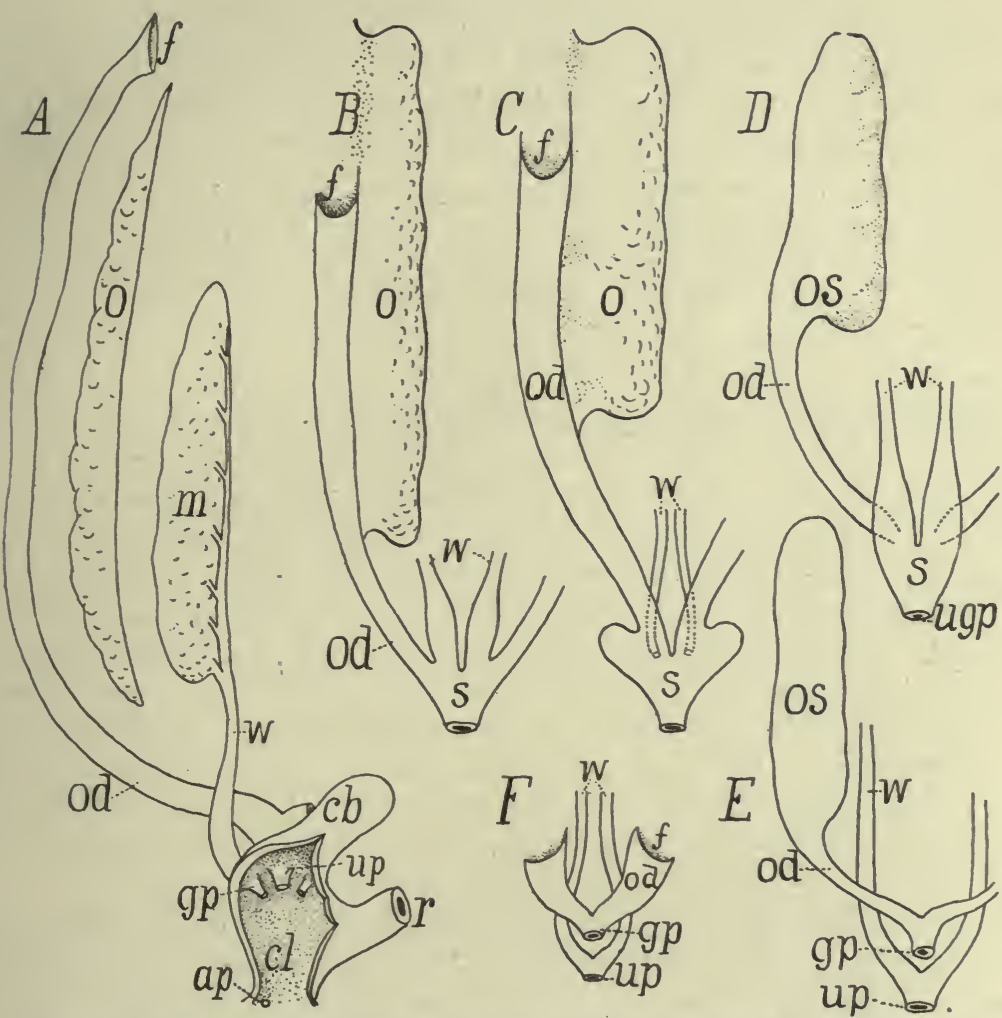

FIG. 326.-Diagrams of urogenital organs of female fishes, after Goodrich. A, Protopterus; $B$, Polypterus; $C, A$ mia; $D$, Lepidosteus; $E$, most teleosts; $F$, salmonid. $a p$, abdominal pore; $c b$, cloacal bladder; $c l$, cloaca; $f$, funnel of oviduct; $g p$, genital pore or papilla; $m$, mesonephros; $o$, ovary; od, oviduct; $r$, rectum; $s$, urogenital sinus; $u p$, urinary pore, (papilla); $u g p$, urogenital pore (papilla); $w$, Wolffian ducts.

behind into the Wolffian ducts, lends probability to the view that the ducts of the ordinary teleosts are Müllerian in character, but greatly modified.

The saccular condition of the ovaries appears to arise in two ways. In the one the primitively free edge of the ovary bends laterally and fuses with the cœlomic wall, thus enclosing a cavity, the parovarial 
canal, closed in front. In the other type a groove of the covering epithelium forms on the surface of the ovary. This closes over and sinks inward, forming what is termed as an entovarial canal. Either canal may extend backward to the hinder end of the body cavity, thus forming an oviduct, or the oviduct may be formed from both kinds of canals, one in front, the other behind. From this it would appear that the ovary originally extended back to the hinder end of the cœlom (as it does in Cyclopterus) or that the par-or entovarial canal had united with a Müllerian duct which has otherwise been entirely lost. The oviducts thus formed usually unite before opening to the exterior, either directly or via a urogenital sinus. The oviducts in the dipnoi (fig. $326, A$ ) are much like those of the selachians, emptying independently into the cloaca. They persist, though of small size, in the males (fig. $325, D$ ).

\section{EXCRETORY ORGANS IN THE SEPARATE GROUPS.}

CYCLOSTOMES.- In the lampreys the pronephros extends over thirteen -somites, but only the anterior five form complete tubules, the remainder, however, join the pronephric duct. The pronephros is best developed in the Ammocœte, ro $\mathrm{mm}$. long, and in this stage the mesonephros is also developed and both are functional. With increase in size there is a degeneration of the mesonephric tubules in front and a formation of new ones behind, the definitive organ extending over about two-fifths of the body length. Each pronephros projects into the cœlom as a band supported by a fold of the peritoneal membrane. The two pronephric ducts unite a little in front of the hinder end, forming a urogenital sinus into which the abdominal pores empty, and which, in turn, opens at the tip of a urogenital papilla just behind the anus.

In the myxinoids the nephridial tubules develop as a continuous series, the organ in the earliest stage known extending over somites Ir-80. Later the organ becomes divided into two parts by the degeneration of the intermediate tubules. The anterior part projects into the body cavity and is provided with nephrostomes, while the posterior part, reaching through some twenty or thirty somites, has its tubules strictly segmental, each with a Malphigian body. This is the functional excretory organ.

ELASMOBRANCHS.-The pronephros is never functional as an excretory organ. The Wolffian bodies of the two sides are somewhat influenced in form by the other viscera, and are sometimes asymmetrical. Usually the nephrostomes are closed in the adult, but they persist in several genera, among them Acanthias, while they are lacking in Scyllium and Raia. The anterior end of each mesonephros is narrowed and serves as the connexion with the testes in the male, while the anterior end of the Wolffian duct forms a much-coiled epidymis in the same sex. A urinary bladder is formed by the union of the ducts of the two sides. In the female the blad - 
der opens to the exterior at the tip of a genital papilla, but in the male it connects with a urogenital sinus, into which a pair of reservoirs of sperm empty. The duct from the urogenital sinus opens into the cloaca at the tip of a urogenital papilla. In Chimara the anterior end of the mesonephros lacks Malphigian bodies and forms a large (Leydig's) gland, the secretion of which may possibly be used in dissolving the spermatophores (fig. 33r).

GANOIDS.-In Polypterus the pronephric tubules are two in number, belonging to the second and fifth post-otic somites; in Lepidosteus there are five or six; sturgeon six; and Amia eight to eleven. The large size of the pronephros in Polypterus is due to the extensive coiling of the anterior end of the duct. In the sturgeon a part of the excretory organ is separated from the rest but it is not certain that this is really a pronephros.

The mesonephros is markedly segmental, the glands of the two sides being enlarged and united behind in the sturgeon. Nephrostomes are late in appearance, not being formed until after the tubules have joined the duct. The urinary bladder differs from that of teleosts in that the Müllerian ducts enter it.

TELEOSTS (fig. 327 ) have a pronephros which extends over from one to five somites. It is usually transitory in character, but it persists through life in several species and functions during the larval stages in many more. The mesonephros varies considerably in shape. Where there is an air bladder this covers some or all of the ventral surface of the mesonephroi. Frequently the organs of the two sides are united behind, while lobes may extend forward from the main mass, or back into the tail. The duct is sometimes visible from below, sometimes it is immersed in the mass of the organ. There is no sexual part to the mesonephros and there are no nephrostomes in the adult. The urinary ducts of the two sides unite behind and from the united portion and from the ventral wall of the cloaca the urinary bladder is formed. Later the opening of the bladder separates from the cloaca and usually comes to lie behind the anus, sometimes united with the sexual openings.

DIPNOI.-In Ceratodus there are two pronephric tubules, that of the third somite being complete, that of the fourth rudimentary. The glomerulus lies beside the open nephrostome. The mesonephros is at first strongly metameric. There are no nephrostomes in the adult and none appear at any time in Lepidosiren. The adult mesonephros is widest behind, but the relations of the efferent ductules of the male are differently arranged in the separate genera, as mentioned above.

AMPHIBIA.-The pronephros (developing from two somites in the urodeles, three in anura and twelve or more in gymnophiones) retains its functions in urodeles and anura until the metamorphosis, when its tubules degenerate. At first the mesonephros consists of a tubule with nephrostome and renal corpuscle for each somite, but in the adult this metamerism is lost, except at the anterior end, by the development of secondary tubules, each complete like the original ones, the nephrostomes sometimes amounting to over a thousand on the ventral surface of each Wolffian body. In the adult anura the nephrostomes lose their connexion with the excretory system and join branches of the renal arteries, thus placing the cœlom in connexion with the circulatory system.

In the urodeles the mesonephroi form a pair of ridges on the dorsal wall of the cœlom, but they occasionally project as folds. Their length is somewhat propor- 
tional to the total body length. The anterior end of each loses its excretory character and in the male becomes accessory to reproduction, as described above ( $p$. 522). In the anura the organs are more compact and the differentiated anterior end is lacking, though the efferent ductules of the testes pass through the organ. The cæcilians (fig. 334) resemble the urodeles, except in having the mesonephroi more lobulated, the result of aggregates of tubules around the collecting tubules.
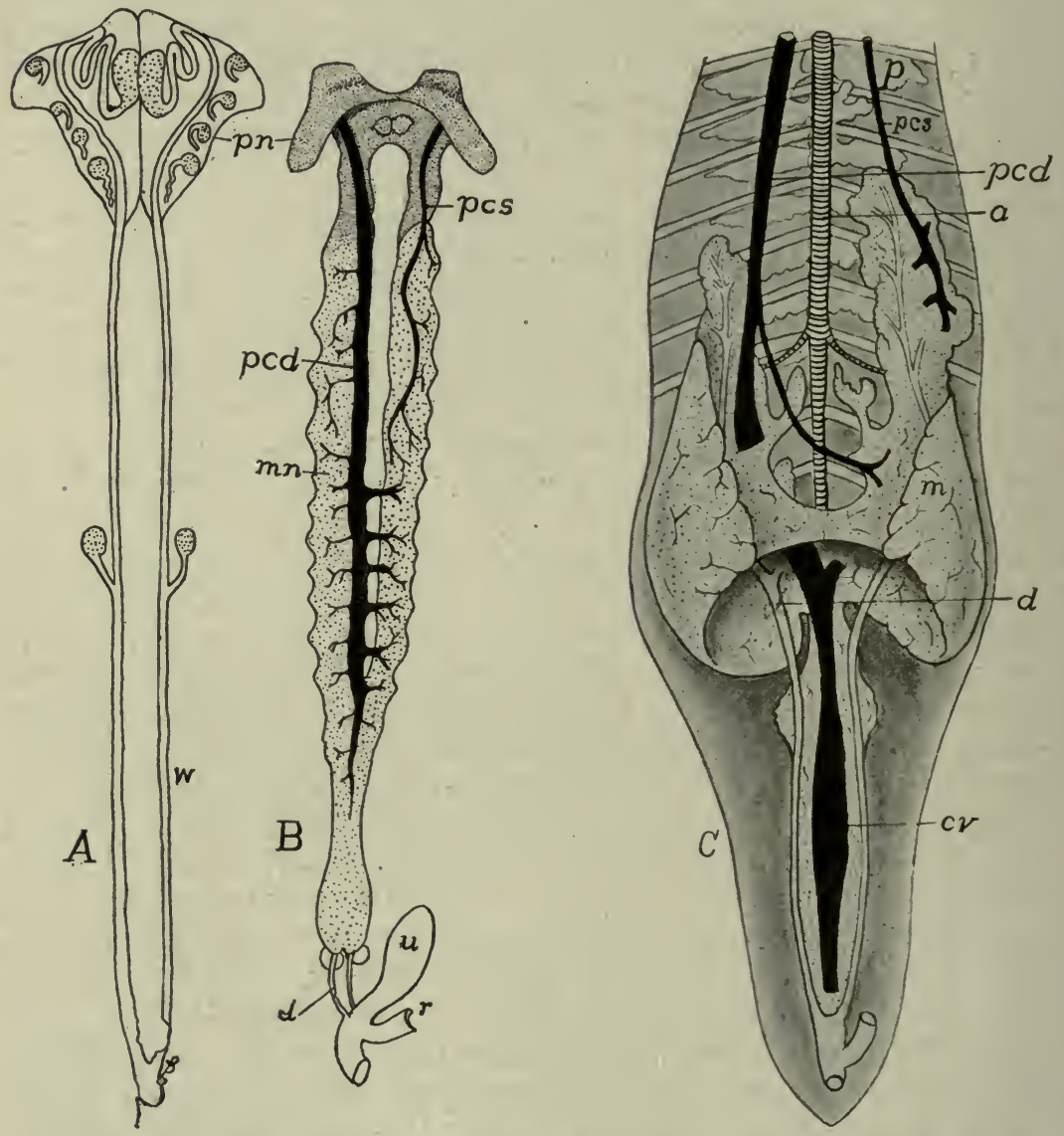

Fig. 327.-Urinary organs of teleosts, after Haller. $A$, pronephros and ducts of young Salmo fario; $B$, excretory organs of adult perch, Perca fluviatilis; $C$, of carp, Cyprinus carpio; $a$, aorta; $c v$, caudal vein; $d$, urinary duct; $m, m n$, mesonephros; $p c d$, pcs, right and left postcardinal veins; $p, p n$, pronephros; $r$, rectum; $u$, urinary bladder; $w$, wd, Wolffian duct.

The Wolffian ducts are excretory in both sexes and are also reproductive in the male. The ducts of the two sides open separately into the cloaca, with, usually in the male, an enlargement, the seminal vesicle, which in the breeding season serves as a reservoir for the sperm. The urinary bladder differs from that of the ichthyopsida in being ventral to the cloaca; it is of the allantoic type (p. $3^{18)}$. It is very 
long in the cæcilians (fig. 334) and Amphiuma, saccular in most urodeles, and bifid at the tip in most anura, being even divided into two sacs, connected only at the opening into the cloaca in some species.

SAUROPSIDA.-In reptiles and birds, as in all amniotes, the pronephros is

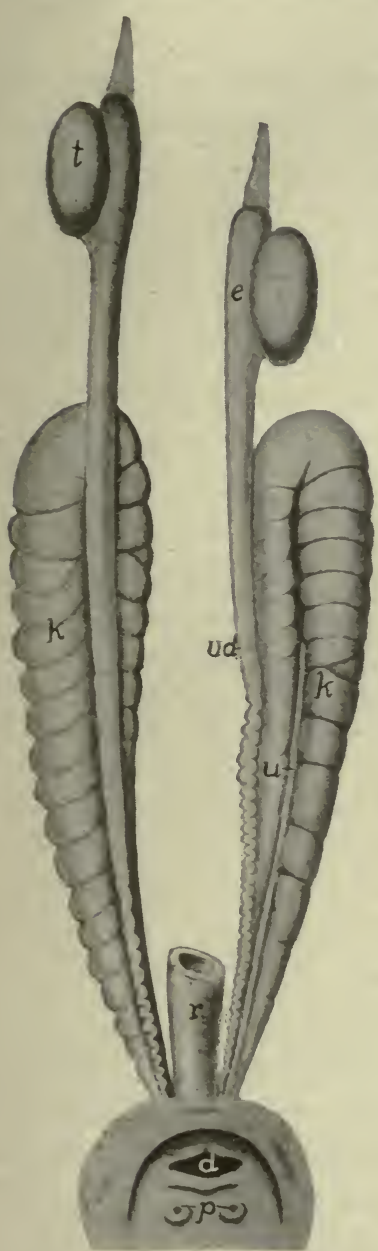

Fig. 328 . rudimentary at all stages and never functions as an excretory organ. The mesonephros takes its place in fotal life, and in some it continues to function for some time after hatching, but in all it is eventually replaced by the metanephros, though its degenerate remains persist in the reptiles (better preserved in the female) forming the so-called 'golden yellow body.' Another part is retained in the male as a part of the efferent ductules of the testes, somewhat as in mammals.

The metanephros (fig. 328 ) never has the extent of the mesonephros of the ichthyopsida, but it is usually restricted to the posterior half of the body cavity, often to the pelvic region. It is usually small and compact (snakes form an exception) or somewhat lobulated, in the snakes the lobulation sometimes being so extensive that the lobules are only connected by the ureter. In the lizards the

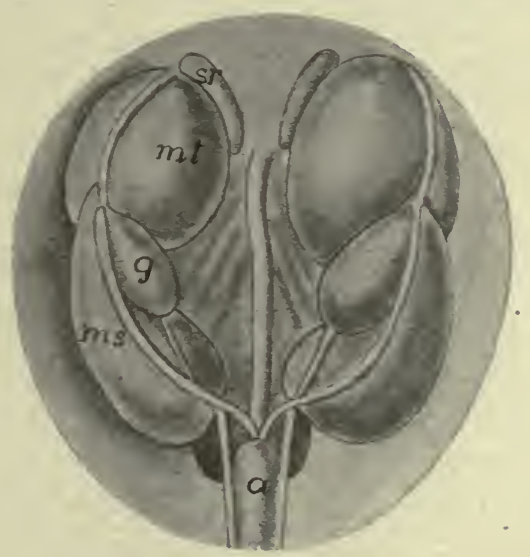

FIG. 329.

Fig. 328.-Urogenital organs of Monitor, after Gegenbaur. $d$, opening of digestive tract into cloaca; $e$, epididymis; $k$, kidney; $p$, papillæ of urogenital system; $r$, rectum; $t$, testes; $u$, ureter; $v d$, vas deferens.

FIG. 329.-Urogenital organs in pig embryo $67 \mathrm{~mm}$. long, after Klaatsch. a, allantois; $g$, gonad; $m s, m t$, meso- and metanephroi; $s r$, adrenal.

organs of the two sides may be connected behind. In the birds there are usually three lobes in each mesonephros, these lying in cavities in the pelvis between the sacral vertebræ and the transverse processes. 
The Wolffian ducts persist only as the ducts of the testes (vasa deferentia) and the ureters take their place as carriers of the nitrogenous waste. These latter tubes open separately into the cloaca. An (allantoic) urinary bladder is found only in lizards and turtles (fig. $3^{1} 3$ ). The urine is semisolid and consists largely of uric acid.

MAMMALS.-In the mammals but two tubules are outlined in the pronephros and these never become functional. The pronephric duct is formed as a solid cord on the surface of the nephrotomic segments which later becomes canalized. Of the fate of the pronephros nothing certain is known. The mesonephros (fig. 329), on the other

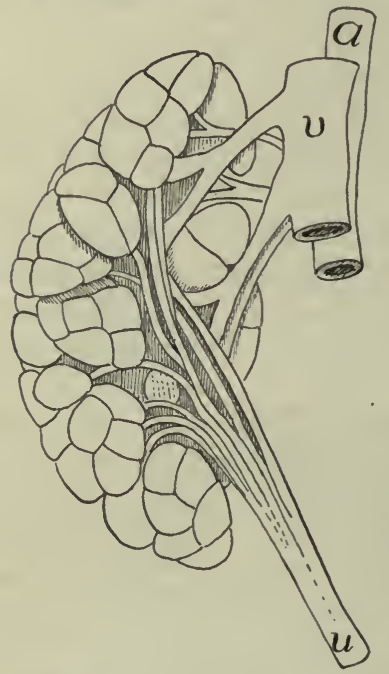

FIG. 330.-Lobulated kidney (metanephros) of otter, Lutra canadensis (Princeton, 2234). a, aorta; $u$, ureter; $v$, postcava. hand, is an important structure in fœtal life, and in the monotremes and marsupials it continues to function in the immature stages. Later it largely disappears in all, with the exception of the parts concerned in the formation of the efferent ductules of the testes and some inconsiderable remnants in both sexes. Only in Echidna are nephrostomes formed and in some rodents there is no formation of glomeruli.

The peculiar development of the mammalian metanephros (p. 3 I6) results in the kidney of the young stages having a lobulated appearance, the lobules corresponding to the ducts given off from the end of the ureter, so that each has its own duct. This condition is retained in the adult elephants, some ungulates, carnivores (fig. 330) and primates, and especially in the aquatic species (whales, seals), the lobules being most numerous in some of the whales. In all other forms the ducts fuse later and the lobules unite into a compact mass lying in the lumbar region near the last rib. Each kidney has a peculiar shape (giving rise to the adjec tive reniform), convex on the lateral, concave on the medial surface, the latter being called the hilum and receiving the excretory duct (ureter) and the blood-vessels of the organ (hepatic artery and vein). Just inside the hilum is a cavity, the pelvis of the kidney, into which one or several papillæ project, each bearing the 
openings of numerous collecting tubules (p. 309). In section the substance of the kidney shows two different textures, recognizable to the naked eye. There is an outer cortical and an inner medullary substance, the two interlocking as a series of pyramids. These different appearances are due to the fact that the cortex contains the renal corpuscles and convoluted tubules, while the medulla is composed of the straight tubules of Henle's loops and of the collecting system.

The ureters are free for most of their course from the kidney to the urinary bladder, into which they enter instead of the cloaca. The bladder, in the monotremes and marsupials, is solely allantoic in nature, but in the placental mammals a portion of the cloaca is also included in it. From the bladder a single tube, the urethra, leads to the exterior. The mammalian urine contains urea instead of uric acid, a resemblance to the amphibia and a contrast to the sauropsida.

\section{REPRODUCTIVE ORGANS OF THE SEPARATE GROUPS.}

CYCLOSTOMES. - The gonads, which are usually unpaired, are supported by a fold of the peritoneal membrane (mesorchium or mesovarium, p. r22). The eggs and sperm escape into the cœelom and are carried thence by way of the abdominal pores. The myxinoids have hermaphroditic gonads, the anterior part being female, the posterior testicular; but one sex predominates. Nansen believes that the sexes alternate in function (proterandric hermaphroditism). The eggs of the petromyzonts are small, those of the myxinoids are larger and are enclosed in a horny shell, with anchoring hooks at either end.

ELASMOBRANCHS.- - In the elasmobranchs, as in all other vertebrates, the gonads are at first paired and symmetrical, though occasionally one side or the other may be reduced or become degenerate or those of the two sides may fuse. Thus in some skates only the left gonad may be functional. Elsewhere in the group they are paired and lie far forward, attached to the dorsal wall of the cœlom. The Müllerian ducts of the two sides in the female meet in front in a common opening (ostium tubæ), the derivative of the pronephric nephrostomes. This receives the eggs, which pass from the ovaries into the cœelom. The different parts of the duct are specialized, the upper part serving as a shell gland, forming the capsule for the eggs. This is horny and in most species is provided with tendril prolongations at the four corners, by which the eggs ('skate barrows') are attached to submerged objects. Some species of both sharks and skates are viviparous. In these the lower part of the Müllerian duct (oviduct) serves as a kind of uterus. In some species the lining of this uterus is covered by vascular villi, by which nourishment and oxygen are conveyed to the growing young which escapes in approximately the perfect shape. The eggs of elasmobranchs are very large, those of some species exceeding even those of the ostrich in size. 
The testes, supported by mesorchia, lie at various levels in the cœlom. The relations of their ducts to the mesonephros are typical (p. 52I). The vasa deferentia of the two side unite just before entrance into the cloaca to form a urogenital sinus, with which an oval sperm sac is connected on either side. In Chimara the genital portion of the mesonephros (fig. 33I) is widely separated from the functional portion, the two being connected by the Wolffian duct. In the male the Müllerian duct is rudimentary and frequently is without a lumen.

GANOIDS.-Nothing is known of the development of the sexual organs of the ganoids, except as to the origin of the germ cells in two species. In most species the ovary is band-like and the oviducts open by broad funnels into the cœlom, but in Lepidosteus the ovary is saccular, the eggs passing into the central cavity, the duct being apparently a sterile, backward prolongation of the ovary. In the male the testes are frequently lobulated and a system of efferent ductules, connected by a longitudinal canal, pass from the testes into the mesonephros (fig. 325) and thence separately or by a single tubule into the Wolffian duct. In the males of all but Lepidosteus there are short tubes with funnels, apparently the homologues of the oviducts of the females.

TELEOSTS.-In some of the lower teleosts (salmonids, etc.) the elongate ovary is solid and the eggs pass from it into the cœlom and are carried thence to the exterior by short peritoneal funnels (fig. $33^{2}$ ), or the tubes and funnels may be absent and

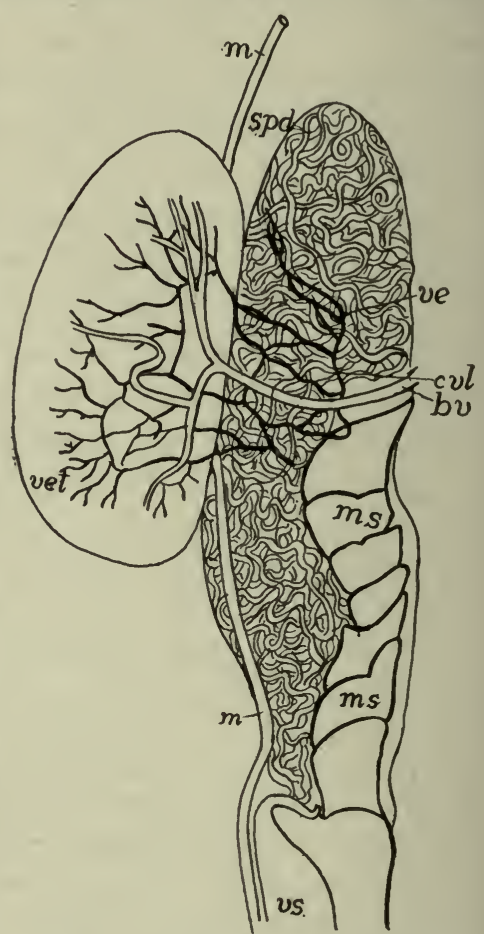

FIG. 331.-Testis and anterior end of mesonephros of Chimara, after Parker and Burland. bv, blood-vessel; $c v l$, longitudinal tubule; $m$, Müllerian duct; $m s$, anterior end of mesonephros (Leydig's gland); spd, sperm duct; ve, $v e t$, vasa efferentia; $v s$, seminal vesicle. the eggs then pass out by abdominal pores. In most teleosts, however, each ovary is a closed sac (like that of Lepidosteus, fig. 326) continued behind by a slender oviduct. The ducts of the two sides may open separately, but usually their hinder ends are united and open by a single genital pore between the anus and the rectum In some instances (fig. $325, \dot{E}$ ), the urinary and genital pores are on a urogenital papilla. In the male the elongate testes are either simple or lobulated. Internally each consists of radial chambers of varying shape which are connected with a complicated system of tubules which lead to a vas deferens running back to open into the hinder end of the Wolffian duct, or separately to the exterior (fig. 333, go).

In most teleosts the number of eggs produced in a season is very large, sometimes numbering millions. Usually, after passing from the oviducts, they are left to the 
mercy of the water, but a number of species (Embiotocids, Gambusia, several Cyprinodonts, etc.) are viviparous, the development of the eggs taking place in the ovary, which sometimes provides nourishment for the growing young. In the lophobranchs the eggs are received in a pouch between the ventral fins of the male and are incubated there. Other peculiar breeding habits are known.

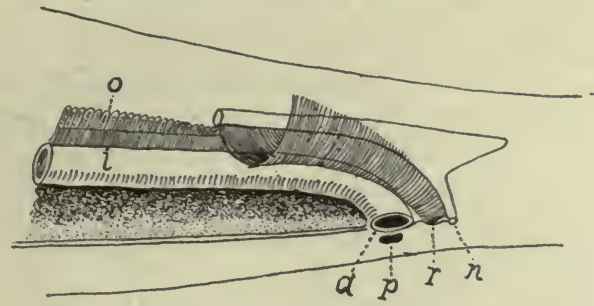

FIG. 332.- Relations of oviducts and pori abdominales in Coregonus, after Weber. $a$, anus; $i$, intestine; $n$, nephridial opening; $o$, ovary; $p$, pore of right side; $r$, opening of oviduct.

DIPNOI.-In the dipnoi more normal conditions occur. There are oviducts with inner ostia, resembling in structure, at least, the Müllerian ducts, and especially those of the amphibia, like them secreting a gelatinous substance around the eggs. These same ducts are also retained in the male Ceratodus and to a less extent in the other genera (Lepidosiren and Protopterus). The gonads are long and are cov-

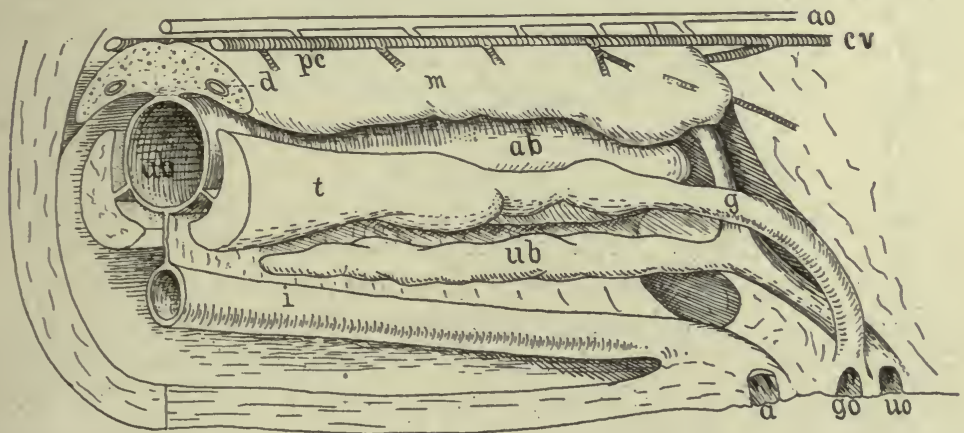

FIG. 333.- Hinder part of urogenital organs of male pike, Esox lucius, after Goodrich $a$, anus; $a b$, air bladder; $a o$, aorta; $d$, Wolffian duct; $c$, cardinal vein; $g$, genital duct; go; genital opening; $i$, intestine; $p c$, postcardinal vein; $u b$, urinary bladder; $u o$, urinary opening.

ered on the ventral side with lymphoid tissue. The testes in Protopterus and Lepidosiren contain numerous alveoli lined with sperm-forming cells. The sperm is carried into a longitudinal tubule (fig. 325) and from thence by one (Protopterus) or several efferent ductules to the Malpighian bodies of the posterior end of the mesonephros, the epididymis thus being posterior in position. In Ceratodus, which is imperfectly known, the ductules are more numerous and the epididymis is anterior.

AMPHIBIA.-The amphibians are the most typical of the anamnia, the elasmo- 
branchs excepted. The gonads are roughly correlated in form to the shape of the body, being shortest in the anura, longest in the cæcilians and urodeles. The ovaries are saccular (a single long sac in urodeles, a number of short ones in anura) and the eggs pass into the cavity and then break into the cœlom. The oviducts are Müllerian ducts with ostia far forward. In the adults
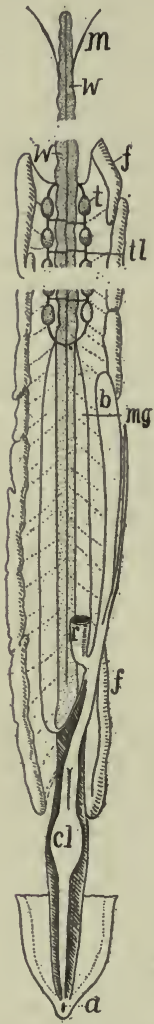

Fig. 334.-Male urogenital organs of Epicrium, after Spengel. $a$, anus; $b$, urinary bladder; $c l$, cloaca; $f$, fat bodies; $m$, Müllerian ducts; $m g$, glandular part of same; $t$, testes; $t l$, longitudinal testicular canal; $w$, Wolffian body. they are greatly coiled and are glandular, their walls secreting the gelatinous substance which envelops the eggs. Usually the oviducts of the two sides open separately into the cloaca, but the two unite behind in Bufo.

The testes have both the longitudinal and the testicular canals connecting the efferent ductules. In the gymnophiona (fig. 334) the testes resemble a string of beads, each bead consisting of a number of seminiferous sacs, the string being united by the testicular canal. The efferent ducts pass through the mesonephros, sometimes utilizing the nephridial tubules, sometimes pursuing a separate course, the two conditions being found in different species of frog (Rana) in Europe. Our species have not been studied in this respect.

The cloaca of the urodeles has a glandular lining and in the females it contains tubules which act as reservoirs of sperm. In the male the glands secrete a substance binding the spermatozoa together In many urodeles fertilization is internal, though there is no intermittent organ save the somewhat protrusible cloacal opening.

There are many interesting accessory reproductive relations among the amphibia. Thus the cæcilians and $\mathrm{Am}$ phiuma lay their eggs in long strings in the soil and the female incubates them. The male of ten takes charge of the eggs. In Pipa each egg undergoes development in a pit in the skin of the back of the female and in Nototrema and Opisthodelphys (South America tree-toads) there is a large pocket in the skin of the back, opening near the coccyx, where the eggs are carried until partially (Nototrema) or entirely developed. Salamandra maculosa and $S$. atra bring forth living young, the former being born with gills, the latter in the perfect condition. Oviposition usually occurs in the spring in colder climates (in the autumn with Cryptobranchus of America) and as the drain on the system is very considerable immediately after hibernation, the substance of the fat body, which always is closely connected with the gonads, is utilized at this time.

SAUROPSIDA.-The birds and reptiles agree in the broader features of the amniote urogenital system as outlined in the general account above. There is a general correlation between the shape of the body and that of the gonads, and often there is a lack of symmetry between the organs of the two sides Thus in snakes 
and lizards the gonad of one side is in advance of the other, while in forms with large eggs there is a marked tendency for one ovary to degenerate (right in birds) the other alone being functional.

The oviducts, which are Müllerian ducts, are modified in accordance with the peculiarites of the eggs. The upper portion is usually much coiled and glandular, this part of the tube secreting the white, while parts farther toward the external opening form the shell membrane and the shell. The walls are also somewhat muscular, the muscles acting like constrictors to force the eggs along. The

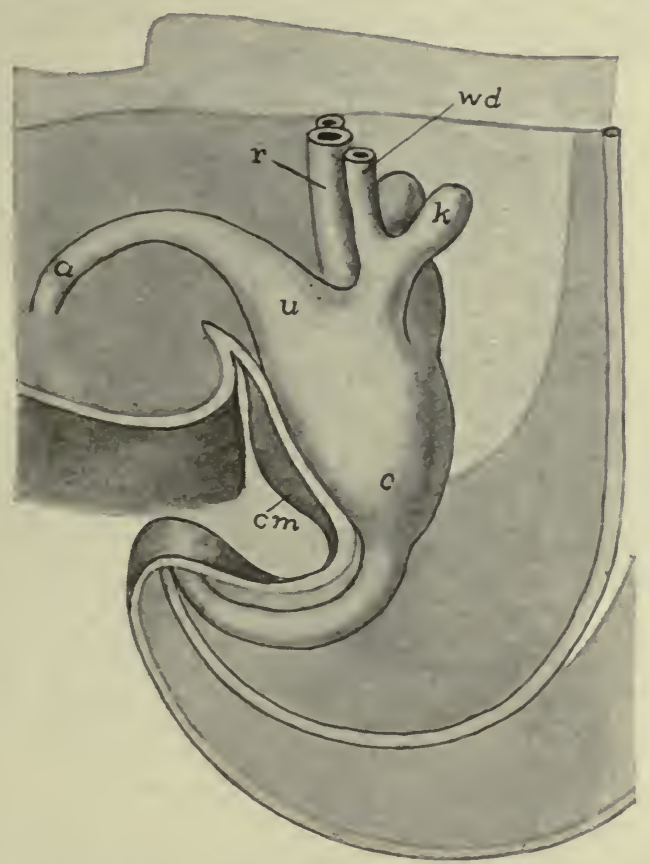

FIG. 335.-Model of cloacal region of human embryo, $6.5 \mathrm{~mm}$. long, after Keibel $a$, allantois; $c$, cloaca; $c m$, cloacal membrane; $k$, outgrowth to form kidney and ureter; $r$, rectum; $u$, where bladder will develop; $w d$, Wolffian duct.

mesonephros and the Wolffian duct are largely degenerate in the female, being represented by rudiments between the oviduct and the vertebral column, best developed in turtles and snakes.

The testes (figs. $3^{1} 3,328$ ) are short, round or oval in outline, and in birds one is usually the larger, though both increase in size at the breeding season. The Wolffian duct is solely reproductive (vas deferens), and its anterior, greatly coiled end, together with the vasa efferentia form the epididymis. Traces of the Müllerian duct persist in the male sauropsida. There are several accessory reproductive glands in the reptiles but little is known of their function.

MAMMALS.--In considering the urogenital structures of the mammals the following parts are to be kept in mind: They are composed of 
the embryonic excretory organs (mesonephroi) and their (Wolffian) ducts; the permanent kidneys (metanephroi) and the ureter; the gonads; the Müllerian ducts; the cloaca and the anlagen of the external genitalia, which arise in the anterior or ventral wall of the urogenital sinus.

In the embryonic stages the Wolffian and Müllerian ducts and the ureters open into the cloaca (fig. 335). Then a part of the latter, with the openings of these ducts, is cut off to form the allantois, a portion of which becomes the urinary bladder, this part receiving the ureters

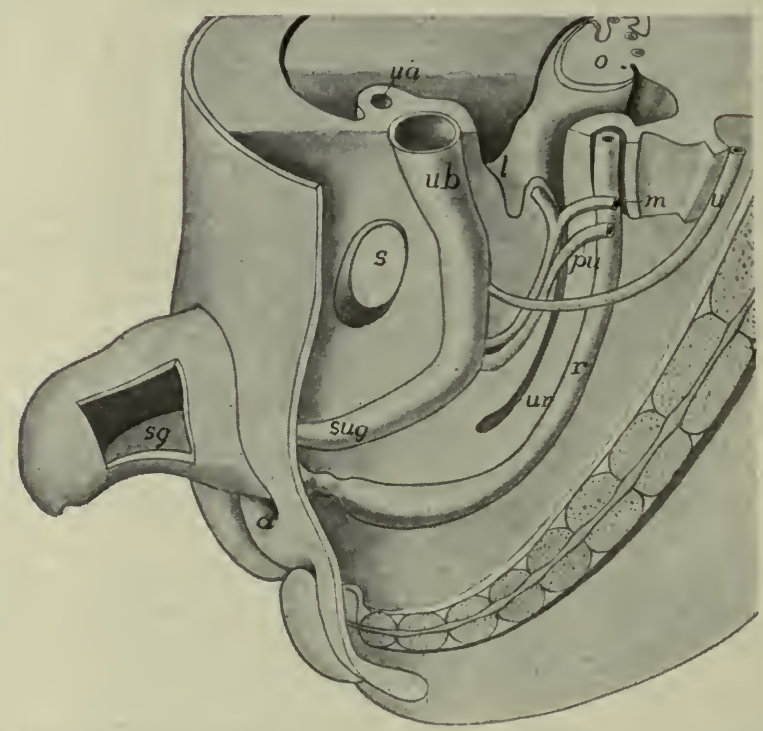

Fig. 336.-Model of pelvic region of human embryo $25 \mathrm{~mm}$. long, after Keibel. (Compare with fig. 335.) $a$, anal opening; $l$, lateral ligament of uterus; $m$, Müllerian duct; $o$, ovary; $p u$, primitive ureter (Wolffian duct); $r$, rectum; $s$, symphysis pubis; $s g$, septum of genital protuberance; sug, urogenital sinus; $u$, ureter; $u b$, urinary bladder; $u r$, recto-uterine excavation.

(except in monotremes) while the Wolffian and Müllerian ducts open into the basal part of the allantoic outgrowth which is separated from the bladder by a narrower stalk which becomes the urethra. This part, into which the two pairs of ducts and the urethra empty, forms the urogenital sinus (fig. 336, sng). With the formation of the permanent kidneys the mesonephros largely disappears (see p. 34I) and the same fate extends to one or the other pair of ducts, the Müllerian largely disappearing in the male, the Wolffian in the female. The parts which persist are more specialized than in any other group of vertebrates, this being in part due to the fact that usually a large part 
of the development of the young is passed inside the body of the mother.

In their early stages the gonads arise anteriorly to the permanent kidneys and they retain this position in the adult monotremes (fig. 337). In all others they are gradually carried farther posterior in the abdominal cavity, so that they lie on the caudal side of the kidneys.

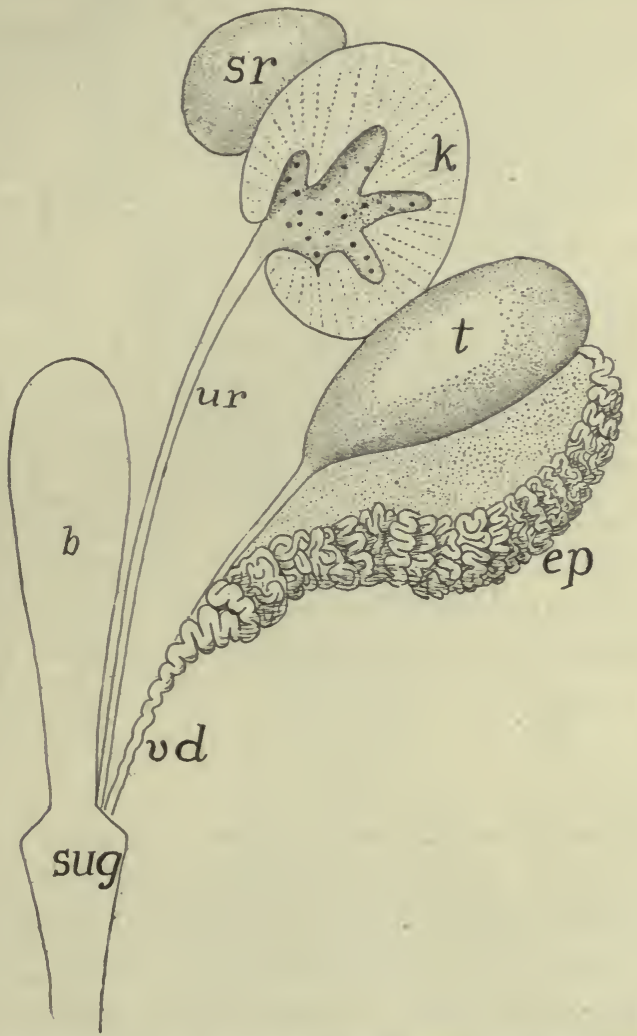

FIG. 337.-Urogenital organs of male Ornithorhynchus, after Gegenbaur. $b$, bladder; $e p$, epididymis; $k$, kidney opened, showing ends of collecting tubules; $s r$, adrenal; sug urogenital sinus; $t$, testis; $u r$, ureter; $v d$, vas deferens.

This transfer of position is effected by a rather complicated apparatus, only the broader features of which can be outlined here. In the early stages the membranes supporting the gonads (mesorchia, mesoaria) are attached to the medial side of the double fold of the serous membrane around the mesonephros. When the latter organ degenerates the fold becomes the broad ligament of the female, while another 
fold continues down the genital ducts forming the ligament of the ovary or testis. In the male broad ligament and ligamentum testis together form the gubernaculum. Unequal growth of body and these ligaments draws the gonads (except in the monotremes) farther back into the pelvic region.

There is some variation in the ovaries. In the monotremes the left is larger ( $c f$. birds) and it is interesting to note that eggs have been found only in the left oviduct. There is also some variation in shape in the marsupials. Elsewhere the ovaries are relatively small (sometimes increasing in size at the breeding season), rounded or oval and with the surface smooth or furrowed.

In male whales, elephants, some edentates, etc., the testes remain permanently in the abdominal cavity. In all others a descent of the testes occurs. By the same relative difference of growth of body and gubernaculum the testes are drawn out of the abdomen into a pouch (scrotum) - really a part of the body wall into which a part of the cœlom (bursa inguinalis) extends. The wall of this is formed in part from the genital folds (see copulatory organs) which surround the genital prominence. This scrotum is in front of the penis in the marsupials, behind it in all placentals. When the canal connecting the cavity of the bursa with the rest of the cœlom remains open (marsupials, insectivores, rodents, bats, etc.) the descent is temporary, the testes being withdrawn into the cœlom at the close of the breeding season by a 'cremaster muscle.' In other mammals the descent is permanent, though in some species it does not occur until the time of sexual maturity.

In the oviducts (Müllerian ducts) two regions can be recognized in monotremes (figs. $338,339, A$ ), three in all other forms. The two are the Fallopian tube, which opens into the body cavity by a broad, fringed ostium tubæ, and second the uterus, in which the egg is retained for a part of its development. In the other mammals Fallopian tube and uterus are retained, the latter being specialized for the longer development of the young, and the third region is added-the vagina, which receives the copulatory organ of the male. The vagina opens into the urogenital sinus (fig. $339, B$ ), but in the monotremes the vagina is lacking and the uterus and the sinus are directly connected. In the marsupials a vagina is developed for each Müllerian duct, and in some there is a peculiar fusion of the ducts distal to the vaginæ so that a cæcal pocket results, and in a few this pocket also connects with the urogenital sinus, thus forming a third vagina (fig. 339, B). 
In the placental mammals the posterior (vaginal) ends of the two Müllerian ducts fuse in the median line, thus forming a single vagina. In some the two uteri remain distinct, each having its own opening (os uteri) into the vagina. This forms the uterus duplex (figs. $339, B$, $340, I I)$, found in most rodents. In carnivores, ruminants, horse and

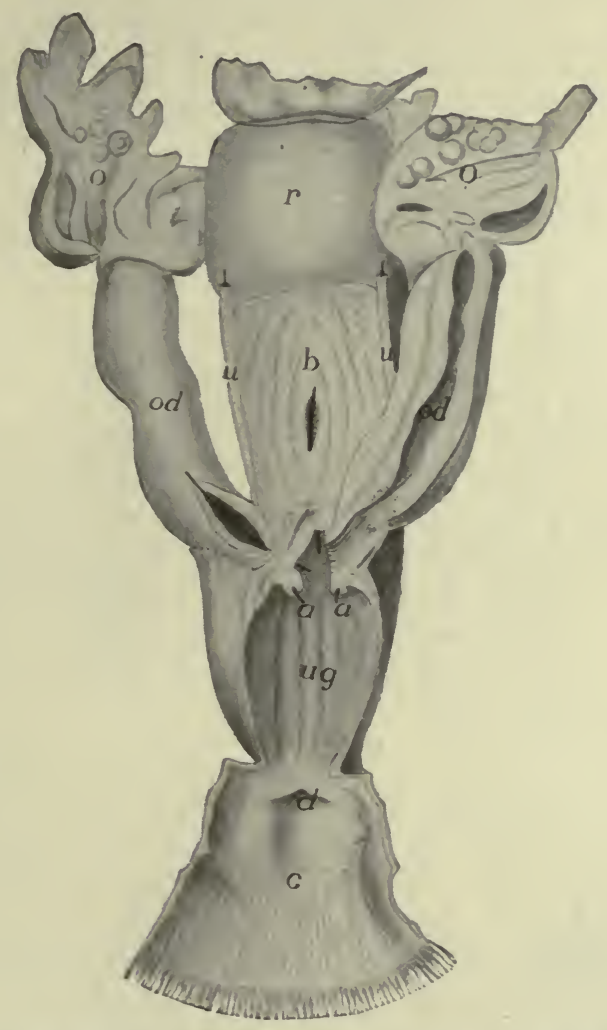

FIG. 338.-Female genitalia of Echidna, after Owen. $a$, openings of ureters into, $u g$, urogenital sinus; $b$, bladder, a bristle passing into urogenital sinus; $c$, cloaca; $d$, opening of rectum into cloaca; $o$, ovary, od, oviduct, the lower part uterine, $r$, rectum; $u$, ureters.

pig the fusion has been carried farther so that there is a single os uteri and the two uteri are almost completely separated (uterus bipartitus, fig. $340, I I I)$ or the fusion is carried farther, the result being the: uterus bicornis (fig. $339, C$ ) in which the double nature is still shown by the two pouches at the upper (anterior) end. Lastly, in the primates, the fusion of the two primitive uteri is complete, the result being the uterus simplex (figs. $339, D ; 340, I I I-V I$ ), in which the 
double nature is shown only by the separate openings of the two Fallopian tubes.

In the monotremes the primitive relation of urogenital sinus and rectum-both emptying into the cloaca (figs. $338,339, A$ )-persists through.life, the result being a single external opening for the digestive

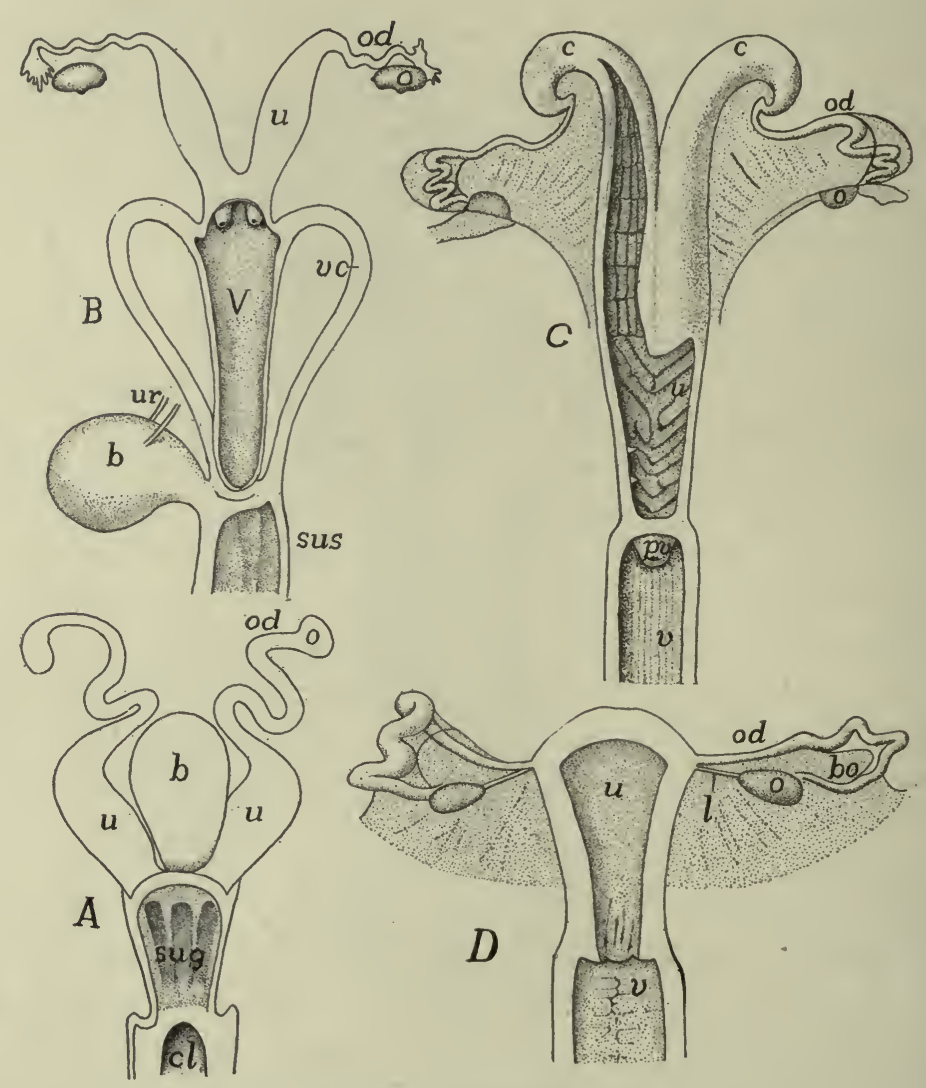

FIG. 339.-Uteri of (A) Ornithorhynchus; (B) Halmaturus; $(C)$ sheep and $(D)$ Inuus, after Gegenbaur. $b$, bladder; bo, bursa ovarica; $c$, cornua uteri; $c l$, cloaca; $l$, ligament of ovary; $o$, ovary; $o d$, oviduct (Fallopian tube); $p v$, processus vaginalis; sus, sug, urogenital sinus; $u$, uterus; $u r$, ureter; $v$, vagina; $v c$, vaginal canals.

tract and the urogenital ducts, whence the name monotreme. In all other mammals the cloaca becomes divided by a partition, the perinæum, between the urogenital and the rectal portions, there thus being formed two external openings. However, in certain mammals, as in marsupials and some rodents, both may be enclosed in a common 
fold of integument (fig. 34I) and in the former group may be provided with a common sphincter muscle.

The testes are relatively small and the outer surface is smooth as the result of the development around them of a fibrous envelope, the tunica albuginea. This sends inward partitions (trabeculæ) which separate groups of seminiferous tubules into lobules. From the

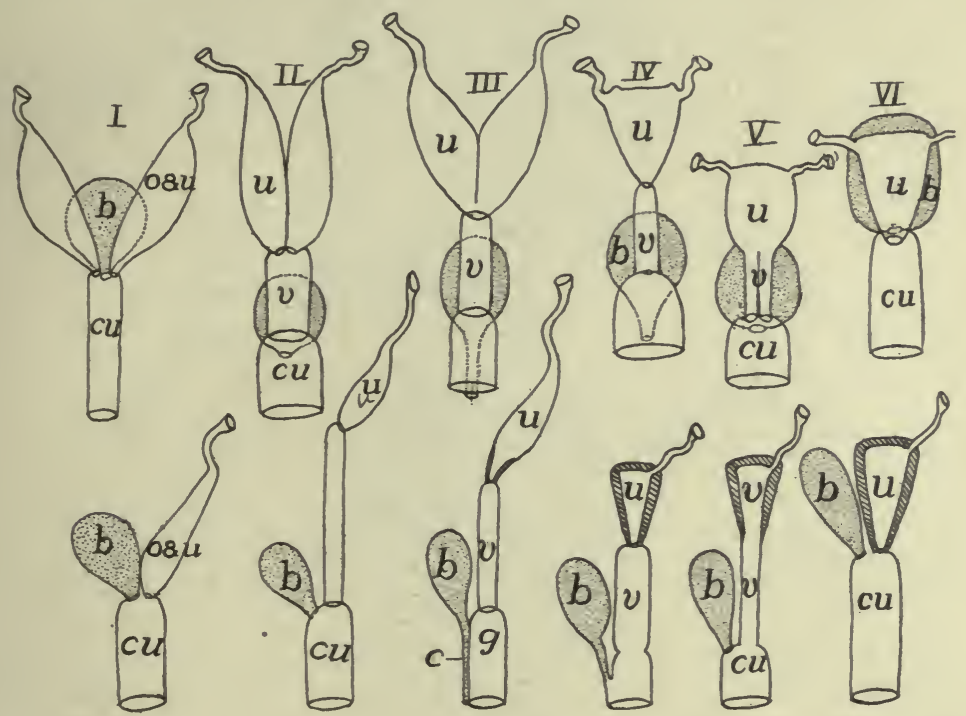

FIG. 340.-Modifications of female urogenital structures in $I$, monotreme; $I I$, Orycteropus (uterus duplex); III, many monodelphs (uterus bipartitus); $I V$, most monodelphs; V, Brodypus; VI, Dasypus; $b$, bladder; $c$, urinary canal, $c u$, urogenital sinus; $g$, genital sinus; $o$, oviduct, $u$, uterus; $v$, vagina.

lobules the sperm is carried outward by numbers of small tubules, the homologues of the efferent ductules of the lower vertebrates, and like them connected together by vessels which correspond to the longitudinal canals. The ductules empty into the anterior end of the Wolffian duct, the upper end of which is greatly coiled, the coiled portion and the ductules forming the epididymis. From the entrance of the ductules to its entrance into the urogenital sinus or canal the duct is called the vas deferens. From this point the urogenital canal is provided with muscular walls and forms an ejaculatory duct.

In the female the Wolffian duct and the mesonephros are largely lost in the adult, the mesonephros forming a small collection of tubules near the anterior end of the ovary which are known as the parovarium. In the male the Müllerian 
duct is also largely lost, the lower portion sometimes persisting as a small blind tubule imbedded in the prostate gland and known as the uterus masculinus.

In the testes between the tubules are small aggregates of cells known as interstitial cells, which have recently been shown to be glands with internal secretion. In man their products, which pass into the blood, apparently cause the assumption of the secondary male characters - growth of hair on the face, change of voice, etc. -at the time of puberty. There would also seem to be some analogous structure in the ovary governing the development of female characteristics and controlling some of the features of menstruation.

There are a number of accessory glands connected with the genital ducts, these being usually better developed in the male than in the female. Only the more

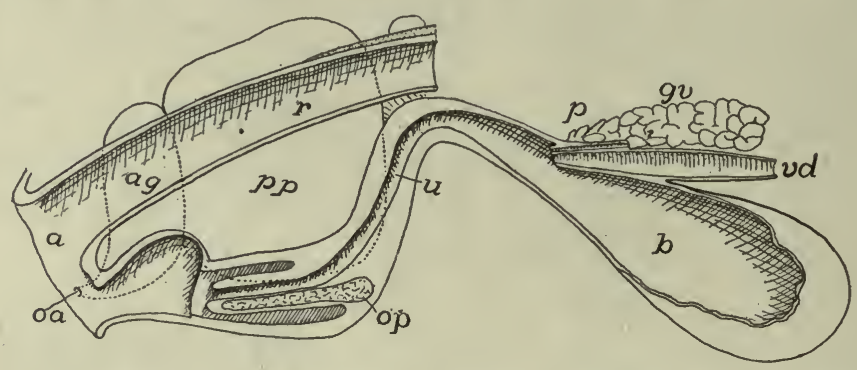

FIG. 34r.-Diagram of male genitalia of beaver, Castor canadensis, after Weber. $a$, anus; $a g$, anal gland; $b$, urinary bladder; $g v$, gland of vas deferens; $o a$, opening of anal gland; $o p$, os penis; $p$, prostate; $p p$, preputial gland; $r$, rectum; $u$, ureter; $v d$, vas deferens.

prominent are mentioned here. The seminal vesicles (present in some rodents, bats, insectivores and in ungulates and primates) are a pair of tubular or saccular glands opening into the vasa deferentia just before their entrance into the urogenital canal. The prostate glands, which occur in all placental mammals with the exceptions of edentates and whales, are connected with the urogenital canal. Farther along the canal are Cowper's glands which occur in almost all mammals as scattered bodies or aggregated into larger masses, and surrounded by smooth muscle.

Concerning the functions of these glands considerable uncertainty exists. From the fact that removal of the prostate and the seminal vesicle in rats prevented fertilization, and the further fact that the secretion of the seminal vesicles increases the activity of the spermatozoa, it seems probable that they are of great importance in connexion with fertilization. Then it has been shown that in some instances the coagulation of the secretion of these glands closes the vagina after copulation has occurred, thus preventing the exit of the sperm.

\section{COPULATORY ORGANS.}

In many vertebrates the eggs are fertilized after passing from the oviducts. This is the case with the cyclostomes, most fishes, with the exception of the elasmobranchs, and with many amphibians. In 
other groups fertilization is internal. In some cases the transfer of the sperm from the male to the female is effected by the apposition of the cloacr of the two sexes, but in others copulatory organs of an intromittent character occur. These are formed on several plans and are not homologous throughout.

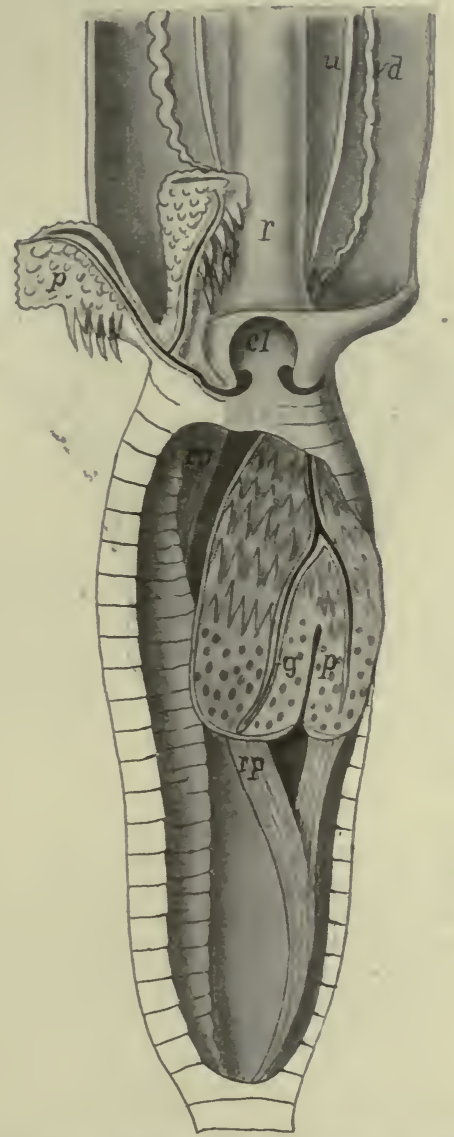

FIG. 342.-Hemipenes of Crotalus horridus, after J. Müller. One hemipenis is exserted, the other retracted but laid open. $c l$, cloaca; $g$, seminal groove; $p$, hemipenis: $r$, rectum, $r p$, retractor muscle of hemipenis; $u$, ureter; $v d$, vas deferens (Wolffian duct). ${ }^{-*}$

In the male elasmobranchs the posterior or inner side of the pelvic fins are specialized for this purpose. The metapterygium (p. II6) and the basalia connected with it are more or less completely separated from the rest and form the so-called clasper ('mixipterygium'). Each of these is grooved along its medial surface and 
when the two are inserted in the cloaca the grooves unite to form a tube for the passage of the sperm. There is a large gland in the clasper but its relation to copulation and fertilization is unknown.

In the snakes and lizards a second kind of structures occurs. In the young there are developed behind the vent a pair of sacs presenting the appearance of appendages. With farther growth these two hemipenes are withdrawn into a sac opening into the hinder side of

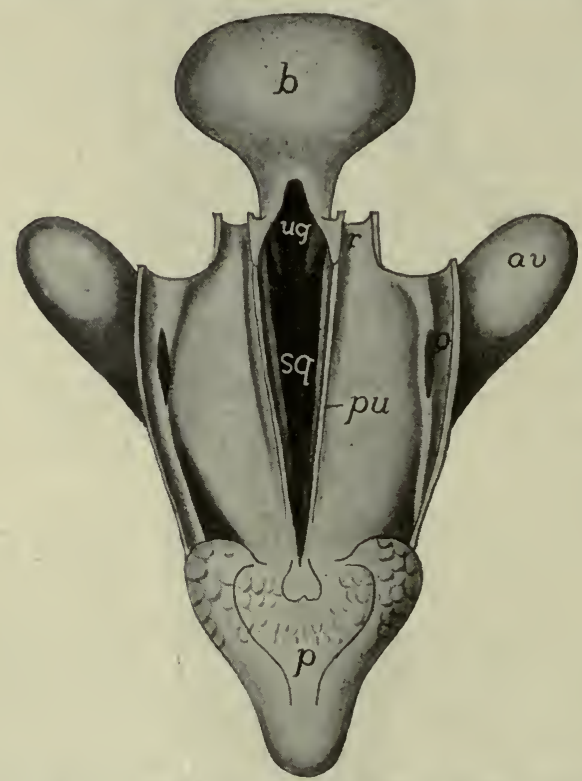

FIG. 343.-Cloacal region of adult turtle (Emys lutaria), after von Moller. The rectum and cloaca have been laid open from the dorsal surface and the urogenital sinus exposed. From the opening of the sinus into the cloaca a seminal groove extends along the ventral cloacal surface and can be cut off by a pair of folds (plice urorectales) from the cloacal cavity. $a v$, anal vesicle; $b$, urinary bladder; $o$, opening of anal vesicle into cloaca; $p$, penis, exserted; $p u$, plicæ urorectales; $r$, rectum; $s g$, seminal groove; $u g$, urogenital groove.

the cloaca. Each hemipenis bears a spiral groove for the passage of the sperm. At the time of copulation these are everted through the anus (fig. 342).

In all other aminotes the copulatory organs are formed from the same anlage. The lower anterior wall of the cloaca is largely concerned in this, the anterior cloacal lip being produced into a genital prominence (fig. 336) which can be traced in many forms as the clitoris of the female and the glans penis of the male. In the embryos of the higher mammals it is surrounded by a pair of integumental 
folds which develop into the labia of the genital opening in the female while in the male they furnish a part of the scrotal envelope.

The most primitive type of the cloacal penis is found in the chelonians (fig. 343) and crocodiles, and slightly more developed in the

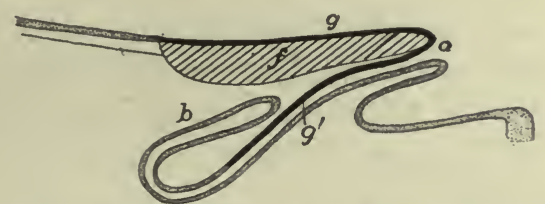

FIG. 344.-Ventral cloacal wall and penis of Rhea (schematized), after Boas. $b$, blind sac; $f$, corpus fibrosum; $g$, seminal groove; $g^{\prime}$, its continuation along blind sac; $o$, opening of blind sac. Mucous membrane dotted, seminal groove black.

ostriches and some of the aquatic birds. In these the ventral or anterior wall of the cloaca and its lip become specialized by the development in it of a longitudinal band of fibrous tissue, covered on the cloacal side by cavernous tissue (containing large spaces, which on
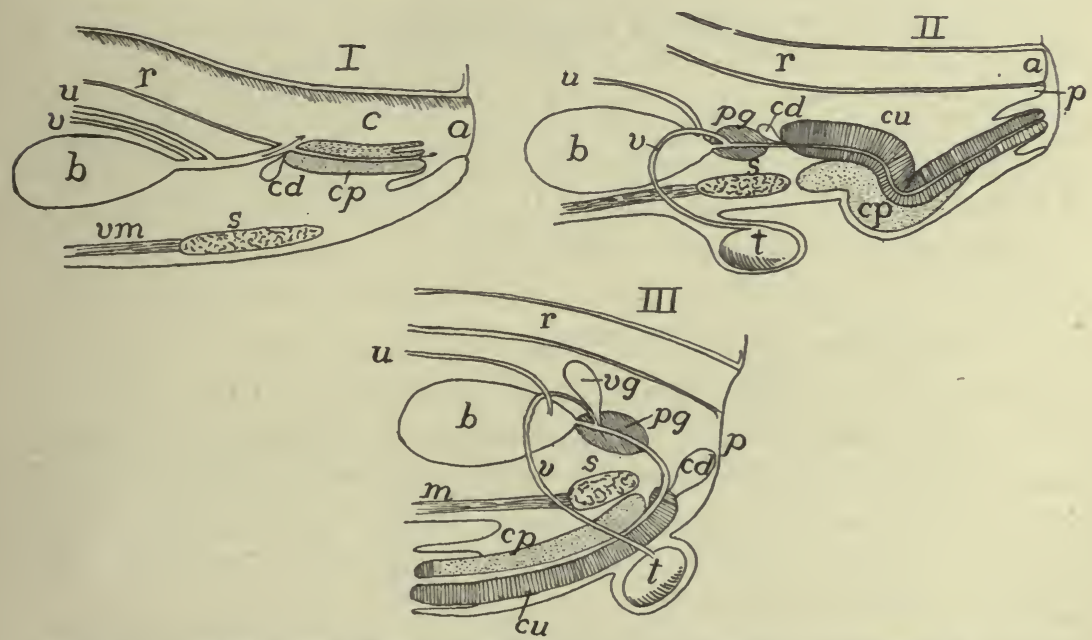

FIG. 345.-Diagrams of male urogenitalia in $I$, monotreme; $I I$, marsupials; and $I I I$; monodelphs, after Weber. $a$, anus; $b$, bladder; $c$, cloaca; $c c$, corpus cavernosus urethra, $c p$, corp. cav. penis; $c d$, Cowper's gland; $p$, perinæum; $p g$, prostate gland; $r$, rectum; $s$, symphysis pubis; $t$, testis; $u$, ureter; $v$, vas deferens; $v g$, vesicular gland; $v m$, ventral muscles.

being filled with blood render the whole firm and enlarged-erectile tissue). The cavernous tissue is marked by a longitudinal groove through which the seminal fluid from the urogenital sinus runs. Besides the enlargement caused by the filling of the cavernous tissue with 
blood, the whole structure, the distal end of which is free, can be protruded from the cloaca and retracted by suitable muscles (fig. 344 ).

In the monotremes (fig. $345, I$ ) the penis is still cloacal in position and the urogenital sinus still communicates with the cloacal cavity. But the advance is made that the groove of the sauropsida has been converted into a tube which carries the urine as well as the sperm. The whole structure can be protruded and retracted again into a sheath formed from the loose mucous membrane of the cloaca. In the other mammals the connection of the urogenital ducts with the alimentary tract is lost and the cloaca disappears. In the lower mammals (figs. $34 \mathrm{I}, 345, I I$ ) the retractile condition is retained but in the higher the organ is permanently external (fig. $345, I I I$ ). In the marsupials the tip of the penis is frequently bifurcate, corresponding to the two vaginæ of the female. In many rodents (fig. $34 \mathrm{I}, o p$ ), bats, many carnivores, whales and some of the primates a penis bone is developed in the middle line of the intromittent organ.

\section{HERMAPHRODITISM.}

Individuals of either sex which have assumed some of the external or secondary sexual characters of the other sex are sometimes spoken of as hermaphrodites, especially in the case of mammals if the copulatory organs be concerned. This is not true hermaphroditism, which consists in having both ovarian and testicular organs or tissues in the såme individual and as a consequence the ability to produce both eggs and spermatozoa. There may be both kinds of tissue in the different parts of the same gonad, or the two may be intermingled (ovotestis) or the gonads of the two sides of the body may be of different sexes. Both ovaries and testes may be functional at the same time, or one may be functional at one time and the other at another (proterandric hermaphroditism).

There is an enormous literature dealing with the problem of the determination of sex. Almost every conceivable possibility has been invoked to account for fact that one individual is male and another female-chance, multiple impregnation, difference in age of parents or of eggs and spermatozoon, matters of temperature and nutrition, etc. Within the last few years there has been a strong tendency to regard the matter as determined at the time of impregnation of the egg and to depend upon differences in chromosomes. 
In the formation and maturation of spermatozoa and eggs a peculiar substance in the nucleus - chromatin - becomes aggregated in small bodies called chromosomes, the number of which in the mature genital products is half of that occurring in the other cells of the body. In most species the number in the body cells is always even and is therefore exactly divisible, but it was found that in certain insects there were differences between the sexes, the male having an odd, the female an even number. When the reduction division occurs, by which the chromosomes are divided between the mature eggs or the spermatozoa (for details see cytological works), the eggs would all have the same number of chromosomes while the spermatozoa would be dimorphic, some having an odd and some an even number of chromosomes. In other cases there is frequently one or more chromosomes (idiochromosomes) which differ from the rest, and these are distributed in the same way at the reduction division. At the fertilization of the egg there is an addition of the chromosomes of the spermatozoa to those of the egg, consequently some of the eggs will have the odd number and some the even number of chromosomes, this being perpetuated in all of the cells of the resulting organism until the next reduction division. It would thus follow that sex was determined at the time of fertilization of the egg. But this is difficult to reconcile with the existence of hermaphroditism.

Another view, which better accords with the facts, is that sex is a matter of Mendelian inheritance, the females in some instances being heterozygous, the males homozygous; or these relations may be reversed In the first condition the element of 'femaleness' dominates over the recessive 'maleness'. In such cases it seems reasonable to suppose that the hermaphrodites are really heterozygous females in which the normally recessive 'maleness' has become equally potent with the female, while under ordinary conditions the matter of sex is dependent upon the character of the chromosomes combined with the Mendelian inheritance.

Among the cyclostomes there are occasional specimens of lampreys which have been regarded as hermaphroditic, but in the myxinoids this is the regular occurrence, the anterior end of the gonad is male and the posterior female. One or the other of these is functional, the animal being predominantly either male or female, and some individuals are regarded as sterile. Nansen regards this as a case of proterandric hermaphroditism. In the teleosts several species of Serramus are regularly hermaphroditic as is Chrysophrys aurata, while in several other species it is an occasional occurrence. Triton teniatus is the only urodele in which it is reported, but in the anura it is more common. Thus it is frequent in the frogs and occasional in other genera. In the toads (Bufo) there is frequently a 'Bidder's organ' in front of the gonads which contains immature ova in the male. Among the birds the phenomenon has been reported in the chaffinch. (The assumption of male plumage by female birds at the 
close of sexual life is not a case of hermaphroditism.) Among the mammals the cases are extremely rare, but cases, apparently well authenticated, have been reported in the goat, pig and man.

\section{NUTRITION AND RESPIRATION OF THE EMBRYO-FETAL ENVELOPES.}

In all vertebrates except the mammals there is enough nourishment stored in the egg to carry the young through its development up to the point where it hatches and shifts for itself. In the cyclo stomes, dipnoi and amphibia this nourishment (food-yolk or deutoplasm) is soon enclosed in the body wall. In ganoids and teleosts, where it is relatively larger in amount, it forms for a time a projecting mass enclosed in a yolk sac, and this condition reaches its extreme in the elasmobranchs and sauropsida. The yolk sac, in the fishes, is an extension of the intestine and the body wall and is richly supplied by vitelline arteries and veins which are derivatives of the omphalomesenteric vessels (p. 276). In the sauropsida, owing to the development of the amnion and the consequent separation of the nonembryonic somatopleure from the yolk, the yolk sac is composed of the splanchnopleure alone, but it has homologous blood-vessels. In the mammals (monotremes excepted) the yolk is greatly reduced and the yolk sac (here often called the umbilical vesicle) is vestigial in character.

The vitelline vessels take the yolk and carry it into the body where it is utilized in building the embryo, all of it being eventually metabolized and used by the cells. The rich supply of capillary vessels in the sac also forms an efficient respiratory apparatus. In the viviparous sharks villi are developed on the oviducal lining and these afford a means of exchange of gases with the embryo, and for getting rid of the nitrogenous waste. It is a question how far there is a transfer of food by the same means. In some species of Mustelus and Carcharias the villi fit into depressions in the yolk sac, thus forming an analogue to the placenta of the mammals - a vitelline placenta-though formed in a greatly different manner.

The viviparous teleosts have saccular ovaries and the development of the egg takes place in the cavity, the walls of which at the breeding season become villous. In the viviparous Salamandra atra only one egg develops and this leaves the mother in the adult shape. The other eggs degenerate and are used as food by the one. There is also 
a modification of the lining of the oviduct in this species which allows some blood to escape and this gives additional nourishment. .

In the amniotes the yolk sac reappears and there are in addition

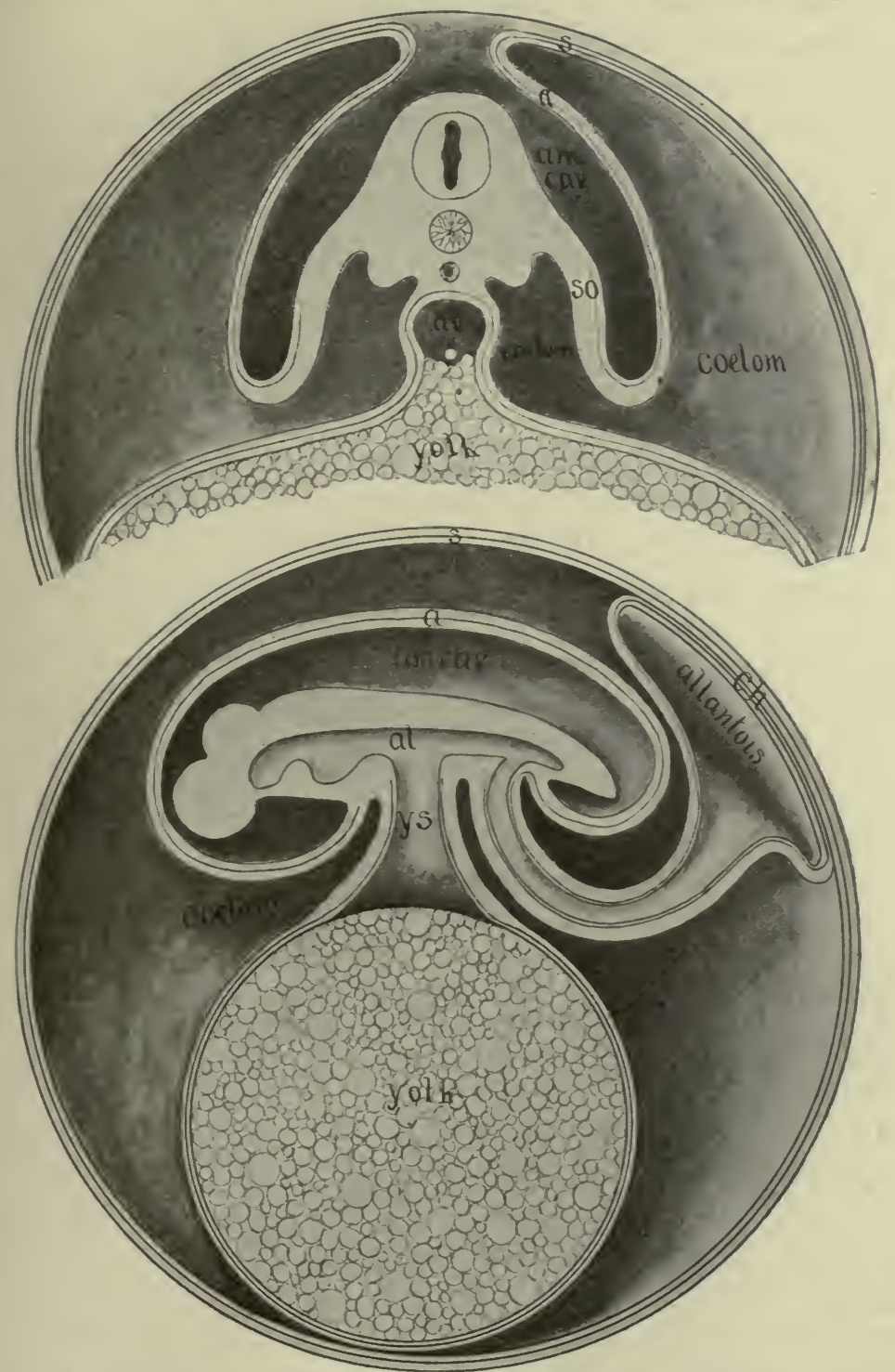

FIG. 346.-Diagrams of the development of amnion and allantois. Upper figure earlier, transverse section; lower later, longitudinal. $a$, amnion; $a l$, alimentary canal; $a m$. cav, amniotic cavity; ch, beginning of chorion; $s$, serosa; so, somatopleure; $y s$, yolk stalk. 
two other embryonic structures which are peculiarly characteristic, the allantois and the amnion, to which reference has been made before.

The amnion arises as a fold of the somatic wall of the cœlom in front of and on either side of the embryo. These folds extend upward and then inward until they finally meet above the embryo, thus enclosing it in an amiotic cavity. The folds fuse in the middle line and then the two sides break through so that above the wall of the amniotic cavity - the true amnion - there is a second cavity directly continuous with the colom, and this is bounded externally by the rest of the amniotic fold, this part being called the serosa or false amnion. This lies immediately beneath the vitelline membrane of the egg or its equivalent, to which many different names have been given.

Little is known as to the phylogeny of the amnion, a structure without parallel in the animal kingdom except in the scorpions, where one is formed in the same way. Of course there is no genetic connexion between the two. It has been suggested that in both groups there is a tendency for the embryo to sink into the yolk and that the amnion is to prevent its being completely covered with this substance.

The homologue of the allantois is found in the urinary bladder of the amphibia. It is an outgrowth from the hinder end of the alimentary tract and consists of a lining of entoderm, covered externally with the splanchnic layer of the mesoderm-is purely splanchnopleuric-and projects into the cœlom. In its outgrowth it carries with it branches of the hypogastric blood-vessels, now known as the allantoic arteries and veins (usually but a single vein). As it develops, the distal end of the allantois swells into a large vesicle, connected with the digestive tract by a slender stalk. The vesicle extends into the cœlom between the amnion and serosa and soon fuses with the serosa. The terminal sac flattens and gradually extends until it encloses the whole embryo and amniotic sac.

In the sauropsida the allantois (and serosa) comes eventually to lie just beneath the shell, and as the latter is porous and the allantois is very vascular, the latter is in position to act as the respiratory apparatus of the growing young. The cavity of the allantois, connected by its stalk with the cloacal region, serves as the reservoir for the urine.

While the embryo is increasing in other respects, the side walls of the body gradually close in ventral to the embryo until they reach the stalks of the yolk sac and the allantois. In this way these structures come to be connected with the body by a narrow cord, called in mam- 
mals the umbilical or navel cord, in which the blood-vessels run. In the mammals there are several variations from the above account of the development of the allantois, but they can be reconciled with the typical condition in the sauropsida. There are also several other variations and the relations of allantois to the other structures is more complicated, but details and the many modifications must be ignored here, only an outline of the broader features being given.

In the mammals there is the same fusion of allantois and serosa as in the sauropsida, the fused area here being called the chorion. On arrival in the uterus by way of the Fallopian tube, the egg becomes implanted in the uterine wall, and a little later, with the development of the chorion, villi are formed on the outer surface of the egg. These are invaded by the chorionic blood-vessels and they branch and extend into depressions or crypts in the walls of the uterus. The latter become very vascular, the blood spaces of the maternal tissue enveloping the villi with only the thinnest of walls between the vessels of the mother and those of the young. (There is never any actual connexion between the blood-vessel of parent and embryo and so blood corpuscles cannot pass from one to the other. All that takes place is largely of the nature of osmosis-solutions of gases, of nourishing substances and of nitrogenous waste passing from one to the other. There is difficulty in explaining the passage of proteids and fats.) This structure, consisting of the allantoic derivatives of the embryo and the mucous lining of the uterus, is known as the placenta.

In the monotremes and in most marsupials no placenta is formed, but it has been recently shown that a true placenta occurs in a few of the latter group. In other mammals a placenta always occurs, the structures presenting many forms, but these may be grouped under a few heads. (It must be borne in mind that this classification is purely morphological and does not necessarily imply close relations of the species included or identity of method of formation.)

In many mammals, at the time of birth, the maternal and embryonic parts of the placenta simply separate, only the latter passing away with the young. These are called non-deciduate placentæ. In the others the union of the fœtal and the maternal tissues is so intimate that the inner surface of the uterus is included in the afterbirth. These form the deciduate type. The non-deciduata include two divisions. In the diffuse placentæ (edentates, whales, perissodactyls, many artiodactyls) the villi are distributed over the entire surface of the 
chorion. In the cotyledonary placenta the villi are grouped in small areas (cotyledons) with spaces of naked chorion between them. This form is characteristic of the ruminants. The deciduate type includes the zonary and the discoidal forms. In the zonary placenta (edentates, sirenians, elephants, hyracoids and carnivores) the villi form a girdle around the placental sac, the ends of the chorion being free from them. In the discoidal forms (insectivores, rodents, bats, edentates, primates) the villi are restricted to one side of the chorion.

\section{ADRENAL ORGANS.}

Under this heading are included two sets of structures, interrenals and suprarenals, of uncertain morphology and function. The names are given in allusion to the fact that they are usually closely associated in position with the nephridial structures, though they have no other relation to them. The two differ in structure and probably in function and are very distinct in the lower vertebrates but in amphibia and amniotes they are united in a common structure, the interrenals forming the cortex, the suprarenals the medulla of the mammalian adrenals.

The interrenals arise from the cœlomic epithelium but it is as yet uncertain as to the details, some thinking that they are connected with the pronephros, others with the mesonephric structures, while still others regard them as distinct in origin. They are at first either isolated clusters of cells or longer bands of cells near the dorsal margin of the mesentery, sometimes bilaterally symmetrical and in the lower vertebrates extending through the length of the cœlom.

The suprarenals find their anlage in the sympathetic ganglia, from which certain cells early separate. Among these are peculiar cells which are called chromaffin cells (chromaphile or phæochrome cells) because of their staining brown or yellow with chromic acid salts. These usually are closely associated with the blood-vessels, either the dorsal branches of the segmental arteries or the postcardinal veins.

In the fishes the two organs are separate, the suprarenals often being more or less metameric in character, and in close relations to the vessels of the mesonephros. The interrenals form more compact organs between the nephridia of the two sides. In all tetrapoda the two organs are more closely associated, the tissues of the two being mixed in the adults of the amphibia and reptiles, while in the mammals 
the interrenal tissue is on the outer side of the adrenal organ, the suprarenal forming the inner portion. In the amphibia the adrenals are closely connected with the mesonephroi, being attached to their inner margins (urodeles) or to the ventral surface (anura). In the reptiles they are lobulated structures near the gonads. In the mammals they are more compact (often called suprarenals) and are placed at the anterior end of the kidneys, often unsymmetrically.

Both organs are regarded as glands of internal secretion, their product being passed directly into the blood. The secretion of the medullary portion (suprarenal) of the mammals is adrenalin, an activator or hormone, which by its action on the muscular system causes an increase in the blood pressure. Even less is known of the function of the interrenal. Certain observations render it probable that the secretion of this is of value in destroying certain products of metabolism which otherwise might be injurious to the organism. 
. 


\section{BIBLIOGRAPHY.}

In this list of books and articles dealing with vertebrate morphology there have been included only such titles as are likely to be accessible in the majority of the laboratories of the country. Hence citations are largely from the periodicals and society publications of America and England and from the leading journals of the Continent. The student who wishes to go farther into any subject will find additional references in the papers quoted here and also in the works of Wiedersheim, Gegenbaur, Hertwig and others, while the current papers are listed in the Anatomischer and Zoologischer Anzeigers. For economy of space the titles have been abbreviated, but in such a way as to indicate something of the character and contents of the work.

\section{JOURNALS AND TRANSACTIONS.}

Academy of Natural Sciences, Philadelphia, Proceedings.

American Naturalist.

American Journal of Anatomy.

American Academy of Arts and Sciences, Proceedings.

Anatomical Record.

Anatomischer Anzeiger.

Anatomische Hefte.

Archiv für Anatomie und Physiologie, Anatomische Abtheilung.

Archiv für mikroscopische Anatomie.

Biological Bulletin.

Boston Society of Natural History, Memoirs and Proceedings.

Ergebnisse der Anatomie und Entwicklungsgeschichte.

Jenaische Zeitschrift für Naturwissenschaften.

Journal of Anatomy and Physiology.

Journal of Comparative Neurology.

Journal of Morphology.

Mittheilungen aus der zoologischen Station zu Neapel.

Morphologische Arbeiten.

Morphologisches Jahrbuch.

Museum of Comparative Zoology. Bulletin.

Quarterly Journal of Microscopical Science.

Royal Society of London, Philosophical Transactions.

Zeitschrift für wissenschaftliche Zoologie.

Zoologischer Anzeiger.

Zoologischer Jahrbücher, Abteilung für Anatomie und Entwicklungsgeschichte.

Zoological Society of London, Proceedings and Transactions.

\section{TEXT-BOOKS, MANUALS AND GENERAL WORKS.}

Balfour: Treatise on comparative embryology. 2 vols., London, $1880-82$.

Barker: Anatomical Terminology. Philadelphia, I907. (Contains nomenclature of Basel Commission-'BNA.').

Böhm und Davidoff: Histology, trans. by Huber, Philadelphia.

Bronn's Klassen und Ordnungen des Thierreichs.

Works of John Samuel Budgett. Cambridge, rg07. (Mostly teleosts, dipnoi and amphibia.) 
Cambridge Natural History. Io vols., London, 1895-1909.

Choronshitzky: Entstehung der Milz, Leber, Gallenblase, Pankreas, und Pfortadersystem bei verschiededen Wirbelthiere. Anat. Hefte, I3, rgro.

Dahlgren and Kepner: Principles of animal histology. N. Y., I908.

Dohrn: Studien zur Urgeschichte des Wirbelthierkörpers. Mitth. zool. Sta. Neapel, 3 - $\mathrm{I}$ 7, I88I-1904.

Festschrift zu 7osten Geburtstage Rudolf Leuckarts. Leipzig, I892.

Gegenbaur: Vergleichende Anatomie der Wirbelthiere. 2 vols. Leipzig, 1898-rgor. Handbuch der vergleichend. und experim. Entwicklungslehre (edited by O. Hertwig). 3 vols., Jena, ryor-1906.

Hertwig: Lehrbuch der Entwicklungsgeschichte des Menschen und der Wirbelthiere, 9th edition, Jena, Igro. (An earlier edition, trans. by Mark. London, 1892.)

Hill: Primary segments of vertebrate head. Zool. Jahrb., I3, IS99.

Hubrecht: Die Säugetiereontogenese. Jena, rgog.

Huxley: Manual of the anatomy of vertebrated animals. N. Y., I872.

Huxley: Scientific memoirs. 5 vols. London, I898-1903.

Keibel and others: Normentafeln zur Entwicklungsgeschichte: Pig (Keibel); hen (Keibel and Abraham); Ceratodus (Semon); rabbit (Taylor); Lacerta (Peter); deer (Keibel); Tarsius (Hubrecht); man (Keibel und Elze); Acanthias (Scammon).

Kingsley: Text-book of vertebrate zoology. N. Y., I899.

Lankester: A treatise on zoology. London, I900-(9 vols. published).

Minot: Human embryology. N. Y., I892.

Minot: Bibliography of vertebrate embryology. Memoirs Boston Socy. Nat. Hist., 4, I892.

McMurrich: Development of the human body. Philadelphia, Ig04.

Oppel: Lehrbuch der vergleichenden mikroscopischen Anatomie der Wirbelthiere. Jena, I896-Incomplete, 6 pts. published.

Owen: Anatomy of vertebrates. 3 vols. London, r866-68.

Parker: Course of instruction in zootomy. London, 1895 .

Parker and Haswell: Text-book of Zoology. 2 vols. London, I897.

Schneider: Lehrbuch der vergleichenden Histologie. Jena, I902.

Stannius: Handbuch der Zootomie, zweiter Theil, Wirbelthiere. (Only fishes, amphibia and reptiles published) Berlin, I856. (Invaluable as summary of older work.)

Stöhr: Text-book of histology, trans. by Lewis. Philadelphia, rgı.

Wiedersheim: Vergleichende Anatomie der Wirbeltiere; 7 th edition, Jena, Igog. (Abridgment trans. by Parker, London, I908.)

Wilder: History of the human body. N. Y., I9०9.

Woodward: Outlines of vertebrate paleontology. Cambridge, $x \& 98$.

Ziegler: Lehrbuch der Entwicklungsgeschichte der niederen Wirbeltiere. Jena, I902.

Zittell: Handbuch der Paläontologie. 5 vols. München, r880-93. (A translation and adaptation by Eastman. 2 vols. London.)

\section{MONOGRAPHS ON SINGLE SPECIES AND GROUPS.}

\section{Cyclostomes.}

Ayers and Jackson: Morphology of Myxinoids. Bull. Cincinnati Univ., I, Igoo. Skeleton and muscles. Jour. Morph., I7, I90r.

Cole: Papers on anatomy of Myxine: Trans. Roy. Socy. Edinburg, I905-I2 .

Dean: Development of Bdellostoma. Quar. Jour. Micr. Sci., 40, 1897 .

Howes: Affinities, interrelationships and systematic position of marsipobranchs, Trans Biol. Socy. Liverpool, 6, 1892 .

Scott, W. B.: Entwicklungsgeschichte der Petromyzonten. Morphol. Jahrb., 7, I882.

Scott, W. B.: Development of Petromyzon. Jour. Morph., I, I887.

Shipley. A.: Development of Petromyzon. Quar. Jour. Micr. Sci., 27, I887. 
Fishes.

Allis: Cranial muscles and nerves of Amia. Jour. Morph., I2, I897; of Scomber. same, I8, I 903.

Ayers: Anatomie und Physiologie der Dipnoer. Jena. Zeitschr., I8, I884.

Balfour: Monograph on the development of Elasmobranch fishes. London, 1878 .

(Ext Jour. Anat. and Physiol., I876-78.)

Balfour and Parker: Structure and development of Lepidosteus. Phil. Trans., I882.

Dean: Fishes, living and fossil. N. Y., 1895.

Dean: Development of garpike and sturgeon. Jour. Morph., I I, I895.

Dean: Chimæroid fishes and their development. Carnegie Inst., I906.

Garman, S.: Chlamydoselachus, a living cladodont shark. Bull. Mus. Comp. Zool., I2. Gunther, A.: Ceratodus. Philos. Trans. Royal Soc'y., r87r.

Gunther: Introduction to the study of fishes. Edinburgh, I880.

Kellicott: Development of vascular and respiratory systems of Ceratodus. Mem. N. Y. Acad. Sci., 2, I905.

Kerr: Development of Lepidosiren. Quar. Jour. Micros. Sci., 45 and 46.

Locy: Contribution to structure and development of vertebrate head (Acanthias). Jour. Morphol., 9, r8gr.

Müller: Muskeln und nerven der Brustflossen und Körperwande bei Acanthias. Anat. Hefte, 43, rgII.

Parker: Anatomy and physiology of Protopterus. Trans. R. Irish Acad., 30, 1892. Pollard: Anatomy and position of Polypterus. Zool. Jahrbuch, Abth. Anat., 5, I892. Rauther: Panzerwelse. Zool. Jahrb. Abt. Anat., 3I, I9Ir.

Wiedersheim: Skelet und Nervensystem von Lepidosiren. Jena. Zeitsch., I4, I892. Wilson: Embryology of sea bass (Serranus). Bull. U. S. Fish Comm., 9, I89r.

Wright et al.: Anatomy of Amiurus. Proceed. Canad. Inst., 2, I884.

\section{Amphibia.}

Brauer: Entwicklungsgeschichte und Anatomie der Gymnophionen. Zool. Jahrbuch, Abth. Anat., I0, 12, I6, 1897-1902.

Cope: Batrachia of North America. Bull. U. S. National Museum, 34, I889.

Emerson: Anatomy of Typhlomolge. Proc. Boston Socy. Nat. Hist., 32, 1905.

Fischer, J. G.: Anatomische Abhandlung über Perennibranchiaten und Derotremen. Hamburg, I864.

Gaupp: Anatomie des Frosches. 3 vols. Braunschweig, I896-I904. Contains extensive bibliography.

Götte: Entwicklungsgeschichte der Unke. Leipzig, 1875 .

Holmes: Biology of frog. N. Y., Igo6.

Hoffmann: Amphibien, in Bronn's Klassen und Ordnung das Thierreiches.

Huxley: Article Amphibia in Encyclop. Brit., 9th edit., vol. I.

Kingsley: Systematic position of Cæcilians. Tufts Coll. Studies, I, I902.

Klinkowstrom: Anatomie der Pipa. Zool. Jahrbuch, Abth. Anat., 7, I894.

Miller and others: Papers on anat. of Necturus (Lung, circulation, brain). Bull. Univ. Wisc., 33, I900.

Platt: Development of cartilaginous skull and branchial and hypoglossal musculature of

Necturus. Morph. Jahrbuch, 25, 1902.

Reese: Anat. of Cryptobranchus. Am. Nat., 40, I906.

Sarasin, P. and F.: Entwicklungsgeschichte und Anatomie der ceylonischen Blindwühle Ichthyophis. Wiesbaden, $1887-1890$.

Seelye: Circulatory and respiratory systems of Desmognathus. Proc. Boson Socy. Nat. Hist., 32, I9o6.

Smith: Development of Cryptobranchus. Jour. Morph., 23, I9r2. 
Wiedersheim: Anatomie der Gymnophionen. Jena, I879.

Wilder: Anatomy of Siren lacertina. Zool. Jahrbuch, Abth. Anat., 4, r8gr.

\section{Reptiles.}

Beddard: Visceral anat. of Lacertilia. Proc. Zool. Socy. London, I888.

Clark: Embryology of turtle, in Agassiz, Contrib. to Nat. Hist. of U. S., 2, 1857.

Clarke: Embryology of alligator. Jour. Morph., 5, I89i.

Coe and Kunkel: Anatomy of Aniella. Trans. Conn. Acad. Arts and Sci., I2, Iyo6.

Cope: Crocodilians, lizards, and snakes of North America. Rept. U. S. Nat. Mus. for I889, r9o0.

Hay: Fossil turtles of North America. Carnegie Inst., I908.

Günther: Anatomy of Hatteria [Sphenodon]. Philos. Trans., $x 867$.

Hoffmann: Reptilia, in Bronn's Klassen u. Ordnungen, 3 vols., r89o.

Martin and Moale: How to dissect a chelonian. N. Y., 1895 .

Orr: Embryology of lizard. Jour. Morph., r, r887.

Reese: Embryology of alligator. Smithsonian Misc. Coll., 51, 56, x908-ro.

Schauinsland: Entwicklungsgeschichte der Hatteria [Sphenodon]. Arch. f. mikr. Anat., 57, I900.

\section{Birds.}

Beddard: Structure and classification of birds. London, 1898 .

Coues: Osteology and myology of Colymbus torquatus. Mem. Bost. Socy., Nat. Hist., I, $x 866$.

Coues: Key to North American birds. Boston, 1887 .

Duval: Atlas d'embryologie. Paris, $\mathbf{I} 888$.

Foster and Balfour: Elements of embryology. London, 1896.

Gadow: Aves, in Bronn's Klassen und Ordnungen d. Thierreichs.

Lillie: Development of the chick. N. Y., r908. (Contains large bibliography.)

Marshall: Anatomy of Phænoptilus. Proc. Am. Philos. Socy., 44, I905.

Parker: Morphology of duck and auk tribes. Cunningham Mem. R. Irish Acad., 6, r89o.

\section{Mammals.}

Caldwell: Embryology of Monotremata and Marsupialia. Part I. Phil. Trans., 178, I887.

Carlsson: Anatomie von Notoryctes. Zool. Jahrb., Abth. Anat., 20, 1904.

Ellenberger und Baum: Vergleich. Anatomie der Haustiere. Berlin, I9oo.

Gegenbaur: Lehrbuch d. Anatomie der Menschen. Leipzig, r898. (New Edition by Fürbringer in course of publication.)

Flower and Lyddeker: Mammals, living and extinct. London, I89r.

Gray: Anatomy, descriptive and surgical. Philadelphia.

Hertwig: Entwicklungsgeschichte des Menschen. Jena, 8th edit., 1906. (3rd edition translated by Mark. N. Y., I892.)

Hubrecht: Descent of the primates. N. Y., I897.

Kingsley: Origin of the mammals. Science, I4, I9or.

Lewis: Gross anatomy of a $12 \mathrm{~mm}$. pig. Am. Jour. Anat., 2, I903.

Leisering und Müller: Vergleich. Anatomie der Haussaugetiere. I885.

McMurrich: Development of the human body. Philadelphia, I904.

Minot: Laboratory text-book of embryology. Philadelphia, rgrr.

Mivart: The cat. London, I88I.

Newman and Patterson: Development of the nine-banded armadillo (Tatusia). Jour. Morph., 21, rgio.

Osborn: Origin of mammals. Amer. Nat., 32, I898. 
Osborn: Age of mammals. N. Y., I9ro.

Piersol: Human Anatomy, Philadelphia, 1907.

Reighard and Jennings: Anatomy of the cat. N. Y., I90I.

Weber: Anatomisches über Cetaceen. Morph. Jahrbuch, I3, r 888.

Weber: Die Säugethiere. Jena, I904.

Wiedersheim: Der Bau des Menschen als Zeugniss für seine Vergangenheit. Tübingen, Igos.

Wilder and Gage: Animal Technology as applied to the cat. N. Y., 1892.

Wilson, J. T., and Hill, J. P.: Development of Ornithorhynchus. Philos. Trans., B I99, 1907 .

Thyng: Anatomy of a $7.8 \mathrm{~mm}$. pig embryo. Anat. Record, 5, I9II.

His: Anatomie menschlicher Embryonen. Leipzig; 1880-84.

Morris: Text-book of anatomy. Philadelphia.

\section{CCELOM, ABDOMINAL PORES.}

Ayers: Pori abdominales. Morph. Jahrb., ro, 1885 .

Bles: On the openings in the wall of the body cavity of vertebrates. Proc. Roy. Soc. London, 62, I897.

Broman: Entwicklung und Bedeutung der Mesenterien und Körperhöhlen bei Wirbeltieren. Ergebnisse, 15, 1905 .

Broman: Entwicklung d. Pericardium und Zwergfells. Ergebnisse, 20, I9 I1.

Gegenbaur: Pori abdominales. Morph. Jahrb., ro, I885.

Klaatsch: Morphologie der Mesenterialbildungen am Darmcanal der Wirbeltieren. Morph. Jahrb., $r \delta, x 892$.

Mall: Development of the human cœlom. Jour. Morph., 12, 1897.

Mathes: Morphologie der Mesenterialbildungen bei Amphibien. Morph. Jahrb., 23, 1895.

Weber: Abdominalporen der Salmoniden nebst Bemerkungen über Geschlechtsorgane. Morph. Jahrb., I2, I887.

\section{INTEGUMENT.}

Batelli: Bau der Reptilienhaut. Arch. mikr. Anat., r7 $_{7} \mathrm{x}_{79}$

Boas: V. Wirbelthierekralle. Morph. Jahrbuch, 23, 1895.

Boas: Morphologie der Nägel, Krallen, Hufe und Klauen. Morph. Jahrb., I I, I8S4. See also $2 \mathrm{I}, \mathrm{r} 894$.

Bonnet: Die Mammarorgane (Summary). Ergebnisse, 2, 1892; 7, I898.

Bonnet: Haarspiral und Haarspindel. Morph. Jahrb., I I, I886.

Bowen: Epitrichium of human epidermis. Anat. Anz., 4, I889.

Brauer: Leuchtorgane der Knochenfische. VerhandI. zool. Gesellsch., I3, r904.

Burckhardt: Luminous organs of selachians. Ann. and Mag. Nat. Hist., VII, 6, I900.

Davies: Entwickelung der Feder, u. s. w. Morph. Jahrb., r5, r889.

Drasch: Giftdrüsen des Salamanders. Verhandl. anat. Gessellsch., 6, 1892.

Esterly: Poison glands of Plethodon. Pubs. Univ. Cal., Zool., I, rgo4.

Göppert: Phylogenie der Wirbelthierkralle. Morph. Jahrb., 25, r8g8.

Green: Phosphorescent organs in Porichthys. Jour. Morphol., I5, I900.

Henneberg: Entwicklung der Mammarorgane der Ratte. Anat. Hefte, 13, r899.

Japha: Haare der Waltiere. Zool. Jahrb., Abt. Anat., 32, I9Ir.

Jeffries: Epidermal system of birds. Proc. Boston Socy. Nat. Hist., 22, I883.

Jones: Development of the nestling feather. Oberlin Lab. Bulletin, r3, 1907 .

Kerbert: Haut der Reptilien. Archiv mikr. Anat., 13, r 876.

Keibel: Ontogenie und Phylogenie von Haare und Feder. Ergebnisse, 5, r895. 
Kerr: Development of skin and derivatives in Lepidosiren. Quar. Jour. Micros., Sci., 46, I902.

Krause: Entwickelung der Epidermis und ihrer Nebenorgane. Handbuch der Entwicklungslehre, 2, Th. I, I9O2.

von Lendenfeld: Phosphorescent organs of fishes. Challenger reports, 22, IS8;. Summary in Biol. Centralblatt, 7, I887.

Leydig: Vascularisiertes Epithel. Archiv mikr. Anat., 52, I898.

Maurer: Vascularisierung der Epidermis bei Anuren. Morph. Jahrb., 26, ISgS.

Maurer: Haut-Sinnesorgane, Feder, und Haaranlagen, Morph. Jahrb., I8, I892; 29, I893 See also 26,1898 .

de Meijere: Die Haare der Säugetiere und ihre Anordnung. Morph. Jahrb. 2 I, I894. Feathers, 23, 1895 .

Muhse: Cutaneous glands of toad. Am. Jour. Anat., 9, I909.

Nicoglu: Hautdrüsen der Amphibien. Zeitschr. wiss. Zool., 56, I893.

O'Donoghue: Growth changes of mammary apparatus of Dasyurus. Quar. Jour. Micr Sci., 57, I9II.

Parker: Movement of melanophore pigment, especially in lizards. Jour. Exp. Zool., 3, I906.

Parker and Starrall: Color changes in skin of Anolis. Proc. Am. Acad. A. and S., 40, I906.

Poulton: Bill and hair of Ornithorhynchus. Quảrterly Jour. Micro. Sci., 36, IS94.

Profé: Ontogenie und Phylogenie der Mammarorgane. Anat. Hefte, II, ISgS.

Pycraft: Interlocking of feathers. Nat. Science, 3, I893.

Reed: Poison glands of catfishes. Amer. Nat., 4I, I907.

Reh: Schuppen der Säugetiere. Jena. Zeitsch., 29, I895.

Romer: Schuppen und Haare am Schwanz von Mus. Jena. Zeit., 30, I8g6. See also 31, 1898.

Sawadsky: Larval Haftapparates bei Acipenser. Anat. Anz., 40, I9II.

Schmidt: Integument von Voeltzkowia (lizard). Zeit. wiss. Zool., 94, I9ro.

Schulz: Giftdrüsen der Kröte und Salamander. Archiv mikr. Anat., 34, ISS9.

Schwalbe: Farbenwechsel winterweisser Thiere. Morph. Arbeiten, 2, I893.

Semon: Mammarorgane der Monotremen. Morph. Jahrb., 28, I899.

Spencer and Sweet: Hairs of Monotremes. Quar. Jour. Mic. Sci., 4I, I899.

Stöhr: Entwicklung des menschlichen Wollhaares. Anat. Hefte, 23, I903.

Strong: Development of the primitive feather. Bull. Mus. Comp. Zool., 40, 1902.

Wallace: Axillary gland of Batrachus. Jour. Morphol., 8, 1893.

Whipple: Naso-labial groove of lungless salamanders. Biol. Bull., II, Igo6.

Wilder: Palms and soles. Amer. Jour. Anat., I, I902.

Zeitschmann: (Odoriferous glands of Cervidæ). Zeits. wiss. Zool., 74, I903.

\section{DERMAL SKELETON.}

Boldt: Ruckenschild der Ceratophrys. Zool. Jahrb. Abt. Anat., 32, I9II.

Hase: Schuppenkleid der Teleostier. Jena. Zeitsch., 42, I907.

Hase: Morphol. Entwicklung der Ktenoidschuppen. Anat. Anz., 40, I9II.

Hertwig: Placoidschuppen und Zähne der Selachier. Jena. Zeitsch., 8, I8 74 .

Hertwig: Hautskelett der Fische. Morph. Jahrb., 2, 1876; 5, I879; 7, I881.

Klaatsch: Morphologie der Fischenschuppen. Morph. Jahrb., I6, I89o.

Nickerson: Development of scales of Lepidosteus Bull. Mus. Comp. Zool., 24, I893.

Parker: Correlated abnormalities in scutes and plates of tortoise. Amer. Nat., 35, Igor.

Römer: Panzer der Gürteltiere. Jena. Zeitsch., 27, 1892.

Tims: Development and morphology of scales of some teleosts. Quar. Jour. Micros. Sci., 49, I905.

Wiedersheim: Histologie der Dipnoerschuppen. Arch. mikr. Anat., I8, I8So. 


\section{SKELETON-GENERAL.}

Baur: Morphology of ribs. Amer. Naturalist, 2 I, 1887. Jour. Morph., 3, I889. (See Anat. Anz., 9, 1883.)

Baur: Carpus and Tarsus der Wirbeltiere. Zool. Anz., 8, I885.

Braus: Gliedmassenpropfung und Grundfragen der Skeletbildung. Morph. Jahrb., 39, rgog.

Cope: Vertebrates of the tertiary formations of the West. Report U. S. (Hayden's) Geol. Survey, 3, 1884 .

Dean: Origin of paired limbs. Amer. Nat., 36, I902.

Gadow: First and second visceral arches with reference to the homologies of the auditory ossicles. Phil. Trans., I79, I888.

Gaupp: Schalleitenden Apparates bei den Wirbeltiere. Ergebnisse, 8, I899.

Gaupp: Schlafendgegend am Wirbeltiereschädel. Morph. Arbeit., 4, I894.

Gaupp: Alte Probleme und neuere Arbeiten über Wirbeltiereschädel. Ergebnisse, ro, I900.

Gaupp: Fragen an d. Lehre vom Kopfskelett. Anat. Anz., Ergänzungshefte, 29, r896.

Gaupp: Unterkiefer der Wirbeltiere. Anat. Anz., 39, I9Ir.

Gaupp: Säugerpterygoid und Echidnapterygoid, u. s. w. Anat. Hefte., 42, I9Io.

Gegenbaur: Skelett der Gliedmassen der Wirbelthiere und der Hintergliedmassen der Selachier. Jena. Zeitsch., 5, I870.

Gegenbaur: Über das Archipterygium. Jena. Zeitsch., 7, I872.

Gegenbaur: Primäre und secundäre Knochenbildung. Jena. Zeitsch., 3, r867.

Gegenbaur: Untersuchungen zur vergl. Anatomie der Wirbelthiere. 3 parts, Leipzig, 1872.

Götte: Morphologie des Skelettsystems der Wirbeltiere. (Girdle and breastbone) Arch. f. mikr. Anat., I5, I878.

Hertwig: Zahnsystem der Amphibien und seine Bedeutung für die Genese des Skeletts der Mundhöhle. Arch. mikr. Anat., I I, I874.

Howes: Morphology of the sternum. Nature, 43, I89r.

Kingsley: The ossicula auditus. Tufts Coll. Studies, I, I900.

Parker and Bettany: Morphology of the skull. London, 1877 .

Parker: Structure and development of the shoulder girdle and sternum. Ray Society; I867.

Parker and Bettany: Morphology of the skull. London, I877.

Reynolds: Vertebrate skeleton. Cambridge (England), $\mathrm{IS}_{97}$.

Thacher: Median and paired fins. Trans. Conn. Acad., 3, 1877 .

Thyng: Squamosal bone in Tetrapoda. Tufts Coll. Studies, 2, I906.

Woodward: Vertebrate paleontology. Cambridge, I8g8.

Wiedersheim: Gliedmassenskelett der Wirbelthiere. Jena, 1892.

Winslow: Chondrocranium in the ichthyopsida. Tufts Coll. Studies, r, I 898 .

Zittell: Handbuch der Palaontologie. München, I884-93. (A translation of an abridgment, by Eastman, London, I900.)

\section{Fishes.}

Adams: Skull of Anarrhichthys. Kansas Univ. Sci. Bull., 4, I908.

Allis: Cranium of Amia. Jour. Morph., 2, I889; I4, I898.

Allis: Jaw bones and breathing valves of Polypterus. Anat. Anz., I 8, I900.

Allis: Skull of Scomber. Jour. Morph., 18, I903.

Balfour: Development of skeleton of paired fins of elasmobranchs. Proc. Zool. Socy. London, I881.

Bridge: Ribs in Polyodon. Proc. Zool. Socy. London, IS97.

Brohmer: Kopf eines embryos von Chlamydoselachus u. d. Segmentirung des Selachierschädels. Jena. Zeitsch., 44, I908. 
Boyer: Mesoderm in teleosts and its share in pectoral fin. Bull. Mus. Comp. Zool., 23, I 892 .

Cartier: Entwicklungsgeschichte der Wirbelsäule. Zeitsch. wiss. Zool., 25, 1875.

Corning: Urwirbelknospen in der Brustflossen der Teleostier. Morph. Jahrb., 22, I894.

Cramer: Skull of Sebastodes. Stanford Univ. Pub., 2, r895.

Dean: Cladoselache. Jour. Morph., 9, r894.

Dean: Fin-fold origin of paired fins. Anat. Anz., r r, 1896.

Derjugin: Entwicklung des Schultergürtels und Brustflosse bei den Teleostiern. Zeit. wiss. Zool., 96, rgro.

Dohrn: Paarigen und unpaarigen Flossen der Selachier. Naples Mittheilungen, 5, I886.

Foote: Extrabranchials in elasmobranchs. Anat. Anz., r3, I897.

Fürbringer: Visceralskelett der Selachier. Morph. Jahrb., 3I, I903.

Gadow and Abbott: Evolution of vertebral column of fishes. Phil. Trans. I86B, I895.

Gaupp: Entwicklung der Schädelknocken b. d. Teleostiern. Anat. Anz., Erganzungshefte $\mathrm{zu} 23$, 1903 .

Gegenbaur: Entwicklungsgeschichte der Wirbelsäule des Lepidosteus. Jena. Zeitschr., 3,1867 .

Gegenbaur: Untersuchungen zu vergleichenden Anatomie der Wirbelthiere. Leipzig, r872. (Skull of elasmobranchs, girdles of fishes.)

Gegenbaur: Kopfskelett von Alepocephalus. Morph. Jahrb., 4, Suppl., I878.

Gegenbaur: Clavicula und Cleithrum. Morph. Jahrb., 23, I895.

Gegenbaur: Flossenskelett der Crossopterygier und das Archipterygium der Fische. Morph. Jahrb., 22, I894.

Gegenbaur: Über das Archipterygium. Jena. Zeitsch., 7, 1872.

Goodrich: Pelvic girdle and fin of Eusthenopteron. Quar. Jour. Micr. Sci., 45, rgor.

Goodrich: Dermal finrays of fishes. Quar. Jour. Micr. Sci., 47, r904.

Goodrich: Development, structure and origin of fins of fishes. Quar. Jour. Micr. Sci., 50, 1906.

Göppert: Morphologie der Fischrippen. Morph. Jahrb., 23, 1896.

Grassi: Entwicklung der Wirbelsäule der Teleostier. Morph. Jahrb.; 8, r882.

Harrison: Entwickelung der unpaaren und paarigen Flossen der Teleostier. Arch. mikr. Anat., 46, r895. .See also 4., 1893 .

Hasse: Entwicklung der Wirbelsäule der Elasmobranchier. Zeitsch. wiss. Zool., 55, r892; Ganoiden, 57, 1893; Cyclostomen, 57, 1893.

Hay: Vertebral column of Amia. Field Columbian Museum, Zool. Publications, r, 1895

Klaatsch: Vergleich. Anat. der Wirbelsäule. Morph. Jahrb., r9-22, I893-95.

Mayer: Unpaaren Flossen der Selachier. Naples Mittheilungen, 6, r885.

Parker: Structure and development of the skull in sharks and skates. Trans. Zool. Socy. London, Io, 1878.

Parker: Skeleton of Marsipobranchs. Phil. Trans., I883.

Parker: Structure and development of skull in Lepidosteus. Phil. Trans., 1882; of sturgeons, same volume.

Pollard: Suspension of jaws in fishes. Anat. Anz., Io, 1894.

Pollard: Oral cirri of siluroids and origin of head. Zool. Jahrb., Anat. Abth., 8, 1895 . Sagemehl: (several papers on skulls of fishes). Morph. Jahrb., 9, ro, I7, I884-1891. Shufeldt: Osteology of Amia (based on Francque). Rept. U. S. Fish Commis. for 1883 I884.

Starks: Several papers. Proc. U. S. Nat. Mus., 2 I-27, I898-I904.

Thacher: Median and paired fins. Trans. Conn. Acad., 3, 1878.

Thacher: Ventral fins of ganoids. Trans. Conn. Acad., 4, ז878.

Veit: Entwicklung des Primordialcranium von Lepidosteus. Anat. Hefte., 44, I9II. Walther: Entwicklung der Deckknochen am Kopfskelett des Hechtes. Jena. Zeitsch., r6, I 883 . 
IVright: Skull and auditory organ of Hypophthalmus. Trans. Roy. Soc. Canada, 4, 1885. Ziegler: Hornfaden der Selachier und die Flossenstrahlen der Knochenfische. Zool. Anz., 33, IgoS.

\section{Amphibia.}

Cope: Hyoid and otic elements in batrachia. Jour. Morph., 2, 1888.

Credner: Stegocephalen und Saurier. Zeitschr. deutsch. geolog. Gesellsch., I881-1893. Eggeling: Aufbau der Skeletteile in Gliedmassen. Jena, IgIr.

Field: Entwickelung der Wirbelsäule der Amphibien. Morph. Jahrb., 22, r895.

Gadow: Evolution of vertebral column of amphibia and amniotes. Phil. Trans., $1 \delta_{\overline{7}}, \mathrm{~B}$, I896.

Gaupp: Primordial-cranium von Rana. Morph. Arbeiten, 2, I893.

Göppert: Amphibienrippen. Morph. Jahrb., 22, 1895.

Kingsbury and Reed: Columella auris in amphibia. Jour. Morph., 20, r909.

Murray: Vertebral column of certain urodeles. Anat. Anz., 13, 1897 .

Parker: Structure and development of skull in urodeles. Phil. Trans., 1877.

Parker: Morphology of skull in Amphibia urodela. Trans. Linn. Socy., Zool., 2, 1879.

Parker: Structure and develop. of skull of common frog. Phil. Trans., I87I.

Parker: Struct. and dev. skull in Batrachia, Pt. II and III. Phil. Trans., r88I

Parker: Struct. and dev. skull in urodeles. Trans. Zool. Socy. London, II, I882.

Peter: Schädel von Ichthyophis. Morph. Jahrb., 25, 1898.

Platt: Development of cartilaginous skull of Necturus. Morph. Jahrb.; 25, 1897.

Shimada: Wirbelsäule und Hüllen des Rückenmark von Cryptobranchus japonicus. Anat.

Hefte, 44, IgrI.

Terry: Nasal skeleton of Amblystoma. Trans. St. Louis Acad. Sci., 16. I906.

Whipple: Ypsiloid apparatus of urodeles. Biol. Bull., ro, r906.

Wiedersheim: Kopfskelett der Urodelen. Morph. Jahrb., 3, I877.

Wilder: Skeletal system of Necturus. Memoirs Boston Socy. Nat. Hist., 5, 1903.

\section{Reptilia.}

Baur: Osteologische Notizen über Reptilien. Zool. Anz., 9 and ro, r886-87.

Baur: Pelvis of the Testudinata. Jour. Morph., 4, $x 89 x$.

Baur: Morphologie des Carpus und Tarsus der Reptillen. Zool. Anz., 8, r885.

Cope: Osteology of lacertilia. Proc. Am. Phil. Socy., 30, I892.

Corning: Neugliederung der Wirbelsäule bei Reptilien. Morph. Jahrb., 17, r891.

Cope: Degenerate scapular and pelvic arches in lacertilia. Jour. Morph., 7 , 1892.

Fürbinger: Knochen und Muskeln der Extremitäten bei schlangenähnlichen Saurien.

Leipzig, 1870.

Gaupp: Chondrocraniun von Lacerta. Anat. Hefte, 15, Iyoo.

Götte: Wirbelbau bei Reptilien. Zeitsch. wiss. Zool., 50, 1892.

Götte: Entwicklung des Carapax der Schildkröten. Zeit. wiss. Zool., 66, 1899.

Hay: Fossil turtles of North America. Carnegie Inst., Igo8.

Howes and Swinnerton: Development of skeleton of Sphenodon. Trans. Zool. Socy. London, r6, rgor.

Kingsley: Reptilian lower jaw. Amer. Nat., 39, 1905.

Marsh: Numerous papers on fossil reptiles. Am. Jour. Sci., r6-50.

Moodie: Reptilian epiphyses. Am. Jour. Anat., 7, I908.

Neit: Schädel d. Dermochelys. Zool. Jahrb., Abt. Anat., 33, I912.

Ogushi: Skelett der japanischen Trionyx. Morph. Jahrb., 43, I9Ix.

Parker: Skull in the common snake. Phil. Trans., 1878.

Parker: Skull in the lacertilia. Phil. Trans., I879. 
Parker: Skull in the crocodile. Trans. Zool. Socy., I9.

Versluys: Mittlere und äussere Ohrsphäre der Lacertilia. Zool. Jahrb., Abth. Anat., I2, I898.

Versluys: Columella auris bei Lacertilien. Zool. Jahrb., Abth. Anat., I9, I903.

\section{Birds.}

Gegenbaur: Becken der Vögel. Jena. Zeitsch., 6, I8, I87 I.

Leighton: Development of wing of Sterna. Tufts Coll. Studies, I, I894.

Lindsay: The avian sternum. Proc. Zool. Socy. London, I885.

Marsh: Odontornithes. U. S. Geol. Survey, I880.

Mehnert: Entwicklung des Os pelvis der Vögel. Morph. Jahrb., I3, I888.

Morse: Carpus and tarsus of birds. Ann. N. Y. Lyceum Nat. Hist., Io, IS 72 .

Osborn: Evidence for a dinosaur-avian stem in the Permian., Am. Nat., 34.

Parker: Skull of the common fowl: Phil. Trans., r869.

Pycraft: Osteology of birds. Proc. Zool. Socy. London, I898.

Parker: Morphology of duck and auk tribes. Royal Irish Acad., Cunningham memoir, $6, \mathrm{r} 890$.

Parker: Structure and development of wing in common fowl. Phil. Trans., I79, I888.

Shufeldt: Osteology of birds. Bulletin N. Y. State Museum, I30, I909. (Gives full list of the author's numerous papers on avian anatomy.)

Siegelbauer: Entwicklung der Vögelextremität. Zeit. wiss. Zool., 97, I9II.

\section{Mammals.}

Allen: Ethmoid bone in mammals. Bull. Mus. Comp. Zool., Io, I883.

Bardeen: Development of human skeleton. Am. Jour. Anat., 4, I905.

Bardeen: Development of thoracic vertebræ in man. Jour. Anat., 4, 1905.

Baur: Morphologie des Carpus der Säuger. Anat. Anz., 4, I889.

Brush: Cervical ribs. J. Hopkins Hosp. Bull., I2, I90I.

Boas: Metatarsus der Wiederkäuer. Morph. Jahrb., I6, I89o.

Collinge: Skull of dog. London, I896.

Dilg: Morphologie des Schädels bei Manatus. Morph. Jahrb., 39, I909.

Eggeling: Clavicula, Præclavicula, Halsrippen und Manubrium sterni. Anat. Anz., 29, I906.

Fischer: Primordialcranium von Talpa. Anat. Hefte, I7, rgor.

Flower: Osteology of the mammalia. London, 1885 .

Frits: Entwicklung der Wirbelsäule von Echidna. Morph. Jahrb., 39, I909.

Froriep: Entwicklung der Wirbelsäule. Arch. Anat. und Phys., I886.

Gaupp: Neue Deutungen a. d. Gebiet der Lehre des Säugetierschädels. Arat. Anz., 27, I905.

Gegenbaur: Episternal Skelettteile. Jena. Zeitsch., I, I864.

Holder: Osteology of right whale. Bull. Am. Mis. Nat. Hist., r, r883.

Howes: Mammalian hyoid. Jour. Anat. and Phys., 30, I897.

Kükenthal: Hand der Cetaceen. Anat. Anz., 3, I888; Morph. Jahrb., I9, IS92.

Mead: Chondrocranium of pig. Am. Jour. Anat., 9, I909.

Olmstead: Primordialcranium eines Hundeembryo. Anat. Hefte, 43, I9I r.

Parker: Skull of pig. Phil. Trans., 1874 .

Parker: Structure and devel. skull in mammalia, Pt. 2, Insectivora. Pt. 3, Edentates. Phil. Trans., I885.

Stromer: Foramen entepicondyloideum und Trochanter tertius. Morph. Jahrb., 29, I902.

Van Kampen: Tympanalgegend des Säugetierschädels. Morph. Jahrb., 34, 1905.

Voit: Primordialcranium des Kaninchens. Anat. Hefte, 38, I909. 
Weiss: Entwicklung der Wirbelsäule der weissen Ratte. Zeitsch. wiss., Zool., 69, I90I. Whitehead and Waddell: Development of human sternum. Am. Jour. Anat., I2, I9I I.

\section{MUSCULAR SYSTEM.}

Allis: Cranial muscles of Amia. Jour. Morph., I2, I 897 .

Ayers and Jackson: Myology of myxinoids. Jour. Morph., I7, IyoI.

Blum: Schwanzmuskulatur des Menschen. Anat. Hefte, 4, I\$94.

Braus: Entwicklung der Musculatur und periph. Nervensystem der Selachier. Morph. Jahrb., 26, 27, 1898-9.

Bruner: Smooth facial muscles of Amphibia. Morph. Jahrb., 29, I901.

Byrnes: Develop. limb muscles in amphibia. Jour. Morph., I4, I897.

Charnock: Muscles of mastication and movements of skull in lacertilia. Zool. Jahrb., Anat. Abth., I8, I903.

Corning: Entwicklung Kopf- und Extremitäten-Muskulatur bei Reptilien. Morph. Jahrb., 28, IS99.

Corning: Vergl. Anat. der Augenmuskulatur. Morph. Jahrb., 29, I900.

Davidoff: Vergl. Anat. der hinteren Gliedmassen der Fische. Morph. Jahrb., 5-6, IS79-So.

Drüner: Zungenbein-, Kiemenbogen- und Kehlkopfmuskeln der Urodelen. Zool. Jahrb. Abth. Anat., I5, I90I; I9, I904.

Edgeworth: Development of head muscles in Gallus. Quar. Jour. Micr. Sci., 51, I907.

Edgeworth: Morphology of the cranial muscles of some vertebrates. Quar. Jour. Micr. Sci., 56, I9II.

Fewkes: Myology of Echidna. Bull. Essex Inst., 9, I877.

Fürbringer: Muskeln der schlangenähnlichen Saurien. Leipzig, I870.

Fürbringer: Vergl. Anat. der Schultermuskeln. Urodeles, Jena. Zeitsch., 7 , 18 $; 3$; Anura. 1. c., 8, I874; Birds, 1. c., 36, I902; Reptiles. Morph. Jahrb., I, I876.

Fürbringer: Muskulatur des Kopf der Cyclostomen. Jena. Zeitsch., 9, I875.

Fürbringer: Muskulatur des Vögelflügels. Morph. Jahrb., 6, I885.

Gadow: Bauchmuskeln der Reptilien. Morph. Jahrb., 7, IS8I.

Gadow: Myologie der Extremitäten der Reptilien. Morph. Jahrb., 7, ISSr.

Humphrey: Several papers on muscles of sharks, dipnoi and urodeles. Jour. Anat. and Phys., I873.

Humphrey: Muscles of Lepidosiren (Protopterus). Jour. Anat. and Phys., 6, I872. Muscles of Ceratodus, same vol.

Lamb: Eye-muscles in Acanthias. Am. Jour. Anat., I, I902.

MacDowell: Myology of Anthropopithecus. Am. Jour. Anat., Io, I910.

McMurrich: Phylogeny of forearm flexors. Am. Jour. Anat., 2, I903; of palmar musculature, same vol.

Mall: Development of human diaphragm. Jour. Morph., I2, I897.

Mall: Development of human diaphragm. Johns Hopkins Hosp. Bull., I2, Igor.

Marion: Mandibular and branchial muscles of elasmobranchs. Am. Nat., 39, I905; Tufts College Studies, 2, I905.

Maurer: Ventral Rumpfmuskulatur der Urodelen. Morph. Jahrb., I7, 1892.

Mivart: Myology of Menopoma, Menobranchus, Chameleon. Proc. Zool. Socy. London, I869-70.

Neal: Development of hypoglossal musculature in Petromyzon and Squalus. Anat. Anz., I3, IS97.

Ribbing: Armmuskulatur der Amphibien, Reptilien und Säugetiere. Zool. Jahrb. Abth. Anat., II, I907.

Rüge: Geschichtsmuskeln der Halbaffen. Morph. Jahrb., II, I885.

Schufeldt: Myology of the raven. London, I890.

Shufeldt: Anatomy (mostly muscles) of Geococcyx. Proc. Zool. Socy. London, I886. 
Uskow: Entwicklung des Zwergfells, u. s. w. Arch. mikr. Anat., 32, I883.

Wilder: Appendicular muscles of Necturus. Zool. Jahrb., Suppl. I5, 2 Bd., rgr2.

\section{ELECTRICAL ORGANS.}

Ballowitz: Anatomie des Zitteraales. Arch. mikr. Anat., 50, 1897.

Ballowitz: Elektrischen Organe von Torpedo. Arch. mikr. Anat., 42, rS93 (Large bibliography.)

Dahlgren and Silvester: Electric organ of Astroscopus. Anat. Anz., 29, Ig06.

Ewart: Development of electric organ in skate. Phil. Trans., r79B, I889.

\section{NERVOUS SYSTEM.}

Barker: The nervous system and its constituent neurones. N. Y., I899.

Edinger: Vorlesungen über den Bau der nervösen Centralorgane des Menschen und der Tiere. 7 th edit., 2 vols., I904-8.

Johnston: Nervous system of vertebrates. Philadelphia, r9o6.

Johnston: Morphology of vertebrate head from viewpoint of functional divisions of nervous system. Jour. Comp. Neurol., r5, 1905.

Johnston: Central nervous system of Vertebrates. Ergebnisse und Fortschritte der Zoologie, 2, I9ro.

\section{BRAIN AND SPINAL CORD.}

Barnes: Development of posterior fissure of spinal cord. Proc. Am. Acad. A. and Sci., I883-4.

Dejerine: Anatomie des centres nerveux. Paris, 1895 .

Herrick: Morphology of forebrain in amphibia and reptiles. Jour. Comp. Neurol., 20, Igro.

Hill: Primary segments of vertebrate head. Zool. Jahrb., I3, I899.

His: Allgemein. Morphologie des Gehirn. Arch. Anat. und Phys., Abth. Anat., I892. Johnston: Morphology of forebrain vesicle in vertebrates. Jour. Comp. Neurol., I9, rgog. Johnston: Morphology of vert. head from point of division of nervous system. Jour. Comp. Neurol. 15 $_{5}$ 1905.

Johnston: Gehirn und Cranialnerven der Anamnier. Ergebnisse, Ir, I90I.

McClure: Segmentation of primitive brain. Jour. Morph., 4, I890.

Nakagawa: Origin of cerebral cortex and homology of optic lobe layers. Jour. Morph., $4, x 890$.

Osborn: Origin of corpus callosum. Morph. Jahrb., I2, I 886.

Smith: Origin of corpus callosum. Trans. Linn. Socy., 7, I897.

Tilney: Hypophysis cerebri. Memoirs Wistar Inst., 2, I9I I.

\section{Cyclostomes and Fishes.}

Ayers and Worthington: Finer anatomy of brain of Bdellostoma. Am. Jour. Anat., 8, I908.

Bing und Burckhardt: Zentralnervensystem von Ceratodus. Anat. Anz., 25, rgo4.

Burckhardt: Centralnervensystem von Protopterus. Berlin, I892.

Chandler: Lymphoid structure above myelencephalon of Lepidosteus. · Univ. Calif. Pub. Zool., 9, rgrr.

Cole: Cranial nerves of Chimæra. Trans. Roy. Socy. Edinb., 38, r896.

Dammerman: Der Saccus vasculosus der Fische ein Tieforgane. Zeit. wiss. Zool., 96, I9I0.

Franz: Das Mormyriden (brain). Zool. Jahrb., Abt. Anat., 32. I9I I.

Franz: Kleinhirn der Knochenfische. Zool. Jahrb., Abt. Anat., 32, Igrr. 
Goronowitsch: Gehirn und Cranialnerven von Acipenser. Morph. Jahrb., I3, I888.

Haller: Bau der Wirbeltiergehirns. I, Salmo und Scyllium. Morph. Jahrb., 26, I898. Herrick: Brains of some American fresh water fishes. Jour. Comp. Neurol., I, I89r. Herrick: Brain of certain ganoids. Jour. Comp. Neurol., I, I89I.

Johnston: Brain of Acipenser. Zool. Jahrb., r5, r9or.

Johnston: Brain of Petromyzon. Jour. Comp. Neurol., I2, I902.

Johnston: Telencephalon of selachians. Jour. Comp. Neurol., 2 I, I9I I.

Johnston: Olfactory lobes, forebrain and habenular tracts of Acipenser. Zool. Bull., I, 1898.

Johnston: Telencephalon of selachians. Jour. Comp. Neurol., 2 I, I9Ir.

Johnston: Telencephalon of ganoids and teleosts. Jour. Comp. Neurol., 2 I. IgII

Kappers: Teleost and selachian brain. Jour. Comp. Neurol., I6, I906.

Kingsbury. Oblongata in fishes. Jour. Comp. Neurol. 7, I897.

Locy: Contribution to structure and development of vertebrate head. Jour. Morph., II, I895.

Mayer: Gehirn der Knochenfische. Arch. Anat. und Phys., I882.

Mayser: Gehirn der Knochenfische (Cyprinoids). Zeit. wiss. Zool., 36, I88I.

Neal: Segmentation of nervous system in Acanthias. Bull. Mus. Comp. Zool., 3I, I\$98.

Nicholls: Reissner's Fibre. Anat. Anz., 40, I912.

Sargent: Reissner's fibre. Bull. Mus. Comp. Zool., 45, I904.

Sargent: Torus longitudinalis of teleost brain. Mark Anniv. Vol., I904.

Waldschmidt: Centralnervensystem und Geruchsorgane von Polyterus. Anat. Anz., 2, I8S7.

Worthington: Brain and cranial nerves of Bdellostoma. Quar. Jour Micr. Sci., 49, r905.

\section{Amphibia.}

Burckhardt: Hirn und Geruchsorgan von Triton und Ichthyophis. Zeitsch. wiss. Zool., $52,1891$.

Fish: Central nervous system of Desmognathus. Jour. Morph., 5, I895.

Fischer: Amphibiorum nudorum neurologiæ specimen primus. Berlin, 1843 .

Gage: Brain of Diemyctylus compared with Amia and Petromyzon. Wilder quartercentury book, I893.

Griggs: Early development of central nervous system in Amblystoma. Jour. Morph., 21, I910.

Kingsbury: Brain of Necturus. Jour. Comp. Neurol., 5, 189.5.

Kingsley and Thyng: Hypophysis in Amblystoma. Tufts Coll. Studies, I, I904.

Osborn: Brain of Amphiuma. Proc. Acad. Nat. Sci., Philadelphia, 188.3.

Osborn: Internal structure of amphibian brain. Jour. Morph., 2, I888.

Waldschmidt: Nervensystem der Gymnophionen. Jena. Zeitsch., 20, I8S6.

\section{Reptilia.}

Gisi: Gehirn von Hatteria [Sphenodon]. Zool. Jahrb., Abth. Anat., 25. Ig07.

Haller: Bau des Wirbeltiergehirns. II, Emys. Morph. Jahrb., 28, I900.

Herrick: Brain of certain reptiles. Jour. Comp. Neurol., I, r89r; see also vol. 3 .

Herrick: Brain of alligator. Jour. Cincinnati Socy. Nat. Hist., I2, r8øo.

Humphrey: Brain of Chelydra. Jour. Comp. Neurol., 4, I894.

Köppen: Anatomie des Eidechsensgehirn. Morph. Arbeiten, I.

Rabl-Rückhard: Centralnervensystem des Alligator. Zeitsch. wiss. Zoo!., 30

Rabl-Rückhard: Gehirn des Riesenschlange. Zeitsch. wiss. Zool., 58, r894. 


\section{Birds.}

Bumm: Grosshirn der Vögel. Zeitsch. wiss. Zool., 38, 1893.

Kamon: Entwicklung des Gehirns des Hünchens. Anat. Hefte, 30, I906.

Streeter: Spinal cord of ostrich. Am. Jour. Anat., 3, I903.

Turner: Avian brain. Jour. Comp. Neurol., $1,189 \mathrm{r}$.

\section{Mammals.}

Bechterew: Leitungsbahnen im Gehirn und Rückenmark. Leipzig, 1898.

Grönberg: Untersuchungen an Gehirn von Erinaceus. Zool. Jahrb., r5, 1891.

Haller: Bau des Gehirn von Mus und Echidna. Morph. Jahrb., 28, I900.

Herrick: Brain of rodents. Bull. Denison Univ., 6, I891.

Landau: Das Katzenshirns. Morph. Jahrb., 38, r9o8.

Sabin: Atlas of medulla and mid brain. Baltimore, rgro.

Smith: Brain of fœtal Ornithorhynchus. Quar. Jour. Micr. Sci., 39, I896.

Smith: Morphology of brain in mammals. Trans. Linn. Socy. London, Zool., 8, I903. Symington: Commissures in marsupialia and monotremes. Jour. Anat. and Phys., 27, 1892.

\section{EPIPHYSIAL STRUCTURES.}

Beard: Parietal eye of cyclostomes. Quar. Jour. Micr. Sci., 29, I888.

Dendy: Devel. parietal eye, etc., in Sphenodon. Quar. Jour. Micr. Sci., 42, I899.

Dexter: Development of paraphysis in fowl. Am. Jour. Anat., 2, I902.

Eycleshymer: Paraphysis and epiphysis in Amblystoma. Anat. Anz., 7, 1892.

Gaupp: Zirbel, Parietalorgan und Paraphysis. Ergebnisse, 7, I897.

Hill: Develop. of epiphysis in Coregonus. Jour. Morph., 5, I89r; of teleosts and Amia, idem, 9, r894.

Kingsbury: Encephalic evaginations in ganoids. Jour. Comp. Neurol., 7 , 1897 .

Minot: Morphology of pineal region based on Acanthias. Am. Jour. Anat., I, r9or.

Nowikoff: Parietalauge von Saurien. Zeit. wiss. Zool., 96, I9ro.

Reese: Develop. of paraphysis and epiphysis in alligator. Smithson. Misc. Coll., 54, I9го.

Ritter: Parietal eye in some lizards. Bull. Mus. Comp. Zool., 20, I891.

Spencer: Pineal eye in Lacertilia. Quar. Micr. Sci., 27, I886.

Warren: Pineal region in Necturus. Am. Jour. Anat., 5, I905.

Warren: Pineal region in reptiles. Am. Jour. Anat., II, I9II.

\section{PERIPHERAL NERVES.}

Allis: Cranial muscles and nerves of Amia. Jour. Morph., I2, I897.

Allis: Cranial nerves in Scomber. Jour. Morph., I8, I903.

Beard: Branchial sense organs and associated ganglia in ichthyopsida. Quar. Jour. Micr. Sci., 25, x885.

Bowers: Cranial nerves of Spelerpes. Proc. Amer. Acad., 36, I901.

Braus: Innervation der paarigen Extremitäten bei Selachiern und Dipnoer. Jena. Zeitsch., 31, I898.

Brook: Bau des sympathet. Nervensystems der Säugetiere. Jour. Morph., 37, 1907; 38, I908.

Brookover: Olfactory nerve, terminalis nerve and preoptic sympathetic in Amia. Jour. Comp. Neurol., 20, I9Io; olfact. and terminalis in Amiurus. Idem, 2 I, I9II.

Carpenter: Develop. oculomotor and abducens nerves and ciliary ganglion in chick. Bull. Mus. Comp. Zool., 48, I906. 
Coghill: Cranial nerves of Amblystoma. Jour. Comp. Neurol., 12, 1902.

Cole: Cranial nerves of Chimæra. Trans.Roy. Socy., Edinburg, 38, 1896.

Cole: Cranial nerves of Gadus. Trans. Linn. Socy. London, Zool., 7, I898.

Fischer: Anat. Abhandl. über Perrennibranchiaten und Derotremen. Hamburg, I $8_{54}$.

See also Amphib. Nudorum, etc., under Brain.

Gegenbaur: Kopfnerven von Hexanchus. Jena. Zeitsch., 6, I87 I.

Hammersten: Innervation der Bauchflossen bei Teleostiern. Morph. Jahrb., 42, I9II.

Herrick: Cranial nerves of Menidia. Jour. Comp. Neurol., 9, r899.

Herrick: Cranial nerves of siluroids. Jour. Comp. Neurol., I I, I90I.

Herrick: Criteria of homology in peripheral nervous system. Jour. Comp. Neurol., I9, I909.

Herrick: Peripheral nervous system of bony fishes. Bull. U. S. Fish Commiss. for 1898 .

Herrick: Nervus terminalis in frog. Jour. Comp. Neurol., I9, I909.

Huber: Sympathetic nervous system. Jour. Comp. Neurol., 7, r897.

Huber: Minute anat. of sympathetic ganglia. Jour. Morph., I6, I899.

Johnston: Cranial nerves of Petromyzonts. Jour. Comp. Neurol., I8, I908.

Johnston: Cranial nerve components of Petromyzon. Morph. Jahrb., 34, I905.

Kunz: Development of sympathetic in turtles. Am. Jour. Anat., II, I9II; mammals and birds. Jour. Comp. Neurol., 20, I9IO; of amphibia, idem, 2 I, I9II; Evolution symp. syst. in vertebrates, idem, 2I, I9II.

Kupffer: Entwicklungsgeschichte des Kopfes. Ergebnisse, r895.

Kupffer: Development of cranial nerves. Jour. Comp. Neurol., I, I89I.

Landacre: Cranial ganglia in Amiurus. Jour. Comp. Neurol., 20, I910.

Landacre: Epibranchial placodes of Lepidosteus and their relation to the cerebral ganglia. Jour. Comp. Neurol., 22, I9I2.

Locy: New cranial nerve in selachians. Mark Anniv. Vol., I903. See also Anat. Anz., 26, I905.

Lubosch: Nervus accesorius Willisii. Arch. mikr. Anat., 54, i\$99.

Mayhoff: 'Monomorphe' Chiasma opticum der Pleuronectiden. Zool. Anz., 39, I9I2.

McKebben: Nervous terminalis in Amphibia. Jour. Comp. Neurol., 2I, I9II.

Neal: Development of ventral nerves in selachii. Mark Anniv. Vol., I903.

Norris: Cranial nerves of Amphiuma. Jour. Comp. Neurol., I8, r9o8.

Parker: Optic chiašma in teleosts. Bull. Mus. Comp. Zool., 40, I903.

Pinkus: Hirnnerven des Protopterus. Morph. Arbeiten, 4, I894.

Prentiss: Development of hypoglossal ganglion in pig. Jour. Comp. Neurol., 20, I9ro.

Punnett: Pelvic plexus and nervus collector in Mustelus. Phil. Trans. I92, B, I900.

Sheldon: Nervus terminalis in carp. Jour. Comp. Neurol., I9, I909.

Stannius: Peripherische Nervensystem der Fische. Rostock, 1849.

Streeter: Development of cranial and spinal nerves in occipital region of man. Am. Jour.

Anat., 4, r904.

Strong: Cranial nerves of amphibia. Jour. Morph., Io, I895.

\section{SENSE ORGANS.}

Okajima: Sinnesorgane von Onychodactylus. Zeit. wiss. Zool., 94, I909.

Osawa: Sinnesorgane der Hatteria [Sphenodon]. Arch. mikr. Anat., 52, IS98.

Schwalbe: Lehrbuch der Anatomie der Sinnesorgane. Erlangen, r883.

\section{Dermal and Lateral Line Organs.}

Allis: Lateral line system in Amia. Jour. Morph., 2, 1889.

Allis: Lateral sensory canals of Mustelus. Quar. Jour. Micr. Sci., 45, 1902.

Allis: Lateral canals of Polyodon. Zool. Jahrb., Abth. Anat., r7, I903.

Ayers and Worthington: Skin end organs of trigeminal and lateralis nerves of Bdellos-

stoma. Am. Jour. Anat., 7, 1907. 
Beard: Segmental sense organs and associated ganglia in ichthyopsida. Quar. Jour. Micr. Sci., 25, I885.

Boll: Savi'schen Bläschen von Torpedo. Arch. Anat. und Phys., 1875 .

Clapp: Lateral line system of Batrachus. Jour. Morph., I5, I899.

Collinge: Sensory canal system of ganoids. Quar. Jour. Micr. Sci., 36, IS94.

Ewart and Mitchell: Lateral sense organs of Elasmobranchs. Trans. Roy. Soc. Edinburg, 38, 1892. (See Garman, Bull. Mus. Comp. Zool., I7, 1888.)

Ewart: Sensory canal of Læmargus. Trans. R. Socy., Edinb., 37, r893.

Harrison: Entwicklung der Sinnesorgane der Seitenlinie der Amphibien. Arch. mikr. Anat., 63 , r903.

Kingsbury: Lateral line system of American amphibia and comparisons with dipnoi. Proc. Amer. Micros. Socy., I7, 1895.

Maurer: Die Epidermis and ihre Abkömmlinge. Leipzig, I895.

Moodie: Lateral line system in extinct amphibia. Jour. Morph., I9, I908.

Morrill: Pectoral appendages of Prionotus. Jour. Morph., II, I895.

Munkert: Lorenzini'schen Ampullen. Anat. Anz., r9, rgor.

Parker: Function of lateral line system in fishes. Bull. Bureau of Fisheries, 24, I905.

Pollard: Lateral line system in siluroids. Zool. Jahrb., 5, I89.3.

Ritter: Eyes, integumental sense papillæ and skin of Typhlogobius. Bull. Mus. Comp. Zool., 24, 1893.

\section{Taste.}

Herrick: Phylogeny and morphol. position of terminal buds of fishes. Jour. Comp. Neurol., 13, I903.

Herrick: Organs and sense of taste in fishes. Bull. U. S. Fish Comm., 22, 1903.

Herrick: Terminal buds of fishes. Jour. Comp. Neurol., I3, I903.

Schwalbe: Geschmacksorgane der Säugetiere. Arch. mikr. Anat., 4, I868

Tuckerman: Gustatory organs of mammals. Jour. Morph., 2, I888; 4, IS90: 7, I892.

\section{Smell.}

Anton: Jacobson'schen Organ und Nasenhöhle der Cryptobranchiaten. Morph. Jahrb., 38, 1908.

Bawden: Nose and Jacobson's organ with reference to amphibia. Jour. Comp. Neurol., 4, I894.

Berliner: Entwicklung des Geruchsorgane der Selachier. Arch. mikr. Anat., 60, I902.

Blaue: Nasenschleimhaut bei Fischen und Amphibien. Arch. Anat. und Phys., Anat. Abth., r884.

Born: Nasenhöhle und Thränennasengang der Amphibien. Morph. Jahrb., 2, 1876; der Amnioten, ibid., 5, 1879; 7, 1882 .

Disse: Riechschleimhaut und Riechnerv bei Wirbeltiere. Ergebnisse, Ir, r9or.

Dogiel: Geruchsorgane bei Ganoiden, Knochenfische, und Amphibien. Arch. mikr. Anat., 29, I887.

Fischer: Nasenhöhle und Tränengange der Amphisbænen. Arch. mikr. Anat., 55, Igoo.

Frets: Entwicklung der Nase bei Affen, Sängern und Menschen. Morph: Jahrb., 44, I9r2.

Gaupp: Nervenversorgen der Mund- und Nasenhöhlendrüsen der Wirbeltiere. Morph. Jahrb., I4, I888.

Gegenbaur: Nasenmuscheln der Vögel. Jena. Zeitsch., 7, I873.

Holm: Develop. Olfactory organ in Teleosts. Morph. Jahrb., 2 I, I894.

McCallum: Nasal region in Eutænia. Proc. Canadian Inst., I, I883.

Peter: Entwicklung d. Geruchsorgane. Ergebnisse, 20, I9I I.

Read: Olfactory apparatus in dog, cat and man. Am. Jour. Anat., 8, Igos.

Schaeffer: Lateral wall of cavum nasi in man. Jour. Morph., 2 I, I9ro. 
Seydel: Nasenhöhle und Jacobson'sche Organ der Amphibien. Morph. Jahrb., 23, I895.

Strong: Olfactory organ and smell in birds. Jour. Morph., 22, rgrr.

Wilder: Nasengegend von Menopoma [Cryptobranchus] und Amphiuma. Zool. Jahrb., Abth. Anat., 5, 1892.

Wilder: Lateral nasal glands of Amphiuma. Jour. Morph., 20, I909.

Zukerkandl: Jacobson'sche Organs. Ergebnisse, r8, I910.

Zukerkandl: Jacobsonsorgane und Riechlappen der Amphibien. Anat. Hefte, 4r, r9ro.

Eyes.

Bage: Retina of lateral eyes of Sphenodon. Quar. Jour. Mic. Sci., 57, rgr2.

Berger: Sehorgane der Fische. Morph. Jahrb., 8, r882.

Brauer: Augen der Tiefseefische. Verhandl. deutsch. zool. Gesellsch., I902.

Carriere: Sehorgane der Thiere. München, 1885 .

Corning: Anatomie der Augenmuskulatur. Morph. Jahrb., 29, I900.

Eggeling: Augenlider der Säugetiere. Jena. Zeitsch., 39, 1904.

Eigenmann: Eyes of blind vertebrates. Biol. Bull., 2, 1900; 5, 1903.

Eigenmann: Eyes of Amblyopsidæ. Arch. Entw. Mechan., 7, 1899.

Eycleshymer: Development of optic vesicles in amphibia. Jour. Morph., 8, 1893.

Eycleshymer: Development of optic vesicles in Amphibia. Jour. Morph., 8, 1890.

Jelgersma: Ursprung des Wirbeltierauges. Morph. Jahrb., 35, r9o6.

Lamb: Development of eye muscles of Acanthias. Am. Jour. Anat., I, rgor.

Locy: Optic vesicles of elasmobranchs and their relations to other structures. Jour. Morph., 9, 1894 .

Mall: Histogenesis of retina. Jour. Morph., 8, r893.

Peters: Harder'schen Drüse. Arch. mikr. Anat., 36, I890.

Rabl: Bau und Entwicklung der Linse. Zeitsch. wiss. Zool., 63, r898; 65, r898; 67, 1899.

Robinson: Formation and structure of optic nerve and its relation to optic stalk. Jour. Anat. and Phys., $30,1896$.

Schaeffer: Develop. nasolacrimal passages in man. Am. Jour. Anat., I3, r9r2.

Studnicka: Sehnerven der Wirbeltiere. Jena. Zeitsch., 31, I897.

Weysse: Histogenesis of retina. Am. Nat., 40, I906.

Williams: Migration of eye in Pseudopleuronecetes. Bull. Mus. Comp. Zool., 40, I902.

\section{Ears.}

Ayers: Vertebrate cephalogenesis (large bibliography). Jour. Morph., 6, I 892.

Ayers: Relations of hair cells of ear. Jour. Morph., 8, 1893.

Bridge and Haddon: Air bladder and Weberian ossicles of siluroids. Phil. Trans., I84, 1893 .

Drüner: Anatomie und Entwicklung des Mittelohres beim Menschen und Maus. Anat. Anz., 24, I904.

Gaupp: Schalleitenden Apparatus bei Wirbeltiere. Ergebnisse, 8 , 1898 .

Kingsbury: Columella auris and nervus facialis. Jour. Comp. Neurol., I3, I903.

Kingsley: Ossicula auditus. Tufts College Studies, r, r9o0.

Mall: Development Eustachian tube, middle ear, etc., of chick. Studies Biol. Lab. Johns Hopkins, 4, 1887.

Norris: Development of auditory vesicle in Amblystoma. Jour. Morph., 7, 1892.

Okajima: Entwicklung d. Gehörorganes von Hydnobius. Anat. Hefte, 45, I9Ir.

Parker: Hearing and allied senses in fishes. Bull. U. S. Fish. Comm. for I902, r903.

See also Am. Nat., 37, 1903.

Streeter: Development of labyrinth and acoustic and facial nerves in human embryo.

Am. Jour. Anat., 6, 1907. 
Versluys: Mittlere und äussere Ohrsphäre der Lacertilier. Zool. Jahrb. Abth. Anat., I2, I898.

Willy: Development of ear and accessory organs in frog. Quar. Jour. Micros. Sci., 30, I89o.

\section{ALIMENTARY CANAL.}

Teeth.

Beard: Teeth of marsipobranchs. Zool. Jahrb., 3, I889.

Burckhardt: Gebiss der Sauropsiden. Morph. Arbeiten, 5, I895.

Cope: Tritubercular molar in human dentition. Jour. Morph., 2, I888.

Harrison: Development and succession of teeth in Hatteria [Sphenodon]. Quart. Jour. Micr. Sci., 44, I90r.

Hertwig: Zahnsystem der Amphibien und seine Bedeutung für den Genese des Skelettes der Mundhöhle. Arch. mikr. Anat., 9, I874.

Kükenthal: Urspring und Entwicklung der Säugetierzähne. Jena. Zeitsch., 26, I892. Laaser: Entw. der Zahnleiste der Selachier. Anat. Anz., I7, I900.

Leche: Entwicklung des Zahnsystem der Säuger. Morph. Jahrb., I9, I892.

Oppel: Verdauungsapparat. Ergebnisse, I3, I903: I4, I904: I6, I906.

Osborn: Evolution of mammalian molars to and from tritubercular type. Am. Nat., 22, I888.

Osborn: Succession of teeth in mammals. Am. Nat., 27, I893.

Osborn: Trituberculy. Am. Nat., 31, I897.

Poulton: Teeth and horny plates of Ornithorhynchus. Quar. Jour. Micr. Sci., 29, I888.

Röse: Entwicklung der Zähne des Menschen. Arch. mikr. Anat., 38, I89I.

Röse: Zahnleiste und Eischwiele der Sauropsiden. Anat. Anz., 7, 1892.

Röse: Phylogenese des Säugetiergebisses. Biol. Centralblatt., 12, 1892.

Ryder: Mechanical genesis of tooth forms. Proc. Acad. Nat. Sci., Philadelphia, 1878.

Tomes: Manual of Dental Anatomy. Philadelphia, I898.

de Terra: Vergl. Anatomie menschlichen Gebisses und der Zähne der Vertebraten. Jena, I9rI.

Warren: Teeth of Petromyzon and Myxine. Quar. Jour. Micr. Sci., 45, I902.

Wilson: Tooth development of Ornithorhynchus. Quar. Jour. Micr. Sci., 5I, I907.

\section{Mouth and Tongue.}

Flint: Submaxillary gland. Am. Jour. Anat., 2, I903.

Gegenbaur: Unterzunge der Säugethiere. Morph. Jahrb., 9, I884.

Gegenbaur: Phylogenese der Zunge. Morph. Jahrb., II, I886; 2 I, I894.

Gegenbaur: Gaumenfalten des Menschen. Morph. Jahrb., 4, I878.

Hammar: Entwicklung der Zunge und Speicheldrüsen. Anat. Anz., 19, I9or.

Heidrich: Mund und Schlundkopfhöhle der Vögel und ihre Drüsen. Morph. Jahrb., 37, 1907.

Kallius: Entwicklung der Zunge. Anat. Hefte, I6, I901; 28, 1905.

Kallius: Entwicklung der Zunge. Anat. Hefte, 4I, I9Io.

Maurer: Blutgefässe im Epithel. Morph. Jahrb., 25, I887.

Oeder: Munddrüsen und Zahnleiste der Anuren. Jena. Zeitsch., 4I, I906.

Pawlowsky: Giftdrüsen einiger Scorpæniden. Zool. Jahrb., Abt. Anat., 3I, I9I I.

Poulton: Tongue of Perameles. Quar. Jour. Micr. Sci., 23, I883.

Reichel: Mundhöhldrüsen der Wirbeltiere. Morph. Jahrb., 7, I882.

Wiedersheim: Kopfdrüsen der Amphibien. Zeit. wiss. Zool., 28, 1877.

Thyreoid Glands, Etc.

Erdheim: Kiemenderiväte bei Ratte, Kaninchen und Igel. Anat. Anz., 29, Igo6. 
Greil: Kiemendarmderiväte von Ceratodus. Anat. Anz. Ergänz. Hefte, 29, rgo6.

Ferguson: Thyreoid in Elasmobranchs. Am. Jour. Anat., Ir, I9Ir.

Gudernatsch: Thyreoid of Teleosts. Jour. Morph., 2 I, I9II.

Hammar: Elasmobranch Thymus. Zool. Jahrb., Abt. Anat., 32, I9II.

Johnstone: Thymus in marsupials. Jour. Linn. Socy., London, Zool., 26, r\$gS.

Kastschenko: Schicksal d. embryon. Schlundspalten bei Säugetieren. Arch. mikr. Anat., 30, 1887 .

Marcus: Schlundspaltgebiet der Gymnophionen. Arch. mikr. Anat., 7 I, I908.

Maurer: Schilddrüse, Thymus und Kiemenreste der Amphibien. Morph. Jahrb., I3, 1887 .

Norris: Ventraler Kiemenreste and Corpus propericardiale of the frog. Anat. Anz., 2 I, I902.

Platt: Development of Thyroid and suprapericardial bodies in Necturus. Anat. Anz., Ix, I896.

Rabl: Anlage der ultimobranchialen Körper bei Vögel. Arch. mikr. Anat., 70, I907.

Schaffer: Schilddrüse von Myxine. Anat. Anz., 28, rgo6.

Söderlund und Bachman: Studien über Thymusinvolution. Arch. mikr. Anat., 73, I909.

Stockard: Development of thyreoid in Bdellostoma. Anat. Anz., 29, I906.

Zuckerkandl: Entwicklung der Schilddrüse und Thymus bei der Ratte. Anat. Hefte, 2 I, r9o3.

\section{Digestive Tract.}

Boas: Magen der Cameliden. Morph. Jahrb., I6, I89o.

Brachet: Développement du foie et pancreas de l'Ammocœtes. Anat. Anz., I3, IS97. Bensley: Pancreas of guinea pig. Am. Jour. Anat., I2, I9rI.

Braun: Pancreas bei Alytes. Morph. Jahrb., 36, I906.

Claypole: Enteron of lamprey. Proc. Am. Micros. Socy., I894.

Choronshitzky: Entstehung der Milz, Leber, Gallenblase, Bauchspeicheldrüse und

Pfortadersystem bei verschieden. Wirbeltiere. Anat. Hefte, 13, r9oo.

Eggeling: Dunndarmrelief und Ernährung bei Knochenfischen. Jena. Zeitsch., 43, 1907.

Göppert: Entwicklung des Pancreas bei Knochenfischen. Morph. Jahrb., 20, I893.

Gadow: Verdauungssystems der Vögel. Jena. Zeitsch., I3, I879.

Helbling: Darm einiger Selachier. Anat. Anz., 22, I903.

Helly: Pancreasentwicklung der Säugetiere. Arch. mikr. Anat., 67, I901.

Howes: Intestinal canal of Ichthyopsida. Jour. Linn. Socy. London, Zool., 23, IS9o.

Johnston: Limit between ectoderm and entoderm in mouth of amphibia. Am. Jour.

Anat., Io, Igro.

Jungklaus: Magen der Cetaceen. Jena. Zeitsch., 32, I898.

Kerr: Development of alimentary tract in Lepidosiren. Quar. Jour. Micr. Sci., 54, Igro.

Killian: Bursa und Tonsilla pharyngea. Morph. Jahrb., I4, I888.

Kingsbury: Enteron of Necturus. Proc. Am. Micros., I894.

Lewis and Thyng: Intestinal diverticula in embryos of pig, rabbit and man. Am. Jour. Anat., 7, I908.

Mayr: Entwicklung des Pancreas bei Selachier. Anat. Hefte, 8, I897.

Mayer: Spiraldarm der Selachier. Neap. Mittheil., r2, I897.

Oppel: Verdauungsapparat. Ergebnisse, 7, I897.

Osawa: Eingeweiden der Hatteria [Sphenodon]. Arch. mikr. Anat., 49, I897.

Parker: Spiral valve in Raia. Trans. Zool. Socy. London, I I, I880.

Piper: Entwicklung von Magen, Duodenum, Schwimmblase, Leber, Pancreas und Milz bei Amia. Arch. Anat. und Physiol., Igo2.

Pohlman: Development of cloaca in human embryos. Am. Jour. Anat., I2, I9II.

Rex: Morphologie der Säugerleber. Morph. Jahrb., I4, I888. 
Rückert: Entwicklung des Spiraldarmes bei Selachiern. Arch.f. Entwick. mechan. 4, 1896.

Segeratsråle: Teleostierleber. Anat. Hefte, 4I, r9ro.

Stieda: Bau und Entwicklung der Bursa Fabricii. Zeit. wiss. Zool., 34, r88o.

Stöhr: Entwicklung der Hypochorda und dorsal Pancreas bei Rana. Morph. Jahrb., 23, 1895 .

Teichmann: Kropf der Tauben. Arch. mikr. Anat., 34, r889.

Thyng: Pancreas in embryos of pig, rabbit, cat and man. Am. Jour. Anat., 7, rgo8.

Volker: Entwicklung des Pancreas bei den Amnioten. Arch. mikr. Anat., 59, I90 I.

\section{RESPIRATORY ORGANS.}

\section{General.}

Clemenz: Äussere Kiemen der Wirbeltiere. Anat. Hefte, 5, rgo4.

Göppert: Kehlkopf der Amphibien und Reptilien. Morph. Jahrb., 22, 1904; 26, I898; 28, 1899 .

Götte: Ursprung der Lunge. Zool. Jahrb., Anat. Abth., 2 r, r905.

Miller: Structure of the lung. Jour. Morph., 8, x893.

Moser: Entwicklungsgeschichte der Wirbeltierlunge. Arch. mikr. Anat., 60, I902 . Oppel: Athmungsapparat. Ergebnisse, 13, I903; 14, 1904; 16, 1906.

Schmidt: Kehlhügel der Amnioten. Morph. Jahrb., 43, r9I I.

Spengel: Schwimmblasen, Lungen und Kiementaschen der Wirbeltiere. Zool. Jahrb. Suppl., 7, r9o4.

\section{Cyclostomes and Fishes.}

Babak: Darmathmung der Cobiten. Biol. Centralb., 27, I907.

Beaufort: Schwimmblase der Malacopterygii. Morph. Jahrb., 39, I909.

Braus: Embryonal Kiemenapparat von Heptanchus. Anat. Anz., 29, Igo6.

Bridge and Haddon: Air-bladder and Weberian ossicles of Siluridæ. Phil. Trans., I84, 1893 .

Corning: Wundernetzbildes in Schwimmblase der Teleostier. Morph. Jahrb., I4, I888.

Dahlgren: Breathing valves of teleosts. Zool. Bull., 2, r898.

Dohrn: Urgeschichte, u.s.w. Spritzlochkieme der Selachier, Opercularkieme d. Ganoiden, Pseudobranchie der Teleostier. Neapel. Mitth., 7, I886.

Greil: Homologie der Anamnierkiemen. Anat. Anz., 28, 1906.

Jaeger: Physiologie der Schwimmblase. Biol. Centralbl., 24, I904.

Kellicott: Develop. vasc. and respiratory systems of Ceratodus. Mem. N. Y. Acad. Sci., 2, 1904.

Mauer: Pseudobranchien der Knochenfisches. Morph. Jahrb., 9, I883.

Moroff: Entwicklung der Kiemen der Knochenfischen. Arch. mikr. Anat., 60, 1902.

Moser: Entwicklung der Schwimmblase. Arch. mikr. Anat., 63, r904.

Muller: Entwicklung und Bedeutung der Pseudobranchie bei Lepidosteus. Arch. mikr. Anat., 49, r897.

Nusbaum: Gasdrüse in Schwimmblase. Anat. Anz., 31, r907.

Rand: Functions of spiracle in skate. Am. Nat., 4I, 1907. See also Darbyshire, Jour. Linn. Socy., Zool., 30, I907.

Stockard: Development of mouth and gills in Bdellostoma. Am. Jour. Anat., 5, 1906.

Thilo: Luftsacke bei Kugelfische. Anat. Anz., r6, I899.

Wiedersheim: Ein Kehlkopf bei Ganoiden und Dipnoern. Zool. Jahrb. Suppl. 7 , I904.

Zograff: Labyrinthine apparatus of labyrinthine fishes. Quar. Jour. Micr. Sci., 28, 1889.

\section{Amphibia.}

Bruner: Smooth facial muscles of anura and salamandrina (respiratory mechanism). Morph. Jahrb., 29, rgor. 
Greil: Anlage der Lungen und Ultimobranchialkörper. Anat. Hefte, 29, 1905.

Fox: Tympano-Eustachian passage in toad. Proc. Acad. Nat. Sci., Phila., rgor

Martens: Entwicklung der Kehlkopfknorpel bei Anuren. Anat. Hefte, 9, I897.

Ochsner: Lung of Necturus. Bull. Univ. Wisconsin, 33, rgoo.

Seelyee: Circulatory and respiratory systems of Desmognathus. Proc. Boston Socy., Nat. Hist., 32, rgo6.

Whipple: Ypsiloid apparatus of Urodeles. Biol. Bull., Io, I906.

Vilder: Phylogenesis of larynx. Anat. Anz., 7, 1892.

Whipple: Naso-labial groove of salamanders. Biol. Bull., I I, I906.

Wilder: Amphibian larynx. Zool. Jahrb. Abth. Anat., 9, I896.

Wilder: Lungless salamanders. Anat. Anz., 9, I894; I2, 1896.

Wilder: Pharyngeo-œsophageal lung of Desmognathus. Am. Nat., 35, I901.

\section{Sauropsida.}

Cope: Lungs of ophidia. Proc. Am. Phil. Socy., 33, I904.

Gage: Aquatic respiration in soft-shelled turtles. Am. Nat., 20, 1886.

Häcker: Unter Kehlkopf der Singvögel. Anat. Anz., I4, I898.

Heidrich: Mund-Schlundhöhle der Vögel. Morph. Jahrb., 37, 1907.

Huxley: Respiratory organs of Apteryx. Proc. Zool. Socy. London, IS82.

Milani: Reptilienlungen. Zool. Jahrb. Abth. Anat., 8, I894; ro, I897.

Müller: Air sacs of pigeon. Smithsonian Misc. Coll., 50, 1907.

Sappey: Recherches sur l'apparaeil respiratoire des oiseaux. Paris, 1847.

Strasser: Luftsacke der Vögel. Morph. Jahrb., 3, 1877.

Mammals.

Bremer: Lungs of opossum. Am. Jour. Anat., 3, I904.

Dubois: Morphologie des Larynx. Anat. Anz., I, I886.

Fox: Pharyngeal pouches and their derivatives. Am. Jour. Anat., 8, I908.

Göppert: Herkunft des Wrisberg'schen Knorpels. Morph. Jahrb., 2 I, I894.

His: Bildungsgeschichte der Lungen bei mensch. Embryonen. Arch. Anat. und Phys., I887.

Justesen: Entwicklung und Verzweigung des Bronchialbaumes der Säugetierlunge. Arch. mikr. Anat., 56, I900.

Mall: Branchial clefts and thymus of dog. Johns Hopkins Studies Biol. Lab., 4, I88S. Shaeffer: Sinus maxillaris in Man. Am. Jour. Anat., ro, Igro.

Schaeffer: Lateral walls of cavum nasi in man. Jour. Morph., $2 \mathrm{I}$, I9Io.

Symington: The marsupial larynx. Jour. Anat. and Physiol., 33, I898; 35, I899.

\section{CIRCULATION.}

\section{General.}

Allis: Pseudobranchial and carotid arteries in gnathostomes. Zool. Jahrb., Abth. Anat.. 27, Igos.

Ayers: Morphology of the carotids. Bull. Mus. Comp. Zool., I7, r889.

Boas: Arterienbogen der Wirbelthiere. Morph. Jahrb., 13, I887.

Broman: Entwicklung, 'Wanderung' und Variation der Bauchaortenzweige bei Wirbeltieren. Ergebnisse, I6, rgo6.

Greil: Anatomie und Entwicklung des Herzens und Truncus arteriosus der Wirbelthiere. Morph. Jahrb., 3I, 1903.

Greil: Entwicklung des Truncus arteriosus der Anamnier. Verhandl. Anat. Gesellsch., I7, I903.

Grosser: Kopfvenensystem der Wirbeltiere. Verh. Anat. Gesellsch., 2 I, I907.

Hochstetter: Vergl. Anat. und Entwicklung des Venensystem der Amphibien und Fische, Morph. Jahrb.. I3, I888. 
Hochstetter: Entwicklungsgeschichte des Gefässsystem. Ergebnisse, I, I\$92. Howell: Life history of the formed elements of the blood. Jour. Morph., 4, I89o. Lewis: Development of the vena cava inferior. Am. Jour. Anat., x, 1902.

Lewis: Sinusoids. Anat. Anz., 25, 1904.

Röse: Vergl. Anat. des Herzens der Wirbeltiere. Morph. Jahrb., I6, I8go.

Weidenreich: Die roten Blutkörperchen. Ergebnisse, 13, I903.

Weidenreich: Morphologie der Blutzellen. Anat. Record, 4, I9ro.

Wright: Histogenesis of blood platelets. Jour. Morph., 21, I910.

Weidenreich: Blut und Blutbildenden und -zerstörenden Organe. Arch. mikr. Anat. $65-72$, I904-8.

\section{Fishes.}

Allen: Blood-vascular system of Loricati. Proc. Washington Acad. Sci., 7, I905.

Allis: Pseudobranchial and carotid arteries in Polypterus and Amiurus. Anat. Anz., 33, rgo8; in Esox, Salmo, Gapdus and Amia, 1. c., 4I, r9r2.

Allen: Subcutaneous vessels in head of Polyodon and Lepidosteus. Proc. Washington Acad. Sci., 9, I907.

Carazzi: Sistema arteriosa di Squalidi. Anat. Anz., 36, 1905.

Danforth: Heart and arteries of Polyodon. Jour. Morph., 23, I9r2.

Hoffmann: Entwicklung des Herzens und Blutgefässe bei Selachiern. Morph. Jahrb., 19, 1893 . Venensystem, idem, 20, 1893.

Holbrook: Origin of endocardium in bony fishes. Bull. Mus. Comp. Zool., 25, r894. Jackson: Vascular system of Bdellostoma. Jour. Cincinnati Socy. Nat. Hist., 20, I901 . Allen: Subcutaneous vessels in tail of Lepidosteus. Am. Jour. Anat., 8, 1908.

Kellicott: Development of vascular and respiratory systems of Ceratodus. Mem. N. Y. Acad. Sci., 2, r905.

Mayer: Entwicklung des Herzens u. d. grossen Gefasssstamme bei Selachier. Mittheil. zool. Sta. Neapel, 7, r887; see also 8, r888.

Parker and Davis: Blood-vessels of heart of Carcharias, Raia and Amia. Proc. Boston Socy. Nat. Hist., 29, 1899.

Parker: Blood-vessels of heart of Orthagoriscus. Anat. Anz., I7, I900.

Rand: Posterior connections of lateral vein in skates. Am. Nat., 39, 1905.

Rex: Hirnvenen der Elasmobranchier. Morph. Jahrb., I7, I89I.

Senior: Conus arteriosus in Tarpon and Megalops. Biol. Bull., x2, 1907.

Senior: Development of heart in shad. Am. Jour. Anat., 9, I909.

Silvester: Blood-vascular system of Lopholatilus. Bull. Bureau of Fisheries, 24, I904.

Sobotta: Entwicklung des Blut, Herzens und grossen Gefässstamme der Salmoniden. Anat. Hefte, I9, I902.

\section{Amphibia.}

Bethge: Blutgefässsystem von Salamandra, Triton und Spelerpes. Zeit. wiss. Zool., 63 , I898.

Bruner: Heart of lungless salamanders. Jour. Morph., x6, xgoo.

Huxley: Skull and heart of Menobranchus [Necturus]. Proc. Zool. Socy. London, I874.

Hopkins: Heart of lungless salamanders. Am. Nat., $30,1896$.

Marshall and Bles: Development of blood-vessels in frog. Studies Biol. Lab. Owens' College, 2, I89o.

Maurer: Kiemen und ihre Gefässe bei Amphibien. Morph. Jahrb., I4, x888.

Miller: Blood- and lymph-vessels of lung of Necturus. Am. Jour. Anat., 4, 1905.

Parker: Persistence of left postcardinal vein in frog; homologies of veins in Dipnoi. Proc. Zool. Socy. London, 1889 .

Rabl: Bildung des Herzens der Amphibien. Morph. Jahrb., I2, I887.

Rex: Hirnvenen der Amphibien. Morph. Jahrb., I9, I892. 
Romeiser: Abnormal venous system. in Necturus. Am. Nat., 39, 1906.

Santhoff and van Vorhis: Vascular system of Necturus. Bull. Univ. Wisc., 33, I900.

Seelye: Circulatory and respiratory systems of Desmognathus. Proc. Boston Socy. Nat. Hist., 32, I906

\section{Sauropsida.}

Bruner: Cephalic veins and sinuses of reptiles. Am. Jour. Anat., 7, 1907.

Davenport: Carotids and Botall's duct of alligator. Bull. Mus. Comp. Zool., 24, IS93. Evans: Earliest blood-vessels in anterior limbs of birds. Am. Jour. Anat., 9, I909.

Grosser and Brezina: Entwicklung der Venen des Kopfes und Halses der Reptilien. Morph. Jahrb., 23, 1895.

Hochstetter: Entwicklungsgeschichte des Venensystems der Amnioten. Reptilien. Morph. Jahrb., I9, I892.

Hochstetter: Arterien des Darmcanals der Saurier. Morph. Jahrb., r6, r898.

Mackay: Development of branchial arches in birds. Trans. Roy. Socy. London, I79, IS8S.

Miller: Development of postcava in birds. Am. Jour. Anat., 2, I903.

Strömsten: Anat. and develop. venous system of Chelonia. Am. Jour. Anat., 4, 1905.

\section{Mammals.}

Beddard: Azygos veins in mammals. Proc. Zool. Socy. London, I907.

Born: Entwicklungsgeschichte des Säugetierherzens. Arch. mikr. Anat., 33, x889.

Davis: Chief veins in early pig embryos. Am. Jour. Anat., Io, I910.

Dexter: Vitelline veins of cat. Am. Jour. Anat., I, I902.

Göppert: Entwicklung von Varietäten im Arteriensystem der weissen Maus. Morph. Jahrb., 40, I909.

Hochstetter: Fntwicklungsgeschichte des Venensystems der Amnioten. Mammalia. Morph. Jahrb., 20, I893.

Hochstetter: Venensystem der Edentaten. Morph. Jahrb., 25, I897.

Lewis: Development of vena cava inferior. Am. Jour. Anat., I, I902.

Lewis: Development of veins in limbs of rabbit. Am. Jour. Anat., 5, I905.

McClure: Abnormalities in postcava of cat. Am. Nat., 34, I900.

McClure: Anatomy and development of venous system of Didelphys. Am. Jour. Anat., 2 , I903; 5,1905 .

Minot: Veins of Wolffian body of pig. Proc. Boston Socy. Nat. Hist., 28, r898.

Parker and Tozier: Thoracic derivatives of postcardinals in swine. Bull. Mus. Comp. Zool., 3r, I 898 .

Reagan: Fifth aortic arch in mammals. Am. Jour. Anat., I2, Igr2.

Röse: Entwicklung des Säugetierherzens. Morph. Jahrb., 15, r89o.

Salzer: Entwicklung der Kopfvenen des Meerschweinnchens. Morph. Jahrb., 23, IS95

Sicher: Entwicklung der Kopfarterien von Talpa. Morph. Jahrb., 44, I9r2

Tandler: Anatomie der Kopfarterien bei Mammalia. Anat. Hefte, r8, I9or.

\section{Lymphatics.}

Allen: Lymphatics of Scorpænichthys. Proc. Washington Acad. Sci., 8, I906. Am. Jour. Anat., II, IgIr.

Allen: Subcutaneous vessels in tail of Lepidosteus. Anat. Record, 3, r908.

Baetjer: Mesenteric lymph sac in pig. Anat. Record, 2, Igo8.

Budge: Lymphherzen bei Hühnerembryonen. Arch. Anat. u. Physiol., I88\%.

Helly: Hämolymphdrüsen. Ergebnisse, x 2, 1902.

Hopkins: Lymphatics and enteric epitheilum of Amia. Wilder Quarter Century Book, I893.

Hoyer und Udziela: Lymphgefässsystem von Salamanderlarven. Morph. Jahrb 44, rgr2. 
Huntington: Anatomy and development of systematic lymphatic vessels of cat. Memoirs Wistar Inst., I, I I I I.

Huntington and McClure: Numerous papers on lymph system of mammals in Am. Jour. Anat. and Anat. Record.

Killian: Bursa und tonsilla pharyngea. Morph. Jahrb., I4, I888.

Knower: Development of lymph hearts and lymph sacs in frog. Anat. Record, 2, Igos.

Lewis: Development of lymphatics in rabbit. Am. Jour. Anat., 5, I905.

McClure: Development of lymphatics in cat. Anat. Anz., 32, 1908.

Marcus: Intersegmentale Lymphherzen der Gymnophionen. Morph. Jahrb., 38, r9o8.

Maurer: Anlage der Milz und lymphat. Zellen bei Amphibien. Morph. Jahrb., I6, I89o.

Meyer: Hæmolymph glands of sheep. Anat. Record, 2, I908.

Miller: Development of jugular lymph sac of birds. Am. Jour. Anat., I2, I9I2.

Müller: Lymphherzenz Chelonier. Abhandl. Berlin Acad., I839.

Sabin: Origin of lymphatic system in pig. Am. Jour. Anat., I, I902; 3, I904; 4, I905.

Sabin: Lymphatic system in human embryos. Am. Jour. Anat., 9, I909.

Sabin: Recent articles on development of lymph system. Anat. Record, 5, I9I I (Bibliography.)

Stöhr: Lymphknoten des Darmes. Arch. mikr. Anat., 33, I889.

Stöhr: Entwicklung von Darmlymphknötchen, u. s. w. Arch. mikr. Anat., 5 r, r898.

Tonkoff: Entwicklung der Milz bei Vögeln. Anat. Anz., I6, I899.

Tonkoff: Entwicklung der Milz bei Amnioten. Arch. mikr. Anat., 56, I900.

Tonkoff: Entwicklung der Milz bei Tropidonotus. Anat. Anz., 23, I903.

Weliky: Vielzählige Lymphherzens bei Salamandra. Zool. Anz., 7, I884.

\section{UROGENITAL ORGANS.}

General.

Bardeleben: Spermatogenese bei Menschen. Jena. Zeitsch., 31, I898.

Born: Entwicklung der Geschlechtsdrüse. Ergebnisse, 4, I895.

Disselhorst: Harnleiter der Wirbeltiere. Anat. Hefte, 4, 1894.

Felix: Entwicklungsgeschichte des Excretionsystemes, von Rückert (I888) bis I904 Ergebnisse, 13, I903.

Fürbringer: Excretionsorgane der Vertebraten. Morph. Jahrb., 4, I878.

Gerhardt: Kopulationsorgans der Wirbeltiere. Ergebnisse und Fortschritt der Zoologie, $x$, xyog.

Hoffmann: Entwicklung der Urogenitalorgane bei Anamnia. Zeits. wiss. Zool., 44, I 886 .

Montgomery: Morphology of excretory organs of metazoa. Proc. Am. Philos. Socy., 47 , I90S.

Peter: Bau und Entwicklung der Niere. Jena, I909.

Rückert: Entwicklung der Exkretionsorgane. Ergebnisse, I, I892.

Semon: Bauplan der Urogenitalsystem der Wirbeltiere, u. s. w. Jena. Zeitsch., 26, I 891 .

Semper: Urogenitalsystem der Plagiostomen. Arbeit. a. d. zool. zoot. Inst. IVürzburg, 2 I875.

Taussig: Development of the hymen. Am. Jour. Anat., 8, I908.

Wijhe: Mesodermsegmente des Rumpfes und Entwicklung des Exkretionsystemes. Arch. mikr. Anat., 33, I889.

\section{Cyclostomes and Fishes.}

Allen: Origin of sex-cells of Amia and Lepidosteus. Jour. Morph., 22, IyII.

Dodds: Segregation of germ-cells of Lophius. Jour. Morph., 2 I, I9IO.

Emery: Kopfniere der Te'eostier. Biol. Centralb., I, I88I-2. 
Balfour and Parker: Lepidosteus. Phil. Trans., r882.

Haller: Phylogenese des Nierenorganes der Knochenfische. Jena. Zeitsch., 43, I908. Kerr: Male genito-urinary organs of Lepidosiren and Protopterus. Proc. Zool. Socy. London, rgor.

Krall: Männliche Beckenflosse von Hexanchus. Morph. Jahrb., 37, I908.

Maas: Entwicklung der Vorniere und Urniere bei Myxine. Zool. Jahrb., Abth. Anat., Io, r897.

Müller: Urogenitalsystem des Amphioxus und der Cyclostomen. Jena. Zeitsch., 9, 1875.

Price: Development of excretory organs of Bdellostoma. Am. Jour. Anat., 4, I904.

Rabl: Entwicklung des Urogenitalsystems der Selachier. Morph. Jahrb., 24, 1896.

Rückert: Entstehung der Exkretionsorgane bei Selachiern. Arch. Anat. u. Physiol., I88S.

Schreiner: Generationsorgane von Myxine. Biol. Centralbl., 24, I904.

Wheeler: Development of urogenital organs of Lamprey. Zool. Jahrb. Abth. Anat., I3, I899.

Wijhe: Entwicklung des Exkretionssystemes und andere Organe bei Selachiern. Anat. Anz., 2, ISSS.

Woods: Origin and migration of germ-cells in Acanthias. Am. Jour. Anat., $\dot{x}, 1902$.

\section{Amphibia.}

Field: Development of pronephros and segmental duct in amphibia. Bull. Mus. Comp. Zool., 2 I, IS9I.

Field: Morphologie der Harnblase bei Amphibien. Morph. Arbeiten, 4, I894.

Hall: Development of mesonephros and Müllerian ducts in amphibia. Bull. Mus. Comp. Zool., 45, Ig04.

King: Bidder's organ in Bufo. Jour. Morph., $\mathrm{x}_{9}, \mathrm{x} 908$.

King: Anomalies in genital organs of Bufo. Am. Jour. Anat., 10, r910.

Marshall and Bles: Development of kidneys and fat bodies in frog. Studies Biol. Lab. Owens Coll., 2, 1890.

Mollendorf: Entwicklung der Darmarterien und Vornieren Glomerulus bei Bombinator. Morph. Jahrb., 43, I9II.

Semon: Bauplan der Urogenitalsystems, dargelegt an Ichthyophis. Jena. Zeitschr., 26, rSgr.

Spengel: Urogenitalsystem der Amphibien. Arbeit. zool. zoot. Inst. Würzburg, 3, I8s6.

\section{Sauropsida.}

Boas: Begattungsorgane der Amnioten. Morph. Jahrb., I7, r89x.

Cope: Hemipenes of the sauria. Proc. Acad. Nat. Sci., Philadelphia, 1896.

Fleck: Entwicklung des Urogenitalsystem beim Gecko. Anat. Hefte, 4I, I9ro.

Gasser: Entstehung der Kloacalöffnung der Hühnerembryonen. Arch. Anat. und Physiol., I880.

Gregory: Development of excretory system in turtles. Zool. Jahrb., Abth. Anat., I3, 1900.

Hoffmann: Entwicklung der Urogenitalorgane bei Reptilien. Zeit. wiss. Zool., 48, r889.

Rabl: Entwicklung der Vorniere bei Vögel. Arch. mikr. Anat., 72, I908.

Schreiner: Entwicklung der Amniotenniere. Zeitsch. wiss. Zool., 7I, 1902.

Wiedersheim: Entwicklung des Urogenitalapparates bei Krokodilien und Schildkröten. Arch. mikr. Anat., 36, 1890.

\section{Mammals.}

Beiling: Anatomie der Vagina und Uterus der Säugetiere. Arch. mikr. Anat., 67, rgo6.

Broek: Urgenital-apparates der Beutler. Morph. Jahrb., 4I, I9Io.

Boas: Begattungsorgane der Amnioten. Morph. Jahrb., I7, r89r. 
Bremer: Morphology of tubules of testis and epididymis. Am. Jour. Anat., II, IgII. Broek: Männlichen Geschlechtsorgane der Beuteltiere. Morph. Jahrb., 4I, I9IO.

Cole: Intromittent sac of male guinea pig. Jour. Anat. and Physiol., 32, I 897 .

Courant: Preputialdrüse des Kaninchens. Arch. mikr. Anat., 62, I903.

Daudt: Urogenitalapparates der Cetaceen. Jena. Zeitschr., 32, I898.

Gerhardt: Entwicklung der bleibenden Niere. Arch. mikr. Anat., 57, Igor.

Gudernatsch: Hermaphroditismus verus in man. Am. Jour. Anat. II, IgII.

Gilbert: Os Priapi der Säuger. Morph. Jahrb., 8, 1892.

Gerhardt: Kopulationsorgane der Säugetiere. Jena. Zeitsch., 39, I904.

Kaudern: Männl. Geschlectsorgane von Insectivoren und Lemuriden. Zool. Jahrb., Abt. Anat., 3r, I9ro.

Keibel: Entwicklung der Harnblase. Anat. Anz., 6, I89r.

Keibel: Entwicklung des menschlichen Urogenitalapparates. Arch. Anat. und Physiol. Anat. Abth., I896.

Klaatsch. Descensus testiculorum. Morph. Jahrb., r6, I89o.

MacCallum. Wolffian body of higher animals. Am. Jour. Anat., I, I892.

Montgomery: Human cells of Sertoli. Biol. Bulletin, 2 r, rgI I.

Müller: Prostate der Haussäugetiere. Anat. Hefte, 26, I904.

Poulton: Structures connected with ovarial ovum of marsupials and monotremes. Quart. Jour. Micros. Sci., 24, 1884.

Robinson: Position and peritoneal relations of mammalian ovum. Jour. Anat. and Physiol., 1887.

Schreiner: Entwicklung der Amniotenniere. Zeitsch. wiss. Zool., 7 I, I902.

Sobotta: Entstehung des Corpus luteum. Ergebnisse, 8, I898; II, I90I.

Weber: Entwicklung des uropoetisches Apparats. bei Säugern. Morph. Arbeiten, 7, r897.

\section{SUPRARENALS.}

Aichel: Entwicklungsgeschichte und Stammesgeschichte der Nebennieren. Arch. mikr. Anat., 56, I900.

Collinge and Vincent: So-called suprarenals in cyclostomes. Anat. Anz., I2, I896.

Flint: The Adrenal. Johns Hopkins Hospital Report, I900.

Kohn: Nebennieren der Selachier. Arch. mikr. Anat., 53, I 898.

Kunz: Develop. adrenals in turtle. Am. Jour. Anat., I3, I9I2.

Srdìnko: Nebennieren bei Anuren. Anat. Anz., I8, I9oo.

Srdìnko: Nebennieren der Knochenfischen. Arch. mikr. Anat., 7 I, I908.

Vincent: Discussion of suprarenals. Jour. Anat. and Phys., 38, I903.

Weldon: Suprarenals of vertebrates. Quar. Jour. Micr. Sci., 24, I884; 25, ISS 5 .

\section{FETAL ENVELOPES, PLACENTA, ETC.}

Corning: Erste Anlage der Allantois bei Reptilien. Morph. Jahrb., 23, I 895.

Hill: Placentation of Perameles. Quar. Jour. Micr. Sci., 40, I898.

Hubrecht: Placentation of Erinaceus. Quar. Jour. Micr. Sci., 30, I889. Of Sorex. idem, 35, 1893. Spolia Nemoris (lemurs and edentates), idem, 36, r904.

Minot: Uterus and embryo. Jour. Morph., 2, I889.

Minot: Theory of the structure of the placenta. Anat. Anz., 6, I89r.

Osborn: Fœtal membranes of marsupials. Jour. Morph., I, I887.

Robinson: Segmentation cavity, archenteron, germ layers and amnion of mammals. Quar. Jour. Micr. Sci., 33, I892.

Turner: Lectures on the anatomy of the placenta. Edinburgh, 1876 .

Van Beneden et Julin: Formation des annexes fœtales chez les Mammiferes. Archives de Biol., 5, 1884 . 


\section{DEFINITIONS OF SYSTEMATIC NAMES.}

Acanthias, genus of sharks including common dogtish.

Acipenser, genus of ganoids; sturgeon.

Aglossa, tongueless toads from Africa and South America.

Allantoidea, the higher vertebrates with allantois: reptiles, birds and mammals.

Amblystoma, genus of tailed amphibians, largely American.

Amia, genus of ganoid fishes peculiar to America.

Ammocœetes, the larval stage of the lampreys.

Amniotes, division of vertebrates with amnion and allantois in development; reptiles, birds and mammal.

Amphibia, class of vertebrates, young with gills, adults with lungs; frogs, toads and salamanders.

Amphioxus, fish-like form without vertebræe, type of group of Leptocardii.

Amphipnous, eel-like fishes from India.

Amphisbænans, legless lizards.

Amphiuma, genus of tailed amphibians with rudimentary legs and gill slits; southern U.S.

Anallantoidea, vertebrates without an allantois; ichthyopsida.

Anamnia, vertebrates without an amnion; ichthyopsida.

Anguis, genus of footless lizards.

Anser, genus of birds including geese.

Anthropoids; sub order of primates including the higher apes and man.

Anura, order containing the tailless amphibians; frogs and toads.

Aquila, genus of birds including eagles.

Archropteryx, a fossil bird with teeth and a reptilian tail

Archegosaurus, genus of extinct stegocephal amphibians

Arcifera, group including toads and tree toads.

Arthrodira, order of extinct dipnoi (lungfishes) some very large.

Artiodactyla, ungulate mammals with even number of toes; cattle, sheep, deer.

Astroscopus, genus of electric fishes; marine.

Atelodus, genus of two-toed rhinoceros.

Aves, the class of birds.

Bdellostoma, genus of myxinoids; hag fishes of the Pacific.
Belone, genus of fishes; bony gars.

Bombinator, genus of European toads, unke.

Bradypus, genus of edentate sloths.

Branchiosaurus, genus of extinct stegocephal amphibia.

Bufo, genus of amphibians, toads.

Buteo, genus of raptorial birds, hawks.

Butyrinus, genus of herring-like fishes.

Cæcilians, a group of legless tropical amphibians.

Caiman, genus of crocodiles.

Calamoichthys, genus of ganoid fishes from Africa.

Callopterus, genus of extinct ganoid fishes.

Camptosaurus, genus.of extinct dinosaur reptiles.

Capitosaurus, genus of extinct stegocephalous amphibia.

Carcharias, genus of sharks; sand shark.

Carinatæ, birds with a keel to the sternum, includes all living birds except ostriches.

Carnivores, order of flesh-eating mammals; cats, dogs, bears, weasels, seals.

Castor, genus of rodents, beaver.

Ceratodus, genus of dipnoi (lung-fishes) from Australia.

Ceratophrys, genus of So. American toads.

Cervus, genus of Ungulates, common deer.

Cestracion, genus of sharks from the Pacific.

Cetacea, order of mammals, whales.

Chauna, genus of So. America crane-like birds; hooded screamers.

Chelonia, order of reptile turtles.

Chelone, genus of turtles, greec turtle.

Chelydra, genus of turtles, snapping turtle.

Chelydrosaurus, genus of extinct stegocephalous amphibia.

Chimæra, genus of peculiar deep-water sharks.

Chimæroids, order of shark-like fishes; Holocephali.

Chiroptera, order of mammal bats.

Chlamydoselache, genus of primitive deepsea sharks from Japan.

- Cholopus, genus of edentates, sloths.

Chondrostei, order of ganoid fishes, stur geon.

Chrysophrys, genus of fishes; sea bream of Europe.

Chrysothrix, a genus of So. American monkeys. 
Cistudo, genus of chelonia; box turtles.

Cladoselache, genus of extinct sharks.

Clupeidæ, family of fishes including herring, shad, alewives and menhaden.

Cobitis, genus of fishes; loaches.

Coregonus, genus of fresh-water fishes; white fish.

Crocodilia, order of reptiles including the alligator.

Crotalus, genus of snakes, rattlesnakes.

Cryptobranchus, genus of tailed amphibians with permanent gill slits; hellbender of No. America.

Cyclostomes; class of vertebrates without jaws, including lampreys and hag fishes.

Cynognathus, genus of extinct theromorph reptiles.

Cyprinids, family of freshwater fishes, carp, minnows.

Delphinus, genus of whales; dolphins.

Derotremes, tailed amphibia with permanent gill slits.

Desmognathus, genus of salamanders.

Didelphys, genus of marsupials, opossums.

Diemyctylus, genus of small spotted salamanders.

Dinosaurs, extinct terrestrial reptiles, some of enormous size.

Dipnoi, sub-class of fishes with gills and lungs, lung-fishes.

Discosaurus, genus of stegocephalous amphibians.

Dromatherium, genus of extinct, primitive mammals.

Echidna, genus of monotremes, spiny anteaters of Australia.

Edentates, order of mammals including sloths, armadillos, etc.

Elasmobranchs, a sub-class of vertebrates including the sharks and skates.

Embiotocids, family of fishes from the Pacific which bear living young; surf perches.

Epicrium, genus of cæcilians.

Erinaceus, genus of insectivorous mammals; hedgehogs.

Erythrinus, genus of tropical fishes.

Euornithes, a name given to all recent birds.

Eupomatus, fresh-water sunfish.

Eurycormus, genus of fossil ganoid fishes.

Firmisternia, anurous amphibia with the halves of the sternum united to each other; frogs.

Fulica, genus of water bird; coots.

Galeocerdo, genus of selachians; tiger sharks.

Galeopithecus, a flying mammal from Asia of uncertain position.

Galeus, genus of sharks; dogfish.
Gallus, genus of birds including the common fowl.

Gambusia, genus of fishes; top-minnow.

Ganoids, subclass of fishes intermediate between sharks and bony fishes; sturgeon, garpike, etc.

Geococcyx, a genus of cuckoos.

Geotrition, a genus of European salamanders.

Gerrhonotus, genus of lizards.

Glyptodon, genus of edentates allied to armadillos.

Gnathostomes, vertebrates. which have jaws; includes all except cyclostomes.

Gobiids, family of small fishes, mostly marine; gobies.

Gymnophiona, order of amphibia without tail or legs; tropical; cæcilians.

Gymnotus, electric eel of So. America.

Halmaturus, genus of kangaroos.

Hatteria, another name for Sphenodon.

Heloderma, poisonous lizard from Arizona; Gila monster.

Heptanchus, primitive shark with seven gill slits.

Hexanchus, primitive shark with six gill slits.

Holocephali, order of shark-like fishes; Chimæra.

Hypogeophis, genus of Cæcilians.

Hyracoidea, order of mammals including Hyrax.

Ichthyophis, genus of cæcilians from Ceylon.

Ichthyopsida, group of vertebrates which have gills; fishes, amphibia.

Ichthyosaurs, extinct aquatic reptiles.

Iguana, genus of tropical American lizards.

Insectivores, order of small mammals; moles, shrews, etc.

Inuus, genus of macaques including the Barbary ape.

Lacerta, genus including the common lizards of Europe.

Lacertilia, sub-order of reptiles including all lizards.

Lagenorhynchus, a genus of dolphins.

Lepidosiren, genus of lung fishes (dipnoi) from South America.

Lepidosteus, genus of ganoid fishes, garpike.

Lopholatilus, genus of teleosts from Gulf Stream; tile fish.

Macropus, genus of marsupials; kangaroos.

Mammals, class of vertebrates, with hair, nourishing the young with milk.

Manatus, genus of sirenians, manatees.

Manis, genus of old-world edentates; scaly ant-eaters. 
Marsupialia, subclass of mammals with pouch for young, opossums, kangaroos, etc.

Megalops, genus of fishes including the tar pon.

- Melanerpeton, genus of extinct stegocephal amphibians.

Monodelphia, subclass of mammals, including all except monotremes and marsupials.

Monotremata, subclass of mammals with cloaca; includes duckbill and Echidna of Australia.

Morones, genus of catfishes.

Mugil, genus of fishes, mullets.

Mustelus, genus of small sharks; dogfish.

Myrmecobius, genus of Australian marsupials.

Myxine, genus of cyclostomes; hag fishes.

Myxinoids, group of Cylostomes; hag fishes.

Necturus, genus of aquatic amphibians with tail and external gills, central U.S.

Notidanids, sub-order of sharks with more than five gill clefts.

Nototrema, genus of South American toads with dorsal brood sac.

Ophidia, sub-order of reptiles; snakes.

Opisthocomus, South American bird, type of a separate sub-order.

Opisthodelphys, genus of tropical American tree-toads.

Ornithorhynchus, genus of monotremes; duckbill of Australia.

Ostariophysi, bony fishes with Weberian apparatus.

Ostracoderms, a group of extinct vertebrates of very uncertain position.

Palæohatteria, a fossil reptile allied to Sphenodon.

Palæospondylus, a problematical fossil vertebrate from Scotland.

Perennibranchs, tailed amphibia which retain the gills through life.

Perissodactyls, sub order of mammals with odd number of toes; horses, rhinoceros, tapirs.

Petrobates, genus of extinct theromorph reptiles.

Petromyzonts, subclass of cyclostomes, lampreys.

Phoca, genus of carnivores including common seals.

Physoclisti, fishes in which the air-bladder is closed.

Physostomi, group of fishes in which the airbladder has a duct; mostly fresh water.

Pipa, tongueless toad from South America.

Pisces, the class of fishes.
Placentalia, all mammals (except marsupials and monotremes) in which a placenta occurs.

Placodus, genus of extinct theriomorph reptiles

Plesiosaurs, order of extinct, long-necked swimming reptiles

Polyodon, genus of ganoid fishes, paddle fish.

Polypterus, genus of ganoids from Africa.

Porichthys, genus of fishes from Pacific; midshipman.

Primates, highest order of mammals, including monkeys, apes and man.

Pristiurus, genus of European dogfish.

Proboscidea, order of mammals, including elephants.

Procolophon, genus of extinct theromorph reptiles.

Proteus, genus of tailed amphibians from caves of Austria, allied to Necturus.

Protopterus, genus of dipnoi from Africa.

Psittacus, genus of parrots.

Pterodactyls, extinct flying reptiles.'

Pterosaurs, extinct flying reptiles, pterodactyls.

Pythonomorphs, a group of extinct swimming reptiles.

Raia, genus of elasınobranchs, including the skates.

Rana, genus of amphibia, frogs.

Ratitæ, birds without keel to sternum, ostriches.

Rhea, three-toed South American ostrich.

Rhynchobatus, genus of tropical skates.

Rhynchocephalia, order of lizard-like reptiles; Sphenodon of New Zealand only living species.

Rodentia, order of mammals with gnawing teeth, rats, rabbits, beaver.

Ruminants, group of ungulate mammals which chew the cud.

Salamandra, genus of tailed amphibia from Europe.

Salamandrina, order of tailed amphibians without gills.

Salmonids, family of fishes including trout and salmon.

Sauropsida, class of vertebrates including reptiles and birds.

Sceleporus, genus of lizards of eastern United States.

Scomber, genus of fishes; mackerel.

Scorpænichthys, genus of sculpins.

Selachii, order of elasmobranchs; sharks.

Serranidæ, family of marine, perch-like fishes.

Siluroids, order of fishes containing the cat-fishes.

Siren, genus of tailed amphibian from U.S. with external gills. 
Sirenia, order of marine mammals; manatees and dugongs

Sirenoidea; order of lung-fishes, containing the living species.

Spalacotherium, genus of extinct mammals.

Sphenodon, genus of lizard-like reptiles from New Zealand; order Rhynchocephalia.

Squamata, order of reptiles including snakes and lizards.

Stegocephala, order of extinct amphibians.

Stegosaurs, family of extinct dinosaur reptiles, some very large.

Stenops, genus of lemurs.

Stenostomus, genus of fishes; scup.

Teleostomes, fishes with true jaw, includes ganoids and teleosts.

Teleosts, order of fishes with bony skeleton, including all common fishes.

Testudo, genus of land turtles.

Testudinata, turtles, same as a Chelonia.

Tetrapoda, term to include amphibia, reptiles, birds, and mammals, which have feet in place of fins.

Theromorpha, extinct reptiles forming the lowest order of the class.

Tinnunculus, genus of hawk-like birds; kestrel.
Torpedo, genus of skates with remarkable electric powers.

Trionyx, genus of fresh-water turtles.

Triton, genus of tailed amphibian, aquatic, European.

Tropidonotus, genus of snakes, including our water snake.

Trygon, genus of skates, string-rays.

Typhlopidæ, family of peculiar tropical serpents.

Ungulates, order of mammals which walk on the tips of the toes; horse, cattle, deer, antelope, etc.

Urodeles, order of tailed amphibia.

Varanus, genus of lizards from Africa.

Xenarthra, sub-order of American edentates, ant-eaters and armadillos.

Xenopus, genus of tongueless toads from Africa.

Zeuglodon a genus of extinct whales (Cetacea).

Ziphius, genus of toothed whales. 


\section{INDEX.}

Abdominal aorta, 284

pores, I24, 322

ribs, $4 \mathrm{I}$

sternum, 57

vein, 289

vertebræ, 49

Abducens nerve, i7o

Abomasum, 227

Accessory nerve, $\mathrm{I}_{77}$

Acetabular bone, II2, II3

Acetabulum, ro4, ro9

Acinous glands, I8

Acrodont, 88, 2 I 3 dentition, $2 I_{3}$

Acromion process. 109

Actinotrichia, I03

Activators, 264, 353

Acustico-lateralis nerves, 167

Acustic nerve, I74

Adductor muscles, I 32

Adenoid tissue, 307

Adipose tissue, 22

Adrenalin, 353

Adrenal organs, $35^{2}$

Advehent vein, 291

Egithognathous, 97

Afferent branchial artery, 274 duct of gills, 239 nerve root, $16 \mathrm{I}$

Air-bladder, 247 ducts, 25 I sacs, 261

Ala orbitalis, 98 temporalis, $6 \mathrm{r}, 98$

Alimentary canal, 205

Alisphenoid, 67 cartilage, 6 I

Allantoic arteries, $278,2 S_{5}, 293$ bladder, 3 r 8 veins, $35^{\circ}$

Allantois, $264,278,350$

Alveolar ducts, 256

Alveoli of jaws, 213 of lung, 256

Amnion, $35^{\circ}$

Amniotes, copulatory organs, 344 development of heart. $27 \mathrm{I}$

Amniotic cavity, $35^{\circ}$

Amphibia, brain, I55

circulation, 295

dermal skeleton, $4 \mathrm{I}$

excretory organs, 327

gills, 242
Amphibia, girdles, I06, I I0

glands, 29

intestine, 229

larynx, $25^{I}$

lateral line organs, 180

limbs, IIS

lungless, $25^{8}$

lungs, 257

reproductive organs, 333

skin, 29

skull, 82

teeth, 2 I 2

thymus, 246

thyreoid, 247

tongue, $2 \mathrm{I} 7$

vertebral column, $5^{\text {I }}$

Amphicœlous, 46

Amphiplatyan, 46

Amphiohinal, I9I

Amphistylic, 73

Ampullæ of ear, 184

of Lorenzini, $\mathrm{I} \& 2$

of Savi, $\mathrm{I} 82$

Amylopsin, 234

Anchylosis, 38

Angulare, $7 \mathrm{I}$

Anlage, vi.

Antibrachium, II6

Anterior abdominal vein, 289 cardinal vein, 279

cephalic duct, $3 \circ 3$

chamber of eye, 203

cornua, I39

process, 74

vena cava, 300

Anthers, Ior

Antrum of Highmore, 197

Aorta, 273,284

Aortic arches, 273 arches, modifications of, 282

Aponeurosis, I29

Appendages, IO2, II 4

Appendicular skeleton, $\mathrm{IO} 2$

Apteria, 32

Aqueduct, I43

Aqueous humor, 203

Arachnoid membrane, ${ }^{1} 5^{2}$

Arbor vitæ, I6I

Arcades, II

Archenteron, 9

Archicœle, 8

Archinepteric duct, 3 I2

Archipterygium, I I5 
Areolar tissue, 22

Argential layer of eye, 202

Arterial ring, 287

Arteries, 266, 284

afferent branchial, 274

allantoic, $278,285,293,35^{\circ}$

axillary, 288

basilar, 287

brachial, 288

branchial, 274

carotid, 275

caudal, 276

central retinal, $20 \mathrm{I}$

ciliary, 202

cœliac, 284

common carotid, 282

coronary, 273

cutaneus, 289

development of, 273

efferent branchial, 274

epigastric, 288

external iliac, 288

femoral, 288

gastric, 284

genital, 286

hepatic, 284

hyaloid, 2 or

hypogastric, $276 ; 285$

iliac, 288

intercostal, 275,286

ischiadic, 288

lumbar, 286

mandibular, $27 \mathrm{I}$

mesenteric, 284

nephridial, 275,285

omphalomesaraic, 276

omphalomesenteric, 276

ovarian, 286

peroneal, 288

popliteal, 288

pulmonary, 283

radial, 288

renal, 286, 300

sacral, 286

sciatic, 288

somatic, 284

spermatic, 286

spinal, 287

splenic, 284

subclavian, 288

tibial, 288

ulnar, 288

umbilical, 285

vertebral, 287

vesical, 285

visceral, 284

vitelline, 293

Articular bone, $7 \mathrm{I}$

Articular process, 46

Articulare, 74

Articulations, 38

Arytenoid cartilage, 25I

Ascending aorta, 284
Ascending process, 82

tracts, 140

Asterospondylous, 5I

Astragalus, II 7

Atlas, 49

Atrial chamber of gills, 240

Atrioventricular canal, 272

Atrium of heart, 272 lungs, $25^{8}$ of nose, 194

Auditory, bulla, roo meatus, 187

nerves, 174

organs, $\mathrm{I} 82$

vesicle, 183

Auricle of heart. 272

Auricularis superficialis nerve, I 7 I

Autostylic, 73

Axial skeleton, 43

Axillary artery, 288 vein, 290

Axis, 49

Axon, 19, I39

Azygos appendages, $\mathrm{IO}_{3}$

Azygos vein, 302

Baleen, 216

Barbs, 3 I

Barbules, 3 I

Basalia, ro3

Basibranchial, 65

Basilar artery, 287 plate, 60

Basioccipital, 67

Basisphenoid, 67

Basitemporal plate, 96

Bicuspids, 213

Bidder's organ, 347

Bile, 23 I duct, 233

Birds, see also Amniotes, Sauropsida. air-sacs, 26 I

brain, 158

circulation, 300

gill pouches, 244

girdles of, IO8, II 3

intestine, 230

limbs, II9

lungs, 259

scales, $3 \mathrm{I}$

skin, 30

skull, 95

stomach, 225

thymus, 246

thyreoid, 247

tongue of, $2 \mathrm{r} 8$

vertebral column of, 52

Biserial fins, II 5

Bladder, air, 247

allantoic, 318

swim, 247

urinary, 318

Blastomeres, 8 
Blastopore, 9

Blastula, 8

Blood, 24, 265

Blood circulation, embryonic, 268 phylogeny of, 267 primitive, 268

Blood corpuscles, 265 -lymph glands, 307 plasma, 265 plates, 266 vascular system, 266 vessels, structure of, 267

Body cavity, I20

Bone, 23 development of, 43 of ear, 73

Botall's duct, 283

Bowman's capsule, 309, $3^{\text {I } 4}$ glands, 197

Brachial artery, 288 plexus, I63 vein, 290

Brachium, I 16

Brain, $I_{40}$ flexures of, I43 sand, 160 ventricles of, I 43

Branchiæ, 236

Branchial arteries, 274 arches, 63 clefts, 236 vein, 274

Branchiomerism, 237

Branchiostegal membrane, 77, 240 rays, 77,240

Breathing valves of teleosts, $24 \mathrm{I}$

Breast bone, 56

Broad ligament, 337

Bronchi, 250, 256

- Bronchioles, 256

Bronchus of lampreys, 238

Buccal glands, 22 I

Buccalis nerve, $\mathrm{I}_{72}$

Bulbus arteriosus, 273 oculi, 203 olfactorius, $\mathrm{I}_{4} 2, \mathrm{I} 67$

Bunodont, 2 I4

Bursa Entiana, 227 inguinalis, 338 omentalis, 122

Cæca, intestinal, 228 pyloric, 227

Calcaneus, II 7

Calcareous glands, 183

Calcified cartilage, 43

Campanula Halleri, 204

Canaliculi, 23

Canines, $2 \times 3$

Capillaries, 267

Capitatum, II 7

Capitular head of rib, 54

Capsules, sense, 60
Carapace, 4I

Cardiac glands, 224 plexus, 163

Cardinal veins, 279

Carotid arteries, 275

Carotid glands, 246, 297

Carpale, II7

Carpus, I I6

Cartilage, 22 bones, 43,66 calcified, 43 lingual, 75 rostral, 76

Cauda equina, 140

Caudal artery, 276 vein, 276 vertebræ, 49

Cavum tympani, 187

Cement, 2 I I

Central canal of nervous system, $13^{8}$

Centrale, II 7

Central nervous system, II, I37

Centrum, 45

Cephalic vein, 290

Ceratobranchial, 65

Cerebellar hemispheres, I6I

Cerebellum, I42, I45

Cerebral hemispheres, I4I

Cerebrospinal fluid, ${ }^{5} \mathbf{2}$

Cerebrum, 148

Cervical plexus, 163 sinus, 244 vertebræ, 49

Chain ganglia, 163

Chambers of eye, 203

Chiasma, 169

Chiropterygia, I 14

Choanæ, So, 193

Choledochar duct, 233

Chondrin, 23

Chondrocranium, 60

Chorda tympani, I73

Chordæ tendiniæ, 272

Chordata, 2

Chorioid coat, 202 fissure, I 99 gland, 202 plexus, I44, I47

Chorion, $35^{\mathrm{r}}$

Chromaffine cells, $35^{2}$

Chromaphile cells, $35^{2}$

Chromatophores, 26

Chyle, 304

Chyle ducts, 304

Cilia, 205

Ciliary arteries, 202

Ciliary ganglion, ${ }^{6} 65, x_{7} 0$ muscles, 202 process, 202

Ciliated epithelium, r8

Circle of Willis, 287

Circulation, allantoic, 278 fœtal, 293 
Circulation, hepatic-portal, 277 portal, 277 pulmonary, 282 renal-portal, 280 respiratory, 282 systemic, 282

Circulatory organs, 264

Cistern of chyle, 303

Claspers, 27, II6, 343

Clavicles, Io6

Claws, 27

Cleft palate, 193

Cleithrum, I06

Cloaca, 228

Coccyx, 52

Cochlea, I86

Cochlear nerve, I74, I86

Cœliac artery, 284 axis, 285

Colom, I0, I4, I20

Collecting tubule, $3 \circ 9$

Collector nerves, I63

Colon, 228

Columella auris, 74

Columnæ carnea, 272

Columnar epithelium, I7

Columns of cord, I39

Commissura mollis, $\mathrm{x}_{4} 6$

Common carotid artery, 282 iliac vein, 289

Concha of ear, 188 of nose, I94

Cones of eye, I99

Conjunctiva, 203

Connective tissues, 2 I

Contour feathers, $3 \mathrm{I}$

Conus arteriosus, 272

Convoluted tubule, $3 \circ 9$

Convolutions of brain, 149,160

Copulæ, 63

Copulatory organs, 342

Coraco-arcual muscles, I 33

Coracoid bone, ro7 process, I08

Corium, 25 region, 105

Cornea, 202

Cornua of cord, I39 trabeculæ, 6I

Cornua radiata, 160

Coronary arteries, 273

Coronoid bone, $7 \mathrm{I}$

Corpora adiposa, 307 bigemina, I 42 quadrigemina, 142,160

Corpus albicans, $\mathrm{I}_{5} \mathrm{I}$ callosum, $I_{50}$

luteum, 320 restiforme, $I_{5} 0$ striatum, I4I

Corpusculum bulboideum, I 79

Cortex of cerebrum, 149

Corti's organ, 186
Cotyloid bone, II 3

Cowper's glands, 342

Cranial bones, table of, 72 nerves, 165

Cranio-quadrate process, 82

Cranium, 60

Cremaster muscle, 338

Cribriform plate, 67 , 100

Cricoid cartilage, $25 \mathrm{I}$

Cristæ acusticæ, I85

Crista galli, roo

Crop, 223

Crura cerebri, I5I

Crus, I 6

Ctenoid scales, 40

Cubical epithelium, I7

Cuboides, II 7

Cuneiform, II 7

Cutaneus artery, 289 magnus vein, 290

Cutis, 25

Cuverian ducts, 271,278

Cycloid scales, 40

Cyclospondylous, $5 \mathrm{I}$

Cyclostomes, brain, $\mathrm{I}_{52}$

circulation, 294

ear, 185

excretory organs, $32 \mathrm{I}$

eyes, 204

gills, 238

intestine, 228

lateral line organs, $x 80$ mouth, 208

nasal organs, $\pm 9 \circ$

reproductive organs, $33 \mathrm{I}$

skull, 75

teeth, 2 I 5

thymus, 245

thyreoid, 246

tongue, 217

vertebral column, $5 \mathrm{r}$

Cylindrical corpusle, 179

Cystic duct, 234

Decussation of fibres, 150

Deiter's cells, r86

Demibranch, 237

Dendrites, I9, I39

Dens, 50

Dental formula, 2 I4

papilla, 209

ridge, 2 Io

shelf, 2 10

Dentary bone, $7 \mathrm{r}$

Dentinal canals, 24

Dentine, 24, 209

Dentitions, 2 II

Depressor mandibulæ, I33 muscles, I3I

Derma, 25

Dermal muscles, I34

skeleton, 38, 39

Dermarticulare, 7 I 
Descending aorta, $28_{4}$ tracts, 40

Desmognathous, 97

Deutoplasm, 8

Diaphragm, I23, I35

Diapophysis, 46

Diarthrosis, 38

Diastole, 272

Diencephalon, 142

Digastric muscle, I33

Digestive tract, 12, 205

Digitigrade, I2O

Digits, I 6

Dilator pupillæ, 202

Diphycercal, $5^{\circ}$

Diphyodont dentition, 2 I I

Dipnoi, brain, ${ }_{54}$ circulation, 292, 295 excretory organs, 327

lungs, 257

reproductive organs, 333

skull of, 80

Discus proligerus, 320

Dorsal aorta, 275 fissure of cord, 139 nerve root, I6I vertebræ, 49

Down feathers, 3 I

Dromæognathous, 97

Ductless glands, 18

Ductus arantii, 277 arteriosus, 283

Botalii, 283

Cuverii, 27I, 278

venosus, 277

Dumb-bell bone, 69, ror

Duodenum, 227

Dura spinalis, 152

Ear, I 82

bones, 73

external, 187

functions of, 188

inner, 183

middle, 187

stones, I86

Ect-ental line, 9

Ectethmoid, 67

Ectobronchus, 259

Ectochondrostosis, 43

Ectoderm, 9

Ectopterygoid, 8o, 88

Ectoturbinals, I96

Efferent branchial artery, 274 duct of gills, 238 nerve root, $16 \mathrm{I}$

Egg, segmentation of, 8 teeth, 216

Ejaculatory duct, 34I

Elasmobranchs, brain, I 53 copulatory organs, 343 excretory organs, 326 gills, 239
Elasmobranchs, girdles of, 105 intestine, 228 reproductive organs, 33 I skull, 76

Elastica externa, 45 interna, 44

Elastic tissue, 22

Electrical organs, 135

Electric plates, I 35

Electroplax, I36

Embolomerous, 48

Embryology, I, 6

Embryonic tissue, 22

Eminentia medialis, 145

Enamel, 40 organ, 40, 200

Endocardium, 269

Endolymph, 185 duct, 183 sac, 183

End organs, 178

Endorhachis, I5I

Endoskeleton, 38, 42

Ensiform process, 56

Entepicondylar foramen, I20

Enterocœle, ro

Enteropneusta, 2

Entobronchus, 259

Entochondrostosis, 43

Entoderm, 9

Entoglossal, 80, 97, 2 I8

Entoplastron, 42, I59

Entopterygoid, 80

Entoturbinals, I96

Entovarial canal, 326

Envelopes of nervous system, I 5 I

Eparterial bronchi, 262

Epaxial muscles, I27

Ependyma, 139

Epibranchial cartilage, 65

Epibranchial ganglia, 176 muscles, 133

Epicardium, 124, 269

Epicœle, I43

Epicoracoid, ro7

Epidermis, 25

Epididymis, 322

Epigastric artery, 288 vein, 289

Epiglottis, 252, 253

Epimerals, 54

Epimere, I3

Epineurals, 54

Epiotic, 67, 69

Epipharyngeal bones, 80

Epiphyses, 43

Epiphysial structures, I46

Epiphysis, 147

Epiplastron, 42, 108

Epipleurals, 54

Epipterygoid, 82

Epipubis, III

Episternalia Io9 
Episternum, 59

Epistropheus, 49

Epithelial bodies, 246 pigmented, of eye, 201

Epithelium, I7

Epitrichium, 25

Erectile tissue, 345

Erythrocytes, 265

Essence of pearl, 29

Ethmoidalia, 67

Ethmoid bone, 68 plate, $6 \mathrm{r}$

Ethmopalatine ligament, 77

Ethmo-turbinals, 195

Eustachian tube, I87, 237

Excitatory cells, I64

Excretory organs, 307 development of, 3 ro

Exoccipital, 67

Extensor muscles, $\mathrm{I}_{32}$

External carotid artery, 275 ear, 187 gills, development of, 242 iliac artery, 288

Extrabranchial cartilages, 65 chamber, 240

Extrinsic muscles, $\mathrm{I}_{3} \mathrm{I}$

Eyelashes, 205

Eyelids, 203

Eye muscles, I28, 203

Eye-muscle nerves, I70

Eye, parietal, $\mathrm{I}_{47}$

Eyes, I98

Fabellæ, II8

Facialis nerve, I72 •

Falciform process, 204

Fallopian tube, $33^{8}$

False amnion, 350

$$
\text { rib, } 55 \text {. }
$$

Falx cerebri, I5 2

Fascia, 128

Fasciculi, 128

Fasciculus communis, 150

Fat, 22 bodies, 307

Fauces, isthmus of, 247

Feather tracts, 32

Feathers, $3 I$

Femoral artery, 288 pores, 30 vein, 290

Fenestra hypophyseos, 6I ovale, 73,186 rotunda, r86 tympani, 186 vestibuli, 73,186

Fibrous tissue, 22

Fibula, II 6

Fibulare, $x$ I7

Fifth ventricle, ${ }_{5} \mathrm{I}$

Filoplumes, $3 \mathrm{I}$

Filum terminale, $\mathrm{I}_{4} \mathrm{O}$
Fins, 102

anal, ro3

biserial, I I 5

caudal, ro3

dorsal, I03

paired, II4

uniserial, II 5

Fishes, circulation, 294

eyes, 204

fins, II 5

gills, 238

girdles, I ro

glands, 27

intestine, 229

lateral line organs, I80

scales, 40

skin, 27

skull, 77

tails of, 50

teeth, 212

thymus, 245

thyreoid, 247

tongue, $2 \mathrm{I} 7$

vertebral column, $5^{\text {I }}$

Fissures of brain, I49, I 59

Flexor muscles, I32

Flocculi, I45

Flexures of brain, 143

Floor plate, 138

Fœtal circulation, 293 envelopes, 348

Folian process, 74

Fontanelles, 6r

Forebrain, 140

Foramen cæcum, 2 I9

epiploicum, I22

incisorum, ror

interventriculares, $\mathrm{I} 43$

lacerum anterior, 67

magnum, 67

of Monro, 143

of Panniza, 282

of Winslow, 122

Fornix, I5I

Fossa hypophyseos, $6 \mathrm{r}$ rhomboidea, I44

Fossæ of skull, 7 I

Fovea centralis, 200

Free appendages, II 4 nerve terminations, $\mathrm{I}_{7} 8$

Frontal bones, 68 lobes, I 59 organs, 147

Fundus glands, 224

Furcula, I08

Gall, 23I

bladder, 233 capillaries, 233

Ganglia of dorsal roots, I6r

Ganglion, 20

cell, $x 9$

of retina, 200 
Ganoids, excretory organs, 327 reproductive ducts, 322 scales, 40 skull of, 78

Ganoin, 40

Gasserian ganglion, I7 I

Gastralia, 4I

Gastric artery, 284

Gastrula, 9

Gastrulation, 9

Geniculate ganglion, 172

General cutaneus nerves, $\mathrm{I}_{7} 7$

Geniohyoid muscle, I30

Genital artery, 286 prominence, 344

Geological distribution, 7

Germ layers, II

Gill arches, 63

basket, 75

clefts, 236

cover, 77,240

pouches, 239

remnants, 246

Gills, 236

Girdles, I04

Gizzard, 225

Gladiolus, 56

Glands, 18 of amphibia, 29

of birds, 30

buccal, 22 I

cardiac, 224

carotid, 297

chorioid, 202

Cowper's, 342

excretory, 307

of fishes, 27

fundus, 224

Harder's, 204

hibernating, 307

intermaxillary, 220

internasal, 220

labial, 22

lacrimal, 204

lingual, 22 I

of mammals, 35

mammary, 36

meiobomian, 205

milk, 36

molar, 22 I

oral, 220

orbital, 22 I

palatal, 22022 I

parotid, 22 I

prostate, 342

poison, 27, $22 \mathrm{I}$

pyloric, 224

rectal, 228

of reptiles, 30

retrolingual, 22 I

sexual, 308

sublingual, 22 I

submaxillary, 22 I
Glands, tarsal, 205

tear, 204

uropygial, $3 \circ$

Glandula membrana nictitans, 204

Glandular epithelium, I8

Glaserian fissure, 74

Glenoid fossa, I00, 104

Glia, I39 cells, I9, 20

Glomerulus, 309

Glomeruli of olfactory nerve, 167

Glomus, 3 I2

Glossopharyngeal nerve, 175

Glottis, 25 I

Gluteus muscle, 132

Gonads, 308, 319

Goniale, 7 I

Gonotomes, 3I9

Graafian follicle, 320

Grandry's corpuscle, I79

Gray matter, 20 of cord, 139

Great omentum, 122

Guanin, 29

Gubernaculum, $33^{8}$

Gular bones, 79

Gyri, I49, I60

Habenular ganglion, 146

Hæmopophysial ribs, 53

Hæmal spine, 46

Hæmapophysis, 46

Hair, 33

Hair cells, 186

Hallux, II 7

Hamatum, Ir 7

Harder's glands, $204^{\circ}$

Hare-lip, I93

Haversian canals, 23

Head cavities, I28 kidney, 310 rib, $8 \mathrm{I}$

Heart, 28I branchial, 28I development, 269 division of, $28 \mathrm{I}$ muscles, I25 portal, 294 structure, 269 venous, $28 \mathrm{I}$

Hemiazygos vein, 302

Hemipenes, 344

Hemispheres, cerebellar, I6r

Hemispheres, cerebral, I4I

Henle's loop, $3 \circ 9$

Hepar, $23 \mathrm{I}$

Hepatic artery, 284

duct, 233

-portal system, 277

veins, 277

Herbst's corpuscle, I79

Hermaphroditism, 346

Heterocercal, 50 
Hibernating glands, 307

Highmore, antrum of, 197

Hilum of kidney, $33^{\circ}$

Hippocampus, I 48

Hindbrain, I4I

Histology, I, I6

Holonephros, 3 I0

Holorhinal, 96

Homocercal, $5^{\circ}$

Honey comb, 227

Hoofs, 27

Hormones, I8, 353

Horns, IOI

Humerus, II6

Humors of eye, 203

Hyoid apparatus, 220

Hyoid arch, 63

Hyoideus nerve, I 72

Hyomandibular bone, 73 cartilage, $6_{3}$ nerve, $\mathrm{I} 72$

Hyoplastron, 42

Hyostylic, 73

Hyparterial bronchi, 262

Hypaxial muscles, I27

Hypobranchial, 65

Hypocentrum, 47

Hypocone, 2 I4

Hypoconid, 2 I4

Hypogastric artery, 276, 285 plexus, $\mathrm{I}_{3}$ vein, 290

Hypoglossal muscles, I 28 nerve, 177

Hypoischium, II I

Hypomere, I3

Hypopharyngeals, 8o

Hypophysial duct, rgr

Hypophysis, I48

Hypoplastron, 42

Hypurals, 50

Ichthyopterygia, II4

Ileum, 228

Ileo-cæcal valve, 228

Ileo-colic valve, 228

Ileocostal muscle, I3I

Iliac artery, 288 vein, 289

Ilium, Io9

Incisive foramina, IOI

Incisors, $2 \mathrm{I} 3$

Incus, 74

Inferior jugular vein, 278 mesenteric artery, 285 oblique muscle, I 28 turbinal, I0o

Infraclavicle, 106

Infratemporal fossa, 7 I

Infundibulum, 148,256

Ingluvies, 223

Inner ear, 183

Innominate vein, 300
Insertion of muscles, 129

Insula 160

Integument, 25

Interbranchial septum, 237

Intercalare, 47

Intercellular substance, 2 I

Intercentrum, 48

Intercerebral fissure, $\mathrm{I}_{4} 8$

Interclavicle, 59

Intercostal arteries, 275,286 muscles, I30

Interhyal, 80

Intermaxillary glands, 220

Intermedium, II 7

Internal iliac artery, 288 vein, 290

Internal secretion, I8

Internasal gland, 220

Interoperculum, 77

Interorbital septum, 6I

Interparietal bone, 68

Interrenal organs, $35^{2}$ veins, 291

Interspinous ligament, 48

Interstitial cells, 342

Intertemporal bones, roo

Intestine, 227

Intratarsal joint, II8

Intrinsic muscles, I3 I

Invagination, 9

Inverted eye, 200

Involuntary muscles, 20, I 25

Iris, 202

Ischiadic artery, 288 vein, 290

Ischio-pubic fenestra, Io9

Ischio-pubis, II 2

Ischium, I09

Island of Riel, I60

Isthmus, I4I

Iter, I 43

Ivory, 209

Jacobson's commissure, ${ }^{6} 6_{5}, I_{7}$ I gland, 194 organ, I90, I96

Jaws, 63

Jejunum, 228

Jugal bone, 70

Jugular ganglion, I 76

lymph sac, 303

vein, 279

Kidney, 3 Io

development of, 316

Krausse's corpuscle, I79

Labial cartilages, $6_{5}$ glands, 220, 22 I

Labyrinth of ear, 185 nasal, I92

Lacrimal bone, 69 duct, 204 
Lacrimal gland, 204

Lacteals, 304

Lacunæ, 23

Lagena, I84

Lamina terminalis, I4I

Laryngeal cartilages, 64

Laryngeal ventricle, 253

Larynx, 250, 25 I

Lateral abdominal vein, 289

column of cord, 139

cornu, I39

ethmoid, 67

line lobe, 145

line organs, 173,179

plate, $I_{3}$

Lateralis nervous system, I73

Latissimus dorsi, I 32

Legs, II6

Lens of eye, 199

Leptocardii, 2

Leucocytes, 265

Levator muscles, I3I scapulæ, $\mathrm{I}_{32}$

Leydig's duct, 3 I 5

Lids of eye, 203

Ligament, interspinous, 48 of ovary, 338 of testis, 338

Ligamentum medium pelvis, I I I teres, 289

Linea alba, 127

Lingual glands, $22 \mathrm{I}$

Lingualis nerve, I7 I

Lips, 208

Liver, 231

Longissimus capitis muscle, I3 I dorsi muscle, I3 I

Lophodont, 2 I4

Lophs, 2 I 4

Lorenzini's ampullæ, 182

Lower jaw, 7 I

Lumbar artery, $2 \$ 6$ plexus, 163 vertebræ, 49

Luminous organs, 28

Lunatum, II 7

Lungs, 250,255

Lungs, phylogeny of, 262

Lung pipes, 259

Lungless salamanders, 299

Lutein cells, 320

Lymph, 265 glands, 302,306

hearts, 302, 304

nodules, 306

sacs, 303

-stomata, 302

vessels, development of, 302

Lymphatic system, 302

Lymphocytes, 266

Lyssa, 219

Macula lutea, 200
Maculæ acusticæ, I 85

Malar bone, 70

Male ducts, 32 I

Malleus, 74

Malpighian corpuscle, 309, 314

Malpighian layer, 25

Mammals, brain, $15^{8}$

circulation, 300

dermal skeleton, $4 \mathrm{I}$

excretory organs, 328

fœtal envelopes, 348

gill pouches, 237,244

girdles of, 108, II3

glands of, 35

intestine, 230

larynx, 254

limbs, II9

lungs, 262

reproductive organs, 335

salivary glands, $22 \mathrm{I}$

skin of, 33

skull of, 98

stomach, 225

teeth, 213

thymus, 246

thyreoid, 247

tongue, 2 I9

vertebral column of, 53

Mammary glands, 36

Mandibular arch, 63

arteries, $27 \mathrm{I}$

nerve, $17 I$

Mantle of cerebrum, I4I

Manubrium, 56 mallei, 74

Manus, II6

Manyplies, 227

Marsupial bones, II4

Masseter muscle, I33

Mastoid process, I00

Matrix, 2I

Maxillaris externus nerve, $I_{7} 2$

Maxillary bone, 70 nerve, $\mathrm{I} 7 \mathrm{I}$

Maxillo-turbinals, I 96

Meatus, external auditory, $I 87$

Meckelian cartilage, 63, 7 I

Mediastinum, I6, I22

Medullary cords, 32 I groove, II

plate, II sheath, I9

Medulla oblongata, I42

Meibomian glands, 205

Meissner's corpuscle, I79

Membrana tectoria, I86

Membrane bones, 42, 65 bones of skull, 68

Membranous labyrinth, $I 85$ skeleton, 37

Meninges, $15^{I}$

Meninx primitiva, $\mathrm{I}_{5} \mathrm{I}$

Mento-Meckelian bone, $7 \mathrm{I}$ 
Merkel's corpuscle, I79

Mesencephalon, I42, I45

Mesenchyme, I0, I6

Mesenteric arteries, 284

Mesenteries, I4, I2 I

Mesenteron, 205

Mesethmoid, 67

Mesobronchus, 259 .

Mesocardia, I6, I22, 270

Mesocolon, I22

Mesoderm, ro

Mesogaster, $\mathrm{r}_{5}, \mathrm{r} 22$

Mesohepar, I5, I2 I

Mesomere, $\mathrm{I}_{3}$

Mesonephric tubules, $3{ }^{1} 3$ ducts, 3 I 3 , 3I 5

Mesonephros, 3 Io, 3 I 3

Mesopterygium, I I 5

Mesopterygoid, 80

Mesorchium, I6, I22, 319

Mesothelium, Io

Mesorectum, I5, I22

Mesovaria, I6, I22, 3 I9

Metacarpals, II7

Metacarpus, I I6

Metacœcle, I23, I43

Metacone, 2 I4

Metaconid, 2 I4

Metamerism, I3

Metanephros, 3 Io

Metapodium, I 6

Metapterygium, II 5

Metapterygoid, 80

Metatarsale, II 7

Metatarsus, Ir6

Metazoa, I

Metencephalon, I42

Midbrain, I4I, I45

Middle ear, 187 plate, I3 turbinal, roo

Milk dentition, 2 I I glands, 36 line, 36 points, 36

Minimus, Ir7

Mitral valve, $28 \mathrm{I}$

Mixipterygium, I 16,343

Molar gland, 22 I

Molars, 2 I 3

Monimostylic, 88

Monophyodont dentition, 2 I2

Monorhinal, IgI

Monro, foramen of, $\mathrm{I}_{43}$ sulcus of, I4I

Morphology, I

Mossy cells, 20

Motor-nerve root, I62

Mouth, 208

Müllerian duct, 3 I 5

Multangulum, II 7

Multicellular glands, I8

Muscle plate, ${ }_{3} 3$

Muscles of appendages, development of, I3 I
Muscles of, dermal, I34 visceral, $\mathrm{I}_{32}$

Muscular system, I24 tissue, 20

Myelencephalon, I42

Myocardium, 269

Myocœle, I4, I2 I, I26

Myocommata, I27

Myoepicardial mantle, 270

Myofibrillæ, 20

Mylohyoid muscle, I33

Myosepta, 38, 127

Myotomes, I4, I2 I, I27

Nails, 27

Nares, external, I9o internal, I93

Naro-hypophysial duct, I 9 I

Nasal bones, 68 capsules, I 90

Naso-palatal canal, I97

Naso-pharyngeal duct, I94

Naso-turbinals, I95

Navel cord, 35I

Naviculare, I I 7 pedis, 1 I 7

Nepopallium, 148

Nephridia, 308

Nephridial arteries, 275,285

Nephrotomes, I4, 308, 3 II

Nerve cell, I9

Nerve-end apparatus, 178

Nerve of Weber, I73, I89

Nervous system, I37 central, 138

development of, I 37 tissue, I9

Neural arch, 45 crest, $\mathrm{x} 6 \mathrm{I}$

folds, II plate, $x \mathrm{x}$ spine, 46

Neurapophysis, 45

Neurenteric canal, I2

Neuroglia, 20, I39

Neuromasts, 167

Neuron, I9

Neuropore, I2

Nictitating membrane, 203

Non-elastic tissue, 22

Nose, 197

Notochord, I 2, 44 sheath of, 45

Nuchal flexure of brain, I43

Nuclei of brain, I44

Nucleus dentatus, I45

Oblique muscles, I30 of eye, 128

Obturator foramen, Io9

Occipitalia, 66

Occipital bone, 68 lobes, ${ }_{59}$ 
Occipital vertebræ, 62

Oculomotor nerve, I70

Odontoblasts, 39, 209

Odontoid process, 50

Esophago-cutaneus duct, 239

Esophagus, 222

Olecranon process, 120

Olfactory bulb, I42, I67

$$
\text { duct, } \mathrm{I} 94
$$

lobe, I 4 I

nerve, 167

organs, 189

sac, 190

tract, 142

Oliva, I45

Olivary bodies, 145

Omasum, 227

Omentum, $x_{5}, 122$

Omosternum, 57

Omphalomesaraic artery, 276 vein, $27 \mathrm{I}$

Omphalomesenteric artery, 276 vein, $27 \mathrm{I}$

Ontogeny, I

Operculare, 77

Opercular gill, $24 \mathrm{I}$

Operculum, 77, 240

Ophthalmic nerve, I 7 I

Ophthalmicus profundus nerve, I 7 I superficialis nerve of seventh, $I 72$ of fifth, I 7 I

Opisthocielous, 46

Opisthotic, 67

Optic capsule, 202

chiasma, 169

cup, I98

ganglion, 169

lobes, 142,169

nerve, 169,200

pedicel, 203

recess, $\mathrm{I}_{4 \mathrm{I}}$

stalk, I98

thalami, $\mathrm{I}_{42}, \mathrm{I}_{4} 6$

tract, I 46

vesicle, I98

Oral cavity, 208

glands, 220

hood, 208

plate, 205

Orbicular muscles, 134

Orbital gland, 221

Orbitosphenoid, 67

Organ of Corti, I86 of Jacobson, 190,196

Origin of muscles, 129

Oronasal groove, 193

Os cloacæ, III

en ceinture, 86

entoglossum, 97, 2 I 8

pubis, Iog

transversum, 88

uncinatum, 96

Ossa suprasternalia, 58
Ossein, 23, 39

Ossicula auditus, 73,187

Ossification, 43

Osteoblasts, 39

Ostium tubæ abdominale, 324

Otic bones, 67 capsule, 60,67 ganglion, I 7 I

Otoliths, 185

Ovarial cords, 320

Ovarian artery, 286

Ovaries, 308, 320

Oviduct, 316, 321, 323

Ovotestis, 346

Ovum, 8

Pacini's corpuscle, I79

Paired appendages, I03 fins, II4

Palatal glands, 220, $22 \mathrm{I}$

Palatine bones, 69 nerve, $\mathrm{I} 72$

Palatoquadrate cartilage, 63

Pallium, I4I, I48

Pancreas, 234

Pancreatic duct, 235

Panniculus carnosus, I34

Parabronchi, 259

Parachordal plates, 60

Paracone, 2I 4

Paraconid, 214

Paraglossæ, 218

Paraglossal, 97

Paramastoid process, 99

Paraphysis, I46

Parapophysis, 46

Parasphenoid, 69

Parietal bones, 68

eye, 147

foramen, 68

lobes, 159

muscles, 125

organ, 147

Paroccipital process, 99

Parotic process, 93

Parotid gland, 221 of Amphibia, 29

Parovarial canal, 325

Parovarium, 34I

Patella, Ir8, I20

Paunch, 227

Pearl organs, 27

Pecten of eye, 204

Pectineal process, IIO, II 3

Pectineus muscle, $\mathbf{1}^{2} 2$

Pectoral girdle, I05

Pectoralis muscle, 132

Peduncles of cerebellum, I $_{50}$

Pelvic girdle, rog

Pelvis, rog plexus, 163 of kidney, 330

Penis, 345 
Pepsin, 224

Pericardial cavity, I4, I23 fluid, 269

Pericardio-peritoneal canals, I23, 27 I

Pericardium, 124, 269

Perichondrium, 39

Periderm, 25

Peridural space, $I_{52}$

Perilymph, 186 duct, $\mathrm{I} 86$

Perimeningeal space, ${ }^{5} 5$

Perimysium, 2I, I28

Perineurium, 20

Periosteum, 24, 39

Peripheral nervous system, I6I

Peristalsis, 207, 227

Peritoneal canals, I 24 cavity, I4, 123

Peritoneum, I24

Permanent dentition, 2 I I

Peroneal artery, 288

Perpendicular plate of ethmoid, 100

Pes, II6

Pessulus, 255

Petrosal bones, 67 ganglion, I 75

Petrotympanic fissure, 74

Phæochrome cells, $35^{2}$

Phalanges, Ir6

Pharyngeal bones, 80 derivatives, 245 plate, 205 tonsils, 247

Pharyngobranchial, 65

Pharynx, 207, 222, 236

Phosphorescent organs, 28

Photophores, 28

Phyllospondylous, 47

Physiology, I

Physoclistous, 248

Physostomous, 248

Pia mater, $\mathrm{I}_{52}$

Pigment cells, 22, 26 layer of eye, 198

Pigmented epithelium of eye $20 \mathrm{r}$

Pillar cells, 186

Pinealis, I47

Pisiforme, II7

Pituitary body, 148

Placenta, 3I8, $35 \mathrm{I}$ vitelline, 348

Placoid scale, 40

Plantigrade, 120

Plasma, blood, 265

Plastron, 4I

Platybasic skull, 6r

Platysma myoides, I34

Pleura, I24

Pleural cavities, I23 rib, 53

Pleurapophysis, 46

Pleurocentrum, 47

Pleurodont, 88
Pleurodont dentition, 213

Plexus, chorioid, 144

Plexuses, I6 3

Plica fimbriata, 2 I9 semilunaris, 203

Plumæ, 3 I

Plumulæ, 3 I

Pneumatic bones, 96 duct, 248

Pneumatocyst, 247

Pneumogastric nerve, $I_{7} 6$

Podium, II6

Poison glands, 27,22 I

Pollex, II 7

Polymastism, 37

Polyphyodont denition, 2 I I

Pons (Varolii), I 50

Pontal flexure of brain, I44

Popliteal artery, 288

Pori abdominales, I24, 322

Portal circulation, 277 heart, 294 vein, 277

Postbranchial bodies, 246

Postcardinal vein, 279

Postcava, 290

Postclavicle, 106

Posterior chamber of eye, 203 column of cord, I 39

cornua, I 39

fissure of cord, 139

horns of cord, 139

lymph sac, 303

Postfrontal bone, 69

Posthepatic digestive tract, 206

Postminimus, I 8

Postorbital bone, 69

Postotic nerves, I 75

Postparietal bone, 69

Postpermanent dentition, 2 I 2

Postpubic process, II 2

Post-temporal bone, Io6 fossa, 7 I

Post-trematic nerves, 175

Postzygapophysis, 46

Precava, 300

Predentary bone, 88

Prefrontal bones, 69

Prefrontals of birds, 96

Prehallux, ir 8

Prehepatic digestive tract, 206

Prelacteal dentition, 2 I2

Premaxillary bone, 70

Premolars, 213

Prenasal bone, Ioo

Preoperculum, 77

Prepollex, I18

Prepubic process, III

Presphenoid, 67

Presternalia, Iog

Pretrematic nerves, I75

Prevertebral ganglia, I63

Prevomer, 69 
Prezygapophysis, 46

Primitive groove, to ova, 3 ry streak, ro

Primordial ova, 3 Iy

Process, articular, 46 transverse, 46

Procœlous, 46

Procoracoid, IO7

Proctodeum, 13, 206

Pronephric duct. 3 I2 tubules, 3 II

Pronephros, 3 Io

Prootic, 67

Propterygium, I I 5

Prosencephalon, I4I

Prostate glands, $34^{2}$

Prosternum, $5 \mathrm{~S}$

Proterandric hermaphroditism, 345

Proteroglypha, 213

Protocone, 214

Protoconid, 214

Protovertebræ, I4

Protractor muscles, I3I

Proventriculus, 225

Psalterium, 227

Pseudobranch, 24I

Pseudoconch, 194

Pterotic, 67

Pterygoid bones, 69, 80 muscle, 133

Pterygoquadrate, 63, 69

Pterylæ, 32

Ptyalin, 220

Pubofemoralis muscle, $\mathrm{I}_{32}$

Pubis, Io9

Pulmonary arteries, $2 \delta_{3}$ circulation, 282 veins, 292

Pulmones, 236

Pulp of tooth, 2 ro

Pupil, 202

Pygostyle, 53

Pyloric cæca, 227 gland, 224

Pylorus, 223

Pyramidalis muscle, $I_{30}$

Pyramidal tracts, $I_{50}$

Pyriform lobes, 159

Pyriformis muscle, $\mathrm{r}_{32}$

Quadrate bone, 69, 74

Quadratogugal bone, 70

Quadritubercular, 2 14

Radial artery, $28 S$ cells, 200

Radiale, $\mathrm{II}_{7}$

Radialia, $\mathrm{ro}_{3}$

Radius, II6

Radix aortæ, 273

Rami communicantes, $16_{3}$

Ramus dorsalis, 162
Ramus intestinalis, $\mathrm{I}_{6}$ of tenth nerve, 176

lateralis accessorius, $\mathrm{I} 73$ of tenth nerve, 176

ventralis, $\mathrm{x}_{2}$

visceralis, $\mathrm{x} 62$

Rathke's pocket, I48, 206

Rectal gland, 228

Rectum, 228

Rectus abdominis muscle, 130 capitis muscles, I3I muscles, I $28,1_{30}$ of eye, 128

Red spots, 249

Reissner's fibres, I $_{5}$ I

Renal artery, 286, 300 corpuscle, 309 portal system, 280

Rennet, 227

Respiration, accessory structures, 263 mechanism of, 263

Respiratory circulation, 282 duct, $x 94$ organs, 235

Reproductive ducts, $32 \mathrm{I}$ organs, 308,319

Reptiles, see also Sauropsida, Amniotes aortic arches, 283

brain, 157

circulation, 299

copulatory organs, 344

dermal skeleton, $4 \mathrm{I}$

gill pouches, 244

girdles, I07, III

glands, 30

intestine, 229

larynx, $25 \mathrm{I}$

limbs, Ir8

lungs, $25^{8}$

scales, 30

skull, 87

thymus, 246

thyreoid, 247

tongue, $2 \mathrm{I} 7$

vertebral column, 52

Rete mirabile, 249, 267

Reticulum, 227

Retina, 199

Retinal artery, 20r ganglion, 200

layer of eye, 198

vein, 201

Retractor bulbi, I28, 203 muscles, $13 \mathrm{I}$

Retrolingual gland, 22 I

Revehent vein, 29I

Rhachitomous, 48

Rhinencephalon, I4I

Ribs, 53 abdominal, $4^{\mathrm{I}}$

Rods of eye, I99

Roof plate, 138

Roots of spinal nerves $16 \mathrm{i}$ 
Rostral bone, 88 cartilage, 76,85

Rostrum sphenoidale, 96

Rotator muscles, I32

Rumen, 227

Sacculo-ventricular canal, $\mathrm{I} 84$

Sacculus endolymphaticus, 183 of ear, 184

Saccus vasculosus, 148

Sacral artery, 286 plexus, 163 vertebræ, 49

Sacrum, 49

Salivary glands, 220

Santorini's duct, 235

Sarcolemma, 2 I

Saurognathous, 97

Sauropsida, eyes, 204 excretory organs, 327

fœtal envelopes, 348 reproductive organs, 334 teeth, 2 I2

Savi's ampullæ, $I 82$

Scala media, I85

Scalæ of ear, 186

Scalene muscles, I30

Scales, 26, 39 ctenoid, 40 cycloid, 40 development of, 39 ganoid, 40 of mammals, 34 placoid, 40

Scaphoid, II 7

Scapular region, 105

Schizocœle, Io

Schizorhinal, 96

Sciatic artery, 288 vein, 290

Sclera, 62, 202

Scleroblasts, 39

Sclerotic bones, 67, 203 coat, 62

Sclerotomes, I4

Scrotum, 32 I, 338

Secodont, 2 I4

Seessel's pocket, 206

Segmentation cavity, 8 of egg, 8

Selenodont, 2 I 4

Sella turcica, 6 I

Semicircular canals, $\mathrm{I} 84$

Semilunar fold, 203 ganglion, $\mathrm{I} 7 \mathrm{I}$

Seminal vesicles, 342

Seminiferous tubule, 32 I

Sense hillocks, I67

Sensory epithelium, I7 nerve root, $16_{2}$ organs, 177

Septum, interorbital, 6r of cerebrum, 148
Septum pellucidum, I 5 I

transversum, I23, 27 I

Serosa, $35^{\circ}$

Serous coat of digestive tract, 207

Serratus anterior muscle, 132

Sertoli's cells, 32 I

Serum, 265

Sesamoid bones, 129

Sheath of Schwann, 20

Shoulder girdle, I05

Sex, determination of, 347

Sexual cords, 320 organs, 308

Sight, organs of, I98

Sinus, cervical, 244 frontal, 197 impar, $25^{\circ}$ maxillary, 197 of Morgagni, 253 sphenoidal, I97 terminalis, 277 urogenitalis, 322 venosus, 272

Sinusoids, 267

Sixth sense, 182

Skeletal labyrinth, I86

Skeleton, 37 appendicular, IO2 axial, 43 dermal, 38 membranous, 37 visceral, 63

Skin, 25 of mammals, 33

'Skull, 59 development of, 59 table of bones of, 72

Small omentum, 122

Smell, organs of, 189

Smooth muscles, 20 I24

Soft commissure, $\mathrm{I} 46$

Solar plexus, I6 3

Solenoglypha, 2 I 3

Somatic layer, Io motor nerves, ${ }^{6} 65$ nerves, I62 wall, I2 I

Somatopleure, I5, I2 I

Spermatic artery, 286

Spermatozoon, 8

Sphenethmoid, 86

Sphenoid bone, 68

Sphenoidalia, 67

Sphenoidal fissure, 67 turbinal, 100

Sphenopalatine ganglion, I65, I7 I

Sphenotic, 67 ganglion, $16_{5}$

Sphincter muscles, I29 pupillæ, 202

Spina scapulæ, Io9

Spinal artery, 287 cord, 138 
Spinal muscles, I3I nerves, $\mathrm{I} 6 \mathrm{I}$

Spiracle, 238

Spiral valve, 228

Splanchnic layer, Io wall, I2I

Splanchnocœle, I2 I

Splanchnopleure, I5, I2 I

Spleen, 307

Splenial bone, $7 \mathrm{I}$

Splenic artery, 284

Squamosal bone, 70

Squamous epithelium, I8

Squatina, genus of sharks.

Stapes, $73, \mathbf{1} 86$

Steapsin, 234

Stenon's duct, 22 I

Stenson's gland, I97

Sternal rib, 54

Sternebræ, 57

Sternocleidomastoid muscle, I30

Sternohyoid muscle, I30

Sternum, 56 abdominal, 57

Stomach, $22 \hat{3}$

Stomata of lymph system, 302

Stomodeum, 12, 205

Stratified epithelium, I8

Stratum corneum, 25 germinativum, 25

Streptostylic, 87

Striped muscles, 20, 125

Styloid process, 100

Subarachnoid space, ${ }_{52}$

Subcardinal veins, 279

Subclavian artery, 288 vein, 289

Subcutis, 26

Subdural space, I $5^{2}$

Subintestinal vein, 276

Sublingua, 2 I9

Sublingual gland, 22 I

Submaxillary ganglion, I 7 I gland, 22 I

Suboperculum, 77

Subspinal muscles, I33

Subunguis, 27

Sulci, 160

Sulcus of Monro, I4I

Superficial petrosal nerve, I 73

Superior intercostal vein, 302 jugular vein, 279 mesenteric artery, 284 oblique muscle, 128 turbinal, Ioo

Supracleithra, I06

Supracondylar foramen, 120

Supraethmoid, 80

Suprangulare, 7 I

Supraoccipital, 67

Supraorbital bones, 69

Suprapericardial bodies, 246

Suprarenal organs, $35^{2}$
Suprascapula, 105, ro7

Suprasternalia, $5^{8}$

Supratemporal bone, 69, ro6 fossa, $7 \mathrm{I}$

Suspensor, 63, 69, 73

Sutures, 38

Sweetbreads, 246

Swim bladder, 247

Sylvian fissure, I59

Sympathetic ganglia, 165 system, 163 trunk, 163

Symplectic, 73,80

Synarthrosis, 38

Synotic tectum, 6I

Synovial membrane, 38

Synsacrum, 53

Syrinx, 254

Systemic circulation, 282

Systole, 272

Tabulare, 69

Tactile corpuscles, I79

Tænia marginalis, 98

Tails of fishes, 50

Talon, 2 I 4

Talus, II 7

Tapetum lucidum, 202

Tarsale, II 7

Tarsal glands, 205

Tarso-metatarsus, I I 9

Tarsus, Ir6

Taste buds, 189 organs of, 189

Tear gland, 204

Tectorial membrane, 186

Teeth, 208 development of, 209 epidermal, $2{ }_{5}$ phylogeny, 2 I $_{5}$

Tegmen cranii, 6 I

Tela subjunctiva, 26

Telencephalon, I4I, I48 brain, $x_{53}$ breathing valves, $24 \mathrm{I}$ excretory organs, 327 girdles, I05 skull, 77 reproductive organs, $33^{2}$

Temnospondylous, $4^{8}$

Temporal fossa, $7 \mathrm{I}$ lobes, 159

Temporalis muscle, $\mathbf{I} 33$

Tenaculum, 203

Tendons, 129

Tentorium, ${ }^{2}{ }^{2}$

Terminalis nerve, 169

Testes, 308,320 descent of, 338

Thalamencephalon, I42

Thalamic nerve, 169

Thalamus, 142,146

Thecodont, 88, 2 I 3 
Thoracic aorta, 284 duct, 303 vertebræ, 49

Thread cells, 29

Thymus glands, 245

Thyreoid cartilage, 252 gland, 246

Thyrohyals, I02

Tibia, II6

Tibiale, II 7

Tibial artery, 288

Tibio-tarsus, II 9

Tissue, $\mathrm{I} 6$

Tongue, $2 \mathrm{I} 7$

Tonsils, 247,307

Trabecula cranii, 6 I communis, $6 \mathrm{I}$

Trachea, 250, 254

Tractus olfactorius, $\mathrm{I}_{42}, \mathrm{I} 67$ solitarius, 150

Transverse bone, 88 muscles, 130 process, 46,55

Transverso-spinal muscles, I 3 I

Trapezium, II 7

Trapezius muscle, 132

Trapezoides, II7

Triconodont, 2 I4

Tricuspid valve, $28 \mathrm{I}$

Trigeminal nerve, I 70

Triquetrum, II 7

Tritubercular, 2 I4

Trochanter, I20

Trochlearis nerve, I 70

Tropibasic skull, 6I

Truncus arteriosus, 272 transversus, $27 \mathrm{I}$

Trypsin, 234

Tuber acusticum, I45

Tubular glands, 18

Tubercular head of rib, 54

Tuberculum impar, 217

Tunica albuginea, $34 \mathrm{r}$ serosa, I2 I vasculosa of eye, 2 or

Tunicata, 2

Turbinal bones, 67, I00, I95

Turtles, armor of, $4 \mathrm{I}$

'Twixt-brain, I42, I48

Tympanic annulus, 82 bone, roo membrane, 187

Tympanum of ear, 187 of syrinx, 255

Ulna, $\mathrm{I} x 6$

Ulnare, $\mathrm{II} 7$

Ulnar artery, 288 lymph duct, 303

Umbilical artery, 285 cord, $35^{\text {I }}$ veins, 278 vesicle, 348
Umbilicus of feather, $3 \mathrm{I}$

Unguis, 27

Unguligrade, 120

Uncinate bone, 97

Unicellular glands, I8

Uniserial fin, II 5

Upper jaw, 70

Ureter, 318

Urethra, 319, 33 r

Urinary bladder, 3 r 8 organs, 307

Urocyst, 3 I 8

Urogenital sinus, 322 system, 307

Urohyal, 80, 97, 2 I8

Uropygial glands, 30

Urostyle, $5^{2}$

Uterus, 338 masculinus, $34^{2}$

Utriculus, $\mathrm{I} 83$

Uvea, 202

Vagina, 338

Vagus nerve, I75

Valve, ileocæcal, 228 ileo-colic, 228 of Vieussens, 145 spiral, 228

Vas efferens, $32 \mathrm{I}$

Vasa deferentia, $32 \mathrm{I}$

Vascular cells, 270

Vater's corpuscle, 179

Veins, 266, 276, 289 abdominal, 289 advehent, $29 \mathrm{I}$ allantoic, $35^{\circ}$ anterior abdominal, 289 cardinal, 279 axillary, 290 azygos, 302 brachial, 290 branchial, 274 caudal, 276 central retinal, $20 \mathrm{I}$ cephalic, 290 common iliac, 289 cutaneus magnus, 290 epigastric, 289 femoral, 290 hemiazygos, 302 hepatic, 277

hypogastric, 290 iliac, 289 inferior jugular, 278 innominate, 300 internal iliac, 290 interrenal, $29 \mathrm{I}$ ischiadic, 290 jugular, 279 lateral abdominal, 289 omphalomesaraic, $27 \mathrm{I}$ omphalomesenteric, $27 \mathrm{I}$ portal, 277 
Veins, postcardinal, 279 pulmonary, 292 revehent, $29 \mathrm{I}$ sciatic, 290 subcardinal, 279 subclavian, 289 subintestinal, 276 superior intercostal, 302 jugular, 279 umbilical, 278 vitelline, 277 vertebral, 292

Velum medullare anterius, I45 transversum, 146

Vena cava, anterior 300 inferior, 290

Ventral aorta, 273 nerve root, $16 \mathrm{I}$

Ventricles, cornua of, I6o fifth, I 5 I laryngeal, 253 of brain, 12,142 of heart, 272 of lungs, 259

Vermis, I 45

Vertebra, development of, 48

Vertebræ, 45 occipital, 62

Vertebral artery, 287 column, 44 rib, 54 vein, 292

Vertebraterial canal, 54

Vertebrata, 2

Vesical arteries, 285

Vestibular nerve, I74

Vestibule of mouth, 208 of nose, 194

Vestibulum, 183

Vidian nerve, $16_{5}$

Vieussens, valve of, I45

Villi, 227

Visceral arches, 63 clefts, 236
Visceral motor nerves, 165 muscles, $\mathrm{r}_{32}$ nerves, 163 pouches, 236 sensory nerves, 167 skeleton, 63

Vitelline veins, 277

Vitreous body, 200

Vocal cords, 25I, 253 sacs, 253

Voluntary muscles, 20, 125

Vomer, 69

Vomero-nasal organ, I96

Weberian apparatus, 54, 250

Weber's nerve, I89

Whalebone, 216

Wharton's duct, 22 I

White matter, 20 of cord, 139 tissue, 22

Willis, circle of, 287

Winslow's foramen, I22

Wirsung's duct, 235

Wishbone, 108

Wolffian body, 310, 3 I3 duct, $3{ }^{2} 5$ ridge, 3 I I

Xiphioid process, 56

Xiphisternum, 57

Yellow spot, 200

Yolk, 8 sac, $206,277,348$

Ypsiloid cartilage, Iro

Zones of nervous system, $14 \mathrm{I}$ Zonula ciliaris, 202

Zinnii, 202

Zygantra, 52

Zygapophysis, 46

Zygomatic bone, ;o

Zygosphenes, 52 



\section{BOOKS FOR STUDENTS OF BIOLOGY.}

KINGSLEY. Comparative Anatomy of Vertebrates. A text-book arranged upon an embryological basis and prepared especially to meet the needs of the under-graduate student. By J. S. Kingsley, Professor of Biology in Tufts college. Octavo; 346 Illustrations drawn or redrawn expressly for this book. ix +4 or pages.

Cloth, \$2.25.

DAVISON. Mammalian Anatomy. With Special Reference to the Anatomy of the Cat. By Alvin Davison, A. M., PH. D., Professor of Biology, Lafayette College, Easton, Pennsylvania. Second Edition, Revised. II4 Illustrations.

Cloth, \$1.50.

FOLSOM. Entomology with Special Reference to Its Biological and Economical Aspects. By Justus Watson Folsom, sc. D. (Harvard), A ssistant Professor of Entomology at the University of Illinois. 5 Plates ( $\mathrm{I}$ in colors) and 300 other Illustrations. 8vo; 485 pages.

Cloth, $\$ 2.00$.

GALLOWAY. Zoology. A Text-book for Secondary Schools, Normal Schools and Colleges. By T. W. Galloway, PH. D., Professor of Biology, James Milliken University, Decatur, Illinois. Second Edition, Revised. 240 Illustrations. 8vo; 460 pages. Cloth, \$2.00. Elementary Zoology. A Text-book for Secondary Educational Institutions. I60 Illustrations. $\mathrm{xx}+4 \mathrm{I} 8$ pages. Cloth, \$1.25.

GREEN. Vegetable Physiology, An Introduction to. By J. REyNolds Green, sc. D., F. R. S., Fellow of Downing College, Cambridge. Third Edition, Revised. I82 Illustrations. Octavo; 482 pages.

Cloth, \$3.00.

JOHNSTON. Nervous System of Vertebrates. BY JoHN BLAcK JoHnston, PH. D., Professor of Comparative Neurology, University of Minnesota. With I80 Illustrations. Octavo; 390 pages.

Cloth, \$3.00.

SCHEFFER. Zoology. Loose Leaf System of Laboratory Notes. Second Edition. Revised and Enlarged. By Theo. H. Schefrer, A. M., formerly A ssistant Professor of Zoology, Kansas State A gricultural College. Square 8vo.

Adjustable Cloth Covers, $\$ .75$.

BRUBAKER. Text-book of Physiology. Illustrated. Fourth Edition. A Text-book of Physiology, specially adapted for the use of Students. Including a Section on Physiologic Apparatus. By A. P. Brubaker, M. D., Professor of Physiology and Medical Jurisprudence at Jefferson Medical College. With an appendix giving a brief account of some essential forms of apparatus suited to those who have not large laboratory opportunities. Fourth Edition. Thoroughly Revised and in Parts Rewritten. I Colored Plate and 377 other Illustrations. Octavo; $x i i+735$ pages.

Cloth, \$3.00.

P. BLAKISTON'S SON \& CO., PHILADELPHIA. 


\section{BOOKS FOR STUDENTS OF BIOLOGY.}

MARSHALL. Microbiology. A Text-book of Microörganisms, General and Applied. By various writers. Edited by Charles E. Marshall, Professor of Microbiology and Director of Graduate School, Massachusetts A gricultural College. Discusses Morphology, Culture and Physiology of Microörganisms, including Nutrition and Metabolism, Physical Influences; Bacteriology of Dairy, Soil, Water Supplies, Sewage Disposal, Air, Special Manufactures, Diseases of Man, Animals and Plants. I Colored Plate. I28 Other Illustrations. I2mo, xxi 724 pages.

Flexible Cloth, $\$ 2.50$.

MINOT. Embryology. A Laboratory Text-book of Embryology. By Charles S. Minot, S. D., Ll.D., Professor of Comparative Anatomy, Harvard University Medical School. Second Edition, Revised. With 262 Illustrations. xii +402 Pages.

Cloth $\$ 3 \cdot 50$.

VINAL. A Guide for Laboratory and Field Studies in Botany. By William Gould Vinal, A. M. (Harvard), Salem Normal School, Salem, Massachusetts. Second Edition, Revised. Square Octavo.

Paper Covers, \$.6o.

STEVENS. Plant Anatomy from the Standpoint of the Development and Functions of the Tissues. By WM. C. Stevens, M. S., Professor of Botany in the University of Kansas. Second Edition, Enlarged. I 52 Illustrations. 8vo; 394 pages.

Cloth, \$2.00.

STOHR. Text-book of Histology. Arranged upon an Embryological Basis. By Dr. FrEDERIC T. LEWIS, A ssistant Professor of Embryology at the Harvard Medical School. From the Twelfth German Edition by Dr. PHIllip StOHR, Professor of Anatomy at the University of Wurzburg. Sixth American Edition, Revised. 450 Illustrations, 45 in Colors. 8vo; 443 pages.

Cloth, $\$ 3.00$.

CRARY. Field Zoology, Insects and Their Near Relatives and Birds. By L. E. Crary, Assistant Professor of Biology and Geology, Kansas State Normal College, Emporia. II 7 Illustrations. I2mo. 376 pages. Cloth, \$I.25.

McMURRICH. The Development of the Human Body. A Manual of Human Embryology. BY J. PlaYFaIR MCMURRICH, A. M., PH. D., Professor of Anatomy, University of Toronto: American Editor of Morris' "Text-book of Anatomy." Third Edition, Revised. 277 Illustrations. Octavo; 528 pages.

Cloth, $\$ 3.00$.

PATTEN. The Evolution of the Vertebrates and Their Kin. By William Patten, PH. D., Professor of Zoology, and Head of the Department of Biology, Dartmouth College, Hanover, N. H. With 307 Figures engraved especially for this book, largely from original sources. Octavo.

Cloth, $\$ 4.50$.

P. BLAKISTON'S SON \& CO., PHILADELPHIA. 



\section{THE LIBRARY \\ UNIVERSITY OF CALIFORNIA \\ San Francisco Medical Center}

THIS BOOK IS DUE ON THE LAST DATE STAMPED BELOW

Books not returned on time are subject to fines according to the Library Lending Code.

Books not in demand may be renewed if application is made before expiration of loan period.

14 DAY

APR 241975

RETURNED

APR 181975 
211070 
